\title{
Land Application Uses for Dry Flue Gas Desulfurization By-Products: Phase 3
}

Final Report, January 1999

Prepared by:

OHOSTATEUNIVERSITY

Ohio Agricultural Research and Development Center 1680 Madison Avenue

Wooster, Ohio 44691-4096
Authors:
W. Dick
J. Bigham
R. Forster
F. Hitzhusen
R. Lal
R. Stehouwer
S. Traina
W. Wolfe

UNITED STATES GEOLOGICAL SURVEY

975 West Third Street

Columbus, Ohio 43212-3192

Authors:

R. Haefner

G. Rowe

Prepared for:

Dravo Technology Center

3600 Neville Road

Pittsburgh, PA 15225

RECEIVEC

MAY $\& 31999$

OSTI 


\section{DISCLAIMER}

This report was prepared as an account of work sponsored by an agency of the United States Government. Neither the United States Government nor any agency thereof, nor any of their employees, make any warranty, express or implied, or assumes any legal liability or responsibility for the accuracy, completeness, or usefulness of any information, apparatus, product, or process disclosed, or represents that its use would not infringe privately owned rights. Reference herein to any specific commercial product, process, or service by trade name, trademark, manufacturer, or otherwise does not necessarily constitute or imply its endorsement, recommendation, or favoring by the United States Government or any agency thereof. The views and opinions of authors expressed herein do not necessarily state or reflect those of the United States Government or any agency thereof. 


\section{DISCLAIMER}

Portions of this document may be illegible in electronic image products. Images are produced from the best available original document. 


\section{ABSTRACT}

New flue gas desulfurization (FGD) scrubbing technologies create a dry, solid by-product material consisting of excess sorbent, reaction product that contains sulfate and sulfite, and coal fly ash. Generally, dry FGD by-products are treated as solid wastes and disposed in landfills. However, landfill sites are becoming scarce and tipping fees are constantly increasing. Provided the environmental impacts are socially and scientifically acceptable, beneficial uses via recycling can provide economic benefits to both the producer and the end user of the FGD .

\section{A study titled "Land Application Uses for Dry Flue Gas Desulfurization By-Products" was initiated in December, 1990 to develop and demonstrate large volume, beneficial uses of FGD by-products. Phase 1 and Phase 2 reports have been published by the Electric Power Research Institute (EPRI), Palo Alto, CA.}

Phase 3 objectives were to demonstrate, using field studies, the beneficial uses of FGD byproducts (1) as an amendment material on agricultural lands and on abandoned surface coal mine land, (2) as an engineering material for soil stabilization and road repair, and (3) to assess the environmental and economic impacts of such beneficial uses.

Application of dry FGD by-product to three soils in place of agricultural limestone increased alfalfa (Medicagosativa $L$.) and corn (Zea mays $L$.) yields. No detrimental effects on soil and plant quality were observed.

An FGD material from an atmospheric fluidized bed combustion (AFBC) process, applied alone or with yard waste compost, successfully reclaimed an acid, toxic abandoned surface coal mine site. Vegetative harvest, however, from the reclaimed mine spoil during the first year of this study was greater when reclamation was done using $20 \mathrm{~cm}$ of resoil material as compared to FGD or a mixture of FGD plus yard waste compost. All three reclamation treatments increased runoff water $\mathrm{pH}$ to $>7$ and decreased soluble $\mathrm{Al}$ concentrations. Groundwater flow and quality were also investigated beneath an area of the same surface coal mine site reclaimed using another type of FGD by-product (i.e. a pressurized fluidized bed combustion 
(PFBC) by-product) mixed with yard waste compost. Groundwater beneath the site exhibited no changes 16 months after FGD application. Interstitial waters in the FGD by-product application area had higher $\mathrm{pH}$ and specific conductance than waters collected in an adjacent area reclaimed using resoil material. Constituents in interstitial waters consistently detected at higher concentrations in the FGD by-product application area, as compared to the resoil area, included $\mathrm{SO}_{4}, \mathrm{Mg}, \mathrm{B}, \mathrm{Cl}$ and $\mathrm{F}$. Water from of fsite domestic wells generally had higher $\mathrm{pH}$ values and much lower concentrations of dissolved constituents than did water from onsite wells.

A dry FGD by-product created by the PFBC process was successfully used in a demonstration highway construction program. Other dry FGD by-product materials may not provide similar results. The FGD by-products used in this study did not swell, exhibited high strength, ease of installation and no measurable change in the environment of the surrounding area. The installation procedures did not require highly specialized equipment or training. The performance of the FGD material during construction clearly demonstrated that the level of care normally required on any construction project should be adequate when working with these materials.

Long-term equilibrium studies were conducted to study solubility and geochemistry of ettringite (an expansive mineral that can affect use of FGD for construction purposes) in high $\mathrm{pH}$ and $\mathrm{Ca}-\mathrm{Al}-\mathrm{SO}_{4}-\mathrm{H}_{2} \mathrm{O}$ systems. Ettringite can exist at $\mathrm{pH}$ values $<10.7$, but only in association with gypsum and $\mathrm{Al}$ hydroxide. Ettringite completely dissolves at near neutral $\mathrm{pH}$ and precipitates gypsum, Al hydroxides, Al hydroxy sulfates such as basaluminite and other previously unidentified Ca-Al-hydroxy sulfate phases.

An annualized least cost disposal model was developed for use of FGD by-product as an agricultural soil amendment, for highway construction, for coal surface mine reclamation, and for landfilling at various geographic locations throughout Ohio. In doing so, total disposal costs and quantities were derived as well as shadow prices for each county (demand node) identified. Under the most realistic scenario, annual disposal of 3.9 million tons of FGD byproduct would cost $\$ 70.1$ million if the full social costs of landfilling are considered. The primary off-site or social cost of landfilling (impact on adjacent property values) was estimated with a two-stage hedonic pricing model. The social benefits of FGD by-products for reclaiming stripmines were estimated utilizing travel cost and hedonic pricing models. If beneficial uses of wet FGD by-products are adopted, a savings of $\$ 11.67$ per ton of FGD may be realized. A significant portion of FGD by-product is still landfilled, however, thereby creating an enormous economic incentive to more fully develop and commercialize beneficial uses. 


\section{ACKNOWLEDGMENTS}

This research was conducted as part of the "Land Application Uses for Dry FGD By-Products" project which is a cooperative research project of the Ohio Agricultural Research and Development Center, the Ohio State University, the U. S. Geological Survey and the Dravo Lime Company. Funding support for this project was obtained from the Ohio Coal Development Office (Columbus, OH) Contract No. CDO/D-89-35, the U.S. Department of Energy (Morgantown Energy Technology Center, Morgantown, WV) Contract No. DE-FC2191MC28060, Dravo Lime Company (Pittsburgh, PA) Contract No. RF768342, Electric Power Research Institute (Palo Alto, CA) Research Contract No. WO-9097-01, American Electric Power Company (Columbus, OH) Contract No. C-8276, Ohio Edison Company (Akron, $\mathrm{OH}$ ), and the Ohio State University (Columbus and Wooster, $\mathrm{OH}$ ).

Appreciation is expressed to the Steering Committee and especially to Dravo Project leader, Joel Beeghly, for insight and help in directing this project. 


\section{EXECUTIVE SUMMARY}

New flue gas desulfurization (FGD) scrubbing technologies create a dry, solid by-product material consisting of excess sorbent, reaction product that contains sulfate and sulfite, and coal fly ash. Generally, dry FGD by-products are treated as solid wastes and disposed in landfills. However, landfill sites are becoming scarce and tipping fees are constantly increasing. Provided the environmental impacts are socially and scientifically acceptable, beneficial uses via recycling can provide economic benefits to both the producer and the end user of the FGD by-product.

A study titled "Land Application Uses for Dry Flue Gas Desulfurization By-Products" was initiated in December, 1990 to develop and demonstrate large volume, beneficial uses of FGD by-products. Phase 1 and Phase 2 reports have been published by the Electric Power Research Institute (EPRI), Palo Alto, CA. The Phase 1 report provides results of extensive characterization of chemical, physical, mineralogical and engineering properties of $58 \mathrm{dry}$ FGD byproduct samples. The Phase 2 report provides information on laboratory, greenhouse and initial field studies related to use of FGD by-products for use in agriculture, for surface coal mine reclamation, and for construction of a truck unloading ramp and cattle feedlot bases. The Phase 2 report concluded that adoption of the new beneficial uses developed for FGD byproducts seemed to be limited by economic constraints, but even more so, by the need to create awareness of the market potential of using these FGD by-products.

Phase 3 objectives were to demonstrate, using field studies, the beneficial use of FGD byproducts (1) as an amendment material on agricultural lands and on abandoned surface coal mine land, (2) as an engineering material for soil stabilization and road repair, and (3) for assessing the environmental and economic impacts of such beneficial uses.

Use of a dry FGD by-product (a 40:60 mixture of bed and cyclone ash from a pressurized fluidized bed combustion (PFBC) process) was investigated as a limestone substitute in a field study on three acidic agricultural soils ( $\mathrm{pH} 4.6,4.8$ and 5.8) in eastem Ohio. The FGD byproduct ( $60 \% \mathrm{CaCO}_{3}$ equivalency) was applied in September 1992 at rates of 0, 0.5, 1.0 and 
2.0 times the amount of lime required by the soils. Test crops were alfalfa (Medicago sativa $\mathrm{L}$.) and corn (Zea mays L.). Soil $\mathrm{pH}$ was increased at all FGD application rates in the zone of incorporation (0-10 cm soil layer) with the highest FGD rate yielding a pH slightly above 7. Alfalfa yields were increased by FGD addition on all three soils but had no effect on corn yield. No detrimental effects on soil and plant quality were observed.

A specific FGD by-product material from an atmospheric fluidized bed combustion (AFBC) by-product process was applied alone ( $\left.280 \mathrm{Mg} \mathrm{ha}^{-1}\right)$ or the same amount of FGD was applied with $112 \mathrm{Mg} \mathrm{ha}^{-1}$ yard waste compost to reclaim an acid, toxic abandoned surface coal mine site located near Dover, OH. This material was applied to six small ( 0.4 ha or 1 acre) watersheds. An additional area of approximately 2.0 to 2.4 ha ( 5 to 6 acres) of the coal mine site received FGD from a pressurized fluidized bed combustion (PFBC) process. This PFBC treated area was used to study the effects of FGD application on interstitial water quality and on groundwater quality. The Pennsylvanian-age rocks that underlie the site are predominantly shales and sandstones with interbedded coal, clay, and limestone. Correlation of rock units between boreholes indicated a dip of about $1^{\circ}$ to the southeast. Groundwater wells were installed at the site to measure water levels and water-transmitting properties and to sample water for chemical analysis. Single well volume displacement tests ("slug" tests) at 14 wells resulted in estimated hydraulic conductivities of 1 to 2 meters per day for the shallow aquifer and 2 to 4 meters per day for the deep aquifer. The dominant direction of horizontal groundwater flow is toward the south. Vertical flow into the deeper aquifer is limited to the upgradient recharge area, which is along the northern part of the study site. The particle-tracking model indicated travel times ranging from 228 days to 26.9 years for recharge to discharge at springs. Surface and groundwater flow and quality studies were began before reclamation commenced and then again after reclamation was completed.

Precipitation collected at the site measured $866 \mathrm{~mm}$ for the 1995 calendar year, approximately 8 percent less than the annual average for the area. Total yield of vegetation on the reclaimed mine spoil during the first year (1995) of this study was greater when reclamation was done using $20 \mathrm{~cm}$ of resoil borrow material as compared to FGD or FGD plus compost. All three reclamation treatments increased runoff water $\mathrm{pH}$ to $>7$ and decreased soluble $\mathrm{Al}$. Concentration of $\mathrm{Ca}$ and $\mathrm{S}$ were larger in surface water runoff and water that percolated through the surface soil layer from the FGD treated watershed than from the resoil treated watershed. Boron was the only trace element that increased in the spoil and water but this increase was not enough to cause any B toxicity in vegetation. Concentrations of other 
measured trace elements in all water samples remained very low and showed almost no treatment effects.

Groundwater flow and quality were also investigated at the surface coal mine site reclaimed by FGD plus yard waste compost. Interstitial waters in the FGD by-product application area had higher $\mathrm{pH}$ and higher specific conductance than waters collected in the resoil area. Constituents in interstitial waters consistently detected at higher concentrations in the FGD by-product application area included $\mathrm{SO}_{4}, \mathrm{Mg}, \mathrm{B}, \mathrm{Cl}$ and $\mathrm{F}$. Water from offsite domestic wells generally had higher $\mathrm{pH}$ values and much lower concentrations of dissolved constituent than did onsite wells. Speciation modeling with WATEQ4F revealed that interstitial waters at the FGD treated site were close to or above saturation with respect to $\mathrm{Ca}$ - and $\mathrm{Mg}$-bearing minerals such as calcite, dolomite, gypsum, and magnetite. This indicates possible dissolution of FGD byproduct. Waters supersaturated with respect to alunite were found only in interstitial water and in one surface water sample. All but one interstitial water sample and all groundwater samples were supersaturated with respect to gibbsite, an $\mathrm{Al}$-bearing phase. The source of $\mathrm{Al}$ is likely from the weathering of clay minerals and (or) fly ash in the FGD by-product. Iron-bearing phases such as ferrihydrite, goethite, greigite, and siderite were either above or at saturation in groundwater samples.

Based on chemical and isotopic data, ground water at the site had not yet been affected 16 months after the application of FGD by-products on the surface. However, chemical data from the interstitial-water samples indicate that the impacts of applying FGD by-product on groundwater quality will first be noted by changes in $\mathrm{pH}, \mathrm{Mg}$ :Ca mole ratios, $\mathrm{B}$ and $\mathrm{F}$ concentrations, and $\delta^{34} S$ values. Longer term monitoring is being conducted at this site.

A specific flue gas desulfurization by-product, created using a PFBC process, was successfully incorporated into a highway construction program. This by-product was successful, in part, because it is nonexpansive. Other dry FGD by-products may not yield similar results. The FGD by-product used in this study also exhibited high strength, ease of installation and, to date, no measurable change in the environment of the surrounding area. The installation procedures used did not require any specialized equipment or training. The performance of the FGD material during construction clearly demonstrated that the level of care normally required on any construction project should be adequate when working with these materials. Excellent strength properties and workability were achieved with both the unamended FGD ash and ash used in a mix to stabilize the local soil. When repairing Ohio 
State Route 83, the FGD and soil were mixed on site in approximately equal proportions and the resulting strengths were similar to those obtained with the FGD ash alone. The ash appears to be well suited as a soil stabilizer and the mixes can be blended in the field.

Long-term equilibrium studies of ettringite solubility and geochemistry were conducted in high $\mathrm{pH}$ and $\mathrm{Ca}-\mathrm{Al}-\mathrm{SO}_{4}-\mathrm{H}_{2} \mathrm{O}$ systems, i.e. systems which are created when many FGD byproducts are used at high rates. This work is important because successful construction applications are impacted by the development of ettringite due to its ability to both create strength and to expand. The results indicated that ettringite can exist at $\mathrm{pH}$ values $<10.7$, but only in association with gypsum and Al hydroxide. Ettringite completely dissolves at near neutral $\mathrm{pH}$ and precipitates gypsum, $\mathrm{Al}$ hydroxides, $\mathrm{Al}$ hydroxy sulfates such as basaluminite and other previously unidentified $\mathrm{Ca}$-Al-hydroxy sulfate phases. Although the geochemistry of the $\mathrm{Ca}-\mathrm{Al}-\mathrm{SO}_{4}-\mathrm{H}_{2} \mathrm{O}$ system is simple above $\mathrm{pH} 7.0$, and can be described as an association of the $\mathrm{Ca}-\mathrm{Al}-\mathrm{SO}_{4}-\mathrm{H}_{2} \mathrm{O}$ and $\mathrm{Al}-\mathrm{SO}_{4}-\mathrm{H}_{2} \mathrm{O}$ systems, it is more complicated at near neutral $\mathrm{pH}$ by the presence of several additional solid phases. Its simplicity above $\mathrm{pH} 7.0$ arises from the absence of Al hydroxy sulfate phases. EQ3/6 model calculations accurately predicted the ettringite weathering sequence and relevant ion activities when the $\mathrm{pH}$ was $>5.0$. These reaction-path simulations also suggested the existence of highly soluble $\mathrm{Ca}$ phases around $\mathrm{pH} 5.0$ which were confirmed by microscopic studies.

Two main economic objectives were addressed in Phase 3 of the project. A least cost disposal linear programming model was developed, based upon annualized costs, for use of FGD byproducts as an agricultural soil amendment, for highway construction, for coal surface mine reclamation and for landfilling at various geographic locations throughout Ohio. Market price based disposal costs and quantities were derived for each county (demand node) identified. In addition social cost estimates of landfilling were made at four central Ohio landfills utilizing a two-stage hedonic pricing model to approximate the negative economic impacts of landfilling on nearby property values. A benefits transfer statistical model was then developed to generalize these results to other landfills. Under the most realistic scenario, annual disposal of 3.9 million tons of FGD by-product would cost $\$ 70.1$ million if the full social costs of landfilling are considered. If widespread beneficial uses are adopted, a potential savings of $\$ 11.67$ per ton of FGD by-product may be realized. With continued landfilling of FGD byproduct, a large economic incentive exists to more fully develop and commercialize beneficial uses. 
A second economic objective was to estimate the social benefits of a specific primary beneficial use of FGD by-product, i.e. reclamation of stripmines. One lake impacted by mining and one unimpacted lake in the Muskingum Conservancy District were chosen for analysis. A travel cost model was utilized to estimate both total and stripmine related recreational benefits at each of the lakes. Next, a single stage hedonic pricing model was utilized to estimate the economic impact of stripmine activity on lakeside property values at each of these lakes. Finally, the results of both analyses were combined showing a potential annual net benefit of $\$ 4,390$ to lakeside property values and an upper bound estimate of $\$ 250,492$ of potential annual recreation net benefits from future reclamation of stripmines in the impacted lake watershed. More analysis is merited from these promising preliminary results, but the results clearly show the social benefits of beneficial uses of FGD by-product, in this case to reclaim lakes impacted by surface mining.

The various land application uses investigated as part of this study illustrate the potential for using FGD by-products as an agricultural limestone substitute, for mineland reclamation, for road construction and repair, and for improving the environmental quality and recreation potential of lakes in coal mine regions. Other land application uses are possible. Further efforts are needed to educate the general public to embrace these technologies, to convince regulatory agencies that FGD by-products are just as safe as other commonly used land application products (e.g. mineral fertilizers, limestone, various types of composts), and to create companies or commercial partnerships that focus on the development and marketing of products derived from FGD. 


\section{TABLE OF CONTENTS}

Section Page

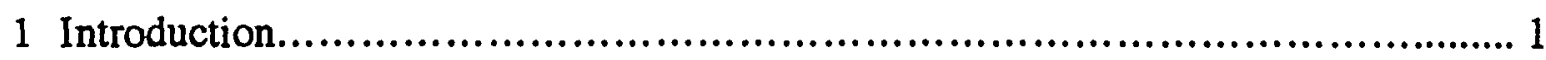

1.1 Background and Project Description.............................................. 1

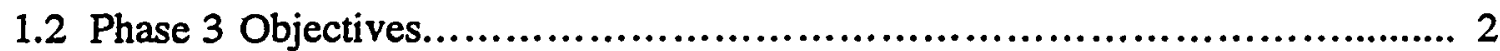

1.3 Approach............................................................................ 3

2 Use of a Dry PFBC By-Product as a Liming Material for Acidic Agricultural Soils....... 5

2.1 Introduction....................................................................... 5

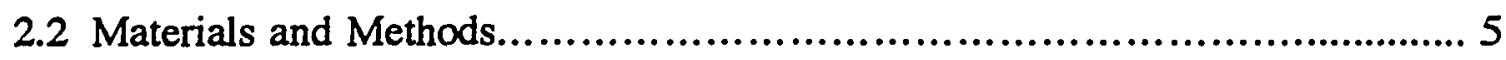

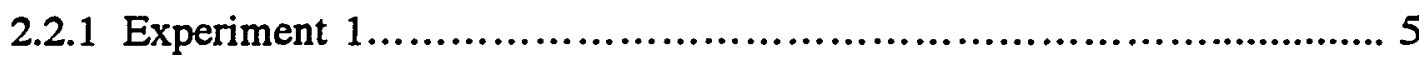

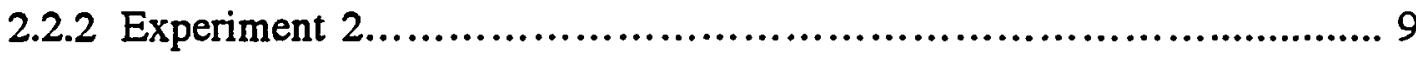

2.3 Results and Discussion....................................................... 10

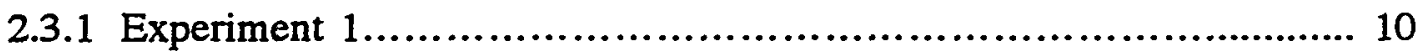

2.3.1.1 Soil Chemistry.................................................... 10

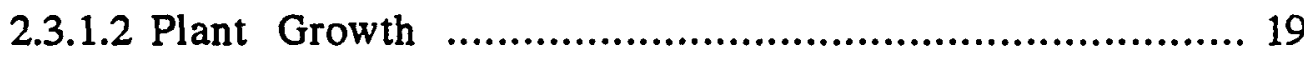

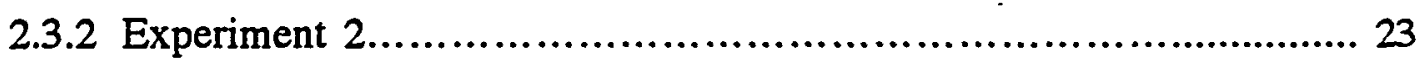

2.3.2.1 Soil Physical Properties................................................. 23

2.3.2.2 Runoff Rate and Amount .............................................. 28

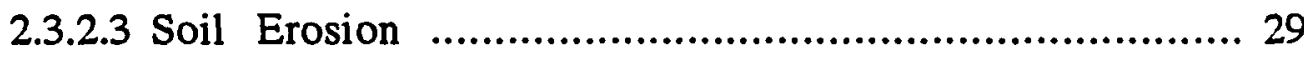

2.4 Summary and Conclusions........................................................ 31

3 Reclamation of an Acidic and Toxic Surface Coal Mine Site In Ohio:

Surface Water, Groundwater, Plant and Soil Responses............................... 32

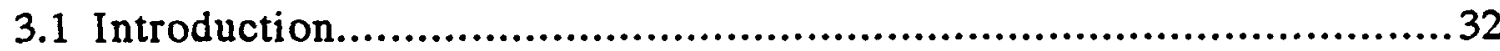

3.2 Experiment 1 - Column Studies (Coshocton, $\mathrm{OH}$ )....................................... 33

3.2.1 Materials and Methods.......................................................... 33

3.2.2 Results and Discussion........................................................ 34

3.2.3 Summary and Conclusions.................................................. 41

3.3 Experiment 2 - Fleming Abandoned Mine Land Site...................................... 41

3.3.1 Materials and Methods...................................................... 41

3.3.1.1 Site Selection and Experimental Design.................................. 41

3.3.1.2 Characterization of Fleming Spoil and FGD Amendments.......... 45

3.3.1.3 Site Lithology...................................................... 51 
3.3.1.4 Precipitation and Surface Water Hydrology and Quality.............. 58

3.3.1.5 Interstitial Water Quality............................................ 63

3.3.1.6 Groundwater Hydrology and Quality.................................. 66

3.3.1.7 Sampling and Analysis of Soil, Plant and Water Samples........... 70

3.3.1.8 Groundwater Flow Modeling...........................................79

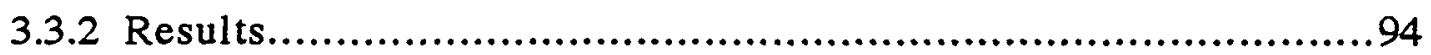

3.3.2.1 Soil and Plant Responses to FGD Amendments

Applied to Mine Spoil.....................................................94

3.3.2.2 Vegetative Growth.................................................. 99

3.3.2.3 Surface Water Quality and Hydrology...................... 103

3.3.2.4 Groundwater Hydrology and Quality...................... 119

3.3.2.5 Precipitation.............................................. 138

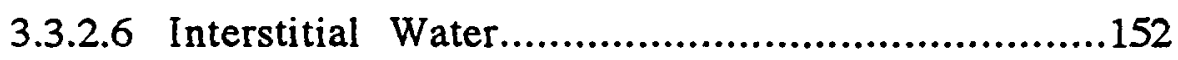

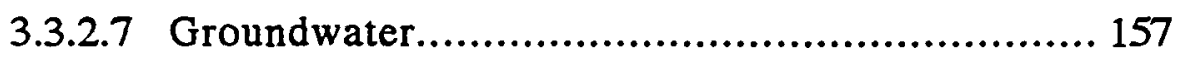

3.3.2.8 Surface Water/Groundwater Interactions.................... 171

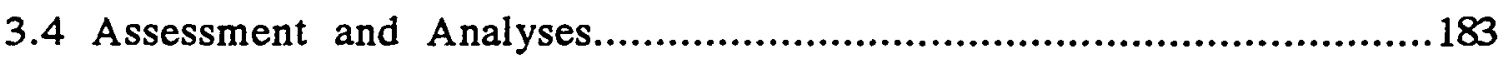

3.5 Conclusions from Mineland Reclamation Study Using FGD..........................187

4 Use of FGD By-Products for Roadway Stabilization.......................................190

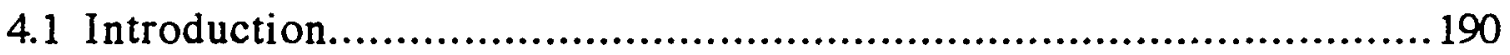

4.2 Description of Study Sites and Repair Procedures..................................... 192

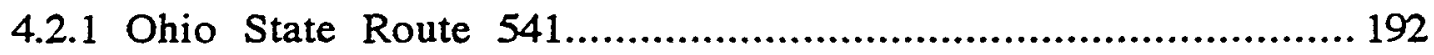

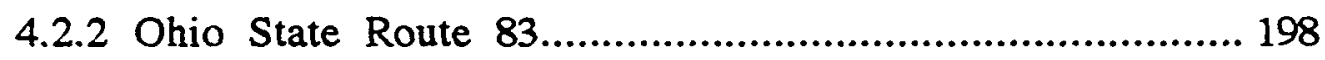

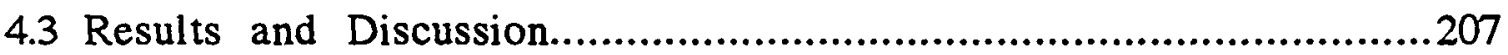

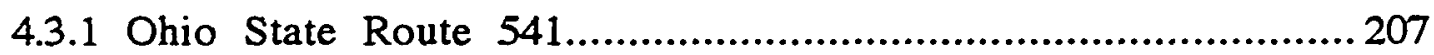

4.3.2 Ohio State Route 83......................................................212

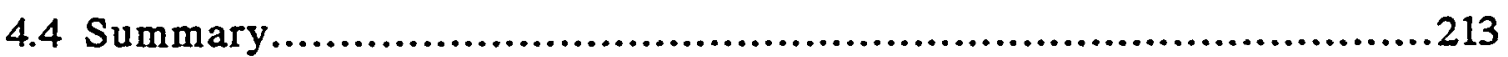

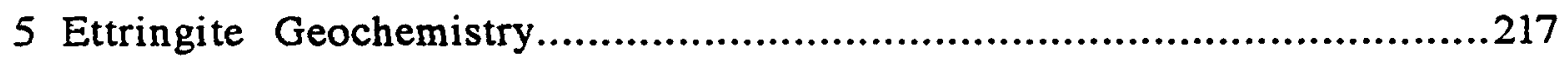

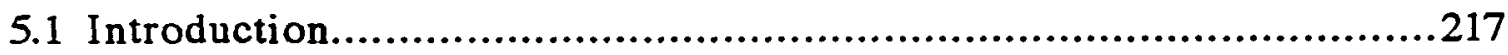

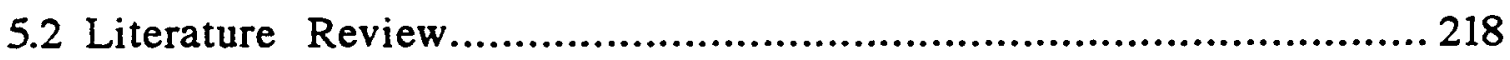

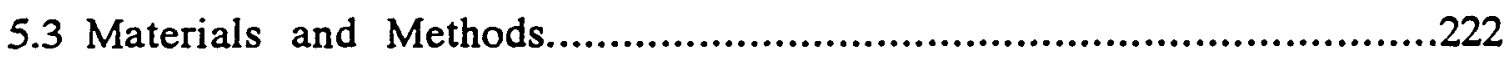

5.3.1 Solutions, Glassware, and Reagents....................................... 222

5.3.2 Ettringite Synthesis and Characterization.........................................223

5.3.3 Solubility Studies as Affected by pH........................................ 223

5.3.4 Geochemical Speciation and Modeling.......................................225 


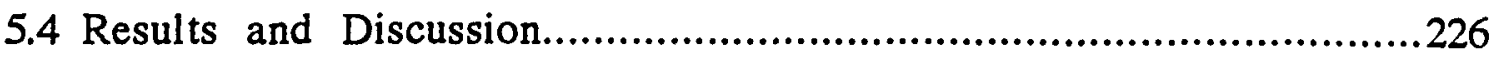

5.4.1 Characterization of Synthetic Ettringite.......................................226

5.4.2 Ettringite Congruent Dissolution and Solubility Product.......................228

5.4.3 Ettringite Incongruent Dissolution................................................ 235

5.4.4 X-ray Diffraction and Microscopic Studies.................................... 241

5.4.5 Geochemistry of the Ca-Al-SO4-H2O System............................... 245

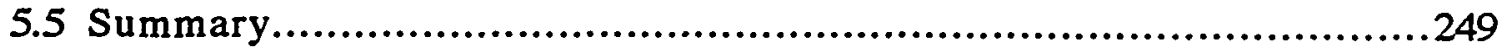

6 Economic Valuation of Recycling FGD By-Products....................................... 250

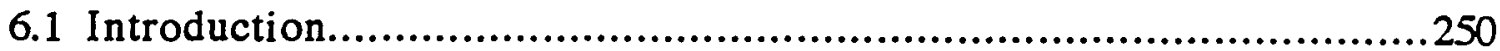

6.2 Nonmarket Valuation of Landfilling FGD By-Product................................251

6.2.1 Theoretical Framework: The Hedonic Pricing Model............................252

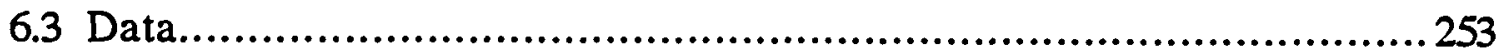

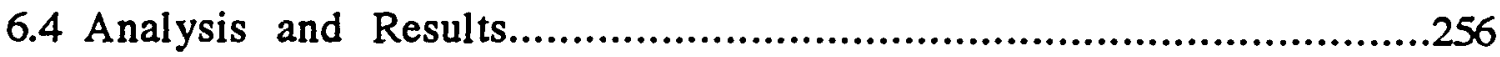

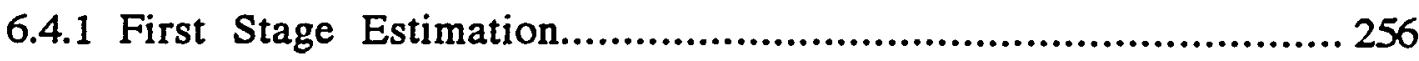

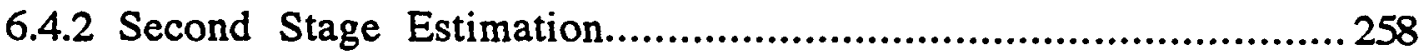

6.4.3 Compensating Variation Measure of Welfare Change......................... 258

6.5 Transfering Social Benefits and Costs................................................ 263

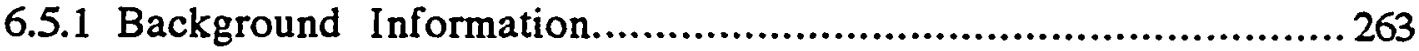

6.5.2 Cost Transfer Methodology for the Hedonic Pricing Model.................. 264 6.5.2.1 Estimation of Total Net Present Value for

Households in the Franklin County Study Site.........................266

6.5.2.2 Estimates from the STF3A Census Micro Data.........................270

6.5.3 Results from Application of the Model........................................ 271

6.6 Estimates of the Social Benefits of Strip Mine Reclamation ...........................274

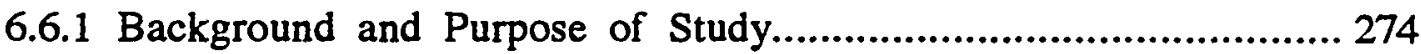

6.6.2 Methodology...............................................................276

6.6.3 Results of Applying the Social Benefits Model for Strip Mine

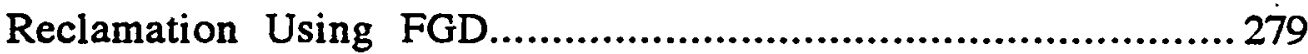

6.6.4 Policy Implications and Conclusions............................................2 285

6.7 The Linear Optimization Model..........................................................286

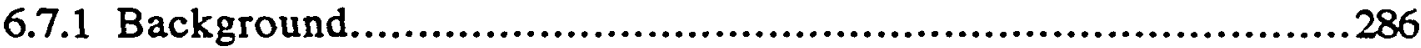

6.7.2 Model Development.........................................................287

6.7.3 Linear Optimization Model Results................................................ 290

6.7.4 Comparisons with EPRI Disposal Economic Models............................. 295

6.7.5 Conclusions................................................................296 
Appendix A. References......................................................... 298

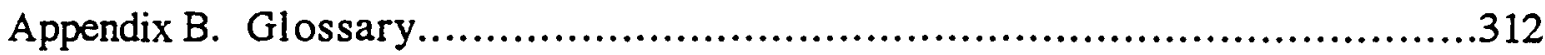

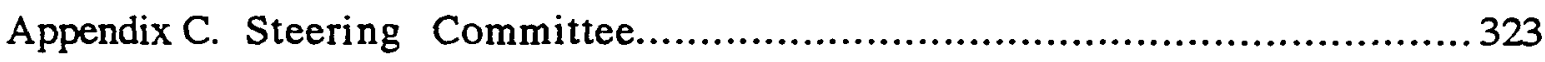

Appendix D. Supporting Data from the Fleming Mine Site..................................326

Appendix E. Supporting Data for Economics Model...........................................368

Appendix F. Quality Control........................................................378 


\section{FIGURES}

Figure

1 Effect of FGD on soil $\mathrm{pH}$ and on water soluble aluminum and manganese in the Wooster soil profile

2 Effect of FGD on soil pH and on water soluble aluminum and manganese in the Coshocton soil profile.

3 Effect of FGD on soil pH and on water soluble aluminum and manganese in the Canfield soil profile.

4 Effect of FGD on water soluble sulfur, calcium, and magnesium concentrations in the Wooster soil profile.

5 Effect of FGD on water soluble sulfur, calcium, and magnesium concentrations in the Coshocton soil profile.

6 Effect of FGD on water soluble sulfur, calcium, and magnesium concentrations in the Canfield soil profile.

7 Effect of FGD on water soluble boron concentrations in the Wooster, Coshocton and Canfield soil profiles.

8 Effect of FGD on the yield of alfalfa hay and com grain grown on the Wooster, Coshocton and Canfield soils. $\left({ }^{*}\right.$, the starred means are significantly different from all other means for a particular year and site.)

9 Schematic of the experimental design developed for the Fleming site to study the potential impacts of using FGD for reclamation of abandoned surface coal mine lands. The FGD applied to the six small watersheds was an AFBC by-product and the FGD applied to the areas outside of the small watersheds was a PFBC by-product.

10 Stratigraphic section of rocks at the Fleming abandoned mine site, Tuscarawas County, Ohio (modified from Lamborn, 1956 and Hull, 1990). Shaded areas refer to aquifers investigated in this study.

11 Diagrammatic illustration of lithology and screened intervals of four core holes and twenty wells. Numbers on the right side of this figure are given in feet above sea level while numbers on the left side of the figure are given in feet above or below land surface. To convert feet to meters, multiply by 0.305

12 Topographic map showing location of core holes, lysimeters, wells and surface geophysical surveys at the Fleming abandoned mine site, Tuscarawas County, Ohio 
13 Location of domestic wells, surface water sites and precipitation gages in relation to Fleming abandoned mine land study site.....................59

14 Schematic drawing of lysimeter installation.........................................64

15 Conceptual model of groundwater flow. Arrows indicate conceptualization direction of flow.

16 Finite difference grid used for groundwater flow model. Each grid cell

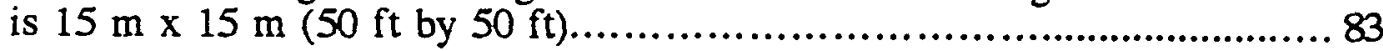

17 Contour maps showing A) measured and simulated heads and B) residuals. Values are given in feet. To convert to meters, multiply by 0.305 .

18 Comparison of observed and simulated heads in selected wells for shallow (layer 1) wells and deep (layer 2) wells. Values are given in feet. To convert to meters, multiply by 0.305 .

19 Schematic diagram of water budget for model simulation. 89

20 Statistical distribution of the difference between measured and simulated heads for sensitivity tests of the groundwater flow model. Values are given in feet. To convert to meters, multiply by 0.305

21 Particle pathlines within FGD by-product application area. Values are given in feet. To convert to meters, multiply by 0.305 .

22 Cross sectional view of particle paths along column 18 . Values are given in feet. To convert to meters, multiply by 0.305 .

23 Distribution of soil $\mathrm{pH}$ and electrical conductivity (EC) in the Fleming spoil profile eight months after reclamation with topsoil material, FGD and FGD + compost. (Error bars indicate plus and minus one standard deviation).

24 Distribution of water soluble $\mathrm{Ca}$ and $\mathrm{S}$ in the Fleming spoil profile eight months after reclamation with topsoil, FGD and FGD+compost.

25 Distribution of water soluble $\mathrm{Al}$ and $\mathrm{Fe}$ in the Fleming spoil profile eight months after reclamation with topsoil, FGD and FGD+compost.............................98

26 Distribution of water soluble B in the Fleming spoil profile eight months after reclamation with topsoil, FGD and FGD+compost.

27 Vegetative biomass production in 1995 on Fleming minespoil reclaimed with topsoil, FGD and FGD+compost.

$28 \mathrm{pH}$ of surface water runoff from Fleming spoil reclaimed with topsoil, FGD and FGD+compost.

29 Dissolved $\mathrm{Al}$ concentrations in surface water runoff from Fleming spoil reclaimed with topsoil, FGD and FGD+compost. 
30 Dissolved Ca concentrations in surface water runoff from Fleming spoil reclaimed with topsoil, FGD and FGD+compost.

31 Dissolved $S$ concentrations in surface water runoff from Fleming spoil reclaimed with topsoil, FGD' and FGD+compost.:

$32 \mathrm{pH}$ of tile flow water from Fleming spoil reclaimed with topsoil, FGD and FGD+compost and in an adjacent pond receiving flow from the Fleming site.

33 Dissolved Al concentrations in tile flow water from Fleming spoil reclaimed with topsoil, FGD and FGD+compost and in an adjacent pond receiving flow from the Fleming site.

34 Dissolved Ca concentrations in tile flow water from Fleming spoil reclaimed with topsoil, FGD and FGD+compost and in an adjacent pond receiving flow from the Fleming site.

35 Dissolved $S$ concentrations in tile flow water from Fleming spoil reclaimed with topsoil, FGD and FGD+compost and in an adjacent pond receiving flow from the Fleming site.

36 Sample curve match and calculation of hydraulic conductivity for slug tests using the method of Cooper et al. (1967).

37 Daily total precipitation (in inches) and water levels (in feet) for well cluster 4 for the time period 8/1/95 through 1/31/96.

38 Daily total precipitation (in inches) and water levels (in feet) for well TU-109-W5Sfor the time period 8/1/95 through 1/31/96.

39 Total daily precipitation (in inches) and water levels (in feet) for well cluster 8 during the time period 8/1/95 through 1/31/96.

40 Total hourly precipitation (in inches) and water levels (in feet) for well TU-109-W5S for the time period 9/11/95 through 9/14/96

41 Potentiometric surface maps showing water levels in A) shallow aquifer in July, 1995; B) shallow aquifer in January, 1996; C) deep aquifer in July, 1995; and D) deep aquifer in January, 1996.

42 Contour maps showing A) measured and simulated heads and B) residuals...... 134

43 Geophysical log responses and lithologic interpretation, core hole 3, Tuscarawas County, $\mathrm{OH}$. (Note scale change on two single point resistivity logs.)

44 Relative abundances of selected elements in lithologic units and FGD by-product samples. 139

45 Piper diagram of all water samples 140 
46 Boxplots of $\mathrm{pH}$, dissolved calcium, and dissolved magnesium in water samples. ( $\mathrm{pH}$ values for lysimeter round 1 were not obtained. Dissolved calcium and magnesium values for precipitation are near zero)

47 Boxplots of dissolved iron, dissolved sulfate and delta $34 \mathrm{~S}$ in sulfate in water samples (dissolved iron and sulfate values for precipitation were near

$48 \mathrm{pH}$ versus depth (in feet) for all water samples (note that $\mathrm{pH}$ values were

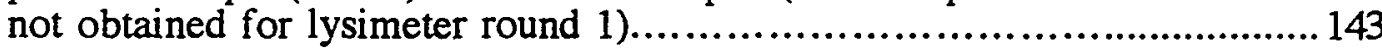

49 Dissolved sulfate versus depth (in feet) for all water samples................... 144

50 Dissolved calcium versus depth (in feet) for all water samples................... 145

51 Dissolved magnesium versus depth (in feet) for all water samples............... 146

52 Dissolved iron versus depth (in feet) for all water samples...................... 147

53 Dissolved cobalt versus depth (in feet) for all water samples.................... 148

54 Dissolved nickel versus depth (in feet) for all water samples.................... 149

55 Tritium concentration versus depth (in feet) for round 1 groundwater samples... 150

56 Delta $34 \mathrm{~S}$ in sulfate versus depth (in feet) for all water samples (note that delta $34 \mathrm{~S}$ in sulfate values were not obtained for lysimeter round 1).

57 Plot of magnesium:calcium mole ratio versus dissolved sulfate for all water samples.

58 Daily total precipitation (in inches) and specific conductance $(\mu \mathrm{S} / \mathrm{cm})$ for well cluster 4 for the time period $8 / 2 / 95$ through $1 / 31 / 96$.

59 Daily total precipitation (in inches) and water temperature $\left({ }^{\circ} \mathrm{C}\right.$ ) for well cluster 4 for the time period 8/2/95 through 1/31/96.

60 Daily total precipitation (in inches) and specific conductance $(\mu \mathrm{S} / \mathrm{cm})$

for well TU-109-W5S for the time period $8 / 2 / 95$ through $1 / 31 / 96$

61 Daily total precipitation (in inches) and water temperature $\left({ }^{\circ} \mathrm{C}\right.$ ) for

TU-109-W5S for the time period 8/2/95 through $1 / 31 / 96$.

62 Daily total precipitation (in inches) and specific conductance $(\mu \mathrm{S} / \mathrm{cm})$

for well cluster 8 for the time period $8 / 2 / 95$ through $1 / 31 / 96$......

63 Daily total precipitation (in inches) and water temperature $\left({ }^{\circ} \mathrm{C}\right.$ ) for well cluster 8 for the time period $8 / 2 / 95$ through $1 / 31 / 96$.

64 Calculated saturation indices in water for anhydrite, calcite and dolomite........ 177

65 Calculated saturation indices in water for alunite, ferrihydrite and goethite....... 178 
66 Calculated saturation indices in water for gibbsite, gypsum and magnesite....... 179

67 Calculated saturation indices in water for greigite and siderite...................... 180

68 Plots of chemical data for all water samples: A) pH versus dissolved iron;

B) $\mathrm{pH}$ versus dissolved nickel; $\mathrm{C}$ ) dissolved sulfate versus dissolved magnesium; and D) dissolved sulfate versus dissolved iron....................... 182

69 Location of road repair field study sites in Coshocton County (State Route 541) and Noble County (State Route 83)........................... 192

70 Landslide in the northbound shoulder of State Route 541 west of Coshocton, Ohio. Photograph taken in 1993

71 Delivery and placement of FGD at the base of the embankment during repair of State Route 541

72 Construction of the FGD buttress at the base of State Route 541................. 197

73 Temporary wearing surface on State Route 541 made from FGD................. 199

74 State Route 541 study site after repairs were completed (1994).................... 200

75 Vertical offset in pavement of State Route 83 (spring, 1993)..................... 201

76 Subsurface profile of State Route 83 in slide area............................... 202

77 Construction of the FGD key on State Route 83 (1994)............................ 204

78 Construction of the FGD/soil embankment section at the State Route 83 study site........................................................205

79 State Route 83 study site after completion of repairs (1994)...................... 206

80 Critical failure surface for the original embankment at State Route 541. Dashed lines represent the estimated location of the water table. 209

81 Potential failure surface for the repaired embankment at State Route 541. Shaded areas contain FGD. Dashed lines represent the estimated location of the water table.

82 Analyses of factor of safety for failure surface passing through the FGD buttress. The shaded areas contain FGD. Dashed lines represent the estimated location of the water table.

83 Analyses of a cross section through the reconstructed soil embankment showing the slip surface with the minimum factor of safety

84 Analyses of a cross section through the reconstructed FGD/soil mixture embankment showing the slip surface with the minimum factor of safety.

85 Analyses of a cross section through the reconstructed FGD

embankment showing the slip surface with the minimum factor of safety. 216 
86 Ettringite stability in alkaline environments (Hampson and Bailey, 1982)....... 221

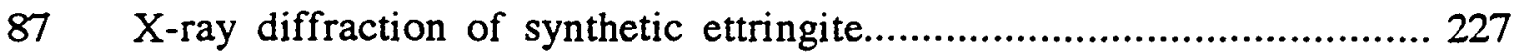

88 Ettingite solubility starting from undersaturated or supersaturated conditions.... 231

89 Total measured concentrations (on y axis) of $\mathrm{Ca}^{2+}, \mathrm{Al}^{3}+$ and $\mathrm{SO}_{4}{ }^{2-}$ ions

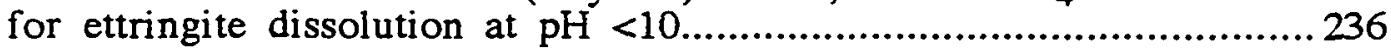

$90 \mathrm{Ca}^{2}+$ and $\mathrm{SO}_{4} 2-$ ion activities for ettringite dissolution at $\mathrm{pH}<10$. Activities (in parentheses) are plotted in log units against $\mathrm{pH}$. Possible mineral phases are also shown (see next page for complete description) 238

$91 \quad \mathrm{Al}^{3}+$ ion activities for ettringite dissolution at $\mathrm{pH}<10$. Activities (in parentheses in log units) are plotted against $\mathrm{pH}$ with possible mineral phases. The solid symbols represent experimental results. Lines are drawn for different mineral phases by fixing the activities of all ions except the ion of interest. Open symbols represent the same but by considering the variability in activities of components. $\mathrm{p}\left(\mathrm{Ca}^{2+}\right)=2.5 ; \mathrm{p}\left(\mathrm{SO}_{4}{ }^{2-}\right)=3.0 ;$ and $\mathrm{p}\left(\mathrm{Al}^{3+}\right)=21.0$ for ettringite and 6.5 for jurbanite and basaluminite 239

92 Mineral stability diagram for the $\mathrm{Ca}-\mathrm{Al}-\mathrm{SO}_{4}-\mathrm{H}_{2} \mathrm{O}$ system. Open circles are experimental data points and the solid line with arrow represents the reaction path predicted using EQ3/6. Estimated $\mathrm{Al} 3+$ activity in the flyash leach and acid mine spoils are also plotted. $\nabla$, Sullivan et al. (1988); 口, Fruchter et al. (1990); $\diamond$, flyashes and $\Delta$, FGD (Mattigod et al., 1990)...... 242

$93 \mathrm{X}$-ray diffraction of ettringite incongruent dissolution products. Peaks around $9.32 \theta$ and $11.82 \theta$ correspond to ettringite and gypsum, respectively....

94 Energy dispersive $x$-ray analysis of different mineral phases (size $<50 \mu \mathrm{m}$ ) of ettringite incongruent dissolution products ( $\mathrm{pH}$ range 4.0 to 6.0 ). a, Al-hydroxy sulfate; b, Al-hydroxides; $c \& d$, Ca-Al-hydroxy-sulfates; and e, gypsum. The samples were coated with graphite prior to measurements. 244

95 Map of Franklin County landfill study sites. 254

Compensating variation for distance from a landfill. 261

Idealized relationship between compensating variations and time. 268 292

99 Effects of landfilling cost on quantities of FGD by-product landfilled and used in alternative uses (i.e. road repair and surface mine reclamation)...... 294 


\section{TABLES}

Table

1 Characterization of the 0 to $20 \mathrm{~cm}$ depth layer of the Wooster, Coshocton,

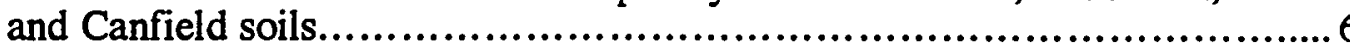

2 Characterization of FGD by-products used as an agricultural limestone substitute

3 Amount of FGD by-product applied to the Wooster, Coshocton, and Canfield soils at each lime requirement rate factor.

4 Effect of FGD on Melich3 extractable trace element concentrations in Wooster, Coshocton, and Canfield soils.

$5 \mathrm{~N}, \mathrm{Al}, \mathrm{As}, \mathrm{B}, \mathrm{Ba}, \mathrm{Ca}, \mathrm{Cd}, \mathrm{Cr}$ and $\mathrm{Cu}$ concentrations in alfalfa tissue and corn grain grown on the Wooster soil amended with FGD.

$6 \mathrm{Fe}, \mathrm{K}, \mathrm{Mg}, \mathrm{Mn}, \mathrm{Mo}, \mathrm{Na}, \mathrm{Ni}, \mathrm{P}, \mathrm{S}$ and $\mathrm{Zn}$ concentrations in alfalfa tissue and corn grain grown on the Wooster soil amended with FGD

7 Effect of FGD treatment (1 $\times$ LR) on bulk density, moisture content and saturated conductivity under simulated rain in 1993 under corn

8 Effect of FGD treatment (1 x LR) on peak runoff rate and total runoff measured in the summer of 1993 with simulated rain on a site growing corn and alfalfa.

9 Effect of FGD treatment (1 x LR) on soil erosion measured with simulated rain on a site growing corn and alfalfa

10 Analyses of mine spoil and FGD used in the column experiment.

11 Effect of type and rate of FGD amendment on alfalfa and fescue seed germination in 1992

12 Effect of type and rate of FGD amendment on number of alfalfa and fescue plants per column in 1992, 1993 and 1994.

13 Effect of type and rate of FGD amendment on dry matter production (g/column) of alfalfa and fescue plants in 1992 and 1993a

14 Ranges and means of $\mathrm{pH}$ and $\mathrm{Al}, \mathrm{Ca}, \mathrm{Fe}$ and $\mathrm{K}$ concentrations as affected by type and rate of FGD application during the years 1992 through 1994

15 Ranges and means of $\mathrm{Mn}, \mathrm{SO}_{4}, \mathrm{Mn}$ and $\mathrm{NO}_{3}$ concentrations as affected by type and rate of FGD application during the years 1992 through 1994. 
16 Chemical properties (as determined by the US Geological Survey) of replicate samples of materials used in the Fleming reclamation field study including FGD by-products (PFBC and AFBC materials), yard-waste compost, mixtures of FGD and compost, and a kiln dust sample.

17 Chemical characterization of minespoil, topsoil, yard-waste compost,

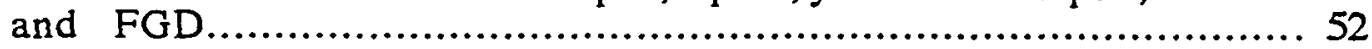

18 List of constituents, analytical methods, and reporting limits for precipitation and other water samplesa.

19 Construction data for the 35 soil-suction lysimeters at the study site...............65

20 Description of monitoring wells installed at the Fleming Site.......................68

21 Summary of analyzing laboratory, analyte class, bottle type, sample volume, and sample preparation and preservation for water samplesa........... 71

22 Onsite chemical stability criteria for monitoring-well purging.....................75

23 Summary of water properties and constituents measured onsite by US Geological Survey personnel. ............................................76

24 Types of internal quality control samples and their purpose, frequency of use, and expected results/acceptance criteria. 77

25 Types of external quality control samples and their purpose, frequency of use, and expected results/acceptance criteria........................................ 78

26 Groundwater flow model input parameters and stresses..........................84

27 Comparison of observed and simulated heads and flows for the

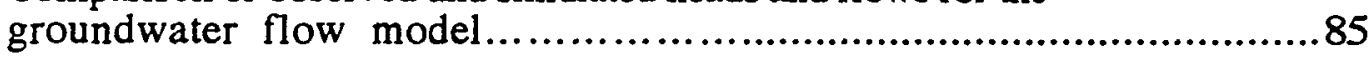

28 Mehlich3 extractable concentrations of trace elements in Fleming spoil reclaimed with topsoil, FGD, and FGD+compost.

29 Dioxin concentrations in FGD, compost, FGD/compost mixes and minespoil applied to the Fleming site (7/29/94)...

30 Tissue composition of vegetation grown on minespoil reclaimed with topsoil, FGD, and FGD+compost.

31 Concentrations of trace elements in pond water and in surface runoff water from minespoil reclaimed with topsoil, FGD, and FGD+compost. Values are means and maximum levels of all flow events in the spring and summer of 1995.

32 Concentrations of trace elements in tile flow water from minespoil reclaimed with topsoil, FGD, and FGD+compost. Values are means and maximum levels of all flow events in the spring and summer of 1995 . 
33 Equilibrium and cumulative infiltration, as determined by the double-ring infiltrometer, in the unreclaimed underclaya

34 Treatment effects on surface runoff and soil erosion for a rainstorm event received on 29 June 1995 (Rainfall $=50.8 \mathrm{~mm}$ ).

35 Effects of reclamation treatments on runoff and soil erosion in 1996 (Rainfall $=829.8 \mathrm{~mm})$.

36 Results of slug test analysis on thirteen wells 122

37 Water levels ( $\mathrm{ft}$ above mean sea level) in monitoring wells for the period June, 1995 through January, 1996.

38 Summary of geologic and geophysical data (in meters above sea level) for the spoil/clay layer.

39 Ranges and medians of selected water quality consituents categorized by sample type.

40 Comparison of median values of selected constituents from pre-mining water quality in the Lower Kittanning Coal with median values in the shallow aquifer obtained in this study.

41 Typical soil properties used for analyses of the State Route 541 study site..... 208

42 Engineering properties of FGD and FGD stabilized soil used for analyses of the State Route 83 study site.

43 Chemical analysis of synthetic ettringites.................................... 228

44 Solubility data from three replicates used to determine the solubility product constant (ett. $\mathrm{K}_{\mathrm{sp}}$ ) for ettringite in under-saturated and supersaturated solutions.

45 Values of the solubility product constant (ett. $\mathrm{K}_{\mathrm{sp}}$ or more specifically the ion activity product, IAP) for ettringite determined from the solubility data presented in Table $41 \mathrm{a}$

46 Chemical analysis of synthetic ettringite sample ETT2 before and after solubility measurements. All elements of the solid are reported as the number of moles per one mole of ettringite and are normalized to six moles of $\mathrm{C}$

47 Effect of $\mathrm{pH}$ and suspension concentration on ettringite solubility. The solubility product constant (ett. $\mathrm{K}_{\mathrm{sp}}$ ) was calculated on the basis of Equation 1. Ion activities are reported as $p$ (ion).

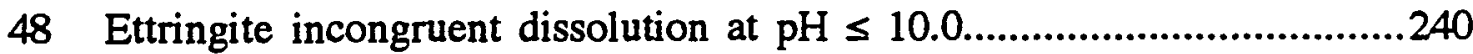

49 Key descriptive statistics for variables included in the second stage estimates of nonmarket valuation of landfilling FGD by-product 
50 Compensating variation (CV) measuresa............................... 262

51 Landfill life expectancy and compensating variation measures for landfills in Franklin County................................................ 267

52 Decay rate and total rate of discount for life of the landfill....................... 269

53 Net present value factors for benefits transfer from Franklin County landfills... 269

54 Descriptive statistics used to estimate cost transfer benefits from the census block group data.

55 Analyses of variance for the final predictive model for benefits transfer $\left(R^{2}=0.93\right)$

56 Regression results of the hedonic pricing model applied to data from

Leesville Lake and Piedmont Lake $\left(n=104 ; R^{2}=0.513\right.$; adjusted

$R^{2}=0.435 ; F=5.27$ )

57 Marginal implicit prices as affected by distance in meters from the impacted area of the lake.

58 Estimation of Aggregate Benefits of reclamation of surface coal mines in rent equivalents determined from the hedonic pricing model.

59 Summary of shipment estimates obtained from the linear optimization model (values in parentheses are percentages).

D-1 Geochemical data for aquifer materials from three core holes at the Fleming site.

D-2 Water quality data collected at the precipitation gage at the Dover Water Works, Dover, Ohio (February 1995 - December 1995). 342

D-3 Monitoring well water quality data in samples collected from sites surrounding the Fleming Site (June 1995 - January 1996). 346

D-4 Domestic well water quality data in samples collected from sites surrounding the Fleming Site (June 1995) 353

D-5 Interstitial water quality data in lysimeter samples collected from sites within the FGD treated areas of the Fleming Site (June 1995 - January 1996).. 357

D-6 Interstitial water quality data in control area lysimeter samples and surface water quality data in samples collected from the Fleming Site (June 1995 - January 1996).

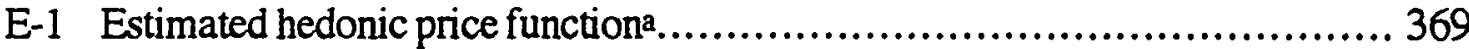

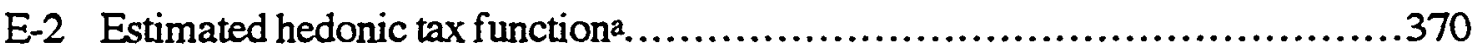

E-3 Mean willingness to pay curves (MWTP) for the translog utility specification.. 371 
E-4 Social cost transfer estimate worksheets for Conesville, Gavin and Zimmer landfills.

E-5 Cost transfer model worksheets for Conesville, Gavin and Zimmer landfills....375

F-1 Results of equipment blanks for quality-control sample analyses for lysimetersa.

F-2 Quality-control analyses of field blanks and trip blanks, sampling round 1......384

F-3 Quality-control analyses of equipment blanks and field blanks, sampling rounds 2 and 3

F-4 Quality-control analyses of blind samples, sampling round 1................... 388

F-5 Quality-control analyses of blind samples, sampling round 2.....................391

F-6 Quality-control analyses of blind sample A3 (sampling round 3)..................392

F-7 Quality-control analyses of split and replicate samples, sampling round 1 . Results are given in relative percent deviation between

OARDC and NWQL split samples or two OARDC split samples.

F-8 Quality-control analyses of split and replicate samples (sampling round 3)a.... 397

F-9 Summary of round 1 samples that did not meet acceptance criteria for field/laboratory comparison of $\mathrm{pH}$, specific conductance, and alkalinity data.

F-10 Field /laboratory comparisons of $\mathrm{pH}$, specific conductance, and alkalinity for round 2 and 3 samples. 402

F-11 Charge-balance errors for round 1 samples evaluated with sulfate data generated by ion chromatography (IC) and.inductively-coupled plasma (ICP) methods 409

F-12 Charge-balance errors for round 2 and 3 samples evaluated with sulfate data generated by ion chromatography (IC) and inductively coupled plasma (ICP) methods. 


\section{1}

\section{INTRODUCTION}

\subsection{Background and Project Description}

The Clean Air Act, as amended in 1992, confirmed the need to develop and implement processes for sulfur dioxide $\left(\mathrm{SO}_{2}\right)$ removal from flue gases when sulfur-containing coal is burned. Some of these flue gas desulfurization (FGD) processes generate by-product material consisting of various amounts of calcium-based excess sorbent, reaction products containing sulfates/sulfites and fly ash (Batelle, 1989).

Studies indicate that as much as 7,000 to 11,000 megawatts of Ohio electric utility generating capacity may be required to install some type of FGD system (Ohio Electric Institute, 1986). In 1996, approximately 21.7 million tons of FGD were produced in the United States (American Coal Ash Association, 1997). Presently FGD by-product materials are generally treated as solid waste and landfilled. However, landfill sites are becoming scarce and tipping fees are increasing. Provided the environmental consequences of FGD by-product materials reuse are socially acceptable, it is highly desirable to find beneficial uses for these materials.

In December of 1990, this project was initiated to demonstrate high volume uses of dry FGD by-product materials which can substitute for other materials now being used for land reclamation (e.g. reclamation of abandoned acid surface coal mine lands), agriculture, and soil stabilization. The work presented in this report, however, is not restricted to only dry FGD byproducts and additional materials produced by other FGD technologies have also been studied.

This project was conducted by The Ohio State University with cooperation from the United States Geological Survey. Dravo Lime Company (Pittsburgh, PA) was the prime contractor with additional direction being provided by a steering committee made up of representatives from funding organizations, industry, state regulatory agencies and a citizen's group (Appendix C). 
Project objectives were developed over an 18-month period during extensive discussions with personnel from industry, regulatory agencies, and research institutions. The specific objectives of the project were as follows:

1. To characterize the material generated by dry FGD processes,

2. To demonstrate the utilization of dry FGD by-products as a soil amendment material on agricultural lands and on abandoned and active surface coal mines in Ohio,

3. To demonstrate the use of dry FGD by-product as an engineering material for soil stabilization,

4. To determine the quantities of dry FGD material that can be utilized in each of these applications,

5. To determine the environmental and economic impact of utilizing the material, and

6. To calibrate environmental, engineering, and economic models that can be used to determine the applicability and costs of utilizing these processes at other sites.

This study was conducted at The Ohio State University main campus (Columbus), at The Ohio Agricultural Research and Development Center (Wooster), at The Ohio State University branch stations, at field-scale active and abandoned coal mine sites, and at various other sites in Ohio. The project was divided into three phases. The first phase focused on characterization of FGD by-products and collection of baseline economic data. Results obtained during the first phase of the project are reported in the Phase 1 report (Stehouwer et al., 1995a). The second phase focused on laboratory, greenhouse and field studies of mixtures of FGD by-products and soil or spoil and the development of economic models (Stehouwer et al., 1998). This third phase primarily focuses on field demonstrations of various high volume uses for FGD by-products and the development of environmental and economic models.

\subsection{Phase 3 Objectives}

The specific objectives for Phase 3 of this project are summarized below.

1. To determine the beneficial use of FGD by-products as an amendment material on agricultural lands and on abandoned surface coal mine land.

2. To conduct field studies to test the beneficial use of FGD by-products as an engineering material for soil stabilization and road repair.

3. To assess the environmental and economic impacts of such beneficial uses. 


\subsection{Approach}

Several different sources and types of FGD materials were used in this study. It may be useful to refer to the following paragraphs, and the Phase 1 and Phase 2 reports (Stehouwer et al., 1995a; 1998), if more information about a specific type of FGD by-product is needed. A brief description of the major types of FGD involved in the various projects described in this report is provided below.

Duct Injection. Sorbent (hydrated lime) is injected into the flue gas as it enters an humidification chamber in the ductwork downstream of the boiler and air heater. The sorbent reacts with the sulfur dioxide gas and a dry FGD by-product is formed that is removed from the flue gas stream in a baghouse or electrostatic precipitator. This by-product contains the reaction products, fly ash and unspent sorbent. In most configurations, recycling and reinjection of the FGD by-product with fresh hydrated lime is a option to reduce requirement for fresh sorbent.

Lime Injection Multistage Burner (LIMB). In the LIMB process, a calcium-based sorbent is injected into the boiler where it calcines to $\mathrm{CaO}$ and reacts with sulfur dioxide and oxygen to form calcium sulfate. The reaction product and unspent sorbent are collected with particulate emission control systems.

Fluidized Bed Combustion (FBC). In FBC systems, a calcium-based sorbent (usually limestone or dolomite) and crushed coal are introduced together into the boiler bed where they are "fluidized" or suspended by jets of air. The fluidizing process intimately mixes the coal and sorbent. Two FGD by-products are created-the heavier, granular-bed ash material and the smaller particles suspended in the flue gas which are removed with the particulate emission control systems.

Spray Dryer. Flue gases enter a separate scrubber vessel located downstream of the boiler and air heater where sorbent, usually a slurry of hydrated lime, is injected. The scrubber vessel increases the residence time of the flue gas and therefore lengthens the time period the injected sorbent can react with sulfur dioxide. Reaction products and unspent sorbent are removed together with the fly ash in the particulate emission control systems.

Wet FGD By-Products. Wet FGD by-product materials are created when a mist of hydrated lime slurry is injected into the flue gas downstream from the particulate removal devices. The 
sulfur dioxide reacts with the lime to primarily form calcium sulfite which is separated from the slurry by a belt filter. The filter cake is then combined with fly ash and 2-3\% additional lime to improve the handling characteristics and strength development for landfilling. In some cases, air is forced into the reaction to create a product that is primarily calcium sulfate instead of calcium sulfite.

The phase 3 objectives were accomplished by designing field studies in Ohio in which FGD by-products were applied to soils at three sites as an agricultural limestone substitute, for reclamation of an acid and toxic abandoned surface coal mine site and for road repair at two sites. The experimental designs were based on results obtained from laboratory and greenhouse studies conducted during Phases 1 and 2 of this project. The most extensive data set was obtained at the surface coal mine reclamation site where $280 \mathrm{Mg} / \mathrm{ha}$ ( 125 tons/acre) of FGD were applied alone or with $112 \mathrm{Mg} / \mathrm{ha}$ ( 50 tons/acre) of yard waste compost. The impacts of this use of FGD were determined by monitoring surface and groundwater quality, soil quality and plant quality on the FGD-treated sites versus results obtained at the same site but reclaimed using resoil material.

An analysis of the potential economic impacts was also conducted as part of Phase 3. This portion of the report provides the development of conceptual economic models, the statistical estimation procedures, results, and implications for future policies related to FGD by-product utilization.

The Phase 3 report is divided into chapters that are based on the field and economic studies conducted. Chapter 2 describes the results of the field studies in which FGD by-product was used as an agricultural limestone substitute. An extensive description of the use of FGD byproduct to reclaim an acid and toxic abandoned surface coal mine site is presented in Chapter 3. Chapter 4 describes the use of FGD by-product materials for road construction/repair. The chemistry of ettringite, an important mineral formed by many alkaline FGD by-products, is presented in Chapter 5. The economics portion of this study is presented in Chapter 6. Various appendices provide a listing of References cited, a glossary of terms, the steering committee members that provided guidance during the study, and other supplementary data. 


\section{2}

\section{USE OF A DRY FGD BY-PRODUCT AS A LIMING MATERIAL FOR ACIDIC AGRICULTURAL SOILS}

\subsection{Introduction}

Because of their alkalinity, one possible beneficial use for dry FGD by-products is as a limestone substitute for amendment of acidic agricultural soils. Land application of fluidized bed combustion by-products (one type of dry FGD by-product) as a lime substitute and a source of $\mathrm{Ca}$ and $\mathrm{S}$ has been investigated in a number of studies (Holmes et al., 1979; Korcak, 1980; Stout et al., 1979; Terman et al., 1978). These studies have generally reported positive effects on plant growth and crop yield, with negative effects occurring only at application rates of $25 \mathrm{wt} \%$ or higher. Most studies with fluidized bed materials have investigated soil $\mathrm{pH}$ and plant responses, with little emphasis on potential environmental impacts. We have investigated the responses of alfalfa (Medicagosativa L.) and com (Zea mays L.) grown on three acidic agricultural soils amended with a dry FGD by-product applied at rates based on the liming requirement of the soils. In addition to crop responses, soil chemical effects and transport of the FGD material were monitored.

\subsection{Materials and Methods}

Two studies were conducted to evaluate the potential of various FGD by-products for use as an agricultural liming material.

\subsubsection{Experiment 1}

Field studies were conducted on three acidic agricultural soils located at Wooster, Coshocton, and Canfield in northeastern Ohio. Characteristics of these soils are given in Table 1. Dry FGD by-product was obtained from a pressurized fluidized bed combustion (PFBC) boiler. The 
Table 1. Characterization of the 0 to $20 \mathrm{~cm}$ depth layer of the Wooster, Coshocton, and Canfield soils.

\begin{tabular}{|c|c|c|c|c|c|c|c|c|}
\hline \multirow[b]{2}{*}{ Soil } & \multirow[b]{2}{*}{ Classification } & \multirow{2}{*}{$\begin{array}{c}\mathrm{LRa} \\
(\mathrm{Mg} / \mathrm{ha})\end{array}$} & \multirow[b]{2}{*}{$\mathrm{pH}$} & \multirow{2}{*}{$\begin{array}{r}\text { Bray } \\
\mathrm{P}_{1} \mathrm{~b}\end{array}$} & \multicolumn{3}{|c|}{$\begin{array}{l}\text { Exchangeable cations } \\
(\mathrm{mg} / \mathrm{kg})\end{array}$} & \multirow[b]{2}{*}{ CECc } \\
\hline & & & & & $\mathrm{K}$ & $\mathrm{Ca}$ & $\mathrm{Mg}$ & \\
\hline Wooster & $\begin{array}{l}\text { Aquic } \\
\text { Fragiudalf }\end{array}$ & $34.4(20.6)$ & 4.6 & 9 & 103 & 430 & 85 & 15.7 \\
\hline Coshocton & $\begin{array}{l}\text { Aquic } \\
\text { Hapludalf }\end{array}$ & $22.8(13.7)$ & 4.8 & 9 & 118 & 300 & 87 & 12.1 \\
\hline Canfield & $\begin{array}{l}\text { Typic } \\
\text { Fragiudalf }\end{array}$ & $4.7(2.8)$ & 5.8 & 29 & 171 & 1130 & 29 & 8.7 \\
\hline
\end{tabular}

aLR; lime requirement is the amount of ag-lime required to raise soil $\mathrm{pH}$ to 7 . Values in parentheses are the LRs in tons/acre.

bBray $P_{1}$ is a measure of plant available $P$ in soil.

${ }^{c} \mathrm{CEC}$; cation exchange capacity.

PFBC boiler produced two by-product streams: a coarse, granular bed material, and a much finer, particulate material collected in a primary cyclone. The FGD by-product used in this study was a 40:60 (wt/wt) mixture of the bed and cyclone materials which was blended in a ready mix cement truck prior to land application. Because a dolomitic limestone was used for $\mathrm{SO}_{2}$ removal, the $\mathrm{Mg}$ concentration in the by-product was much higher than if calcitic limestone was used. This has implications regarding the reactivity of the by-product after it is land applied. Other characteristics of the by-product are presented in Table 2.

The FGD was applied in September 1992 at rates equivalent to 0, 0.5, 1, and 2 times the lime requirement (LR) of each soil. The soil's LR was determined by use of the SMP buffer method (Shoemaker et al., 1962). The amount of calcium carbonate required to raise the soil pH to 7 
Table 2. Characterization of FGD by-products used as an agricultural limestone substitute.

\begin{tabular}{|c|c|c|}
\hline Parameter & FGD, cyclone & FGD, bed \\
\hline $\mathrm{pH}$ & 10.5 & 12.2 \\
\hline $\mathrm{CaCO}_{3}$ equivalence $\%$ & 60.3 & 60.0 \\
\hline Coal Ash & 32.1 & 10.0 \\
\hline \multicolumn{3}{|c|}{ Particle size distribution, \% } \\
\hline$>2 \mathrm{~mm}$ & 0.0 & 4 \\
\hline $2-0.1 \mathrm{~mm}$ & 0.0 & 95 \\
\hline $100-50 \mu \mathrm{m}$ & 23.5 & 1 \\
\hline $50-2 \mu \mathrm{m}$ & 76.1 & 0 \\
\hline$<2 \mu \mathrm{m}$ & 0.4 & 0 \\
\hline \multicolumn{3}{|l|}{ Major minerals, \% } \\
\hline Dolomite & 25 & $\mathrm{NDa}$ \\
\hline Anhydrite & 22 & 36 \\
\hline $\begin{array}{l}\text { Periclase } \\
\text { Total Chemical Analysis }\end{array}$ & Total Chemical Analysis & 27 \\
\hline $\mathrm{Al}(\%)$ & 3.93 & 2.75 \\
\hline As (mg/kg) & 75.0 & 46.7 \\
\hline $\mathrm{B}(\mathrm{mg} / \mathrm{kg})$ & 169 & 206 \\
\hline $\mathrm{Ca}(\%)$ & 17.5 & 24.4 \\
\hline $\mathrm{Cd}(\mathrm{mg} / \mathrm{kg})$ & 1.0 & 3.5 \\
\hline $\mathrm{Cr}(\mathrm{mg} / \mathrm{kg})$ & 36.9 & 17.5 \\
\hline $\mathrm{Cu}(\mathrm{mg} / \mathrm{kg})$ & 35.0 & 913 \\
\hline $\mathrm{Fe}(\%)$ & 5.17 & 2.08 \\
\hline$K(\%)$ & 0.53 & 0.14 \\
\hline $\mathrm{Mg}(\%)$ & 10.6 & 16.3 \\
\hline $\mathrm{Pb}(\mathrm{mg} / \mathrm{kg})$ & 24.5 & 28.0 \\
\hline$S(\%)$ & 5.21 & 8.64 \\
\hline Si $(\%)$ & 7.24 & 45.3 \\
\hline
\end{tabular}

aNot detected. 
was divided by the $\mathrm{CaCO}_{3}$ equivalency of the FGD $(0.60)$ and multiplied by the lime requirement rate treatment factor to arrive at the amount of FGD to be applied to each of the three soils (Table 3). The FGD was surface-applied using a lime spreader and then incorporated to a depth of $10 \mathrm{~cm}$ with a rototiller. Separate plots of each treatment were planted to alfalfa and corn. Alfalfa was planted immediately after FGD incorporation, while com plots were seeded with a rye (Secale cereale L.) cover crop. In the spring of 1993 the rye cover was killed with glyphosate ( $N$-(phosphonomethyl)glycine), and corn was planted in early May. In 1994 the corn was also planted in early May using no-tillage practices. No soil disturbance of any kind was applied to the site after initial site preparation and planting of the crops was completed in 1993. Corn plots were fertilized with $\mathrm{N}, \mathrm{P}$, and $\mathrm{K}$, and alfalfa plots with $\mathrm{P}$ and $\mathrm{K}$ according to soil test and The Ohio Agronomy Guide (1990) recommendations.

All FGD rate and crop treatment combinations were replicated four times at each location using a randomized complete block experimental design. Corn and alfalfa were run as separate experiments.

Soil samples were collected from all plots immediately after FGD application and again in the spring and fall of 1993 and 1994. Samples were collected in 10-cm depth increments to a depth of $20 \mathrm{~cm}$ in the first sampling and up to $110 \mathrm{~cm}$ in subsequent samplings. Soil samples were air-dried, crushed, and passed through a 2-mm sieve. Soil pH was determined in a 1:1 (soil:water, wt/wt) paste, and water extracts were prepared by shaking a 1:10 (soil:water, $w t / w t)$ mixture for $30 \mathrm{~min}$, followed by filtering though a $0.45 \mu \mathrm{m}$ membrane filter. Water extracts were analyzed for $\mathrm{Al}, \mathrm{As}, \mathrm{B}, \mathrm{Ba}, \mathrm{Be}, \mathrm{Ca}, \mathrm{Cd}, \mathrm{Co}, \mathrm{Cr}, \mathrm{Cu}, \mathrm{Fe}, \mathrm{K}, \mathrm{Li}, \mathrm{Mg}, \mathrm{Mn}, \mathrm{Mo}$, $\mathrm{Na}, \mathrm{Ni}, \mathrm{P}, \mathrm{Pb}, \mathrm{S}, \mathrm{Sb}, \mathrm{Se}, \mathrm{Si}, \mathrm{Sr}, \mathrm{V}$, and $\mathrm{Zn}$ by inductively coupled plasma emission spectrophotometry (ICP). Soil samples collected from the 0 and the $2 \times$ LR treatments were also extracted using the Mehlich3 extractant (Mehlich,1984) at a 1:10 (soil:extractant, wt/wt) ratio and shaking for $30 \mathrm{~min}$. Mehlich 3 extracts were filtered through a $0.45 \mu \mathrm{m}$ filter and analyzed by ICP for the elements listed above.

In 1993, two cuttings of alfalfa were made at Wooster and Coshocton and one cutting at Canfield. In 1994 and 1995 three cuttings of alfalfa were made at all three locations. Com grain was harvested at all locations in 1993, 1994, and 1995. Harvested alfalfa and corn grain were dried, weighed, ground, digested and analyzed by ICP for the elements listed previously. 
Table 3. Amount of FGD by-product applied to the Wooster, Coshocton, and Canfield soils at each lime requirement rate level.

\begin{tabular}{cccc}
\hline \multirow{2}{*}{$\begin{array}{c}\text { Fraction of lime } \\
\text { requirement }\end{array}$} & \multicolumn{3}{c}{ Amount of FGD by-product applied to soil $(\mathrm{Mg} / \mathrm{ha})^{\mathrm{a}}$} \\
\cline { 2 - 4 } & Wooster & Coshocton & Canfield \\
\hline 0.0 & 0.0 & 0.0 & 0.0 \\
0.5 & 17.5 & 11.5 & 2.5 \\
1.0 & 35.0 & 23.0 & 5.0 \\
2.0 & 70.0 & 46.0 & 10.0 \\
\hline
\end{tabular}

aTo convert to tons/acre multiply the $\mathrm{Mg} / \mathrm{ha}$ value by 0.446 .

\subsubsection{Experiment 2}

At the same field experiment site at Coshocton as described for Experiment 1 (above) we also evaluated the impact of FGD application rate on soil physical properties, surface water runoff and soil erosion. This site has a $11 \%$ slope and contains 1.5 to $2.0 \%$ organic matter in the top $20 \mathrm{~cm}$ ( 8 inches) of soil. A factorial experimental design was used and included two rates of FGD application ( 0 and $22.5 \mathrm{Mg} /$ ha which is equivalent to 0 and 10 tons/acre), two crops (alfalfa and com) and four replications. The amount of FGD applied corresponded to the lime requirement rate as described previously.

Soil physical properties were measured in 1993 and included moisture retention characteristics (Klute, 1986), bulk density (Klute, 1986), and saturated hydraulic conductivity (Blake and Hartge, 1986). Erosion estimates from the treated plots were made by using an instrument to deliver artificial rain. This instrument, called a rainulator, was built at Purdue University according to specifications described by Norton and McAfee (1992). Artificial rainfall was 
applied at two different times during the year. In 1993 the rains were applied when the corn was 12 to 14 weeks old and then again after harvest. In 1994 the rains were applied to the corn before planting and then again when the plants were 8 to 10 weeks old. The alfalfa plots were rained on at the same time as were the corn plots. A high intensity rainstorm was applied to achieve extreme conditions and thus maximize effects on runoff and surface water quality. The rains applied were $7.5 \mathrm{~cm}$ in 30 minutes (equivalent to 6 inches/hours).

\subsection{Results and Discussion}

Applications to acid soils of dry FGD by-product was effective in improving alfalfa growth but seemed to have little effect on corn growth. The FGD also impacted soil properties. Results are presented separately for each experiment.

\subsubsection{Experiment 1}

\subsubsection{Soil Chemistry}

The FGD material (i.e. PFBC by-product) used in this study was clearly effective as a liming material. Soil pH was rapidly raised in the Wooster and Coshocton soils, and the increase was sustained throughout the study (Figs. 1 and 2). In the Canfield soil no effect on $\mathrm{pH}$ was seen immediately after incorporation, although $\mathrm{pH}$ in the zone of incorporation did increase during the next 8 mo with the $2 \times$ LR rate (Fig. 3). Apparently the SMP buffer underestimated the lime requirement of this moderately acidic soil, and an insufficient amount of FGD was applied.

The major elements in the FGD are $\mathrm{Ca}, \mathrm{S}$, and $\mathrm{Mg}$ (Table 2), and in each soil, application of FGD increased the water-soluble levels of these elements (Figs. 4 to 6). The greatest effects on water soluble concentrations of $\mathrm{Ca}, \mathrm{Mg}$, and $\mathrm{S}$ occurred in the Wooster and Coshocton soils where the $1 \times$ LR rates were equivalent to 35 and $23 \mathrm{Mg} /$ ha, respectively. In the Canfield soil, where the $1 \times$ LR rate was only $5 \mathrm{Mg} / \mathrm{ha}$, the effects of FGD application on $\mathrm{Ca}, \mathrm{Mg}$, and $\mathrm{S}$ were much less. In the Wooster and Coshocton soils there was definite movement of surface applied $\mathrm{Ca}, \mathrm{Mg}$, and $\mathrm{S}$ to a depth of at least $60 \mathrm{~cm}$ within the first year after surface application, and up to $120 \mathrm{~cm}$ after two years. Such rapid movement was expected with $\mathrm{S}$ which was present almost entirely as the sulfate anion $\left(\mathrm{SO}_{4}{ }^{2-}\right)$. In the case of $\mathrm{Ca}$ and $\mathrm{Mg}$, both of which were present as divalent cations, this represented more rapid movement than would be expected to result from surface application of either limestone $\left(\mathrm{CaCO}_{3}\right)$ or dolomite $\left(\mathrm{CaMg}\left(\mathrm{CO}_{3}\right)_{2}\right)$. The greater mobility of $\mathrm{Ca}$ was because much of the $\mathrm{Ca}$ in the $\mathrm{FGD}$ was present as $\mathrm{CaSO}_{4}$, which 


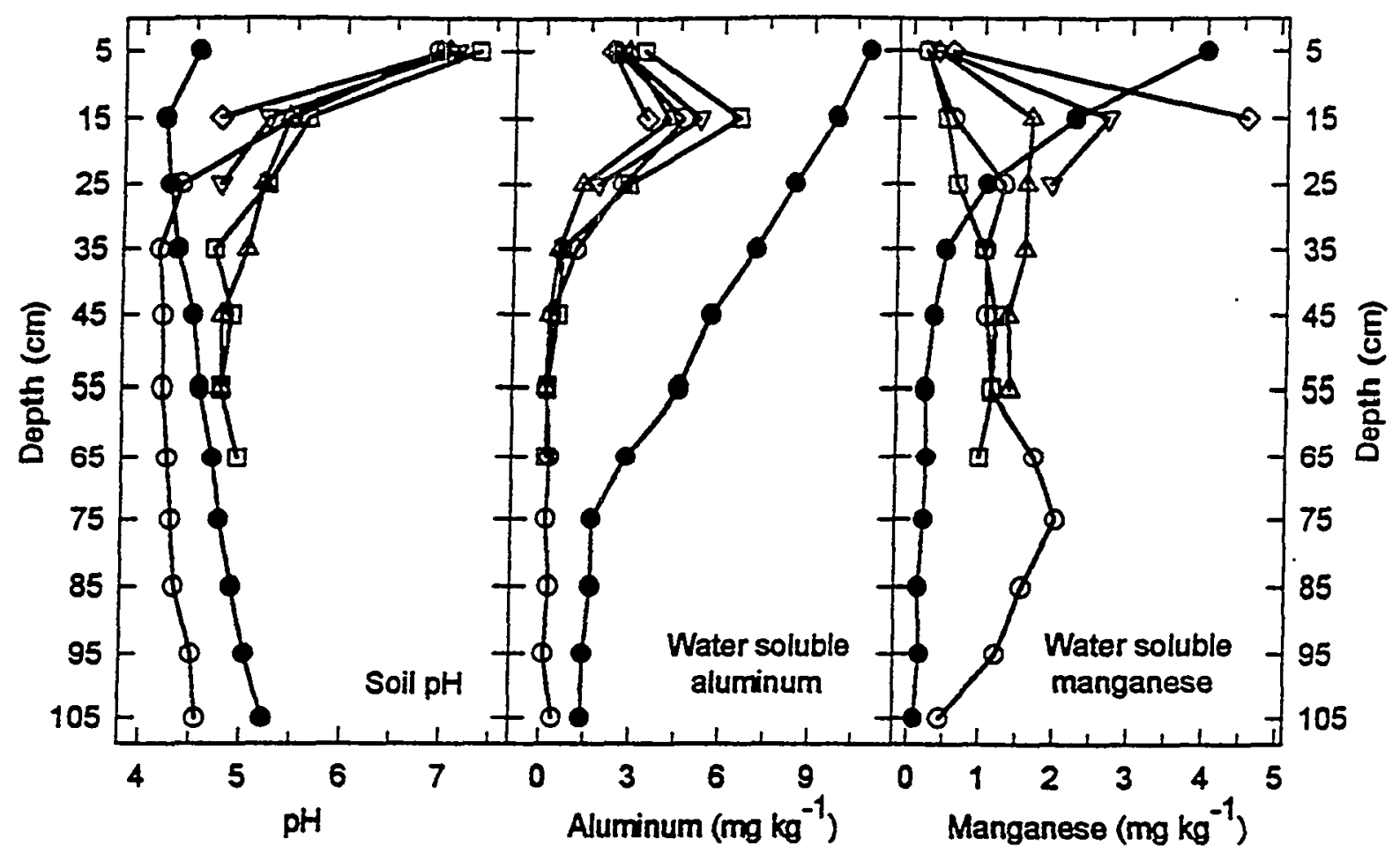

$$
\begin{array}{lll}
\rightarrow \text { Control } & - \text { Spring } 1993-\text { Spring } 1994 \\
- \text { Fall } 1992 \rightarrow \text { Fall } 1993 & \leftarrow \text { Fall } 1994
\end{array}
$$

Figure 1. Effect of FGD on soil $\mathrm{pH}$ and on water soluble aluminum and manganese concentrations in the Wooster soil profile. 


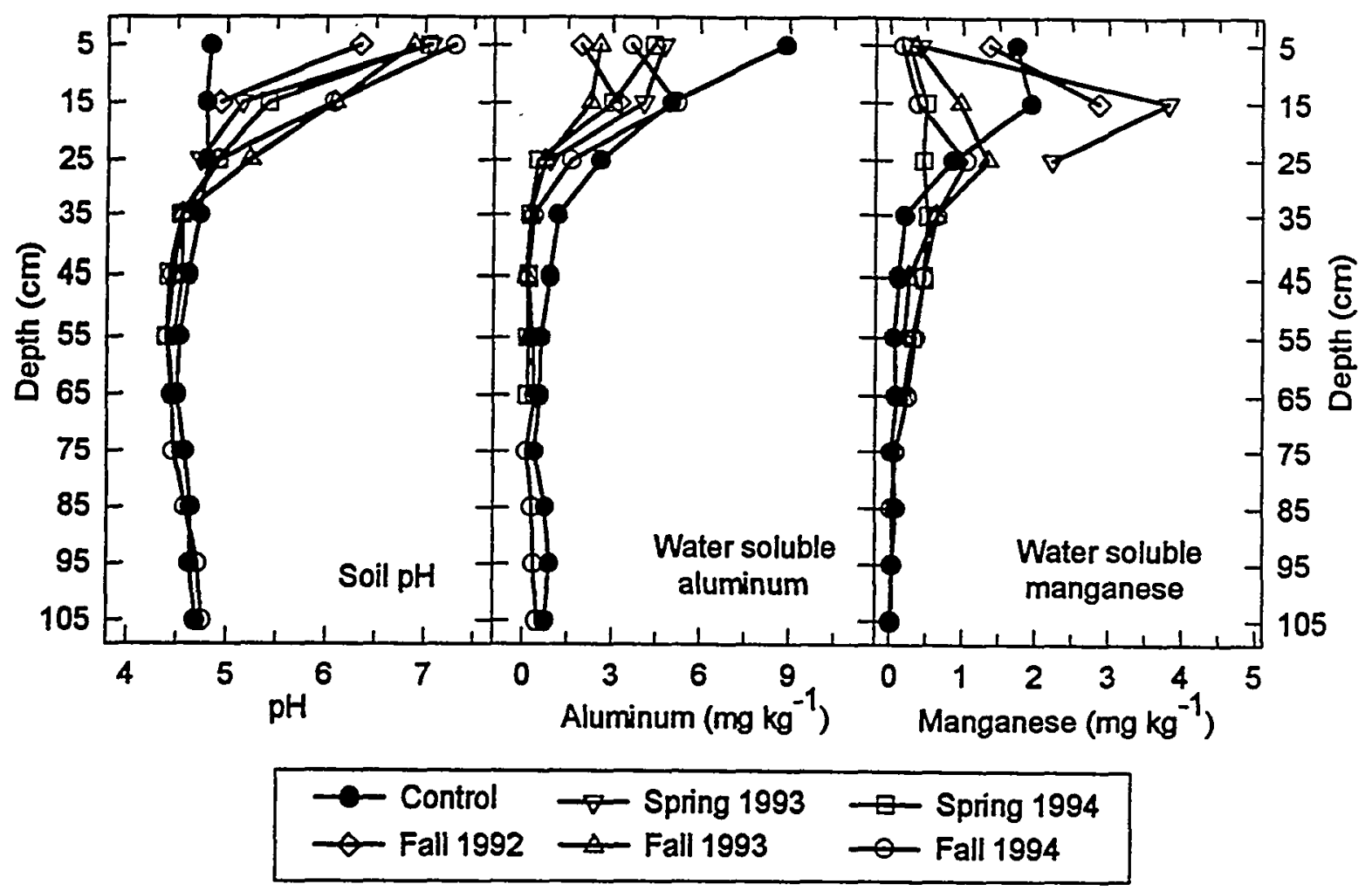

Figure 2. Effect of FGD on soil $\mathrm{pH}$ and on water soluble aluminum and manganese concentrations in the Coshocton soil profile. 


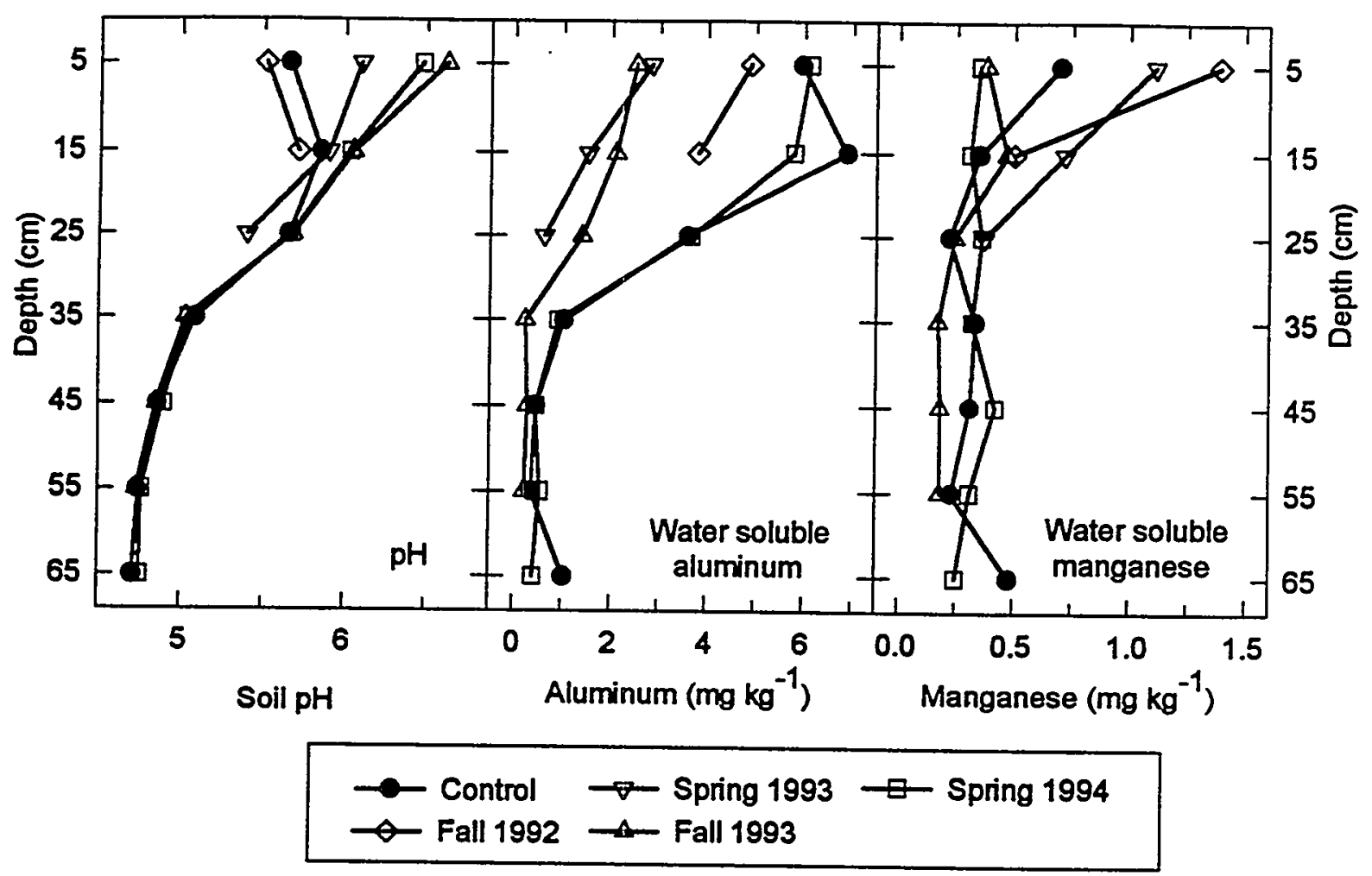

Figure 3. Effect of FGD on soil pH and on water soluble aluminum and manganese concentrations in the Canfield soil profile. 

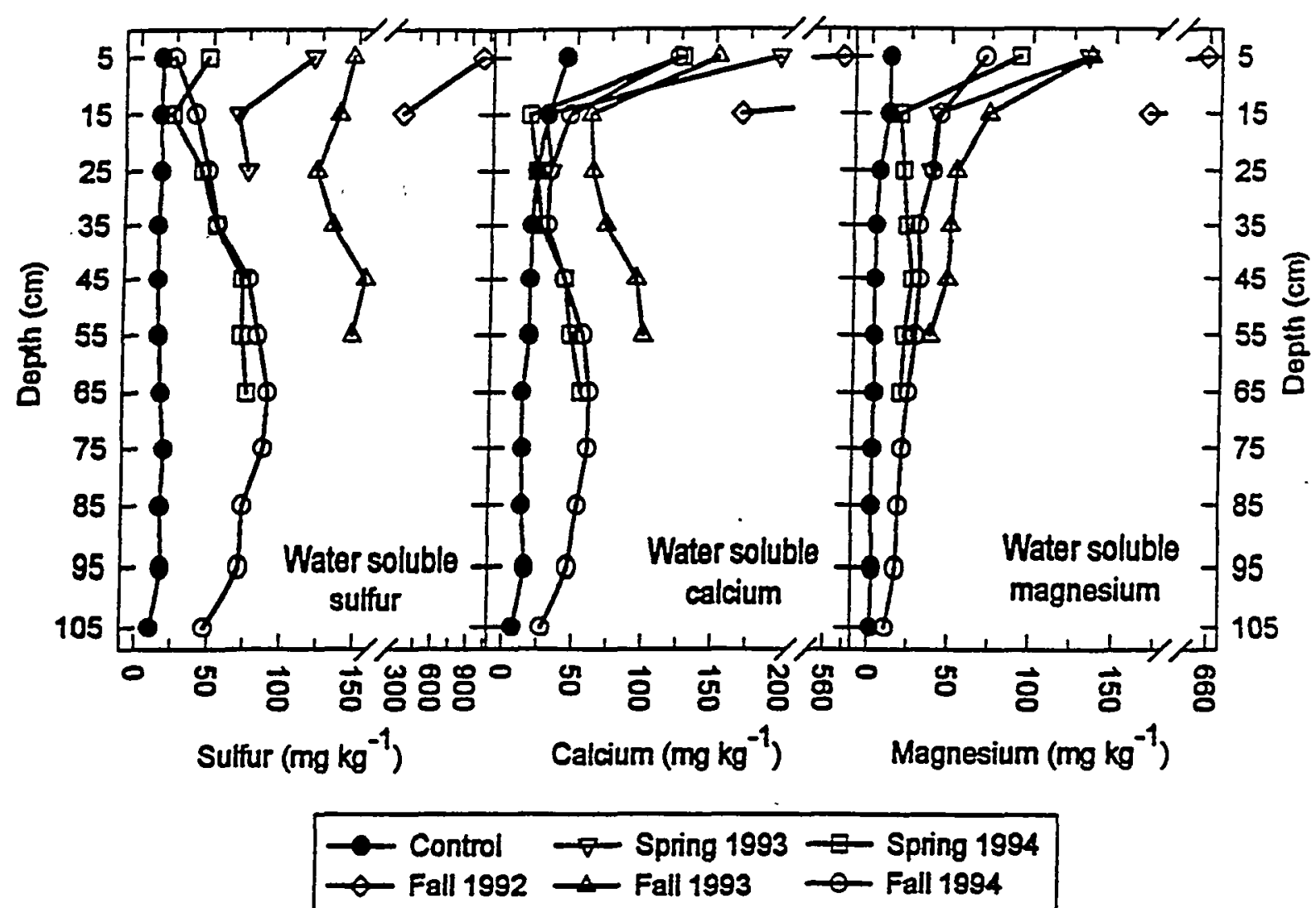

Figure 4. Effect of FGD on water soluble sulfur, calcium, and magesium concentrations in the Wooster soil profile. 


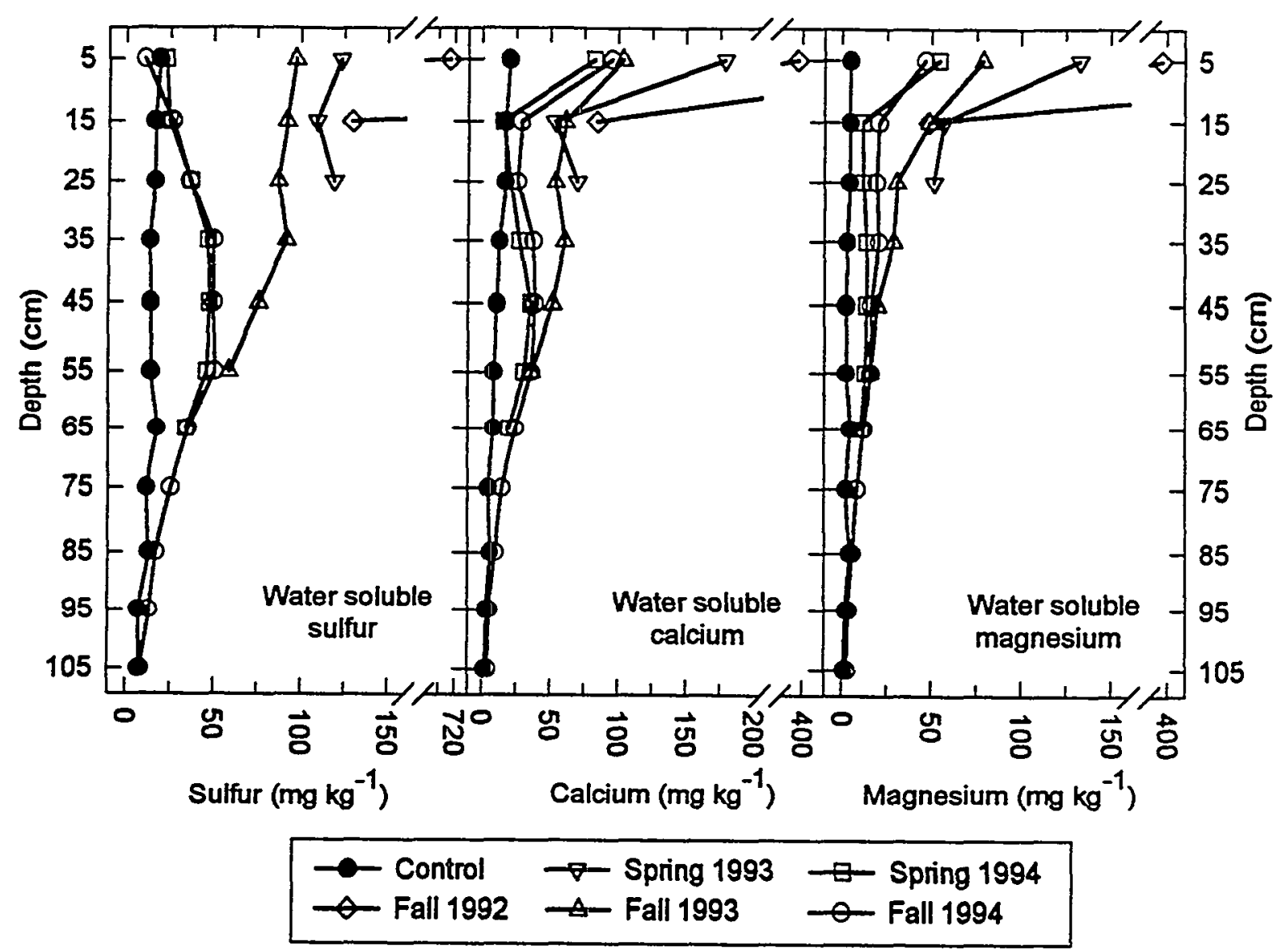

Figure 5. Effect of FGD on water soluble sulfur, calcium, and magnesium concentrations in the Coshocton soil profile. 


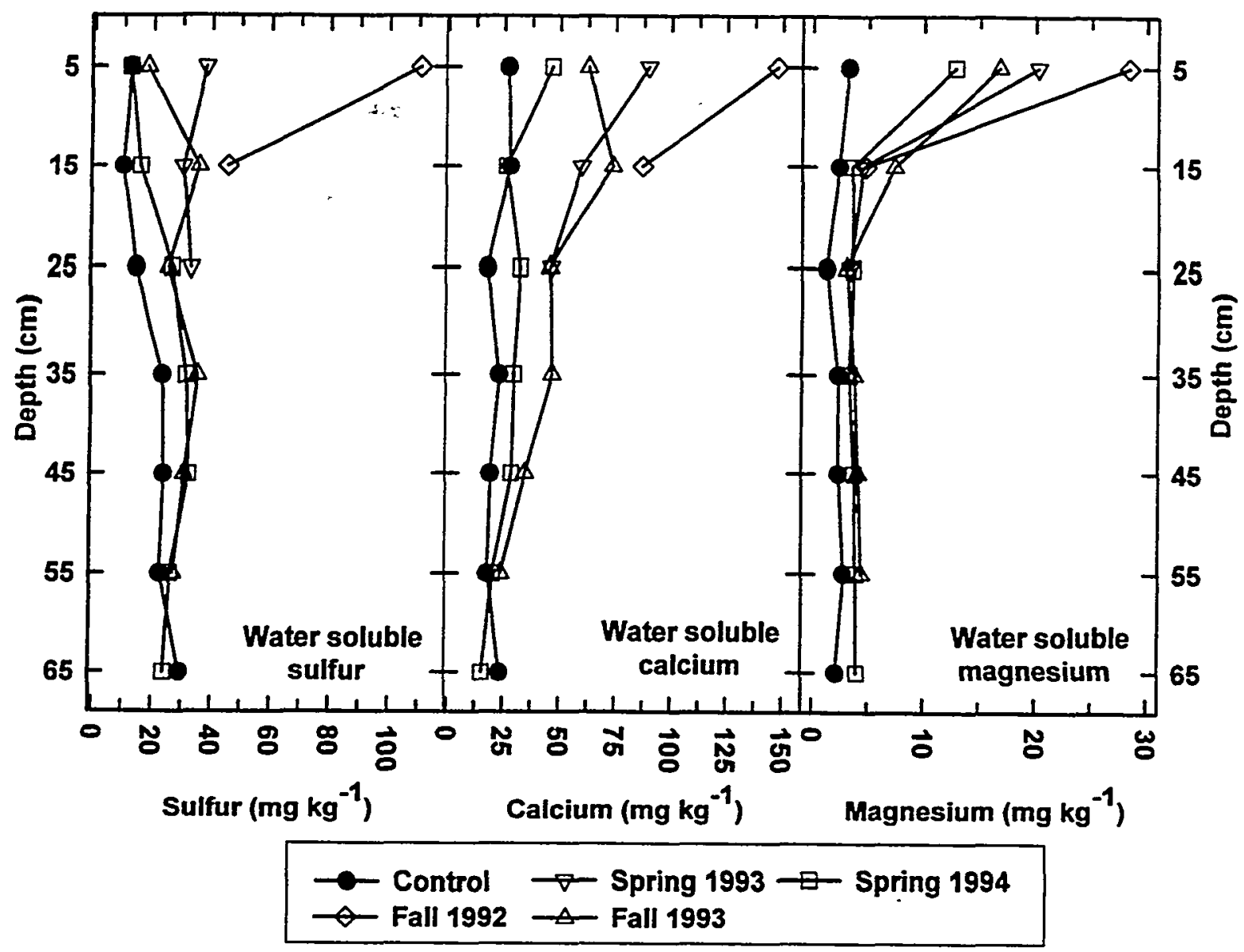

Figure 6. Effect of FGD on water soluble sulfur, calcium, and magesium concentrations in the Canfield soil profile. 
is over 100 times more soluble than $\mathrm{CaCO}_{3}$, and thus more likely to be leached downward. While most of the $\mathrm{Mg}$ in FGD was present in the form of $\mathrm{MgCO}_{3}$, its mobility in soil was greatly increased by the presence of $\mathrm{SO}_{4}{ }^{2}$. This is because when these two moieties dissolved they formed the relatively stable ion pair $\mathrm{MgSO}_{4}{ }^{\circ}$ (aq). This phenomenon was confirmed in a separate study which involved geochemical modeling of leachates from FGD-amended minespoils (Stehouwer et al., 1995d). Because of its neutrality, this ion-pair was highly mobile in soil. The rapid movement of $\mathrm{Ca}$ and $\mathrm{Mg}$ results in a substantial increase in the base-status of sub-soils well below the zone of incorporation and represents a beneficial aspect of FGD byproducts not realized with conventional liming materials.

Surface-soil concentrations of water-soluble $\mathrm{Al}, \mathrm{Fe}$, and $\mathrm{Mn}$, ions which are frequently phytotoxic in acidic soils, were decreased by FGD amendment in all three soils (Figs. 1 to 3 ). This can be attributed to the increase in $\mathrm{pH}$ that occurred in these soils because the solubility of these ions is known to decrease as $\mathrm{pH}$ increases above the acid range (Bohn et al., 1985). The smallest decreases were in the Canfield soil where the lowest rates were applied. The $\mathrm{pH}$ increases were the least and initial concentrations of $\mathrm{Al}, \mathrm{Mn}$, and Fe were the lowest in this soil. In the case of the Wooster soil, and to a lesser extent in the Coshocton and Canfield soils, $\mathrm{Al}$ and $\mathrm{Fe}$ were decreased throughout the profile even though there was no change in $\mathrm{pH}$ below approximately $30 \mathrm{~cm}$. The decrease in water soluble Al was likely the result of displacement of the most labile $\mathrm{Al}$ by exchange with $\mathrm{Ca}^{2+}$ and $\mathrm{Mg}^{2+}$. The subsequent downward transport of $\mathrm{Al}$ may have been facilitated by formation of aluminum sulfate ion pairs. There is also some evidence in the literature that decreases in labile $\mathrm{Al}$ and $\mathrm{Fe}$ could be caused by precipitation of $\mathrm{Al}$, and possibly $\mathrm{Fe}$, with $\mathrm{SO}_{4}{ }^{2-}$ (Adams and Rawajfih, 1977).

By contrast, $\mathrm{Mn}$ in the Wooster and Coshocton soils was increased below the surface soil layer, apparently because of $\mathrm{Mn}$ mobilization from the zone of incorporation to the underlying soil (Figs. 1 and 2). The mobilization of $\mathrm{Mn}$ appeared to be the result of cation exchange of $\mathrm{Mn}^{2+}$ with $\mathrm{Ca}^{2+}$ and $\mathrm{Mg}^{2+}$. The solubility of $\mathrm{Mn}$ transported deeper in the profile was increased because of the lower soil $\mathrm{pH}$ below $10 \mathrm{~cm}$. Thus, while $\mathrm{Al}$ and $\mathrm{Fe}$ phytotoxicity were decreased throughout the upper $100 \mathrm{~cm}$ of these soils, $\mathrm{Mn}$ phytotoxicity may have been increased deeper in the profile. It should be noted, however, that there was no evidence of $\mathrm{Mn}$ toxicity in alfalfa or corn grown on any of the FGD-amended plots.

With the exception of $B$, water soluble concentrations of trace elements were unaffected by FGD application. Concentrations of water-soluble $B$ were increased in the zone of FGD incorporation in all three soils (Fig. 7). The coal fly ash component of the FGD material is the 


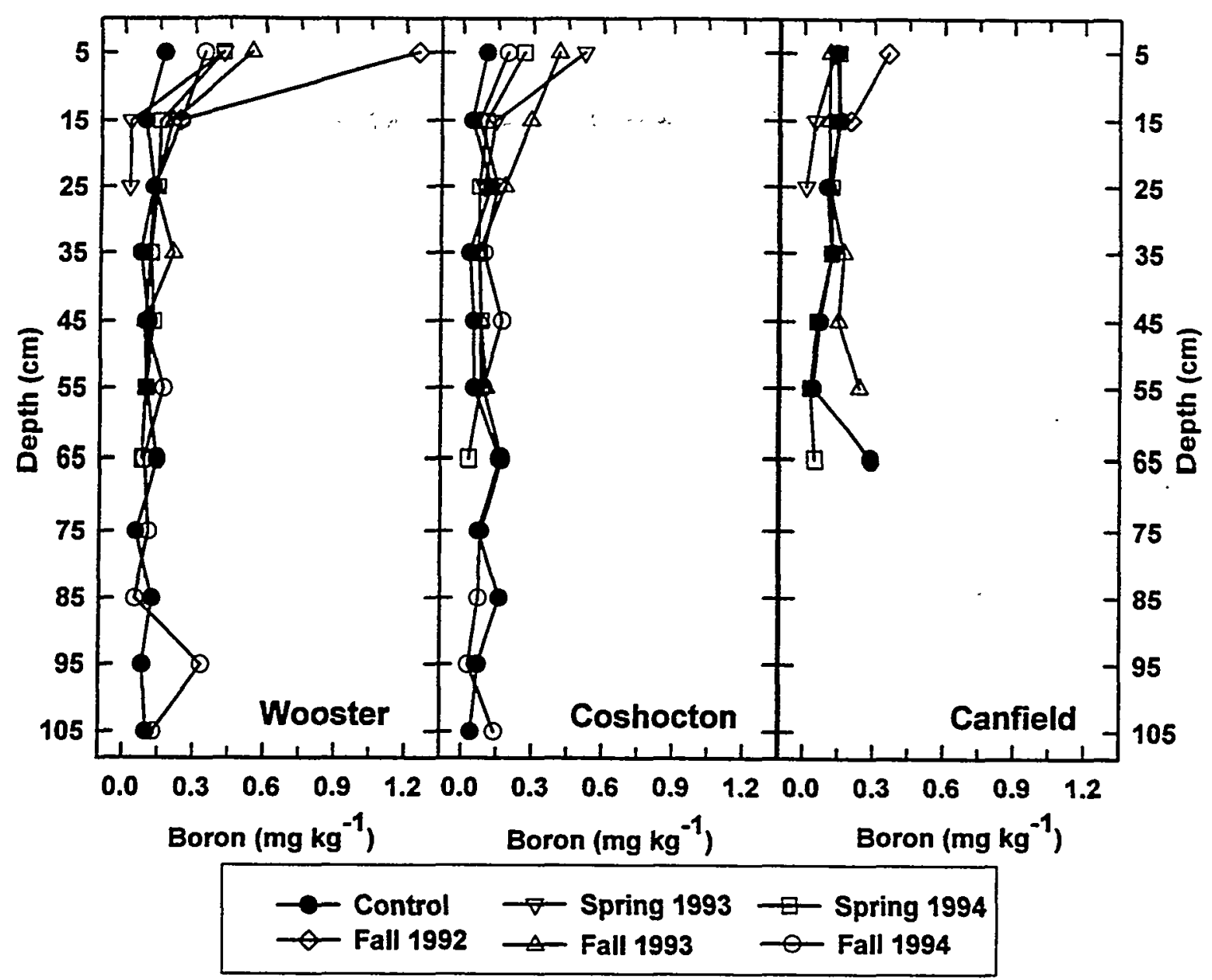

Figure 7. Effect of FGD on water soluble boron concentrations in the Wooster, Coshocton and Canfield soil profiles. 
primary source for the B. Elevated B, or B phytotoxicity, has been reported in several studies involving land application of coal fly ash (Carlson and Adriano, 1993). However, the waterprimary source for the B. Elevated B, or B phytotoxicity, has been reported in several studies involving land application of coal fly ash (Carlson and Adriano, 1993). However, the watersoluble B concentrations observed in this study were well below phytotoxic levels. Indeed, B toxicity was not observed on alfalfa or corn plants grown on any of these three FGD-amended soils.

Water-soluble concentrations of all other measured elements showed no measurable changes in response to FGD application in any of the three soils. Mehlich3 extractable concentrations of some trace elements were affected by FGD application (Table 4). In the Wooster soil As and $\mathrm{Cr}$ were increased by FGD in the depth of incorporation. The increases were relatively small and occurred only in the first sampling one week after FGD application. Extractable concentrations of $\mathrm{Ba}, \mathrm{Cd}, \mathrm{Ni}, \mathrm{P}$, and $\mathrm{Pb}$ were decreased by FGD in some instances. These decreases are likely due to the increased soil $\mathrm{pH}$ in the case of $\mathrm{Cd}, \mathrm{Ni}$, and $\mathrm{Pb}$, and precipitation of highly insoluble $\mathrm{BaSO}_{4}$ in the case of $\mathrm{Ba}$. The FGD-induced decreases in available $\mathrm{P}$ are likely due to the large amount of added $\mathrm{Ca}$ and consequent precipitation of relatively insoluble calcium phosphates. The decreased availability of $\mathrm{P}$ is of significance for plant nutrition and indicates it may be necessary to adjust $\mathrm{P}$ fertility programs when using FGD materials as substitutes for agricultural limestone. Overall there appears to be a very low potential for surface- or groundwater contamination, or increased plant uptake of any trace elements of environmental concern resulting from application of FGD at agricultural rates.

\subsubsection{Plant Growth}

Much of eastern Ohio suffered from a midsummer drought in 1993. No significant precipitation occurred at any of the three sites from July 12 until September 2, with the exception of a $25 \mathrm{~mm}$ rain at Canfield on July 29. This drought severely reduced alfalfa and corn growth and yield and overshadowed any FGD effects. Growing conditions were much better in 1994 and 1995.

Corn grain yield was not affected by FGD in eight of the nine site-years of data (Fig. 8). In the first year (1993) and only on the Coshocton soil in 1993, the FGD application caused a small decrease in com grain yield. Drought conditions in this year and resulting low soil moisture conditions may have increased soil solution salt concentrations. Yield suppression from application of high rates of fluidized bed combustion by-products has been reported with 
Table 4. Effect of FGD on Mehlich3 extractable trace element concentrations in Wooster, Coshocton, and Canfield soils.

\begin{tabular}{|c|c|c|c|c|c|c|c|c|c|c|c|c|c|}
\hline \multirow{2}{*}{$\begin{array}{c}\text { FGD } \\
\text { rate } \\
\mathrm{Mg} / \mathrm{ha}\end{array}$} & \multirow{2}{*}{$\begin{array}{c}\text { Depth } \\
\text { cm }\end{array}$} & \multicolumn{12}{|c|}{ Concentration $(\mathrm{mg} / \mathrm{kg})$} \\
\hline & & As & $\mathrm{Ba}$ & $\mathrm{Cd}$ & $\mathrm{Cr}$ & $\mathrm{Cu}$ & Mo & $\mathrm{Na}$ & $\mathrm{Ni}$ & $\mathrm{P}$ & $\mathrm{Pb}$ & $\mathrm{Se}$ & $\mathrm{Zn}$ \\
\hline \multicolumn{14}{|c|}{ Wooster, Fall 1992} \\
\hline 0 & $0-10$ & $<0.04$ & 18.9 & 0.131 & 0.090 & 1.42 & $<0.01$ & 12.4 & 1.35 & 98.6 & 5.83 & $<0.09$ & 3.61 \\
\hline 0 & $10-20$ & $<0.04$ & 29.0 & 0.074 & 0.079 & 1.05 & $<0.01$ & 8.6 & 2.10 & 28.0 & 4.15 & 0.25 & 1.52 \\
\hline 70 & $0-10$ & 0.28 & 6.64 & 0.113 & 0.184 & 1.57 & $<0.01$ & 18.4 & 0.90 & 111.0 & 5.18 & $<0.09$ & 3.92 \\
\hline 70 & $10-20$ & $<0.04$ & 8.41 & 0.065 & 0.090 & 1.02 & $<0.01$ & 9.8 & 2.01 & 23.7 & 3.91 & $<0.09$ & 1.31 \\
\hline Rate effe & ecta & * & * & * & * & ns & ns & ns & $\mathrm{ns}$ & ns & ns & ns & ns \\
\hline
\end{tabular}

Wooster, Fall 1994

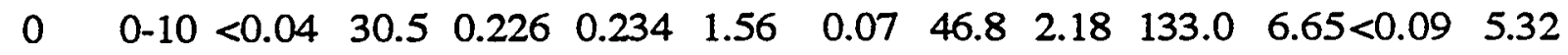

$\begin{array}{llllllllllll}0 & 10-20<0.04 & 34.9 & 0.174 & 0.244 & 1.42 & 0.08 & 37.2 & 2.30 & 29.5 & 4.99<0.09 & 2.63\end{array}$

$\begin{array}{lllllllllllll}70 & 0-10 & 0.07 & 26.0 & 0.118 & 0.238 & 1.69 & 0.01 & 48.4 & 1.62 & 96.4 & 5.50<0.09 & 4.09\end{array}$

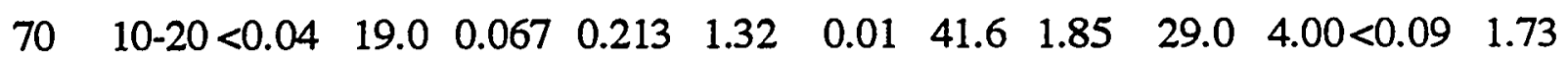

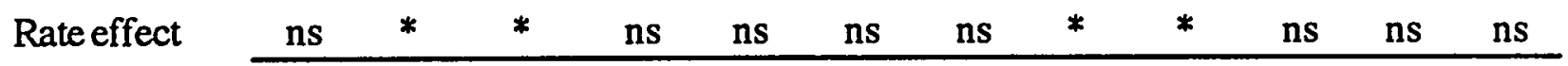

Coshocton, Fall 1992

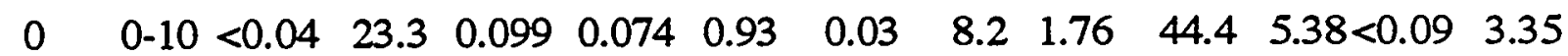

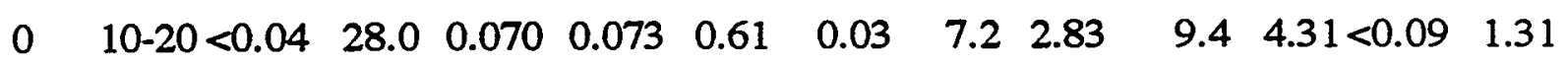

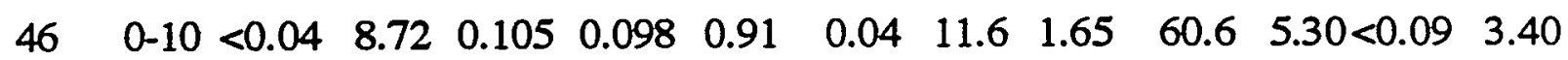

$\begin{array}{llllllllllll}46 & 10-20<0.04 & 18.4 & 0.078 & 0.070 & 0.88 & 0.02 & 10.0 & 2.63 & 16.6 & 4.39<0.09 & 1.77\end{array}$

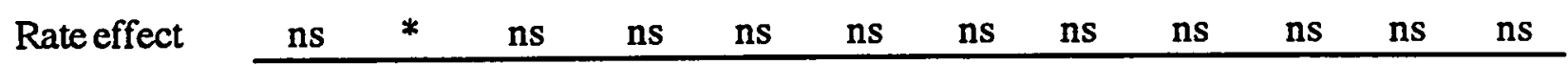


Table 4. (continued)

Coshocton, Fall 1994

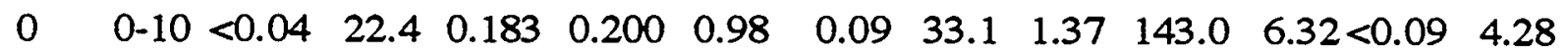

$\begin{array}{llllllllllll}0 & 10-20<0.04 & 22.4 & 0.129 & 0.208 & 0.80 & 0.06 & 32.3 & 1.45 & 27.4 & 4.99<0.09 & 2.06\end{array}$

$\begin{array}{lllllllllllll}46 & 0-10 & 0.09 & 24.3 & 0.112 & 0.196 & 1.14 & 0.05 & 34.8 & 0.96 & 83.5 & 5.40<0.09 & 4.34\end{array}$

$\begin{array}{llllllllllll}46 & 10-20<0.04 & 20.9 & 0.062 & 0.217 & 0.81 & 0.03 & 29.4 & 1.18 & 17.2 & 4.88<0.09 & 1.54\end{array}$

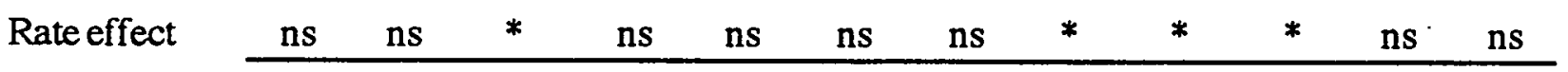

Canfield, Fall 1992

$\begin{array}{lllllllllllll}0 & 0-10 & 0.09 & 31.8 & 0.122 & 0.060 & 24.6 & 0.01 & 10.8 & 0.82 & 43.8 & 31.7<0.09 & 2.36\end{array}$

$\begin{array}{llllllllllll}0 & 10-20<0.04 & 15.5 & 0.123 & 0.062 & 15.7 & 0.02 & 10.3 & 0.79 & 59.5 & 22.6<0.09 & 2.19\end{array}$

$\begin{array}{lllllllllllll}10 & 0-10 & <0.04 & 31.7 & 0.107 & 0.064 & 18.8 & <0.01 & 9.9 & 1.31 & 23.6 & 24.3<0.09 & 2.15\end{array}$

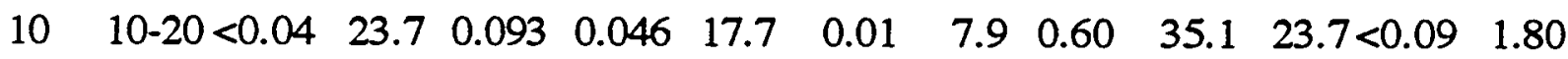

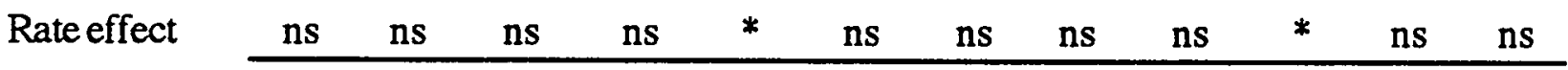

Canfield, Fall 1993

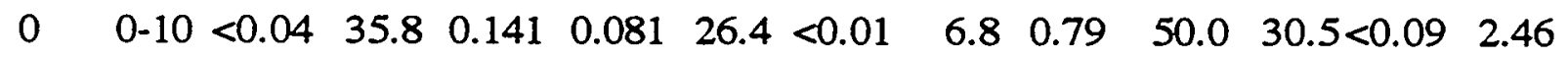

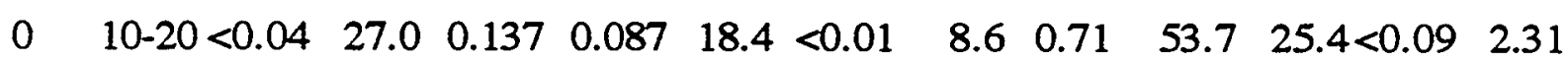

$\begin{array}{llllllllllllll}10 & 0-10 & <0.04 & 35.0 & 0.097 & 0.085 & 18.5 & 0.02 & 8.7 & 0.72 & 23.6 & 20.6 & 0.09 & 1.59\end{array}$

$\begin{array}{llllllllllll}10 & 10-20<0.04 & 30.0 & 0.096 & 0.094 & 12.3<0.01 & 10.2 & 0.71 & 12.5 & 17.3<0.09 & 1.36\end{array}$

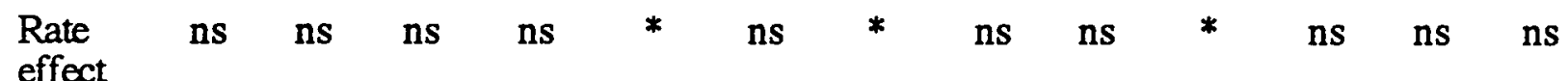

$\mathrm{a}^{*}$ and "ns" indicate the linear regression of the FGD rate effect was significant or not

significant at the 0.1 probability level, respectively. 


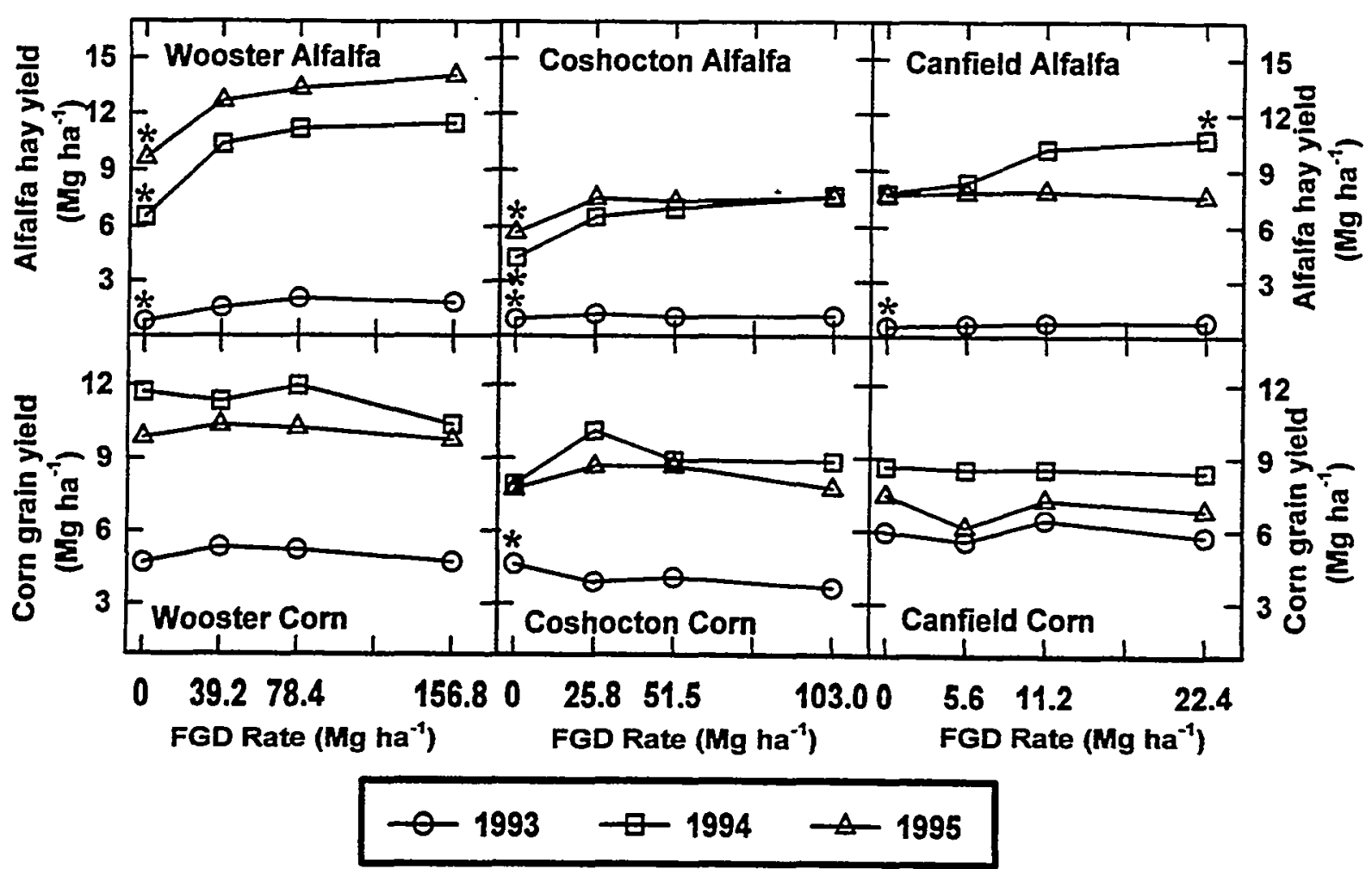

Figure 8. Effect of FGD on the yield of alfalfa hay and corn grain grown on the Wooster, Coshocton and Canfield soils. ( ${ }^{*}$, the starred means are significantly different from all other means for a particular year and site.) 
peanuts (Terman et al., 1978) and red clover (Stout et al., 1979) and has been attributed to high alkalinity and/or high soluble salt content.

Alfalfa yields were increased by FGD treatment in 7 of 9 site-years (Fig. 8). On the Canfield soil where the smallest (and likely insufficient) amounts of FGD were applied, there were no significant alfalfa yield increases in 1995 . Yields at all three locations in 1993 were very low due to poor establishment and drought. These data are based on total biomass production with each treatment. The actual alfalfa yield increases were actually greater than these data indicate because the unamended control plots consisted primarily of weed species with very little alfalfa, whereas plots with some level of FGD contained nearly pure stands of alfalfa.

Elemental composition of both alfalfa foliage and corn grain was affected by FGD application (Tables 5 and 6). The largest increases occurred with $\mathrm{Mg}$ and $\mathrm{S}$, two major and highly soluble elements in the FGD. There was no evidence of any toxicity problems due to these elements, and the increase was much less in the second growing season (1994) than it was in the first levels. There were significant increases in Mo concentrations for both alfalfa and corn. Increased Mo uptake is frequently noted when soils are limed and $\mathrm{pH}$ is increased. Thus the source of the Mo is likely not from the FGD. Aside from B and Mo, there was no evidence of FGD increasing any other trace elements. There was some evidence of decreased tissue concentrations of $\mathrm{Cd}, \mathrm{Ni}$ and $\mathrm{Zn}$ in 1993. Calcium, the other major element in the FGD was either unaffected or decreased by FGD application. Calcium uptake was likely inhibited by the large amount of soluble $\mathrm{Mg}$ in the soil following FGD application. Although there was some evidence of a small increase in alfalfa B concentrations resulting from FGD application, concentrations remained well below phytotoxic levels.

\subsubsection{Experiment 2}

\subsubsection{Soil Physical Properties}

The data showed that application of FGD at a rate of $22.5 \mathrm{Mg} /$ ha (i.e. $1 \times \mathrm{LR}$ ) had no significant effect on soil physical properties including soil bulk density, moisture retention characteristics and saturated conductivity (Table 7).

Mean soil bulk density was 1.18 and $1.20 \mathrm{Mg} / \mathrm{m}^{3}$ for the control and the FGD treatments, respectively. Soil moisture retention for control and FGD treatments, respectively, was 35.3\% vs. $33.6 \%$ at $0.006 \mathrm{MPa}$ tension, $29.1 \%$ vs. $28.1 \%$ at $0.03 \mathrm{MPa}$ tension, and $15.8 \%$ vs. 
Table 5. $\mathrm{N}, \mathrm{Al}, \mathrm{As}, \mathrm{B}, \mathrm{Ba}, \mathrm{Ca}, \mathrm{Cd}, \mathrm{Cr}$, and $\mathrm{Cu}$ concentrations in alfalfa tissue and corn grain grown on the Wooster soil amended with FGD.

\begin{tabular}{|c|c|c|c|c|c|c|c|c|c|}
\hline \multirow{2}{*}{$\begin{array}{l}\text { FGD } \\
\text { rate } \\
\text { Mg/ha }\end{array}$} & \multirow{2}{*}{$\begin{array}{c}\mathrm{Na} \\
\%\end{array}$} & \multicolumn{8}{|c|}{ Concentration (mg/kg) } \\
\hline & & $\mathrm{Al}$ & As & $\mathrm{B}$ & $\mathrm{Ba}$ & $\mathrm{Ca}$ & $\mathrm{Cd}$ & $\mathrm{Cr}$ & $\mathrm{Cu}$ \\
\hline & \multicolumn{9}{|c|}{ Alfalfa hay, 1993} \\
\hline 0 & 2.98 & 51.2 & 0.05 & 39.3 & 55.6 & 14200 & 0.39 & 0.46 & 8.89 \\
\hline 17.5 & 3.10 & 50.0 & $<0.04$ & 42.2 & 21.3 & 15800 & 0.21 & 0.35 & 8.98 \\
\hline 35 & 3.19 & 49.5 & 0.16 & 42.5 & 11.4 & 14200 & 0.25 & 0.41 & 8.84 \\
\hline 70 & 3.20 & 57.7 & $<0.04$ & 46.5 & 6.79 & 14100 & 0.16 & 0.35 & 8.47 \\
\hline \multirow[t]{2}{*}{ Rate effectb } & ns & ns & ns & ns & * & ns & * & ns & ns \\
\hline & \multicolumn{9}{|c|}{ Alfalfa hay, 1994} \\
\hline 0 & 2.98 & 32.8 & $<0.04$ & 25.1 & 40.9 & 11200 & 0.24 & 0.22 & 7.21 \\
\hline 17.5 & 3.25 & 30.2 & $<0.04$ & 26.5 & 19.8 & 10700 & 0.11 & 0.20 & 8.04 \\
\hline 35 & 3.12 & 28.8 & $<0.04$ & 28.3 & 14.5 & 9780 & 0.04 & 0.13 & 7.33 \\
\hline 70 & 3.09 & 26.4 & $<0.04$ & 28.9 & 10.2 & 9680 & 0.18 & 0.27 & 6.90 \\
\hline \multirow[t]{2}{*}{ Rate effect } & ns & ns & ns & * & * & $*$ & ns & ns & ns \\
\hline & \multicolumn{9}{|c|}{ Corn grain, 1993} \\
\hline 0 & 11.5 & 0.90 & 0.23 & 1.48 & 0.26 & 43 & 0.09 & 0.10 & 2.29 \\
\hline 17.5 & 11.1 & 1.88 & $<0.04$ & 1.42 & 1.03 & 40 & $<0.01$ & 0.10 & 2.16 \\
\hline 35 & 11.3 & 0.67 & 0.31 & 1.36 & 0.07 & 36 & 0.05 & 0.11 & 2.11 \\
\hline 70 & 11.0 & 0.81 & 0.16 & 1.61 & 0.00 & 34 & 0.01 & 0.07 & 2.36 \\
\hline Rate effect & ns & ns & ns & ns & ns & * & ns & ns & ns \\
\hline
\end{tabular}


Table 5. (continued)

\begin{tabular}{cccccccccc}
\hline & \multicolumn{10}{c}{ Corn grain, 1994 } \\
0 & 9.65 & 2.34 & 0.12 & 2.70 & 0.29 & 62 & 0.05 & 0.06 & 1.40 \\
17.5 & 9.85 & 4.00 & 0.51 & 2.96 & 0.16 & 75 & 0.04 & 0.11 & 1.24 \\
35 & 9.68 & 1.04 & 0.29 & 2.12 & 0.03 & 43 & 0.02 & 0.08 & 1.00 \\
70 & 9.80 & 2.07 & 0.22 & 2.99 & 0.12 & 86 & 0.07 & 0.11 & 1.23 \\
Rate effect & ns & ns & ns & ns & $*$ & ns & ns & ns & ns \\
\hline
\end{tabular}

aPercent $\mathrm{N}$ in alfalfa hay and percent protein in corn grain.

$b *$ and "ns" indicate the linear regression of the FGD rate effect was significant or not significant at the 0.1 probability level, respectively. 
Table 6. Fe, $\mathrm{K}, \mathrm{Mg}, \mathrm{Mn}, \mathrm{Mo}, \mathrm{Na}, \mathrm{Ni}, \mathrm{P}, \mathrm{S}$ and $\mathrm{Zn}$ concentrations in alfalfa tissue and corn grain grown on the Wooster soil amended with FGD.

\begin{tabular}{|c|c|c|c|c|c|c|c|c|c|c|}
\hline \multirow{2}{*}{$\begin{array}{c}\text { FGD } \\
\text { rate } \\
\mathrm{Mg} / \mathrm{ha}\end{array}$} & \multicolumn{10}{|c|}{ Concentration (mg/kg) } \\
\hline & $\mathrm{Fe}$ & $\mathrm{K}$ & $\mathrm{Mg}$ & Mn & Mo & $\mathrm{Na}$ & $\mathrm{Ni}$ & $\mathrm{P}$ & $S$ & $\mathrm{Zn}$ \\
\hline & \multicolumn{10}{|c|}{ Alfalfa hay, 1993} \\
\hline 0 & 101 & 19400 & 3390 & 82.3 & 0.37 & 77.0 & 1.60 & 2430 & 3190 & 37.6 \\
\hline 17.5 & 104 & 16200 & 4670 & 78.3 & 1.32 & 83.4 & 1.24 & 2390 & 4100 & 37.1 \\
\hline 35 & 97.5 & 18000 & 4850 & 74.6 & 2.18 & 80.2 & 1.25 & 2420 & 4240 & 30.2 \\
\hline 70 & 106 & 16500 & 6270 & 80.6 & 2.78 & 73.1 & 0.90 & 2470 & 4670 & 31.0 \\
\hline \multirow[t]{2}{*}{ Rate effecta } & ns & ns & * & ns & $*$ & $\mathrm{~ns}$ & * & ns & $*$ & ns \\
\hline & \multicolumn{10}{|c|}{ Alfalfa hay, 1994} \\
\hline 0 & 64.0 & 24000 & 2720 & 63.0 & 0.19 & 100.0 & 1.90 & 2650 & 2600 & 57.7 \\
\hline 17.5 & 71.4 & 25000 & 3190 & 40.6 & 0.96 & 89.0 & 1.49 & 3020 & 2760 & 47.0 \\
\hline 35 & 69.4 & 26400 & 2850 & 37.6 & 1.52 & 84.6 & 1.18 & 3060 & 2790 & 30.7 \\
\hline 70 & 68.4 & 25600 & 3240 & 36.9 & 2.15 & 97.8 & 1.27 & 3080 & 2900 & 31.6 \\
\hline \multirow[t]{2}{*}{ Rate effect } & ns & ns & $*$ & * & * & ns & * & ns & * & * \\
\hline & \multicolumn{10}{|c|}{ Corn grain, 1993} \\
\hline 0 & 22.8 & 3470 & 1260 & 7.61 & $<0.01$ & 1.31 & 0.74 & 3080 & 1100 & 24.2 \\
\hline 17.5 & 24.8 & 3500 & 1300 & 6.89 & 0.08 & 0.78 & 0.61 & 3130 & 1140 & 22.3 \\
\hline 35 & 23.2 & 3460 & 1340 & 6.78 & 0.13 & 1.09 & 0.71 & 3270 & 1140 & 23.3 \\
\hline 70 & 22.6 & 3550 & 1330 & 6.68 & 0.17 & 0.40 & 0.60 & 3170 & 1150 & 22.2 \\
\hline Rate effect & ns & ns & * & * & * & ns & ns & ns & ns & ns \\
\hline
\end{tabular}


Table 6. (continued).

Corn grain, 1994

\begin{tabular}{ccccccccccc}
0 & 18.9 & 3510 & 975 & 7.55 & 0.08 & 0.82 & 0.43 & 2780 & 1090 & 37.4 \\
17.5 & 23.3 & 3850 & 1120 & 5.25 & 0.31 & $<0.05$ & 0.39 & 3170 & 1060 & 51.9 \\
35 & 18.6 & 3710 & 1060 & 4.59 & 0.24 & $<0.05$ & 0.13 & 2990 & 1020 & 25.3 \\
70 & 20.0 & 3750 & 1100 & 4.26 & 0.27 & $<0.05$ & 0.20 & 3030 & 1030 & 53.2 \\
Rate effect & $\mathrm{ns}$ & $\mathrm{ns}$ & $*$ & $*$ & $*$ & $\mathrm{~ns}$ & $*$ & $\mathrm{~ns}$ & $*$ & $\mathrm{~ns}$ \\
\hline \hline
\end{tabular}

a* and "ns" indicate the linear regression of the FGD rate effect was significant or not significant at the 0.1 probability level, respectively. 
Table 7. Effect of FGD treatment ( $1 \times$ LR) on bulk density, moisture content and saturated conductivity under simulated rain in 1993 under corn.

\begin{tabular}{|c|c|c|c|c|c|}
\hline \multirow[b]{2}{*}{ Treatment } & \multirow{2}{*}{$\begin{array}{c}\text { Soil bulk } \\
\text { density } \\
\left(\mathrm{Mg} / \mathrm{m}^{3}\right)\end{array}$} & \multicolumn{3}{|c|}{ Tension (MPa) } & \multirow{2}{*}{$\begin{array}{l}\text { Saturated } \\
\text { conductivity } \\
(\mathrm{mm} / \mathrm{h})\end{array}$} \\
\hline & & 0.006 & 0.03 & 1.5 & \\
\hline & \multicolumn{5}{|c|}{ Moisture content (\%) } \\
\hline Control & 1.18 & 35.3 & 29.1 & 15.8 & 7.2 \\
\hline FGDa & 1.20 & 33.6 & 28.1 & 15.4 & 6.8 \\
\hline $\operatorname{LSD}(0.05)$ & 0.07 & 2.0 & 2.0 & 1.0 & 5.3 \\
\hline
\end{tabular}

aFGD was applied to the soil at the $1 \times$ LR application rate $(22.5 \mathrm{Mg} / \mathrm{ha})$.

$15.4 \%$ at $1.5 \mathrm{MPa}$ tension. The mean saturated hydraulic conductivity was $7.2 \mathrm{~mm} / \mathrm{h}$ for control treatment compared with $6.8 \mathrm{~mm} / \mathrm{h}$ for the FGD treatment.

\subsubsection{Runoff Rate and Amount}

The effect of FGD treatment on runoff rate and total runoff amount are shown in Table 8. Application of the FGD by-product had no effect on runoff rate. Similar results were observed for measurements made at different stages of crop growth and for other growing seasons. However, there were differences in total runoff due to the FGD treatment. Mean runoff amount was $20.4 \%$ for the untreated control compared with $8.2 \%$ for the FGD treatment, a ratio of 2.5:1. Therefore, application of the FGD material decreased runoff loss by a factor of 2.5 . This is attributed primarily to the improved plant growth that was stimulated by amending the soil with FGD.

The crop grown also had some effect on runoff rate and amount. The peak runoff rate was $11.4 \mathrm{~mm} / \mathrm{h}$ under corn and $5.8 \mathrm{~mm} / \mathrm{h}$ under alfalfa, yielding a ratio of $1.97: 1$. In comparison, 
Table 8. Effect of FGD treatment ( $1 \times$ LR) on peak runoff rate and total runoff measured in the summer of 1993 with simulated rain on a site growing corn and alfalfa.

\begin{tabular}{|c|c|c|c|c|c|c|}
\hline \multirow[b]{2}{*}{ Treatment } & \multicolumn{3}{|c|}{$\begin{array}{l}\text { Peak runoff rate } \\
\qquad(\mathrm{mm} / \mathrm{h})\end{array}$} & \multicolumn{3}{|c|}{$\begin{array}{c}\text { Total runoff } \\
\text { (percent of applied rain) }\end{array}$} \\
\hline & Corn & Alfalfa & Mean & Corn & Alfalfa & Mean \\
\hline Control & 11.8 & 6.4 & 9.1 & 26.6 & 14.2 & 20.4 \\
\hline$F_{G D}$ & 11.0 & 5.2 & 8.1 & 13.3 & 3.1 & 8.2 \\
\hline Mean & 11.4 & 5.8 & & 20.0 & 20.0 & \\
\hline \multicolumn{7}{|l|}{$\operatorname{LSD}(0.05)$ for: } \\
\hline Crop (C) & & 8.4 & & & 20.0 & \\
\hline FGD treatment $(T)$ & & 2.7 & & & 16.6 & \\
\hline $\mathrm{CXT}$ & & 3.8 & & & 23.4 & \\
\hline
\end{tabular}

aFGD was applied to the soil at the $1 \times \mathrm{LR}$ application rate $(22.5 \mathrm{Mg} / \mathrm{ha})$.

peak runoff rate was $9.1 \mathrm{~mm} / \mathrm{h}$ for control compared with $8.1 \mathrm{~mm} / \mathrm{h}$ for the FGD treatment, yielding a ratio of 1.12:1. Crop grown also had an effect on total runoff loss. Mean runoff loss was $20.0 \%$ for corn compared with $8.7 \%$ for alfalfa, yielding a ratio of $2.3: 1$.

\subsubsection{Soil Erosion}

An example of the effects of FGD material on soil erosion under simulated rain is shown by the data in Table 9. Data were obtained at two different times in 1993 and again at two different times in 1994. Mean soil erosion was consistently higher for the untreated control plots than 
Table 9. Effect of FGD treatment ( $1 \times$ LR) on soil erosion measured with simulated rain on a site growing corn and alfalfa.

\begin{tabular}{|c|c|c|c|}
\hline \multirow[b]{2}{*}{ Treatment } & \multicolumn{3}{|c|}{ Soil erosion $(\mathrm{kg} / \mathrm{ha})$} \\
\hline & Corn & Alfalfa & Mean \\
\hline & \multicolumn{3}{|c|}{ Summer, 1993} \\
\hline Control & 176 & 566 & 371 \\
\hline FGD $(22.5 \mathrm{Mg} / \mathrm{ha})$ & 203 & 82.9 & 143 \\
\hline Mean & 190 & 324 & \\
\hline \multicolumn{4}{|l|}{$\operatorname{LSD}(0.05)$ for: } \\
\hline Crop (C) & & 710 & \\
\hline Treatment $(T)$ & & 563 & \\
\hline \multirow[t]{2}{*}{$\mathrm{C} \times \mathrm{T}$} & & 796 & \\
\hline & \multicolumn{3}{|c|}{ Fall, 1993} \\
\hline Control & 1370 & 1160 & 1260 \\
\hline FGD $(22.5 \mathrm{Mg} / \mathrm{ha})$ & 800 & 785 & 793 \\
\hline Mean & 1090 & 970 & \\
\hline \multicolumn{4}{|l|}{$\operatorname{LSD}(0.05)$ for: } \\
\hline Crop (C) & \multicolumn{3}{|c|}{2650} \\
\hline Treatment $(\mathrm{T})$ & \multicolumn{3}{|c|}{1150} \\
\hline \multirow[t]{2}{*}{$\mathrm{CxT}$} & \multicolumn{3}{|c|}{1630} \\
\hline & \multicolumn{3}{|c|}{ Spring, 1994} \\
\hline Control & 16.6 & 12.4 & 14.5 \\
\hline FGD $(22.5 \mathrm{Mg} / \mathrm{ha})$ & 13.7 & 7.7 & 18.8 \\
\hline Mean & 15.2 & 10.1 & \\
\hline \multicolumn{4}{|l|}{$\operatorname{LSD}(0.05)$ for: } \\
\hline Crop (C) & \multicolumn{3}{|c|}{13.8} \\
\hline Treatment $(T)$ & \multicolumn{3}{|c|}{11.1} \\
\hline \multirow[t]{2}{*}{$\mathrm{C} \times \mathrm{T}$} & \multicolumn{3}{|c|}{15.8} \\
\hline & \multicolumn{3}{|c|}{ Summer, 1994} \\
\hline Control & 312 & 10.7 & 161 \\
\hline FGD $(22.5 \mathrm{Mg} / \mathrm{ha})$ & 254 & 12.0 & 133 \\
\hline Mean & 283 & 11.4 & \\
\hline \multicolumn{4}{|l|}{$\operatorname{LSD}(0.05)$ for: } \\
\hline Crop (C) & & 266 & \\
\hline Treatment $(T)$ & & 194 & \\
\hline $\mathrm{CxT}$ & & 274 & \\
\hline
\end{tabular}


where FGD was applied, although the effect was not statistically significant at the 5\% probability level. Nevertheless, the consistent results suggest the FGD by-product may have had a beneficial impact on protecting the soil against erosion. The reasons for this are not totally clear but undoubtably are due, in part, to increased plant growth that occurred when soils were amended with the FGD.

The com crop consistently resulted in greater soil erosion than did the alfalfa crop but again this effect was not significant at the $5 \%$ probability level. The alfalfa provides a more complete ground cover and protects the soil against raindrop impact. In addition, the alfalfa provides cover throughout the year whereas corn production, especially if tillage is used for seedbed preparation, will leave the soil bare and susceptible to erosion for various times of the year.

\subsection{Summary and Conclusions}

Soil application of FGD at the recommended liming rate effectively and rapidly neutralized acidity in the zone of incorporation. There was also evidence of increasing $\mathrm{pH}$ in underlying soil to a depth of $30 \mathrm{~cm}$ within one year of application. Soil chemistry was made more favorable for plant growth as the increased $\mathrm{pH}$ in the zone of incorporation resulted in an immediate decrease in water-soluble concentrations of $\mathrm{Al}, \mathrm{Fe}$, and $\mathrm{Mn}$ and an increase in $\mathrm{Ca}$, $\mathrm{Mg}$, and $\mathrm{S}$ concentrations. Owing to the greater solubility of $\mathrm{CaSO}_{4}$ and $\mathrm{MgSO}_{4}$ compared to that of $\mathrm{CaMg}\left(\mathrm{CO}_{3}\right)_{2}$, the elements $\mathrm{Ca}, \mathrm{Mg}$, and $\mathrm{S}$ were rapidly transported through the soil profile and resulted in decreased concentrations of easily extractable $\mathrm{Al}$ and Fe, even well below the zone of incorporation. Mobilization of $\mathrm{Mn}$ from the zone of incorporation to lower $\mathrm{pH}$ subsoil resulted in increased Mn concentrations in the subsoil. There was no evidence that land application of FGD at the recommended liming rate would lead to elevated levels of potentially toxic trace elements in soil or water.

With pH-sensitive crops such as alfalfa, FGD application increased growth and yield on acidic soils. Even when applied at twice the lime requirement rate of the soils, there was no adverse effect on yield. With a crop such as com that is less $\mathrm{pH}$ sensitive, the potential yield benefit from FGD application may be less than for a more sensitive crop such as alfalfa.

Reduction in total runoff rate was relatively more when comparing the differences between the alfalfa and com crops as compared to the FGD treated and untreated plots. However, a decrease in soil erosion of approximately 40 to $70 \%$ was observed for the FGD treated plots as compared to the untreated control plot. 


\section{RECLAMATION OF AN ACIDIC AND TOXIC SURFACE COAL MINE SITE IN OHIO: SURFACE WATER, GROUNDWATER, PLANT AND SOIL RESPONSES}

\subsection{Introduction}

Reclamation of abandoned mined lands normally involves placement of a layer of topsoil over the graded minespoil. Because topsoil was generally not conserved when these sites were surface mined for coal prior to the reclamation laws, soil must be "borrowed" from adjacent land thereby creating another disturbed area. The cost of reclamation becomes prohibitive if sufficient borrow soil is not available adjacent to the mine site. Direct revegetation of minespoil by amendment with by-product materials such as FGD by-products and yard waste composts would reduce or eliminate the need for borrow soil, reduce reclamation costs, and help eliminate the concept that these materials are only wastes that must be landfilled.

The residual alkalinity, anhydrite $\left(\mathrm{CaSO}_{4}\right)$ and coal ash contained in FGD by-products make it a beneficial material for correcting acidic agricultural soils (Marsh and Grove, 1992; Korcak, 1980; Stehouwer et al., 1995b) and minespoils (Stehouwer et al., 1995c; 1995d). Composted yard wastes contain a large amount of microbially available organic $C$ and thus represent a major energy input into the low-energy minespoil environment. Composts could also provide some of the same benefits for minespoil reclamation as has been found for sewage sludge (Sopper, 1992). Both compost and FGD by-products may also contain large quantities of soluble salts and some trace elements of environmental concern which could negatively impact soil and water quality both directly and through mobilization of trace elements in the spoil. Greenhouse experiments showed that when used at the appropriate rate, FGD by-products could ameliorate phytotoxic conditions in the spoil and improve plant growth (Stehouwer et al., 1995c; 1995d, 1998). Analysis of greenhouse pot leachates also showed that at agronomically appropriate application rates, trace element concentrations remained at very low levels. 
Two studies were conducted to investigate the use of FGD by-product materials for treating toxic and acidic coal mine spoil. The first was a preliminary column experiment designed to learn something about plant growth and water quality responses to high rates of FGD applied to toxic mine spoil. The second was a field study initiated to compare conventional reclamation of an acidic minespoil, using a resoil borrow material, with direct revegetation of the spoil amended with an FGD by-product alone or with a mixture of FGD by-product and yard-waste compost. The study was designed to investigate the revegetation success and the impacts of the reclamation treatments on soil, plant, and water quality (both surface water and groundwater).

\subsection{Experiment 1 - Column Studies (Coshocton, $\mathrm{OH}$ )}

\subsubsection{Materials and Methods}

Column studies were conducted for 3 years from 1992 through 1994 at the USDA-ARS research station located near Coshocton, $\mathrm{OH}$. A pit $(5 \times 8 \times 2 \mathrm{~m})$ was dug and separated into two compartments by a treated wood wall. Plastic columns $30 \mathrm{~cm}$ in diameter and $97 \mathrm{~cm}$ deep were placed into one compartment on treated lumber $(15 \times 40 \times 10 \mathrm{~cm})$ which was laid in the bottom of the pit. A base was attached to the bottom of each column and this base contained grooves which lead to a drainage hole that served as the column outlet. Polyvinyl chloride tubing of $1.25 \mathrm{~cm}$ diameter connected the drainage hole $(1.25 \mathrm{~cm})$ at the bottom of the columns to a $5 \mathrm{~L}$ plastic bucket placed in the other compartment of the pit. Sand was filled in the space between columns to within $15 \mathrm{~cm}$ of the top of the columns to prevent rain splash from the surface outside of the column into the column. The columns were then buried flush with the ground surface.

This factorial experiment involved (a) 2 FGD materials-LIMB and OSU spray dryer material, and (b) 3 rates of application $-10 \%, 20 \%$ and $40 \%$ by weight. An untreated control was also included. All treatments were replicated three times for a total of 21 columns. Treatments were randomly assigned to each column.

After placement of columns in the pit, $56 \mathrm{~kg}$ of mine spoil were packed into columns yielding a depth of $72 \mathrm{~cm}$. For columns without amendments, an additional $11 \mathrm{~kg}$ of mine spoil were added to raise the total depth to $86 \mathrm{~cm}$. For columns with FGD amendments, $11 \mathrm{~kg}$ of mine spoil were mixed with 1.1,2.2, and $4.4 \mathrm{~kg}$ of FGD materials (10,20, and $40 \%$ by weight) and then placed into columns. The total heights of materials in columns with amendments were not more than $97 \mathrm{~cm}$. To prevent mine spoil from blocking drainage holes of columns, a sheet 
of fiber glass mesh was laid at the bottom of columns. Packing of the columns was finished in one day which was on 15 April 1992.

Mine spoil and FGD were characterized at the start of experiment (Table 10). Analyses of various elements were determined af ter acid digestion followed by inductively coupled plasma (ICP) emission spectrometry.

On 8 May 1992, 60 seeds of both alfalfa (Medicago sativa L.) and fescue (Festucaarundinacea schreb), with germination rates exceeding $90 \%$, were mixed into the top one $\mathrm{cm}$ surface layer of each column. Columns were covered with a layer of cheese cloth to hold moisture for seed germination. During the next 20 days, a total of $6 \mathrm{~L}$ distilled water was applied onto the surface of the columns to stimulate plant growth. Germination rate of seeds was measured on June 5 , 1992. The number of plants and total plant weight of plants in each column were recorded on August 14 in 1992, June 11 (plant number) and August 22 (plant weight) in 1993, and because of drought only plant numbers were measured on June 6 in 1994.

Column leachates were measured for $\mathrm{pH}$ and various major plant nutrients (by ICP). Frequency of collection of leachate depended on the amount of rainfall and was normally in the range of every 3 to 21 days. There was no collection of leachate from August 1993 to March 1994.

\subsubsection{Results and Discussion}

Germination rates (Table 11) were significantly affected by FGD treatment. Without any addition of FGD the mine spoil was toxic and completely inhibited all alfalfa and fescue seed from germinating. Generally the optimum germination occurred at the 20\% FGD application rate (equivalent to approximately $900 \mathrm{Mg} / \mathrm{ha}$ or 400 tons/acre). A significant decrease was observed when the application rate of the FGD by-product materials was increased to $40 \%$. There did not seem to be any adverse effect on germination due to sulfite. Both the LIMB and OSU spray dryer materials caused similar results in germination even though the LIMB byproduct contains no sulfite and the spray dryer material contains approximately $30 \%(\mathrm{wt} / \mathrm{wt})$ calcium sulfite (Stehouwer et al., 1995).

The number of plants that survived and grew to maturity was much less than those that germinated (Table 12). Plant numbers were highest for the $10 \%$ application rate and decreased as rates were increased to $20 \%$ and $40 \%$. Also the number of plants tended to decrease each 
Table 10. Analyses of mine spoil and FGD used in the column experiment.

\begin{tabular}{lccc}
\hline \hline & & & Mine \\
Parameter & LIMB $^{\mathrm{a}}$ & OSU $^{\mathrm{b}}$ & spoil \\
\hline $\mathrm{pH}$ & 12.5 & 12.1 & 3.1 \\
$\mathrm{CaCO}_{3}$ equivalence \% & 59 & 64 & $\mathrm{ND}^{\mathrm{c}}$ \\
Total Chemical Analysis & & & \\
$\mathrm{Al}(\%)$ & 3.5 & 2.2 & 11.5 \\
$\mathrm{As}(\mathrm{mg} / \mathrm{kg})$ & 55.1 & 32.5 & 46.3 \\
$\mathrm{~B}(\mathrm{mg} / \mathrm{kg})$ & 233 & 338 & $\mathrm{ND}$ \\
$\mathrm{Ca}(\%)$ & 18.9 & 32.2 & 0.04 \\
$\mathrm{Cd}(\mathrm{mg} / \mathrm{kg})$ & 1.0 & 1.3 & 0.8 \\
$\mathrm{Cr}(\mathrm{mg} / \mathrm{kg})$ & 28.0 & 19.7 & 94.4 \\
$\mathrm{Cu}(\mathrm{mg} / \mathrm{kg})$ & 21.0 & 17.6 & 26.8 \\
$\mathrm{Fe}(\%)$ & 6.8 & 2.8 & 5.57 \\
$\mathrm{~K}(\%)$ & 0.91 & 1.10 & 2.36 \\
$\mathrm{Mg}(\%)$ & 0.6 & 0.56 & 0.50 \\
$\mathrm{~Pb}(\mathrm{mg} / \mathrm{kg})$ & 16.0 & 13.3 & 78.0 \\
$\mathrm{~S}(\%)$ & 5.3 & 10.5 & 1.02 \\
$\mathrm{Si}(\%)$ & 6.6 & 3.8 & 22.7 \\
\hline \hline
\end{tabular}

aLIMB - lime injection multistage burner FGD by-product. See Section 1.3.

bOSU - spray dryer FGD by-product obtained from Ohio State University. See Section 1.3.

cND, not determined. 
Table 11. Effect of type and rate of FGD amendment on alfalfa and fescue seed germination in 1992.

\begin{tabular}{lcc}
\hline & \multicolumn{2}{c}{1992} \\
\cline { 2 - 3 } Treatment & Alfalfa & Fescue \\
\hline & -.-.-- (germination, \%) -.-...- \\
Control & 0.0 & 3.3 \\
10\% LIMBa & 63.8 & 60.5 \\
20\% LIMB & 75.5 & 68.8 \\
40\% LIMB & 52.2 & 43.8 \\
10\% OSUb & 61.2 & 58.8 \\
20\% OSU & 69.5 & 66.2 \\
40\% OSU & 58.3 & 45.0 \\
LSD(0.05) & 7.4 & 9.3 \\
\hline \hline
\end{tabular}

aLIMB - lime injection multistage burner FGD

by-product. See Section 1.3.

bOSU - spray dryer FGD by-product. See Section 1.3.

year from 1992 to 1994. Since no additional seedings were made after that which was done in 1992, any plants that were counted in 1993 were either those that survived from the previous year or which grew from seed produced naturally by the plants as they matured. The number of fescue plants was higher than the number of alfalfa plants indicating fescue was better able to survive the conditions in the amended spoil.

Dry matter yield of alfalfa and fescue were also significantly affected by the FGD treatments. There was no dry matter produced in the control (unamended columns). The maximum dry matter produced during the first 125 days after planting (1992 data) occurred for the 10\% FGD application rate for both materials (Table 13). Dry matter production declined drastically for the $20 \%$ rate. Since the plant germination was maximum at the $20 \%$ FGD application rate, it 
Table 12. Effect of type and rate of FGD amendment on number of alfalfa and fescue plants per column in 1992, 1993 and 1994.

\begin{tabular}{|c|c|c|c|c|c|c|}
\hline \multirow[b]{2}{*}{ Treatment } & \multicolumn{2}{|c|}{1992} & \multicolumn{2}{|c|}{1993} & \multicolumn{2}{|c|}{1994} \\
\hline & Alfalfa & Fescue & Alfalfa & Fescue & Alfalfa & Fescue \\
\hline & \multicolumn{6}{|c|}{ number of plants/column -- } \\
\hline Control & 0.0 & 0.0 & 0.0 & 0.0 & 0.0 & 0.0 \\
\hline $10 \%$ LIMB $^{\mathrm{a}}$ & 13.3 & 18.9 & 9.4 & 15.6 & 8.9 & 15.0 \\
\hline $20 \%$ LIMB & 4.4 & 1.7 & 3.3 & 1.1 & 3.3 & 1.1 \\
\hline $40 \%$ LIMB & 0.0 & 1.7 & 0.0 & 1.1 & 0.0 & 1.1 \\
\hline $10 \%$ OSUb & 17.2 & 17.2 & 11.7 & 12.2 & 11.7 & 11.7 \\
\hline $20 \%$ OSU & 12.8 & 17.2 & 5.6 & 11.1 & 5.0 & 11.1 \\
\hline $40 \%$ OSU & 1.1 & 2.8 & 0.6 & 1.7 & 0.0 & 1.7 \\
\hline
\end{tabular}

aLIMB - lime injection multistage burner FGD by-product. See Section 1.3. bOSU - spray dryer FGD by-product. See Section 1.3.

implies that seed germination and emergence was optimal at 20\% rate but seedling growth was poor. Dry matter yield associated with the $40 \%$ application treatment was zero for alfalfa in 1992 and $10 \mathrm{~g} /$ column for fescue. However, fescue dry matter yield in 1993 at the $40 \%$ rate decreased to near zero. Similar trends in dry matter production were observed for 1993. Because of drought, no dry matter yields were recorded in 1994.

Water that leached from the bottom of the columns was collected and analyzed in 1992 through 1994. This data is significant because it represents natural weathering of a coal mine spoil treated with high rates of two different types of FGD materials. Tables 14 and 15 provide range and median values for $\mathrm{pH}, \mathrm{Al}, \mathrm{Ca}, \mathrm{Fe}, \mathrm{K}, \mathrm{Mg}, \mathrm{SO}_{4}, \mathrm{Mn}$ and $\mathrm{NO}_{3}$. These represent the major elements that would be leached from the spoil. 
Table 13. Effect of type and rate of FGD amendment on dry matter production (g/column) of alfalfa and fescue plants in 1992 and $1993^{\mathrm{a}}$.

\begin{tabular}{|c|c|c|c|c|}
\hline \multirow[b]{2}{*}{ Treatment } & \multicolumn{2}{|c|}{1992} & \multicolumn{2}{|c|}{1993} \\
\hline & Alfalfa & Fescue & Alfalfa & Fescue \\
\hline & \multicolumn{4}{|c|}{ - } \\
\hline Control & 0.0 & 0.0 & 0.0 & 0.0 \\
\hline $10 \%$ LIMB $^{b}$ & 6.8 & 1.6 & 15.9 & 2.9 \\
\hline $20 \%$ LIMB & 4.0 & 0.5 & 6.3 & 0.0 \\
\hline $40 \%$ LIMB & 0.0 & 10.0 & 0.0 & 0.0 \\
\hline $10 \%$ OSUc & 14.2 & 1.0 & 17.2 & 1.8 \\
\hline $20 \%$ OSU & 2.8 & 9.3 & 16.0 & 0.7 \\
\hline $40 \%$ OSU & 0.0 & 10.0 & 0.6 & 0.0 \\
\hline $\mathrm{LSD}(0.05)$ & 3.9 & 0.6 & 6.8 & 0.7 \\
\hline
\end{tabular}

aThere was no harvest in 1994 because of a drought and plant growth on all treatments was minimal.

bLIMB - lime injection multistage burner FGD by-product. See Section 1.3. cOSU - spray dryer FGD by-product. See Section 1.3.

Although pH of leachate seemed to be little affected by FGD treatment, concentrations of $\mathrm{Al}, \mathrm{Ca}$, $\mathrm{Fe}, \mathrm{K}, \mathrm{Mg}$ and $\mathrm{Mn}$ were increased in the leachates as FGD application rates were increased. This was attributed to Ca causing displacement of these elements on the surface of the spoil particles. As a result, these elements entered the aqueous solutions that percolated through the spoil and was collected in the leachate. Sulfate and $\mathrm{K}$ concentrations were especially increased the third year after treatment indicating some delay in the transport of these elements to the leachate collection point at the bottom of the columns. However, $\mathrm{Al}$ and Fe were substantially reduced in concentrations in the third year compared to the first two years, although not nearly to the levels that were found for the untreated control columns. 
Table 14. Ranges and means of $\mathrm{pH}$ and of $\mathrm{Al}, \mathrm{Ca}, \mathrm{Fe}$ and $\mathrm{K}$ concentrations as affected by type and rate of FGD application during the years 1992 through 1994.

\begin{tabular}{|c|c|c|c|c|c|c|c|c|c|c|}
\hline \multirow[b]{2}{*}{ Treatment } & \multicolumn{2}{|c|}{$\mathrm{pH}$} & \multicolumn{2}{|c|}{$\mathrm{Al}$} & \multicolumn{2}{|c|}{$\mathrm{Ca}$} & \multicolumn{2}{|c|}{$\mathrm{Fe}$} & \multicolumn{2}{|c|}{$\mathrm{K}$} \\
\hline & Range & Med $^{a}$ & Range & Med & Range & Med & Range & Med & Range & Med \\
\hline \multicolumn{11}{|c|}{1992} \\
\hline Control & 2.3 & 2.7 & $44-181$ & 109 & $18-230$ & 108 & $0.3-69$ & 25 & $0.02-4.6$ & 0.5 \\
\hline $10 \%$ LIMB $^{b}$ & 2.3 & 2.7 & $52-267$ & 174 & $49-501$ & 215 & $0.6-92$ & 38 & $0.03-3.4$ & 0.6 \\
\hline 20\% LIMB & 2.3 & 2.6 & $11-403$ & 207 & $39-447$ & 172 & $0.1-90$ & 52 & $0.01-8.4$ & 0.8 \\
\hline $40 \%$ LMB & 2.4 & 2.8 & $20-140$ & 232 & $68-419$ & 226 & $0.1-81$ & 42 & $0.06-2.6$ & 0.4 \\
\hline $10 \%$ OSU' & 2.3 & 2.8 & $6-223$ & 145 & $9-298$ & 179 & 0.473 & 25 & $0.02-1.9$ & 0.7 \\
\hline $20 \%$ OSU & 2.5 & 3.1 & $9-230$ & 153 & $10-194$ & 125 & $0.4-44$ & 20 & $0.01-3.5$ & 0.5 \\
\hline $40 \%$ OSU & 2.4 & 2.7 & $3-427$ & 215 & $3-313$ & 139 & $0.7-86$ & 45 & $0.04-4.0$ & 0.3 \\
\hline \multicolumn{11}{|c|}{1993} \\
\hline Control & 2.4 & 2.8 & $12-96$ & 17 & $21-122$ & 48 & $1-59$ & 15 & $0.01-2.0$ & 0.4 \\
\hline $10 \%$ LMB & 2.4 & 2.5 & $35-196$ & 108 & 159 & 293 & $8-70$ & 42 & $.003-0.5$ & 0.01 \\
\hline $20 \%$ LIMB & 2.3 & 2.6 & $59-286$ & 114 & 261 & 381 & $2-85$ & 35 & $0.01-0.4$ & 0.35 \\
\hline $40 \%$ LIMB & 2.3 & 2.6 & $39-397$ & 190 & 111 & 319 & $10-79$ & 47 & $0.01-.04$ & 0.01 \\
\hline $10 \%$ OSU & 2.3 & 2.6 & $59-197$ & 76 & 210 & 262 & $17-51$ & 27 & $0.01-0.3$ & 0.01 \\
\hline $20 \% \mathrm{OSU}$ & 2.3 & 2.4 & $27-166$ & 76 & $73-327$ & 121 & $1-53$ & 29 & $.003-6.0$ & 0.06 \\
\hline $40 \%$ OSU & 2.2 & 2.6 & $33-391$ & 157 & 135 & 212 & $3-84$ & 36 & $0.01-0.5$ & 0.02 \\
\hline \multicolumn{11}{|c|}{1994} \\
\hline Control & 2.7 & 3.3 & $2-17$ & 4 & $9-73$ & 28 & 0.1 & 0.5 & $0.03-5.9$ & 1.9 \\
\hline $10 \%$ LMB & 2.7 & 3.0 & $6-23$ & 20 & 157 & 268 & 0.2 & 4.0 & $0.6-2.9$ & 1.2 \\
\hline 20\% LIMB & 2.6 & 2.9 & $11-44$ & 22 & $92-588$ & 280 & $0.1-10$ & 6.5 & $0.2-6.5$ & 3.6 \\
\hline $40 \%$ LMMB & 2.5 & 2.7 & $10-72$ & 65 & 128 & 290 & $0.1-19$ & 15.8 & $7.4-38.7$ & 14.9 \\
\hline $10 \%$ OSU & 2.6 & 2.9 & $5-26$ & 20 & 154 & 247 & 0.2 & 5.6 & $0.02-0.9$ & 0.4 \\
\hline $20 \% \mathrm{OSU}$ & 2.5 & 2.8 & $10-25$ & 14 & 119 & 191 & 0.1 & 3.9 & $1.1-7.9$ & 1.7 \\
\hline $40 \%$ OSU & 2.4 & 2.7 & $33-62$ & 53 & 146 & 270 & $15-18$ & 16.2 & $1.1-12.3$ & 5.1 \\
\hline
\end{tabular}

aMed; median value.

bLIMB - lime injection multistage burner FGD by-product. See Section 1.3. cOSU - spray dryer FGD by-product. See Section 1.3. 
Table 15. Ranges and means of $\mathrm{Mn}, \mathrm{SO}_{4}, \mathrm{Mn}$ and $\mathrm{NO}_{3}$ concentrations as affected by type and rate of FGD application during the years 1992 through 1994.

\begin{tabular}{|c|c|c|c|c|c|c|c|c|}
\hline \multirow[b]{2}{*}{ Treatment } & \multicolumn{2}{|c|}{$\mathbf{M g}$} & \multicolumn{2}{|c|}{$\mathrm{SO}_{4}^{\mathrm{b}}$} & \multicolumn{2}{|c|}{ Mn } & \multicolumn{2}{|c|}{$\mathrm{NO}_{3}{ }^{\mathrm{c}}$} \\
\hline & Range & $\operatorname{Med}^{\mathbf{a}}$ & Range & Med & Range & Med & Range & Med \\
\hline & \multicolumn{8}{|c|}{1992} \\
\hline Control & $1.5-15.8$ & 4.9 & $429-1420$ & 1170 & $0.1-0.9$ & 0.3 & $0.2-1.8$ & 0.8 \\
\hline $10 \% \operatorname{LMB}^{d}$ & $2.6-12.23$ & 6.9 & $1100-3150$ & 1730 & $0.1-0.9$ & 0.3 & $0.3-2.8$ & 1.0 \\
\hline $20 \%$ LIMB & $2.3-16.7$ & 7.2 & $332-2780$ & 1760 & $0.1-0.6$ & 0.5 & $0.1-7.3$ & 0.7 \\
\hline $40 \%$ LIMB & $3.4-14.4$ & 9.7 & $5-3002$ & 1860 & $0.2-1.1$ & 0.6 & $0.2-1.4$ & 0.6 \\
\hline $10 \%$ OSUe & $0.4-10.3$ & 6.6 & $709-2010$ & 1280 & $0.02-0.6$ & 0.3 & $0.6-3.3$ & 1.1 \\
\hline $20 \%$ OSU & $0.5-8.7$ & 5.6 & $44-2140$ & 1050 & $0.03-0.4$ & 0.3 & $0.1-2.5$ & 0.7 \\
\hline \multirow[t]{2}{*}{$40 \%$ OSU } & $0.2-12.4$ & 7.1 & $386-2720$ & 1660 & $0.2-1.4$ & 0.5 & $0.1-2.0$ & 0.4 \\
\hline & \multicolumn{8}{|c|}{1993} \\
\hline Control & $1-4.3$ & 1.6 & $321-1810$ & 561 & $0.03-0.2$ & 0.1 & $0.2-2.5$ & 1.0 \\
\hline $10 \%$ LMB & $4.7-16.5$ & 7.3 & $633-3170$ & 1930 & $0.05-0.3$ & 0.2 & $0.2-1.4$ & 0.5 \\
\hline $20 \%$ LIMB & $3.4-7.7$ & 5.0 & $1250-3460$ & 2230 & $0.04-0.3$ & 0.1 & $0.3-2.2$ & 0.9 \\
\hline $40 \%$ LIMB & $1.2-9.4$ & 4.8 & $679-3010$ & 2260 & $0.05-0.6$ & 0.3 & $0.2-0.8$ & 0.5 \\
\hline $10 \%$ OSU & $6.4-19.8$ & 9.8 & $656-2170$ & 1680 & $0.06-0.2$ & 0.1 & $0.5-2.5$ & 1.2 \\
\hline $20 \%$ OSU & $1.6-9.9$ & 2.3 & $311-1960$ & 978 & $0.03-0.2$ & 0.1 & $0.1-3.2$ & 0.3 \\
\hline \multirow[t]{2}{*}{$40 \%$ OSU } & $2.3-11.2$ & 5.0 & $722-2720$ & 1670 & 0.040 .7 & 0.2 & $0.3-2.4$ & 0.9 \\
\hline & \multicolumn{8}{|c|}{1994} \\
\hline Control & $0.2-2.1$ & 0.9 & $77-678$ & 364 & $0.01-0.06$ & 0.03 & $0.4-2.4$ & 1.5 \\
\hline $10 \%$ LIMB & $5.2-12.5$ & 8.4 & $902-1990$ & 1350 & $0.03-0.16$ & 0.04 & $0.4-0.9$ & 0.7 \\
\hline $20 \%$ LIMB & $1.0-11.4$ & 3.6 & $32-2380$ & 1740 & $0.01-0.07$ & 0.03 & 0.43 .7 & 0.6 \\
\hline $40 \%$ LIMB & $1.8-9.3$ & 4.0 & $626-2560$ & 2450 & $0.02-0.11$ & 0.06 & $0.2-0.6$ & 0.4 \\
\hline $10 \%$ OSU & $7.2-16.9$ & 11.6 & $840-1820$ & 1300 & $0.01-0.09$ & 0.03 & $0.7-1.4$ & 0.8 \\
\hline $20 \%$ OSU & $6.0-17.9$ & 9.6 & $649-1800$ & 1070 & $0.01-0.10$ & 0.03 & $0.4-1.3$ & 0.9 \\
\hline $40 \%$ OSU & $3.6-12.0$ & 7.7 & $1460-1930$ & 1740 & $0.02-0.09$ & 0.05 & $1.8-3.6$ & 2.9 \\
\hline
\end{tabular}

aMed; median value.

bTo express on an elemental basis as $\mathrm{SO}_{4}-\mathrm{S}$, multiply the values in this column by 0.333 .

cTo express on an elemental basis as $\mathrm{NO}_{3}-\mathrm{N}$, multiply the values in this column by 0.226 .

dLIMB - lime injection multistage burner FGD by-product. See Section 1.3.

eOSU - spray dryer FGD by-product. See Section 1.3. 
In general the water quality seemed little affected by the FGD treatments. The surface layer only was treated and water that interacted with this layer still had to travel through the untreated spoil layers below. This untreated layer continued to significantly impact leachate water quality. In field scale experiments, the use of surface FGD treatments should improve plant growth and stop the rapid weathering of the spoil. However, any weathering impacts that had occurred prior to FGD treatments would continue to reveal themselves until enough water had flushed through the spoil to remove the elements solubilized by the weathering. Thus FGD treatments would probably be most beneficial, not immediately, but some time later after application.

\subsubsection{Summary and Conclusions}

The data on plant growth from the column study support the following conclusions:

(a) Crop germination was the best at about the 20\% FGD application rate for both materials, but many seedlings did not survive to produce mature plants. This was attributed to the initially high $\mathrm{pH}$ and salt concentrations created by the FGD amendments.

(b) The highest dry matter production of fescue and alfalfa were obtained at the FGD application rate of $10 \%$ for both materials.

(c) Water quality seemed little affected by FGD treatment the first two years after application but seemed to be improving in the third year.

\subsection{Experiment 2 - Fleming Abandoned Mine Land Site}

\subsubsection{Materials and Methods}

\subsubsection{Site Selection and Experimental Design}

The site-selection process involved gathering data about abandoned mine sites in eastern Ohio, then categorizing and ranking the sites on the basis of their water quality and erosion problems. Additionally, the Ohio Department of Natural Resources, Division of Reclamation, was requested to give input on sites that required immediate reclamation. Seven candidate sites were identified. Each of these sites was an abandoned mine for which evidence of acid mine drainage was documented.

As a result of complaints from local residents and the Tuscarawas County Engineers office, the Fleming abandoned mine sit was placed on a reclamation priority list by the U.S. 
Department of Interior, Office of Surface Mining. Because the site was targeted for federal funding and met the site selection criteria, the Fleming abandoned mine site was selected to study the potential benefits of using FGD by-products for reclamation.

The Fleming site is located in Franklin County, Tuscarawas County, OH. It contained approximately 10 ha ( 25 acres) of exposed, highly erodible underclay bordered on two sides by about 18 ha ( 45 acres) of unreclaimed spoil and coal refuse. Baseline data collected by the Ohio Department of Natural Resources indicated this site was characterized by high erosion rates of $1010 \mathrm{Mg} /$ ha/year (450 tons/acre/year) based on a 2-year, 24 hour storm. Acid mine drainage is derived from the oxidation of pyrite contained in the mining overburden associated with the $\# 5$ and $\# 6$ coal (middle and upper Kittanning) seams. Some of the most acid overburden in the state of Ohio is associated with these two coal seams. The spoil and underclay was very acidic and nutrient poor and the ability of this material to support plant growth was extremely limited. Visits clearly indicated vegetation was sparse or nonexistent on much of the site. Total clay content was high suggesting water infiltration and availability would limit plant growth and contribute to rapid surface water runoff. Equilibrium water infiltrations measured at eight different locations on the exposed underclay revealed values ranging from $1.2 \times 10^{-6} \mathrm{~cm} / \mathrm{s}$ to $8.4 \times 10^{-6} \mathrm{~cm} / \mathrm{s}$. $\mathrm{pH}$ of the spoil and underclay was 3.1 and surface drainage water samples exhibited $\mathrm{pH}$ values ranging from 2.5 to 3.9 with high concentrations of total acidity and soluble aluminum, iron, sulfate and manganese.

A schematic of the experimental design developed to study the use of FGD by-products for reclamation of toxic surface coal mine lands is shown in Figure 9. This field design permitted measurements of soil quality, plant quality, interstitial soil water quality, and surface and groundwater hydrology and quality as impacted by the use of FGD by-product for mineland reclamation.

In the summer and fall of 1994, six 0.4 ha ( 1 acre) watersheds were constructed. Exposed underclay material on the site was graded to a $4 \%$ slope and recompacted to serve as an aquitard. Thickness of the clay pad ranged from $3 \mathrm{~m}$ to greater than $10 \mathrm{~m}$ (10 to $30 \mathrm{ft}$ ) in an area $205 \mathrm{~m}$ by $137 \mathrm{~m}$ ( $670 \mathrm{ft}$ by $450 \mathrm{ft}$ ). A $1.5 \mathrm{~m}$ ( $5 \mathrm{ft}$ ) wide by $30 \mathrm{~cm}$ ( $1 \mathrm{ft}$ ) high clay berm was constructed on the clay surface to hydrologically separate each 0.4 ha watershed. Following preparation of the clay aquitard, $1.2 \mathrm{~m} \mathrm{(} 4 \mathrm{ft}$ ) of acidic minespoil material was placed over the recompacted clay and graded to a $4 \%$ slope. Each watershed was hydrologically separated by building a $3 \mathrm{~m}(10 \mathrm{ft})$ wide by $60 \mathrm{~cm}(2 \mathrm{ft})$ high berm directly above the underlying clay berm. Berms were similarly constructed at the lower end of each watershed to 


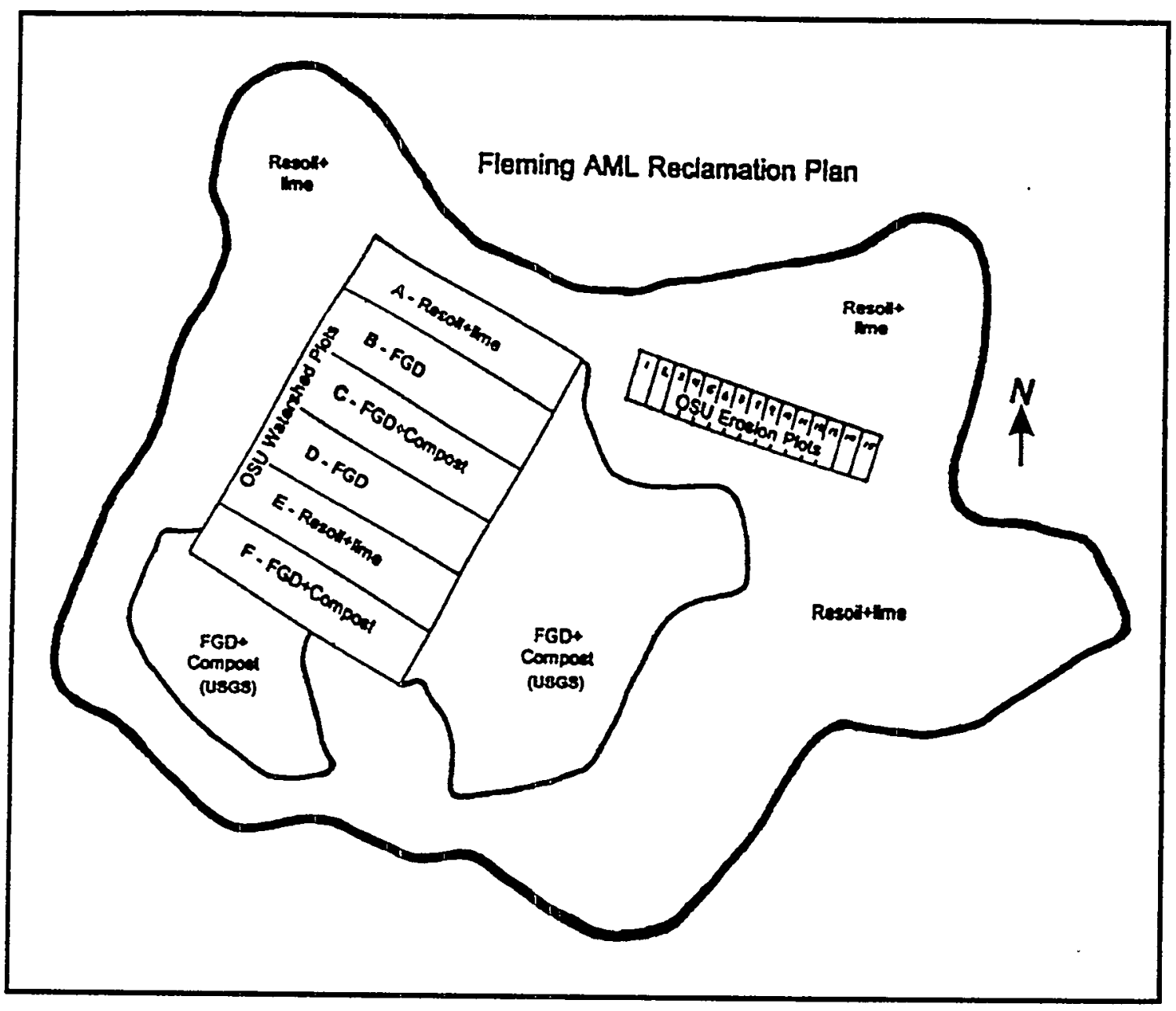

Figure 9. Schematic of the experimental design developed for the Fleming site to study the potential impacts of using FGD for reclamation of abandoned surface coal mine lands. The FGD applied to the six small watersheds was an AFBC by-product and the FGD applied to the areas outside of the small watersheds was a PFBC byproduct. 
direct surface water flow into a $3 \mathrm{~m}$ (10 ft) long approach. Water flowed through an H-flume instrumented with a stilling well and a water stage recorder. Approximately $0.3 \%$ of total surface water flow was automatically diverted to a holding tank to allow sampling of each flow event.

Following construction of the watersheds, three surface treatments were applied to the spoil surface in each of 2 watersheds.

1. Conventional reclamation practice which involved adding $112 \mathrm{Mg} / \mathrm{ha}$ ( 50 tons/acre) of agricultural limestone on the spoil surface followed by placement of $20 \mathrm{~cm}(8 \mathrm{in})$ of borrowed topsoil material above the spoil. Additional agricultural limestone was spread on the topsoil surface at a rate of $45 \mathrm{Mg} / \mathrm{ha}$ (20 tons/acre) and incorporated to a depth of approximately 15 to $20 \mathrm{~cm}$ ( 6 to $8 \mathrm{in}$ ) with a chisel plow and offset disc.

2. Application of $280 \mathrm{Mg} / \mathrm{ha}$ ( 125 tons/acre) of FGD by-product followed by incorporation to a depth of approximately $20 \mathrm{~cm}(8 \mathrm{in})$ by multiple passes with a chisel plow and an offset disk.

3. Application of a mixture of FGD by-product and yard waste compost applied at a rate of $280 \mathrm{Mg} / \mathrm{ha}$ ( 125 tons/acre) FGD and $112 \mathrm{Mg} / \mathrm{ha}$ ( 50 tons/acre) compost followed by incorporation to a depth of approximately $20 \mathrm{~cm}$ ( 8 in) by multiple passes with a chisel plow and an offset disk.

Areas outside of the six small watersheds were reclaimed either by conventional methods (i.e. by covering the spoil with $20 \mathrm{~cm}$ of resoil plus lime) or by using FGD plus compost. These FGD plus compost areas were located next to the six watersheds (Figure 9) and were used primarily by scientists from the U.S. Geological Survey to study the potential effects of FGD on interstitial and groundwater quality. The watershed treatments did not impact the measurements made by the US Geological Survey because all surface and percolation water that was derived from these watersheds was diverted through measuring flumes and then immediately exited the study site.

The source of the FGD for the watersheds and the surrounding treated areas was different. For watersheds, the FGD was from an atmospheric fluidized bed combustion (AFBC) burner located at a General Motors plant in Pontiac, MI. This plant burned coal from Tuscarawas County, $\mathrm{OH}$ and used Ohio limestone to remove $\mathrm{SO}_{2}$ before the flue gases were emitted to the 
atmosphere. This FGD material was hauled back to our Ohio study site from Michigan after the coal had been delivered to the General Motors plant. The AFBC material was a blend of byproduct collected from both the bed and fly ash streams. It was conditioned with water at the power plant which resulted in the hydration of anhydrite to form gypsum and the hydration of lime to form portlandite $\left(\mathrm{Ca}(\mathrm{OH})_{2}\right)$. The AFBC by-product had a neutralizing potential of approximately $39 \%$ of that of calcium carbonate. The source of the alkalinity in this material was predominantly $\mathrm{Ca}(\mathrm{OH})_{2}$ with minor amounts of $\mathrm{CaCO}_{3}$.

The FGD applied to the other areas was from a pressurized fluidized bed combustion (PFBC) burner located at the American Electric Power's Cardinal Plant near Brilliant, OH. Yard waste compost was also used in this study and was obtained from Earth-N-Wood. This company in North Canton, $\mathrm{OH}$ collects grass clippings, chipped branches and brushes and leaves from the Akron and Canton and then composts them in windrows.

Construction of the six small watersheds was completed in October, 1994 and the watersheds and all other FGD treated areas were seeded to a grass-legume sward in November, 1994. The seeding mix included orchard grass (Dactylis glomerata), timothy (Phleum pratense), annual ryegrass (Lolium multiflorum), ladino clover (Trifolium repense Ladino), birdsfoot trefoil (Lotus sp.), and winter wheat (Agropyron sp.).

\subsubsection{Characterization of Fleming Spoil and FGD Amendments}

The chemistry of FGD by-products had been previously researched extensively by other workers affiliated with this study (Stehouwer et al. 1995a; 1998). Additional analyses were completed as part of this study, however, to document the chemistry of the materials actually applied at the study site. This is important because, the composition of FGD by-products can change in response to operating conditions of the coal-fired boiler, coal quality, and chemistry of the sorbent used in the FGD process. A complete description of the chemical properties of the various materials used in this field study along with a kiln dust sample, another by-product that is commonly land applied to correct acid soil pH, is provided in Table 16.

Grab samples of each FGD material and of the final mix of FGD plus compost were collected just prior to their application on the Fleming site. Analyses of these samples were conducted in laboratories located in the geochemistry and isotope laboratory of the U.S. Geological Survey (Reston, VA). Major and minor element concentrations (Table 16) were determined using an inductively coupled plasma emission spectrometer and an atomic absorption spectrometer. The 
Table 16. Chemical properties (as determined by the US Geological Survey) of replicate samples of materials used in the Fleming reclamation field study including FGD by-products (PFBC and AFBC materials), yard-waste compost, mixtures of FGD and compost, and a kiln dust sample.

\begin{tabular}{|c|c|c|c|c|c|c|}
\hline \multirow[b]{2}{*}{ Sample name } & $\mathrm{Al}$ & $\mathrm{Ca}$ & $\mathrm{Fe}$ & $\mathrm{K}$ & $\mathrm{Mg}$ & $\mathrm{Na}$ \\
\hline & \multicolumn{6}{|c|}{ weight percent } \\
\hline PFBC-FGD-1 & 3.3 & 18.0 & 4.3 & 0.59 & 9.40 & 0.10 \\
\hline PFBC-FGD-2 & 3.3 & 18.0 & 4.4 & 0.59 & 9.50 & 0.10 \\
\hline PFBC-FGD+COM-1 & 3.8 & 11.0 & 4.0 & 1.00 & 5.10 & 0.37 \\
\hline PFBC-FGD+COM-2 & 3.8 & 11.0 & 4.0 & 1.00 & 5.10 & 0.37 \\
\hline AFBC-FGD-1 & 5.3 & 20.0 & 6.7 & 0.58 & 3.20 & 0.10 \\
\hline AFBC-FGD-2 & 5.1 & 19.0 & 6.5 & 0.56 & 3.20 & 0.09 \\
\hline AFBC-FGD+COM-1 & 4.7 & 14.0 & 5.5 & 0.92 & 3.10 & 0.23 \\
\hline AFBC-FGD+COM-2 & 4.7 & 14.0 & 5.4 & 0.93 & 3.00 & 0.24 \\
\hline Compost-1 & 3.8 & 3.5 & 3.3 & 1.40 & 0.92 & 0.50 \\
\hline Compost-2 & 3.8 & 3.6 & 3.3 & 1.50 & 0.93 & 0.52 \\
\hline Kiln dust-1 & 1.1 & 33.0 & 0.67 & 0.40 & 1.40 & 0.04 \\
\hline \multirow[t]{3}{*}{ Kiln dust-2 } & 1.1 & 34.0 & 0.66 & 0.41 & 1.40 & 0.04 \\
\hline & $\mathrm{P}$ & $\mathrm{Ti}$ & $\mathrm{Mn}$ & Total-S & $\mathrm{SO}_{4}-\mathrm{S}$ & ${ }^{34} \mathrm{SSO}_{4}$ \\
\hline & \multicolumn{5}{|c|}{ weight percent } & per mil \\
\hline PFBC-FGD-1 & 0.03 & 0.15 & 0.01 & 4.94 & 4.93 & 4.6 \\
\hline PFBC-FGD-2 & 0.03 & 0.14 & 0.01 & 4.94 & 4.92 & $--^{a}$ \\
\hline PFBC-FGD+COM-1 & 0.10 & 0.17 & 0.85 & 2.27 & 2.16 & 4.8 \\
\hline PFBC-FGD+COM-2 & 0.09 & 0.16 & 0.83 & 2.27 & 2.16 & - \\
\hline AFBC-FGD-1 & 0.03 & 0.25 & 0.25 & 7.11 & 6.94 & -3.8 \\
\hline AFBC-FGD-2 & 0.03 & 0.23 & 0.24 & 7.13 & 6.97 & - \\
\hline AFBC-FGD+COM-1 & 0.07 & 0.23 & 0.64 & 4.24 & 4.07 & -6.3 \\
\hline AFBC-FGD+COM-2 & 0.07 & 0.23 & 0.64 & 4.22 & 4.05 & - \\
\hline Compost-1 & 0.19 & 0.20 & 2.10 & 0.12 & $<0.05$ & - \\
\hline Compost-2 & 0.19 & 0.20 & 2.10 & 0.12 & $<0.05$ & - \\
\hline Kiln dust-1 & 0.01 & 0.07 & 0.01 & 1.29 & 1.17 & -6.6 \\
\hline Kiln dust-2 & 0.01 & 0.06 & 0.01 & 1.28 & 1.17 & - \\
\hline
\end{tabular}

aData not determined. 
Table 16 (continued).

\begin{tabular}{|c|c|c|c|c|c|c|}
\hline \multirow[b]{2}{*}{ Sample name } & \multirow{2}{*}{$\frac{\text { Sulfide-S }}{\text { wt. percent }}$} & \multirow{2}{*}{$\frac{{ }^{34} \delta \text { Sulfide-S }}{\text { per mil }}$} & Org-S & Total-C & Org-C & $\mathrm{CaCO}_{3}-\mathrm{C}$ \\
\hline & & & \multicolumn{4}{|c|}{ weight percent } \\
\hline PFBC-FGD-1 & $<0.05$ & 5.2 & $<0.05$ & 4.50 & 0.73 & 3.77 \\
\hline PFBC-FGD-2 & $<0.5$ & $--^{a}$ & $<0.05$ & 4.53 & 0.87 & 3.66 \\
\hline PFBC-FGD+COM-1 & 0.08 & -9.0 & $<0.05$ & 7.85 & 5.61 & 2.24 \\
\hline PFBC-FGD+COM-2 & 0.08 & - & $<0.05$ & 7.94 & 5.72 & 2.22 \\
\hline AFBC-FGD-1 & 0.15 & -3.8 & $<0.05$ & 5.82 & 5.13 & 0.69 \\
\hline AFBC-FGD-2 & 0.12 & - & $<0.05$ & 5.79 & 5.10 & 0.69 \\
\hline AFBC-FGD+COM-1 & 0.14 & -7.7 & $<0.05$ & 7.74 & 6.55 & 1.19 \\
\hline AFBC-FGD+COM-2 & $<0.05$ & - & $<0.05$ & 7.78 & 6.58 & 1.20 \\
\hline Compost-1 & 0.09 & - & $<0.05$ & 12.9 & 12.50 & 0.41 \\
\hline Compost-2 & 0.09 & - & $<0.05$ & 12.6 & 12.20 & 0.40 \\
\hline Kiln dust-1 & 0.09 & -19.0 & $<0.05$ & 8.90 & 0.16 & 8.74 \\
\hline \multirow[t]{3}{*}{ Kiln dust-2 } & 0.09 & - & $<0.05$ & 8.90 & $<0.01$ & 8.90 \\
\hline & $\mathbf{H}$ & Total-N & $\mathrm{Ag}$ & As & $\mathrm{Au}$ & $\mathrm{B}$ \\
\hline & \multicolumn{2}{|c|}{ weight percent } & \multicolumn{4}{|c|}{ Parts per million } \\
\hline PFBC-FGD-1 & 0.94 & $<0.01$ & $<2$ & 75 & $<8$ & 190 \\
\hline PFBC-FGD-2 & 0.97 & $<0.01$ & $<2$ & 70 & $<8$ & 190 \\
\hline PFBC-FGD+COM-1 & 1.30 & 0.30 & $<2$ & 43 & $<8$ & 130 \\
\hline PFBC-FGD+COM-2 & 1.30 & 0.32 & $<2$ & 44 & $<8$ & 120 \\
\hline AFBC-FGD-1 & 1.40 & 0.08 & $<2$ & 47 & $<8$ & 320 \\
\hline AFBC-FGD-2 & 1.30 & 0.08 & $<2$ & 47 & $<8$ & 320 \\
\hline AFBC-FGD+COM-1 & 1.50 & 0.22 & $<2$ & 43 & $<8$ & 220 \\
\hline AFBC-FGD+COM-2 & 1.50 & 0.23 & $<2$ & 42 & $<8$ & 220 \\
\hline Compost-1 & 2.00 & 0.74 & $<2$ & 11 & $<8$ & 86 \\
\hline Compost-2 & 2.00 & 0.75 & $<2$ & 11 & $<8$ & 92 \\
\hline Kiln dust-1 & 0.84 & $<0.01$ & $<2$ & 4 & $<8$ & 34 \\
\hline Kiln dust-2 & 0.83 & $<0.01$ & $<2$ & 4 & $<8$ & 34 \\
\hline
\end{tabular}

aData not determined. 
Table 16 (continued).

\begin{tabular}{|c|c|c|c|c|c|c|}
\hline & $\mathrm{Ba}$ & $\mathrm{Be}$ & $\mathrm{Bi}$ & $\mathrm{Cd}$ & $\mathrm{Ce}$ & Co \\
\hline Sample name & \multicolumn{6}{|c|}{ parts per million } \\
\hline PFBC-FGD-1 & 150 & 3 & $<10$ & $<2$ & 28 & 10 \\
\hline PFBC-FGD-2 & 150 & 3 & $<10$ & $<2$ & 29 & 11 \\
\hline PFBC-FGD+COM-1 & 270 & 2 & $<10$ & $<2$ & 39 & 12 \\
\hline PFBC-FGD+COM-2 & 190 & 2 & $<10$ & $<2$ & 40 & 12 \\
\hline AFBC-FGD-1 & 67 & 6 & $<10$ & $<2$ & 55 & 23 \\
\hline AFBC-FGD-2 & 64 & 6 & $<10$ & $<2$ & 54 & 22 \\
\hline AFBC-FGD+COM-1 & 110 & 5 & $<10$ & $<2$ & 54 & 18 \\
\hline AFBC-FGD+COM-2 & 110 & 5 & $<10$ & $<2$ & 52 & 18 \\
\hline Compost-1 & 390 & 1 & $<10$ & $<2$ & 43 & 13 \\
\hline Compost-2 & 400 & 1 & $<10$ & $<2$ & 44 & 12 \\
\hline Kiln dust-1 & 51 & $<1$ & $<10$ & $<2$ & 12 & 4 \\
\hline \multirow[t]{3}{*}{ Kiln dust-2 } & 50 & $<1$ & $<10$ & $<2$ & 11 & 4 \\
\hline & $\mathrm{Cr}$ & $\mathrm{Eu}$ & $\mathrm{Ga}$ & Ho & $\mathrm{La}$ & $\mathrm{Li}$ \\
\hline & \multicolumn{6}{|c|}{ Parts per million } \\
\hline PFBC-FGD-1 & 37 & 19 & $<2$ & 10 & $<4$ & 14 \\
\hline PFBC-FGD-2 & 37 & 21 & $<2$ & 10 & $<4$ & 14 \\
\hline PFBC-FGD+COM-1 & 76 & 25 & $<2$ & 10 & $<4$ & 21 \\
\hline PFBC-FGD+COM-2 & 71 & 27 & $<2$ & 11 & $<4$ & 21 \\
\hline AFBC-FGD-1 & 76 & 51 & $<2$ & 28 & $<4$ & 28 \\
\hline AFBC-FGD-2 & 73 & 48 & $<2$ & 27 & $<4$ & 27 \\
\hline AFBC-FGD+COM-1 & 81 & 41 & $<2$ & 22 & $<4$ & 28 \\
\hline AFBC-FGD+COM-2 & 83 & 40 & $<2$ & 21 & $<4$ & 26 \\
\hline Compost-1 & 290 & 37 & $<2$ & 11 & $<4$ & 25 \\
\hline Compost-2 & 250 & 37 & $<2$ & 13 & $<4$ & 24 \\
\hline Kiln dust-1 & 17 & 20 & $<2$ & 4 & $<4$ & 11 \\
\hline Kiln dust-2 & 16 & 20 & $<2$ & $<4$ & $<4$ & 12 \\
\hline
\end{tabular}

aData not determined. 
Table 16 (continued).

\begin{tabular}{|c|c|c|c|c|c|c|}
\hline \multirow[b]{2}{*}{ Sample name } & Mo & $\mathrm{Nb}$ & $\mathrm{Nd}$ & $\mathrm{Ni}$ & $\mathrm{Pb}$ & Sc \\
\hline & \multicolumn{6}{|c|}{ parts per million } \\
\hline PFBC-FGD-1 & 2 & 9 & 9 & 23 & 15 & 6 \\
\hline PFBC-FGD-2 & 3 & 6 & 8 & 23 & 16 & 7 \\
\hline PFBC-FGD+COM-1 & 2 & 10 & 18 & 31 & 36 & 6 \\
\hline PFBC-FGD+COM-2 & $<2$ & 10 & 19 & 31 & 29 & 7 \\
\hline AFBC-FGD-1 & 11 & 14 & 25 & 56 & 36 & 16 \\
\hline AFBC-FGD-2 & 11 & 13 & 22 & 54 & 37 & 15 \\
\hline AFBC-FGD+COM-1 & 9 & 12 & 26 & 53 & 44 & 12 \\
\hline AFBC-FGD+COM-2 & 10 & 12 & 23 & 54 & 51 & 12 \\
\hline Compost-1 & 5 & 7 & 23 & 33 & 110 & 6 \\
\hline Compost-2 & 4 & 7 & 21 & 37 & 99 & 6 \\
\hline Kiln dust-1 & $<2$ & 4 & $<4$ & 9 & 82 & 2 \\
\hline \multirow[t]{3}{*}{ Kiln dust-2 } & $<2$ & $<4$ & $<4$ & 9 & 81 & 2 \\
\hline & $\mathrm{Se}$ & Sn & $\mathrm{Sr}$ & $\mathrm{Ta}$ & $\mathrm{Th}$ & $\mathrm{U}$ \\
\hline & \multicolumn{6}{|c|}{ Parts per million } \\
\hline PFBC-FGD-1 & 1.3 & $<5$ & 160 & $<40$ & 5 & $<100$ \\
\hline PFBC-FGD-2 & 1.4 & $<5$ & 160 & $<40$ & 4 & $<100$ \\
\hline PFBC-FGD+COM-1 & 0.9 & $<5$ & 140 & $<40$ & 6 & $<100$ \\
\hline PFBC-FGD+COM-2 & 1.0 & $<5$ & 140 & $<40$ & 5 & $<100$ \\
\hline AFBC-FGD-1 & 11.0 & $<5$ & 200 & $<40$ & 9 & $<100$ \\
\hline AFBC-FGD-2 & 11.0 & $<5$ & 190 & $<40$ & 8 & $<100$ \\
\hline AFBC-FGD+COM-1 & 6.6 & $<5$ & 170 & $<40$ & 9 & $<100$ \\
\hline AFBC-FGD+COM-2 & 6.6 & $<5$ & 170 & $<40$ & 7 & $<100$ \\
\hline Compost-1 & 0.4 & $<5$ & 120 & $<40$ & 7 & $<100$ \\
\hline Compost-2 & 0.4 & $<5$ & 130 & $<40$ & 5 & $<100$ \\
\hline Kiln dust-1 & 5.1 & $<5$ & 180 & $<40$ & $<4$ & $<100$ \\
\hline Kiln dust-2 & 4.8 & $<5$ & 180 & $<40$ & $<4$ & $<100$ \\
\hline
\end{tabular}

aData not determined. 
Table 16 (continued).

\begin{tabular}{lccccc}
\hline & $\mathrm{V}$ & $\mathrm{Y}$ & $\mathrm{Yb}$ & $\mathrm{Zn}$ & Ash \\
\cline { 2 - 4 } \cline { 5 - 6 } Sample name & \multicolumn{2}{c}{ parts per million } & & percent \\
\hline PFBC-FGD-1 & 47 & 12 & 1 & 90 & 90.1 \\
PFBC-FGD-2 & 47 & 12 & 1 & 84 & 90.1 \\
PFBC-FGD+COM-1 & 54 & 14 & 1 & 120 & 83.4 \\
PFBC-FGD+COM-2 & 53 & 14 & 1 & 120 & 83.7 \\
AFBC-FGD-1 & 120 & 27 & 2 & 120 & 87.2 \\
AFBC-FGD-2 & 120 & 26 & 2 & 110 & 87.0 \\
AFBC-FGD+COM-1 & 89 & 24 & 2 & 110 & 80.2 \\
AFBC-FGD+COM-2 & 88 & 23 & 2 & 110 & 80.2 \\
Compost-1 & 57 & 16 & 1 & 160 & 72.7 \\
Compost-2 & 57 & 16 & 1 & 150 & 70.3 \\
Kiln dust-1 & 18 & 11 & $<1$ & 27 & 91.9 \\
Kiln dust-2 & 17 & 11 & $<1$ & 26 & 91.9 \\
\hline \hline
\end{tabular}

aData not determined.

methodology and detection limits for each element are as described by Briggs (1990) and Welsch et al. (1990). Forms of carbon and sulfur were determined by techniques described in Curry (1990) and Curry and Papp (1996), respectively. Total nitrogen and total hydrogen were determined by use of carbon-hydrogen-nitrogen analyzer as described in Skeen (1996).

Sulfur isotopic ratios from sulfate and sulfide fractions isolated from FGD by-products were prepared and analyzed according to techniques described by Shanks (W.C. Shanks, USGS, written communication, 1995). The samples were analyzed on a mass spectrometer, and results are reported relative to the Canyon Diablo Troilite (CDT) reference standard by use of the following notation and calculation:

Equation 3-1

$$
\delta^{34} S=\left[\left({ }^{4} S / 32 S\right)_{\text {sample }}-\left(34 S / 32 S_{\text {standard }}\right)\right] /\left({ }^{34} S / 32 S_{\text {standard }}\right) * 1,000
$$


$\delta^{34} \mathrm{~S}$ is reported in units of per mil and is also referred to as "delta ${ }^{34} \mathrm{~S}$." Sulfur isotope values have a standard error of \pm 0.2 per mil. The $\delta^{34} S$ value determined for the sulfate and sulfide fractions of the FGD by-product (an AFBC material obtained from the General Motors plant, Pontiac, MI-see section 3.3.1.1) was -3.8 per mil. The $\delta^{34} \mathrm{~S}$ values of the sulfate and sulfide fractions of the same FGD by-product/ compost mixture were isotopically heavier, ranging from +4.6 per mil for the sulfate fraction to +5.2 per mil for the sulfide fraction. Hence, dissolved sulfate in leachate derived from the FGD by-product/compost mixture applied to the buffer area (where PFBC by-product was applied) would be expected to have $\delta^{34} S$ values in the range of +4.6 to +5.2 per mil.

Analyses of the various materials used in the Fleming site reclamation study were also conducted by scientists at the Ohio State University (Table 17). These analyses were not as comprehensive as those conducted by the US Geological Survey and the only FGD sample analyzed was the AFBC material used to treat the six small watersheds (Figure 9). The purpose in conducting these analyses was to provide a comparison of concentrations in the reclamation materials with the spoil that existed at the Fleming mine site. Concentrations for most trace elements found in the AFBC and AFBC plus compost mixture were greater than those found in the spoil that underlies the site (Table 17). Exceptions to this generalization include $\mathrm{Ba}$ and $\mathrm{Cr}$ which were found in greater concentrations in the spoil. Similarly, the highest concentrations of Se were found in the FGD material. The data also indicated that significant amounts of some trace elements including $\mathrm{Ba}, \mathrm{Cr}$, and $\mathrm{Pb}$ were derived from the compost component of the AFBC plus compost mixtures.

The two sources of FGD by-product used at the Fleming site were predominantly composed of $\mathrm{Ca}, \mathrm{Al}, \mathrm{Mg}$, sulfate-S and carbonate-C. Solid phases in FGD by-products identified in previous studies by $X$-ray diffraction analyses include lime $(\mathrm{CaO})$, portlandite $\left(\mathrm{Ca}(\mathrm{OH})_{2}\right)$, calcite $\left(\mathrm{CaCO}_{3}\right)$, dolomite $\left(\mathrm{CaMg}\left(\mathrm{CO}_{3}\right)_{2}\right)$, magnesite $\left(\mathrm{MgCO}_{3}\right)$, periclase $(\mathrm{MgO})$, hemihydrate $\left(\mathrm{CaSO}_{3} \cdot 0.5 \mathrm{H}_{2} \mathrm{O}\right)$, anhydrite $\left(\mathrm{CaSO}_{4}\right)$, gypsum $\left(\mathrm{CaSO}_{4} \cdot 2 \mathrm{H}_{2} \mathrm{O}\right)$, and ettringite $\left(\mathrm{Ca}_{6} \mathrm{~A}_{12}\left(\mathrm{SO}_{4}\right)_{3}(\mathrm{OH})_{12} \bullet 26 \mathrm{H}_{2} \mathrm{O}\right)$ (Stehouwer et al. 1995a; 1998).

\subsubsection{Site Lithology}

Four cores were drilled to determine the lithology beneath the site and to collect rock samples for chemical analysis. The cores were drilled by use of a hollow, diamond-tipped drill bit that produces a $7.5 \mathrm{~cm}$ ( $3 \mathrm{in}$ ) diameter core. Three cores were drilled to $45 \mathrm{~m}$ ( $150 \mathrm{ft}$ ), and the 
Table 17. Chemical characterization of minespoil, topsoil, yard-waste compost, and FGD.

\begin{tabular}{lcccc}
\hline Parameter & Spoil & Topsoil & Compost & FGDa \\
\hline Major Elements (\%) & & & & \\
Organic C & 11.1 & NDb & 16.7 & ND \\
Total N & ND & ND & 0.84 & ND \\
Aluminum & 11.5 & 8.6 & ND & 2.5 \\
Calcium & 0.04 & 0.07 & 1.69 & 26.1 \\
Magnesium & 0.50 & 0.53 & 0.35 & 3.65 \\
Iron & 5.57 & 3.96 & 1.77 & 5.9 \\
Potassium & 2.36 & 2.35 & 0.56 & 0.36 \\
Phosphorus & 0.07 & 0.04 & 0.15 & 0.03 \\
Silicon & 22.7 & 19.0 & $\mathrm{ND}$ & 6.4 \\
Sulfur & 1.02 & 0.06 & $\mathrm{ND}$ & 12.3 \\
& & & & \\
Trace Elements $(\mu \mathrm{g} / \mathrm{g})$ & & & & \\
Arsenic & 46.3 & 5.5 & 11.5 & 71.5 \\
Barium & 701 & 503 & $\mathrm{ND}$ & 204 \\
Boron & $\mathrm{ND}$ & $\mathrm{ND}$ & 39.11 & 418 \\
Cadmium & 0.8 & 3.3 & $<0.2$ & 1.5 \\
Chromium & 94.4 & 95.6 & 284 & 42.2 \\
Copper & 26.8 & 62.8 & 69 & 49.5 \\
Lead & 78.0 & 15.9 & 26 & 17.4 \\
Molybdenum & 14.0 & $<0.2$ & 27.8 & 22.4 \\
Nickel & 28.5 & 44.8 & 383 & 78.8 \\
Selenium & 4.5 & $<0.7$ & 0.25 & 8.6 \\
Sodium & 150 & 150 & 208 & 1100 \\
Zinc & $<0.3$ & 138 & 108 & 112 \\
& & & & \\
pH (1:1 in water) & 3.1 & 4.3 & 7.4 & 12.4 \\
\hline
\end{tabular}

aThe FGD used was an AFBC by-product (see section 3.3.1.1). bND; not determined. 
fourth core was drilled to $90 \mathrm{~m}$ ( $300 \mathrm{ft}$ ). After the cores were extracted, each hole was grouted to the surface with cement-bentonite grout by use of a tremie pipe.

Stratigraphic columns by Lamborn (1956), with updates from Hull (1990) were used to tentatively define the stratigraphy of the cores (Figure 10). Mining records indicate that the mining companies removed the Lower Kittanning (No. 5) coal and underlying clay during their mining operations. Thus, the top of the stratigraphic section begins at this lithologic unit. Additionally, the site sits on top of a hill and rises above the adjacent topography by about 30 $\mathrm{m}(100 \mathrm{ft})$ so the total section considered for this study was also about $30 \mathrm{~m}$.

Samples from three cores were obtained by splitting the core in half by use of a diamond rock saw. Half of the core was submitted for analysis and the other half was stored in the Ohio Department of Natural Resources core warehouse. Composite samples were collected every meter ( $3 \mathrm{ft}$ ) or at changes in lithology. Core samples were prepared for analysis by grinding and homogenization.

The uppermost 0.6 to $9.1 \mathrm{~m}$ ( 2 to 30 feet) of core in each hole (an interval that was not recovered) represented a mixture of spoil, coal refuse, and clay (hereafter referred to as the "spoil/clay layer"). The lithologic logs of each core (Figure 11) indicates the location of the sandstones and coals that represent the shallow and deep aquifers investigated as part of this study. General observations included the following:

- In each of the four cores, the top 6.1 to $9.1 \mathrm{~m}$ (20 to 30) feet of rock (shale and sandstone) were stained brownish orange by Fe-oxide or hydroxide precipitates.

- Rock coring was made difficult by the presence of clays and fractured rock.

- Clays were susceptible to erosion from the drilling fluid and also caused clogging of the drill bit.

- Fractures caused poor recovery of core and loss of circulation of the drilling fluid.

The lithologic distribution observed in the cores is not unlike that of coal sequences elsewhere in Ohio. The coring reveals that the rocks dip slightly to the southeast with a strike of approximately N. $45^{\circ}$ E. Estimated dip measurements obtained from the base of the sandstone denoted as the shallow aquifer are approximately $1.74 \times 10^{-2}$ meters per meter $\left(1.74 \times 10^{-2}\right.$ feet per foot) or about $1^{\circ}$ to the southeast. The vertical distribution and horizontal discontinuity of rocks demonstrate the heterogeneity of the aquifer system. 


\begin{tabular}{|c|c|c|c|c|c|}
\hline Age & Group & Member & Lithology & $\begin{array}{c}\text { Approx- } \\
\text { imate } \\
\text { thickness } \\
m(\mathrm{ft})\end{array}$ & Comments \\
\hline \multirow{14}{*}{$\begin{array}{l}P \\
E \\
N \\
N \\
S \\
Y \\
L \\
V \\
A \\
N \\
I \\
A \\
N\end{array}$} & \multirow{8}{*}{ Allegheny } & $\begin{array}{l}\text { Lower } \\
\text { Kittanning (5) }\end{array}$ & $\begin{array}{l}\text { Coal } \\
\text { Clay }\end{array}$ & $\begin{array}{l}0.70(2.3) \\
2.65(8.7)\end{array}$ & Mined-out coal and clay \\
\hline & & unnamed & Shale & $6.79(22.3)$ & \\
\hline & & Vanport & Limestone & $0.99(3.3)$ & wanting \\
\hline & & Clarion (4a) & $\begin{array}{l}\text { Coal } \\
\text { Clay }\end{array}$ & $\square$ & wanting \\
\hline & & Clarion & Sandstone & $6.10(20)$ & \multirow{4}{*}{ (4) } \\
\hline & & Putnam Hill & Limestone & $0.40(1.3)$ & \\
\hline & & unnamed & Shale & $0.12(0.4)$ & \\
\hline & & Brookville (4) & Coal & $0.46(1.5)$ & \\
\hline & \multirow{6}{*}{ Pottsville } & Brookville & Clay & $2.06(6.8)$ & \\
\hline & & Homewood & Sandstone & $7.78(25.5)$ & 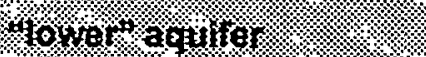 \\
\hline & & \multirow[t]{2}{*}{ Tionesta (3b) } & Coal & $0.76(2.5)$ & \\
\hline & & & Clay & $0.98(3.2)$ & \\
\hline & & unnamed & Shale & $3.89(12.8)$ & \\
\hline & & Upper Mercer & Limestone & $0.76(2.5)$ & \\
\hline
\end{tabular}

Figure 10. Stratigraphic section of rocks at the Fleming abandoned mine site, Tuscarawas County, Ohio (modified from Lamborn, 1956 and Hull, 1990). Shaded areas refer to aquifers investigated in this study. 


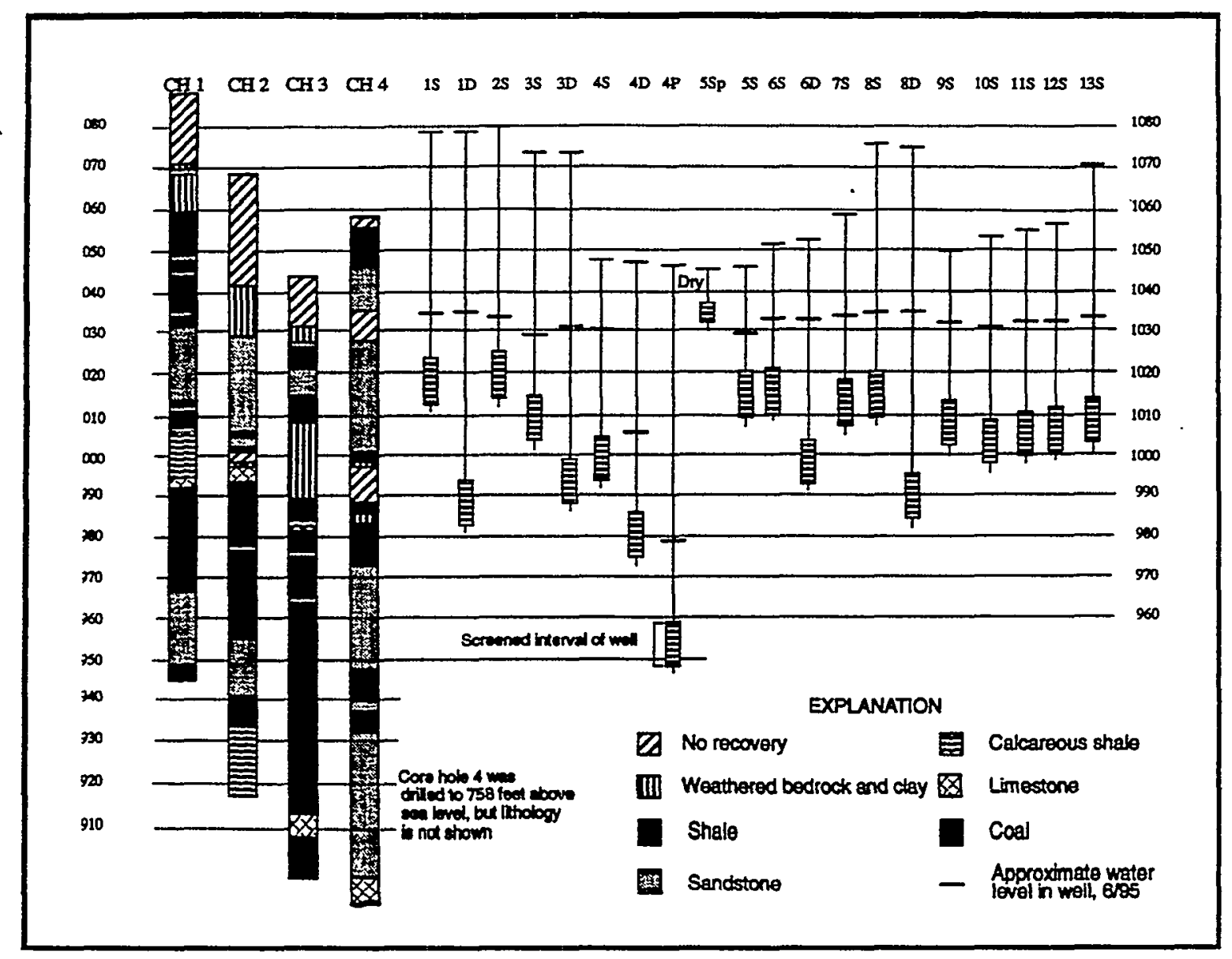

Figure 11. Diagrammatic illustration of lithology and screened intervals of four core holes and twenty wells. Numbers on the right side of this figure are given in feet above sea level while numbers on the left side of the figure are given in feet above or below land surface. To convert feet to meters, multiply by 0.305 . 
Surface and borehole geophysical surveys were done to further refine the knowledge of distribution of spoil and bedrock underlying the site. The surface geophysics involved vertical electric soundings (VES) of direct-current electrical resistivity. Borehole geophysical measurements on selected wells were done before installation of the PVC casing to evaluate subsurface lithologic distributions.

These geophysical surveys were done at 18 transects at the study site (Figure 12). The minimum electrode spacing for all VES was about $0.3 \mathrm{~m}(1 \mathrm{ft})$. The maximum electrode spacing ranged from 44.7 to $91.2 \mathrm{~m}$ ( 147 to $300 \mathrm{ft}$ ) at VES1 through VES17 and was $182 \mathrm{~m}$ $(600 \mathrm{ft}$ ) at VES18. The near-surface conditions, which were moist to moderately dry clayey soil, were such that an electrical current could be readily applied through current electrodes.

The VES were a series of direct current electrical-resistivity measurements on the land surface. Successively greater electrode spacings were made about a fixed point, yielding information about resistivity with depth. High resistivities indicate siltstone, sandstone, or limestone. Low resistivities indicate clay, spoil or shale. The Schlumberger electrode array (Tellford et al., 1974; Von Nostrand and Cook, 1966) was used for all VES surveys.

The VES field data were processed by use of an earth-resistivity program developed by Zohdy (1973) and A. Zohdy and R. Bisdorf (U.S. Geological Survey, personal communication, 1987). Earth resistivity models.were developed for each VES survey site. The resistivity models provided interpretation of the layer thickness and formation resistivity corresponding to modeled layers. Most VES curves (graphs of apparent resistivity and layer resistivity plotted as the ordinate, and electrode spacing and layer depth plotted as the abscissa) have forms that represent three- or four-layer stratigraphic models. An isoresistive layer with a VES model may represent more than one geologic layer.

Borehole geophysical logs recorded in selected boreholes included temperature, electric, caliper, and natural gamma-ray logs. These methods are discussed in detail in Keys and MacCary (1971). Temperature logs were recorded beneath the water table to detect slight changes in water temperature, which may indicate a source or sink of water to or from the borehole.

Three electric logs were recorded: self-potential, single-point resistance, and resistivity. A selfpotential log documents the natural potential difference, or voltage, created by two strata of different lithology such as shale and sandstone. A single-point resistance log measures the drop 


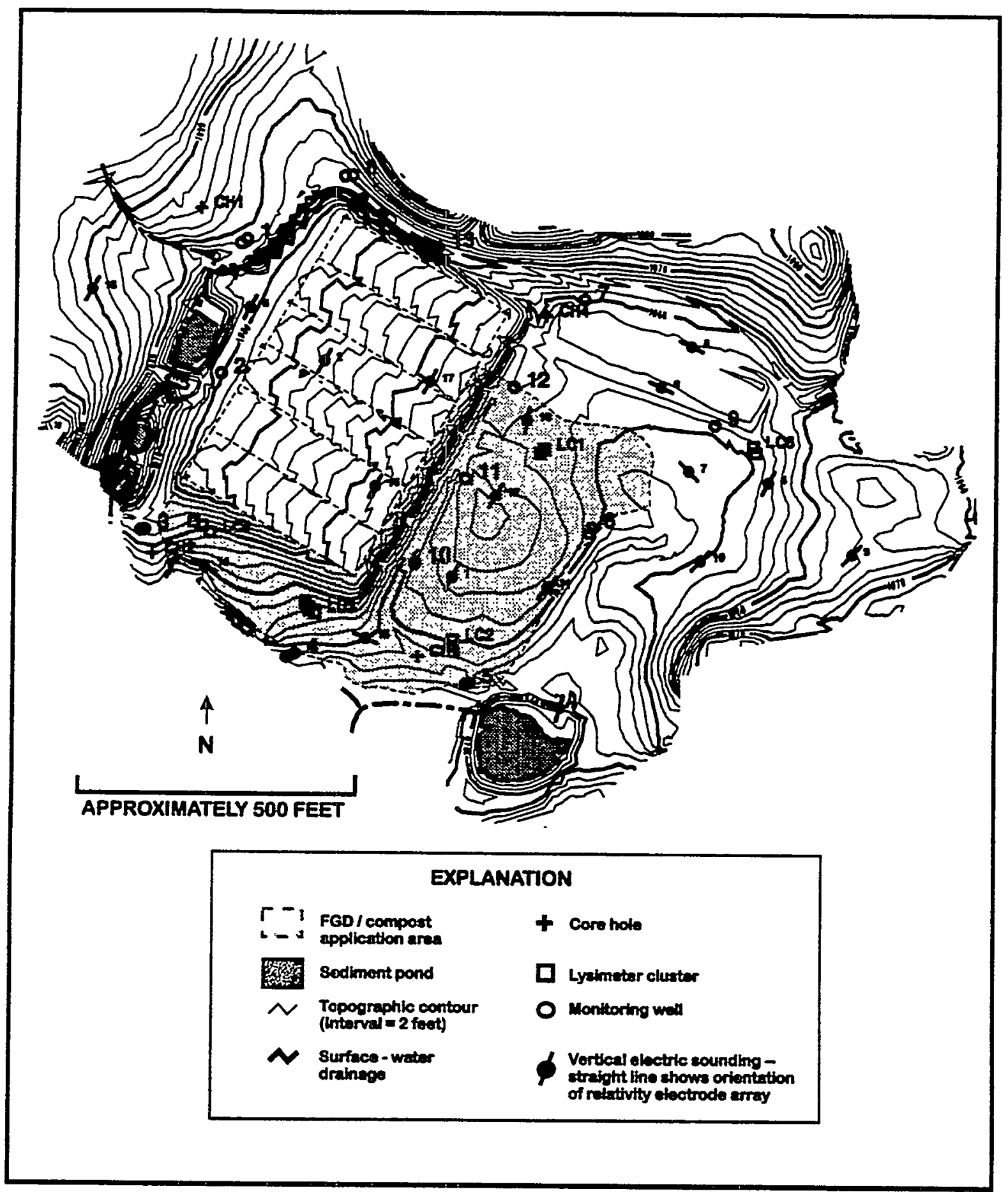

Figure 12. Topographic map showing location of core holes, lysimeters, wells and surface geophysical surveys at the Fleming abandoned mine site, Tuscarawas County, Ohio. 
in current between a source of electric current placed in the borehole and a surface electrode. It differs from a resistivity log in that the resistivity probe and the receiving electrode are both placed in the borehole. A resistivity log; produced when an electric current is passed through the rocks, measures the resistivity of solid and liquid materials between two measuring points. The recorded resistivity is related in a general way to the porosity and hydraulic conductivity of the rocks, but is also affected by the composition (salinity) of pore water. Interpretation of the lithology by use of resistivity logs requires the assumption that either the water quality remains constant as the lithology changes or the lithology remains constant as the water quality changes. For the purposes of this study, the water quality was assumed to remain constant.

A caliper log records variations in the diameter of the borehole. The borehole diameter is rarely constant, owing to variable lithology and "washouts". Washouts are places where the formation has been eroded by drilling fluid. Caliper logs are useful in the interpretation of other logs and can aid in locating fractures and clay layers (broken rock and clay are especially susceptible to washouts). A natural gamma-ray $\log$ records the relative radioactivity of the geologic materials adjacent to the borehole. Shale and clay, because of their high potassium concentrations, emit relatively high levels of natural gamma radiation, whereas coal and limestone emit low levels of radiation (Keys and MacCary, 1971). Natural gamma logs are ideal for use in coal-bearing strata because the gamma log of a coal/underclay sequence has a clearly visible low/high response.

\subsubsection{Precipitation and Surface Water Hydrology and Quality}

A wet/dry precipitation gage was established to observe rainfall amounts and to collect water samples for chemical analysis. A gage located off-site at the Dover Water Works (Figure 13) was equipped with a wet/dry precipitator collector and moisture-activated mechanism that moves a cover from a "wet" to a "dry" bucket in the event of precipitation. Samples were collected monthly and submitted for analyses of constitutents listed in Table 18. All precipitation samples were analyzed for $\mathrm{pH}$, specific conductance, residue on evaporation, and major ions by use of procedures specifically designed for analysis of low ionic strength precipitation samples. The analyses were performed primarily by the National Water Quality Laboratory of the U.S. Geological Survey (Arvada, CO). Three of the samples were analyzed for trace elements by the laboratory located at the Ohio Agricultural Research and Development Center (Wooster, $\mathrm{OH}$ ). 

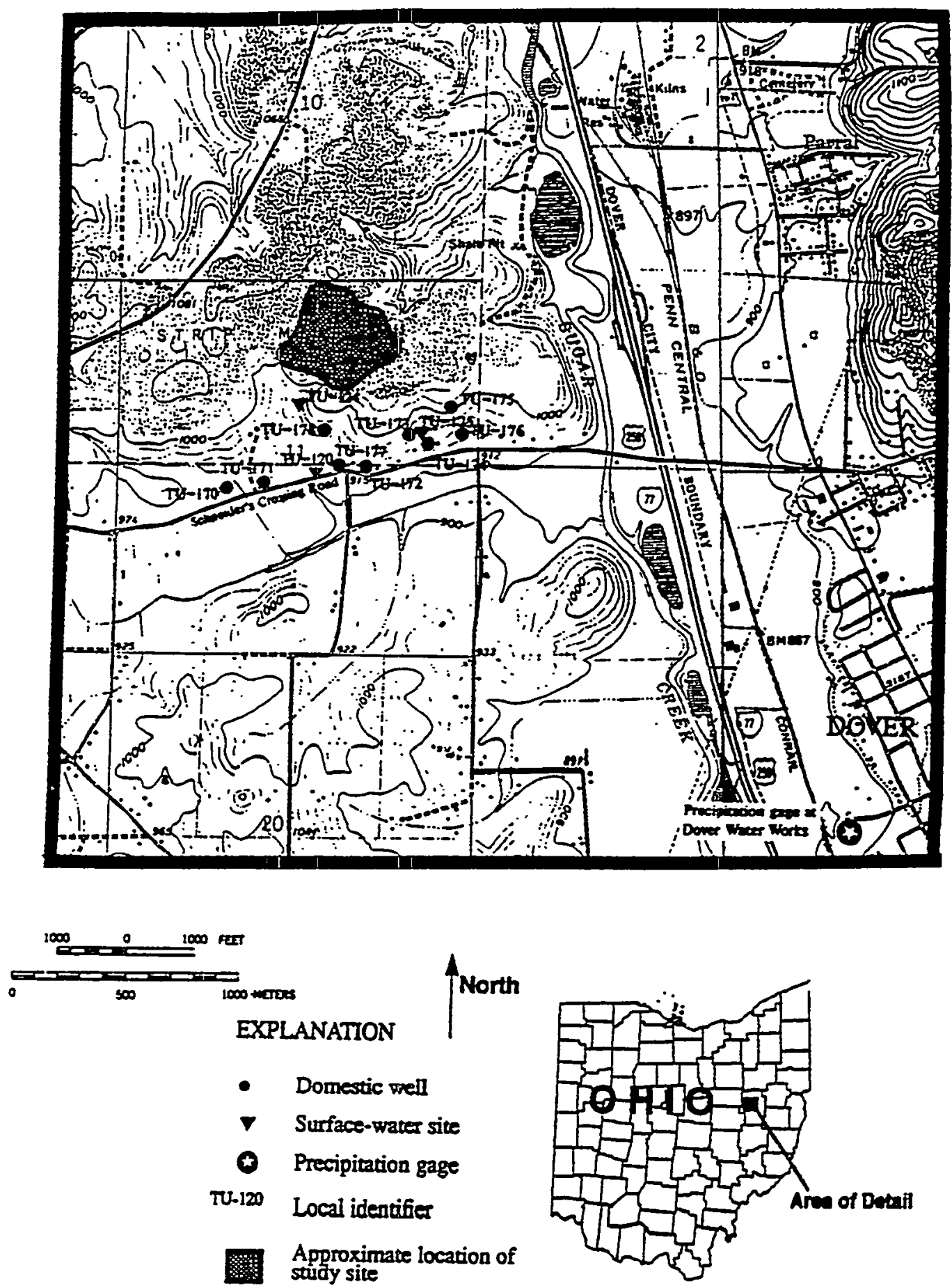

Figure 13. Location of domestic wells, surface water sites and precipitation gages in relation to Fleming abandoned mine land study site. 
Table 18. List of constituents, analytical methods, and reporting limits for precipitation and other water samples ${ }^{\mathrm{a}}$.

\begin{tabular}{|c|c|c|c|c|}
\hline Analyte & $\begin{array}{l}\text { OARDC } \\
\text { method }\end{array}$ & $\begin{array}{l}\text { NWQL } \\
\text { method }\end{array}$ & $\begin{array}{c}\text { OARDC } \\
\text { reporting limit } \\
(\mathrm{mg} / \mathrm{L})\end{array}$ & $\begin{array}{l}\text { NWQL reporting } \\
\text { limit } \\
(\mathrm{mg} / \mathrm{L})\end{array}$ \\
\hline Acidity & ET & ET & 1.0 & 1.0 \\
\hline Alkalinity & $\mathrm{ET}$ & ET & 1.0 & 0.5 \\
\hline Aluminum, total & ICP & DCP & 0.03 & 0.01 \\
\hline Aluminum, dissolved & ICP & $\mathrm{DCP}$ & 0.03 & 0.01 \\
\hline Arsenic, dissolved & ICP & AA-Hydide & 0.035 & 0.001 \\
\hline Barium, dissolved & $\mathrm{ICP}$ & $\mathrm{ICP}$ & 0.001 & 0.001 \\
\hline Beryllium, dissolved & ICP & ICP & 0.001 & 0.001 \\
\hline Boron, dissolved & ICP & $\mathrm{DCP}$ & 0.006 & 0.01 \\
\hline Bromide, dissolved & IC & Colorimetric ASF & 0.1 & 0.01 \\
\hline Calcium, dissolved & ICP & $\mathrm{ICP}$ & 0.003 & 0.1 \\
\hline Cadmium, dissolved & $\mathrm{ICP}$ & ICP & 0.001 & 0.001 \\
\hline Chloride, dissolved & IC & IC & 0.1 & 0.1 \\
\hline Chromium, dissolved & ICP & ICP & 0.002 & 0.005 \\
\hline Cobalt, dissolved & ICP & ICP & 0.006 & 0.003 \\
\hline Copper, dissolved & $\mathrm{ICP}$ & ICP & 0.002 & 0.01 \\
\hline Fluoride, dissolved & IC & IC & 0.1 & 0.1 \\
\hline Iron, total & ICP & $\mathrm{AA}$ & 0.01 & 0.01 \\
\hline Iron dissolved & ICP & ICP & 0.01 & 0.003 \\
\hline Lead, dissolved & ICP & GFAA & 0.02 & 0.01 \\
\hline Lithium, dissolved & ICP & ICP & 0.004 & 0.004 \\
\hline Magnesium, dissolved & ICP & ICP & 0.02 & 0.01 \\
\hline Manganese, total & ICP & AA & 0.001 & 0.01 \\
\hline Manganese, dissolved & ICP & ICP & 0.001 & 0.001 \\
\hline Molybdenum, dissolved & ICP & ICP & 0.015 & 0.01 \\
\hline Mercury, dissolved & - & CVAA auto & - & 0.0001 \\
\hline Nickel, dissolved & ICP & ICP & 0.004 & 0.01 \\
\hline Nitrogen-NH3, dissolved & Micro-Kjeldahl & Colorimetric ASF & 0.1 & 0.01 \\
\hline Nitrogen-NO2, dissolved & IC & Colorimetric ASF & 0.1 & 0.01 \\
\hline Nitrogen-NO2+NO3, & IC & Colorimetric ASF & 0.1 & 0.05 \\
\hline Phosphorus (as PO4), & IC & Colorimetric ASF & 0.02 & 0.01 \\
\hline Potassium, dissolved & ICP & $\mathrm{AA}$ & 0.2 & 0.1 \\
\hline Residue on evaporation & Gravimetric & Gravimetric & 1 & 1 \\
\hline Selenium, dissolved & ICP & AA-Hydride & 0.1 & 0.001 \\
\hline
\end{tabular}


Table 18 (continued). List of constituents, analytical methods, and reporting limits for precipitation and other water samplesa.

\begin{tabular}{lllll} 
Silica (as SiO2), dissolved & ICP & ICP & 0.015 & 0.01 \\
Silver, dissolved & ICP & ICP & 0.01 & 0.001 \\
Sodium, dissolved & ICP & ICP & 0.06 & 0.2 \\
Vanadium, dissolved & ICP & ICP & 0.005 & 0.006 \\
Zinc, dissolved & ICP & ICP & 0.001 & 0.003 \\
Dissolved organic C & - & Carbonanalyzer & - & 0.1 \\
pH & Electrometric & Electrometric & 0.1 & 0.1 \\
Specific conductance $(\mu S)$ & Electrometric & Electrometric & 1.0 & 1.0 \\
S34S, dissolved sulfate & - & Mass spectrometry & - & 0.1 per mil \\
Tritium & - & LSC-EE & - & 0.1 TU \\
& & & \\
\hline
\end{tabular}

aOARDC, Ohio Agricultural Research and Development Center; NWQL, National Water Quality Lab; double dash --, not available; ET, electrometric titration; AA, atomic absorption spectrometry; AA-Hydride, atomic absorption spectrometry with hydride generation; ASF, automated segmented-flow analyzer, CVAA-auto, automated cold-vapor atomic absorption spectrometry; DCP, direct-current plasma-atomic absorption spectrometry; GFAA, graphite-fumace atomic absorption spectrometry; ICP, inductively-coupled argon plasmaatomic emission spectrometry; IC, ion chromatography; LSC-EE, liquid-scintillation counting with electrolytic enrichment; $\mathrm{mg} / \mathrm{L}$, milligrams per liter; $\mathrm{TU}$, tritium units $=3.24$ picocuries per liter. 
The precipitation gage operated from December 2, 1994 through January 31, 1996. During this period, 18 composite samples ( 9 wet and 9 dry deposition samples) were collected. The quantity of precipitation was recorded in 5-minute increments. The total annual precipitation through 1995 was approximately $880 \mathrm{~mm}$ ( 34.7 inches). Average rainfall for the six-county area (Tuscarawas, Harrison, Jefferson, Carroll, Columbiana, and Stark Counties) was 890 $\mathrm{mm}$ (35.0 inches) or about 8 percent lower than the annual average of $965 \mathrm{~mm}$ (38 inches) (Ohio Department of Natural Resources, 1995). Thus 1995 was slightly drier than previous years on record.

Surface water sample collection from the six $0.4 \mathrm{~h}$ ( 1 acre) watersheds began in the spring of 1995. Surface water samples collected before reclamation (and before pond construction) were obtained from intermittent stream flow draining the site.

Surface water samples were also collected as part of the study conducted by the US Geological Survey. Because the study site is positioned on top of a hill, flow of water onto the site from outside sources such as streams or springs is minimal. Additionally, the presence of low permeability sediments (spoil, clay, and shale) near the surface indicates that most the precipitation that falls on the site leaves as surface runoff.

Groundwater that enters the system presumably flows downward until it reaches an impermeable layer such as shale or clay. It then flows horizontally and exits the groundwater system at a spring or seep. Several seeps were located as part of this study. However, they were all of fsite and on land that was used for cattle and horse grazing. Thus, permanent installation of a discharge measurement or of sample-collection devices such as a flue or weir was not attempted.

Three down gradient sites were selected, however, for sampling, and are shown in Figure 13. The three sampling sites were located south of the Feming Site, where the springs flow into a small system of streams. The first site (TU-124) was established at the outflow of the lower most sediment pond. The second site (TU-120) was established at the culvert beneath Schneiders Crossing Road. The third site (TU-125) was to the southeast of the Fleming Site and was a small brook that drained the southeast part of the study site. These sites were sampled only during base flow. Thus all water samples were believed to be from groundwater and not surface runoff. Discharge (measured before water quality sampling) ranged from 1.92 $\times 10^{-4} \mathrm{~m}^{3} / \mathrm{sec}\left(6.8 \times 10^{-3} \mathrm{ft}^{3} / \mathrm{sec}\right)$ at site TU-125 to $1.25 \times 10^{-3} \mathrm{~m}^{3} / \mathrm{sec}\left(4.4 \times 10^{-2} \mathrm{ft}^{3} / \mathrm{sec}\right)$ at site TU-120.

Accurate measurement of discharge from springs was difficult because of the small amount of flow that occurred. As a result, during each round of sampling, a section of stream was 
selected where rocks or other locally available material could be used to form a weir-like structure that diverted all flow through one point. Discharge was then quantified by measuring the time required to file a 7.6 liter ( 2 gallon) bucket. Each discharge measurement was made at least three times and the reported result is the average of measured values.

\subsubsection{Interstitial Water Quality}

Interstitial water, i.e. water residing in the soil profile above the permanent groundwater table, was sampled by soil suction lysimeters. The quality of this water is an important parameter to measure because of concerns over whether the effects of FGD by-product would be seen in groundwater during the short duration of this project. The chemistry of interstitial water yields important information regarding the geochemistry of soil and the quality of recharge water that will eventually reach the groundwater system.

Lysimeters were used to collect interstitial water. They were constructed of ceramic cups attached to polyvinyl chloride (PVC) casing approximately $5 \mathrm{~cm}(2 \mathrm{in})$ in diameter and ranged from 15 to $30 \mathrm{~cm}$ ( 6 to 12 in) in length (Figure 14). Two types of lysimeters were installed; one constructed with standard ceramic material and the other constructed from an "ultrapure" ceramic material. The ultrapure ceramic lysimeter does not have a PVC casing and is constructed entirely of ceramic material with minimal concentrations of trace elements. Two polyethylene tubes were inserted into each lysimeter. The first was used to exert a negative (vacuum) or positive pressure on the lysimeter and the second, which extended to the bottom of the lysimeter, was used as the discharge tube.

Thirty-five soil-suction lysimeters were installed at five locations at depths ranging from 0.45 to $1.37 \mathrm{~m}$ ( 1.5 to $4.5 \mathrm{ft}$ ) (Figure 12 and Table 19). Four lysimeter clusters (clusters 1 through 4) were placed within the FGD (i.e. PFBC area) by-product application area, whereas one cluster (cluster 5) was placed outside the application area to serve as control.

The lysimeters were installed in accordance with recommendations from the manufacturer (Soilmoisture Equipment Corp., Santa Barbara, California). (Note that use of trade or product names is for identification purposes only and does not constitute endorsement by the US Geological Survey). A $10 \mathrm{~cm}$ (4 in) diameter hole was drilled to the desired depth into the unsaturated zone by use of a portable auger drill, and a slurry of silica flour and distilled, deionized water was used to create a filter pack around each lysimeter to reduce the possibility of clogging from fine-grained sediments. The lysimeter assembly was installed in the hole, and the hole was then filled to about $0.3 \mathrm{~m}$ from the surface with native soil. A 5 to $10 \mathrm{~cm}$ ( 2 to 4 in) thick layer of bentonite chips was placed in the hole to serve as a barrier to downward migration of water within the borehole. The remainder of the hole was filled to the surface with 


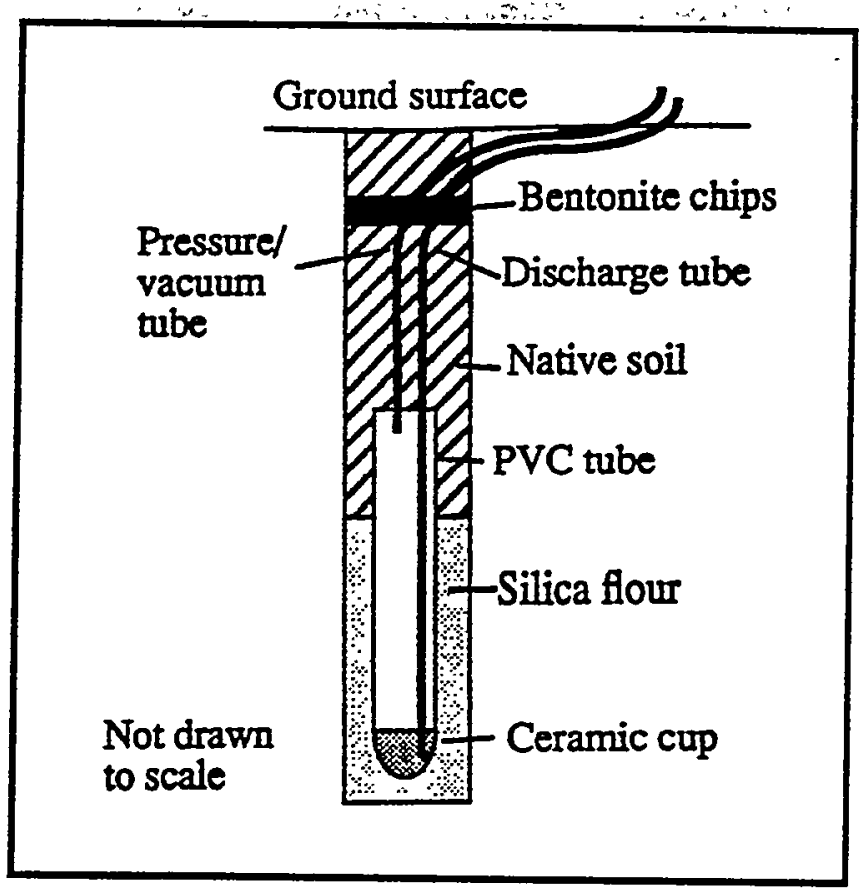

Figure 14. Schematic drawing of lysimeter installation. 
Table 19. Construction data for the 35 soil-suction lysimeters at the study site.

\begin{tabular}{|c|c|c|c|c|}
\hline $\begin{array}{l}\text { Lysimeter } \\
\text { cluster (see } \\
\text { Figure 12) }\end{array}$ & $\begin{array}{l}\text { Local } \\
\text { identifier }\end{array}$ & $\begin{array}{l}\text { Depth } \\
\text { (m) }\end{array}$ & $\begin{array}{l}\text { Length of } \\
\text { lysimeter } \\
\text { (cm) }\end{array}$ & Description/model of lysimeter \\
\hline \multirow[t]{3}{*}{ LC1 A } & TU-130 & 46 & 15 & 1920LO6-B2M2 Pressure-vacuum soil water sampler \\
\hline & TU-131 & 76 & 30 & 1920L12-B2M2 Pressure-vacuum soil water sampler \\
\hline & TU-132 & 107 & 30 & 1920L12-B2M2 Pressure-vacuum soil water sampler \\
\hline \multirow[t]{3}{*}{ B } & TU-133 & 46 & 15 & 1920L06-B2M2 Pressure-vacuum soil water sampler \\
\hline & TU-134 & 76 & 30 & 1920L12-B2M2 Pressure-vacuum soil water sampler \\
\hline & TU-135 & 107 & 30 & 1920L12-B2M2 Pressure-vacuum soil water sampler \\
\hline \multirow[t]{3}{*}{ LC2 A } & TU-136 & 46 & 15 & 1920L06-B2M2 Pressure-vacuum soil water sampler \\
\hline & TU-137 & 76 & 30 & 1920L12-B2M2 Pressure-vacuum soil water sampler \\
\hline & TU-138 & 107 & 30 & 1920L12-B2M2 Pressure-vacuum soil water sampler \\
\hline \multirow[t]{3}{*}{$\mathrm{B}$} & TU-139 & 46 & 15 & 1920L06-B2M2 Pressure-vacuum soil water sampler \\
\hline & TU-140 & 76 & 30 & 1920L12-B2M2 Pressure-vacuum soil water samplet \\
\hline & TU-141 & 107 & 30 & 1920L12-B2M2 Pressure-vacuum soil water sampler \\
\hline \multirow[t]{2}{*}{ LC3 A } & TU-142 & 137 & 30 & 1920L12-B2M2 Pressure-vacuum soil water sampler \\
\hline & TU-143 & 137 & 30 & 1920L12-B2M2 Pressure-vacuum soil water sampler \\
\hline \multirow[t]{3}{*}{ B } & TU-144 & 46 & 15 & 1920L06-B2M2 Pressure-vacuum soil water sampler \\
\hline & TU-145 & 76 & 30 & 1920L12-B2M2 Pressure-vacuum soil water sampler \\
\hline & TU-146 & 107 & 30 & 1920L12-B2M2 Pressure-vacuum soil water sampler \\
\hline \multirow[t]{3}{*}{$\mathrm{C}$} & TU-147 & 46 & 15 & 1920L06-B2M2 Pressure-vacuum soil water sampler \\
\hline & TU-148 & 76 & 30 & 1920L12-B2M2 Pressure-vacuum soil water sampler \\
\hline & TU-149 & 107 & 30 & 1920L12-B2M2 Pressure-vacuum soil water sampler \\
\hline \multirow[t]{3}{*}{ LC4 A } & TU-150 & 46 & 15 & 1920L06-B2M2 Pressure-vacuum soil water sampler \\
\hline & TU-151 & 76 & 30 & 1920L12-B2M2 Pressure-vacuum soil water sampler \\
\hline & TU-152 & 107 & 30 & 1920L12-B2M2 Pressure-vacuum soil water sampler \\
\hline \multirow[t]{3}{*}{ B } & TU-153 & 46 & 15 & 1920L06-B2M2 Pressure-vacuum soil water sampler \\
\hline & TU-154 & 76 & 30 & 1920L12-B2M2 Pressure-vacuum soil water sampler \\
\hline & TU-155 & 107 & 30 & 1920L12-B2M2 Pressure-vacuum soil water sampler \\
\hline \multirow[t]{3}{*}{ C } & TU-156 & 46 & 15 & 1922 Ultra Soil Water Sampler \\
\hline & TU-157 & 76 & 30 & 1922 Ultra Soil Water Sampler \\
\hline & TU-158 & 107 & 30 & 1922 Ultra Soil Water Sampler \\
\hline \multirow[t]{3}{*}{ LC5 A } & TU-159 & 46 & 15 & 1920L06-B2M2 Pressure-vacuum soil water sampler \\
\hline & TU-160 & 76 & 30 & 1920L12-B2M2 Pressure-vacuum soil water sampler \\
\hline & TU-161 & 107 & 30 & 1920L12-B2M2 Pressure-vacuum soil water sampler \\
\hline \multirow[t]{3}{*}{ B } & TU-162 & 46 & 15 & 1920L12-B2M2 Pressure-vacuum soil water sampler \\
\hline & TU-163 & 76 & 30 & 1920L12-B2M2 Pressure-vacuum soil water sampler \\
\hline & TU-164 & 107 & 30 & 1920L12-B2M2 Pressure-vacuum soil water sampler \\
\hline
\end{tabular}


native soil. All native soil removed from the borehole was placed on a canvas tarp so that it could be used as backfill once the installation was complete. This process ensured that the backfill was not contaminated with the FGD by-product surface amendment.

To create a vacuum within the lysimeter, the discharge tube was clamped and a specially adapted air pump was used to create a negative pressure. The manufacturer recommended 60 centibars or more of negative pressure be applied to the lysimeter to draw in interstitial water. The spoil at the mine site is composed of relatively low permeability clay and shale; thus, a greater negative pressure - approximately 70 centibars - was applied to each lysimeter. In preparation for sampling, positive pressure was exerted on the lysimeter to expel any water that may have infiltrated into the lysimeter since the last sampling round. The discharge tube was then clamped and negative pressure was applied through the pressure/vacuum tube. After 24 to 36 hours, the clamps on each end of the two tubes were removed and a positive pressure was exerted on the pressure/vacuum tube of the lysimeter forcing the water sample out through the discharge tube. Lysimeters were installed in clusters of three to depths of 45,75 and $105 \mathrm{~cm}$ $(1.5,2.5$ and $3.5 \mathrm{ft})$ from the surface with all discharge and vacuum tubes leading into one central surface enclosure. One lysimeter cluster had an additional lysimeter installation at 137 $\mathrm{cm}$ (4.5 ft).

Quality-control samples were collected from a selected set of five lysimeters before installation. The objectives of the overall project include determination of trace metals at very low concentrations in water. It was, therefore, desirable to evaluate the potential for contamination from the ceramic cups. Additionally, previous workers, including Creasey and Dreiss (1988) and McGuire et al. (1992) have found that significant sample bias may result from contamination by trace elements leached from or sorbed to the ceramic cups. The selected lysimeters were first soaked in distilled, deionized water, then about 1 liter of certified inorganic-free water was forced through the entire lysimeter assembly including the sampling tubes. Water samples were then analyzed and were found to be free of the constituents listed in Table 18.

\subsubsection{Groundwater Hydrology and Quality}

Groundwater samples were collected from onsite and offsite wells to assess water quality in aquifers beneath and down gradient from the site. Offsite domestic wells, i.e. approximately 304 to $912 \mathrm{~m}$ (1,000 to 3,000 ft) down gradient from the site were sampled to document water quality in deep domestic wells for future reference. Twenty onsite monitoring wells were also 
installed after results of the rock coring were evaluated. These wells were used to monitor groundwater levels, measure hydraulic properties, and obtain samples for water-quality analysis. Two separate rounds of drilling were done: (1) an early phase in which 15 monitoring wells were drilled, and (2) a later phase wherein 5 additional wells were drilled.

The horizontal and vertical placement of wells and well screens was intended to monitor onsite effects of acid mine drainage and leachate from FGD by-product. The groundwater most likely to be affected by FGD by-product leachate should be within the shallow groundwater system; therefore, 14 of the 20 wells installed at the site were screened in the shallow aquifer (Figure 11 and Table 20). Five wells were screened in the next deepest aquifer, and one was drilled in the deepest aquifer down gradient from the site. The network of monitoring wells was also designed to allow for sampling of water up gradient from the site, where influences of FGD by-product leachate would be non-existent or minimal. The up gradient wells also served as a control to monitor temporal changes in groundwater quality caused by reclamation activities unassociated with FGD by-product.

The early-phase drilling procedure involved drilling a $15 \mathrm{~cm}$ (6 in) diameter pilot hole by the air rotary drilling method and then reaming the hole to a final diameter of $25 \mathrm{~cm}$ (10 in) by an auger. Ten cm ( 6 in) schedule 80 PVC casing was installed with a $3 \mathrm{~m} \mathrm{(10} \mathrm{ft),} 0.05 \mathrm{~cm}(0.020$ in) slot-size screen. $A 60 \mathrm{~cm}(2 \mathrm{ft})$ deep sump was installed beneath each screen to prolong the life of the well by allowing sediment to collect within the sump, beneath the screened interval. The gravel pack consisted of pure quartz sand. Approximately $60 \mathrm{~cm}(2 \mathrm{ft})$ of fine sand was placed above the gravel pack to serve as a barrier between the gravel pack and the grout. The grout consisted of a 20:1 cement-bentonite mixture and was tremied into the annulus from the fine-sand barrier to the surface. A steel surface casing with a locking cap was installed into a 30 by $30 \mathrm{~cm}$ ( 2 by $2 \mathrm{ft}$ ) concrete pad to minimize contamination by surface water. The drill rig and all drilling equipment were steam cleaned between holes to reduce cross-hole contamination. Placement of wells during this phase was designed to capture up gradient and down gradient groundwater and to enable collection of water samples from the shallow and next deepest water-bearing hydrologic unit identified during rock coring.

The later phase of drilling was also done with an air rotary rig. The hole diameter, however, was only $15 \mathrm{~cm}$ ( 6 in) and the final casing diameter was $5 \mathrm{~cm}$ ( 2 in). All other construction details of the later phase of drilling were the same as in the earlier phase. The placement of wells installed during the second round of drilling was designed to fill in gaps revealed by the previous round of drilling. 
Table 20. Description of monitoring wells installed at the Fleming Site.

\begin{tabular}{|c|c|c|c|c|c|c|c|c|}
\hline $\begin{array}{l}\text { Local } \\
\text { Identifi- } \\
\text { cation }\end{array}$ & $\begin{array}{l}\text { Hole } \\
\text { number }\end{array}$ & $\begin{array}{l}\text { Surface } \\
\text { altitudea } \\
\text { (m) }\end{array}$ & $\begin{array}{l}\text { Drilled } \\
\text { depthb } \\
\text { (m) }\end{array}$ & $\begin{array}{l}\text { Total } \\
\text { depth of } \\
\text { wellb } \\
\text { (m) }\end{array}$ & $\begin{array}{l}\text { Screen } \\
\text { lithologyc }\end{array}$ & $\begin{array}{l}\text { Aquifer } \\
\text { thickness } \\
\text { (m) }\end{array}$ & 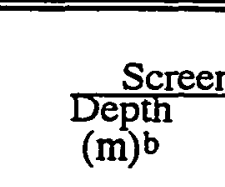 & 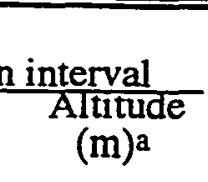 \\
\hline TU-100 & 1S & 328 & 20.7 & 20.7 & $\mathrm{SS} / \mathrm{CL}$ & 6.8 & $17.0-20.1$ & $311-308$ \\
\hline TU-101 & $1 \mathrm{D}$ & 328 & 30.4 & 29.8 & CLתS & 1.0 & $26.1-29.2$ & $302-299$ \\
\hline TU-102 & $2 S$ & 328 & 21.3 & 20.7 & $\mathrm{SS} / \mathrm{CL}$ & 7.3 & $17.0-20.1$ & $311-308$ \\
\hline TU-103 & $3 S$ & 326 & 21.9 & 21.3 & $\mathrm{SS} / \mathrm{CL}$ & 7.7 & $17.6-20.7$ & $309-306$ \\
\hline TU-104 & $3 \mathrm{D}$ & 326 & 26.1 & 26.1 & CL/S & 0.9 & $22.5-25.5$ & $304-301$ \\
\hline TU-105 & $4 S$ & 319 & 14.0 & 14.0 & $\mathrm{SS} / \mathrm{CL}$ & 5.6 & $10.3-13.42$ & $308-305$ \\
\hline TU-106 & 4D & 318 & 19.5 & 19.3 & CLIS & 0.9 & $15.7-18.7$ & $290-300$ \\
\hline TU-107 & $4 \mathrm{P}$ & 318 & 30.4 & 30.4 & SS/CL & 0.7 & $26.8-29.8$ & $291-288$ \\
\hline TU-108 & $5 S P$ & 318 & 4.9 & 4.9 & Spoil & 4.6 & $2.8-4.3$ & $315-314$ \\
\hline TU-109 & $5 S$ & 318 & 11.6 & 11.6 & SS/CL & 3.5 & $7.9-10.9$ & $310-307$ \\
\hline TU-110 & $6 S$ & 320 & 13.1 & 13.1 & SS/CL & 5.2 & $9.4-12.5$ & $310-307$ \\
\hline TU-111 & ద & 320 & 30.2 & 18.2 & CL几S & 0.9 & $18.6-17.6$ & $305-302$ \\
\hline TU-112 & $7 \mathrm{~S}$ & 322 & 18.5 & 19.2 & $\mathrm{SS} / \mathrm{CL}$ & 5.2 & $12.5-15.5$ & $309-306$ \\
\hline TU-113 & $8 S$ & 327 & 20.7 & 20.7 & SS/CL & 6.9 & $17.0-20.1$ & $309-307$ \\
\hline TU-114 & $8 D$ & 327 & 28.9 & 28.0 & CL/LS & 1.0 & $24.3-27.4$ & $303-300$ \\
\hline TU-115 & $9 \mathrm{~S}$ & 319 & 14.9 & 14.9 & $\mathrm{SS} / \mathrm{CL}$ & 7.0 & $11.2-14.3$ & $308-305$ \\
\hline TU-116 & $10 \mathrm{~S}$ & 320 & 17.3 & 17.3 & $\mathrm{SS} / \mathrm{CL}$ & 7.0 & $13.7-16.7$ & $307-304$ \\
\hline TU-117 & $11 \mathrm{~S}$ & 321 & 17.6 & 17.6 & $\mathrm{SS} / \mathrm{CL}$ & 5.8 & $14.0-17.0$ & $307-304$ \\
\hline TU-118 & $12 S$ & 321 & 17.6 & 17.5 & SS/CL & 6.6 & $13.0-16.9$ & $307-304$ \\
\hline TU-119 & $13 S$ & 326 & 21.3 & 21.3 & $\mathrm{SS} / \mathrm{CL}$ & 9.1 & $17.6-20.7$ & $308-305$ \\
\hline
\end{tabular}

aValues are given in meters above sea level.

bValues are given in meters below land surface.

cScreen lithology is as follows: SS, sandstone; CL, coal; LS, limestone. 
Each well was developed by use of a pump and surge technique. Initially, all wells produced cloudy or gray water, an indication of residues due to drilling cuttings and (or) grout. Continued pumping and surging improved water clarity and helped remove most cuttings and sediment from within the well casing and filter pack. Well development was necessary to ensure collection of representative groundwater samples and to ensure hydraulic connection with the formation along the screen interval.

Water levels in wells were measured by two different techniques: (1) manual measurement by steel tape (monthly), and (2) automated measurement by a pressure transducer (hourly). Two up gradient and five down gradient wells were outfitted with automated data collection platforms to monitor hourly water levels, temperature, and specific conductance. Water levels were measured manually in each well and a pressure transducer was calibrated to the measured water level. The temperature and specific conductance probes were calibrated before installation and were routinely checked during water-quality sampling. A site visit was scheduled each month to make sure the water-level calibration was correct and to download the stored data into a laptop computer.

Single-well-volume displacement tests ("slug" tests) were done at 13 of the 20 wells to determine water-transmitting properties of the aquifers beneath the site. The slug tests involved installing a pressure transducer that can measure rapid changes in water levels due to an instantaneous addition or withdrawal of a known volume. Insertion or withdrawal of the slug caused an instantaneous rise or fall in the water level in the well. Two different slugs were used in the aquifer tests, one with a volume of $1.8 \times 10^{-3}$ cubic meter $\left(6.2 \times 10^{-2}\right.$ cubic feet) (the "small" slug) and one with a volume of $1.1 \times 10^{-2}$ cubic meters $\left(3.79 \times 10^{-1}\right.$ cubic feet) (the "large" slug). The small slug was used on wells that responded slowly to water-level changes, whereas the large slug was used on wells that responded relatively quickly. Tests were done at least four times (two additions and two withdrawals) at each well.

The results of the tests were evaluated by use of the method of Cooper et al. (1967). The premise behind this aquifer-test method is that the rate at which the water level returns to the pretest level after the injection or withdrawal of a slug is proportional to the hydraulic conductivity of the aquifer. The data-analysis procedure involves plotting the change in hydraulic head (represented by water level) with time and matching the data points to a set of theoretical curves. A match point is selected from the plot of field data and the best-fit theoretical curve. Corresponding values from the axes of each graph are inserted into an 
analytical equation that solves for transmissivity. The transmissivity is divided by the aquifer thickness to derive hydraulic conductivity.

\subsubsection{Sampling and Analysis of Soil, Plant and Water Samples}

Baseline soil/spoil samples were collected in November, 1994 and again in June, 1995 by digging 3 cores ( $5 \mathrm{~cm}$ diameter) in each watershed. Cores were sampled in $5 \mathrm{~cm}$ increments in the upper $30 \mathrm{~cm}$, and in $10 \mathrm{~cm}$ increments from the $30 \mathrm{~cm}$ depth down to the compacted clay layer. Soil samples were air-dried and ground to pass a 2-mm screen. Samples were analyzed for $\mathrm{pH}$, electrical conductivity (EC), and for water soluble and Mehlich3 (Mehlich, 1984) extractable concentrations of $\mathrm{Al}, \mathrm{As}, \mathrm{B}, \mathrm{Ba}, \mathrm{Ca}, \mathrm{Cd}, \mathrm{Cr}, \mathrm{Cu}, \mathrm{Fe}, \mathrm{K}, \mathrm{Mg}, \mathrm{Mn}, \mathrm{Mo}, \mathrm{Na}, \mathrm{Ni}, \mathrm{P}$, $\mathrm{Pb}, \mathrm{S}, \mathrm{Se}, \mathrm{Si}$, and $\mathrm{Zn}$ by ICP.

Plant biomass production was determined by cutting three strips $(0.75 \times 20 \mathrm{~m})$ across each watershed in August, 1995. Plant material from each strip was dried for $48 \mathrm{~h}$ at $60^{\circ} \mathrm{C}$ and weighed. Dried material was ground to pass a $1 \mathrm{~mm}$ sieve, digested in hot perchloric and nitric acid, and analyzed by inductively coupled plasma emission spectrometry (ICP) for concentrations of the elements listed above.

Sample volumes, bottle types, preservatives, and preservation and filtration techniques used in this study to analyze various types of water samples followed guidelines issued by the National Water Quality Laboratory (NWQL). On the basis of these guidelines, bottle types, sample volumes, and sample preparation and preservation methods listed in Table 21 were used for water samples.

Water was analyzed in laboratories for the constituents listed in Table 21. Several laboratories were used for these analyses, including the NWQL of the US Geological Survey in Arvada, Colorado; the Ohio Agricultural Research and Development Center, The Ohio State University Laboratory (OARDC/OSU) Wooster, Ohio; and the isotope laboratory of the US Geological Survey in Reston, Virginia. Constituents listed in Table 21 were selected on the basis of known composition of FGD by-product, acid mine drainage, and anticipated water-rock interactions.

The primary laboratory responsible for trace and major element chemistry in water was the OARDC/OSU laboratory. Additionally, for selected samples, the NWQL analyzed an aliquot of the sample for all of the water constituents in Table 21 as an external quality control check 
Table 21. Summary of analyzing laboratory, analyte class, bottle type, sample volume, and sample preparation and preservation for water samples ${ }^{a}$.

\begin{tabular}{|c|c|c|c|c|}
\hline Laboratory & $\begin{array}{l}\text { Analyte } \\
\text { class }\end{array}$ & $\begin{array}{l}\text { Bottle } \\
\text { type }\end{array}$ & $\begin{array}{l}\text { Sample } \\
\text { volume }\end{array}$ & $\begin{array}{l}\text { Sample preparation and } \\
\text { preservation }\end{array}$ \\
\hline OARDC/OSUb & $\begin{array}{l}\text { Acidity, alkalinity, } \\
\text { pH, specific } \\
\text { conductance, ROE, } \\
\text { anions (dissolved) }\end{array}$ & $\begin{array}{l}\text { FU (polyethylene } \\
\text { bottle,field-rinsed) }\end{array}$ & $250 \mathrm{~mL}$ & $\begin{array}{l}\text { Filter with } 0.45-\mu \mathrm{m} \text { capsule filter. } \\
\text { Rinse bottle with filtrate before } \\
\text { filling. }\end{array}$ \\
\hline OARDCIOSU & Total Al, Fe, Mn & $\begin{array}{l}\text { RA (polyethylene } \\
\text { bottle, acid-rinsed) }\end{array}$ & $250 \mathrm{~mL}$ & Acidify to $\mathrm{pH}<2$ with $\mathrm{HNO}_{3}$. \\
\hline OARDCIOSU & $\begin{array}{c}\text { Metals } \\
\text { (dissolved) }\end{array}$ & $\begin{array}{l}\text { FA (polyethylene } \\
\text { bottle, acid-rinsed) }\end{array}$ & $250 \mathrm{~mL}$ & $\begin{array}{l}\text { Filter with } 0.45-\mu \mathrm{m} \text { capsule filter. } \\
\text { Rinse bottle with filtrate before } \\
\text { filling. Acidify to } \mathrm{pH}<2 \text { with } \\
\qquad \mathrm{HNO}_{3} \text {. }\end{array}$ \\
\hline NWQLc & $\begin{array}{l}\text { As, } \mathrm{Se}, \mathrm{Pb} \\
\text { (dissolved) }\end{array}$ & $\begin{array}{l}\text { FA (polyethylene } \\
\text { bottle, acid-rinsed) }\end{array}$ & $250 \mathrm{~mL}$ & $\begin{array}{l}\text { Filter with } 0.45-\mu \mathrm{m} \text { capsule filter. } \\
\text { Rinse bottle with filtrate before } \\
\text { filling. Acidify to } \mathrm{pH}<2 \text { with } \\
\mathrm{HNO}_{3} \text {. }\end{array}$ \\
\hline NWQL & $\begin{array}{l}\text { Mercury } \\
\text { (dissolved) }\end{array}$ & $\begin{array}{l}\text { FAM (glass bottle, } \\
\text { acid-rinsed) }\end{array}$ & $250 \mathrm{~mL}$ & $\begin{array}{c}\text { Filter with } 0.45-\mu \mathrm{m} \text { capsule filter. } \\
\text { Rinse bottle with filtrate before } \\
\text { filling. Acidify to } \mathrm{pH}<2 \text { with } \\
\qquad \mathrm{HNO}_{3} / \mathrm{K}_{2} \mathrm{Cr}_{2} \mathrm{O}_{7}\end{array}$ \\
\hline NWQL & $\begin{array}{l}\text { Nutrients } \\
\text { (dissolved) }\end{array}$ & $\begin{array}{l}\text { FCC (brown } \\
\text { polyethylene bottle, } \\
\text { field-rinsed) }\end{array}$ & $125 \mathrm{~mL}$ & $\begin{array}{l}\text { Rinse bottle with filtrate before } \\
\text { filling. Filter with } 0.45-\mu \mathrm{m} \text { capsule } \\
\text { filter. Maintain at } 4{ }^{\circ} \mathrm{C} \text {. }\end{array}$ \\
\hline NWQL & DOC & $\begin{array}{l}\text { DOC (oven-baked at } \\
450^{\circ} \mathrm{C} \text { in amber glass } \\
\text { bottle) }\end{array}$ & $125 \mathrm{~mL}$ & $\begin{array}{c}\text { Filter with } 0.45-\mu \mathrm{m} \text { silver filter. } \\
\text { Rinse bottle with filtrate before } \\
\text { filling. }\end{array}$ \\
\hline $\begin{array}{l}\text { Isotope } \\
\text { laboratoryd }\end{array}$ & Tritium & $\begin{array}{l}\text { RU (high-density } \\
\text { polyethylene bottle } \\
\text { with polyseal cap) }\end{array}$ & $1 \mathrm{~L}$ & Submit untreated \\
\hline $\begin{array}{l}\text { Isotope } \\
\text { laboratory }\end{array}$ & $8^{34} \mathrm{~S}$ in $\mathrm{SO}_{4}$ & $\begin{array}{l}\text { FU (high-density } \\
\text { polyethylene bottle } \\
\text { with polyseal cap) }\end{array}$ & $\begin{array}{l}\text { Enough so that } \\
30 \mathrm{mg} \text { of sulfate } \\
\text { is submitted }\end{array}$ & Filter with $0.45-\mu \mathrm{m}$ capsule filter. \\
\hline
\end{tabular}

aROE, residue on evaporation; FU, filtered, untreated; RA, raw, acidified; FA, filtered, acidified; FAM, filtered, acidified mercury bottle; FCC, filtered, untreated nutrients samples chilled to $4 \circ \mathrm{C}$; DOC, dissolved organic carbon; RU, raw, untreated.

bOhio Agricultural Research and Development Center, The Ohio State University laboratory, Wooster, $\mathrm{OH}$.

cNational Water Quality Laboratory, US Geological Survey, Arvada, CO.

dsotope laboratory, US Geological Survey, Reston, VA. 
designed to assess the accuracy of analytical data reported by the OARDC. The NWQL was responsible for determining dissolved organic carbon, nutrients, $\mathrm{As}, \mathrm{Se}, \mathrm{Pb}$, and $\mathrm{Hg}$ on all samples. Descriptions of analytical methods used by NWQL are given by Fishman and Friedman (1989) and Fishman (1993). Tritium and $\delta^{34} \mathrm{~S}$ in $\mathrm{SO}_{4}$ were determined by the isotope laboratory in Reston, Virginia.

Precipitation and dry deposition were sampled monthly from December 1994 through December 1995. Samples were collected with an automated wet/dry deposition gage in plastic $19 \mathrm{~L}$ ( $5 \mathrm{gal}$ ) buckets. A hole at the bottom of the wet-deposition bucket allowed sample water to drain through Teflon tubing connected to a 20-liter plastic carboy. At the end of each monthly sampling period, the carboy was removed, capped, and taken back to the office for sample processing. The carboy was replaced with a new carboy that had been cleaned by means of progressive rinsing with dilute soap (1 percent Liquinox solution), tap water, dilute acid ( 5 percent hydrochloric $(\mathrm{HCl})$ acid), and distilled water. The approximate volume of wet deposition was recorded each month as a check on the accuracy of the tipping-bucket gage. This was done by turning the carboy with the nozzle end up and recording the volume to the nearest $500 \mathrm{~mL}$ as marked on the side of the carboy.

Dry deposition was sampled by rinsing the dry deposition bucket with approximately $500 \mathrm{~mL}$ of inorganic-free water. This water was poured into a weighed, clean, polyethylene bottle. The dry deposition sample was weighed again to calculate total sample volume, and then filtered and preserved with ultrapure nitric acid. Dry and wet deposition samplers were both cleaned by means of progressive rinses of dilute soap (1 percent Liquinox solution), tap water, dilute acid ( 5 percent $\mathrm{HCl}$ ), and distilled water. The dry deposition bucket was scrubbed with a plastic brush and dilute soap solution to remove grime buildup on the inner bucket surface.

Interstitial waters were sampled three times during the course of this study. Sampling round 1 was done on July 7, 1995, round 2 on October 10, 1995, and round 3 on January 18, 1996. These dates correspond to approximately 10,13, and 16 months after application of FGD byproducts, respectively. Sampling of interstitial water required a major rainfall or snowmelt event to provide enough water to permit recovery of samples from the lysimeters and, in fact, the sampling round in January 1995 coincided with major snowmelt.

Surface water baseflow samples and conditions from various locations on and surrounding the Fleming site were required for complete analyses of the hydrologic systems. However, surface water samples may not have been collected at the same time groundwater samples were 
collected. Surface water sites were sampled by US Geological Survey personnel one time during the course of this study. These surface water samples were collected as grab samples. A churn splitter was used to collect a sample from each of the three sites sampled during the study. Each churn was cleaned before use by progressive rinses with a 1 percent Liquinox solution, tap water, dilute acid ( 5 percent $\mathrm{HCl}$ ), and distilled water. Inert plastic tubing was then attached to a peristaltic pump and used to withdraw an aliquot from the churn and process the sample according to protocols given above. Discharge measurements were also made at the time of sampling.

Surface water samples were also collected by Ohio State University personnel from the six small watershed created on the Fleming site after each precipitation event that produced runoff. For each runoff event a hydrograph was constructed. Also, sediment deposited in the approaches and $\mathrm{H}$-flumes was removed, weighed and sampled. Two liters of water and suspended sediment samples were collected from the holding tanks. Water samples were analyzed for $\mathrm{pH}$, electrical conductivity, acidity and alkalinity before and after filtering through a $0.45 \mu \mathrm{m}$ membrane filter. Sediment concentration was determined by drying and weighing the filter cake. Filtrates were analyzed by ICP for dissolved concentrations of the same elements as listed previously. Total element concentrations of water samples were determined by digesting unfiltered samples in hot perchloric and nitric acid. Digests were analyzed by ICP for the same elements listed above. Water samples were also collected and similarly analyzed from a sediment pond which collected surface water flow from the entire reclamation site.

The 15 wells installed during the first phase of the study were sampled twice, whereas the additional 5 wells installed at the later time were sampled once. The first groundwater sampling round was in June 1995, approximately 9 months after final reclamation and application of FGD materials (round 1); the second was in January 1996, approximately 16 months after application (round 2). In addition to the 20 wells installed at the site, 9 domestic wells were sampled once during June 1995 to document water quality at down gradient domestic wells completed in deeper aquifers.

Groundwater samples were collected from 19 of 20 wells installed at the site (one well was dry since installation) and from 9 of fsite domestic wells. To reduce cross-contamination risks associated with the use of a single sampling pump, dedicated electric submersible pumps were installed in 15 monitoring wells. For the five remaining monitoring wells, a reel-mounted submersible pump was used for sampling. The pump and tubing were cleaned after sampling 
by progressive flushing of a 1 percent Liquinox solution, tap water, dilute acid ( 5 percent $\mathrm{HCl}$ ), and distilled water.

Standard purge and monitoring techniques described by Wood (1976) and Claassen (1982) were used to ensure that a representative sample of groundwater was obtained from each well. Purging began with initial pumping of three casing volumes, and it continued until three successive sets of onsite measurements met the allowable variation criteria listed in Table 22.

After volumetric and chemical stability criteria were met, sampling of the groundwater began. Samples for field determinations of alkalinity, $\mathrm{Fe}^{2+} / \mathrm{Fe}^{3+}$ ratio, dissolved sulfate, and $\mathrm{H}_{2} \mathrm{~S}$ were collected first. All sample bottles were then filled and preserved according to protocols designed to minimize sample contamination at the parts per billion level. Because of the potential for contamination from airborne particulates, processing and preservation of all samples was done onsite by use of a processing chamber. A section of acid-rinsed inert plastic tubing was attached to the discharge line exiting the well and was run directly into the sampleprocessing chamber.

USGS personnel were responsible for all groundwater quality measurements and analyses made at the time of sample collection. Onsite measurements included water temperature, alkalinity, $\mathrm{pH}$, redox potential, specific conductance, and dissolved oxygen concentration. In addition, USGS personnel recorded air temperature and air pressure at the time of sampling and measured or estimated discharge of springs, seeps, and streams. Determination of $\mathrm{Fe}^{2+}$ and $\mathrm{Fe}_{\mathrm{T}}$ (total iron) were done by use of a field spectrophotometer (Hach, 1990). The Fe ${ }^{3+}$ concentration was determined by subtracting the $\mathrm{Fe}^{2+}$ concentration from the $\mathrm{Fe}_{\mathrm{T}}$ concentration, and the $\mathrm{Fe}^{2+} / \mathrm{Fe}^{3+}$ ratio was calculated. If the odor of $\mathrm{H}_{2} \mathrm{~S}$ was noted in any samples, the field spectrophotometer was used to determine the $\mathrm{H}_{2} \mathrm{~S}$ concentration of the sample. Analytical requirements for determination of $\delta^{34} \mathrm{~S}$ in $\mathrm{SO}_{4}$ required submitting a minimum of 30 milligrams sulfur as $\mathrm{SO}_{4}$. Therefore, a field sulfate analysis was done with the field spectrophotometer by use of a turbidimetric technique (Hach, 1990) to ensure that sufficient sample was collected. Field determinations that were done for each sample type are summarized in Table 23.

Internal quality-control $(\mathrm{QC})$ practices were designed to ensure that sampling and analytical procedures did not provide a source of contamination to samples. Five types of internal QC samples, all described in Table 24, were run regularly during water analyses: (1) laboratory blanks, (2) laboratory spikes, (3) check standards, (4) sample spikes, (5) duplicate samples. 
Table 22. Onsite chemical stability criteria for monitoring well purging.

\begin{tabular}{ll}
\hline Measurement & Allowable variation \\
\hline & \\
pH & 0.1 Standard units \\
Specific conductance & $<100 \mu \mathrm{S} / \mathrm{cm}$ within $5 \%$ \\
& $>100 \mu \mathrm{S} / \mathrm{cm}$ within $3 \%$ \\
Dissolved oxygen & $0.3 \mathrm{mg} / \mathrm{L}$ \\
Temperature & $0.2 \mathrm{deg} . \mathrm{C}$ \\
Eh & $\pm 50 \mathrm{mv}$ \\
& \\
\hline \hline
\end{tabular}

Frequencies of use and quality control data-acceptance criteria were derived from consultation with the US Geological Survey Branch of Technical Data and Quality Systems. Control charts were constructed for all laboratory-blank, laboratory-spike, and sample-spike samples and were used by OARDC and NWQL personnel to determine the need for reanalysis. Results of internal quality control sampling and analyses are not published in this report.

External quality control samples were submitted to both participating laboratories to assess overall accuracy and precision of the reported water-quality data (Table 25). Complete results of quality assurance/quality control are reported in Appendix F. Three types of QC samples were submitted as part of this external quality assurance/quality control plan. Split or replicate samples used for intralaboratory comparisons and reference samples were used to assess reported precision and accuracy of analytical results. Both types constituted no less than 5 percent of the total number of samples. Standard reference water samples for major cations, anions, trace metals, and nutrients were obtained from the US Geological Survey Branch of Technical Data and Quality Systems for use as reference samples (Janzer, 1985). These samples were submitted as blind samples to both laboratories. 
Table 23. Summary of water properties and constituents measured onsite by US Geological Survey personnel.

\begin{tabular}{|c|c|c|c|c|}
\hline Field analysis & Precipitation & $\begin{array}{c}\text { Interstitial } \\
\text { water }\end{array}$ & $\begin{array}{c}\text { Ground } \\
\text { water }\end{array}$ & $\begin{array}{c}\text { Surface } \\
\text { water }\end{array}$ \\
\hline Alkalinity & No & Conditionala $^{\mathrm{a}}$ & Yes & Yes \\
\hline Eh & No & No & Yes & Yes \\
\hline $\mathrm{pH}$ & Yes & Conditional $^{\mathrm{a}}$ & Yes & Yes \\
\hline Dissolved oxygen & No & No & Yes & Yes \\
\hline Specific conductance & Yes & Conditionala $^{a}$ & Yes & Yes \\
\hline Temperature & No & No & Yes & Yes \\
\hline $\mathrm{Fe}^{2+} / \mathrm{Fe}^{3+}$ ratio & No & No & Yes & Yes \\
\hline $\mathrm{H}_{2} \mathrm{~S}$ & No & No & Conditionalb & No \\
\hline Dissolved sulfate & No & Conditional $b$ & Yes & Yes \\
\hline
\end{tabular}

${ }^{a}$ Conditional analysis was dependent on volume of sample obtained from lysimeter. If only minimal volumes $(<50 \mathrm{ml}$ ) were obtained, this water was submitted for trace element analysis only. bConditional analysis was done only if sample was selected for isotopic analysis of dissolved sulfate. 
Table 24. Types of internal quality control samples and their purpose, frequency of use, and expected results/acceptance criteria.

$\begin{array}{lll}\text { Type of sample } & \text { Purpose } & \text { Expected results/ } \\ \text { acceptance criteria }\end{array}$

$\begin{array}{lccc}\text { Laboratory blank } & \begin{array}{c}\text { Assess analytical } \\ \text { contamination }\end{array} & 5 \% \text { total samples } & \begin{array}{c}\text { Control-chart check } \\ \text { against reporting limit }\end{array} \\ \text { Laboratory spike } & \text { Assess analyte recovery } & 5 \% \text { total samples } & 80 \text { to } 120 \% \text { recovery } \\ \text { Sample spike } & \text { Assess matrix interference } & 5 \% \text { total samples } & 80 \text { to } 120 \% \text { recovery } \\ \text { Check standard } & \text { Assess instrument stability } & 10 \% \text { total samples } & \text { RPD }^{a}<10 \% \\ \text { Replicate sample } & \text { Assess analytical precision } & 5 \% \text { total samples } & \text { RPD }<20 \%\end{array}$

aRPD, relative percent deviation.

Blank samples were of four types. Equipment blanks, which were used to assess contamination or sorption effects caused by pumps, lysimeters, and other sampling equipment, constituted approximately 8 percent of the total number of samples collected. Field blanks were submitted to assess the combined effects of sample collection equipment and processing on contamination. They constituted no less than 5 percent of the total number of samples. Ambient or trip blanks consisted of clean bottles filled with inorganic blank water. They were used to identify contamination that may have occurred during collection, transport and analyses of water samples, and they constituted approximately 2 percent of the total samples collected. Preservative blanks, which consisted of inorganic blank water preserved with acid from the same lot used to preserve actual samples, constituted no less than 2 percent of the total samples. A summary of the types of external quality control samples collected during the project and results/acceptance criteria associated with each type of quality control sample are 
Table 25. Types of external quality control samples and their purpose, frequency of use, and expected results/acceptance criteria.

\begin{tabular}{|c|c|c|c|}
\hline Type of sample & Purpose & Frequency of use & $\begin{array}{l}\text { Expected results/ } \\
\text { acceptancecriteria }\end{array}$ \\
\hline Splits/replicates & $\begin{array}{l}\text { Assess intralaboratory } \\
\text { precision }\end{array}$ & $\begin{array}{l}5 \% \text { total } \\
\text { samples }\end{array}$ & $\mathrm{RPD}^{\mathrm{a}}<15 \%$ \\
\hline Reference samples & Assess laboratory accuracy & $\begin{array}{l}5 \% \text { total } \\
\text { samples }\end{array}$ & $\begin{array}{l}\text { Within } 2 \text { standard } \\
\text { deviations of MPV }\end{array}$ \\
\hline \multicolumn{4}{|l|}{ Blank Samples: } \\
\hline Equipment blanks & $\begin{array}{l}\text { Assess contamination by } \\
\text { equipment }\end{array}$ & $\begin{array}{l}8 \% \text { total } \\
\text { samples }\end{array}$ & $\begin{array}{l}\text { Less than reporting } \\
\text { limit }\end{array}$ \\
\hline Field blanks & $\begin{array}{l}\text { Assess contamination during } \\
\text { sampling }\end{array}$ & $\begin{array}{l}5 \% \text { total } \\
\text { samples }\end{array}$ & $\begin{array}{l}\text { Less than reporting } \\
\text { limit }\end{array}$ \\
\hline Ambient/trip blanks & $\begin{array}{l}\text { Assess contamination } \\
\text { during sample collection and } \\
\text { analysis }\end{array}$ & $\begin{array}{l}2 \% \text { total } \\
\text { samples }\end{array}$ & $\begin{array}{l}\text { Less than reporting } \\
\text { limit }\end{array}$ \\
\hline Preservative blanks & $\begin{array}{c}\text { Assess trace metal } \\
\text { contamination from acid } \\
\text { preservatives }\end{array}$ & $\begin{array}{l}2 \% \text { total } \\
\text { samples }\end{array}$ & $\begin{array}{c}\text { Less than reporting } \\
\text { limit }\end{array}$ \\
\hline
\end{tabular}

aRPD, relative percent deviation.

bMPV, most probable value. 
given in the Appendix. Together, the total number of external quality control samples collected constituted approximately 25 percent of the total number of environmental samples.

Scatterplots of process-control variables, including $\mathrm{pH}$, dissolved sulfate, dissolved iron, and residue on evaporation (residue on evaporation ( $R O E$ ) is a measure of dissolved solids determined by evaporating a sample at $180^{\circ} \mathrm{C}$ for exactly 2 hours and weighing the residue) were prepared to examine the distribution of elements with regard to overall water quality. Additionally, the distribution of concentrations of all elements were examined in relation to depth below land surface and location with respect to groundwater flow directions.

To evaluate potential solubility constraints on the major and trace element chemistry of water at the site, the computer program WATEQ4F (Ball and Nordstrom, 1991) was used. WATEQ4F is a FORTRAN 77 computer program that computes major element and trace element speciation and mineral saturation for natural waters. Concentrations of dissolved major and minor elements in water samples are input into the program, which then calculates the chemical speciation of dissolved constituents in the water and saturation indices of various minerals. The saturation index is a measure of the saturation state of the water with respect to a given mineral and indicates if the mineral is likely to dissolve or precipitate from the given water.

\subsubsection{Groundwater Flow Modeling}

A conceptual model was developed during the early part of Phase 3 to further define the groundwater flow system and to estimate travel times of particles of water that enter and exit the system. This calibrated flow model was used as a basis for particle-tracking analysis. A quasi-three dimensional, steady state, finite-difference groundwater flow model was constructed based on previous work by Saad and Cravotta (1991) and Helgeson et al (1982) (Figure 15). This model was assembled by use of the modular finite-difference computer code (McDonald and Harbaugh, 1988). Particle tracking was done by use of the MODPATH postprocessor created by Pollock (1989). Solute transport modeling with computer codes such as the EPRI code MYGRT (EPRI, 1989) was beyond the scope of this study.

To understand how the model was developed, several basic site characteristics must be defined and known. For example, the Fleming site is on top of a hill and is bounded by ridges that serve as surface water and, presumably, groundwater divides. The conceptual model dictates that the sole source of water to the system is recharge from precipitation and that surface and groundwater influx from off site are negligible. Recharge to the shallow aquifer occurs 


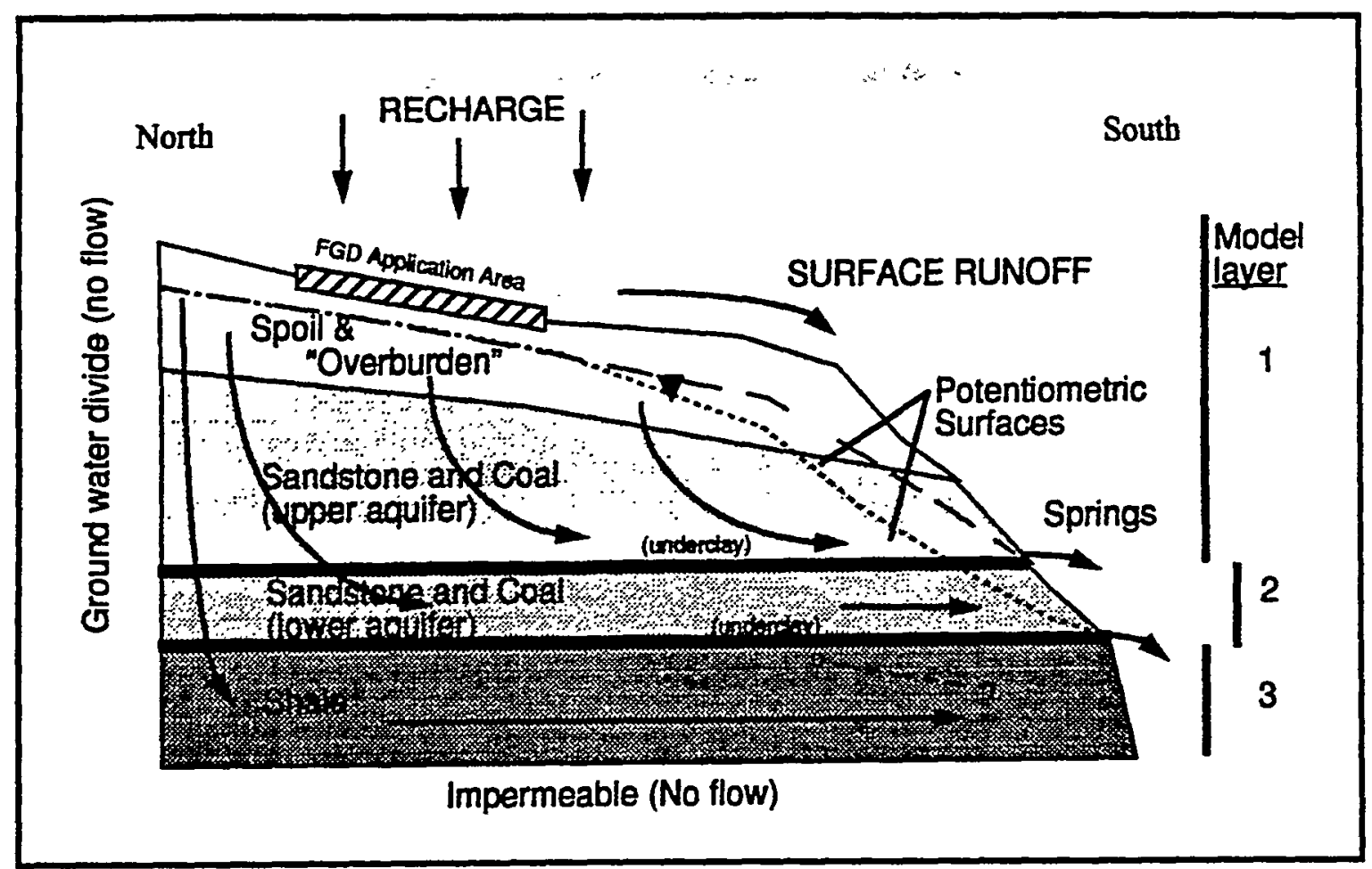

Figure 15. Conceptual model of groundwater flow. Arrows indicate conceptualization direction of flow. 
throughout the site, whereas recharge to the deeper aquifer occurs primarily in the up gradient areas.

The surface of the site is draped by mine spoil which is a combination of shale, clay, coal refuse, and topsoil. Immediately underlying the mine spoil is relatively impermeable clay and shale. The vertical hydraulic conductivity of clay and shale is typically low, but significant amounts of water may enter underlying bedrock if fractures are present or the spoil/clay layer is thin (see, for example, the area near well cluster 6 , where tile surface geophysics indicated spoil/clay layer thicknesses of less than $0.3 \mathrm{~m}(1 \mathrm{ft})$. Where the spoil/clay layer is thick and fractures are absent, recharge to the underlying groundwater system is limited by very low vertical hydraulic conductivity.

Water that does enter the bedrock aquifers may travel preferentially along a fracture system or bedding plane and discharge at a spring or seep. If another fracture intersects the flowpath, water may continue to travel downward to another relatively impermeable zone, then travel laterally and exit at a spring. Groundwater flow beneath the Fleming Site is predominantly horizontal, the only exit from the system being through springs or seeps down gradient on the hillside. The lowermost layer considered in this model is a relatively impermeable shale. The shale, which is thought to transmit only small amounts of water compared to the overlying layers, serves as a barrier to downward migration of water.

In the construction of a finite-difference model, the groundwater system is segmented into layers and cells (a process known as discretization) and values of vertical and horizontal hydraulic conductivity and thickness are assigned to each cell. The groundwater flow equation is then solved for each cell by use of an iterative calculation, and water fluxes between cells are calculated. The model was calibrated to observed values of hydraulic head (water levels in wells) and discharge (flux) of water from springs.

The flow model constructed for this site has three layers corresponding to the layers defined in the conceptual model. The uppermost layer (layer 1) includes the spoil and first sandstone and coal included in the rock cores. The thickness of layer 1 ranges from 0.3 to $9.1 \mathrm{~m}$ ( 1 to $30 \mathrm{ft}$ ). As shown in the conceptual model (Figure 15), layer 1 is a confined aquifer throughout the model area except at the hillside, where the aquifer becomes unconfined. Layer 2 includes a second sequence of sandstone and coal that ranges in thickness from 0.3 to $6.7 \mathrm{~m}$ ( 1 to $22 \mathrm{ft}$ ). Layer 2 is similar to layer 1 in that it is confined except near the down gradient part, where it 
becomes unconfined. Layer 3 , the lowermost layer, represents the relatively impermeable shale. Thickness of layer 3 ranges from 0.3 to $8.5 \mathrm{~m}$ ( 1 to $28 \mathrm{ft}$ ).

For the Fleming study site, the area was discretized into 56 tows and 42 columns with grid cells measuring $15 \mathrm{~m} \mathrm{(50)}$ feet on a side (Figure 16). These dimensions were chosen because distances between data points were generally greater than $15 \mathrm{~m}(50 \mathrm{ft}$ ), and smaller spacing could not be justified on the basis of available data. Simulations would show that this discretization interval produced simulated potentiometric surfaces that matched the observed surfaces within calibration limits. The grid was oriented north-south, parallel to the primary direction of groundwater flow. The input values and stresses to the model are listed in Table 26. Tops and bottoms of model layers were estimated by use of the topographic map and core data. Horizontal hydraulic conductivities were estimated from aquifer tests discussed previously. Vertical hydraulic conductivities were developed from average values determined on core samples reported by Rattan.Lal (School of Natural Resources, The Ohio State University, written communication, 1994). Vertical conductance, as reported in Table 26, incorporates both thickness and vertical hydraulic conductivity in a single term (McDonald and Harbaugh, 1988). Porosities were based on lithologic composition and published values (Domenico and Schwartz, 1990). Springs and sets located during field mapping were simulated as drains. Discharge from each drain is calculated by comparison of the hydraulic head in the cell with the altitude of the drain and by use of a conductance term that is a function of the dimensions of the cell and the hydraulic conductivity.

Calibration targets included water levels in wells measured in July 1995 and spring discharge measured during water sampling at TU-120 on June 26, 1995. Discharge at TU-120 represents combined discharge from all samplings from all springs exiting the base of the site.

In Table 27, observed and simulated heads and spring discharges are listed, along with a comparison in terms of mean absolute difference. Mean absolute difference was calculated by use of the following equation:

Equation 3-2 Mean absolute difference $=\left(\sum h_{0}-h_{1} \mid\right) / \mathrm{n}$

where $h_{\mathrm{o}}$ is the observed head in the well, $h_{1}$ is the simulated head at the center of the grid cell, and $\mathrm{n}$ is the number of comparisons made. Note that the location of the well where head was observed may not necessarily correspond to the center of the grid cell. This deviation was not considered significant because the hydraulic gradient across individual grid cells was generally 


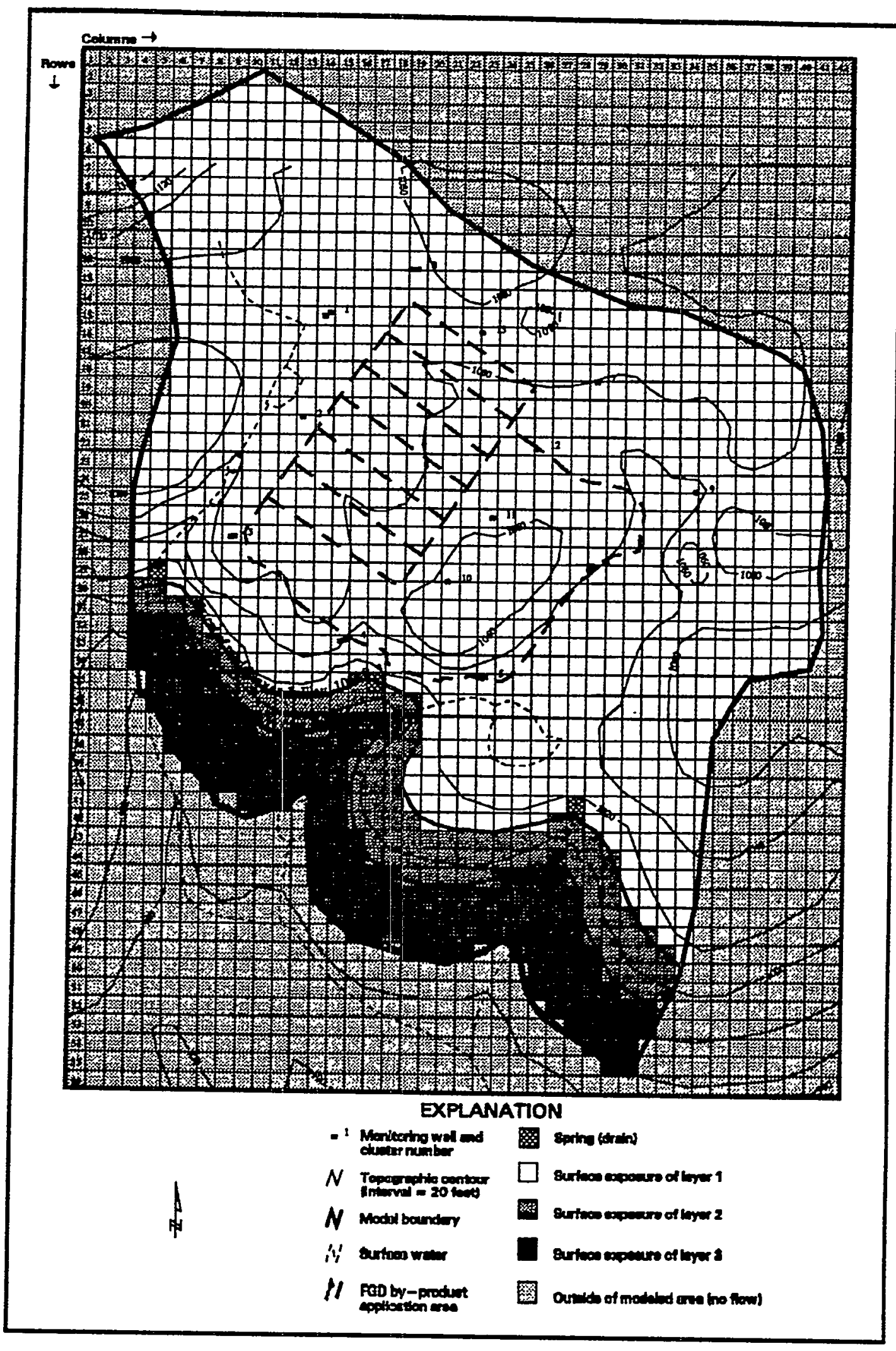

Figure 16. Finite difference grid used for groundwater flow model. Each grid cell is $15 \mathrm{~m} \times 15$ $\mathrm{m}(50 \mathrm{ft}$ by $50 \mathrm{ft})$. 
Table 26. Groundwater flow model input parameters and stresses.

\begin{tabular}{|c|c|c|c|c|c|c|}
\hline Layer & \multicolumn{2}{|l|}{ Parameter } & \multicolumn{2}{|l|}{ Value(s) } & \multicolumn{2}{|l|}{ Units } \\
\hline & & $\because 3$ & \multicolumn{2}{|c|}{ Modêl inpút } & & \\
\hline 1 & \multicolumn{2}{|l|}{ Top of layer } & \multicolumn{2}{|c|}{$318-308$} & \multicolumn{2}{|c|}{ m above mean sea } \\
\hline & \multicolumn{2}{|l|}{ Bottom of layer } & \multicolumn{2}{|l|}{308} & \multicolumn{2}{|c|}{ m above mean sea } \\
\hline & \multicolumn{2}{|c|}{ Horizontal hydraulic conductivity } & \multicolumn{2}{|c|}{$1.5-3.0$} & \multicolumn{2}{|l|}{$\mathbf{m} /$ day } \\
\hline & \multicolumn{2}{|c|}{ Vertical conductance between layers } & \multicolumn{2}{|c|}{$3 \times 10^{-3}-1.2 \times 10^{-2}$} & \multicolumn{2}{|l|}{ m/day } \\
\hline & \multicolumn{2}{|c|}{ Porosity (used in MODPATH } & \multicolumn{2}{|l|}{10} & \multicolumn{2}{|l|}{ percent } \\
\hline 2 & \multicolumn{2}{|c|}{ Top of layer } & \multicolumn{2}{|l|}{$308-302$} & \multicolumn{2}{|c|}{ m above mean sea. } \\
\hline & \multicolumn{2}{|c|}{ Bottom of layer } & \multicolumn{2}{|l|}{301} & \multicolumn{2}{|c|}{ m above mean sea } \\
\hline & \multicolumn{2}{|c|}{ Horizontal hydraulic conductivity } & \multicolumn{2}{|c|}{$3.7-7.3$} & \multicolumn{2}{|c|}{ m/day } \\
\hline & \multicolumn{2}{|c|}{ Vertical conductance between layers } & \multicolumn{2}{|c|}{$3.3 \times 10^{-6}-1.3 \times 10^{-5}$} & \multicolumn{2}{|l|}{ m/day } \\
\hline & Porosity (used in ? & ATH & 20 & & percent & \\
\hline 3 & Top of layer & & $301-293$ & & m above $\mathbf{m e}$ & \\
\hline & Bottom of layer & & 292 & & $\mathrm{~m}$ above $\mathrm{me}$ & \\
\hline & Horizontal hydraul & uctivity & $6.1-12.2$ & & m/day & \\
\hline & Porosity (used in I & ATH & 20 & & percent & \\
\hline & & Mod & el stresses & & & \\
\hline $\begin{array}{l}\text { Rechar } \\
\text { Uppermo }\end{array}$ & st active grid cell & & $\begin{array}{l}5.8 \times 10^{4}-5.8 \\
0.21-21.3\end{array}$ & $10^{-6}$ & $\begin{array}{l}\mathrm{m} / \text { day } \\
\mathrm{cm} / \mathrm{yr}\end{array}$ & \\
\hline Drains & & & & & & \\
\hline & Row & Column & Elevation(m) & Conductance & Units & Fáce \\
\hline 1 & 29 & & 308 & 0.74 & $\mathrm{~m}^{2 / d}$ & 3 \\
\hline 1 & 35 & 17 & 308 & 0.93 & $\mathrm{~m}^{2 / d}$ & 3 \\
\hline 1 & 41 & 28 & 308 & 0.0093 & $\mathrm{~m}^{2} / \mathrm{d}$ & 3 \\
\hline 2 & 32 & 6 & 301 & 0.011 & $\mathrm{~m}^{2 / d}$ & 3 \\
\hline 2 & 34 & 8 & 301 & 0.011 & $\mathrm{~m}^{2 / d}$ & 3 \\
\hline 2 & 37 & 18 & 301 & 0.064 & $\mathrm{~m}^{2 / d}$ & 1 \\
\hline 2 & 44 & 27 & 301 & 0.022 & $\mathrm{~m}^{2 / d}$ & 3 \\
\hline 3 & 41 & 14 & 292 & 1.39 & $\mathrm{~m}^{2 / d}$ & 1 \\
\hline 3 & 48 & 25 & 292 & 1.39 & $\mathrm{~m}^{2 / d}$ & 3 \\
\hline
\end{tabular}

aFace, face numbers are required for MODPATH particle tracking. Refer to Pollock (1989) for definition of face numbers. 
Table 27. Comparison of observed and simulated heads and flows for the groundwater flow model.a

\begin{tabular}{|c|c|c|c|c|c|c|c|}
\hline Well & Layer & Row & Column & $\begin{array}{c}\text { Measured } \\
\text { head on } \\
\text { July } 13,1995 \\
\text { (m above mean } \\
\text { sea level) }\end{array}$ & $\begin{array}{l}\text { Simulated head } \\
\text { (m above mean } \\
\text { sea level) }\end{array}$ & $\begin{array}{l}\text { Measured } \\
\text { minus } \\
\text { simulated } \\
\text { head(m) }\end{array}$ & $\begin{array}{l}\text { Absolute } \\
\text { differenceb } \\
\text { (m) }\end{array}$ \\
\hline is & 1 & 15 & 14 & 315.2 & 315.1 & +0.1 & 0.1 \\
\hline $1 \mathrm{D}$ & 2 & 15 & 14 & 315.3 & 315.1 & +0.2 & 0.2 \\
\hline $2 S$ & 1 & 21 & 13 & 315.1 & 314.8 & +0.3 & 0.3 . \\
\hline $3 S$ & 1 & 27 & 9 & 314.1 & 314.5 & -0.4 & 0.4 \\
\hline D & 2 & 27 & 9 & 314.2 & 314.5 & -0.3 & 0.3 \\
\hline $4 S$ & 1 & 33 & 15 & 314.0 & 314.2 & -0.2 & 0.2 \\
\hline $5 S$ & 1 & 35 & 23 & 313.8 & 314.1 & -0.3 & 0.3 \\
\hline $6 S$ & 1 & 29 & 29 & 314.9 & 314.7 & +0.2 & 0.2 \\
\hline $6 \mathrm{D}$ & 2 & 29 & 29 & 314.9 & 314.7 & +0.2 & 0.2 \\
\hline $7 S$ & 1 & 19 & 29 & 314.9 & 315.1 & -0.2 & 0.2 \\
\hline $8 S$ & 1 & 12 & 19 & 315.2 & 315.2 & 0.0 & 0.0 \\
\hline $8 D$ & 2 & 12 & 19 & 315.2 & 315.1 & -0.1 & 0.1 \\
\hline
\end{tabular}

aMeasured flow from springs on July $18,1995=107.7 \mathrm{~m}^{3} /$ day and simulated flow from springs $=107.7 \mathrm{~m}^{3} /$ day.

bMean absolute difference for all shallow wells $=0.18 \mathrm{~m}$. Mean absolute difference for all deep wells $=0.19 \mathrm{~m}$. 
small. Because the cell dimensions are $15 \mathrm{~m}$ by $15 \mathrm{~m}$ ( $50 \mathrm{ft}$ by $50 \mathrm{ft}$ ), the maximum distance a

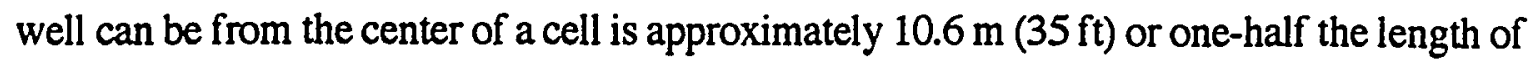
the diagonal of the cell. The observed hydraulic gradient in layer 1 was approximately $3.96 \mathrm{x}$ $10^{-3}$ meters per meter ( $3.96 \times 10^{-3}$ feet per foot). Thus, the maximum deviation of hydraulic hand from a well $10.6 \mathrm{~m}$ (35 ft) from the center of the grid cell is approximately $0.42 \mathrm{~m}$ or $0.14 \mathrm{ft}$ (determined by multiplying $35 \mathrm{ft} \times 3.96 \times 10^{-3}$ feet per foot), which was within the calibration limits identified for this model. Observed heads in wells 4D and 4P were not used in the model calibration because the screened interval for well 4D lies between layers 2 and 3 and the screened interval for well $4 \mathrm{~S}$ lies beneath layer 3 . The mean absolute difference for the calibrated model in layer 1 was $0.18 \mathrm{~m}(0.59 \mathrm{ft})$ and that for layer 2 was $0.19 \mathrm{~m}(0.63 \mathrm{ft})$.

All the simulated heads were within $0.36 \mathrm{~m}(1.2 \mathrm{ft})$ of observed heads except in the deep aquifer at well cluster 4 , where the observed heads were much lower than the simulated head. Numerous attempts were made to decrease simulated heads in this vicinity, including increasing the conductances of the springs and reducing discharge to the cells surrounding the springs. However, all of these attempts resulted in outflows from drains that greatly exceeded observed flows. These attempts also produced heads in the rest of the model that were much lower than observed heads.

A potentiometric surface map of simulated and observed head in layer 1 is shown in Figure 17. The simulated potentiometric surface in the shallow aquifer indicates that simulated groundwater flow in upper aquifer is from north to south with a gradient of approximately 3.25 $\times 10^{-3}$ meters per meter $\left(3.25 \times 10^{-3}\right.$ feet per foot) as observed from well cluster 8 to well cluster 4 . Figures 18 shows simulated heads in up gradient cells are slightly lower than observed heads, whereas simulated heads in down gradient cells are slightly higher than observed heads. The resulting simulated potentiometric surface is flatter than the observed potentiometric surface. As mentioned previously, the observed gradient between well clusters 8 and 4 in the shallow aquifer is $3.96 \times 10^{-3}$ meters per meter $\left(3.96 \times 10^{-3}\right.$ feet per foot), a fairly substantial difference of $7.1 \times 10^{-4}$ meters per meter ( $7.1 \times 10^{-4}$ feet per foot) (18 percent) from the simulated gradient. Observed flow from the site was approximately 107.6 cubic meters ( 3801.7 cubic $\mathrm{ft}$ ) per day, whereas simulated flow was 107.5 cubic meters ( 3800.7 cubic $\mathrm{ft}$ ) per day - a negligible difference. A potential explanation for this discrepancy between the relative accuracy of gradient and flow is that all three layers were simulated with a horizontal base, but correlation of lithologic units and borehole geophysical logs shows a slight dip of the rocks to the southeast. The dip of the rocks is close to the primary direction of 


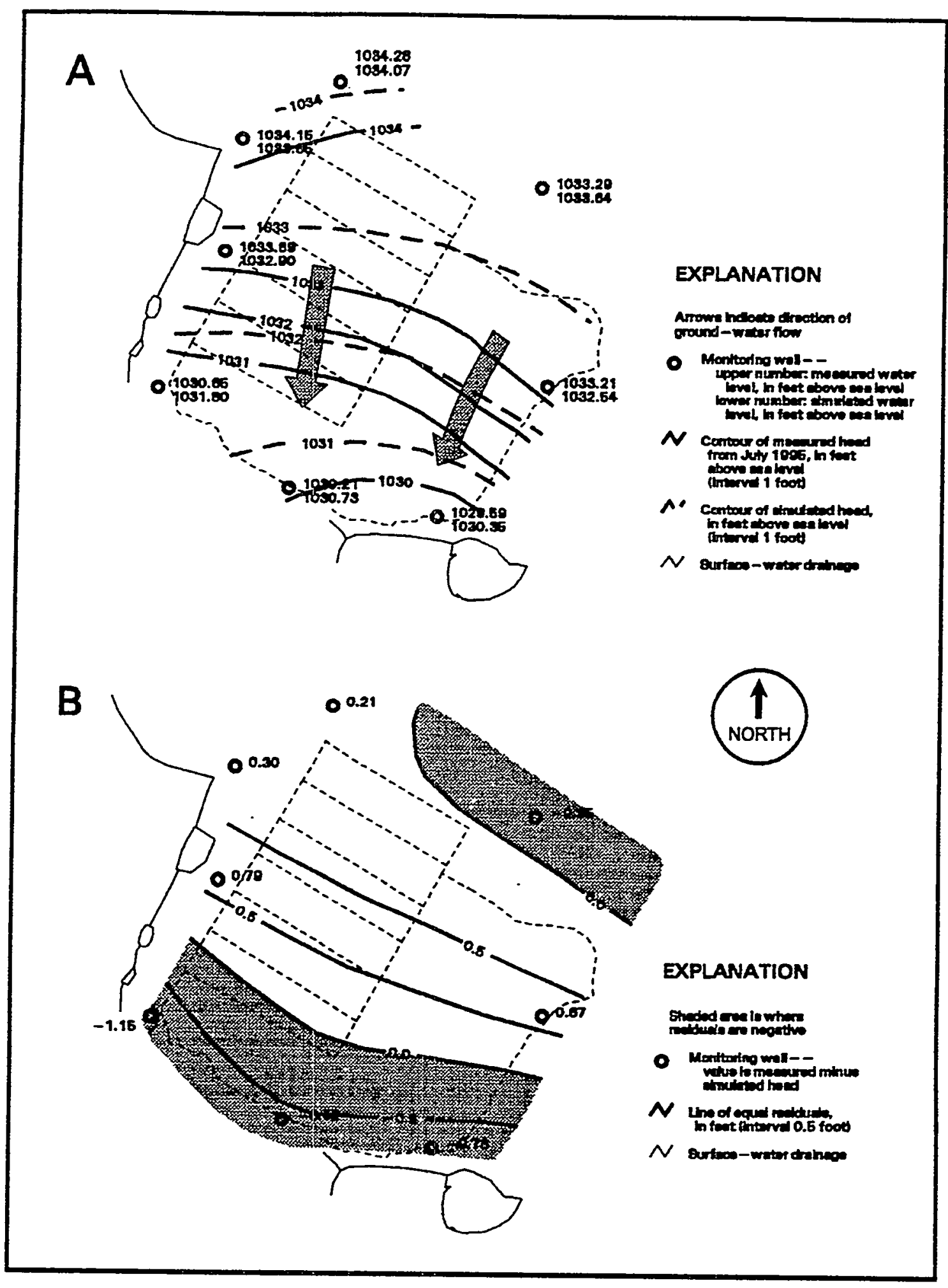

Figure 17. Contour maps showing A) measured and simulated heads and B) residuals. Values are given in feet. To convert to meters, multiply by 0.305 . 


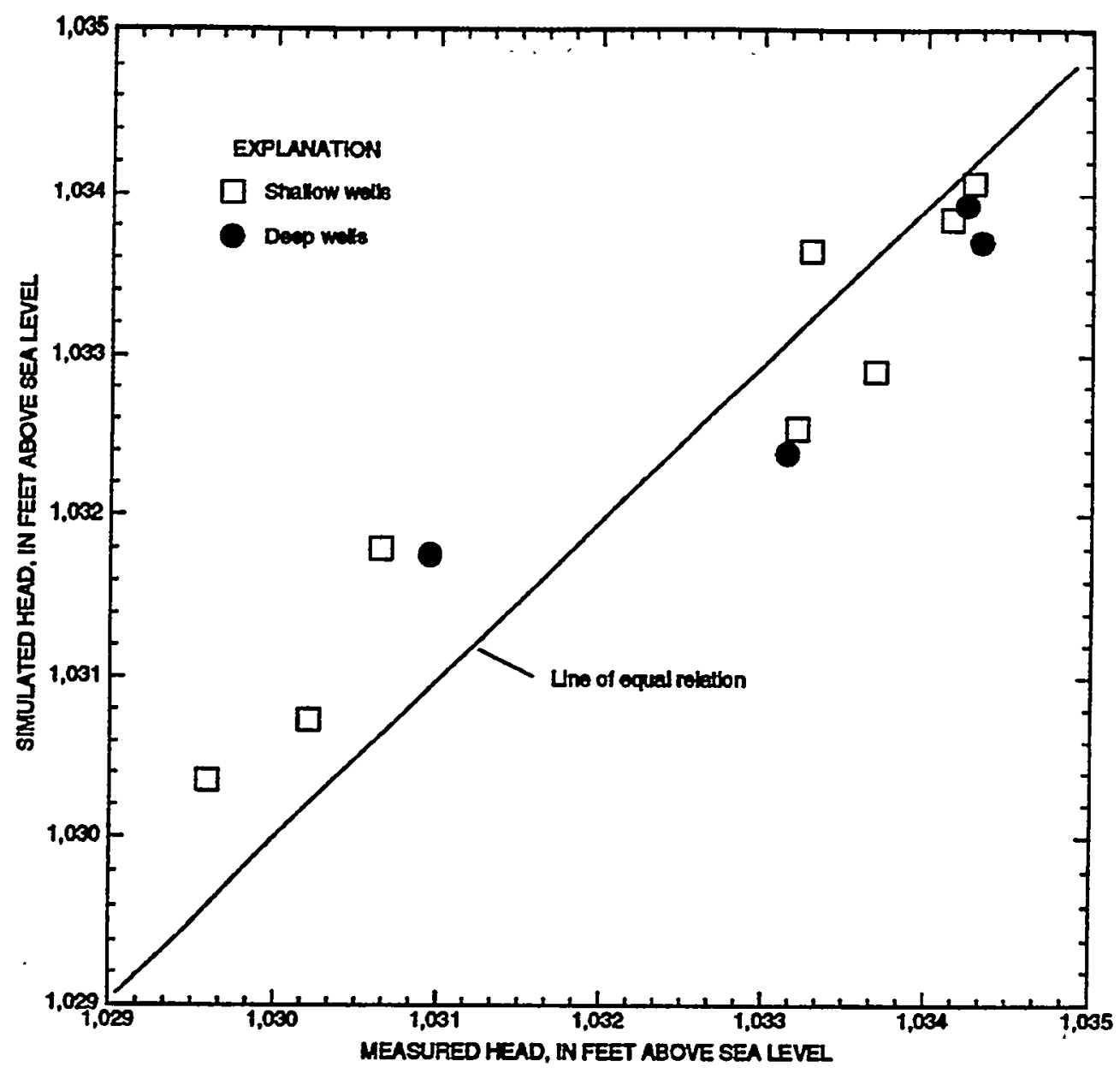

Figure 18. Comparison of observed and simulated heads in selected wells for shallow (layer 1) wells and deep (layer 2) wells. Values are given in feet. To convert to meters, multiply by 0.305 . 


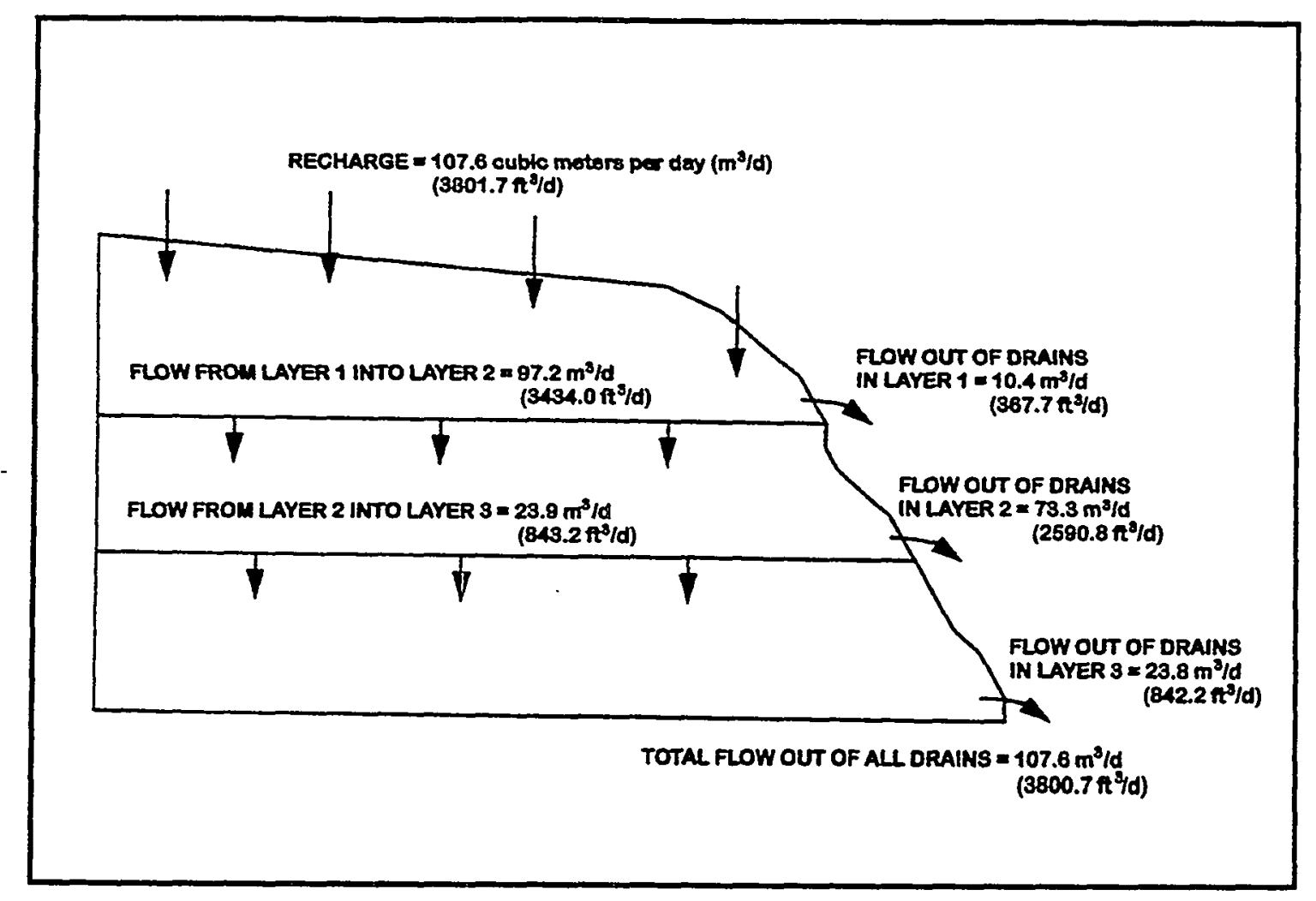

Figure 19. Schematic diagram of water budget for model simulation. 
groundwater flow and could, therefore, increase the hydraulic gradient at the site. Figure 19 shows a schematic diagram of flows into and out of each layer and summarizes the simulated hydrologic budget of the study site.

To evaluate the response of the model to variations in input variables, and to help define additional data needs, a sensitivity analysis was done where input variables were varied over a realistic range of values. Differences in modeled and observed groundwater levels and spring flow were used to evaluate the effect of the changes on model's calibration. All the input variables were varied by a factor of 10 because hydraulic-conductivity distributions within an aquifer are typically lognormally distributed. The results of the sensitivity analysis are shown in a series of boxplots (Figure 20). The sensitivity analysis shows that two variables are critical to the calibration of the flow model, the vertical conductance between layers 2 and 3 , and the conductance of the drains in layer 2.

A particle tracking procedure was used in concert with the calibrated flow model to trace the movement of particles of water as they traversed the groundwater flow system at the Fleming Site. This procedure permits estimation of how long it would take for water, potentially affected by FGD by-product, to travel through the groundwater system and exit through one of the down gradient springs. A program called MODPATH was used and allows for instantaneous release of particles throughout a given area (in this case, the FGD by-product application area) and computation of travel times for each individual particle. The particle of water may also be thought of as representing a conservative tracer that travels through the groundwater flow system by advective flow.

The minimum time needed for a particle to travel from the water table near cluster 4 to the spring at the base of the hill in layer 1 was approximately 228 days. The maximum time needed for a particle to travel from the up gradient edge of the FGD by-product application area to a spring in layer 3 was approximately 26.9 years. The average time for 251 particles released on the water table within the FGD by-product application area to travel to springs was approximately 9.5 years. Selected flowpaths are shown in Figures 21 and 22. Because the simulated potentiometric surface was flatter than the observed potentiometric surface, these estimates of travel times should be considered as maximum time periods for particies of water to travel from the recharge area to tile spring. 


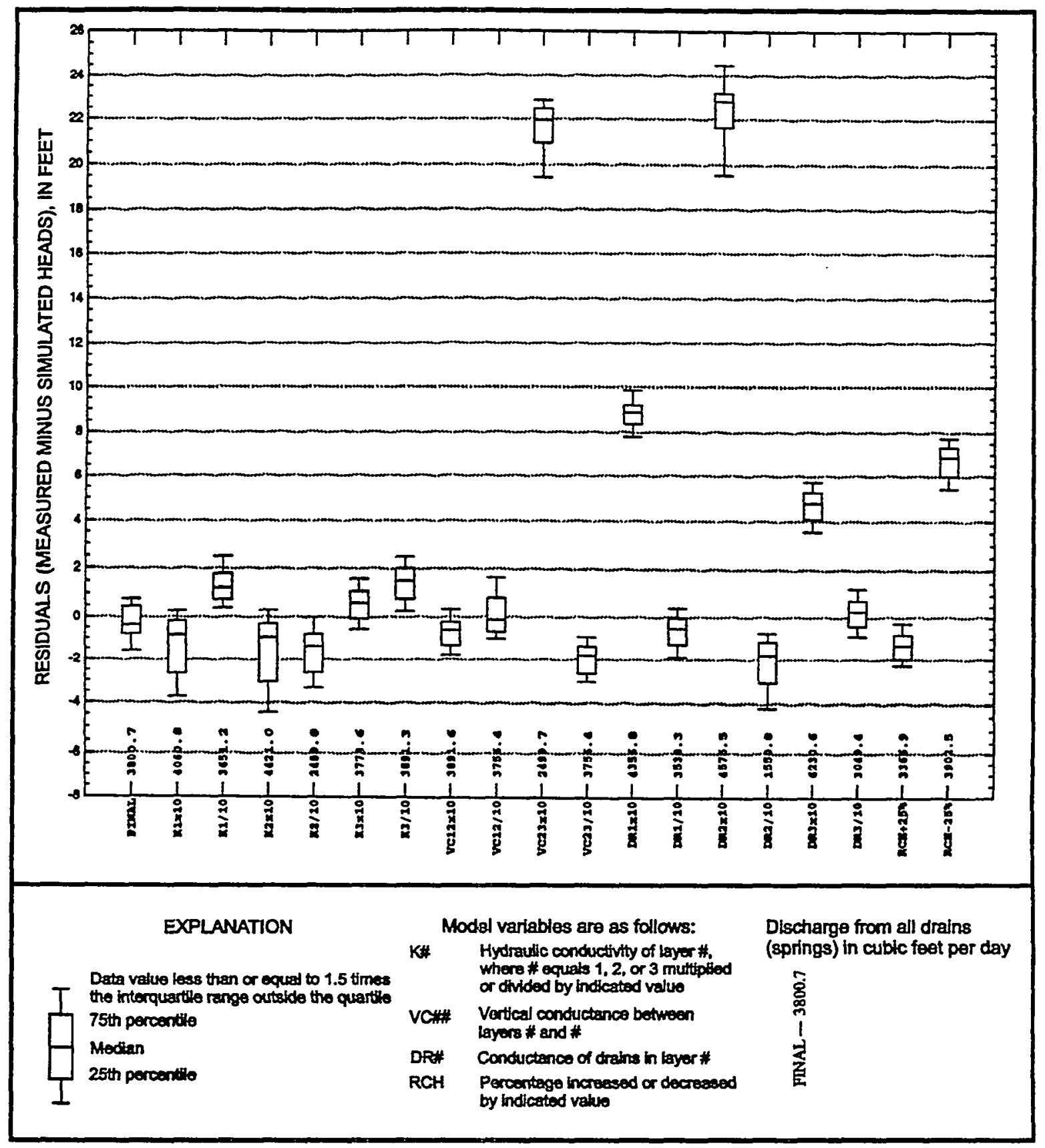

Figure 20. Statistical distribution of the difference between measured and simulated heads for sensitivity tests of the groundwater flow model. Values are given in feet. To convert to meters, multiply by 0.305 . 


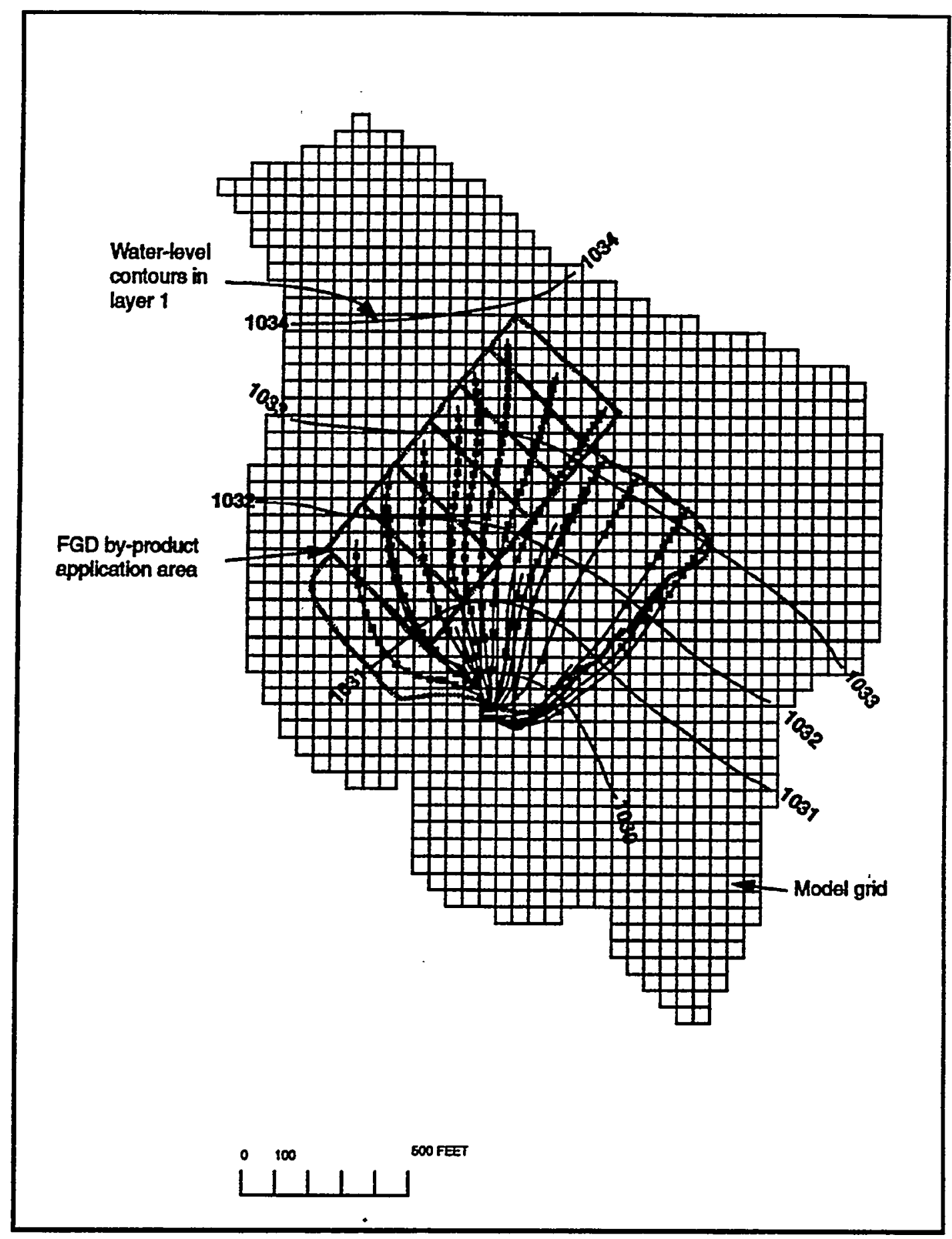

Figure 21. Particle pathlines within FGD by-product application area. Values are given in feet. To convert to meters, multiply by 0.305 . 


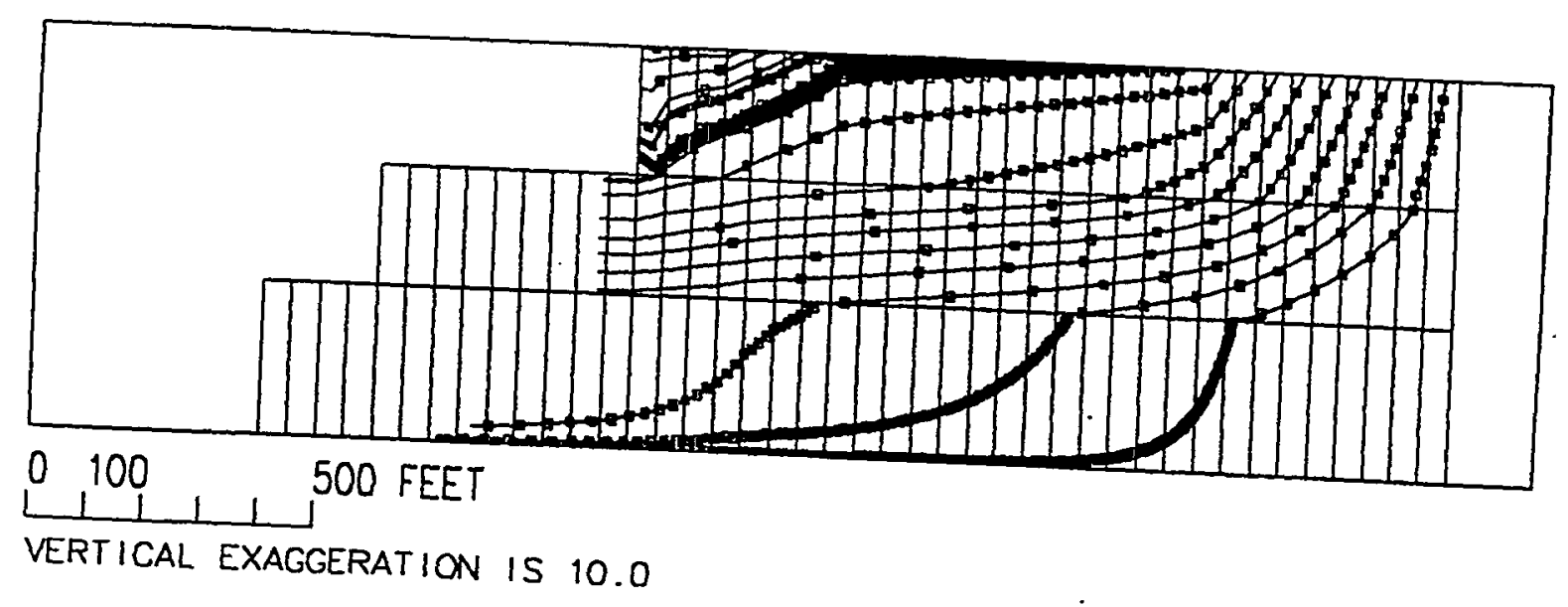

Figure 22. Cross sectional view of particle paths along column 18. Values are given in feet. To convert to meters, multiply by 0.305 . 
The particle tracking results confirm the assertions of the conceptual model. Groundwater flow paths in layer 1 are vertical in the recharge area (the northern part of the study area), whereas they are predominantly horizontal throughout the test of the modeled area. During reclamation, six test watersheds were constructed by use of clay and spoil as a base. These materials have low hydraulic conductivity and were intentionally placed there to limit downward migration of water. The particle tracking results show the influence of the clay and spoil in this area. The water that does penetrate the clay and spoil travels in a southerly, horizontal direction and discharges at springs at tile base of layer 1 (Figure 19).

There are several limitations to the numerical model constructed for this study. This model was designed to help in understanding the groundwater flow system and to describe how water potentially affected by FGD by-product leachate moves through the aquifers. However, the simulated flow directions and rates depend on the input variables, most of which were observed at specific points throughout the modeled area. Hydraulic conductivities, for example, were assigned to each of the cells of the model. However, measurements were available for wells (points) within only 14 of the cells. Therefore, the modeler must assume a certain level of homogeneity which,as stated previously, is not representative of rocks in this geologic setting For purpose of this model (to describe flow directions and rates of flow), the assumption should not cause significant deviations from what is actually occurring. Finally, because spring flows from individual aquifers could not be measured, the model may be biased towards the initial conceptualization. Discharge from springs from each layer was estimated on the basis of personal observations.

\subsubsection{Results}

The results of this study provide a qualitative and quantitative evaluation of the effect of FGD by-product on soil, plant, surface water and groundwater quality. The groundwater model, especially, has been designed to enhance understanding of the complexity of the groundwater flow system at the Fleming Site and to develop preliminary concepts about the potential effects of the FGD by-products on water quality when it is used as a surface amendment.

\subsubsection{Soil and Plant Responses to FGD Amendments Applied to Mine Spoil}

Soil cores collected in June, 1995, eight months after reclamation, showed that the $\mathrm{pH}$ at the surface of the profiles in the six small watersheds was, in all three treatments, near or slightly above neutral (Figure 23). (For review of treatment descriptions, see Figure 9 and section 


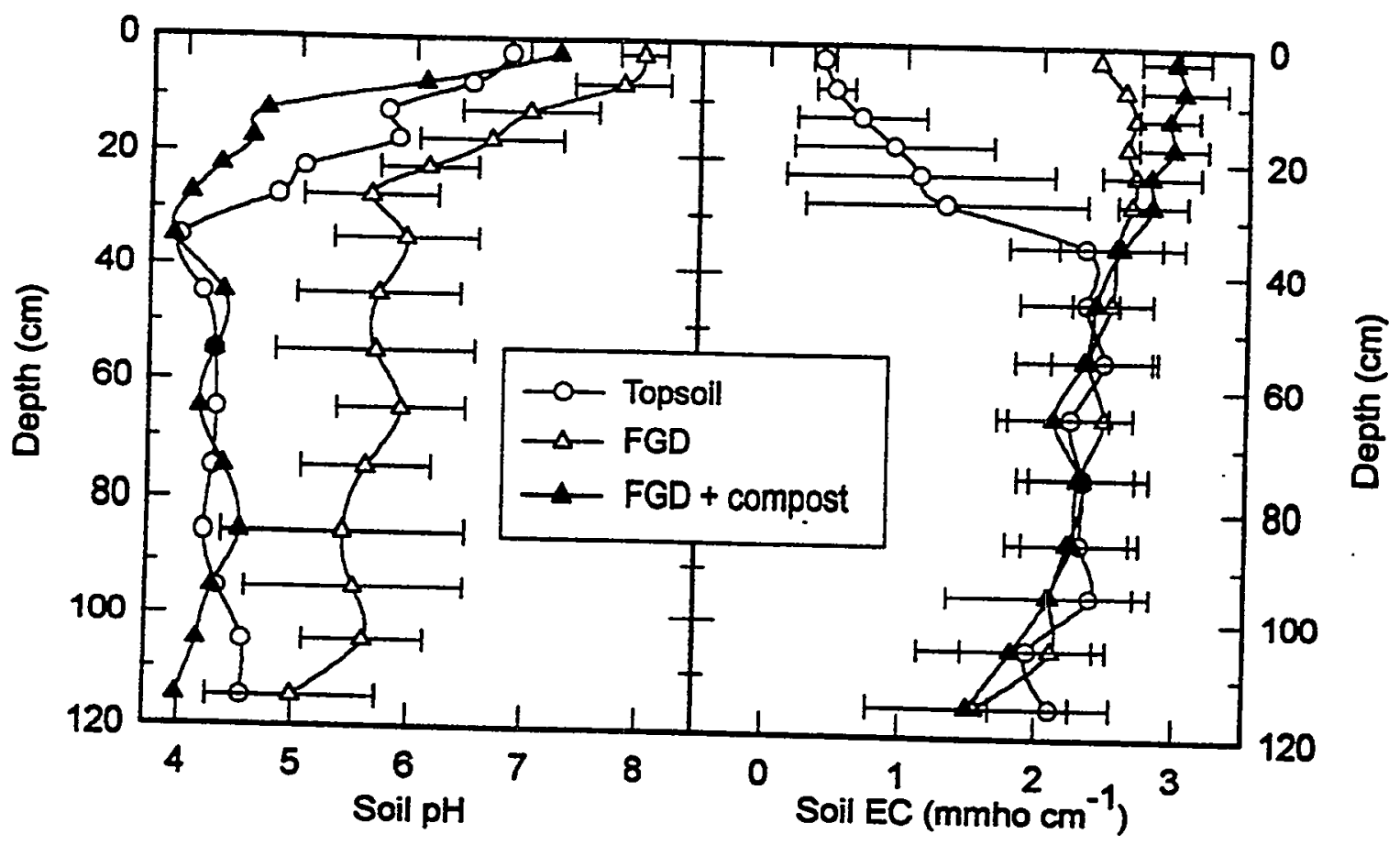

Figure 23. Distribution of soil $\mathrm{pH}$ and electrical conductivity (EC) in the Fleming spoil profile eight months after reclamation with topsoil material, FGD and FGD + compost. (Error bars indicate plus and minus one standard deviation). 
3.3.1.1). There was little indication of any increase in $\mathrm{pH}$ below the depth to which treatments were applied. In all three profiles $\mathrm{pH}$ in the subjacent, nonamended spoil remained much lower than in the surface layer. The $\mathrm{pH}$ of topsoil and FGD+compost profiles decreased to the range 4 to 4.5. In the FGD profile, however, $\mathrm{pH}$ was somewhat higher, in the range 5 to 6 . The reasons for the higher $\mathrm{pH}$ with FGD are not clear. Although the gypsum component of FGD is expected to be more mobile than agricultural limestone (Sumner et al., 1986), downward transport of $\mathrm{Ca}^{2+}$ and $\mathrm{SO}_{4}{ }^{2-}$ would not be expected to have such a large influence on $\mathrm{pH}$. Furthermore, concentrations of Ca and $\mathrm{S}$ were not increased in spoil below the depth of FGD incorporation indicating little if any downward movement of these constituents. If the $\mathrm{pH}$ increase was due to the FGD, the FGD+compost treatment would also be expected to show a similar $\mathrm{pH}$ response with depth. It remains to be seen if this $\mathrm{pH}$ difference persists in subsequent sampling.

Soluble salt concentrations, as measured by electrical conductivity, in the surface layer of topsoil were much lower than in the FGD or FGD+compost amended minespoil (Figure 23). Although FGD alone did not increase soluble salt concentrations, the addition of $112 \mathrm{Mg} / \mathrm{ha}$ of yard waste compost did increase salt concentrations slightly. Below the treated layers there were no differences among the three treatments with respect to soluble salts. The salt burden in the FGD treated depth was due to the gypsum component of the FGD as indicated by the large increases in water soluble $\mathrm{Ca}$ and $\mathrm{S}$ concentrations (Figure 24). In contrast to what occurred with FGD application to agricultural soils (see Chapter 2), Ca and S concentrations remained elevated at the spoil surface. There was also little indication of downward movement of these elements. The much slower movement of $\mathrm{Ca}$ and $\mathrm{S}$ in the spoil than in the agricultural soil is apparently due to limited percolation in the spoil. The minespoil was placed over the clay in several 10 to $15 \mathrm{~cm}$ lifts with heavy earth-moving pans. This caused extreme compaction and total loss of any structure in the spoil material.

Concentrations of water soluble $\mathrm{Al}$ and $\mathrm{Fe}$ at the top of the soil profiles were relatively low in all treatments with little apparent difference among them (Figure 25). However, in the profile layer immediately below the depth of treatment incorporation, the FGD+compost treatment caused a large increase in water soluble $\mathrm{Al}$ and $\mathrm{Fe}$ concentrations. This increase did not occur with the FGD alone amendment. Additions of organic matter to acidic soil or spoil environments are generally associated with decreased rather than increased concentrations of soluble $\mathrm{Al}$ and $\mathrm{Fe}$. This apparent contradiction may be due to movement of soluble organic ligands added in the compost. Aluminum and Fe form stable complexes with organic ligands and thus would have been transported downward as the soluble organic ligands were leached 


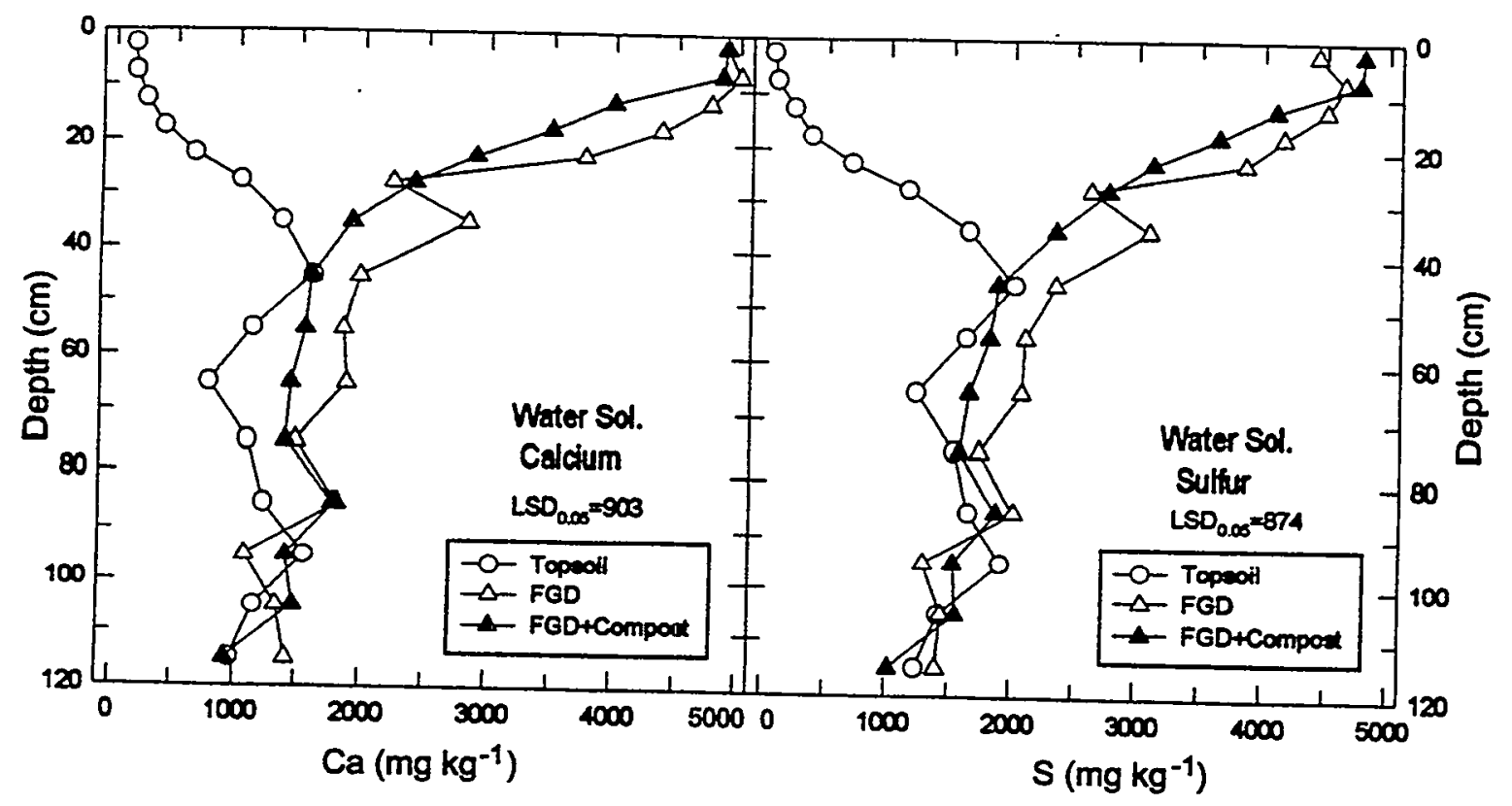

Figure 24. Distribution of water soluble $\mathrm{Ca}$ and $\mathrm{S}$ in the Fleming spoil profile eight months after reclamation with topsoil, FGD and FGD+compost. 


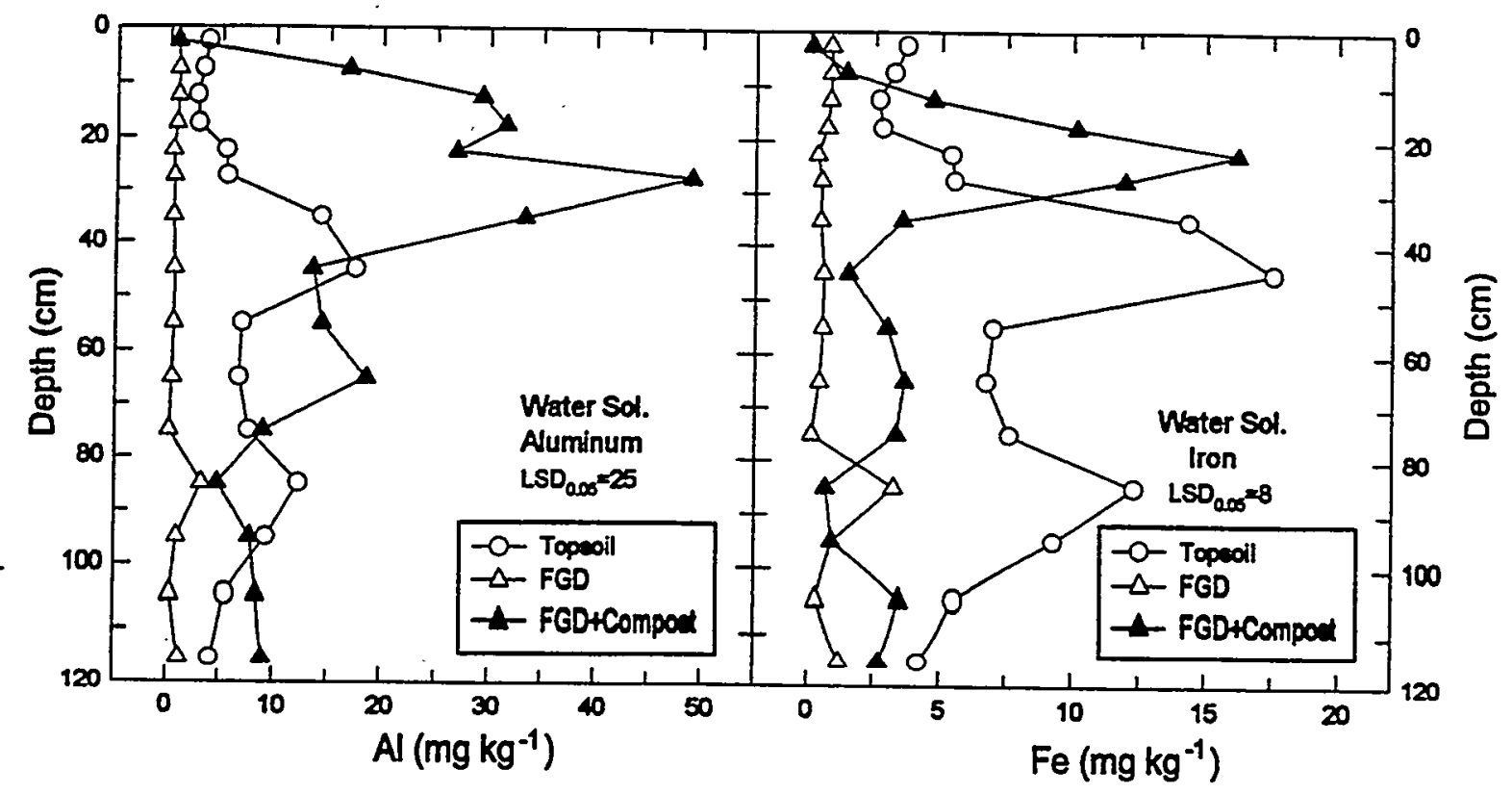

Figure 25. Distribution of water soluble $\mathrm{Al}$ and $\mathrm{Fe}$ in the Fleming spoil profile eight months after reclamation with topsoil, FGD and FGD+compost. 
from the application zone. In the layer immediately below the nonplowed spoil, percolation of water would be greatly inhibited and the ligands and associated metals would accumulate at the interface between the plowed surface spoil and compacted subsurface.

Water soluble concentrations of trace elements were largely unaffected by the reclamation treatments. The notable exception was the increase in surface concentrations of $B$ which resulted from the FGD and FGD+compost treatments (Figure 26). Boron was present in the FGD (Table 16) and is also relatively soluble. Thus it is not surprising that spoil concentrations were increased.

With more vigorous acid extraction (Mehlich3) there were differences among the surface treatments with respect to several trace elements (Table 28). In addition to the increases in $B$ discussed above, $\mathrm{Cr}$ and $\mathrm{Se}$ were the only trace elements which appear to have been increased by FGD application. While these increases were measurable, they were of a very small magnitude. While $\mathrm{pH}$ decreased with depth in all three treatments, there was no difference among the treatments. Barium was apparently decreased by FGD which is likely due to the insolubility of $\mathrm{BaSO}_{4}$. The differences in $\mathrm{Ni}$ and $\mathrm{Zn}$ concentrations appear to be related to spoil versus soil differences rather than to the FGD. There is evidence, however, that Ni was increased by compost (compost contained a large amount of $\mathrm{Ni}$ ) and its downward movement may have been facilitated by the same mechanism discussed for $\mathrm{Al}$ and Fe. Extractable phosphorous concentrations were much lower in the spoil than in the topsoil. Because equal amounts of $\mathrm{P}$ fertilizer were added to all watersheds, the reduction in $\mathrm{P}$ appears to be due to the FGD. It is possible that the large amount of $\mathrm{Ca}$ added with the FGD could cause $P$ solubility to decrease due to precipitation of relatively insoluble calcium phosphates.

Dioxin concentrations in the various FGD samples and compost and in the minespoil is shown in Table 29. Concentrations were below 5 parts per trillion toxicity equivalence units. The actual concentrations may have been less because in the calculation of the toxicity equivalence values, the use of the detection limit is required even if a nondetect is encountered. The 5 parts per trillion level is considered to be within the range of normal or baseline levels for environmental samples.

\subsubsection{Vegetative Growth}

Establishment of vegetative cover was successful on all reclamation treatments, with $100 \%$ vegetative cover on almost all areas of all watersheds throughout the summer of 1995. 


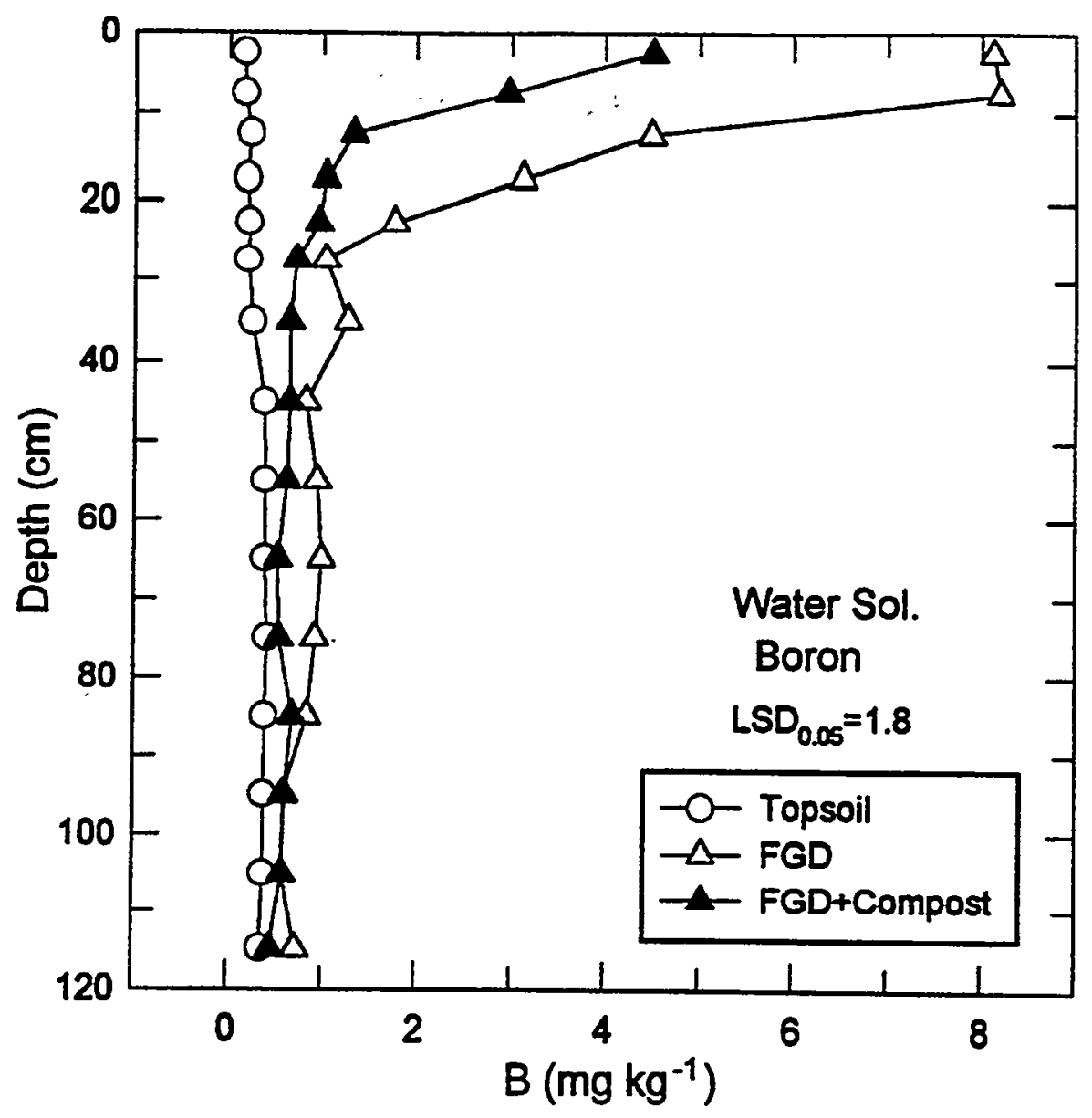

Figure 26. Distribution of water soluble $B$ in the Fleming spoil profile eight months after reclamation with topsoil, FGD and FGD+compost. 
Table 28. Mehlich3 extractable concentrations of trace elements in Fleming spoil reclaimed with topsoil, FGD, and FGD+compost.

\begin{tabular}{|c|c|c|c|c|c|c|c|c|c|c|c|}
\hline \multirow{2}{*}{$\begin{array}{l}\text { Depth } \\
\text { (cm) }\end{array}$} & \multicolumn{11}{|c|}{ Concentration $(\mathbf{m g} / \mathrm{L})$} \\
\hline & As & $\mathrm{B}$ & $\mathrm{Ba}$ & $\mathrm{Cd}$ & $\mathrm{Cr}$ & $\mathrm{Cu}$ & $\mathrm{Ni}$ & $\mathbf{P}$ & $\mathrm{Pb}$ & $\mathrm{Se}$ & $\mathbf{Z n}$ \\
\hline & \multicolumn{11}{|c|}{ Topsoil } \\
\hline $0-10$ & $<0.04$ & 1.67 & 11.02 & 0.073 & 0.159 & 2.26 & 2.21 & 45.0 & 3.84 & 0.06 & 3.34 \\
\hline $10-20$ & $<0.04$ & 1.38 & 7.44 & 0.047 & 0.189 & 2.38 & 3.32 & 21.4 & 2.16 & $<0.1$ & 3.80 \\
\hline \multirow[t]{2}{*}{$20-30$} & $<0.04$ & 1.50 & 2.88 & 0.056 & 0.262 & 3.06 & 5.03 & 34.9 & 1.09 & $<0.1$ & 6.27 \\
\hline & \multicolumn{11}{|c|}{ FGD } \\
\hline $0-10$ & $<0.04$ & 26.66 & 3.41 & 0.097 & 0.564 & 4.22 & 5.91 & 9.3 & 3.42 & 0.29 & 9.55 \\
\hline $10-20$ & $<0.04$ & 5.61 & 1.30 & 0.059 & 0.307 & 3.14 & 7.28 & 16.6 & 1.31 & $<0.1$ & 8.60 \\
\hline \multirow[t]{2}{*}{$20-30$} & $<0.04$ & 4.36 & 1.34 & 0.069 & 0.359 & 3.77 & 7.61 & 25.1 & 1.36 & $<0.1$ & 8.57 \\
\hline & \multicolumn{11}{|c|}{ FGD + Compost } \\
\hline $0-10$ & $<0.04$ & 21.17 & 4.53 & 0.125 & 0.470 & 3.17 & 6.42 & 18.8 & 4.23 & 0.47 & 13.6 \\
\hline $10-20$ & $<0.04$ & 6.20 & 1.64 & 0.082 & 0.338 & 3.06 & 9.55 & 18.4 & 1.55 & $<0.1$ & 14.3 \\
\hline $20-30$ & $<0.04$ & 3.97 & 1.37 & 0.086 & 0.407 & 6.13 & 11.4 & 44.0 & 1.37 & $<0.1$ & 12.8 \\
\hline $\operatorname{LSD}_{0.05}$ & ns & 5.87 & 2.28 & ns & 0.128 & ns & 2.94 & ns & 1.16 & 0.25 & 5.1 \\
\hline
\end{tabular}


Table 29. Dioxin concentrations in FGD, compost, FGD/compost mixes and minespoil applied to the Fleming site (7/29/94).

\begin{tabular}{lc}
\hline \hline Sample & $\begin{array}{c}\text { Dioxin toxicity equivalents } \\
\text { (parts per trillion) }\end{array}$ \\
\hline & \\
PFBC $^{b}$ & 0.53 \\
AFBC $^{c}$ & 0.48 \\
Compost & \\
PFBC/compost mix $^{d}$ & 4.33 \\
AFBC/compost mix & 2.83 \\
Minespoil & 3.08 \\
\end{tabular}

aCalculated based upon a full scan of various dioxin congeners according to a worksheet procedure prescribed by the Ohio Environmental Protection Agency (Columbus, OH). bPFBC, pressurized fluidized bed combustion FGD by-product obtained from the American Electric Power plant (Brilliant, $\mathrm{OH}$ ). cAFBC, atmospheric fluidized bed combustion FGD by-product obtained from the General Motors facility (Pontiac, MI). dCompost material was obtained from Earth-N-Wood (North Canton, $\mathrm{OH})$.

eRepresentative minespoil was obtained from the surface of the Fleming site located near Dover, $\mathrm{OH}$ ). 
Establishment was more rapid and growth was more vigorous on the topsoil treated watersheds. Topsoiled watersheds produced over twice as much plant biomass than did either the FGD or the FGD+compost treatments (Figure 27). Much of the first year difference in biomass production was due to very vigorous winter wheat growth on the topsoiled watershed. Measurements of biomass productivity will continue in subsequent years to assess the longterm ability of the various treatments to maintain vegetative growth.

Although topsoil is clearly a better medium for plant growth than the minespoil material, amendment with FGD did permit establishment of good vegetative cover on this otherwise toxic material. The high soluble salt concentration in the spoil material may account in large part for the less vigorous growth than on topsoil. It is expected that over time these salts will be leached downward. When this occurs, and if the spoil begins to develop other properties of a natural soil, plant growth may begin to approach that of the topsoil.

Vegetation grown directly on minespoil treated with FGD or FGD+compost had larger foliar concentrations of $\mathrm{Al}, \mathrm{Fe}$, and $\mathrm{B}$ concentrations than that grown on topsoil (Table 30). The tendency for compost to increase foliar Al concentrations reflects the increase in soluble Al in the profile of this watershed. Aluminum is not readily transported from plant roots, so it is likely that differences in Al concentrations in the roots would be even greater than what was observed in the above ground tissue. These differences in $\mathrm{Al}$ and $\mathrm{Fe}$, together with the differences in soluble salt concentrations, undoubtably contributed to the smaller biomass production on the FGD and FGD+compost treated spoil. While B concentrations were increased with application of FGD, these concentrations are not large enough to be considered toxic for most species (Marschner, 1995) and B toxicity symptoms were not observed in plant tissues.

\subsubsection{Surface Water Quality and Hydrology}

All three reclamation treatments applied to the six small watersheds (see Figure 9) improved surface water quality. Prior to reclamation, surface water $\mathrm{pH}$ was in the range of 2 to 3 with soluble $\mathrm{Al}$ concentrations as high as $120 \mathrm{mg} \mathrm{L}^{-1}$ (Figures 28 and 29). All three reclamation treatments increased surface runoff water $\mathrm{pH}$ to the range 7 to 8 , although the FGD treatments tended to produce runoff water with slightly higher $\mathrm{pH}$ than did the topsoil. Changes in soluble Al showed just the opposite result. All three treatments decreased soluble $\mathrm{Al}$ to less than 0.3 $\mathrm{mg} / \mathrm{L}$. This was expected given the increased $\mathrm{pH}$ and low solubility of $\mathrm{Al}$ at near neutral $\mathrm{pH}$. 


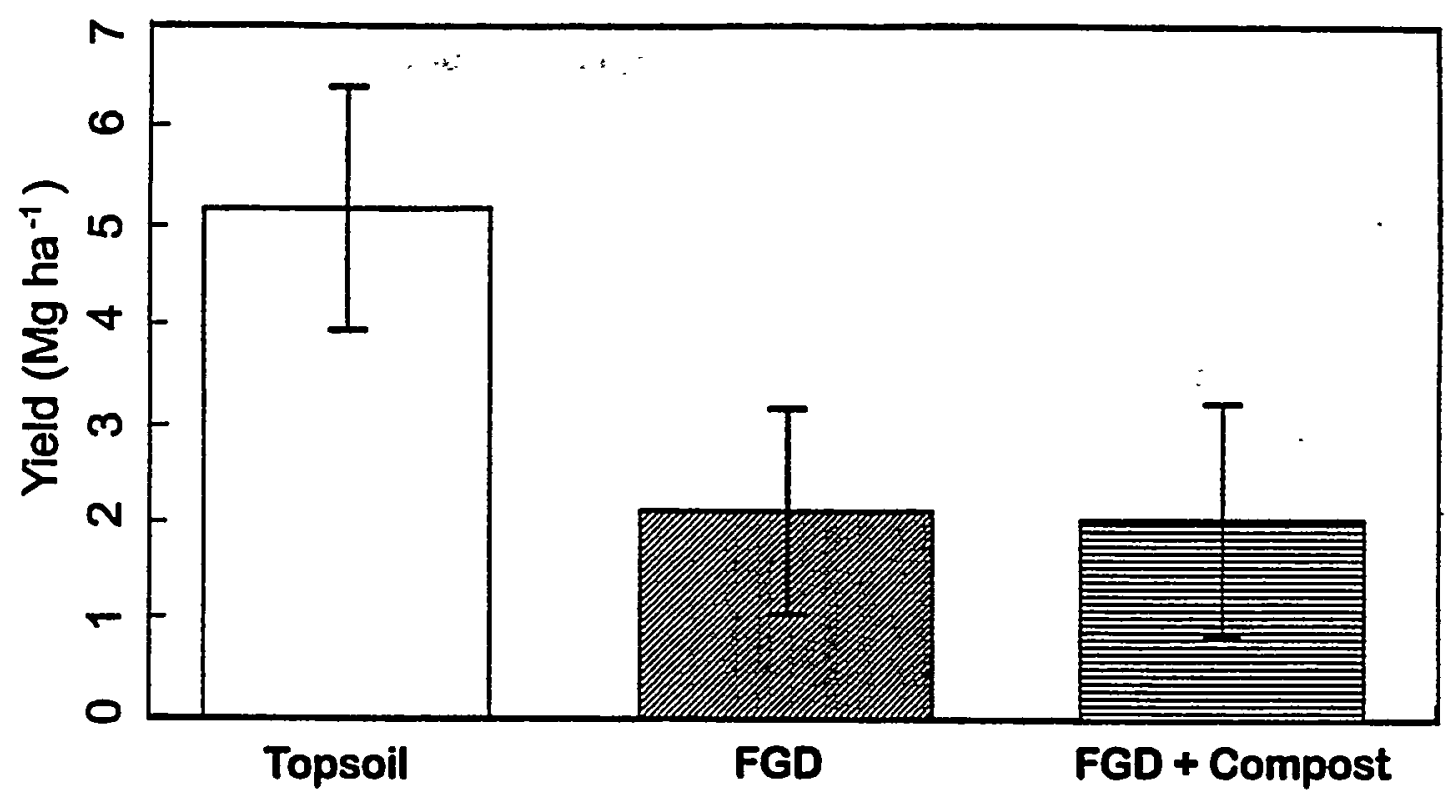

Figure 27. Vegetative biomass production in 1995 on Fleming minespoil reclaimed with topsoil, FGD and FGD+compost. 
Table 30. Tissue composition of vegetation grown on minespoil reclaimed with topsoil, FGD, and FGD+compost.

\begin{tabular}{lccccc}
\hline & \multicolumn{5}{c}{ Tissue concentration } \\
\cline { 2 - 6 } Treatment & $\mathrm{Ca}$ & $\mathrm{S}$ & $\mathrm{Al}$ & $\mathrm{Fe}$ & $\mathrm{B}$ \\
\hline & & & & & \\
& & & & & \\
Topsoil & 0.20 & 0.10 & 57 & 65 & 5.6 \\
FGD & 0.24 & 0.15 & 145 & 170 & 45.3 \\
FGD+Compost & 0.19 & 0.17 & 204 & 168 & 39.9 \\
& & & & & \\
LSD & $\mathrm{ns}$ & $\mathrm{ns}$ & 100 & 62 & 9.8 \\
\hline \hline
\end{tabular}

Calcium and sulfur concentrations in surface runoff water were clearly larger from the FGDtreated watersheds than from the topsoiled watersheds (Figures 30 and 31). This increased Ca and $S$ load can be attributed to the much larger solubility of gypsum (a major component of FGD) than limestone. As soluble gypsum is removed, the runoff and downward leaching will be decreased. In addition, as vegetative cover becomes more vigorous, it is expected that this will also decrease the differences in soluble $\mathrm{Ca}$ between the FGD and topsoil treatments.

Surface reclamation treatments had similar effects on tile flow water quality as were observed with the surface runoff. Tile flow was obtained from the tile outlet installed at the downslope end of each watershed. Its quality is impacted as it percolates through the treated surface layer and the underlying spoil to reach the impermeable clay layer which then forces it laterally to the tile outlet. Tile water $\mathrm{pH}$ was near neutral (Figure 32) and Al concentrations were generally less than $3 \mathrm{mg} \mathrm{L}^{-1}$ (Figure 33) from all watersheds. Tile water from FGD treated watersheds (Figures 34 and 35) had larger $\mathrm{Ca}$ and $\mathrm{S}$ concentrations than the topsoiled watersheds. These differences again reflect the large addition of gypsum in the FGD amendments. 


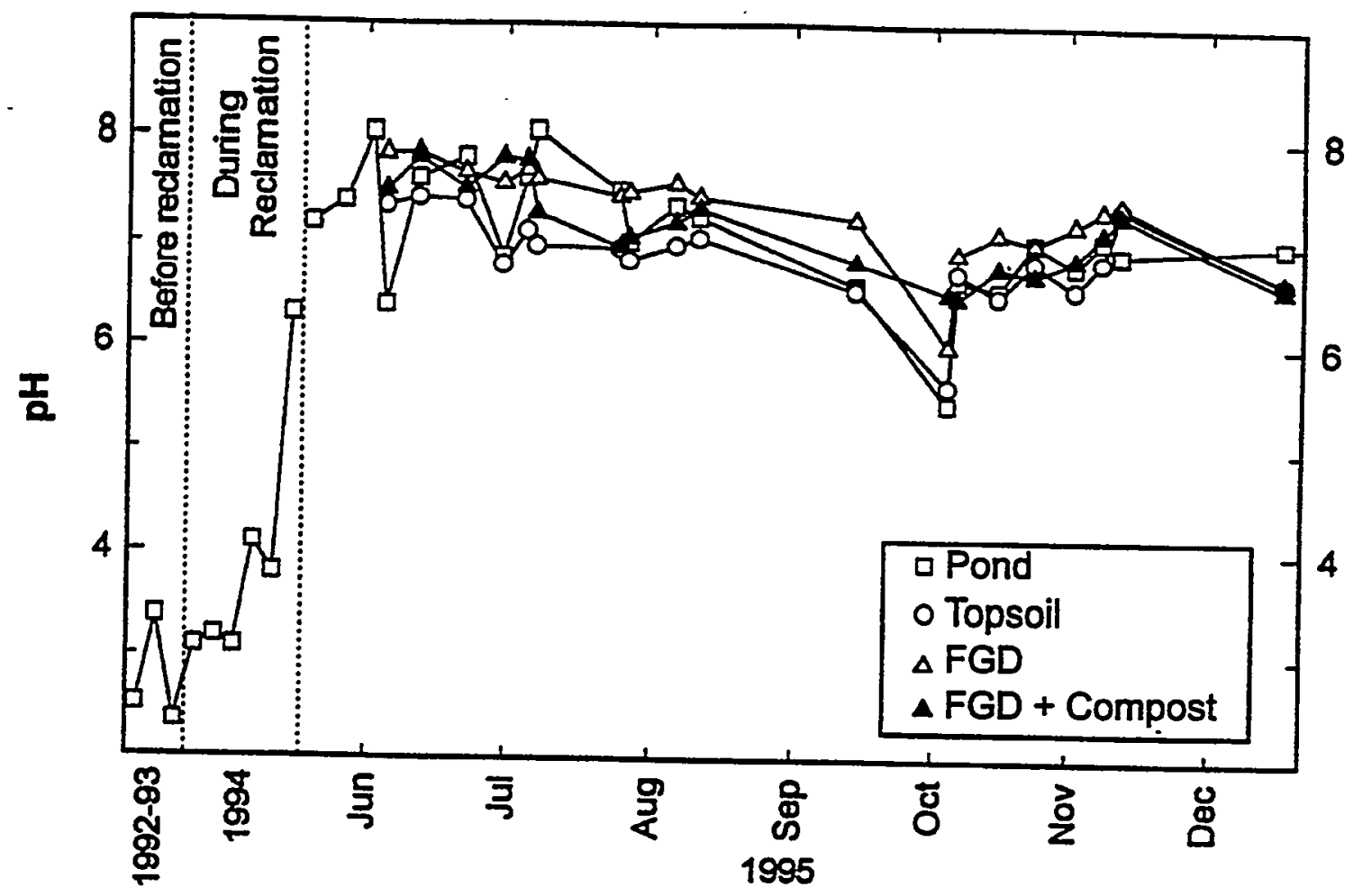

Figure 28. pH of surface water runoff from Fleming spoil reclaimed with topsoil, FGD and FGD+compost. 


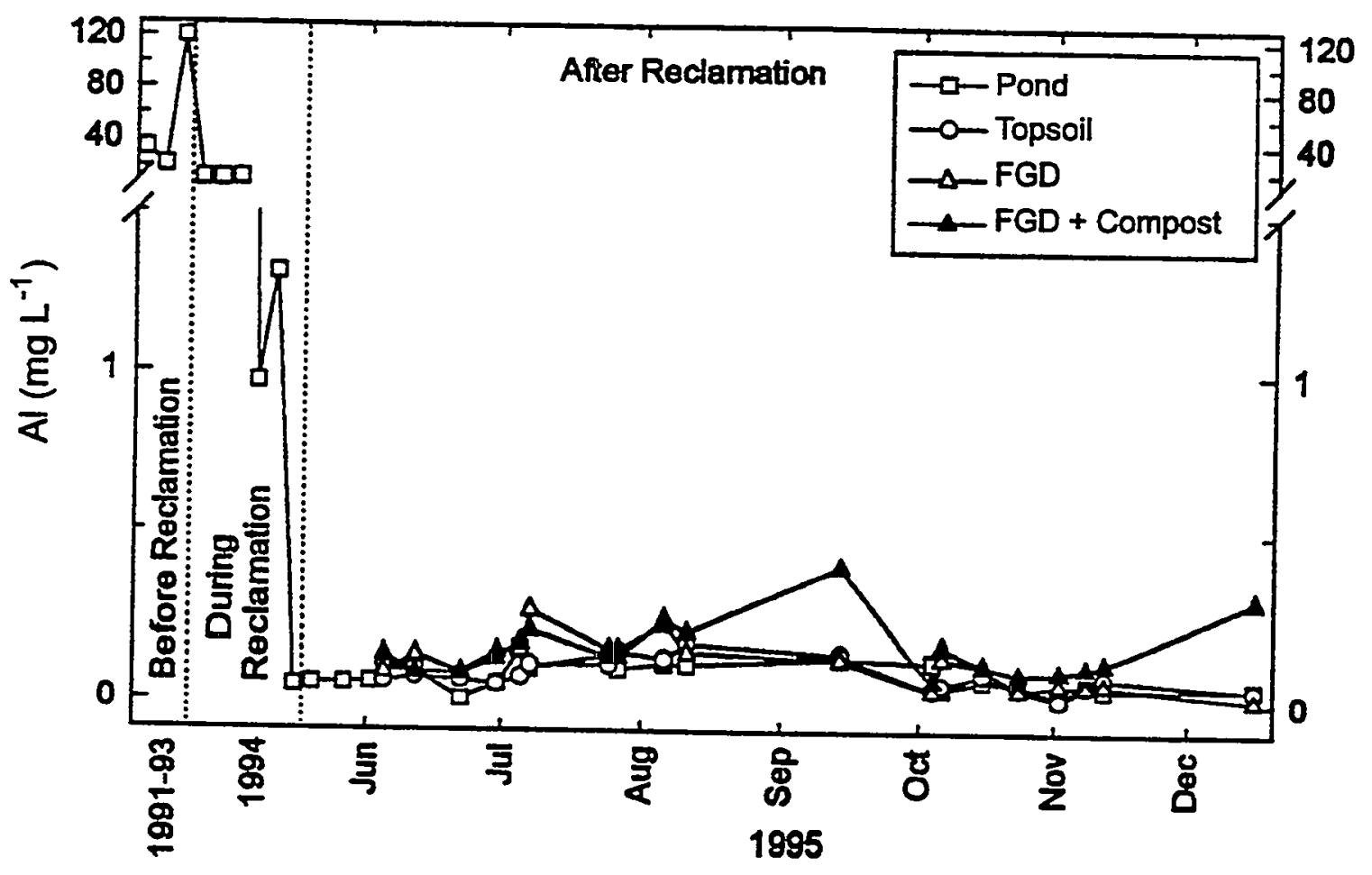

Figure 29. Dissolved Al concentrations in surface water runoff from Fleming spoil reclaimed with topsoil, FGD and FGD+compost. 

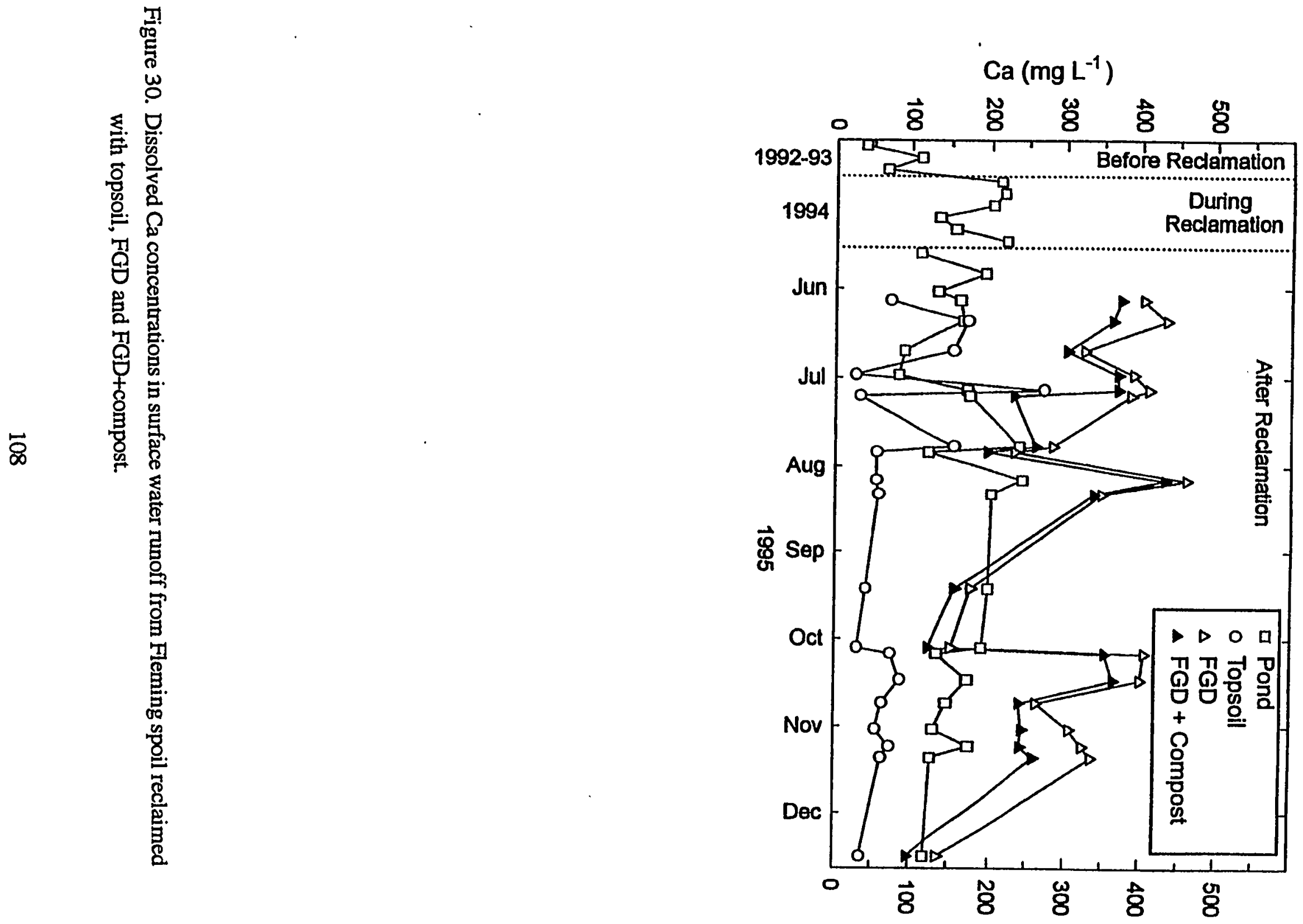


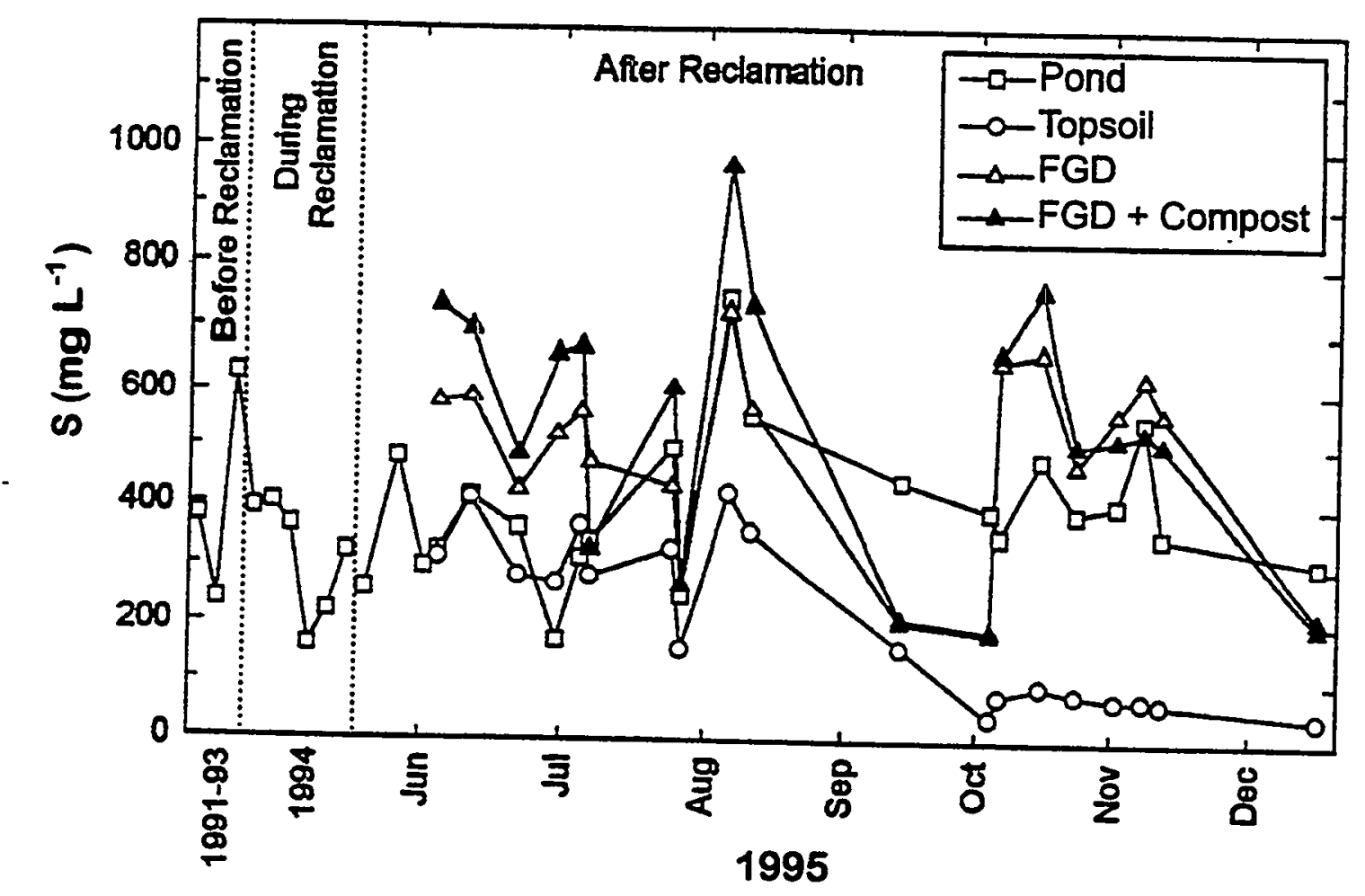

Figure 31. Dissolved $\mathrm{S}$ concentrations in surface water runoff from Fleming spoil reclaimed with topsoil, FGD and FGD+compost. 


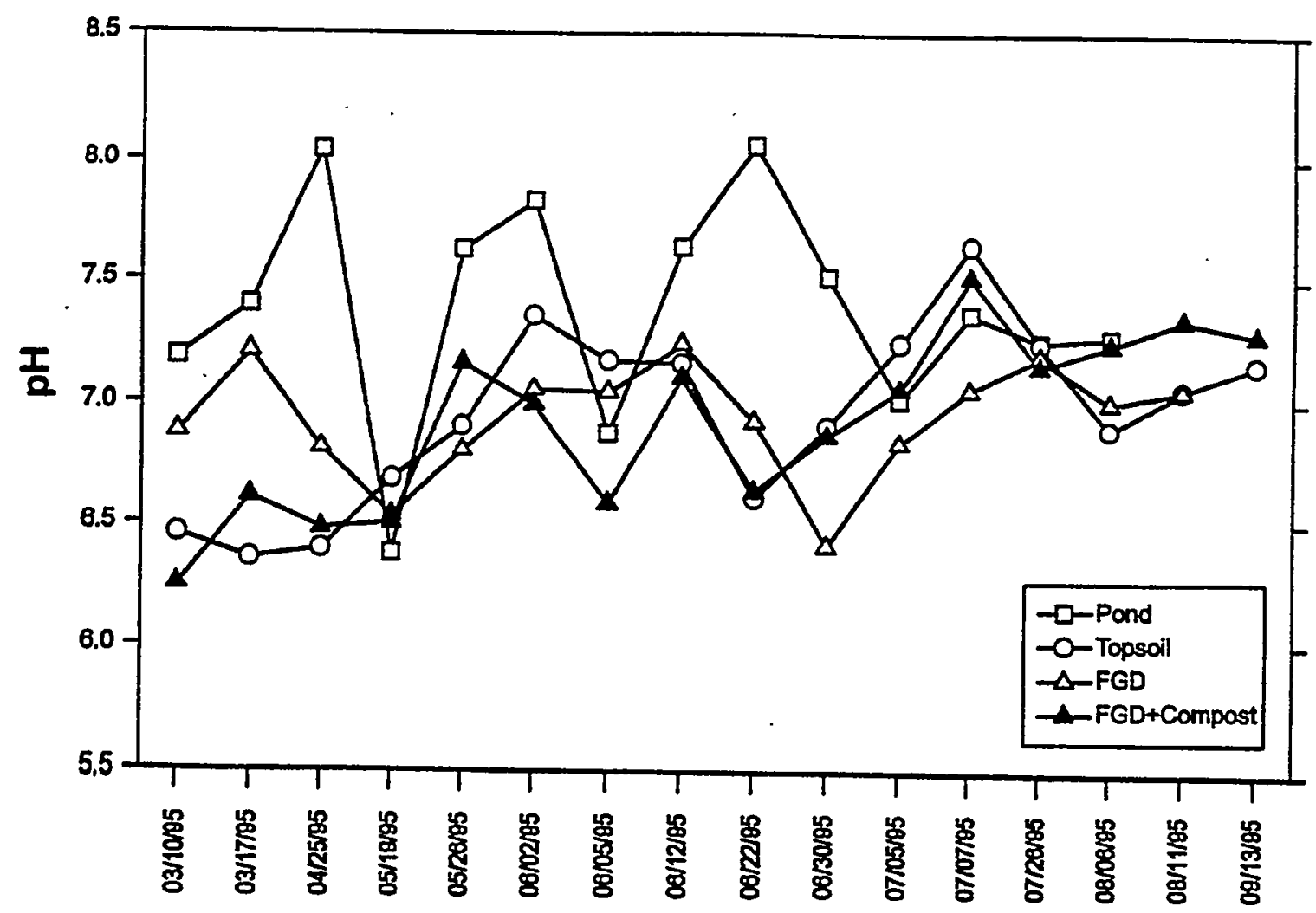

Figure 32. $\mathrm{pH}$ of tile flow water from Fleming spoil reclaimed with topsoil, FGD and FGD+compost and in an adjacent pond receiving flow from the Fleming site. 


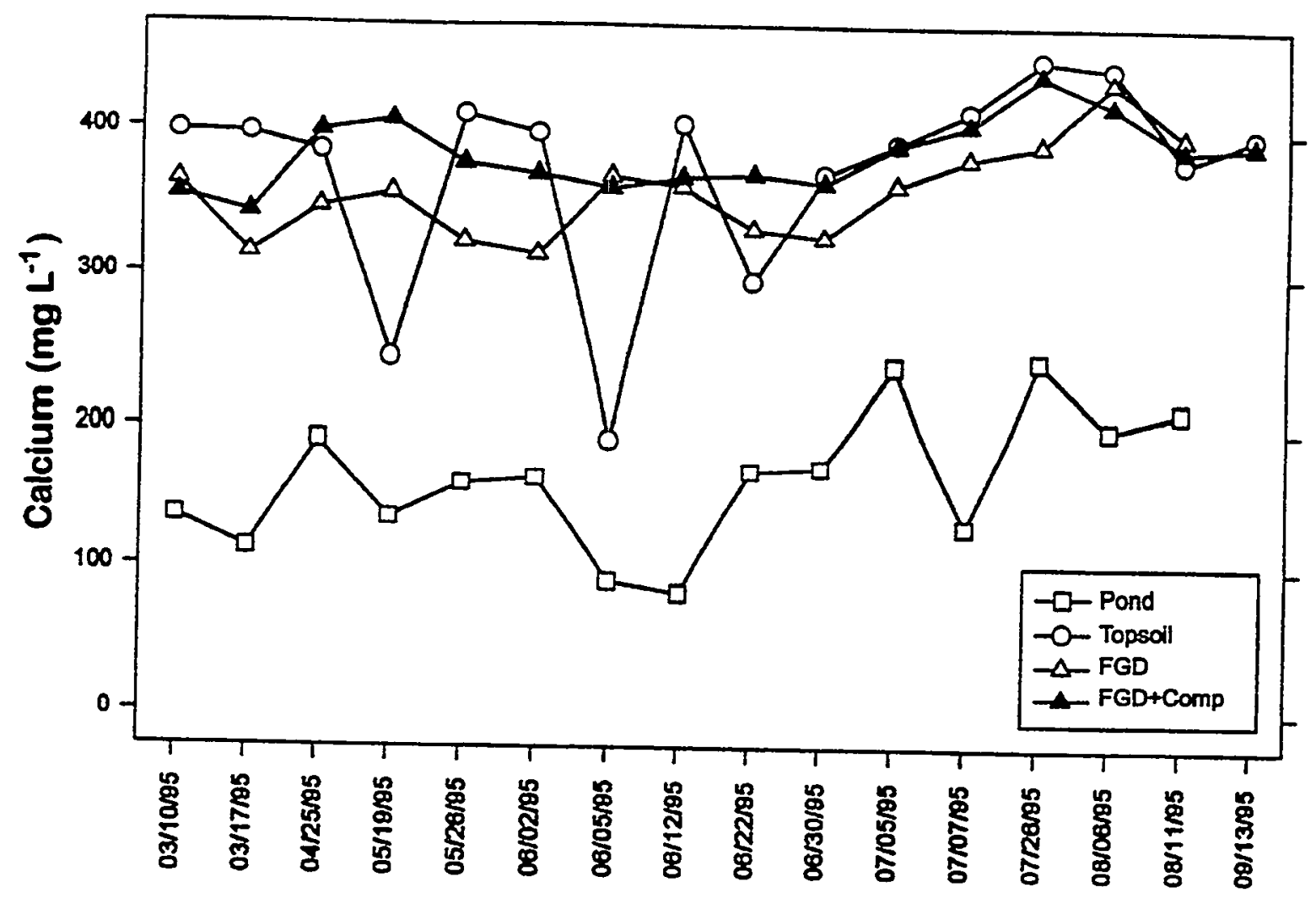

Figure 33. Dissolved Al concentrations in tile flow water from Fleming spoil reclaimed with topsoil, FGD and FGD+compost and in an adjacent pond receiving flow from the Fleming site. 


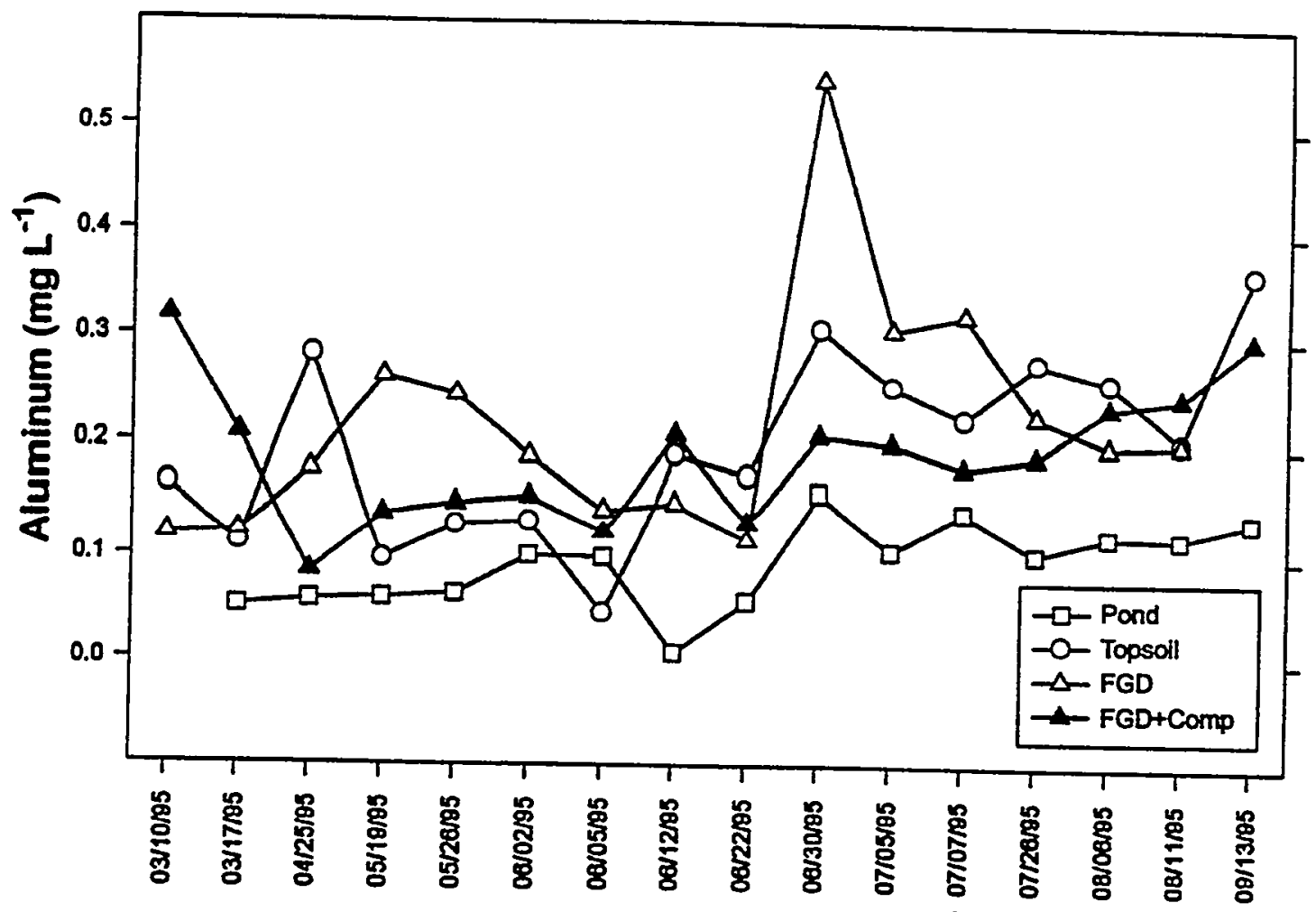

Figure 34. Dissolved Ca concentrations in tile flow water from Fleming spoil reclaimed with topsoil, FGD and FGD+compost and in an adjacent pond receiving flow from the Fleming site. 


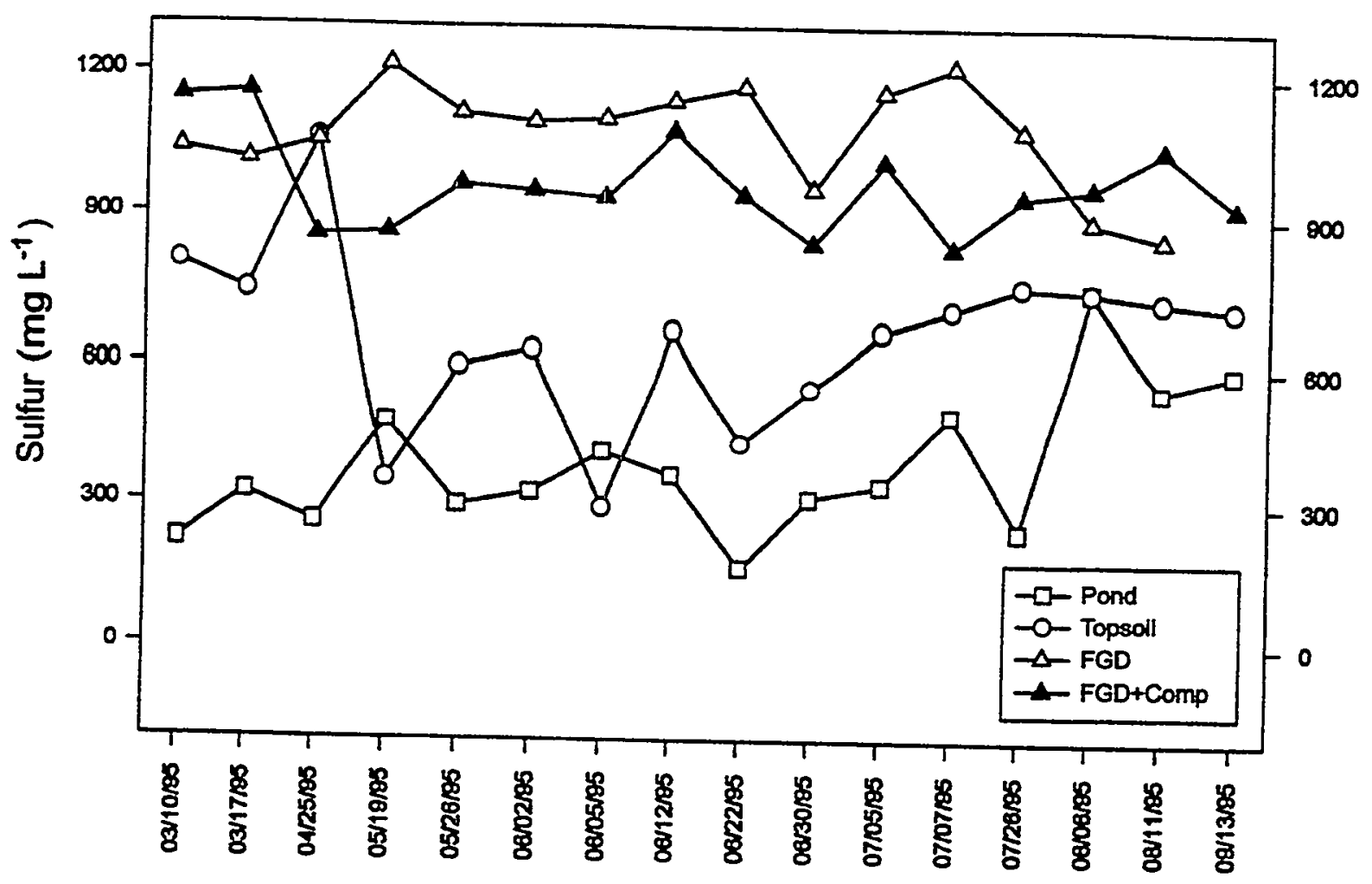

Figure 35. Dissolved S concentrations in tile flow water from Fleming spoil reclaimed with topsoil, FGD and FGD+compost and in an adjacent pond receiving flow from the Fleming site. 
With the exception of boron, trace metal concentrations in surface water, tile water, and pond water generally remained very low and unaffected by the reclamation treatments (Tables 31 and 32). Mean concentrations of $\mathrm{As}, \mathrm{Ba}, \mathrm{Cd}, \mathrm{Cr}, \mathrm{Cu}$, and $\mathrm{Se}$ were below detection limits or below primary drinking water standards. Although occasional samples had higher concentrations of these regulated metals, these could not be ascribed to the FGD or compost as all three reclamation practices gave values generally in the same range.

Boron was the only trace element which was clearly increased in surface runoff and tile water by the addition of FGD (Tables 31 and 32). Boron poses no threat to vertebrate or invertebrate organisms. It is an essential plant nutrient and is of interest here because of its potential for phytotoxicity at elevated concentrations. Boron is associated with the coal ash component of the FGD. Therefore its concentration in the by-product is a function of the coal combusted during FGD production. In this particular FGD material and at the application rates used in this study, boron concentrations were not large enough to cause phytotoxicity. Furthermore, the most phytotoxic $B$ species are also highly water-soluble. Therefore the $B$ enrichment in surface and tile waters indicated that the most phytotoxic $B$ was being removed from the spoil rooting zone.

Infiltration rates of unreclaimed underclay were measured in 1993 prior to land forming and application of soil reclamation treatments (Table 33). The equilibrium infiltration rate was extremely low and ranged from 0.1 to $0.4 \mathrm{~mm} / \mathrm{h}$. The mean infiltration rate was only $0.26 \pm$ $0.12 \mathrm{~mm} / \mathrm{h}$. Small differences in infiltration rate among different watersheds were due to soil variability. The 3-hour cumulative infiltration ranged from $4.7 \mathrm{~mm}$ to $11.0 \mathrm{~mm}$, with a mean of $6.7 \pm 2.3 \mathrm{~mm}$. Because of extremely low infiltration capacity, the unreclaimed site was extremely susceptible to high runoff and soil erosion.

Runoff and soil erosion measurements were also made on the watersheds after reclamation. Results obtained when simulated rainstorm events were applied indicated little difference in runoff rates. Simulated rainfall measurements were also made at different times corresponding to different stages of cover establishment. As one would expect, runoff and soil erosion were very low for measurements made after canopy cover was fully established.

Results for surface runoff were similar to those found using simulated rains when measurements were made for two natural rainstorm events. The first rainstorm event was on June 29, 1995 (Table 34). Mean runoff was $45.1 \%$ for topsoil, 50.0\% for FGD, and $45.1 \%$ for FGD+compost. In contrast to runoff, there were differences in soil erosion. The least soil 
Table 31. Concentrations of trace elements in pond water and in surface runoff water from minespoil reclaimed with topsoil, FGD, and FGD+compost. Values are means and maximum levels of all flow events in the spring and summer of 1995.

\begin{tabular}{|c|c|c|c|c|c|c|c|c|}
\hline \multirow[b]{3}{*}{ Element } & \multicolumn{2}{|c|}{ Pond } & \multicolumn{6}{|c|}{ Surface Water Runoff } \\
\hline & \multirow[b]{2}{*}{ Mean } & \multirow[b]{2}{*}{ Max } & \multicolumn{2}{|c|}{ Topsoil } & \multicolumn{2}{|c|}{ FGD } & \multicolumn{2}{|c|}{ FGD +Compost } \\
\hline & & & Mean & $\operatorname{Max}$ & Mean & $\operatorname{Max}$ & Mean & $\operatorname{Max}$ \\
\hline & & & & & & & & \\
\hline Ag & $<0.05$ & $<0.05$ & $<0.05$ & $<0.05$ & $<0.05$ & $<0.05$ & $<0.05$ & $<0.05$ \\
\hline As & $<0.04$ & 0.083 & $<0.04$ & 0.088 & $<0.04$ & 0.096 & $<0.04$ & 0.069 \\
\hline $\mathbf{B}$ & 0.526 & 1.082 & 0.147 & 1.867 & 3.163 & 6.875 & 1.977 & 3.681 \\
\hline $\mathrm{Ba}$ & 0.023 & 0.040 & 0.017 & 0.032 & 0.012 & 0.020 & 0.010 & 0.017 \\
\hline $\mathrm{Be}$ & $<0.001$ & 0.001 & $<0.001$ & $<0.001$ & $<0.001$ & $<0.001$ & $<0.001$ & 0.001 \\
\hline $\mathrm{Cd}$ & $<0.001$ & 0.001 & $<0.001$ & 0.001 & $<0.001$ & 0.001 & $<0.001$ & 0.002 \\
\hline Co & 0.008 & 0.024 & 0.008 & 0.025 & 0.010 & 0.034 & 0.014 & 0.036 \\
\hline $\mathrm{Cr}$ & 0.003 & 0.009 & 0.003 & 0.010 & 0.005 & 0.012 & 0.005 & 0.011 \\
\hline $\mathrm{Cu}$ & 0.009 & 0.023 & 0.010 & 0.030 & 0.006 & 0.029 & 0.013 & 0.027 \\
\hline Mn & 1.33 & 3.527 & 1.63 & 7.330 & 1.06 & 3.722 & 2.68 & 8.042 \\
\hline Mo & $<0.011$ & 0.030 & $<0.011$ & 0.020 & 0.028 & 0.065 & 0.018 & 0.043 \\
\hline $\mathrm{Ni}$ & 0.023 & 0.053 & 0.014 & 0.075 & 0.015 & 0.101 & 0.035 & 0.091 \\
\hline $\mathrm{Pb}$ & $<0.02$ & 0.048 & $<0.02$ & 0.055 & $<0.02$ & 0.050 & $<0.02$ & 0.055 \\
\hline Se & $<0.09$ & $<0.09$ & $<0.09$ & $<0.09$ & $<0.09$ & $<0.09$ & $<0.09$ & $<0.09$ \\
\hline $\mathrm{Zn}$ & 0.065 & 0.144 & 0.065 & 0.135 & 0.021 & 0.139 & 0.002 & 0.113 \\
\hline
\end{tabular}


Table 32. Concentrations of trace elements in tile flow water from minespoil reclaimed with topsoil, FGD, and FGD+compost. Values are means and maximum levels of all flow events in the spring and summer of 1995.

\begin{tabular}{|c|c|c|c|c|c|c|}
\hline \multirow[b]{2}{*}{ Element } & \multicolumn{2}{|c|}{ Topsoil } & \multicolumn{2}{|c|}{ FGD } & \multicolumn{2}{|c|}{ FGD + Compost } \\
\hline & Mean & $\operatorname{Max}$ & Mean & $\operatorname{Max}$ & Mean & Max \\
\hline & & & & $/ \mathrm{L}$ & & \\
\hline Ag & $<0.05$ & $<0.05$ & $<0.05$ & $<0.05$ & $<0.05$ & $<0.05$ \\
\hline As & $<0.04$ & 0.106 & $<0.04$ & 0.162 & $<0.04$ & 0.095 \\
\hline B & 0.207 & 0.961 & 2.945 & 5.178 & 1.644 & 3.279 \\
\hline $\mathrm{Ba}$ & 0.017 & 0.032 & 0.017 & 0.024 & 0.019 & 0.042 \\
\hline $\mathrm{Be}$ & $<0.001$ & 0.001 & $<0.001$ & 0.002 & $<0.001$ & 0.001 \\
\hline $\mathrm{Cd}$ & $<0.001$ & 0.010 & 0.001 & 0.011 & $<0.001$ & 0.004 \\
\hline Co & 0.223 & 1.216 & 0.416 & 2.258 & 0.341 & 1.266 \\
\hline $\mathrm{Cr}$ & 0.009 & 0.019 & 0.010 & 0.031 & 0.010 & 0.019 \\
\hline $\mathrm{Cu}$ & 0.005 & 0.048 & 0.002 & 0.022 & 0.006 & 0.035 \\
\hline Mn & 23.94 & 124.7 & 32.80 & 198.4 & 34.27 & 122.4 \\
\hline Mo & $<0.011$ & 0.017 & $<0.011$ & 0.033 & $<0.011$ & 0.018 \\
\hline $\mathrm{Ni}$ & 0.738 & 2.935 & 1.195 & 4.246 & 0.940 & 2.986 \\
\hline $\mathrm{Pb}$ & 0.026 & 0.087 & 0.027 & 0.105 & 0.023 & 0.050 \\
\hline $\mathrm{Se}$ & $<0.09$ & 0.100 & $<0.09$ & $<0.09$ & $<0.09$ & $<0.09$ \\
\hline $\mathbf{Z n}$ & 0.139 & 0.192 & 0.382 & 0.204 & 0.131 & 0.217 \\
\hline
\end{tabular}


Table 33. Equilibrium and cumulative infiltration, as determined by the double-ring infiltrometer, in the unreclaimed underclaya.

\begin{tabular}{ccc}
\hline Replication & $\begin{array}{c}\text { Equilibrium infiltration rate } \\
(\mathrm{mm} / \mathrm{h})\end{array}$ & $\begin{array}{c}\text { Cumulative infiltration } \\
(\mathrm{mm} / 3 \mathrm{~h})\end{array}$ \\
\hline & & \\
2 & 0.30 & 7.0 \\
3 & 0.30 & 4.7 \\
4 & 0.30 & 6.0 \\
5 & 0.12 & 11.0 \\
6 & 0.42 & 4.7 \\
& 0.12 & 7.0 \\
Mean & 0.26 & 6.7 \\
Standard deviation & 0.12 & 2.3 \\
\hline \hline
\end{tabular}

${ }^{a}$ Measurements were taken from sites where plans showed the small experimental watersheds were eventually to be built.

erosion was observed for the topsoil treatment. The soil erosion was in the order of FGD > FGD+compost > topsoil and the relative soil erosion was 100:67:46 for FGD, FGD+compost, and topsoil treatments, respectively. There were drastic differences in bedload among the three treatments. Bedload is the amount of sediment that accumulated in the bed or approach prior to passing through the weir. The bedload loss was $32 \mathrm{~kg} / \mathrm{ha}$ for topsoil, $61 \mathrm{~kg} / \mathrm{ha}$ for FGD+compost, and $441 \mathrm{~kg} / \mathrm{ha}$ for the FGD treatment.

Measurements on runoff and soil loss made on a watershed scale for a natural rainstorm event in 1996 are shown in Table 35. Similar to the measurements with simulated rain and the 1995 natural rainstorm event, there were no drastic differences in total runoff. Mean cumulative runoff was 36.0\% of rainfall for topsoil, 37.5\% for FGD and 41.2\% for FGD+compost. 
Table 34. Treatment effects on surface runoff and soil erosion for a rainstorm event received on 29 June 1995 (Rainfall $=50.8 \mathrm{~mm}$ ).

\begin{tabular}{lccc}
\hline \hline Parameter & Topsoil & FGD & FGD + Compost \\
\hline & & & \\
Runoff (mm) & 22.9 & 25.4 & 22.9 \\
Erosion (kg/ha) & 1955 & 4225 & 2844 \\
Bedload (kg/ha) & 32 & 441 & 61 \\
\hline
\end{tabular}

Table 35. Effects of reclamation treatments on runoff and soil erosion in 1996 (Rainfall $=829.8 \mathrm{~mm}$ ).

\begin{tabular}{lcr}
\hline \hline Treatment & $\begin{array}{c}\text { Runoff } \\
\text { (\% of rainfall) }\end{array}$ & \multicolumn{1}{c}{$\begin{array}{c}\text { Erosion } \\
(\mathrm{kg} / \mathrm{ha} / \mathrm{yr})\end{array}$} \\
\hline & & \\
Topsoil & $36.0 \pm 2.0$ & $382 \pm 11$ \\
FGD & $37.5 \pm 4.8$ & $1,828 \pm 356$ \\
FGD + Compost & $41.2 \pm 2.5$ & $1,422 \pm 448$ \\
& & \\
\hline
\end{tabular}


There were, however, drastic differences in soil erosion. Soil erosion was in the order FGD > FGD+compost > topsoil, with mean rate of $1828 \mathrm{~kg} / \mathrm{ha} / \mathrm{yr}$ for FGD, $1422 \mathrm{~kg} / \mathrm{ha} / \mathrm{yr}$ for FGD+compost, and $328 \mathrm{~kg} / \mathrm{ha} / \mathrm{yr}$ for topsoil. The relative soil erosion rate was 100:78:18 for FGD:FGD+compost:topsoil. In comparison to results shown in Tables 34 and 35, the Ohio Department of Natural Resources estimated a 2-year, 24 hour storm event would erode 1000 times more sediment (approximately $10^{6} \mathrm{~kg} / \mathrm{ha} / \mathrm{yr}$ ) than that measured in this study after reclamation was completed.

The data from measurements made under both simulated and natural rainfall conditions reflect the fact that FGD is a very fine material. It does not naturally form soil aggregates and is, therefore, highly erodible. Most of the soil loss, including bedload, comprises the FGD material. However, the rate of soil erosion even with the FGD is low at $1.8 \mathrm{Mg} / \mathrm{ha} / \mathrm{yr}$. Erosion rate is likely to be high, however, when the canopy cover is not yet established. A management system should be identified that will decrease the erosion risks during the initial stages of vegetative cover establishment.

\subsubsection{Groundwater Hydrology and Quality}

The majority of the groundwater hydrologic data obtained in this study was measured using English units because these types of studies in the United States are still conducted using such units. Where conversion of units in tables or figures was easily accomplished, the data are presented in SI units. Where English units are maintained, the reader can readily convert the English unit of feet by multiplying by 0.305 to obtain the equivalent SI result in meters.

The hydrologic information obtained permitted both qualitative and quantitative evaluation of the groundwater flow system and the chemistry of groundwater that enters, flows through, and exits the reclaimed mine site. The experimental procedures used to obtain these data are described in Section 3.3. The results of this study enhance our understanding of the complexity of the system at the Fleming mine site and allows for the development of preliminary concepts about potential effects of FGD by-products on water quality where it is used as a surface amendment at a reclaimed mine.

Single well displacement tests ("slug" tests) done at 14 wells were analyzed by use of the method of Cooper et al. (1967). Water levels in most wells responded quickly and returned to the static (pretest) water levels in less than one-half hour. However, several wells responded 
much more slowly, requiring recording of water levels overnight. A typical response curve and an example of the computation of transmissivity and hydraulic conductivity for well $8 \mathrm{D}$ are shown in Figure 36. Results and methods of all the slug tests have been archived at the US Geological Survey office in Columbus, Ohio, and are available for inspection. Only summary data are presented here.

Table 36 lists the results of the aquifer tests and summarizes results for both the shallow and deep aquifers in terms of a mean value and a geometric mean of the hydraulic conductivity. As Table 36 shows, different conductivities were obtained for tests when the slug was introduced (IN) than for tests when it was withdrawn (OUT). The differences in calculated hydraulic conductivity can be explained by difficulties in trying to introduce or withdraw a volume of water instantaneously. The slug used for these tests, which was secured with a nylon rope, was approximately 5 feet long and weighed about 40 pounds, and it proved to be quite cumbersome in its application. Thus, an instantaneous introduction or withdrawal was rarely achieved.

The results of the analysis indicate that horizontal hydraulic conductivity ranges from 0.3 to $3.6 \mathrm{~m}$ ( 1 to $12 \mathrm{ft}$ ) per day within the shallow aquifer and 0.1 to $7.6 \mathrm{~m}(0.3$ to $25 \mathrm{ft}$ ) per day in the deep aquifer. Geometric means range from 0.9 to $1.5 \mathrm{~m}$ ( 3 to $5 \mathrm{ft}$ ) per day for the shallow wells and 1.8 to 3.9 (6 to $13 \mathrm{ft}$ ) per day for the deep wells.

Monthly water levels for each well are given in Table 37 and hydrographs from automated measurement of groundwater levels in 6 wells are shown in Figures 37 through 39.

Water levels varied less than $0.45 \mathrm{~m}(1.5 \mathrm{ft})$ in any given well during the study period. At three of the well clusters where a shallow and a deep well were constructed, unexpected upward vertical hydraulic gradients were found. These gradients were generally small and ranged from $2.8 \times 10^{-3}$ to $1.4 \times 10^{-2}$ meters per meter (feet per foot). Gradients at clusters 1 and 3 were consistently upward, whereas gradients at cluster 8 changed from slightly upward to slightly downward. In comparison, vertical gradients at well cluster 4 were strongly downward and ranged from 0.96 to 1.35 meters per meter ( 0.96 to 1.35 feet per foot)

Comparison of precipitation records with groundwater levels indicate that the groundwater flow system is in hydraulic connection with surface recharge. Hydrographs of water levels in well clusters 4,5 , and 8 clearly show water level response within a few hours of a recharge event. For example, water levels in well $5 \mathrm{~S}$ responded almost immediately to an $5.6 \mathrm{~mm}(0.22$ 


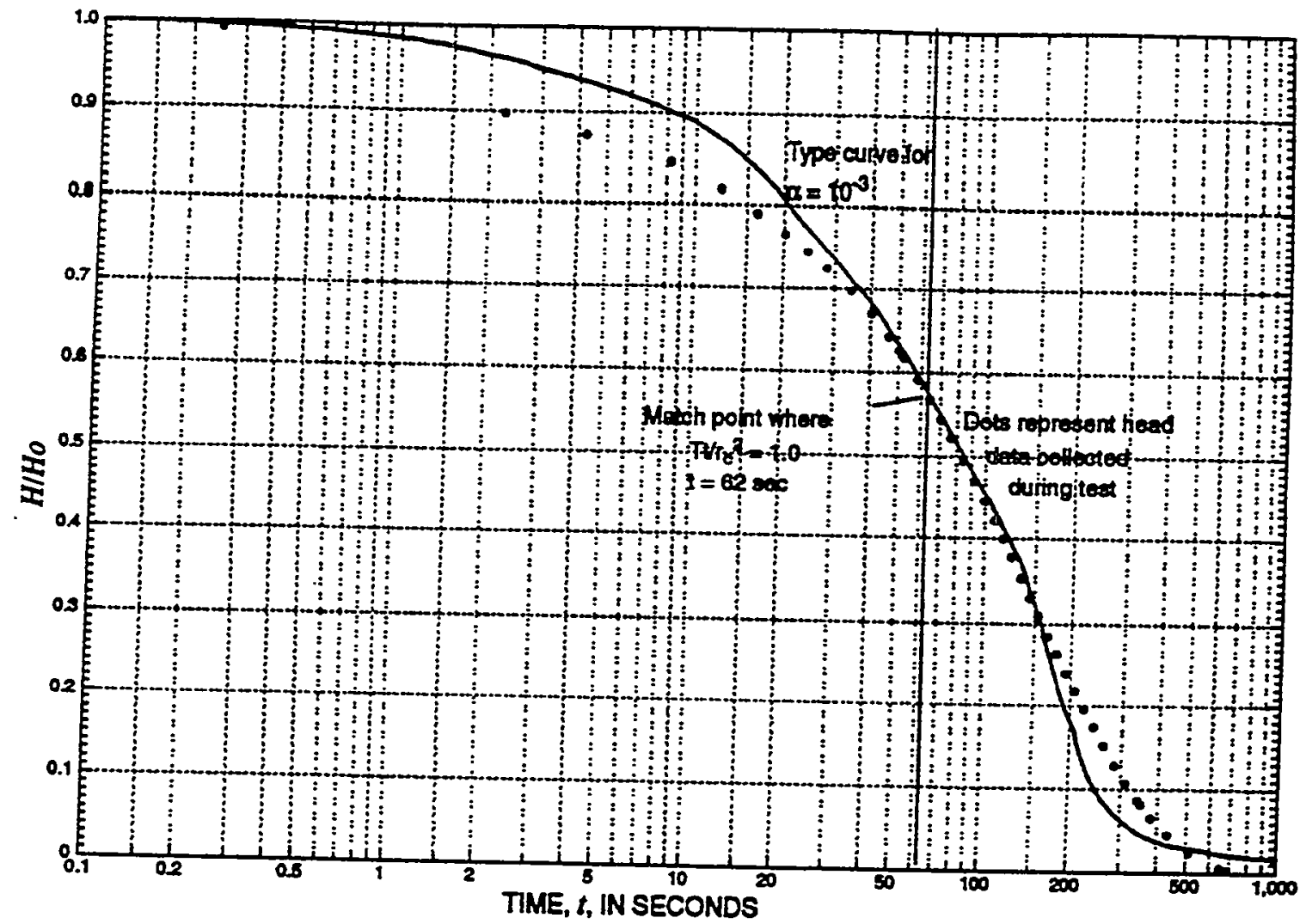

$$
\begin{aligned}
& \text { For } \\
& \alpha \quad=10^{-3} \\
& t \quad=62 \mathrm{sec} \\
& T=\frac{(1.0) r_{c}^{2}}{t}=\frac{(1.0)(0.24004)^{2}}{62}=0.00092934 \mathrm{ft}^{2} / \mathrm{s}=80.295 \mathrm{ft}^{2} / \mathrm{s} \\
& r_{c}=2.88 \text { in }=0.24004 \mathrm{ft} \\
& b=3.20 \mathrm{ft} \\
& K=\frac{T}{b}=\frac{80.295 \mathrm{ft}^{2} / \mathrm{d}}{3.20 \mathrm{ft}}=25.092 \mathrm{ft} / \mathrm{d}=25 \mathrm{ft} / \mathrm{d}
\end{aligned}
$$

where

$H \quad=$ head in well at time $t(\mathrm{~L})$

Ho = head in well after instantaneous introduction or removal of slug (L)

$r \quad=$ transmissivity $\left(\mathrm{L}^{2} / \mathrm{T}\right)$

$r_{c} \quad$ = radius of well casing over which change in water level occurs (L)

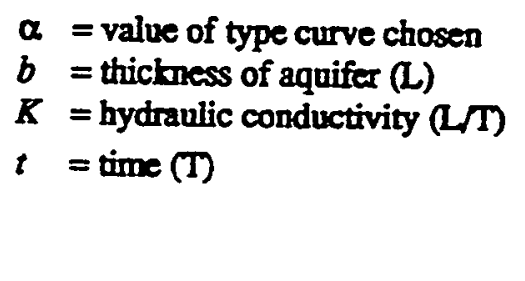

$b=$ thichess of aquifer (L)

$K=$ hydraulic conductivity (L/T)

$t=$ time (T)

Figure 36. Sample curve match and calculation of hydraulic conductivity for slug tests using the method of Cooper et al. (1967). 
Table 36. Results of slug test analysis on thirteen wells.

\begin{tabular}{lcccccc}
\hline \hline $\begin{array}{l}\text { Test } \\
\text { number }\end{array}$ & $\begin{array}{c}\text { Slug } \\
\text { size }\end{array}$ & $\begin{array}{c}\text { Curve chosen } \\
\text { (alpha, unitless) }\end{array}$ & $\begin{array}{c}\text { Time, } \mathrm{t} \\
(\mathrm{sec})\end{array}$ & $\begin{array}{c}(1.0)^{*} \mathrm{r}_{\mathrm{c}}{ }^{2 / \mathrm{t}} \\
\left(\mathrm{m}^{2} / \mathrm{sec}\right)^{\mathrm{c}}\end{array}$ & $\begin{array}{c}\mathrm{T} \\
\left(\mathrm{m}^{2} / \text { day }\right)\end{array}$ & $\begin{array}{c}\mathrm{K}_{\mathrm{h}} \\
(\mathrm{m} / \mathrm{d})\end{array}$ \\
\hline Well 1 & shallow; aquifer thickness $=6.86$ \\
1 IN & $\mathrm{L}$ & $10^{-3}$ & 70 & $7.61 \times 10^{-5}$ & 6.61 & 0.96 \\
1 OUT & $\mathrm{L}$ & $10^{-2}$ & 73 & $7.33 \times 10^{-5}$ & 6.34 & 0.92 \\
2 IN & $\mathrm{L}$ & $10^{-2}$ & 110 & $4.83 \times 10^{-5}$ & 4.20 & 0.61 \\
2 OUT & $\mathrm{L}$ & $10^{-2}$ & 47 & $1.14 \times 10^{-5}$ & 9.84 & 1.44 \\
3 IN & $\mathrm{S}$ & $10^{-3}$ & 85 & $6.31 \times 10^{-5}$ & 5.44 & 0.79 \\
3 OUT & $\mathrm{S}$ & $10^{-4}$ & 26 & $2.06 \times 10^{-5}$ & 17.8 & 2.59
\end{tabular}

Well 1 deep; aquifer thickness $=0.98 \mathrm{~m}$

$\begin{array}{lllllll}1 \mathrm{IN} & \mathrm{S} & 10^{-2} & 630 & 8.26 \times 10^{-6} & 0.74 & 0.75 \\ 3 \mathrm{IN} & \mathrm{L} & 10^{-4} & 800 & 6.56 \times 10^{-6} & 0.58 & 0.59 \\ 3 \text { OUT } & \mathrm{L} & 10^{-5} & 650 & 8.26 \times 10^{-6} & 0.71 & 2.59\end{array}$

Well 2 shallow; aquifer thickness $=23.9 \mathrm{ft}$

$\begin{array}{lllllll}1 \mathrm{IN} & \mathrm{L} & 10^{5} & 18 & 2.97 \times 10^{-4} & 25.7 & 3.53 \\ 1 \text { OUT } & \mathrm{L} & 10^{-5} & 19 & 2.81 \times 10^{-4} & 24.3 & 3.34 \\ 2 \mathrm{IN} & \mathrm{L} & 10^{-2} & 30 & 1.78 \times 10^{-4} & 15.4 & 2.12 \\ 2 \text { OUT } & \mathrm{L} & 10^{-2} & 28 & 1.91 \times 10^{-4} & 16.5 & 2.27\end{array}$

Well 3 shallow; aquifer thickness $=7.29 \mathrm{~m}$

$\begin{array}{lllllll}1 \mathrm{IN} & \mathrm{L} & 10^{-4} & 62 & 8.63 \times 10^{-5} & 7.46 & 0.97 \\ 1 \text { OUT } & \mathrm{L} & 10^{-5} & 62 & 8.63 \times 10^{-5} & 7.46 & 0.97 \\ 2 \mathrm{IN} & \mathrm{L} & 10^{-3} & 78 & 6.87 \times 10^{-5} & 5.93 & 0.77 \\ 2 \text { OUT } & \mathrm{L} & 10^{-3} & 61 & 8.73 \times 10^{-5} & 7.58 & 0.98\end{array}$

Well 3 deep; aquifer thickness $=0.85 \mathrm{~m}$

$\begin{array}{lllllll}1 \mathrm{IN} & \mathrm{L} & 10^{-1} & 120 & 4.45 \times 10^{-5} & 3.85 & 4.52 \\ 2 \mathrm{IN} & \mathrm{L} & 10^{-1} & 120 & 4.45 \times 10^{-5} & 3.85 & 4.52\end{array}$

Well 4 shallow; aquifer thickness $=5.61 \mathrm{~m}$

$\begin{array}{lllllll}1 \mathrm{IN} & \mathrm{L} & 10^{-5} & 35 & 1.53 \times 10^{-5} & 13.2 & 2.36 \\ 1 \text { OUT } & \mathrm{L} & 10^{-5} & 43 & 1.57 \times 10^{-5} & 13.6 & 2.43 \\ 2 \mathrm{IN} & \mathrm{L} & 10^{-4} & 48 & 1.41 \times 10^{-5} & 12.2 & 2.17 \\ 2 \text { OUT } & \mathrm{L} & 10^{-5} & 33 & 1.63 \times 10^{-5} & 14.0 & 2.50\end{array}$


Table 36. (continued)

\begin{tabular}{|c|c|c|c|c|c|c|}
\hline $\begin{array}{l}\text { Test } \\
\text { number }\end{array}$ & $\begin{array}{l}\text { Slug } \\
\text { size }^{b}\end{array}$ & $\begin{array}{l}\text { Curve chosen } \\
\text { (alpha, unitless) }\end{array}$ & $\begin{array}{l}\text { Time, } t \\
(\mathrm{sec})\end{array}$ & $\begin{array}{l}(1.0)^{*} \mathrm{r}_{\mathrm{c}}{ }^{2 / \mathrm{t}} \\
\left(\mathrm{ft}^{2} / \mathrm{sec}\right)^{\mathrm{c}}\end{array}$ & $\begin{array}{c}\mathrm{T} \\
\left(\mathrm{m}^{2} / \text { day }\right)^{d}\end{array}$ & $\begin{array}{c}K_{h} \\
(f t / d)^{e}\end{array}$ \\
\hline \multicolumn{7}{|c|}{ Well 4 deep; aquifer thickness $=0.66 \mathrm{~m}$} \\
\hline $1 \mathrm{IN}$ & L & $10^{-2}$ & 230 & $2.32 \times 10^{-5}$ & 2.01 & 2.42 \\
\hline 1 OUT & L & $10^{-1}$ & 195 & $2.78 \times 10^{-5}$ & 2.40 & 2.78 \\
\hline 2 IN & $\mathrm{L}$ & $10^{-2}$ & 190 & $2.78 \times 10^{-5}$ & 2.47 & 2.85 \\
\hline \multicolumn{7}{|c|}{ Well 5 shallow; aquifer thickness $=3.51 \mathrm{~m}$} \\
\hline $1 \mathrm{IN}$ & $\mathrm{L}$ & $10^{-3}$ & 110 & $4.83 \times 10^{-5}$ & 4.20 & 1.21 \\
\hline 1 OUT & L & $10^{-3}$ & 105 & $5.10 \times 10^{-5}$ & 4.43 & 1.26 \\
\hline $2 \mathbb{N}$ & $\mathrm{L}$ & $10^{-3}$ & 100 & $5.38 \times 10^{-5}$ & 4.63 & 1.32 \\
\hline \multicolumn{7}{|c|}{ Well 6 shallow; aquifer thickness $=5.19 \mathrm{~m}$} \\
\hline $1 \mathrm{IN}$ & $\mathrm{L}$ & $10^{-2}$ & 280 & $1.95 \times 10^{-5}$ & 1.65 & 0.32 \\
\hline 1 OUT & $\mathrm{L}$ & $10^{-3}$ & 170 & $3.15 \times 10^{-5}$ & 2.72 & 0.52 \\
\hline $2 \mathbb{N}$ & $\mathrm{L}$ & $10^{-3}$ & 185 & $2.87 \times 10^{-5}$ & 2.50 & 0.48 \\
\hline 2 OUT & $\mathrm{L}$ & $10^{-3}$ & 170 & $3.15 \times 10^{-5}$ & 2.72 & 0.52 \\
\hline \multicolumn{7}{|c|}{ Well 6 deep; aquifer thickness $=0.85 \mathrm{~m}$} \\
\hline I IN & $\mathrm{L}$ & $10^{-3}$ & 5500 & $9.29 \times 10^{-7}$ & 0.085 & 0.098 \\
\hline 1 OUT & $L$ & $10^{-1}$ & 300 & $1.76 \times 10^{-5}$ & 1.54 & 1.81 \\
\hline \multicolumn{7}{|c|}{ Well 7 shallow; aquifer thickness $=5.19 \mathrm{~m}$} \\
\hline $1 \mathrm{IN}$ & L & $10^{-2}$ & 88 & $6.03 \times 10^{-5}$ & 5.44 & 1.01 \\
\hline 1 OUT & $\mathrm{L}$ & $10^{-2}$ & 62 & $8.63 \times 10^{-5}$ & 7.46 & 1.44 \\
\hline $2 \mathrm{IN}$ & $\mathrm{L}$ & $10^{-2}$ & 86 & $6.22 \times 10^{-5}$ & 5.38 & 1.04 \\
\hline 2 OUT & $L$ & $10^{-2}$ & 60 & $8.91 \times 10^{-5}$ & 7.69 & 1.49 \\
\hline \multicolumn{7}{|c|}{ Well 8 shallow; aquifer thickness $=6.86 \mathrm{~m}$} \\
\hline $1 \mathrm{IN}$ & $\mathrm{L}$ & $10^{-3}$ & 76 & $7.06 \times 10^{-5}$ & 6.08 & 0.89 \\
\hline 1 OUT & $\mathbf{L}$ & $10^{-3}$ & 95 & $5.66 \times 10^{-5}$ & 4.87 & 0.71 \\
\hline $2 \mathbb{N}$ & $\mathrm{L}$ & $10^{-2}$ & 110 & $4.83 \times 10^{-5}$ & 4.20 & 0.61 \\
\hline 2 OUT & $\mathrm{L}$ & $10^{-3}$ & 73 & $7.33 \times 10^{-5}$ & 6.34 & 0.92 \\
\hline \multicolumn{7}{|c|}{ Well 8 deep; aquifer thickness $=0.98 \mathrm{~m}$} \\
\hline $1 \mathrm{IN}$ & L & $10^{-3}$ & 62 & $8.63 \times 10^{-5}$ & 7.46 & 7.65 \\
\hline 1 OUT & $\mathrm{L}$ & $10^{-3}$ & 63 & $8.45 \times 10^{-5}$ & 7.34 & 7.53 \\
\hline 2 IN & $\mathrm{L}$ & $10^{-3}$ & 62 & $8.63 \times 10^{-5}$ & 7.46 & 7.65 \\
\hline 2 OUT & $\mathrm{L}$ & $10^{-3}$ & 64 & $8.36 \times 10^{-5}$ & 7.23 & 7.41 \\
\hline
\end{tabular}


Table 36. (continued)

\begin{tabular}{lccccc} 
Summary of horizontal hydraulic conductivity (Kh) values & & & \\
& & & $\begin{array}{c}\text { Geometric } \\
\text { mean }\end{array}$ & $\begin{array}{c}\text { Rounded } \\
\text { mean }\end{array}$ & $\begin{array}{c}\text { Rounded } \\
\text { geometric } \\
\text { mean }\end{array}$ \\
\cline { 3 - 6 } & & \multicolumn{3}{c}{ (m/day) } \\
All shallow wells & (IN) & 1.24 & 1.03 & 1.2 & 0.9 \\
All deep wells & (OUT) & 1.52 & 1.30 & 1.5 & 1.2 \\
& (IN) & 3.44 & 1.92 & 3.4 & 1.8 \\
& (OUT) & 4.05 & 2.91 & 4.0 & 3.0 \\
\hline \hline
\end{tabular}

aIN, slug introduction resulted in rise of water level in well; OUT, slug withdrawal resulted in drop of water level in well.

bL, large; $S$, small.

$\mathrm{cr}_{c}$, radius of casing $(0.061 \mathrm{~m})$.

dT, transmissivity.

$\mathrm{eK}_{\mathrm{h}}$, horizontal hydraulic conductivity. 
Table 37. Water levels (m above mean sea level) in monitoring wells for the period June, 1995 through January, 1996.

\begin{tabular}{|c|c|c|c|c|c|}
\hline Date & $\begin{array}{l}\text { Water level } \\
\text { (m) }\end{array}$ & Date & $\begin{array}{l}\text { Water level } \\
(\mathrm{m})\end{array}$ & Date & $\begin{array}{l}\text { Water level } \\
\text { (m) }\end{array}$ \\
\hline \multicolumn{6}{|c|}{ Well 1S } \\
\hline $6 / 21 / 95$ & 315.4 & $9 / 7 / 95$ & 315.4 & $12 / 13 / 95$ & 315.2 \\
\hline $7 / 13 / 95$ & 315.4 & $10 / 20 / 95$ & 315.3 & $1 / 16 / 96$ & 315.2 \\
\hline $8 / 10 / 95$ & 315.5 & & & & \\
\hline \multicolumn{6}{|c|}{ Well $1 D$} \\
\hline $6 / 21 / 95$ & 315.4 & 9/7/95 & 315.5 & $12 / 13 / 95$ & 315.6 \\
\hline 7/13/95 & 315.4 & $10 / 20 / 95$ & 315.5 & $1 / 16 / 96$ & 315.6 . \\
\hline $8 / 10 / 95$ & 315.5 & & & & \\
\hline \multicolumn{6}{|c|}{ Well 2S } \\
\hline 6/27/95 & 315.3 & 9/7/95 & 315.3 & $12 / 13 / 95$ & 315.0 \\
\hline $7 / 13 / 95$ & 315.3 & $10 / 20 / 95$ & 315.2 & $1 / 16 / 96$ & 315.1 \\
\hline $8 / 10 / 95$ & 315.4 & & & & \\
\hline \multicolumn{6}{|c|}{ Well 3S } \\
\hline $6 / 28 / 95$ & 313.9 & 9/7/95 & 314.3 & $12 / 13 / 95$ & 314.2 \\
\hline $7 / 13 / 95$ & 314.3 & $10 / 20 / 95$ & 314.3 & $1 / 16 / 96$ & 314.2 \\
\hline $8 / 10 / 95$ & 314.4 & & & & \\
\hline \multicolumn{6}{|c|}{ Well 3D } \\
\hline $6 / 28 / 95$ & 314.4 & 9/7/95 & 314.4 & $12 / 13 / 95$ & 314.3 \\
\hline $7 / 13 / 95$ & 314.4 & $10 / 20 / 95$ & 314.4 & $1 / 16 / 96$ & 314.3 \\
\hline $8 / 10 / 95$ & 314.4 & & & & \\
\hline \multicolumn{6}{|c|}{ Well 4S } \\
\hline $6 / 29 / 95$ & 314.2 & 9/7/95 & 314.2 & $12 / 13 / 95$ & 314.0 \\
\hline $7 / 13 / 95$ & 314.2 & $10 / 20 / 95$ & 314.1 & $1 / 16 / 96$ & 314.1 \\
\hline $8 / 10 / 95$ & 314.2 & & & & \\
\hline \multicolumn{6}{|c|}{ Well 4D } \\
\hline 6/29/95 & 306.8 & $9 / 7 / 95$ & 306.9 & $12 / 13 / 95$ & 307.0 \\
\hline $7 / 13 / 95$ & 306.8 & $10 / 20 / 95$ & 307.0 & $1 / 16 / 96$ & 307.0 \\
\hline $8 / 10 / 95$ & 306.9 & & & & \\
\hline
\end{tabular}


Table 37. (continued)

\begin{tabular}{|c|c|c|c|c|c|}
\hline Date & $\begin{array}{l}\text { Water level } \\
\text { (m) }\end{array}$ & Date & $\begin{array}{l}\text { Water level } \\
\text { (m) }\end{array}$ & Date & $\begin{array}{l}\text { Water level } \\
\text { (m) }\end{array}$ \\
\hline \multicolumn{6}{|c|}{ Well $4 P$} \\
\hline $6 / 29 / 95$ & 298.6 & 9/7/95 & 298.9 & $12 / 13 / 95$ & 299.0 \\
\hline $7 / 13 / 95$ & 298.8 & $10 / 20 / 95$ & 298.9 & $1 / 16 / 96$ & 299.1 \\
\hline $8 / 10 / 95$ & 298.9 & & & & \\
\hline \multicolumn{6}{|c|}{ Well 5SP } \\
\hline $6 / 27 / 95$ & Dry & $9 / 7 / 95$ & Dry & $12 / 13 / 95$ & Dry \\
\hline $7 / 13 / 95$ & Dry & $10 / 20 / 95$ & Dry & $1 / 16 / 96$ & Dry \\
\hline $8 / 10 / 95$ & Dry & & & & \\
\hline \multicolumn{6}{|c|}{ Well SD } \\
\hline $6 / 27 / 94$ & 314.0 & 9/7/95 & 313.9 & $12 / 13 / 95$ & 313.8 \\
\hline $7 / 13 / 95$ & 314.0 & $10 / 20 / 95$ & 313.9 & $1 / 16 / 96$ & 313.9 \\
\hline $8 / 10 / 95$ & 314.0 & & & & \\
\hline \multicolumn{6}{|c|}{ Well 6S } \\
\hline $6 / 22 / 95$ & 315.1 & 9/7/95 & 315.1 & $12 / 13 / 95$ & 314.8 \\
\hline $7 / 13 / 95$ & 315.1 & $10 / 20 / 95$ & 315.0 & $1 / 16 / 96$ & 314.9 \\
\hline $8 / 10 / 95$ & 315.1 & & & - & \\
\hline \multicolumn{6}{|c|}{ Well 6D } \\
\hline $6 / 22 / 95$ & 315.0 & $9 / 7 / 95$ & 315.1 & $12 / 13 / 95$ & 314.8 \\
\hline $7 / 13 / 95$ & 315.1 & $10 / 20 / 95$ & 314.9 & $1 / 16 / 96$ & 314.8 \\
\hline $8 / 10 / 95$ & 315.1 & & & & \\
\hline \multicolumn{6}{|c|}{ Well 7S } \\
\hline $6 / 21 / 95$ & 315.3 & 9/7/95 & 315.1 & $12 / 13 / 95$ & 314.8 \\
\hline $7 / 13 / 95$ & 315.2 & $10 / 20 / 95$ & 314.9 & $1 / 16 / 96$ & 314.9 \\
\hline $8 / 10 / 95$ & 315.1 & & & & \\
\hline \multicolumn{6}{|c|}{ Well 8S } \\
\hline $6 / 27 / 95$ & 315.5 & 9/7/95 & 315.5 & $12 / 13 / 95$ & 315.2 \\
\hline $7 / 13 / 95$ & 315.5 & $10 / 20 / 95$ & 315.4 & $1 / 16 / 96$ & 315.2 \\
\hline $8 / 10 / 95$ & 315.5 & & & & \\
\hline \multicolumn{6}{|c|}{ Well 8D } \\
\hline $6 / 21 / 95$ & 315.5 & 9/7/95 & 315.5 & $12 / 13 / 95$ & 315.2 \\
\hline $7 / 13 / 95$ & 315.4 & $10 / 20 / 95$ & 315.4 & $1 / 16 / 96$ & 315.2 \\
\hline $8 / 10 / 95$ & 315.5 & & & & \\
\hline
\end{tabular}


Table 37. (continued)

\begin{tabular}{|c|c|c|c|}
\hline Date & $\begin{array}{l}\text { Water level } \\
\text { (m) }\end{array}$ & Date & $\begin{array}{l}\text { Water level } \\
\text { (m) }\end{array}$ \\
\hline \multicolumn{4}{|c|}{ Well 9S } \\
\hline $12 / 13 / 95$ & 314.7 & $61 / 16 / 96$ & 314.7 \\
\hline \multicolumn{4}{|c|}{ Well 10S } \\
\hline $12 / 13 / 95$ & 314.9 & $61 / 16 / 96$ & 314.4 \\
\hline \multicolumn{4}{|c|}{ Well 11s } \\
\hline $12 / 13 / 95$ & 314.9 & $61 / 16 / 96$ & 315.0 \\
\hline \multicolumn{4}{|c|}{ Well $12 \mathrm{~S}$} \\
\hline $12 / 13 / 95$ & 314.9 & $61 / 16 / 96$ & 315.0 \\
\hline \multicolumn{4}{|c|}{ Well 13S } \\
\hline $12 / 13 / 95$ & 315.0 & $61 / 16 / 96$ & 315.2 \\
\hline
\end{tabular}



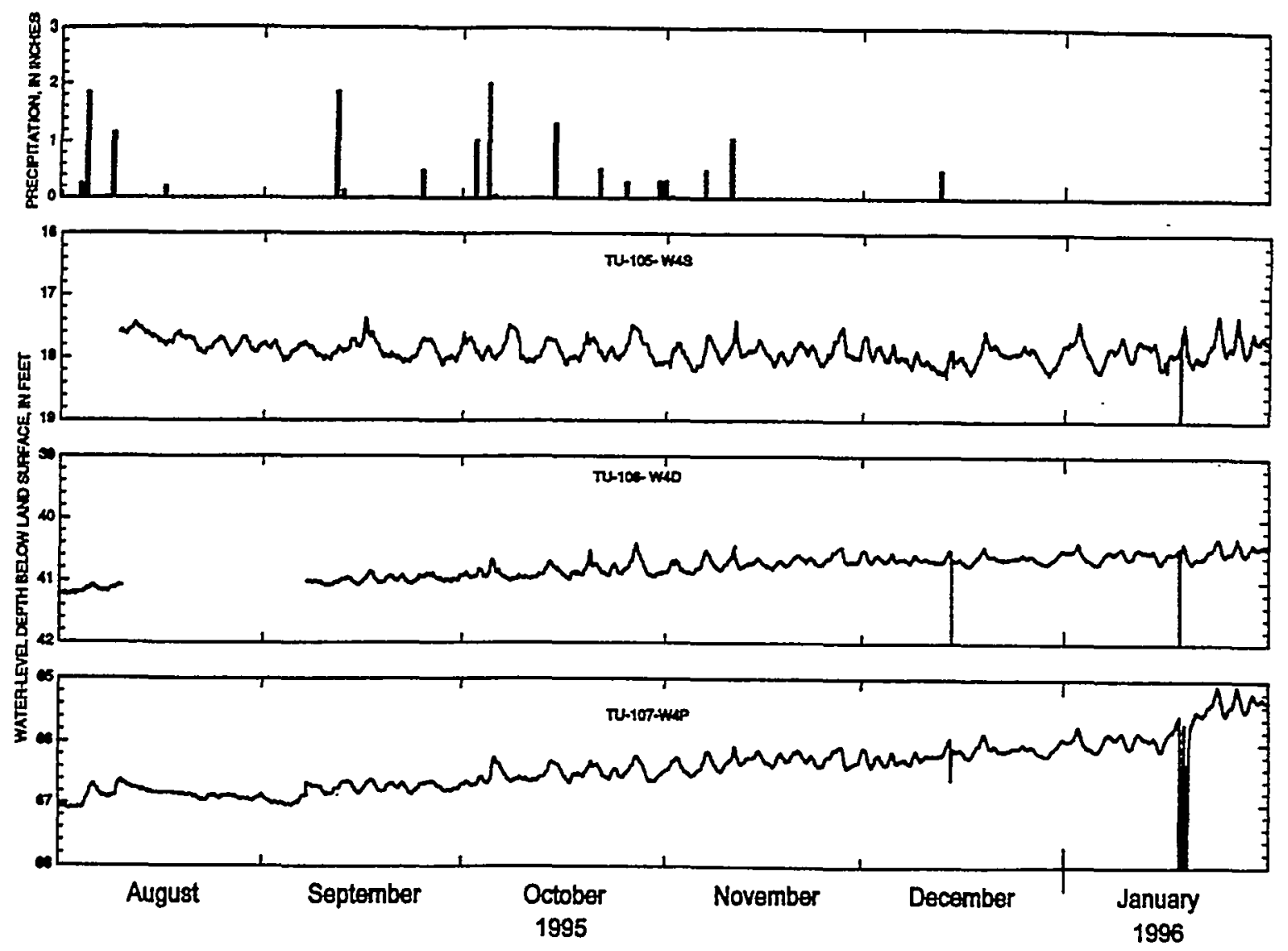

Figure 37. Daily total precipitation (in inches) and water levels (in feet) for well cluster 4 for the time period 8/1/95 through 1/31/96. 

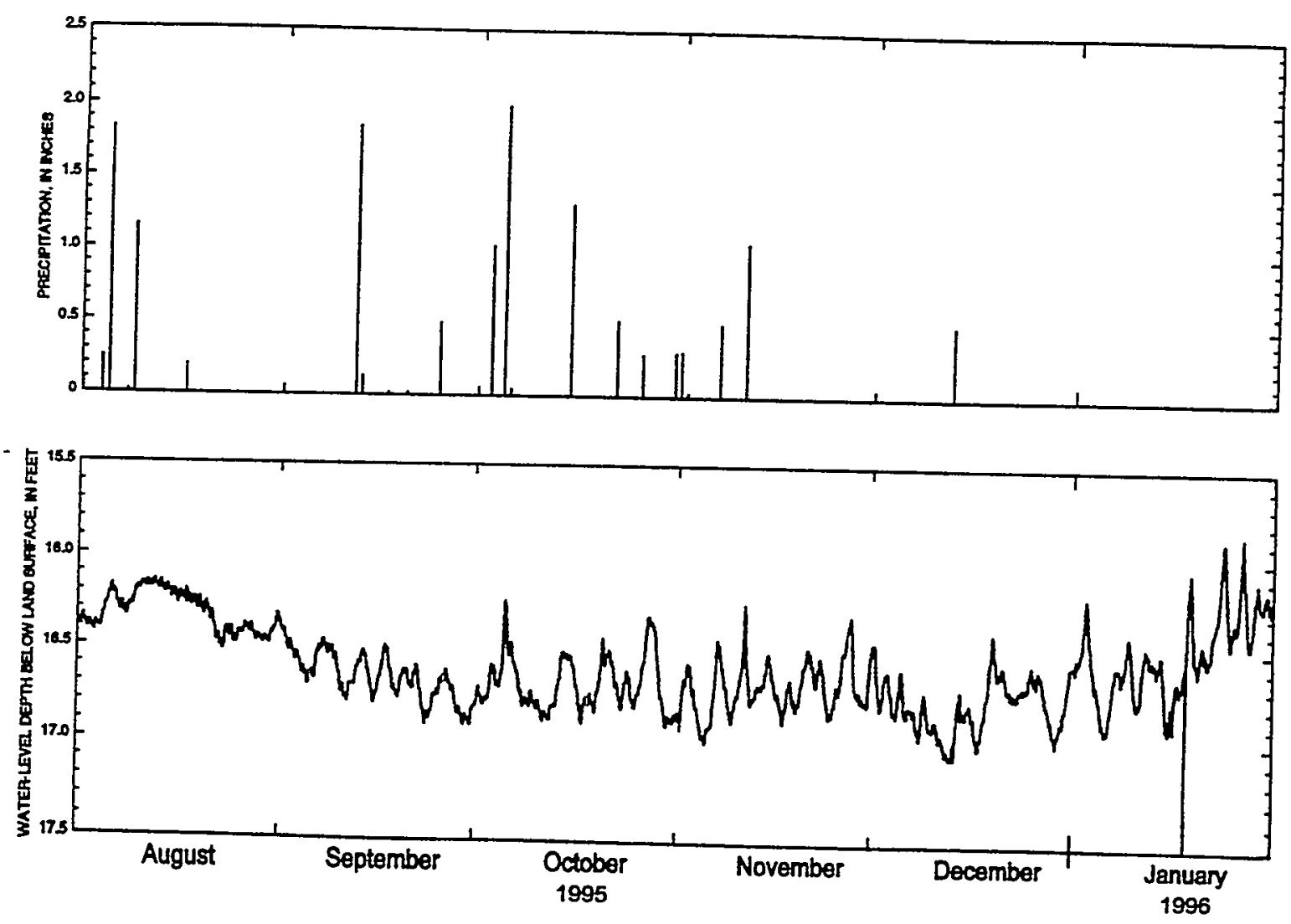

Figure 38. Daily total precipitation (in inches) and water levels (in feet) for well TU-109-W5S for the time period 8/1/95 through 1/31/96. 

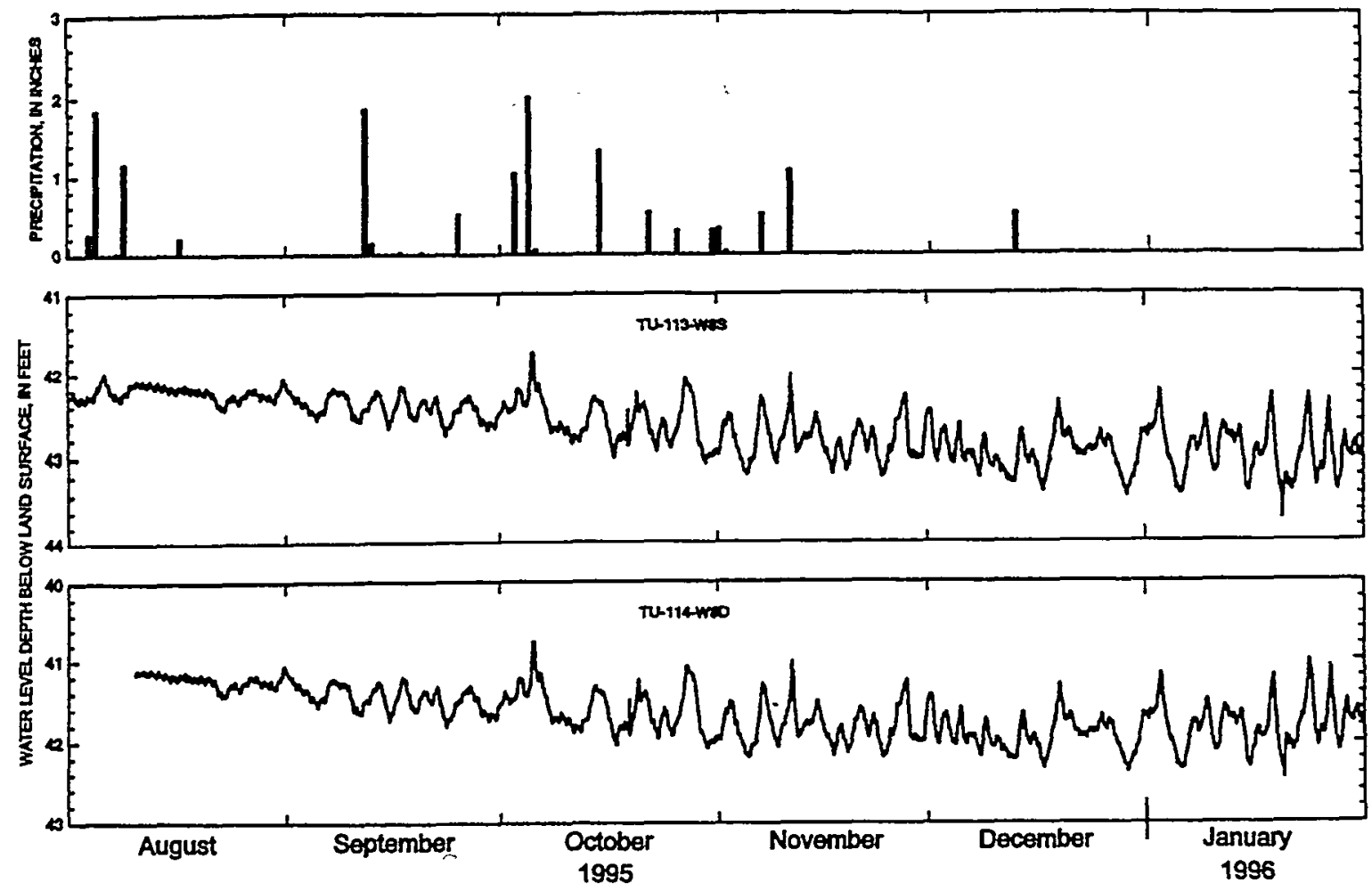

Figure 39. Total daily precipitation (in inches) and water levels (in feet) for well cluster 8 during the time period $8 / 1 / 95$ through $1 / 31 / 96$. 
in) rainfall event observed on September 12, 1995 (Figure 40). Additionally, hydrographs of wells at clusters 4 and 8 show differing degrees of hydraulic connection between aquifers. Rainfall on September 23 caused a significant rise in the shallow water levels in wells $4 S, 5 S$, $8 \mathrm{~S}$, and $8 \mathrm{D}$, but water levels in wells $4 \mathrm{D}$ and $4 \mathrm{P}$ rose only slightly. In contrast, water-level responses in wells $8 S$ and $8 D$ were almost identical, an indication of a high degree of hydraulic connection.

Potentiometric surface maps for the shallow aquifer for July 1995 and January 1996 are shown in Figure 41. These maps show that groundwater flow in the shallow aquifer is generally from north to south. The hydraulic gradient, as measured from well $8 \mathrm{~S}$ to $4 \mathrm{~S}$, is approximately 3.96 $\times 10^{-3}$ meters per meter ( $3.96 \times 10^{-3}$ feet per foot). For comparison, potentiometric surface maps are also shown for the deep aquifer. Again, groundwater flow is from north to south, and the gradient under the FGD-by-product application area is similar to that for the shallow aquifer; however, the gradient in the south part of the study area (near well cluster 4) is much greater (approximately $2.7 \times 10^{-1}$ meters per meter). These maps show that although water levels in wells change with respect to time and recharge, the overall flow directions and gradients do not change appreciably in either the shallow aquifer or the deep aquifer.

To understand the groundwater system, a complete analysis of geologic material as well as the FGD material need to be included in this discussion. Results of the geophysical surveys indicate that the thickness of the spoil/clay layer ranges from less than $0.3 \mathrm{~m}(1 \mathrm{ft})$ to about $10.5 \mathrm{~m}$ ( $35 \mathrm{ft}$ ) (Figure 42 and Table 38) and is greater than $0.3 \mathrm{~m}$ ( $1 \mathrm{ft}$ ) in about 75 percent of the study area. The median thickness of the spoil/clay layer at boreholes and monitoring wells and along vertical electric soundings (VES) is about $1.8 \mathrm{~m}(6 \mathrm{ft})$.

At VES 2, 15, and 17, in the interior of the test watersheds, the thickness of the spoil/clay layer ranges from 2.3 to $4.9 \mathrm{~m}$ ( 7 to $16 \mathrm{ft}$ ). These thicknesses are in agreement with the watershed construction specifications; the thickness of recontoured spoil ranged from $1.2 \mathrm{~m}(4 \mathrm{ft})$ at the eastern edge to $6.7(22 \mathrm{ft})$ on the western edge of the watersheds. Based on a small amount of data and excluding the sediment ponds that were excavated into bedrock, the thickness of the spoil/clay layer west of the test watersheds approaches $3 \mathrm{~m}(10 \mathrm{ft})$. North of the test watersheds, the spoil/clay layer thins to less than 4 feet. South of the test watersheds, the spoil/clay layer thins to less than $0.6 \mathrm{~m} \mathrm{(} 2 \mathrm{ft}$ ); however, thickness is extremely variable (for example, the layer is $10.6 \mathrm{~m}$ (35ft) at monitoring well cluster 3$)$. The thickness of the spoil/clay layer in the FGD by-product application area is nearly uniform and ranges from 1.2 

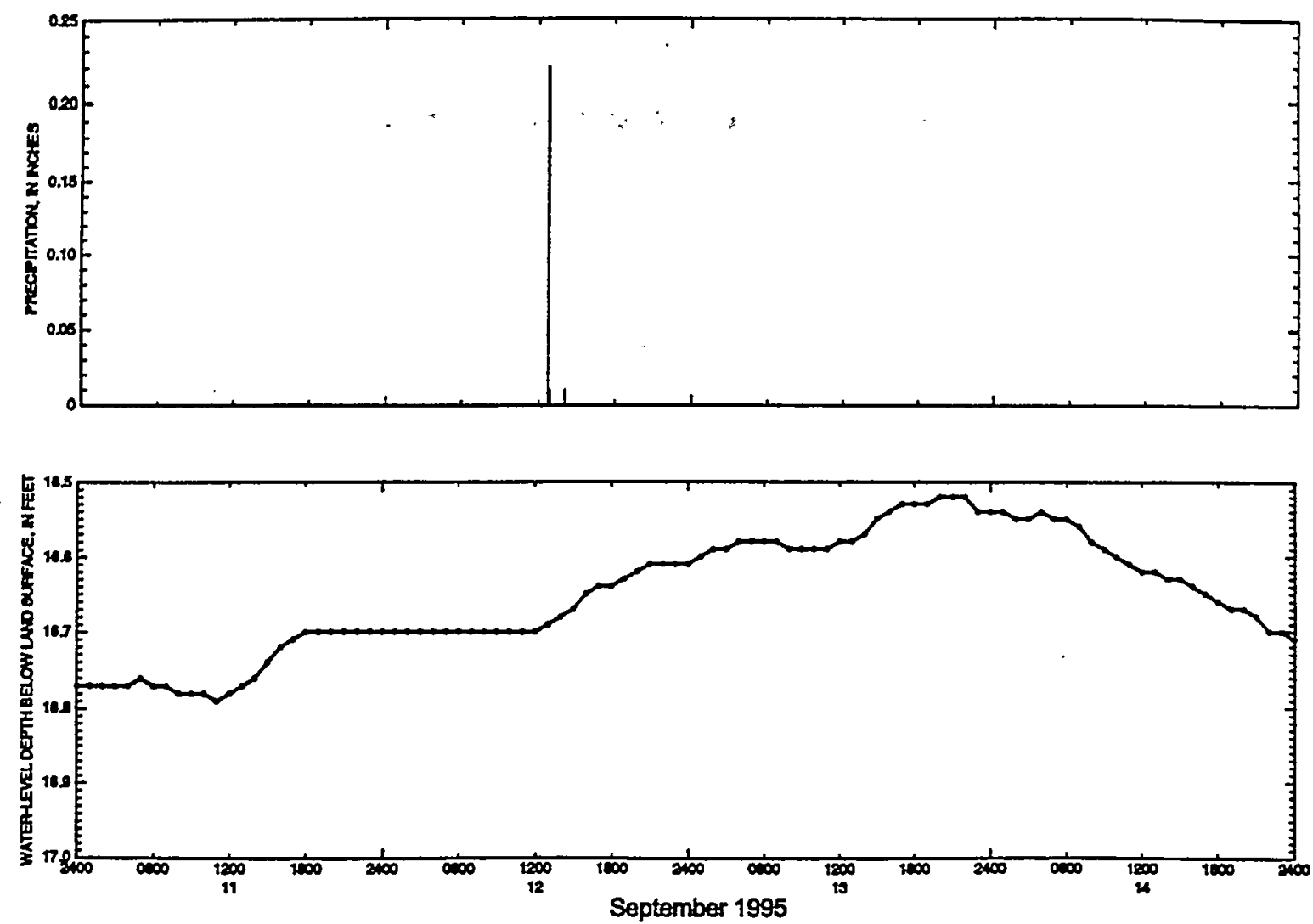

Figure 40. Total hourly precipitation (in inches) and water levels (in feet) for well TU-10SW5S for the time period 9/11/95 through 9/14/96. 


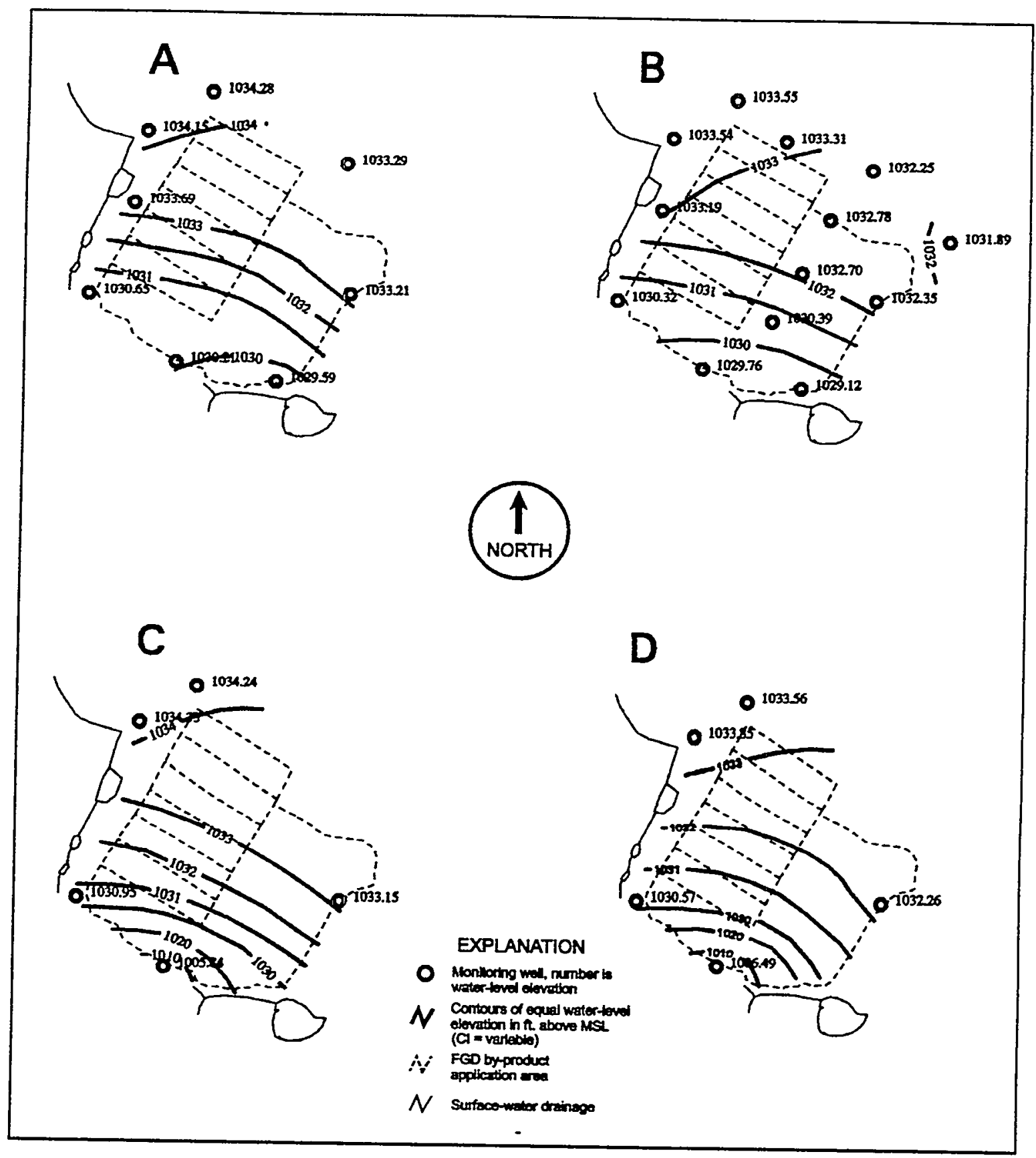

Figure 41. Potentiometric surface maps showing water levels (in feet) in A) shallow aquifer in July, 1995; B) shallow aquifer in January, 1996; C) deep aquifer in July, 1995; and D) deep aquifer in January, 1996. 
A. Elovation of the base of the spoll/ctay layer, in feet above sea level.

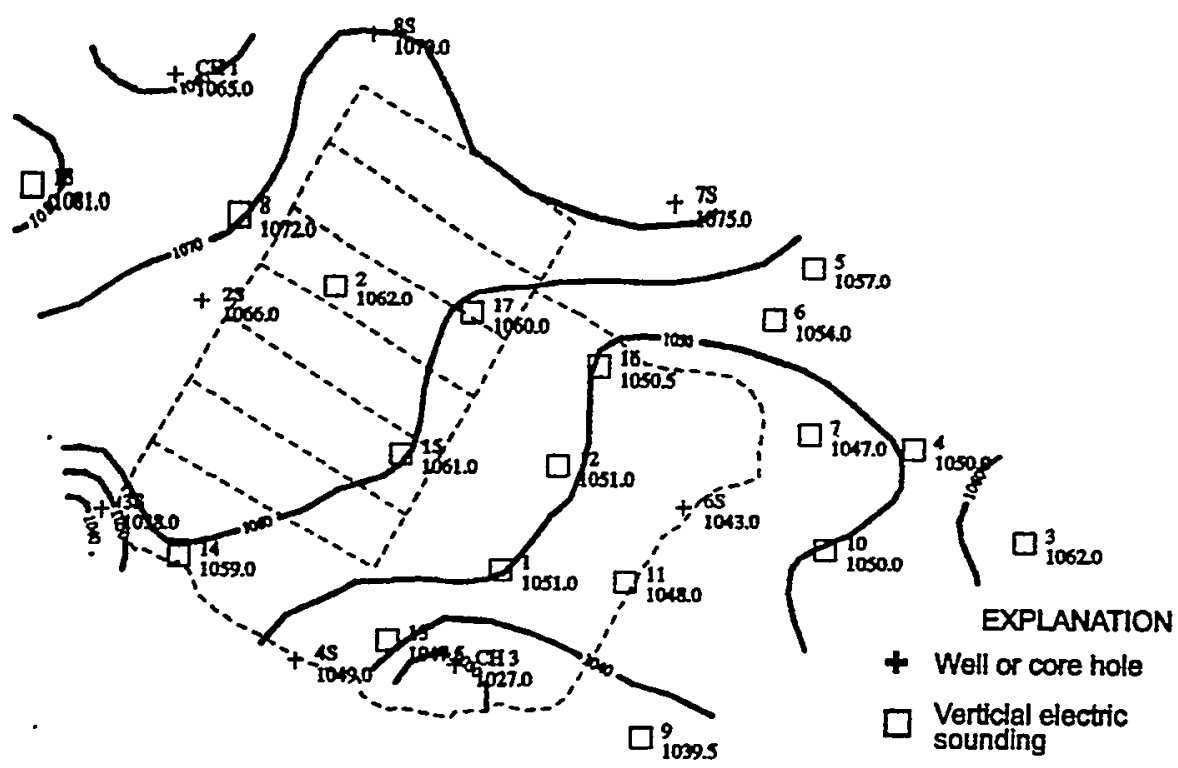

B. Thickness of the spoil/ciay layer, in feet.

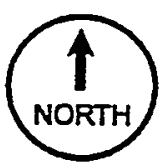

$N$ Line of equal altitude for the base $(\mathrm{Cl}=10 \mathrm{ft})$

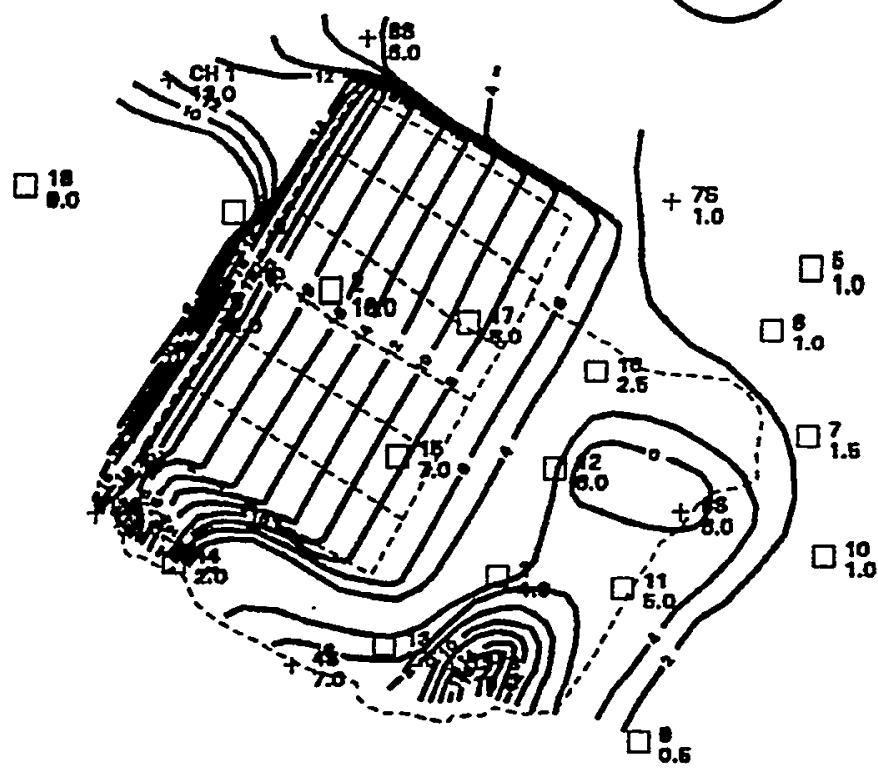

$\square_{0.5}^{f}$

$\square_{0.6}^{8}$ EXPLANATION

+ Well or core holo

Verticlal electric sounding

$N$ Line of equal thickness of the spoil clay layer, in $\mathrm{ft}$ $(\mathrm{Cl}=2 \pi)$

Figure 42. Contour maps showing A) measured and simulated heads and B) residuals. Values are given in feet. 
Table 38. Summary of geologic and geophysical data (in meters above sea level) for the spoil/clay layera.

\begin{tabular}{|c|c|c|c|c|c|c|c|}
\hline $\begin{array}{l}\text { Site identifier } \\
\text { (see Figure } \\
42)^{b}\end{array}$ & $\begin{array}{l}\text { Altitude } \\
\text { (m) }\end{array}$ & $\begin{array}{l}\text { Altitude at } \\
\text { base of } \\
\text { clay/spoil } \\
\text { (m) }\end{array}$ & $\begin{array}{l}\text { Thickness } \\
\text { (m) }\end{array}$ & $\begin{array}{c}\text { VES } \\
\text { average } \\
\text { resistivity } \\
\text { (ohms/m) }\end{array}$ & $\begin{array}{c}\text { EM log } \\
\text { average } \\
\text { resistivity of } \\
\text { spoil/clay } \\
\text { layer } \\
\text { (ohms/m) }\end{array}$ & $\begin{array}{l}\text { Average } \\
\text { resistivity of } \\
\text { upper } 3 \mathrm{~m} \text { of } \\
\text { bedrock } \\
\text { (obms/m) }\end{array}$ & $\begin{array}{c}\text { Available } \\
\text { borehole } \\
\text { logsc }\end{array}$ \\
\hline $\mathrm{CH} 1, \mathrm{MW} 1$ & 328 & 324 & 4.0 & - & 50 & 300 & $\mathrm{G}, \mathrm{J}, \mathrm{EM}, \underline{\mathrm{C}}$ \\
\hline $\mathrm{CH} 2, \mathrm{MW} 3$ & 326 & 316 & 10.6 & - & 30 & 250 & G,J,EM, $\underline{C}$ \\
\hline $\mathrm{CH} 3, \mathrm{MW5}$ & 318 & 312 & 5.8 & - & - & - & G,J,C \\
\hline Well cluster 2 & 328 & 324 & 4.9 & - & 35 & 70 & $G, J, E M, G$ \\
\hline Well cluster 4 & 321 & 319 & 2.1 & - & - & - & $\mathrm{G} \underline{\mathrm{J}}$ \\
\hline Well cluster 6 & 319 & 317 & 1.8 & - & 90 & 400 & G. J, EM \\
\hline Well cluster 7 & 327 & 327 & $<0.3$ & - & 45 & 65 & $G, \underline{E M}$ \\
\hline Well cluster 8 & 327 & 325 & 1.8 & - & 30 & 65 & $\mathrm{G}, \underline{\mathrm{EM}}$ \\
\hline VES1 & 321 & 320 & 1.2 & 40 & - & 300 & NA \\
\hline VES2 & 328 & 323 & 4.9 & 75 & - & 300 & NA \\
\hline VES3 & 323 & 323 & 0.2 & 95 & - & 200 & $\mathrm{NA}$ \\
\hline VES4 & 320 & 319 & 0.2 & 85 & - & 110 & NA \\
\hline VESS & 322 & 321 & 0.3 & 300 & - & 600 & NA \\
\hline VES6 & 321 & 321 & 0.3 & 70 & - & 65 & NA \\
\hline VES7 & 319 & 318 & 0.5 & 85 & - & 150 & NA \\
\hline VES8 & 328 & 326 & 0.2 & 95 & - & 200 & NA \\
\hline VES9 & 316 & 316 & 0.5 & 60 & - & 250 & NA \\
\hline VES10 & 320 & 319 & $<0.3$ & 160 & - & 130 & NA \\
\hline VES11 & 320 & 319 & 1.5 & 60 & - & 200 & NA \\
\hline VES12 & 321 & 320 & 1.8 & 60 & - & 300 & NA \\
\hline VES13 & 319 & 318 & 0.8 & 50 & - & 200 & NA \\
\hline VES14 & 323 & 322 & 0.6 & 110 & - & 200 & NA \\
\hline VES15 & 325 & 323 & 2.1 & 85 & - & 300 & $\mathrm{NA}$ \\
\hline VES16 & 320 & 319 & 0.8 & 68 & - & 150 & $\mathrm{NA}$ \\
\hline VES17 & 325 & 322 & 2.4 & 65 & - & 90 & $\mathrm{NA}$ \\
\hline VES 18 & 331 & 329 & 2.7 & 65 & - & 120 & $\mathrm{NA}$ \\
\hline
\end{tabular}

aVES, vertical electric sounding; EM electromagnetic induction log; J, borehole gamma log; $C$, core lithologic log; --, data not available; N/A, not applicable.

bValues in this table are given in meters while those in Figure $\mathbf{4 2}$ are given in feet. To convert feet to meters,multiply by 0.305 .

cUnderline indicates the primary borehole log used to determine the thickness of the spoil/clay layer 
to $1.6 \mathrm{~m}$ ( 4 to $6 \mathrm{ft}$ ). East and north of the FGD by-product application area, a thin veneer of spoil and clay is present and generally is less than $0.3 \mathrm{~m}(1 \mathrm{ft})$ thick. South of the application area, the thickness of the spoil/clay layer increases to $5.8 \mathrm{~m}$ (19 ft) at monitoring well cluster 5 .

The altitude of the base of the spoil/clay layer ranges from 308 to $329 \mathrm{~m}(1,027$ to $1,081 \mathrm{ft})$ above sea level (Figure 42). The altitude of the base of the spoil/clay layer (top of bedrock) probably indicates the lowest altitude of surface mining of coal and (or) clay. The altitude of the base of the spoil/clay layer is greatest west and north of the test watersheds and east of the FGD by-product application area. Altitudes are lowest southeast of the application area along a drainage swale.

Borehole geophysical measurements supplied an additional data set to verify the depths and thicknesses of lithologic units penetrated during drilling. An example of the geophysical logs is presented for core hole 3 in Figure 43. Logs for other boreholes are on file at the US Geological Survey office in Columbus, Ohio. The logs show the usefulness of these geophysical techniques in identifying the coal/clay sequence. Additionally, vertical control can sometimes be inaccurate during coring due to lost core, washouts, or drill rig operator error. Geophysical logging can serve as an accurate check of depths to major stratigraphic units.

Solid phase samples were analyzed to assess relative concentrations of major and trace elements in rock, mine spoil, and the FGD by-product/compost mixture applied to the mine site. These data also help explain water-rock reactions that may be occurring in the aquifer system and they provide constraints on geochemical models of interactions involving the FGD by-product. The isotopic composition of the reduced and oxidized sulfur phases in the FGD by-product/compost mixture was determined to assess the potential of sulfur isotope ratios of dissolved sulfate as a tracer of FGD by-product leachate.

Rocks that form the aquifers beneath the study site include sandstone, shale, limestone, coal, and clay. Geochemical data were obtained and provided information on the amounts of major and trace elements that can be contributed to groundwater through water-rock reaction. These geochemical data were determined for aquifer materials from three core holes and is provided in the Appendix Table D-1. Major-element compositions were correlated with rock type. For example, high $\mathrm{Al}, \mathrm{Mg}, \mathrm{K}$, and $\mathrm{Fe}$ concentrations are associated with underclay and shale. High Fe concentrations were found in the coal samples. For all three lithologies, $\mathrm{Fe}$ is present predominantly as pyrite $\left(\mathrm{FeS}_{2}\right)$. Pyrite is the primary source of iron, sulfur, and acidity in acid 


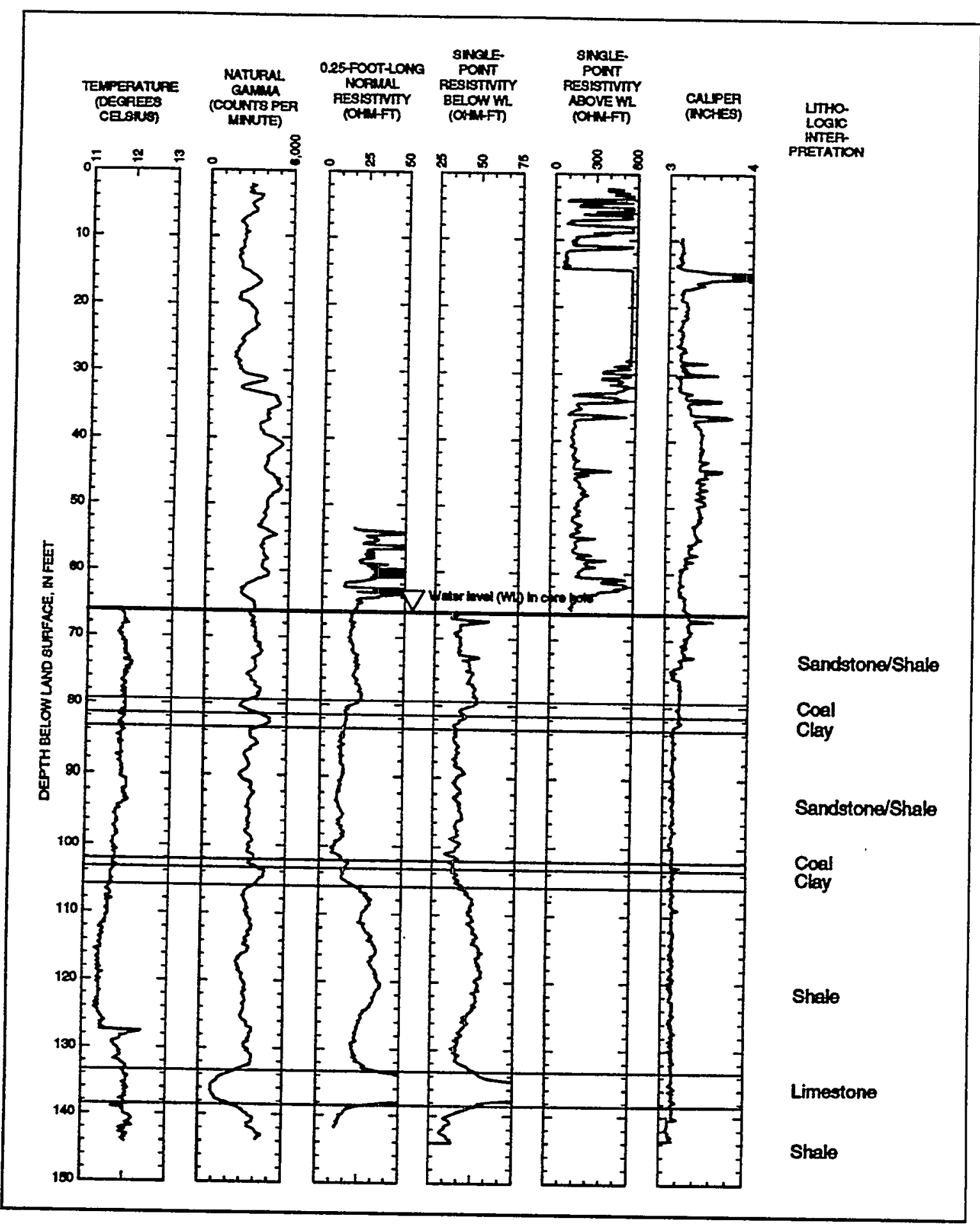

Figure 43. Geophysical log responses and lithologic interpretation, core hole 3, Tuscarawas County, OH. (Note scale change on two single point resistivity logs.) 
mine drainage affecting the mine site. Relative median concentrations of selected elements for lithologic units at the study site are shown in Figure 44. The elements As, Fe, and Se are most concentrated in coal samples, whereas $\mathrm{Ba}, \mathrm{Cr}, \mathrm{Co}$, and $\mathrm{Ni}$ are most concentrated in underclay and shale samples.

Water samples were collected from four sources during the course of this study: precipitation, the shallow unsaturated zone (i.e. interstitial water), groundwater, and surface water. All of the analytical results are provided in the Appendix (Tables D-2 through D-6). Various properties and constituents used to distinguish sources of water at the site include $\mathrm{pH}$, specific conductance, selected major ions and trace elements $\left(\mathrm{Ca}, \mathrm{Mg}, \mathrm{SO}_{4}, \mathrm{Fe}\right.$, and $\left.\mathrm{B}\right)$ and $\delta^{34} \mathrm{~S}$ of dissolved $\mathrm{SO}_{4}$. A Piper diagram (Figure 45) and a series of boxplots were also used to graphically and statistically differentiate water from various sources and sampling rounds (Figures 46 and 47). Depth profiles of $\mathrm{pH}$, major and trace elements, tritium, and $\mathrm{S}$ isotopes are shown in Figures 48 through 56 and are used to evaluate the effects of depth on water quality. Precipitation and surface quality are shown on these plots for reference.

\subsubsection{Precipitation}

Precipitation that fell on the site was acidic, with $\mathrm{pH}$ ranging values ranging from 3.7 to 4.5 (median $\mathrm{pH}$ was 4.2). On a milliequivalent basis, the dominant cation in the wet deposition samples was $\mathrm{H}^{+}$and the dominant anion was $\mathrm{SO}_{4}$. Specific conductance for the wet deposition samples ranged from 25 to $50 \mu \mathrm{S} / \mathrm{cm}$.

In contrast, the $\mathrm{pH}$ of dry deposition samples obtained by rinsing the dry collector bucket with approximately $500 \mathrm{~mL}$ of deionized water ranged from 4.9 to 6.4 (median $\mathrm{pH}$ was 6.0). On a milliequivalent basis, the dominant cation was $\mathrm{Ca}$ and the dominant anion was $\mathrm{SO}_{4}$. Specific conductance of the dry deposition samples ranged from 20 to $146 \mu \mathrm{S} / \mathrm{cm}$. With the exception of $\mathrm{Mn}$ and $\mathrm{Zn}$, concentrations of most trace elements were at or below reporting limits for both wet and dry deposition samples. The $\mathrm{pH}$ and major ion composition of wet and dry deposition recorded at the Dover gage were similar to those reported for acid precipitation in other parts of the northeastern United States (National Atmospheric Deposition Program/National Trends Network). 

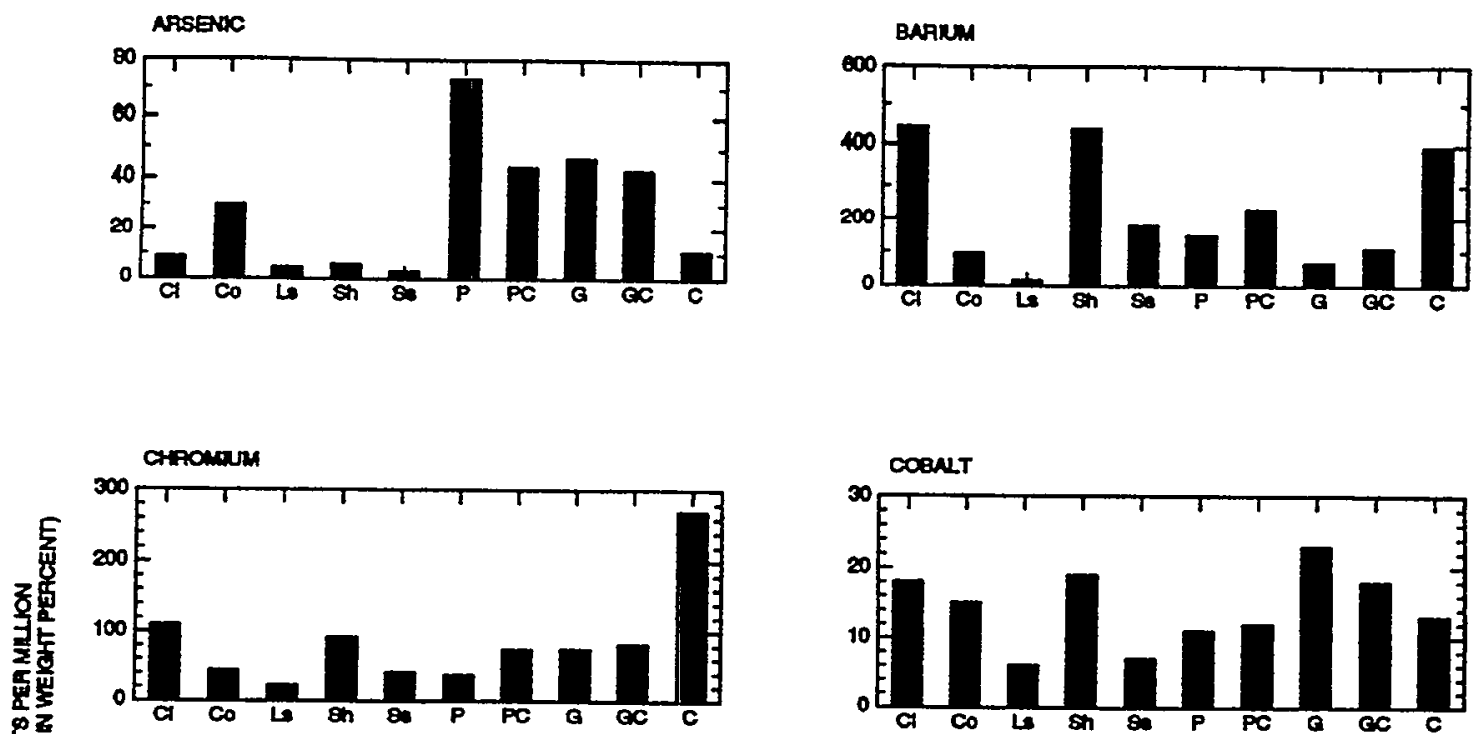

RON
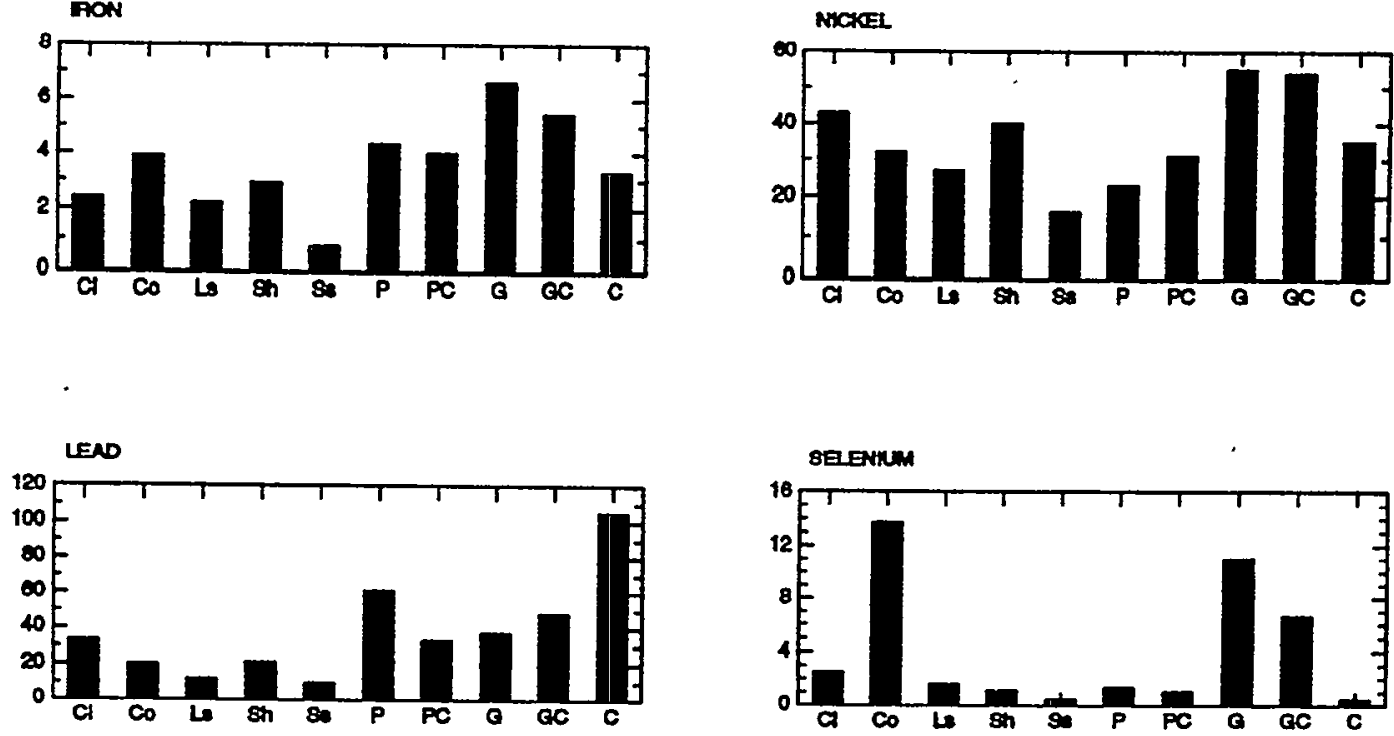

\begin{tabular}{|ll|}
\hline & EXPLANATION \\
Cl Clay & P PFBC FGD by-product \\
Co Coal & PC PFBC plus compost \\
Ls Limestone & G GMC FGD by-product \\
Sh Shale & GC GMC plus compost \\
SS Sandstone & C Compost
\end{tabular}

Figure 44. Relative abundances of selected elements in lithologic units and FGD by-product samples. 


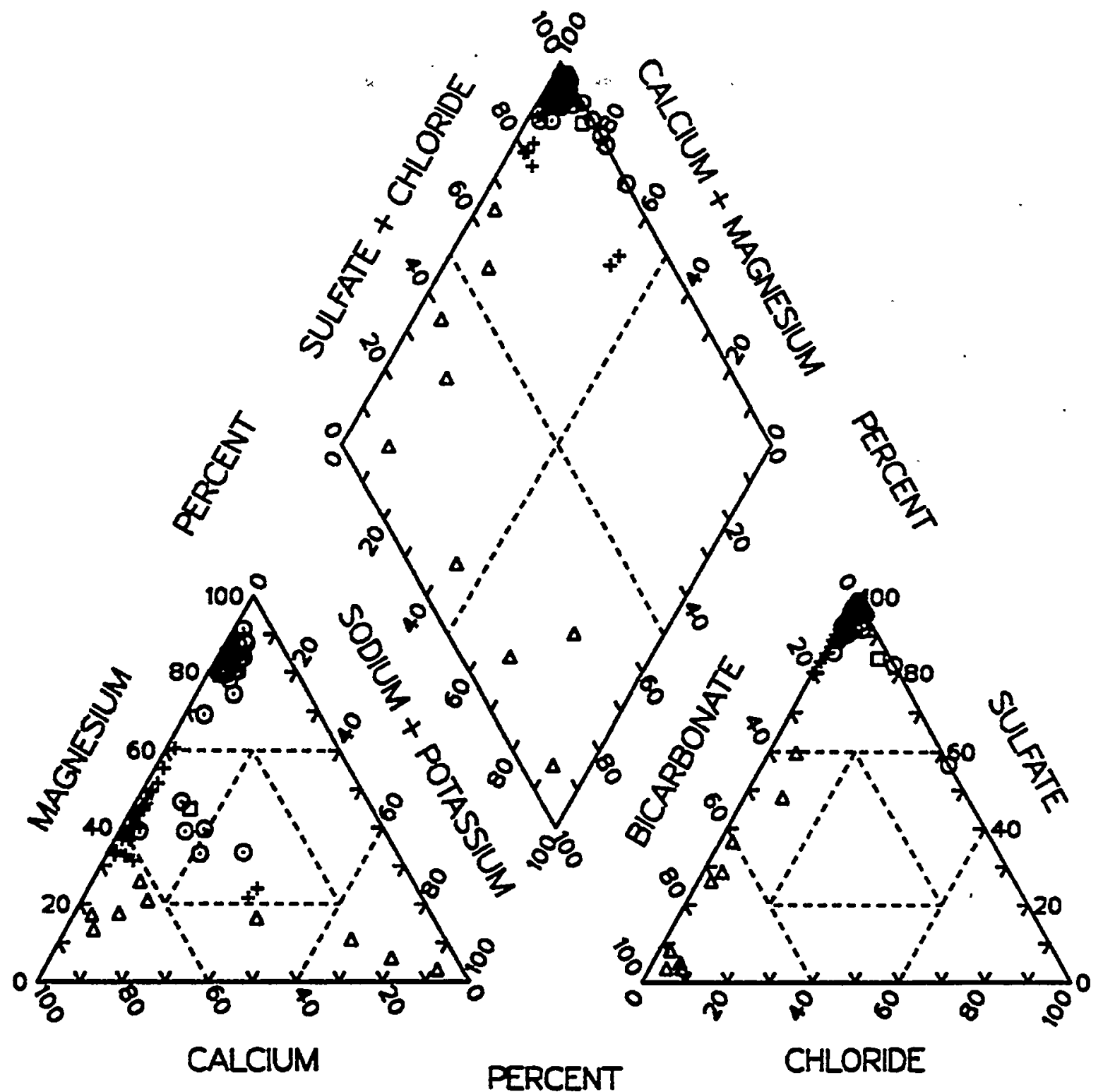

\begin{tabular}{|l|}
\hline \multicolumn{1}{|c|}{ EXPLANATION } \\
$\odot$ Interstitial water \\
+ Onsite ground water \\
$\Delta$ Offsite domestic - well water \\
$\square$ Surface water
\end{tabular}

Figure 45. Piper diagram of all water samples. 

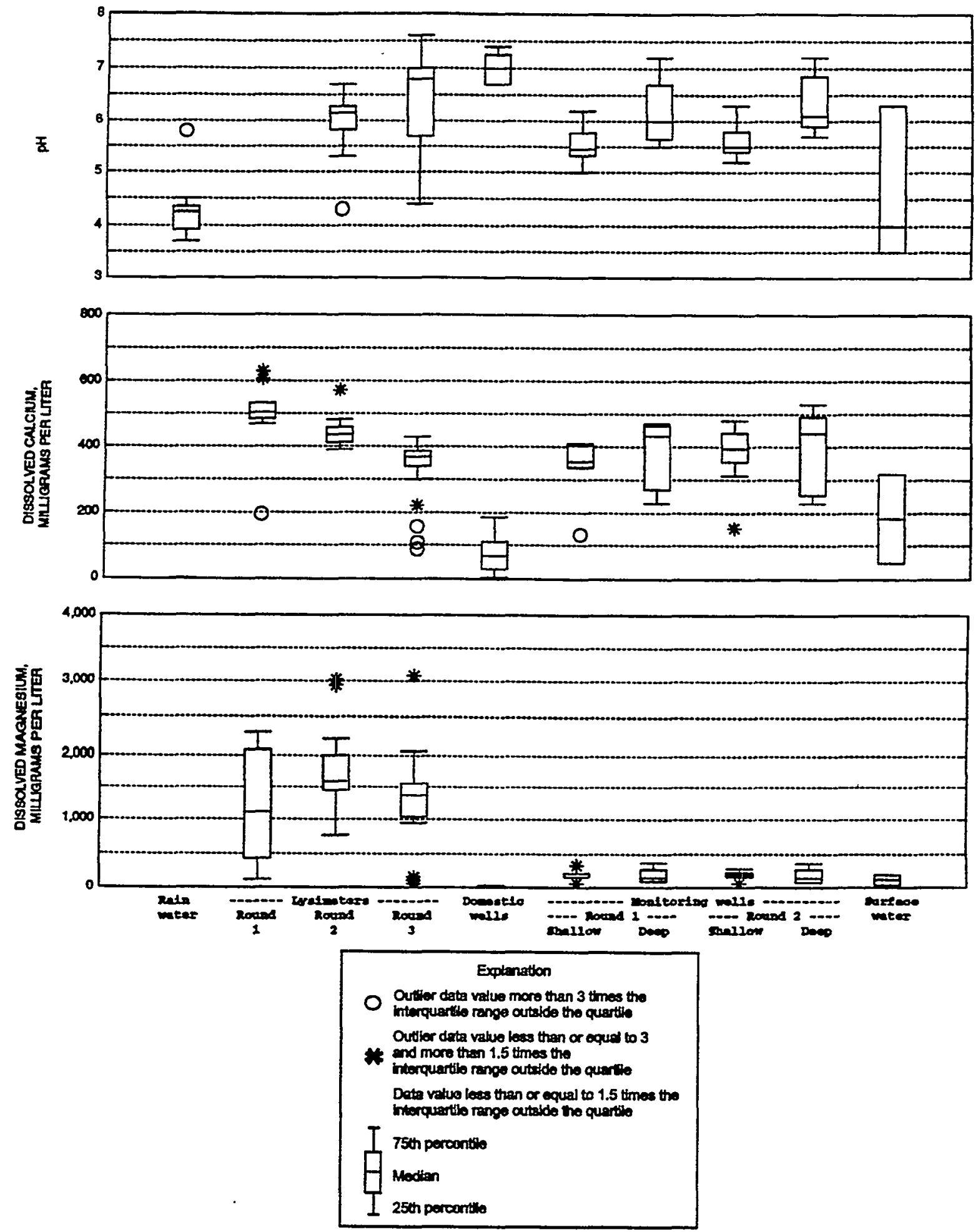

Figure 46. Boxplots of $\mathrm{pH}$, dissolved calcium, and dissolved magnesium in water samples. ( $\mathrm{pH}$ values for lysimeter round 1 were not obtained. Dissolved calcium and magnesium values for precipitation are near zero). 

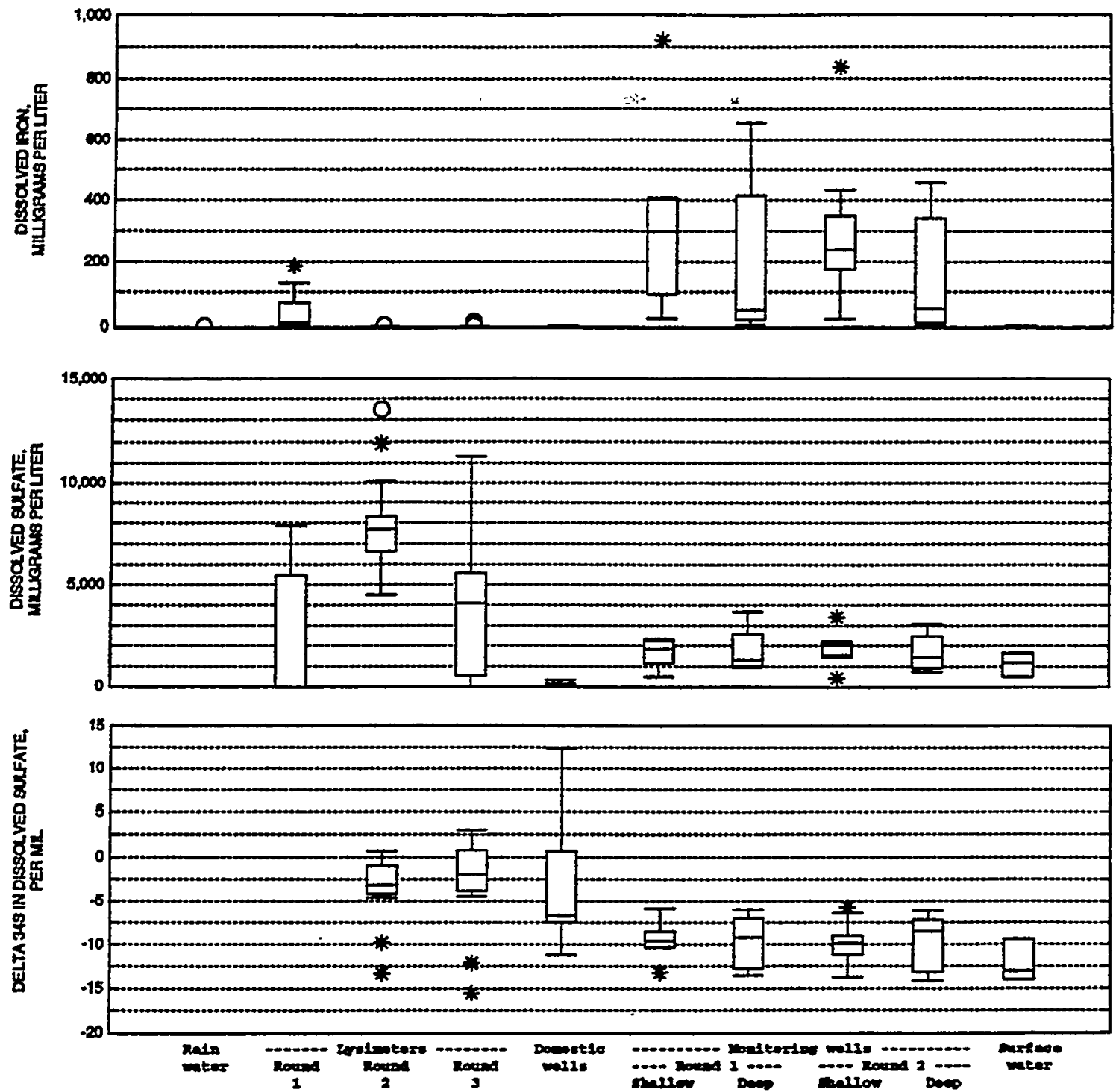

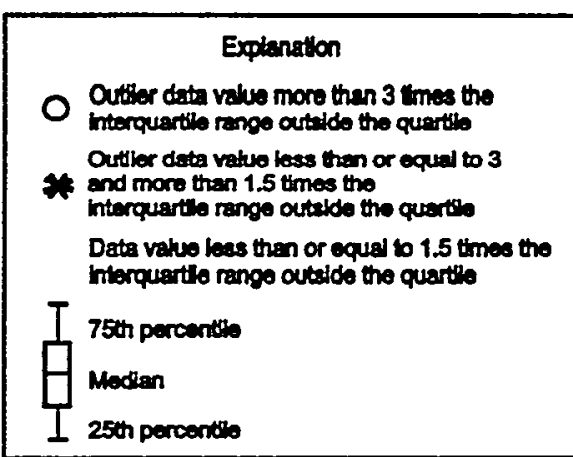

Figure 47. Boxplots of dissolved iron, dissolved sulfate and delta ${ }^{34} \mathrm{~S}$ in sulfate in water samples (dissolved iron and sulfate values for precipitation were near zero). 

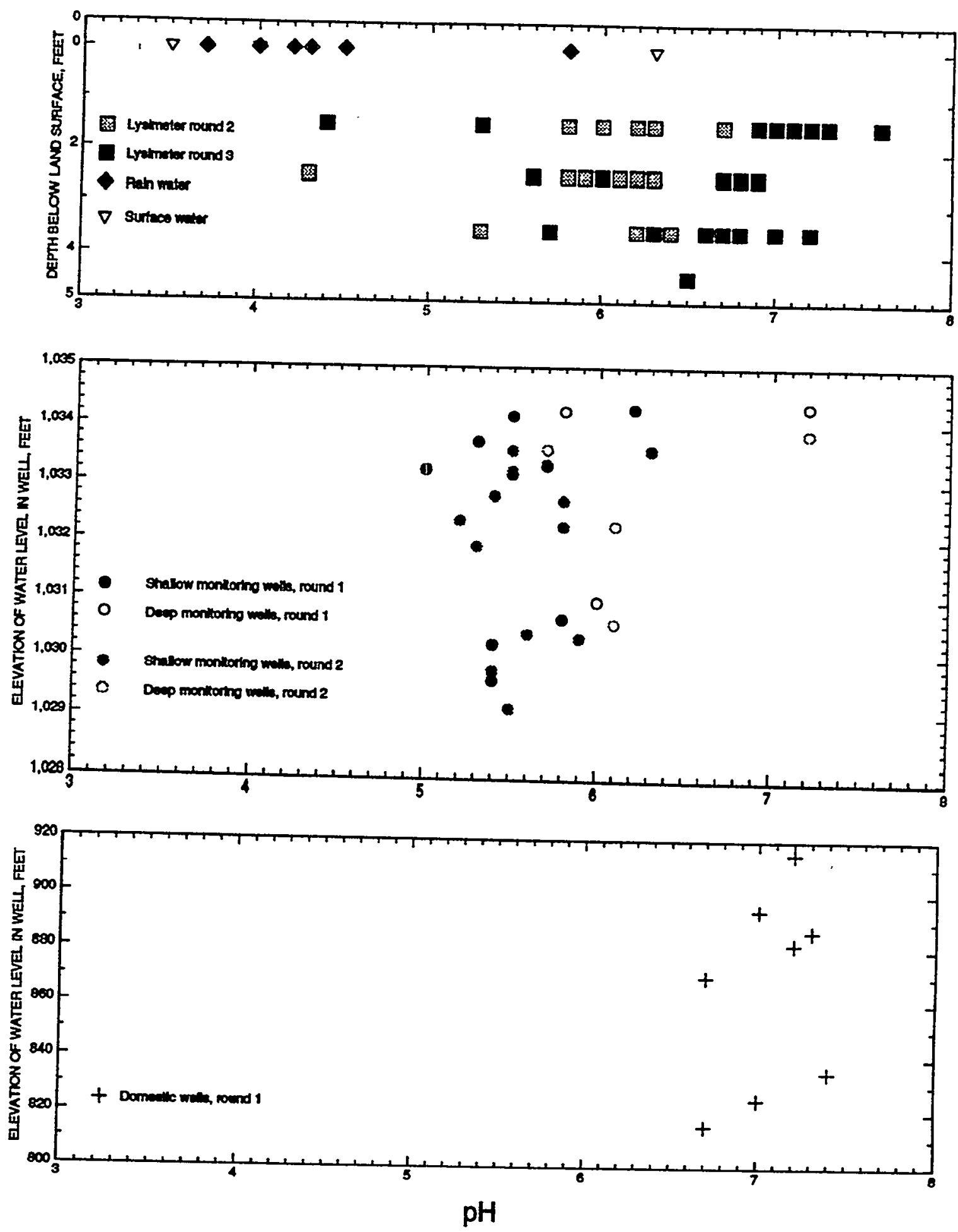

Figure 48. $\mathrm{pH}$ versus depth (in feet) for all water samples (note that $\mathrm{pH}$ values were not obtained for lysimeter round 1 ). 

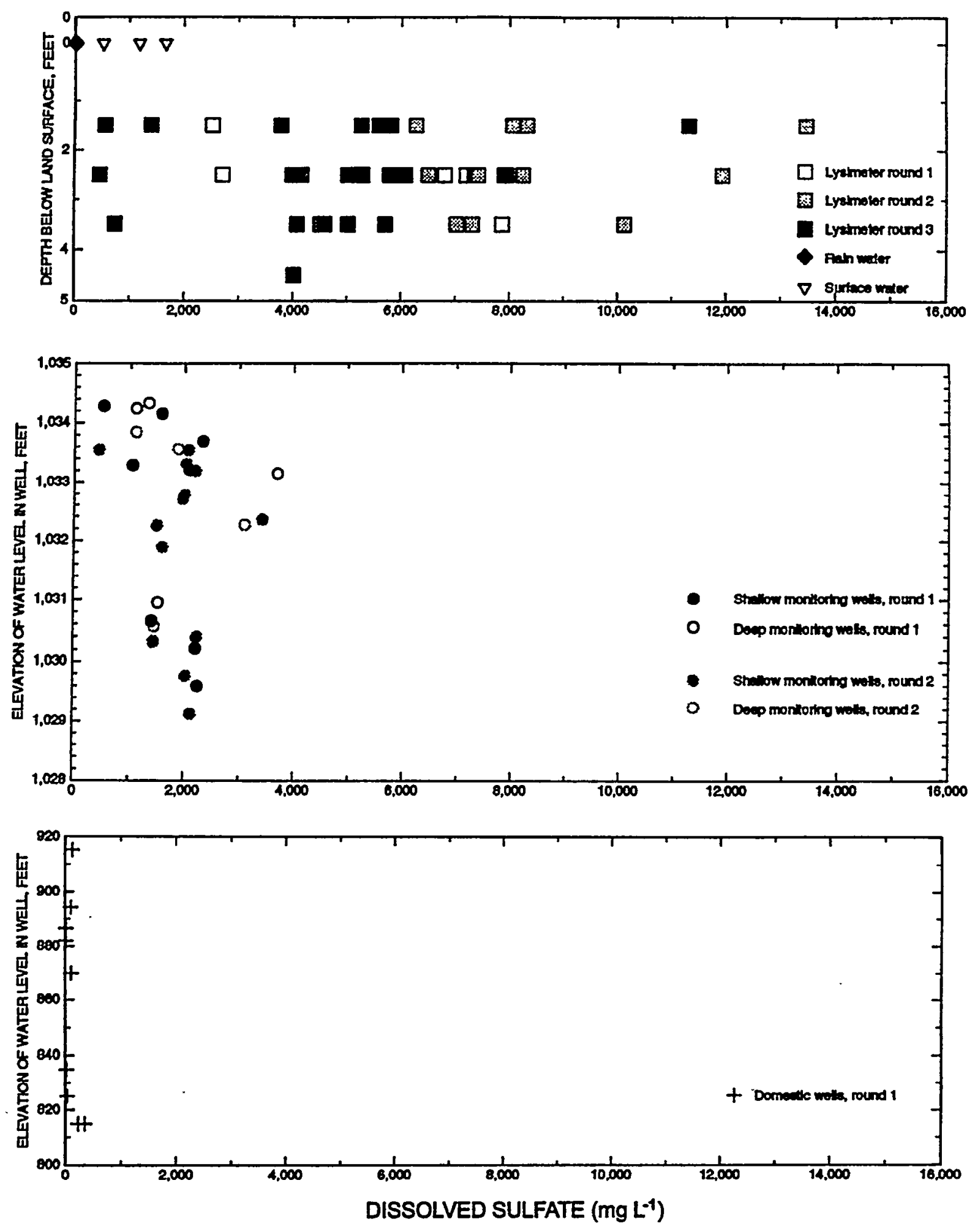

Figure 49. Dissolved sulfate versus depth (in feet) for all water samples. 

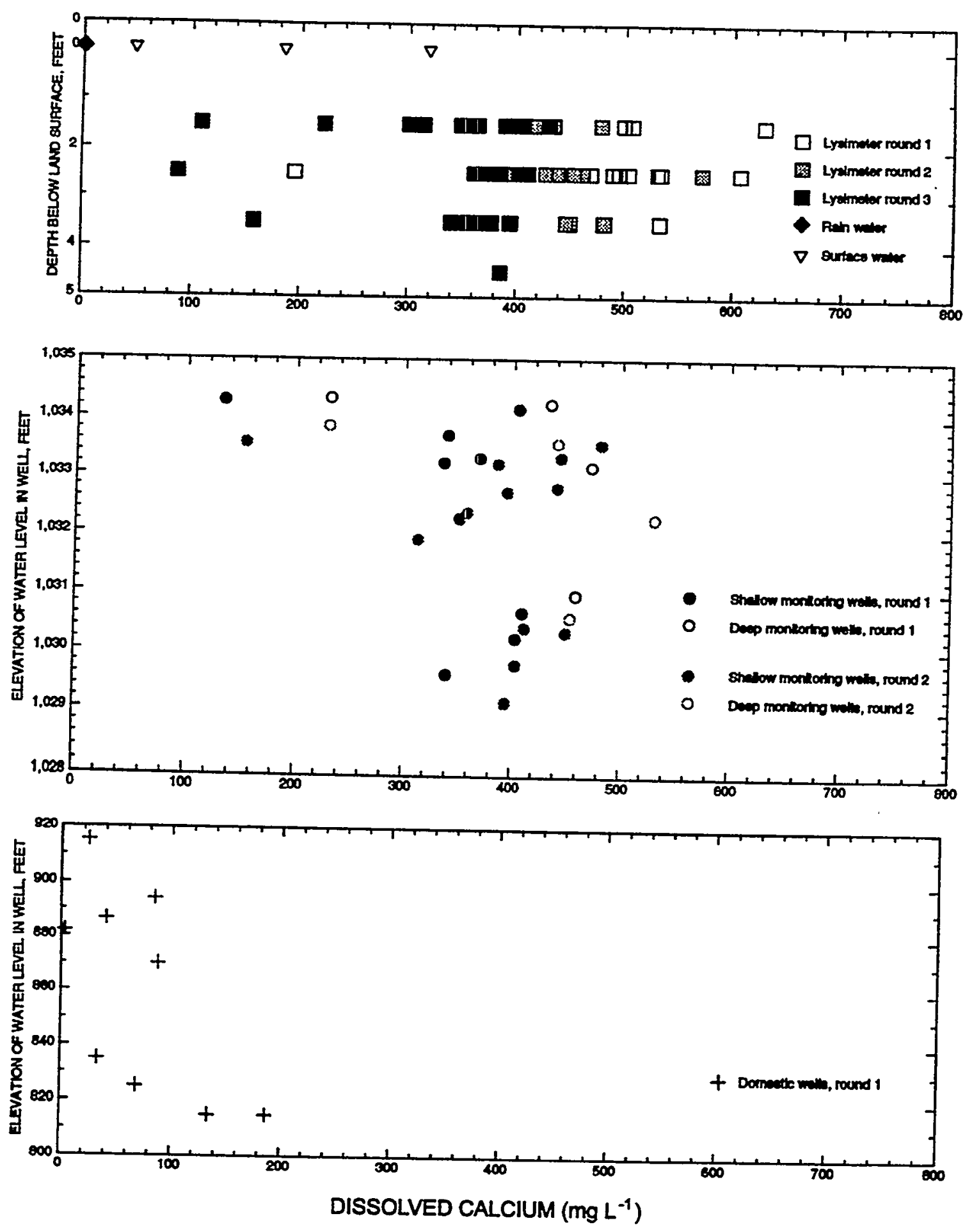

Figure 50. Dissolved calcium versus depth (in feet) for all water samples. 

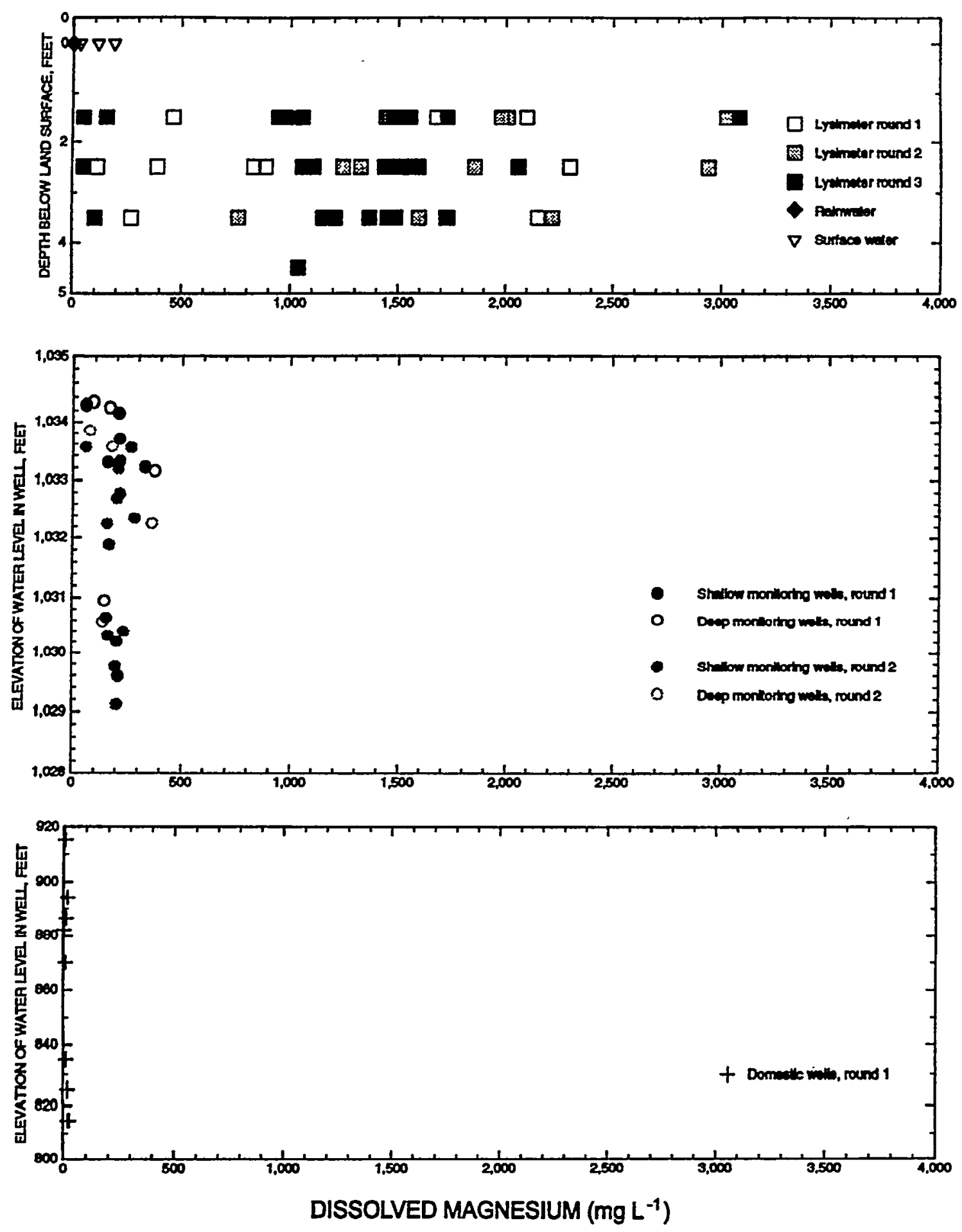

Figure 51. Dissolved magnesium versus depth (in feet) for all water samples. 

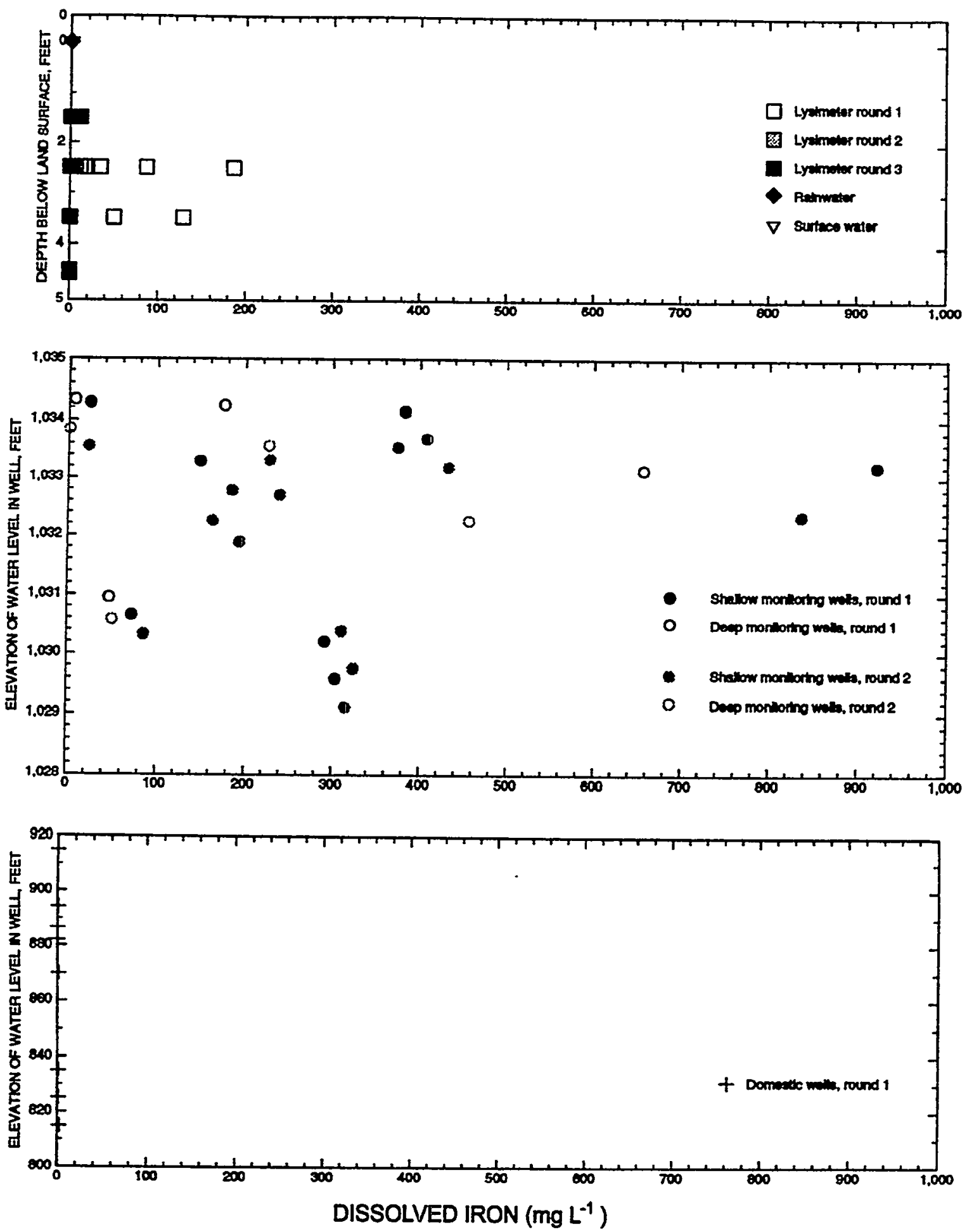

Figure 52. Dissolved iron versus depth (in feet) for all water samples. 

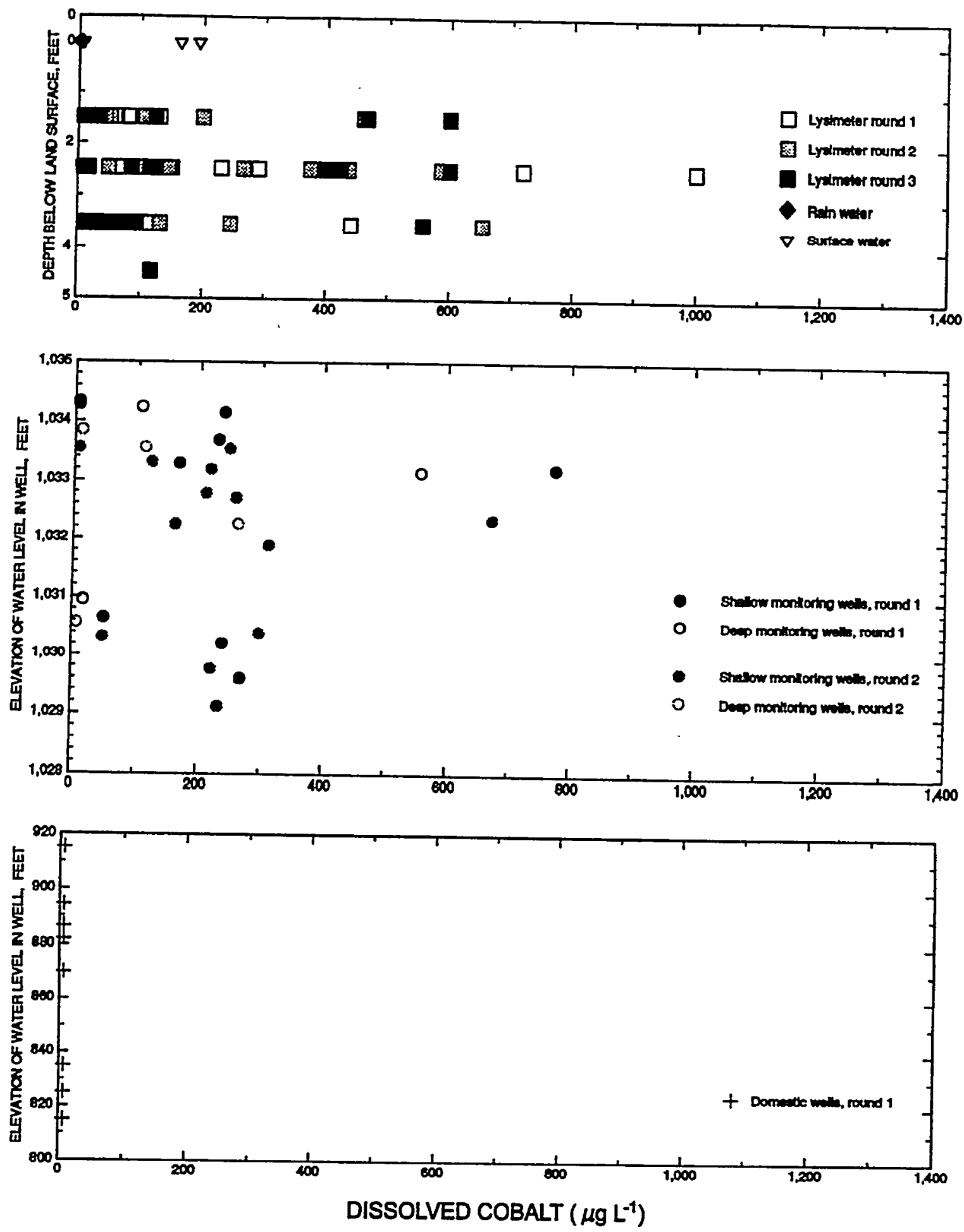

Figure 53. Dissolved cobalt versus depth (in feet) for all water samples. 

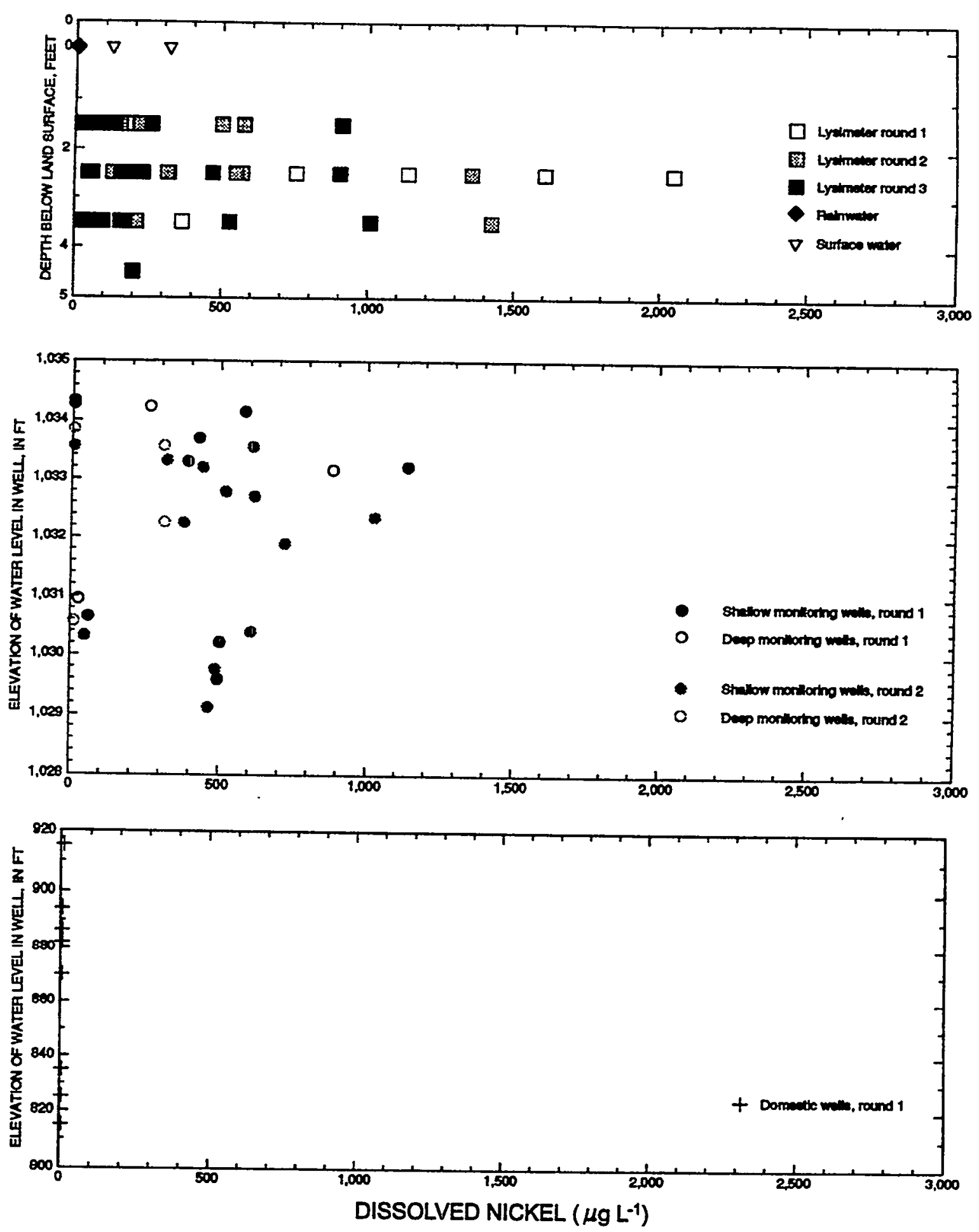

Figure 54. Dissolved nickel versus depth (in feet) for all water samples. 

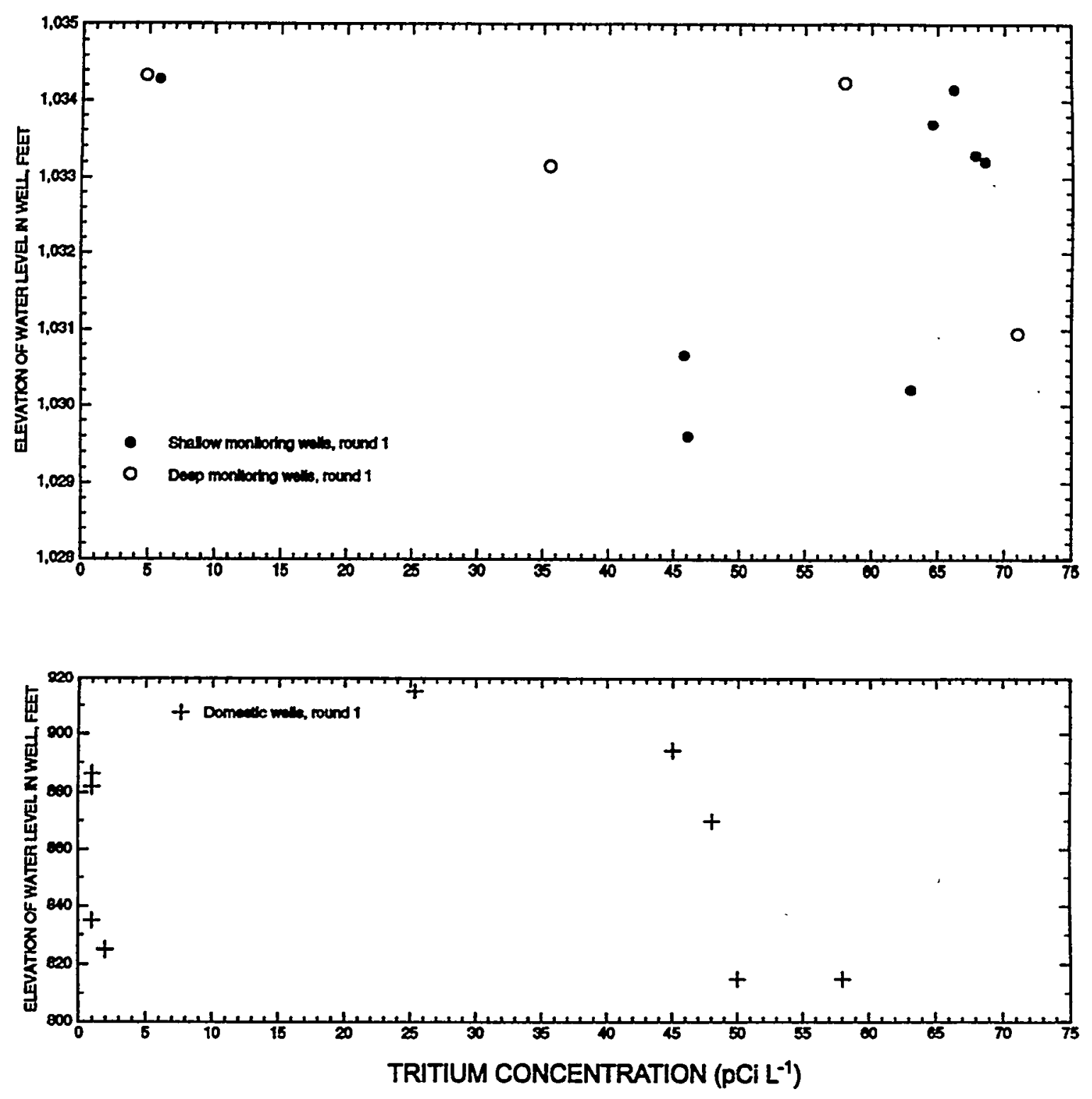

Figure 55. Tritium concentration versus depth (in feet) for round 1 groundwater samples. 

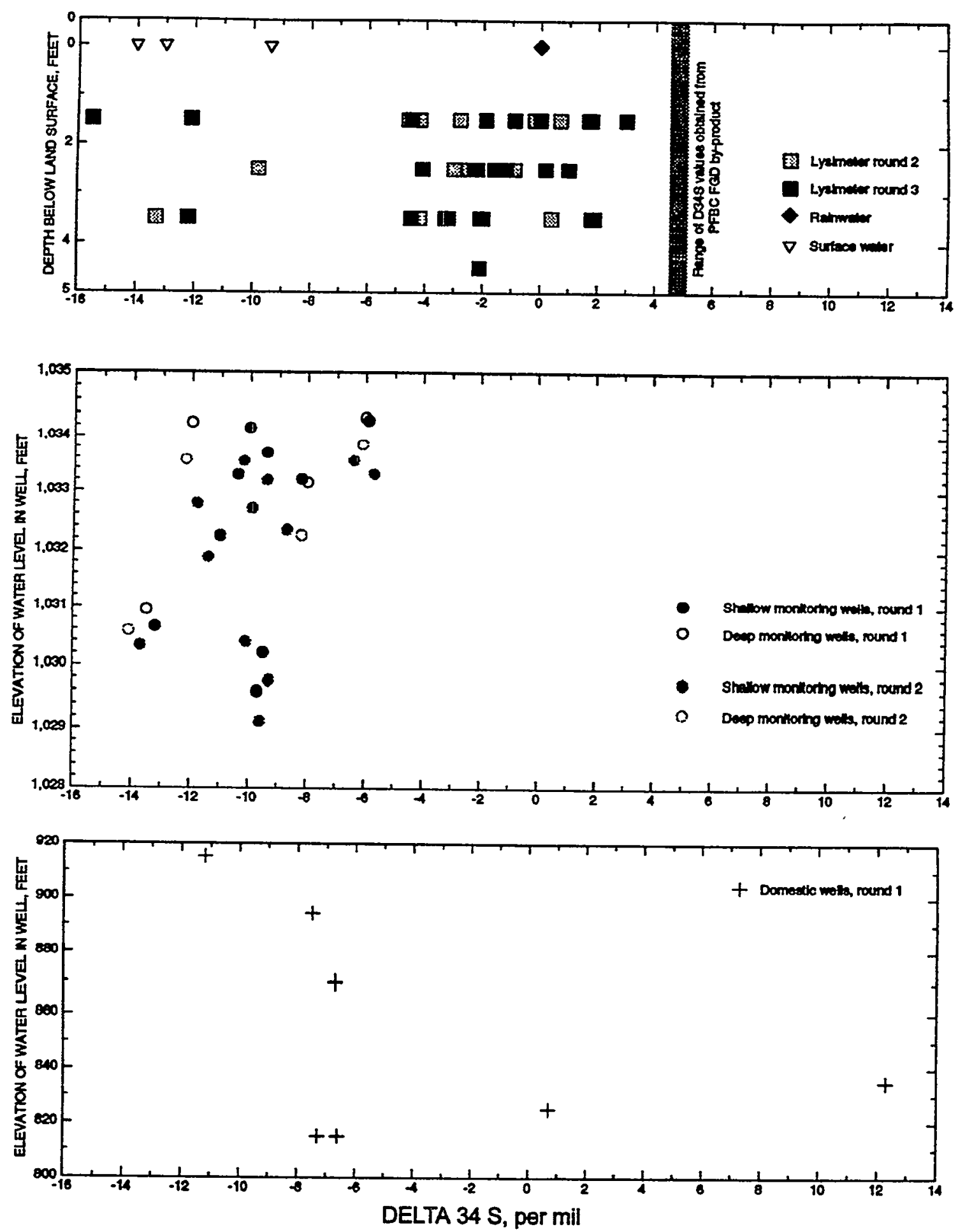

Figure 56. Delta ${ }^{34} \mathrm{~S}$ in sulfate versus depth (in feet) for all water samples (note that delta ${ }^{34} \mathrm{~S}$ in sulfate values were not obtained for lysimeter round 1). 


\subsubsection{Interstitial Water}

The performance of the lysimeters installed at the site varied considerably (in this context, performance refers to the number of lysimeters that produced water of sufficient quantity for chemical analysis). During the first round of sampling, only 9 of 35 lysimeters yielded enough water. Thus, many round 1 analysis are incomplete. The performance improved with time, however, with 15 and 24 samples being obtained during sampling rounds 2 and 3 , respectively. A reason for the improving performance may be that the moisture content of the spoil slowly increased after reclamation (the period preceding the reclamation of the mine site was exceptionally dry). It should be noted that, for rounds 1 and 3, only one and four control area lysimeters yielded enough water for analysis, respectively.

Round 2 and 3 data show that interstitial water $\mathrm{pH}$ ranged from 4.3 to 7.6. The median $\mathrm{pH}$ value for round 2 samples in the application area was near 6.2, and the median $\mathrm{pH}$ of round 3 samples was 6.9. The median $\mathrm{pH}$ for control area interstitial waters was 5.3 for round 3 samples. (No control area lysimeters yielded enough water for $\mathrm{pH}$ measurement in round 1.) Lysimeters that yielded water with $\mathrm{pH}$ values $<5.0$ included $\mathrm{LCl}$ A (TU-131) during round 2 (pH of 4.3 at depth of $0.76 \mathrm{~m}$, i.e. $2.5 \mathrm{ft}$ ) and LC5 A (TU-159) during round 3 (pH of 4.4 at depth of $0.45 \mathrm{~m}$, i.e. 1.5 feet). On average, $\mathrm{pH}$ increased by about 0.8 units between round 2 and round 3. A decrease was found at only one of the 14 lysimeters yielding sufficient sample for $\mathrm{pH}$ determinations in rounds 2 and 3 .

Interstitial water samples were the most concentrated waters found in the study areas. Specific conductance for round 2 samples collected from clusters within the FGD by-product application area ranged from 5,810 to $14,700 \mu \mathrm{S} / \mathrm{cm}$ (median of $9,340 \mu \mathrm{S} / \mathrm{cm}$ ), and ROE ranged from 6,560 to $20,900 \mathrm{mg} / \mathrm{L}$ (median of $11,700 \mathrm{mg} / \mathrm{L}$ ). In round 3 , most lysimeters yielded interstitial waters that were less concentrated than the round 2 samples. Round 3 specific conductance ranged from 5,890 to $13,100 \mu \mathrm{S} / \mathrm{cm}$ (median of $7,440 \mu \mathrm{S} / \mathrm{cm}$ ), and residue on evaporation ranged from 5,650 to $18,000 \mathrm{mg} / \mathrm{L}$ (median of $8,710 \mathrm{mg} / \mathrm{L}$ ).

Specific conductance values in samples obtained from control area lysimeters were markedly lower than those from the FGD by-product application area. Specific conductance ranged from 1,210 to $2,580 \mu \mathrm{S} / \mathrm{cm}$ (median for round 3 samples from the control area lysimeters was 1,445 . $\mu \mathrm{S} / \mathrm{cm})$. Residue on evaporation data were not available for this subset of samples. 
Changes in the concentrations of the major ions were evident between lysimeter sampling rounds. (Rounds 1, 2, and 3 took place 9, 13, and 16 months after reclamation and FGD byproduct application, respectively.) In particular, $\mathrm{Mg}$ and $\mathrm{SO}_{4}$ concentrations generally increased between rounds 1 and 2 but decreased between rounds 2 and 3 . Calcium concentrations tended to decrease during all three sampling rounds (Figures 46 and 50). Temporal trends in individual ion concentrations between sample rounds must be viewed with caution, however, because major snowmelt (recharge) occurred immediately before collection of the round 3 samples. Dilution of the interstitial waters during such a recharge event is probable and would yield the declining concentrations observed for several constituents. A more reliable indicator of temporal changes is the use of element ratios, which, if both elements are conservative, are unaffected by dilution. Magnesium to calcium (Mg: $\mathrm{Ca}$ ) mole ratios increased between rounds 1 and 2 and then remained fairly constant between rounds 2 and 3 (Figure 57). This pattern would indicate that chemical processes controlling interstitial water chemistry did not vary significantly between rounds 2 and 3 despite the significant changes in calcium and magnesium concentrations observed between the two sampling rounds.

Interstitial waters are classified as ${\mathrm{Mg}-\mathrm{SO}_{4}}_{4}$ waters (Figure 45). Magnesium concentrations of interstitial water samples collected over rounds 1,2 , and 3 ranged from 944 to $3,080 \mathrm{mg} / \mathrm{L}$ (median of $1,451 \mathrm{mg} / \mathrm{L}$ ) within the FGD by-product application area and from 48 to $154 \mathrm{mg} / \mathrm{L}$ (median of $77.5 \mathrm{mg} / \mathrm{L}$ ) in the control area. Similarly, $\mathrm{SO}_{4}$ concentrations ranged from 3,506 to $9,414 \mathrm{mg} / \mathrm{L}$ (median of $4,960 \mathrm{mg} / \mathrm{L}$ ) within the application area and from 485 to $1,506 \mathrm{mg} / \mathrm{L}$ (median of $691 \mathrm{mg} / \mathrm{L}$ ) in the control area.

A few interstitial water samples are classified as mixed-cation- $\mathrm{SO}_{4}$ waters. These samples were collected during round 3 from interstitial water outside the FGD by-product application area (cluster 5; Figure 12). Water samples from the lysimeters installed outside the application area have Mg:Ca mole ratios near 1 (mean Mg:Ca of 0.91), similar to the mean Mg:Ca mole ratio obtained for round 2 groundwater samples (mean $\mathrm{Mg}: \mathrm{Ca}$ of 0.80 ). The interstitial waters from lysimeters in the application area have much higher $\mathrm{Mg}: \mathrm{Ca}$ mole ratios (mean $\mathrm{Mg}: \mathrm{Ca}$ of 6.56; Figure 57).

Iron concentrations in the interstitial water were generally low relative to those in groundwater samples, with the exception of a few round 1 samples in which dissolved Fe concentrations exceeded $15 \mathrm{mg} / \mathrm{L}$. Dissolved $\mathrm{Mn}$ concentrations in interstitial water collected from within the FGD application area ranged from 0.6 to $114 \mathrm{mg} / \mathrm{L}$. Manganese concentrations decreased between rounds 1,2 , and 3 , and median values were $51.8,25.9$, and $7.56 \mathrm{mg} / \mathrm{L}$, respectively. 


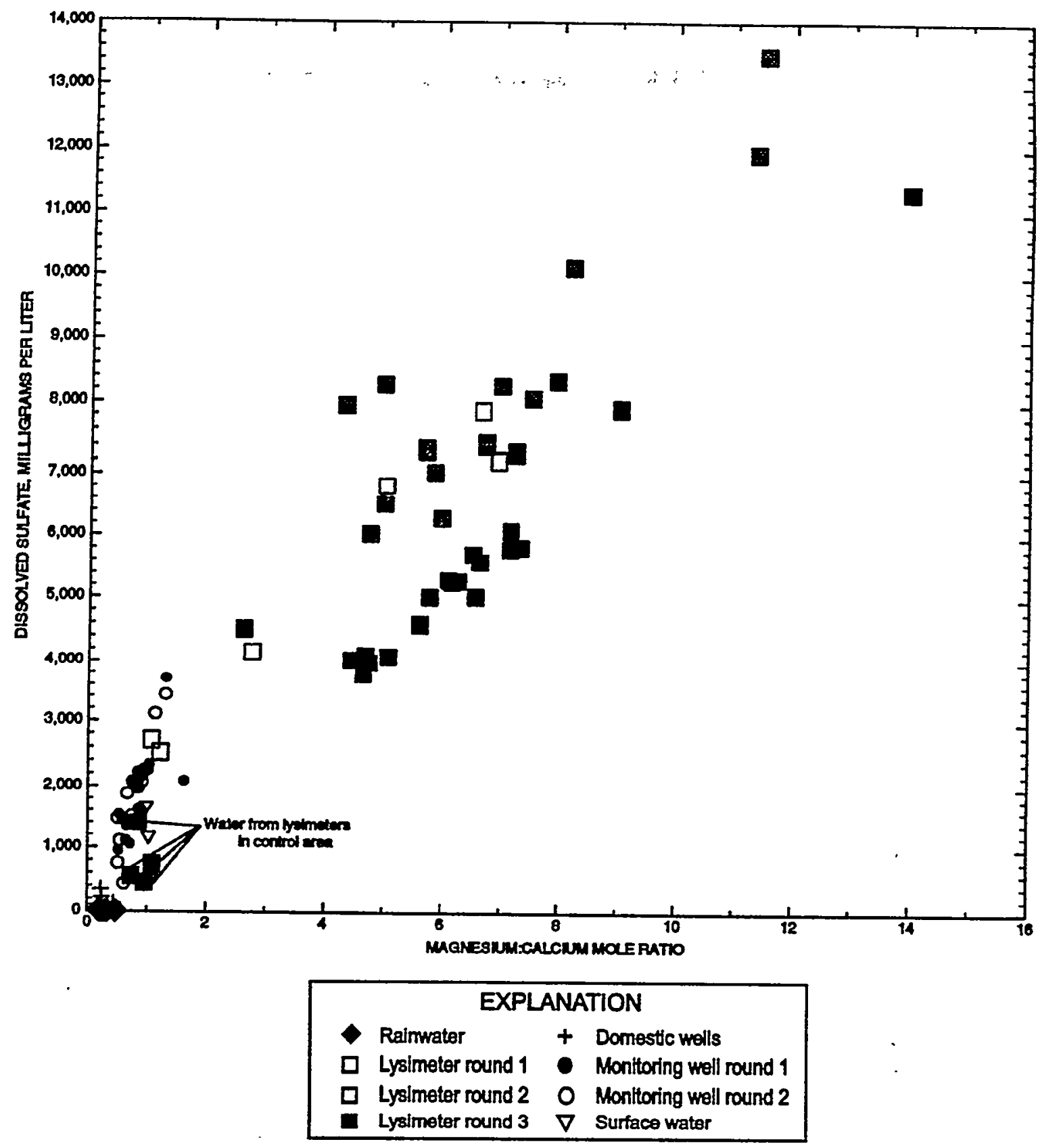

Figure 57. Plot of magnesium:calcium mole ratio versus dissolved sulfate for all water samples. 
Dissolved $\mathrm{Al}$ concentrations varied considerably between sampling locations. Four of 47 application area samples exceeded 1,000 $\mu \mathrm{g} / \mathrm{L}$. Aluminum concentrations for all application area samples ranged from 102 to $4,126 \mu \mathrm{g} / \mathrm{L}$. Medians for samples collected during rounds 1 , 2 , and 3 were 312,411 , and $233 \mu \mathrm{g} / \mathrm{L}$, respectively. Concentrations of five control area samples ranged from 117 to $3,763 \mu \mathrm{g} / \mathrm{L}$ and the median $\mathrm{Al}$ concentration was $303 \mu \mathrm{g} / \mathrm{L}$.

Trace elements found at elevated concentrations in the interstitial water samples collected within the FGD by-product application area included $\mathrm{B}, \mathrm{Co}$, and $\mathrm{Zn}$. Boron concentrations ranged from 290 to $1,200 \mu \mathrm{g} / \mathrm{L}$, and median values of 850,823 , and $448 \mu \mathrm{g} / \mathrm{L}$ were observed for rounds 1,2 , and 3 , respectively. Cobalt concentrations ranged from 8 to $1,000 \mu \mathrm{g} / \mathrm{L}$ and median concentrations for rounds 1,2 , and 3 were 180,173 , and $50 \mu \mathrm{g} / \mathrm{L}$, respectively. Zinc concentrations ranged from 6 to $2,640 \mu \mathrm{g} / \mathrm{L}$ and median concentrations were 72.5, 199, and $50 \mu \mathrm{g} / \mathrm{L}$, respectively. Interstitial waters collected from the control areas had B concentrations that were much lower than those in the application area; $200 \mu \mathrm{g} / \mathrm{L}$ for one sample collected during round 1 and a median value of $45 \mu \mathrm{g} / \mathrm{L}$ for four samples collected in round 3. Cobalt concentrations in control area interstitial waters also were generally lower than those from application area interstitial waters, with a concentration of $150 \mu \mathrm{g} / \mathrm{L}$ for the round 1 sample and a median value of $120 \mu \mathrm{g} / \mathrm{L}$ for the round 3 samples. Zinc concentration in interstitial water from the round 1 control area sampling was $180 \mu \mathrm{g} / \mathrm{L}$, but the median value for round 3 samples was $618 \mu \mathrm{g} / \mathrm{L}$.

Other trace elements that may be of environmental concern including $\mathrm{As}, \mathrm{Cr}, \mathrm{Hg}, \mathrm{Pb}$, and $\mathrm{Se}$, were detected at or near the reporting limits of the analytical equipment. Arsenic was detected at a reporting limit of $1 \mu \mathrm{g} / \mathrm{L}$ in 10 of 16 interstitial water samples with the maximum concentration being $10 \mu \mathrm{g} / \mathrm{L}$ and the median $1.5 \mu \mathrm{g} / \mathrm{L}$. Chromium was found above the reporting limit of $2 \mu \mathrm{g} / \mathrm{L}$ in 52 of 55 samples and the maximum concentration was $26 \mu \mathrm{g} / \mathrm{L}$ and the median was $10 \mu \mathrm{g} / \mathrm{L}$. The median concentration for $\mathrm{Cr}_{\mathrm{r}}$ in all interstitial waters in the FGD by-product application area was $11 \mu \mathrm{g} / \mathrm{L}$, whereas the median for interstitial waters in the control area was at the reporting limit $(2 \mu \mathrm{g} / \mathrm{L})$. Mercury was not detected at a reporting limit of $0.1 \mu \mathrm{g} / \mathrm{L}$ in any interstitial water samples. Lead was detected in only one sample at a concentration of $3 \mu \mathrm{g} / \mathrm{L}$ (close to the reporting limit of $1 \mu \mathrm{g} / \mathrm{L}$ ). Selenium was detected near the reporting limit of $1 \mu \mathrm{g} / \mathrm{L}$ in 3 of 19 interstitial water samples.

Dissolved organic carbon concentrations in the interstitial waters ranged from 0.6 to $64 \mathrm{mg} / \mathrm{L}$ in samples collected during rounds 1 and 3 . Four samples collected from the FGD by-product application area during round 1 had a range of 22 to $64 \mathrm{mg} / \mathrm{L}$ and a median of $50 \mathrm{mg} / \mathrm{L}$, 
whereas 23 samples collected during round 3 had a range of 0.6 to $30 \mathrm{mg} / \mathrm{L}$ and a median of 21 $\mathrm{mg} / \mathrm{L}$. Four samples collected during round 3 from the control area had a range of 2.8 to 8.6 $\mathrm{mg} / \mathrm{L}$ and a median of $5.7 \mathrm{mg} / \mathrm{L}$.

The $\delta^{34} \mathrm{~S}$ of dissolved $\mathrm{SO}_{4}$ in interstitial water samples were obtained for rounds 2 and 3 only. Sixteen samples collected in the application area from round 2 had a range of -13.3 to +0.7 per mil and a median of -1.6 per mil. $\delta^{34} \mathrm{~S}$ for three samples of interstitial waters collected in the control area during round 3 had a range of -15.5 to -12.1 per mil and a median of -12.2 per mil.

U.S. Environmental Protection Agency (USEPA) maximum contaminant levels (MCLs) for Be $(4 \mu \mathrm{g} / \mathrm{L}), \mathrm{Cd}(5 \mu \mathrm{g} / \mathrm{L}), \mathrm{Ni}(100 \mu \mathrm{g} / \mathrm{L})$, and $\mathrm{F}(4 \mathrm{mg} / \mathrm{L})$ were exceeded in some interstitial water samples (see Appendix D for details). Beryllium concentrations exceeded the maximum contaminant limit in only 1 of 13 samples collected during round 1 . Cadmium concentrations exceeded the maximum contaminant limit in 1 of 13 samples in round 1 and 2 of 16 samples in round 2. With few exceptions, the observed concentrations of $\mathrm{Be}$ and $\mathrm{Cd}$ were close to reporting limit for inductively coupled plasma analysis and, in cases where data from multiple sampling rounds were available, the exceedances were generally not reproducible. In contrast, exceedances of the maximum contaminant limit for $\mathrm{Ni}$ were noted in nearly 70 percent of all samples from round 1, 2, and 3. Maximum Ni concentrations exceeded 2,000 $\mu \mathrm{g} / \mathrm{L}$ with the median Ni concentrations for a single interstitial water in round 1 in the control area being 754 $\mu \mathrm{g} / \mathrm{L}$, whereas the median concentration for four samples collected in round 3 was $394 \mu \mathrm{g} / \mathrm{L}$. Fluoride concentration was greater than the maximum contaminant limit of $4 \mathrm{mg} / \mathrm{L}$ in 5 of 6,16 of 16 , and 12 of 21 samples for rounds 1,2 , and 3, respectively. Median flouride concentration of FGD by-product application area for all three sampling rounds was $8 \mathrm{mg} / \mathrm{L}$, well above the median of $<0.1 \mathrm{mg} / \mathrm{L}$ for control area interstitial waters.

Chloride concentration was greater that the reporting limit and it exceeded secondary drinking water standards of $250 \mathrm{mg} / \mathrm{L}$ in 1 of 40 samples collected during round 1 (see Appendix D). The median $\mathrm{Cl}$ concentration in the FGD by-product application area was $63 \mathrm{mg} / \mathrm{L}$, whereas the median $\mathrm{Cl}$ concentration in control area interstitial waters was $17.5 \mathrm{mg} / \mathrm{L}$. Concentrations of $\mathrm{F}$, $\mathrm{Cl}$, and $\mathrm{SO}_{4}$ were all determined by use of ion chromatography. Results of $\mathrm{QC}$ samples submitted during round 1 indicate that anion data obtained by ion concentrations of the interstitial waters coupled with the very high sulfate concentrations may have affected the accuracy of the $\mathrm{F}$ and $\mathrm{Cl}$ data. 
No maximum contaminant limit exceedances were recorded for $\mathrm{As}, \mathrm{Cr}, \mathrm{Pb}, \mathrm{Hg}$, and $\mathrm{Se}$ and, with the exception of $\mathrm{Cr}$, these elements were rarely detected in any interstitial water samples.

\subsubsection{Groundwater}

The results from the groundwater sampling rounds are listed in Table 39 and shown as boxplots (Figures 46 and 47).

The $\mathrm{pH}$ of water samples collected during round 1 from nine offsite domestic wells ranged from 6.7 to 7.4 and the median was 7.0. The domestic well waters had low residue on evaporation values that ranged from 195 to $721 \mathrm{mg} / \mathrm{L}$ with the median being $319 \mathrm{mg} / \mathrm{L}$. Correspondingly, specific conductances also were relatively low, with a range of 462 to 966 $\mu \mathrm{S} / \mathrm{cm}$ and a median of $581 \mu \mathrm{S} / \mathrm{cm}$. Water sampled from these wells had no exceedances of any drinking water standards on the USEPA's maximum contaminant level list. Waters from domestic wells sampled during this study can be classified as $\mathrm{Ca}-\mathrm{HCO}_{3}$ and $\mathrm{Na}$ - and $\mathrm{K}-\mathrm{HCO}_{3}$ water types.

The groundwater beneath the study site from sampling rounds 1 and 2 had $\mathrm{pH}$ ranging from 5.3 to 7.2 , residue on evaporation from 848 to $5,940 \mathrm{mg} / \mathrm{L}$, and specific conductance from 1,110 to $4,440 \mu \mathrm{S} / \mathrm{cm}$. Measurements of reduction-oxidation potential (Eh) indicate values of 108 to 457 millivolts and only 2 of 30 groundwater samples had negative Eh values. Dissolved organic $\mathrm{C}(\mathrm{DOC})$ ranged from 0.4 to $2.0 \mathrm{mg} / \mathrm{L} . \delta^{34} \mathrm{in} \mathrm{SO}_{4}$ ranged from -14.1 to -5.7 per mil.

Major element chemistry of water from all onsite wells dominated by dissolving $\mathrm{SO}_{4}, \mathrm{Fe}, \mathrm{Ca}$, $\mathrm{Mg}$, and $\mathrm{Mn}$. Sulfate concentrations ranged from 438 to $3,710 \mathrm{mg} / \mathrm{L}$ and $\mathrm{Fe}$ concentrations ranged from 0.9 to $921 \mathrm{mg} / \mathrm{L}$. All groundwater samples had sulfide concentrations at or near the reporting limit of the Hach field spectrophotometer analysis $(<1 \mu \mathrm{g} / \mathrm{L})$. Concentrations of $\mathrm{Ca}$ and $\mathrm{Mg}$ ranged from 134 to $531 \mathrm{mg} / \mathrm{L}$ and 57 to $373 \mathrm{mg} / \mathrm{L}$, respectively. Manganese concentrations ranged from 0.261 to $67.2 \mathrm{mg} / \mathrm{L}$. Water types from onsite monitoring wells generally fall in the category of mixed cation (predominately $\mathrm{Fe}, \mathrm{Ca}$, and $\mathrm{Mg}$ )- $-\mathrm{SO}_{4}$ water types (Figure 45). Concentrations of $\mathrm{Al}$ were generally less than those in interstitial waters. Rounds 1 and 2 had ranges of 30 to $6,620 \mu \mathrm{g} / \mathrm{L}$ and 55 to $5,101 \mu \mathrm{g} / \mathrm{L}$ respectively. Median Al concentrations were 97 and $171 \mu \mathrm{g} / \mathrm{L}$ for the 2 sampling rounds.

Discussion of the trace element chemistry in water from onsite wells is limited to $\mathrm{B}, \mathrm{Co}, \mathrm{Ni}$, and $\mathrm{Zn}$ because concentrations of all other trace elements were at or near the reporting limits. 
Table 39. Ranges and medians of selected water quality consituents categorized by sample type.

\begin{tabular}{|c|c|c|c|c|c|c|c|}
\hline \multirow[b]{2}{*}{ Value type } & \multirow{2}{*}{$\begin{array}{c}S C^{\mathbf{a}^{\circ}} \\
\mu \mathrm{S} / \mathrm{cm}\end{array}$} & \multirow[t]{2}{*}{$\mathrm{pH}$} & $\mathrm{SO}^{4}$ & $\mathrm{Ca}$ & $\mathrm{Fe}$ & $\mathrm{Mg}$ & Mn \\
\hline & & & \multicolumn{5}{|c|}{ - } \\
\hline \multicolumn{8}{|c|}{ Domestic wells ( 9 samples) } \\
\hline Min & 462 & 6.7 & 9 & 3 & 0.011 & 0.5 & $<0.001$ \\
\hline $\operatorname{Max}$ & 966 & 7.4 & 345 & 187 & 1.460 & 25.3 & 0.743 \\
\hline Med & 581 & 7.0 & 95 & 68.4 & 0.436 & 10.1 & 0.137 \\
\hline \multicolumn{3}{|c|}{ Shallow wells } & \multicolumn{5}{|c|}{ Round 1 (8 samples) } \\
\hline Min & 1114 & 5.0 & 516 & 134 & 23.5 & 58.1 & 1.15 \\
\hline $\operatorname{Max}$ & 4440 & 6.2 & 2340 & 410 & 921 & 329 & 67.2 \\
\hline \multirow[t]{2}{*}{ Med } & 2920 & 5.5 & 1840 & 355 & 298 & 206 & 15.3 \\
\hline & $:$ & & \multicolumn{5}{|c|}{ Round 2 (13 samples) } \\
\hline Min & 1160 & 5.2 & 438 & 154 & 22.3 & 57 & 0.884 \\
\hline $\operatorname{Max}$ & 3830 & 6.3 & 3430 & 481 & 836 & 281 & 61.5 \\
\hline Med & 3090 & 5.5 & 2020 & 395 & 240 & 203 & 16.1 \\
\hline \multicolumn{3}{|c|}{ Deep wells } & \multicolumn{5}{|c|}{ Round 1 (5 samples) } \\
\hline Min & 2350 & 5.5 & 1110 & 231 & 6.29 & 91.2 & 0.672 \\
\hline $\operatorname{Max}$ & 4280 & 7.2 & 3710 & 473 & 657 & 373 & 47.2 \\
\hline \multirow[t]{2}{*}{ Med } & 2640 & 5.8 & 1530 & 449 & 176 & 167 & 10.0 \\
\hline & & & \multicolumn{5}{|c|}{ Round 2 (5 samples) } \\
\hline Min & 2370 & 5.5 & 1110 & 230 & 0.90 & 75 & 0.261 \\
\hline Max & 3900 & 7.2 & 3110 & 531 & 457 & 361 & 30.5 \\
\hline Med & 2880 & 6.1 & 1880 & 441 & 227 & 177 & 12.3 \\
\hline \multicolumn{3}{|c|}{ Upgradient shallow wells } & \multicolumn{5}{|c|}{ Round 1 (3 samples) } \\
\hline Min & 1110 & 5.5 & 516 & 134 & 23.5 & 58.1 & 1.15 \\
\hline $\operatorname{Max}$ & 3130 & 6.2 & 1580. & 405 & 383 & 209 & 17.9 \\
\hline \multirow[t]{2}{*}{ Med } & 2470 & 5.7 & 1050 & 369 & 149 & 148 & 10.5 \\
\hline & & & \multicolumn{5}{|c|}{ Round 2 (5 samples) } \\
\hline Min & 1160 & 5.3 & 438 & 154 & 22.3 & 57 & 0.884 \\
\hline $\operatorname{Max}$ & 3190 & 6.3 & 2070 & 481 & 375 & 264 & 20.4 \\
\hline Med & 2420 & 5.7 & 1600 & 351 & 194 & 165 & 10.3 \\
\hline \multicolumn{3}{|c|}{ Upgradient deep wells } & \multicolumn{5}{|c|}{ Round 1 (2 samples) } \\
\hline Min & 2410 & 5.8 & 1110 & 231 & 6.29 & 91.2 & 0.672 \\
\hline $\operatorname{Max}$ & 2640 & 7.2 & 1340 & 434 & 176 & 167 & 10.0 \\
\hline \multirow[t]{2}{*}{ Med } & 2525 & 5.7 & 1230 & 333 & 91.1 & 129 & 5.34 \\
\hline & & & \multicolumn{5}{|c|}{ Round 2 (2 samples) } \\
\hline Min & 2560 & 5.7 & 1110 & 230 & 0.90 & 75 & 0.261 \\
\hline $\operatorname{Max}$ & 2880 & 7.2 & 1880 & 441 & 227 & 177 & 12.3 \\
\hline Med & 2720 & 6.5 & 1490 & 336 & 114 & 126 & 6.30 \\
\hline
\end{tabular}


Table 39 (continued).

\begin{tabular}{|c|c|c|c|c|c|c|c|}
\hline \multicolumn{3}{|c|}{ Downgradient shallow wells } & \multicolumn{5}{|c|}{ Round 1 (4 samples) } \\
\hline Min & 2250 & 5.0 & 1420 & 336 & 72.9 & 155 & 8.66 \\
\hline $\operatorname{Max}$ & 4440 & 5.8 & 2260 & 410 & 921 & 329 & 67.2 \\
\hline \multirow[t]{2}{*}{ Med } & 2920 & 5.4 & 2160 & 372 & 298 & 206 & 15.3 \\
\hline & & & \multicolumn{5}{|c|}{ Round 2 (6 samples) } \\
\hline Min & 2460 & 5.2 & 1450 & 358 & 86.3 & 163 & 8.54 \\
\hline $\operatorname{Max}$ & 3830 & 5.9 & 3430 & 450 & 836 & 281 & 61.5 \\
\hline Med & 3090 & 5.6 & 2090 & 400 & 313 & 202 & 16.0 \\
\hline \multicolumn{3}{|c|}{ Downgradient deep wells } & \multicolumn{5}{|c|}{ Round 1 (3 samples) } \\
\hline Min & 2350 & 5.5 & 1530 & 449 & 47.1 & 146 & 3.42 \\
\hline $\operatorname{Max}$ & 4280 & 6.0 & 3710 & 473 & 657 & 373 & 47.2 \\
\hline \multirow[t]{2}{*}{ Med } & 2960 & 5.5 & 2010 & 459 & 243 & 208 & 12.5 \\
\hline & & & \multicolumn{5}{|c|}{ Round 2 (3 samples) } \\
\hline Min & 2370 & 5.5 & 1460 & 441 & 50.7 & 138 & 3.27 \\
\hline $\operatorname{Max}$ & 3900 & 6.1 & 3110 & 531 & 457 & 361 & 30.5 \\
\hline Med & 3060 & 6.1 & 2070 & 454 & 285 & 202 & 13.7 \\
\hline
\end{tabular}

aSC, specific conductance.

bROE, residue on evaporation at $180^{\circ} \mathrm{C}$.

cDOC, dissolved organic carbon. 
Table 39 (continued).

\begin{tabular}{|c|c|c|c|c|c|c|c|}
\hline \multirow[b]{2}{*}{ Value type } & \multirow{2}{*}{$\begin{array}{l}\mathrm{ROE}^{\mathrm{b}} \\
\mathrm{mg} / \mathrm{L}\end{array}$} & \multirow{2}{*}{$\begin{array}{l}D O C^{c} \\
\mathrm{mg} / \mathrm{L}\end{array}$} & \multirow{2}{*}{$\begin{array}{c}\delta^{34} S \\
\text { per mil }\end{array}$} & B & Co & $\mathrm{Ni}$ & \multirow[t]{2}{*}{$\mathrm{Zn}$} \\
\hline & & & & \multicolumn{3}{|c|}{$\mathrm{mg} / \mathrm{L}$} & \\
\hline \multicolumn{8}{|c|}{ Domestic wells (9 samples) } \\
\hline Min & 195 & 0.4 & -11.2 & 65 & $<6$ & $<4$ & $<1$ \\
\hline $\operatorname{Max}$ & 721 & 1.0 & 12.3 & 643 & $<6$ & 10 & 15 \\
\hline Med & 319 & 0.5 & -6.7 & 152 & $<6$ & $<4$ & 2 \\
\hline \multicolumn{4}{|c|}{ Shallow wells } & \multicolumn{4}{|c|}{ Round 1 (8 samples) } \\
\hline Min & 848 & 0.6 & -13.2 & 12 & $<6$ & $<4$ & 6 \\
\hline $\operatorname{Max}$ & 5860 & 1.6 & -5.9 & 403 & 775 & 1140 & .1860 \\
\hline \multirow[t]{2}{*}{ Med } & 3340 & 0.8 & -9.6 & 234 & 235 & 462 & 363 \\
\hline & & \multicolumn{6}{|c|}{ Round 2 (13 samples) } \\
\hline Min & 918 & 0.5 & -13.7 & 10 & 7 & 6 & 2 \\
\hline $\operatorname{Max}$ & 5590 & 1.7 & -5.7 & 468 & 673 & 1030 & 1620 \\
\hline Med & 3200 & 0.9 & -9.9 & 276 & 222 & 488 & 465 \\
\hline \multicolumn{4}{|l|}{ Deep wells } & \multicolumn{4}{|c|}{ Round 1 (5 samples) } \\
\hline Min & 2190 & 0.7 & -13.5 & 99 & $<6$ & $<4$ & 4 \\
\hline $\operatorname{Max}$ & 5940 & 1.4 & -6.0 & 300 & 557 & 883 & 674 \\
\hline \multirow[t]{2}{*}{ Med } & 3100 & 1.0 & -9.6 & 202 & 106 & 261 & 87 \\
\hline & & \multicolumn{6}{|c|}{ Round 2 (5 samples)<1 } \\
\hline Min & 1860 & 0.4 & -14.1 & 150 & 7 & $<4$ & $<1$ \\
\hline Max & 4950 & 2.0 & -6.1 & 311 & 263 & 423 & 326 \\
\hline Med & 3100 & 1.0 & -9.4 & 209 & 112 & 309 & 5 \\
\hline \multicolumn{4}{|c|}{ Upgradient shallow wells } & \multicolumn{4}{|c|}{ Round 1 (3 samples) } \\
\hline Min & 848 & 0.6 & -10.4 & 159 & $<6$ & $<4$ & 6 \\
\hline $\operatorname{Max}$ & 3930 & 0.8 & -5.9 & 403 & 239 & 583 & 323 \\
\hline \multirow[t]{2}{*}{ Med } & 2830 & 0.8 & -10.0 & 303 & 167 & 391 & 228 \\
\hline & & \multicolumn{6}{|c|}{ Round 2 (5 samples) } \\
\hline Min & 918 & 0.5 & -11.4 & 159 & 7 & 6 & 2 \\
\hline $\operatorname{Max}$ & 3610 & 1.2 & -5.7 & 468 & 313 & 721 & 933 \\
\hline Med & 2530 & 0.7 & -10.2 & 276 & 162 & 378 & 211 \\
\hline \multicolumn{4}{|c|}{ Upgradient deep wells } & \multicolumn{4}{|c|}{ Round 1 ( 2 samples) } \\
\hline Min & 2190 & 1.0 & -12.0 & 200 & $<6$ & $<4$ & 4 \\
\hline Max & 3140 & 1.2 & -6.0 & 300 & 106 & 261 & 87 \\
\hline \multirow[t]{2}{*}{ Med } & 2670 & 1.1 & -9.0 & 250 & 56 & 133 & 46 \\
\hline & & \multicolumn{6}{|c|}{ Round 2 (2 samples) } \\
\hline Min & 1860 & 0.4 & -12.2 & 150 & 11 & $<4$ & $<1$ \\
\hline $\operatorname{Max}$ & 3100 & 1.0 & -6.1 & 301 & 112 & 309 & 98 \\
\hline Med & 2480 & 0.7 & -9.2 & 226 & 62 & 157 & 50 \\
\hline
\end{tabular}


Table 39 (continued)

\begin{tabular}{|c|c|c|c|c|c|c|c|}
\hline \multicolumn{4}{|c|}{ Downgradient shallow wells } & \multicolumn{4}{|c|}{ Round 1 (4 samples) } \\
\hline Min & 2410 & 0.8 & -13.2 & 12 & 50 & 59 & 26 \\
\hline Max & 5860 & 1.6 & -8.2 & 301 & 775 & 1140 & 1860 \\
\hline \multirow[t]{2}{*}{ Med } & 3340 & 1.1 & -9.6 & 189 & 255 & 500 & 508 \\
\hline & & \multicolumn{6}{|c|}{ Round 2 (6 samples) } \\
\hline Min & 2290 & 0.8 & -13.7 & 10 & 49 & 47 & 14 \\
\hline $\operatorname{Max}$ & 5590 & 1.7 & -8.7 & 384 & 673 & 1027 & 1620 \\
\hline Med & 3320 & 1.1 & -9.8 & 277 & 247 & 548 & 529 \\
\hline \multicolumn{4}{|c|}{ Downgradient deep wells } & \multicolumn{4}{|c|}{ Round 1 ( 3 samples) } \\
\hline Min & 2510 & 0.7 & -13.5 & 99 & 17 & 25 & 9 \\
\hline $\operatorname{Max}$ & 5940 & 1.4 & -8.0 & 291 & 557 & 883 & 674 \\
\hline \multirow[t]{2}{*}{ Med } & 3530 & 0.8 & -9.6 & 202 & 200 & 417 & 301 \\
\hline & & \multicolumn{6}{|c|}{ Round 2 ( 3 samples) } \\
\hline Min & 2410 & 0.8 & -14.1 & 181 & 7 & 11 & $<1$ \\
\hline $\operatorname{Max}$ & 4950 & 2.0 & -8.2 & 311 & 263 & 423 & 326 \\
\hline Med & 3410 & 1.0 & -9.4 & 209 & 200 & 312 & 5 \\
\hline
\end{tabular}

aSC, specific conductance.

bROE, residue on evaporation at $180^{\circ} \mathrm{C}$.

cDOC, dissolved organic carbon. 
Boron concentrations ranged from 10 to $468 \mu \mathrm{g} / \mathrm{L}$ and Co concentrations ranged from $<6 \mu \mathrm{g} / \mathrm{L}$ to $775 \mu \mathrm{g} / \mathrm{L}$. Nickel concentrations ranged from $<4 \mu \mathrm{g} / \mathrm{L}$ to $1,140 \mu \mathrm{g} / \mathrm{L}$. Zinc concentrations ranged from $<1 \mu \mathrm{g} / \mathrm{L}$ to $1,468 \mu \mathrm{g} / \mathrm{L}$.

As was the case for interstitial waters, exceedances of maximum contaminant levels in groundwater were limited to $\mathrm{Be}, \mathrm{Cd}$, and $\mathrm{Ni}$. Beryllium concentrations exceeded the maximum contaminant level of $4 \mu \mathrm{g} / \mathrm{L}$ in 6 of 14 samples during round 1 and 6 of 19 in round 2 . Concentrations of Be in samples from four of nine shallow wells exceeded the maximum contaminant level during round 1 , and all 6 exceedances during round 2 were from shallow wells. Only two deep wells (well 3D and 6D) produced water in which Be concentrations during round 1 exceeded $4 \mu \mathrm{g} / \mathrm{L}$. Concentrations of $\mathrm{F}$ and $\mathrm{Cl}$ did not exceed the primary or secondary maximum contaminant levels in any of the groundwater samples.

Tritium (the radioactive isotope of hydrogen) is a general indicator of the age of groundwater because it was introduced by fallout from thermonuclear bomb testing that began in the early 1950's. This isotopic tracer, however, can only be used as a qualitative indicator of groundwater age because the tritium input function peaked during the mid 1960's. Thus, water with a given tritium concentration would have two possible dates for recharge into the aquifer. The presence of detectable concentrations of tritium ( $>1$ tritium unit, $T U$ ) indicates that some component of the water was recharged after the initiation of the bomb testing in the early 1950's (i.e. within the last 40 years). Tritium concentrations (see Appendix) were used to assess the recharge and groundwater flow rates at the mine site. If elevated tritium concentrations were not present in wells at the mine site, the effects of FGD by-product probably would not be seen during the course of this study. However, tritium concentrations were well above background levels. Samples from all wells at the mine site that were sampled during round 1 had elevated concentrations of tritium (above $4 \mathrm{TU}$ ), whereas samples from only five of nine domestic wells had elevated concentrations. Thus, waters in the shallow groundwater system at the mine site are all younger than 40 years old.

Data from automated data collection platforms were collected hourly for specific conductance and temperature (Figures 58 through 63). The overall quality of these data is far from ideal. Specific conductance measurements, which fluctuate diurnally, seem to have been influenced by extreme temperature variations in the well casing and the surface enclosure for the data logger. Additionally, a slimy, black precipitate was found on downhole sensors when they were removed from the well during routine maintenance. This precipitate may have compromised the ability of the sensors to accurately measure water quality. In addition to these 

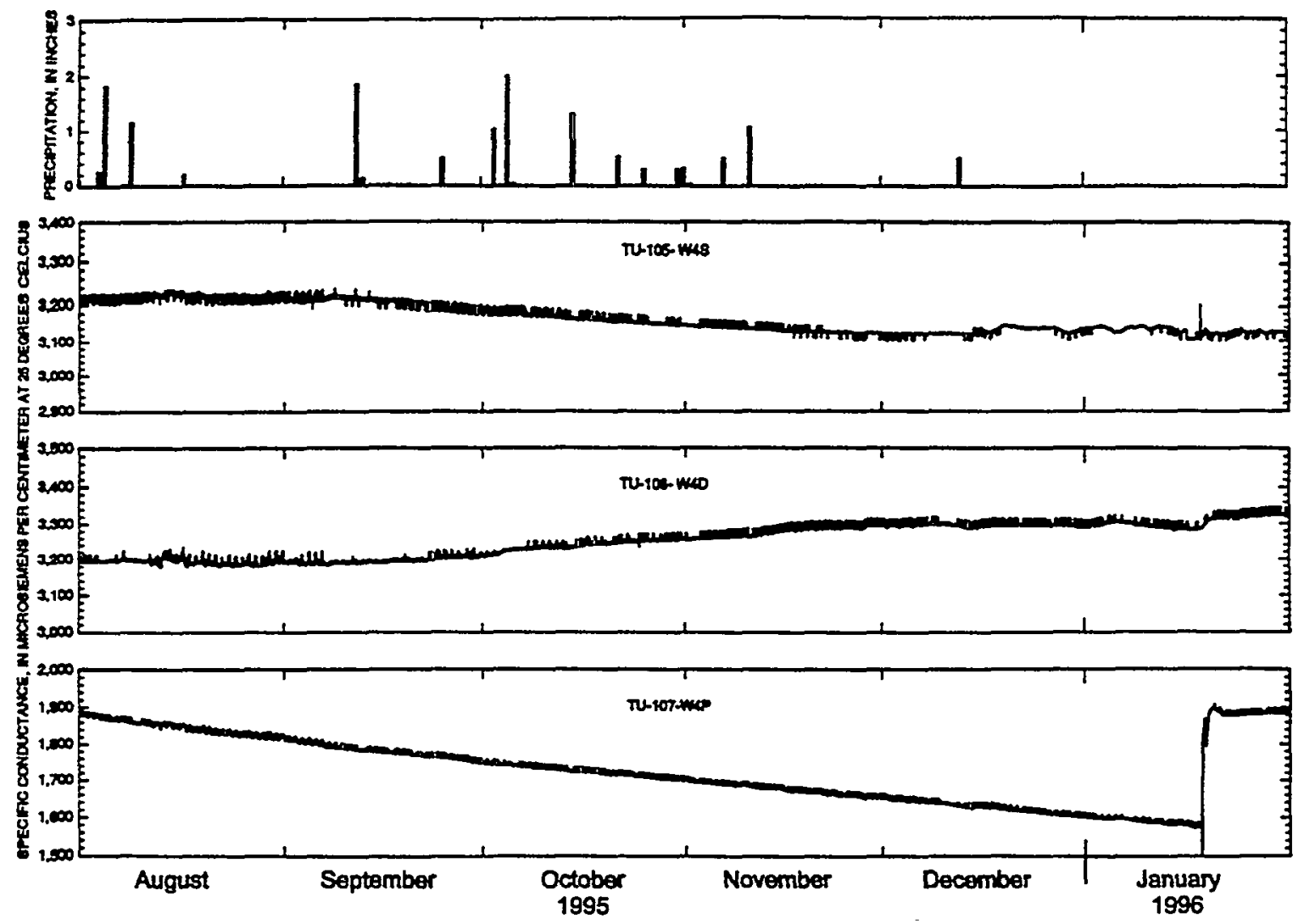

Figure 58. Daily total precipitation (in inches) and specific conductance $(\mu \mathrm{S} / \mathrm{cm})$ for well cluster 4 for the time period $8 / 2 / 95$ through $1 / 31 / 96$. 

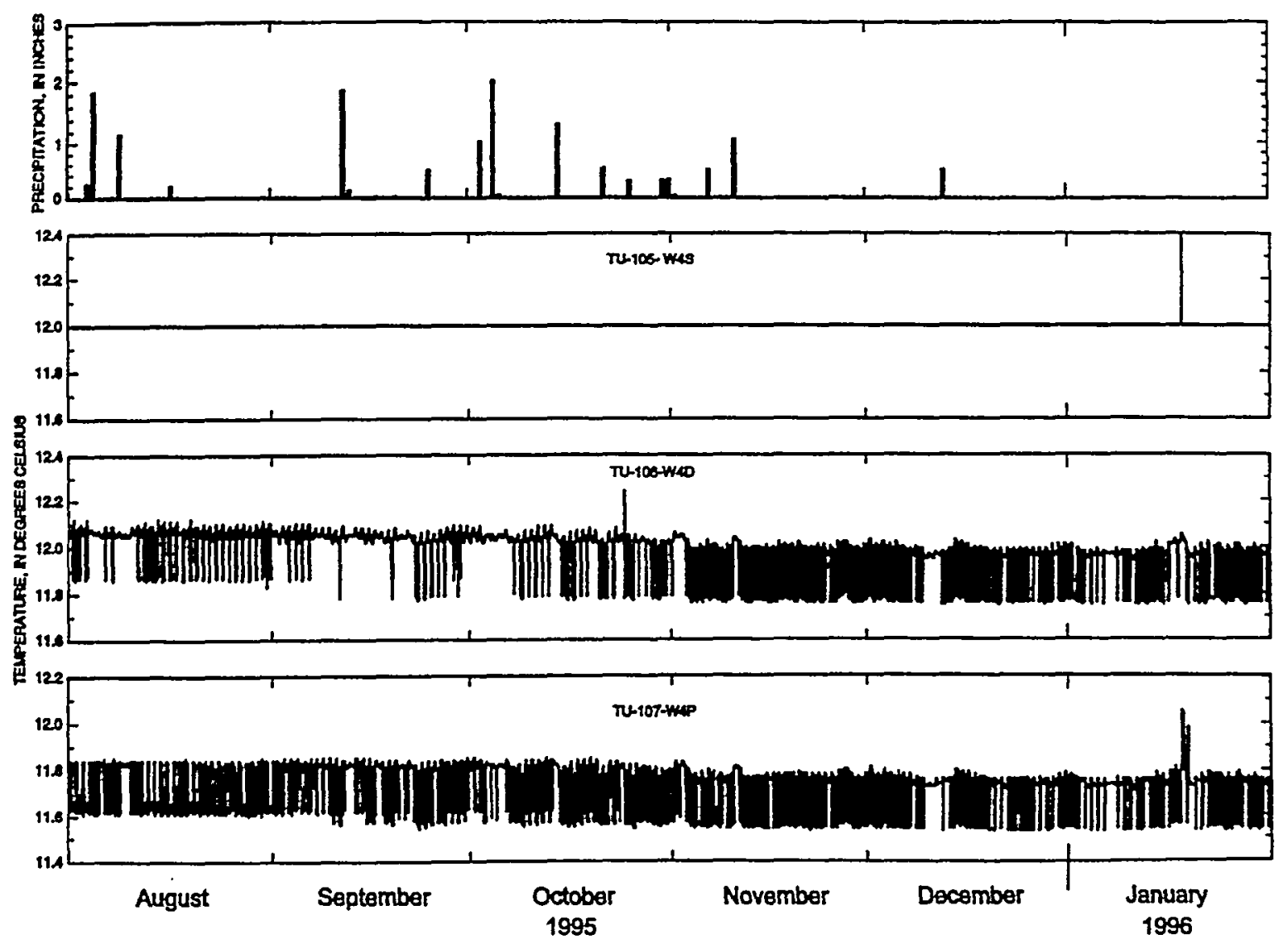

Figure 59. Daily total precipitation (in inches) and water temperature $\left({ }^{\circ} \mathrm{C}\right)$ for well cluster 4 for the time period $8 / 2 / 95$ through $1 / 31 / 96$. 

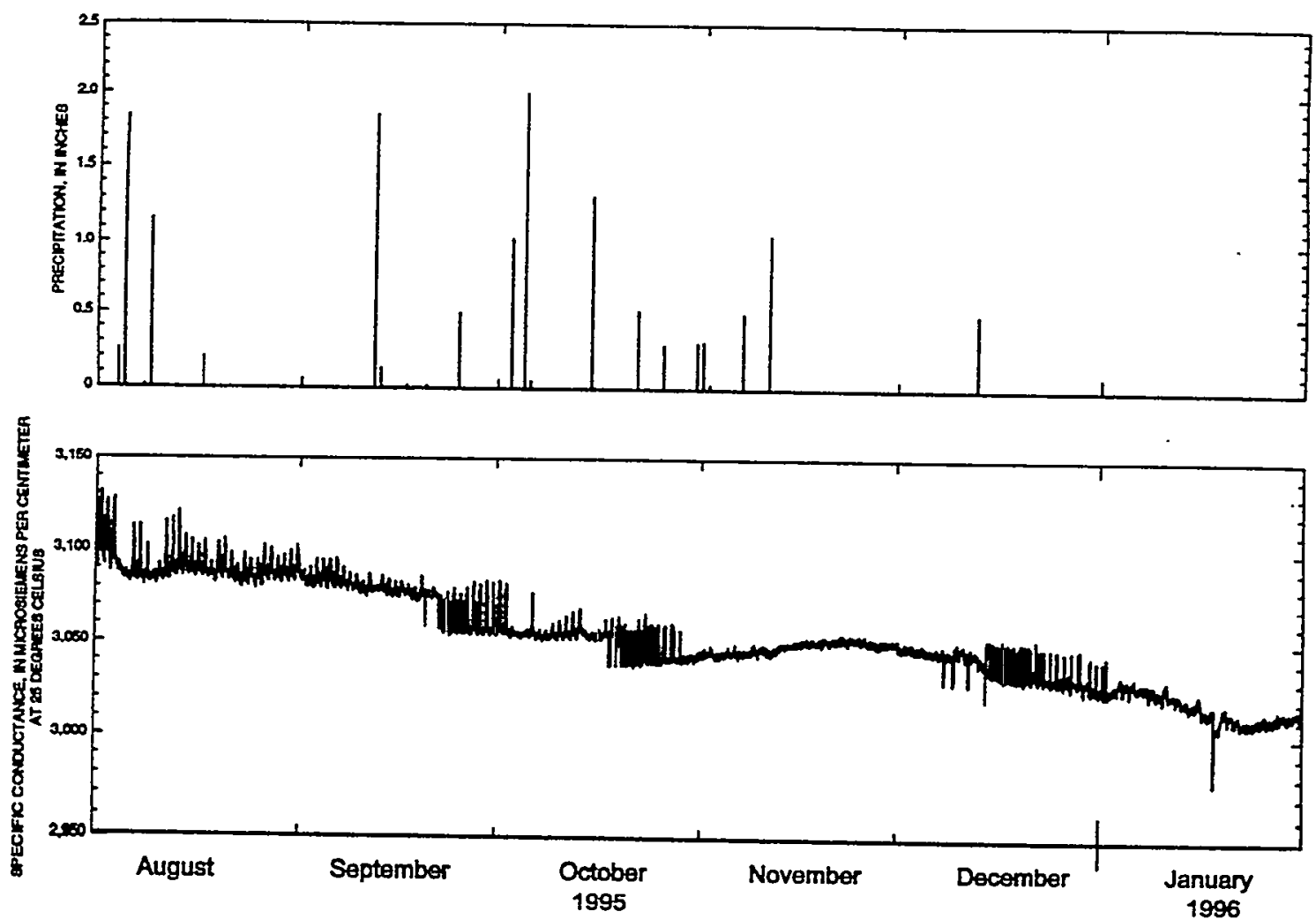

Figure 60. Daily total precipitation (in inches) and specific conductance $(\mu \mathrm{S} / \mathrm{cm})$ for well TU109-W5S for the time period 8/2/95 through 1/31/96. 

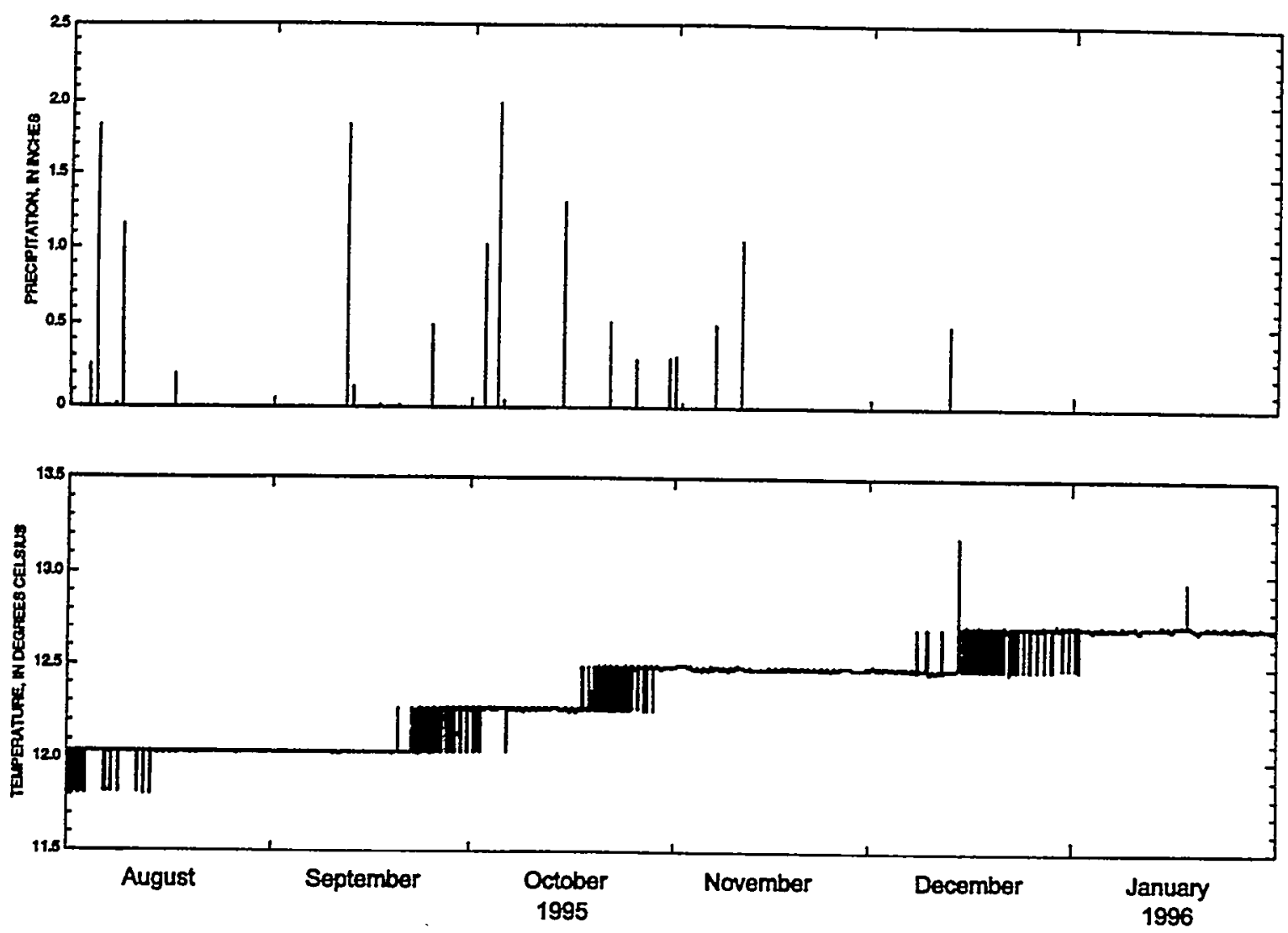

Figure 61. Daily total precipitation (in inches) and water temperature $\left({ }^{\circ} \mathrm{C}\right.$ ) for TU-109-W5S for the time period 8/2/95 through 1/31/96. 

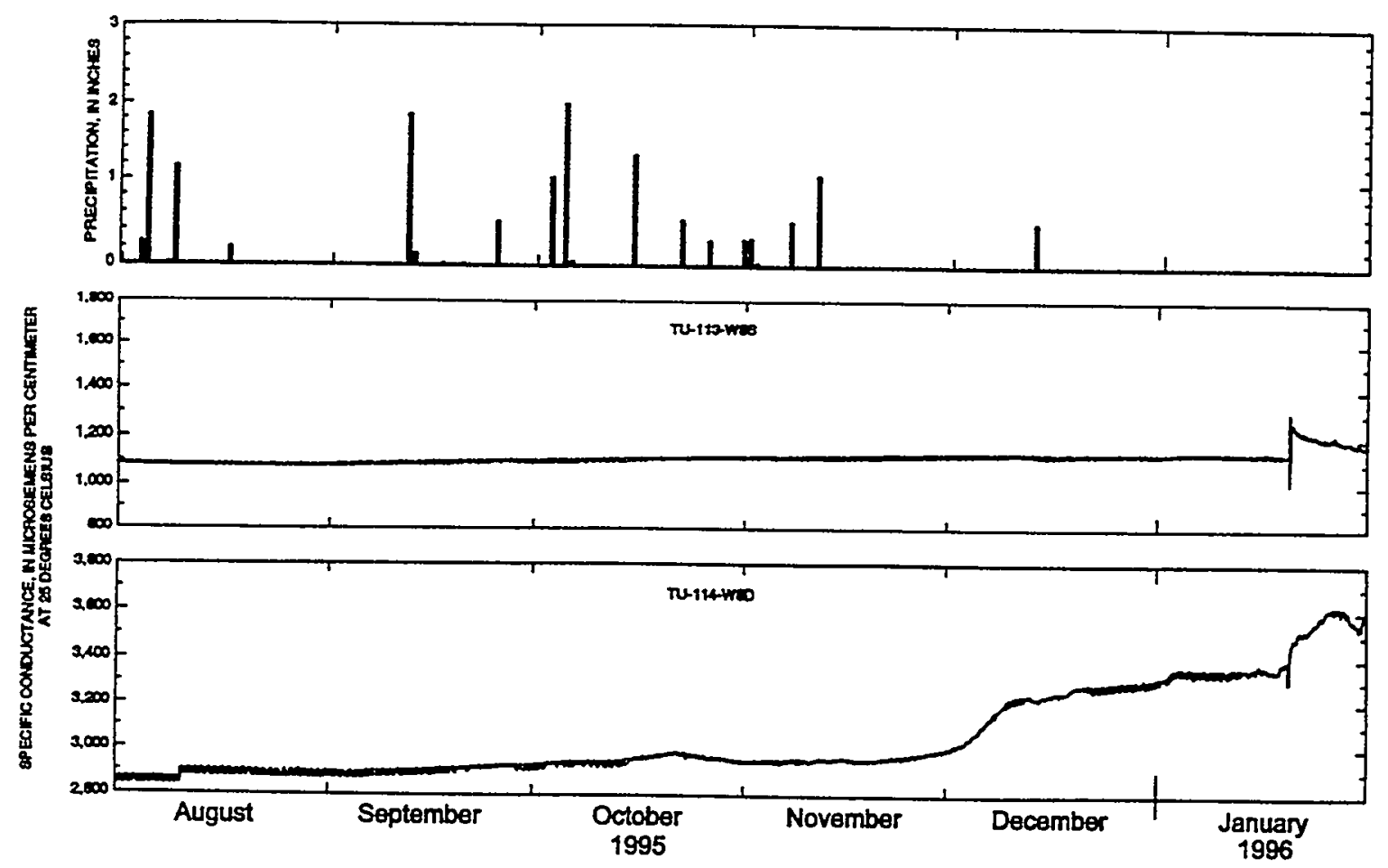

Figure 62. Daily total precipitation (in inches) and specific conductance $(\mu S / \mathrm{cm})$ for well cluster 8 for the time period $8 / 2 / 95$ through $1 / 31 / 96$. 

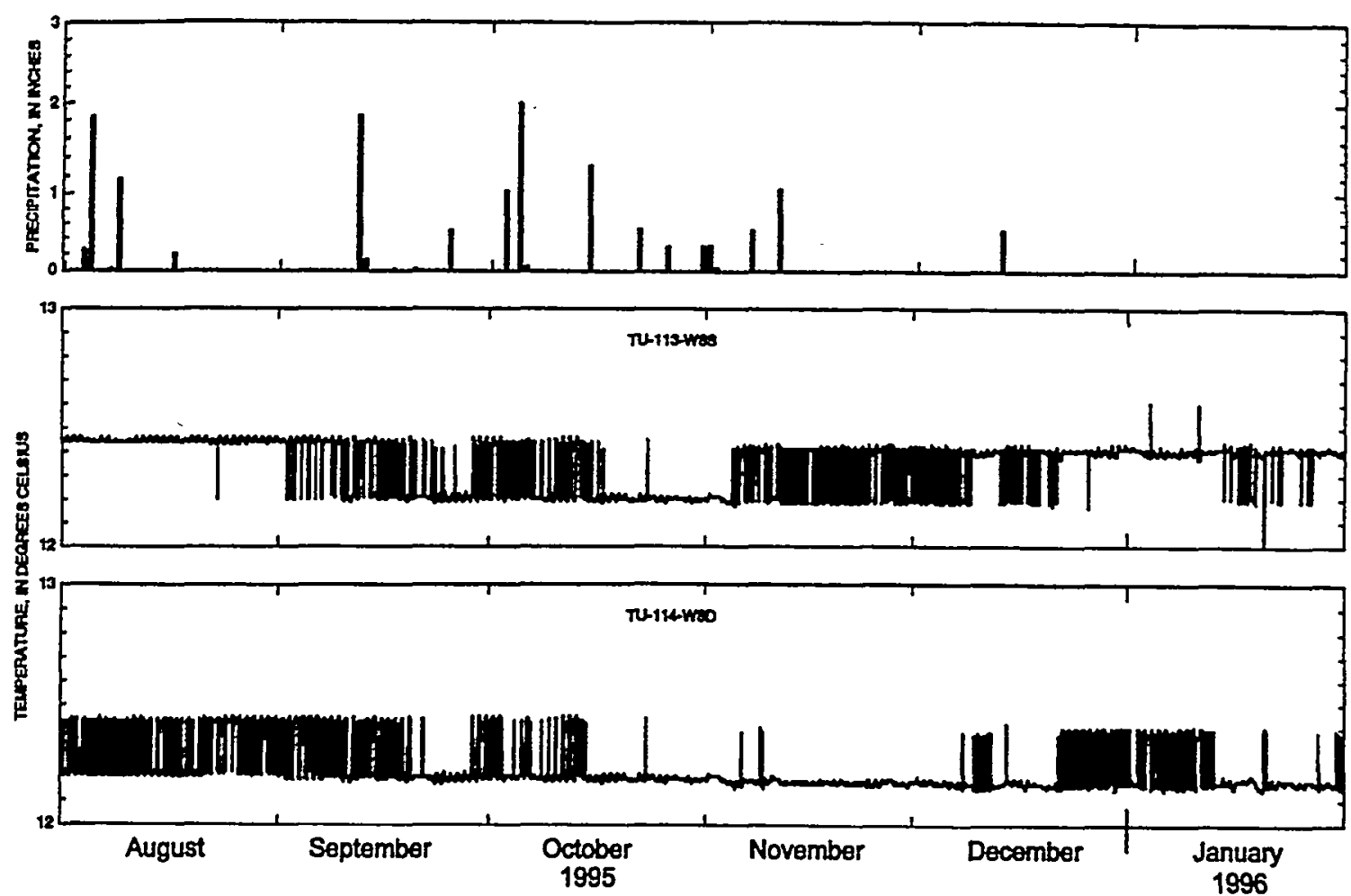

Figure 63. Daily total precipitation (in inches) and water temperature $\left({ }^{\circ} \mathrm{C}\right.$ ) for well cluster 8 for the time period $8 / 2 / 95$ through $1 / 31 / 96$. 
daily rises and falls, Figure 58 shows changes in specific conductance with time. At well $4 \mathrm{~S}$, specific conductance decreases slightly with time, whereas at well 4D, specific conductance increases slightly. The graph for well 4P, shows a linear decrease in specific conductance with respect to time but a sharp increase of more than $300 \mu \mathrm{S} / \mathrm{cm}$ in January 1996. This abrupt increase occurred during sampling round 2 , when all wells at this cluster were purged before sampling. Well 4P is screened in a shale/sandstone aquifer that has a very low hydraulic conductivity. This well requires purge and sample techniques spanning 2 days because of slow water level recovery rates. The linear decrease in specific conductance and subsequent rise during pumping may be due to slow oxidation and precipitation of iron and (or) manganese in the stagnant casing water that had not recently been flushed with ambient groundwater .

At well $5 S$ (Figures 60 and 61) specific conductance decreased slightly with respect to time whereas temperature of water in this well increased by about $0.7^{\circ} \mathrm{C}$ from August to January. Specific conductance increased linearly at well $8 \mathrm{~S}$, but at well 8D it rose significantly during early December 1995. Reasons for the linear increase in 8S and dramatic rise in 8D are unclear. Temperature variations observed in both wells were similar.

Because one of the objectives of this study was to identify elements derived from FGD byproduct that are mobile in groundwater, a discussion of relevant factors such as well depth and position relative to the FGD by-product application area is warranted. Because of shorter residence times in the shallow aquifer, it was expected that the quality of groundwater from the shallow aquifer might be affected by leachate from the FGD by-product. However, neither shallow nor deep aquifer samples have chemical characteristics suggestive of an FGD byproduct leachate component, nor are major compositional differences observed in groundwater samples collected from wells screened in the shallow and deep aquifers (Table 39).

Groundwater from the shallow aquifer wells tends to be slightly acidic (pH 5.0-6.3, median $\mathrm{pH}=5.5$ for rounds 1 and 2 ) and is highly mineralized. Residue on evaporation ranged from 848 to $5,860 \mathrm{mg} / \mathrm{L}$ and median values were $3,340 \mathrm{mg} / \mathrm{L}$ and $3,200 \mathrm{mg} / \mathrm{L}$ for rounds 1 and 2 , respectively. Specific conductance for rounds 1 and 2 ranged from 1,110 to $4,440(\mu \mathrm{S} / \mathrm{cm})$. Medians were $2,920(\mu \mathrm{S} / \mathrm{cm})$ for round 1 and $3,090(\mu \mathrm{S} / \mathrm{cm})$ for round 2.

Major ion chemistry in groundwater in the shallow aquifer at the study site is dominated by dissolved $\mathrm{SO}_{4}, \mathrm{Ca}, \mathrm{Fe}, \mathrm{Mg}$, and $\mathrm{Mn}$. Sulfate concentrations ranged from 438 to $3,430 \mathrm{mg} / \mathrm{L}$ with median values of 1,840 and $2,030 \mathrm{mg} / \mathrm{L}$ for rounds 1 and 2 , respectively. Iron concentrations were high relative to those in all other waters with a range of 6.29 to $921 \mathrm{mg} / \mathrm{L}$ 
and medians of $298 \mathrm{mg} / \mathrm{L}$ for round 1 and $240 \mathrm{mg} / \mathrm{L}$ for round 2 . Concentrations of $\mathrm{Ca}$ and $\mathrm{Mg}$ ranged from 134 to $481 \mathrm{mg} / \mathrm{L}$ and 57 to $329 \mathrm{mg} / \mathrm{L}$, respectively. Medians for Ca were 355 $\mathrm{mg} / \mathrm{L}$ for round 1 and $395 \mathrm{mg} / \mathrm{L}$ for round 2, whereas medians for $\mathrm{Mg}$ were $206 \mathrm{mg} / \mathrm{L}$ and 203 $\mathrm{mg} / \mathrm{L}$. Manganese concentrations were also high, with a range of 0.884 to $67.2 \mathrm{mg} / \mathrm{L}$ and medians of 15.3 and 16.1 for rounds 1 and 2 , respectively.

Trace element chemistry in the shallow aquifer was highly variable. Boron concentrations ranged from 10 to $468 \mu \mathrm{g} / \mathrm{L}$ and median values were 234 and $276 \mu \mathrm{g} / \mathrm{L}$ for rounds 1 and 2 , respectively. Cobalt concentrations ranged from $<6$ to $775 \mu \mathrm{g} / \mathrm{L}$ with medians being 235 and $222 \mu \mathrm{g} / \mathrm{L}$ for rounds 1 and 2 respectively. Nickel concentrations were ranged from $<4$ to 1,140 $\mu \mathrm{g} / \mathrm{L}$ and medians were 462 and $488 \mu \mathrm{g} / \mathrm{L}$ for rounds 1 and 2 , respectively. Concentrations of dissolved $\mathrm{Zn}$ ranged from 2 to $1,860 \mu \mathrm{g} / \mathrm{L}$ and medians were 363 and $465 \mu \mathrm{g} / \mathrm{L}$.

Dissolved organic $C$ (DOC) in water samples from the shallow aquifer ranged from 0.5 to 1.7 $\mathrm{mg} / \mathrm{L}$ and medians were 0.8 and $0.9 \mathrm{mg} / \mathrm{L}$ for rounds 1 and 2 , respectively. $\delta^{34} \mathrm{~S}$ in $\mathrm{SO}_{4}$ ranged from -13.7 to -5.7 per mil and medians were -9.6 and -9.9 per mil for rounds 1 and 2 , respectively.

Water collected from deep wells at the study site was similar in most respects to shallow groundwater . However, some differences were noted, however, particularly in $\mathrm{pH}$ and indicators of mineralization. $\mathrm{pH}$ of water from deep wells was slightly higher than that from shallow wells and ranged from 5.5 to 7.2 with medians being 5.8 and 6.1 for rounds 1 and 2 , respectively. Specific conductances in the deeper aquifer were generally lower than those in the shallow aquifer; with values ranging from 2, 350 to 4, $280(\mu \mathrm{S} / \mathrm{cm})$. Medians were 2,640 and $2,880(\mu \mathrm{S} / \mathrm{cm})$ for rounds 1 and 2 , respectively. Residue on evaporation (ROE) values, however, were similar to those in the shallow aquifer and ranged from 1,860 to $5,940 \mathrm{mg} / \mathrm{L}$ with medians of 3,140 and $3,100 \mathrm{mg} / \mathrm{L}$ for rounds 1 and 2 , respectively.

Major ion chemistry in the deep aquifer was also dominated by dissolved $\mathrm{SO}_{4}, \mathrm{Fe}, \mathrm{Ca}, \mathrm{Mg}$, and $\mathrm{Mn}$. Sulfate concentrations in the deep aquifer were less than those in the shallow aquifer, ranging from 1,110 to $3,710 \mathrm{mg} / \mathrm{L}$. Medians were 1,530 and $1,880 \mathrm{mg} / \mathrm{L}$ for rounds 1 and 2 , respectively. As can be seen in Table 39, Ca concentrations increased slightly between the shallow aquifer and the deep aquifer, whereas $\mathrm{Fe}, \mathrm{Mg}$, and $\mathrm{Mn}$ concentrations decreased.

With regard to trace element chemistry, concentrations of $\mathrm{B}, \mathrm{Co}, \mathrm{Ni}$, and $\mathrm{Zn}$ in the deep aquifer were less than those in the shallow aquifer in both rounds 1 and round 2. For example, 
shallow well samples from round 1 had a median Co concentration of $235 \mu \mathrm{g} / \mathrm{L}$, whereas the median for all deep well samples was only $106 \mu \mathrm{g} / \mathrm{L}$.

Dissolved organic C (DOC) did not differ significantly between aquifers or sampling rounds. The minimum concentration was $0.4 \mathrm{mg} / \mathrm{L}$ and the maximum was $2 \mathrm{mg} / \mathrm{L}$. The median for both sampling rounds was $1.0 \mathrm{mg} / \mathrm{L}$. $\delta^{34} \mathrm{~S}$ values for dissolved $\mathrm{SO}_{4}$ in deep aquifer were similar to values obtained in the shallow aquifer, with a range of -13.7 to -6.0 per mil and medians of -9.6 and -9.4 per mil for rounds 1 and 2 , respectively.

Categorization of wells as upgradient and downgradient from the FGD by-product application area allowed for comparison of potential effects from FGD by-products (Table 39). Upgradient wells included wells at clusters $1,7,8,9$, and 13 , whereas downgradient wells were at clusters $3,4,5,6,10$, and 11 (Figure 12). Wells at clusters 2 and 12 were excluded from this analysis because available data were insufficient for accurately determining if these wells were up or downgradient of the application area. Table 39 shows that, of the selected constituents, $\mathrm{pH}$ invariably decreased and almost all properties and constituents (except for $\mathrm{B}$, dissolved organic $\mathrm{C}$ and $\delta^{34}$ in $\mathrm{SO}_{4}$ ) were lower at wells upgradient from the FGD by-product application area than at downgradient wells. For example, median $\mathrm{SO}_{4}$ concentrations for shallow downgradient samples were 2,160 and $2,090 \mathrm{mg} / \mathrm{L}$. It should be noted that changes in overall shallow groundwater quality between rounds 1 and 2 may, in part, be a result of sampling five additional shallow wells during round 2 .

Groundwater with the highest concentrations of dissolved constituents was found at well cluster 6. This well cluster, which is in an area where the spoil/clay layer is the thinnest (Figure 42), may represent an area where coal and clay were both mined. Direct recharge of acidic and highly mineralized surface water to the shallow aquifer could occur in such an area.

\subsubsection{Surface Water/Groundwater Interactions}

Discharge (measured before water quality sampling) ranged from $1.94 \times 10^{-4} \mathrm{~m}^{3} / \mathrm{sec}(6.8 \times 10$ $\left.3 \mathrm{ft}^{3} / \mathrm{sec}\right)$ at site TU-125 to $1.25 \times 10^{-3} \mathrm{~m}^{3} / \mathrm{sec}\left(4.4 \times 10^{-2} \mathrm{ft}^{3} / \mathrm{sec}\right)$ at site TU-120 and are believed to be only from groundwater and not from surface runoff. Surface water was sampled only once during this study, during a period thought to represent base flow (when all streamwater flowing downgradient from the sites was contributed by groundwater discharge). The chemical data from the three surface water sampling sites are listed in Appendix Table D-6. These data indicate that $\mathrm{pH}$ of surface water was significantly lower than for groundwater. The 
range was 3.5 to 6.3 and the median was 4.0 . The lowest $\mathrm{pH}$, measured at TU-124, represents effluent from the sediment pond immediately downgradient from the study site. The highest $\mathrm{pH}$ was measured at TU-125, a small brook draining the eastern part of the study site. Specific conductance ranged from 609 to $2,380(\mu \mathrm{S} / \mathrm{cm})$ and the median was $1,680(\mu \mathrm{S} / \mathrm{cm})$. Residue on evaporation (ROE) ranged from 402 to $2 ; 950 \mathrm{mg} / \mathrm{L}$ and the median was $1,220 \mathrm{mg} / \mathrm{L}$. The lowest ROE was associated with TU-125 and the highest with TU-124.

Surface water sampled at the study site was compositionally similar to onsite groundwater samples but less concentrated. Sulfate concentrations ranged from 515 to $1,660 \mathrm{mg} / \mathrm{L}$ and the median was $1,180 \mathrm{mg} / \mathrm{L}$. Iron concentrations, which were much lower than those in groundwater, ranged from 0.557 to $0.978 \mathrm{mg} / \mathrm{L}$. Concentrations of $\mathrm{Ca}$ and $\mathrm{Mg}$ ranged from 47.7 to $318.1 \mathrm{mg} / \mathrm{L}$ and 30.8 to $189 \mathrm{mg} / \mathrm{L}$, respectively. Surface water at the study site can be categorized as mixed cation $\mathrm{SO}_{4}$ type water (Fig. 45). Concentrations of $\mathrm{Al}$ were relatively low $(178 \mu \mathrm{g} / \mathrm{L})$ for TU-125, but were much higher $(2,182$ and $5,852 \mu \mathrm{g} / \mathrm{L})$ for TU-120 and TU124 , respectively.

Trace element chemistry for several constituents was similar to that in groundwater . Concentrations of $\mathrm{B}, \mathrm{Mn}$, and $\mathrm{Zn}$ in surface water were similar to those in groundwater (in terms of ranges in medians). Nickel concentrations were lower in surface water but were similar to those in deep aquifer (range, 123 to $319 \mu \mathrm{g} / \mathrm{L}$; median, $319 \mu \mathrm{g} / \mathrm{L}$ ). Cobalt concentrations were consistently lower in surface water, ranging from $<6$ to $193 \mu \mathrm{g} / \mathrm{L}$ (median, $163 \mu \mathrm{g} / \mathrm{L})$.

Dissolved organic $\mathrm{C}$ concentrations were similar to those in groundwater except for the sample from TU-125 which was somewhat higher $(3.1 \mathrm{mg} / \mathrm{L})$. This sampling site was overgrown with grass and vegetation, and abundant organic matter was lodged between rocks in the streambed. $\delta^{34} \mathrm{~S}$ in $\mathrm{SO}_{4}$ ranged from -14 to -9.4 per mil with a median value of -13 per mil. This range and median were almost identical to those found for groundwater samples.

With regard to the US Environmental Protection Agency's drinking water standards, only $\mathrm{Ni}$ exceeded the maximum contaminant level in surface water. Samples from all three surface water sites exceeded the maximum contaminant level for $\mathrm{Ni}(100 \mu \mathrm{g} / \mathrm{L})$ with a median concentration of $319 \mu \mathrm{g} / \mathrm{L}$.

Hydrologic and chemical controls on the observed water quality can be directly inferred from the data collected at the site. They can also be indirectly inferred from results of the 
groundwater flow and chemical speciation modeling. The four sources of water sampled during this study have chemical compositions that indicate the influences of coal combustion on rainfall, FGD by-product leachate in interstitial waters, and the effects of acid mine drainage on groundwater and surface water. The following section describes both hydrologic and chemical controls on the water quality observed at the study site.

The primary hydrologic controls on the chemistry of the groundwater system appear to be the rate and spatial distribution of recharge, rates and directions of groundwater flow in the aquifers beneath the site, and the hydrogeologic characteristics of discharge areas (springs).

The relatively impermeable spoil/clay layer at the surface limits the amount of recharge that can enter the groundwater system. Water that infiltrates through the unsaturated zone presumably has a long residence time and tends to have higher concentrations of dissolved $\mathrm{Fe}, \mathrm{SO}_{4}$, and other dissolved constituents than would be expected if the surficial material were more permeable. This is because conditions of partial saturation allow oxygen to diffuse into the unsaturated zone and react with pyrite to produce acid mine drainage. During extended periods of no precipitation, evaporation will occur and soluble $\mathrm{Fe}-\mathrm{SO}_{4}$ salts will precipitate; these salts quickly dissolve during major recharge events, yielding acidic waters with high concentrations of dissolved metals and sulfate (Nordstrom et al., 1979). Analysis of the hydrographs from the automated data-collection platforms indicates that the uppermost aquifer responds relatively quickly to recharge events, but response varies considerably between wells and aquifers.

Additionally, the groundwater level data indicate that small $(<0.076 \mathrm{~m}$ or $<0.25 \mathrm{ft}$ ) upward gradients exist in areas where only downward gradients can be simulated by the flow model. The error associated with water levels in the numerical model (expressed as the MAD) was $0.18 \mathrm{~m}$ and $0.19 \mathrm{~m}(0.59$ and $0.63 \mathrm{ft})$ for layers 1 and 2 , respectively. Therefore, the upward gradients were within the limitations of error in the model. Alternatively, these differences may be a result of aquifer heterogeneities and fractures. Logistical and funding limitations prohibited investigation of the fracture flow system.

Flow rates in the groundwater system are controlled by the hydraulic gradient and the hydraulic properties of the porous media. Measurements of hydraulic head throughout the study period indicate that although water levels change with time, the overall direction and magnitude of hydraulic gradient does not change appreciably. Thus, the gradient can be considered to be constant with respect to time. The range of hydraulic conductivities obtained in this study are consistent with estimates derived by other workers for similar hydrogeologic settings (Saad 
and Cravotta, 1991; Helgesen et al, 1982). However, caution should be expressed in the use of data from slug-test analyses because the volume of aquifer material tested by this type of test is small compared to the volume of aquifer material underlying the site. An interconnected system of fractures and bedding plane fractures may result in unrepresentative values of water levels and hydraulic conductivity from aquifer tests. Additionally, heterogeneity of aquifer materials, which typifies rocks of Pennsylvanian age, can be overlooked as a potential reason for unexplained differences in rates and velocities of groundwater flow. For the purposes of this study, both aquifers were assumed homogenous, and the effects of fractures, bedding planes, and heterogeneity were not quantified.

The particle tracking analysis indicates as much as 27 years may be required for water that enters the upgradient part of the site to discharge at a spring; thus, flow rates are slow, and water may have long time to equilibrate with the surrounding matrix. The particle tracking analysis indicates that the source of water in the deep aquifer is from upgradient recharge areas, whereas water in the shallow aquifer represents water that percolated through the area amended with FGD by-product. The chemical composition of water in the deep aquifer should therefore be different from that in the shallow aquifer, and the effects of mining and FGD by-product application should be most evident in water pumped from shallow downgradient wells.

A question remains as to whether the site is in hydrologic equilibrium because water levels in wells have been measured for a period of only 8 months. Although the potentiometric configuration has not changed, a period of record to document a steady-state condition has not yet been achieved. Other studies, such as those reported by Cunningham and Jones (1990) and Eberle and Razem (1985) indicate hydrologic equilibrium of a site that has recently been mined and reclaimed may take 5 years or more to attain. Although the Fleming site was mined more than 25 years before the onset of this investigation, the effects of reclamation may still be affecting the hydrologic flow regime.

The springs that serve as groundwater discharge areas are along the side and at the base of the hills to the south of the FGD by-product application area. If these springs are the primary route for water to leave the groundwater system, then their ability to conduct water will undoubtedly influence water levels and flow rates throughout the entire study area. On the other hand, the size and discharge rates of the springs may be proportional to the amount of water that is available to them from the groundwater system, which in turn is controlled by recharge rates and all other hydrologic properties. The springs observed during field reconnaissance were all small in areal extent compared to the recharge area. 
Chemical processes that affect the quality of water sampled at the study site include water-rock reactions that occur in unsaturated minespoil and clay, and in saturated aquifer material. The two main processes of interest in this study are (1) dissolution and leaching of FGD byproducts applied to the surface of the study area and (2) the generation of acid mine drainage in minespoil left at the surface of the site after mining ceased. Other processes, such as biological activity, were beyond the scope of this study. The main geochemical process affecting the FGD by-product was dissolution because the by-product is composed of moderate to highly soluble minerals (e.g., Ca-Mg carbonates, gypsum). Dissolution of these minerals will occur until solubility constraints imposed by secondary minerals are reached. With respect to generation of acid mine drainage, reaction rates are governed by various factors including $\mathrm{pH}$, redox conditions, temperature, availability of oxygen and water, amount of pyrite and its grain size and morphology, and microbial activity (Brant et al., 1971; Caruccio et al., 1977; Nordstrom et al., 1979).

The computer program WATEQ4F (Ball and Nordstrom, 1991) was used to evaluate the speciation and saturation state of water samples from the site with respect to various minerals. WATEQ4F calculates solution speciation and the saturation indices of selected minerals. This output was generated by use of onsite measurements of $\mathrm{pH}, \mathrm{Eh}, \mathrm{Fe}^{2+} / \mathrm{Fe}^{3}+$ ratios, $\mathrm{H}_{2} \mathrm{~S}$, temperature, dissolved oxygen, and alkalinity, in combination with major and minor ion data for each sample. Saturation indices are computed as $\log 10$ (IAP/K), where IAP is the ionactivity product and $\mathrm{K}$ is the equilibrium solubility constant. If the computed saturation index is greater than zero for a given mineral, the water is said to be supersaturated with respect to that mineral and precipitation of the mineral is thermodynamically favored. If the saturation index is less than zero, the water is said to be undersaturated with respect to that mineral and dissolution of the mineral may occur. If the saturation index is equal to zero, then neither dissolution nor precipitation is favored, and equilibrium between the mineral and the water has been reached. Redox equilibria were evaluated only for samples where onsite determinations of the $\mathrm{Fe}^{2+} / \mathrm{Fe}^{3+}$ ratio were available for input into WATEQ4F. Redox equilibria for other redox-sensitive trace elements were not evaluated because redox couples rarely reach equilibrium in waters at nearneutral pH (Lindberg and Runnels, 1984; Hem, 1989). Observed redox (Eh) values usually represent mixed potentials and cannot be used to evaluate the redox speciation. Also not evaluated in the WATEQ4F model runs was the effect of organic complexing on the speciation of $\mathrm{Al}, \mathrm{Fe}$, and other trace elements. Such complexing is potentially important in interstitial waters with high dissolved organic carbon concentrations. 
Saturation indices of selected minerals in relation to the residue on evaporation concentrations for interstitial water, groundwater, and surface water samples are shown in Figures 64 through 67. The minerals shown in these figures were based on minerals identified in FGD by-products and those that are commonly associated with acid mine drainage. Minerals identified by X-ray diffraction in the FGD by-product included anhydrite $\left(\mathrm{CaSO}_{4}\right)$, gypsum $\left(\mathrm{CaSO}_{4} \cdot 2 \mathrm{H}_{2} \mathrm{O}\right)$, calcite $\left(\mathrm{CaCO}_{3}\right)$, dolomite $\left(\mathrm{CaMg}\left(\mathrm{CO}_{3}\right)_{2}\right)$, magnesite $\left(\mathrm{MgCO}_{3}\right)$, and periclase $(\mathrm{MgO})$ (Stehouwer et al., 1995a). Secondary minerals that may affect concentrations of constituents released during the oxidation of pyrite and subsequent water-rock interactions include gibbsite $\left(\mathrm{Al}(\mathrm{OH})_{3}\right)$, alunite $\left(\mathrm{KAl}_{3}\left(\mathrm{SO}_{4}\right)_{2}(\mathrm{OH})_{6}\right)$, ferrihydrite $\left(\mathrm{Fe}(\mathrm{OH})_{3}\right)$, goethite $(\mathrm{FeOOH})$, greigite $\left(\mathrm{Fe}_{3} \mathrm{~S}_{4}\right)$, and siderite $\left(\mathrm{FeCO}_{3}\right)$ (Nordstrom et al., 1979; Nordstrom and Ball, 1986).

Results of the WATEQ4F calculations show that interstitial waters are, with few exceptions; saturated with respect to gypsum, magnesite, and dolomite. The waters are generally undersaturated with respect to calcite and anhydrite, an indication that dissolution of these minerals could occur. These results indicate that dissolution of magnesite or dolomite is not producing the elevated $\mathrm{Mg}$ :Ca mole ratios observed in the interstitial water samples. Instead, dissolution of a more soluble magnesium bearing solid phase such as brucite $\left[\mathrm{Mg}(\mathrm{OH})_{2}\right]$ may be occurring. Results of the WATEQ4F calculations indicate that interstitial water is undersaturated with respect to brucite by several orders of magnitude so dissolution of brucite is favored. Brucite is the hydration product of periclase $(\mathrm{MgO})$. According to Stehouwer et al (1995a), the FGD material (i.e., a PFBC by-product) contains 13 weight percent $\mathrm{MgO}$. This $\mathrm{MgO}$ would quickly hydrate and form brucite on exposure to water. Dissolution of brucite would explain the elevated Mg:Ca mole ratios observed in FGD by-product leachate and would be consistent with the results of column leaching studies done by Stehouwer et al. (1995d).

Inspection of Figures 6467 reveals the $\mathrm{Ca}-\mathrm{SO}_{4}$ minerals, gypsum and anhydrite, approach saturation with increasing residue on evaporation. Saturation with respect to gypsum is reached in a few of the most concentrated groundwater samples. With respect to alunite, groundwater and surface water are undersaturated, whereas almost all waters are supersaturated with respect to gibbsite. Groundwater is supersaturated with respect to ferric iron minerals such as ferrihydrite and goethite, although two out of the three surface water samples are nearly saturated with respect to ferrihydrite. Equilibrium with ferrihydrite is commonly observed in oxygenated acid mine drainage (Nordstrom et al., 1979), but ferrihydrite is rarely in equilibrium with anoxic groundwater because of the low solubility of ferric hydroxide (Hem, 1989). Groundwater is also supersaturated with respect to the ferrous sulfide mineral greigite, and precipitation of an amorphous iron sulfide phase could be occurring in the aquifer. This 

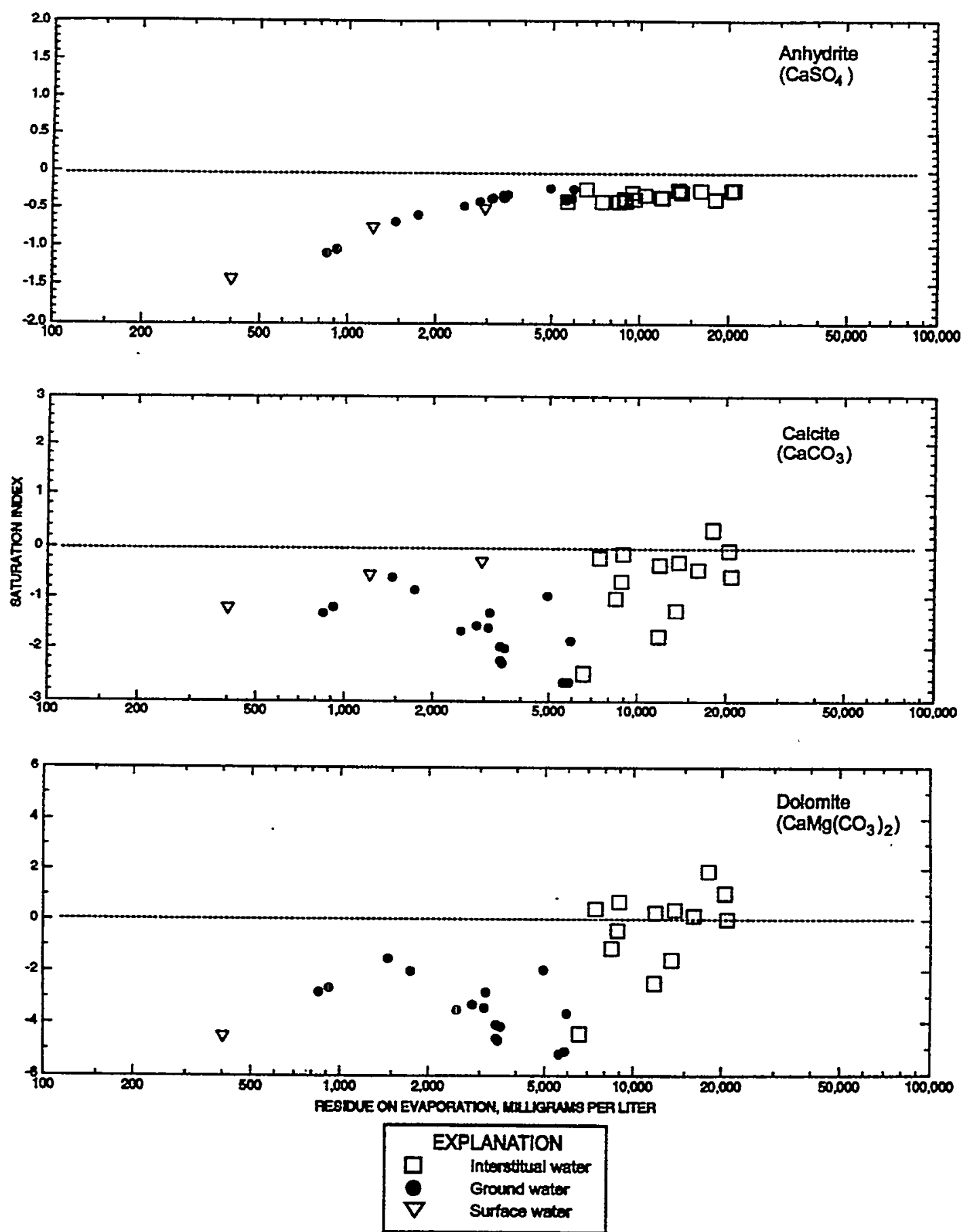

Figure 64. Calculated saturation indices in water for anhydrite, calcite and dolomite. 

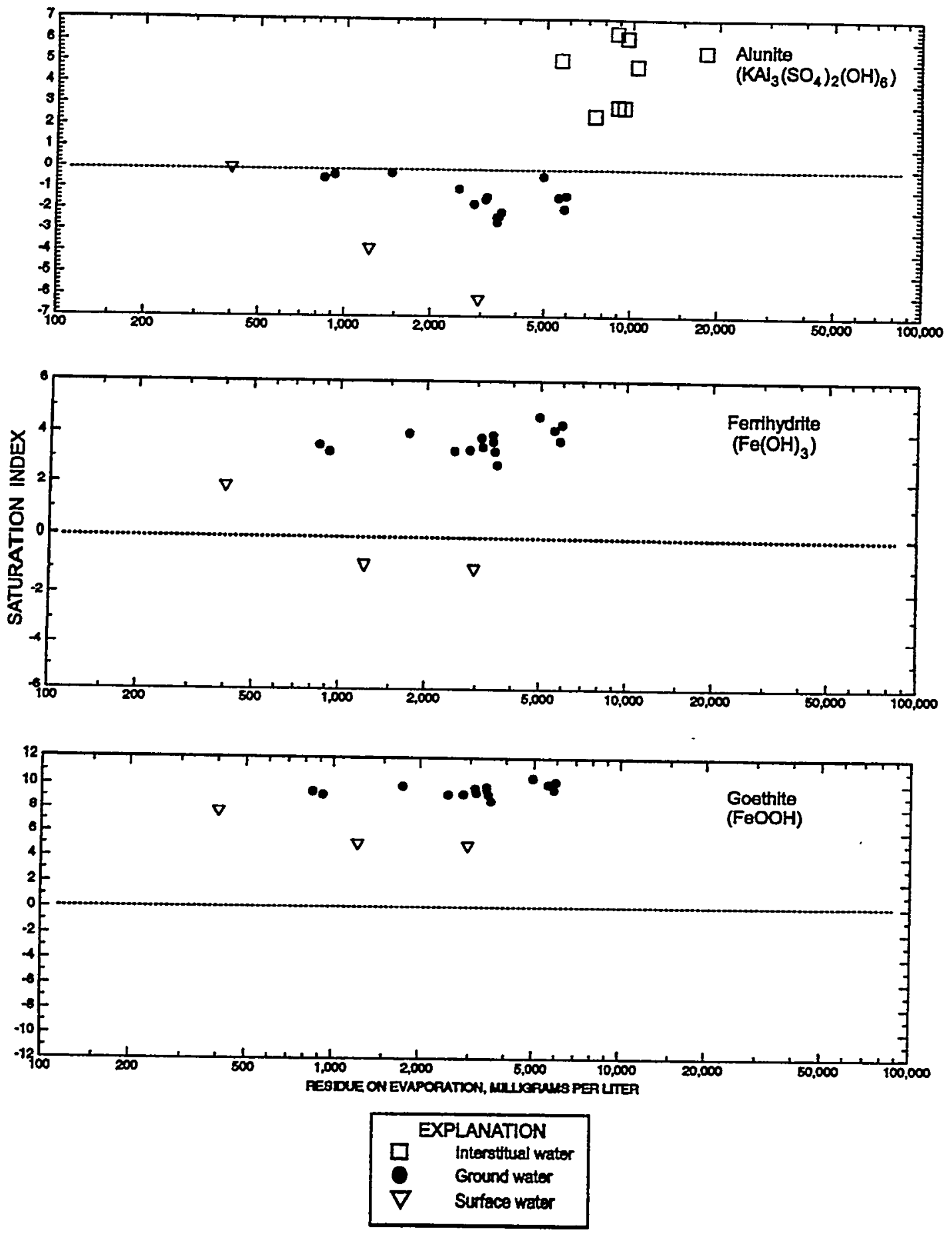

Figure 65. Calculated saturation indices in water for alunite, ferrihydrite and goethite. 

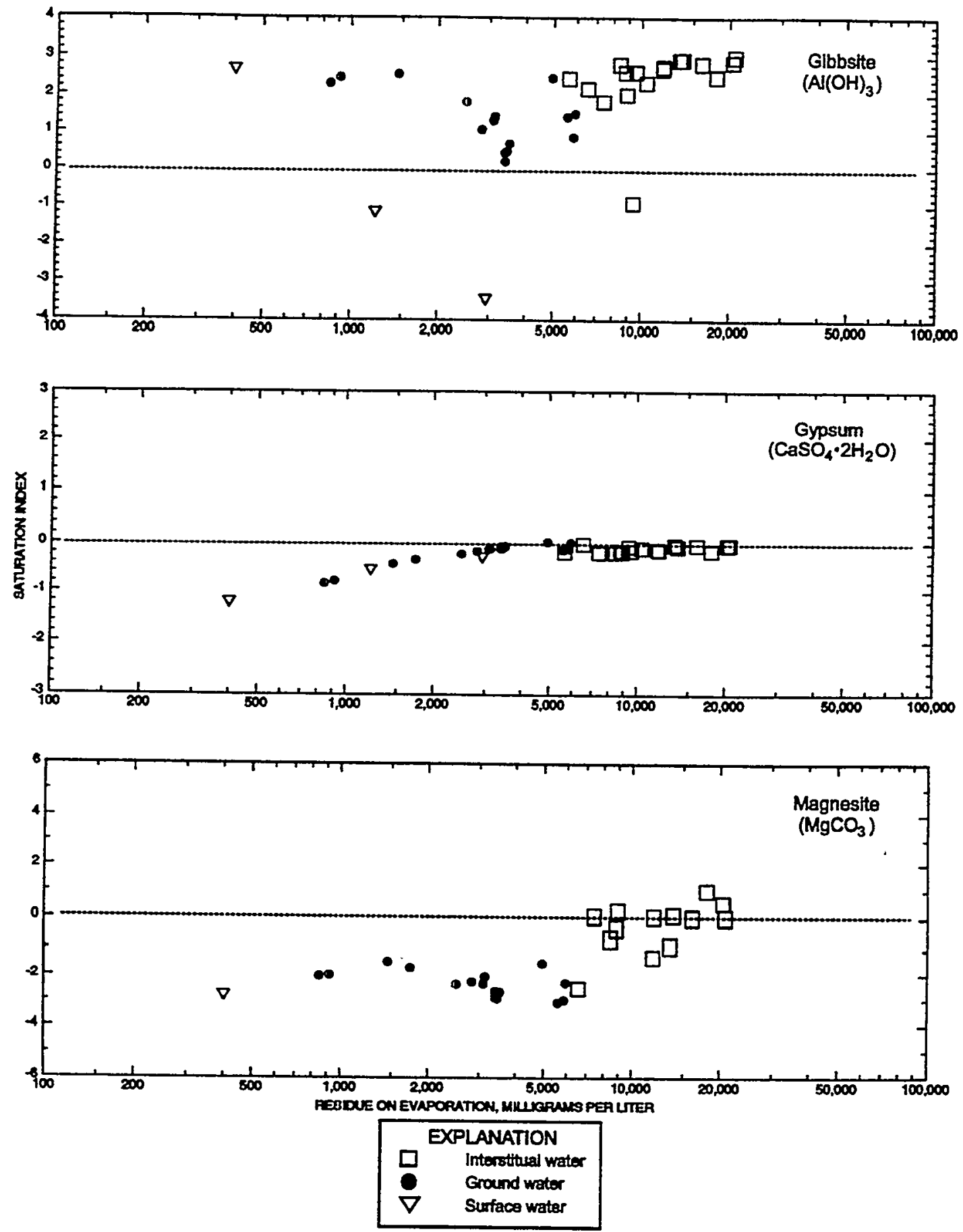

Figure 66. Calculated saturation indices in water for gibbsite, gypsum and magnesite. 

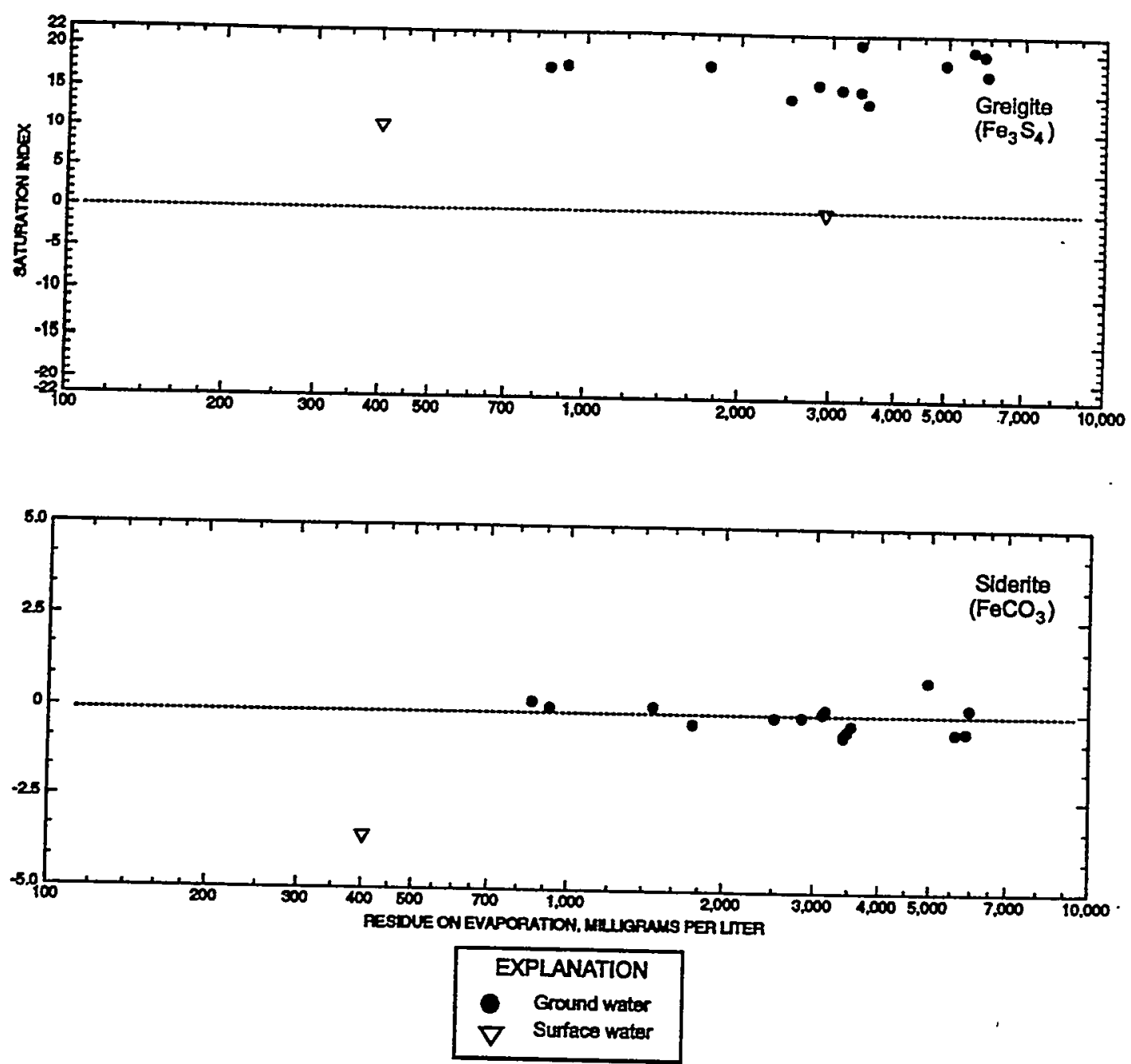

Figure 67. Calculated saturation indices in water for greigite and siderite. 
would account for the apparent lack of $\mathrm{H}_{2} \mathrm{~S}$ in groundwater. In contrast, the ferrous carbonate mineral siderite is close to equilibrium with groundwater, and precipitation of siderite may be regulating the maximum concentration of ferrous iron in groundwater.

Solution $\mathrm{pH}$ is also an important variable that controls the solubility and speciation of elements found in interstitial water and groundwater samples collected at the study site. In general, $\mathrm{pH}$ of groundwater beneath the site is low as a result of reactions between oxygen, pyrite, and water in the unsaturated zone. Most major and trace elements found in the Pennsylvanian rocks beneath this site are more soluble at low $\mathrm{pH}$ than at high $\mathrm{pH}$, so elevated concentrations of these elements in acid mine drainage waters is to be expected. Two examples of $\mathrm{pH}$ control on constituent concentration, dissolved $\mathrm{Fe}$ and $\mathrm{Ni}$ concentrations, are shown in Figure 68. For all groundwater samples, the maximum concentrations of $\mathrm{Fe}$ and $\mathrm{Ni}$ coincide with the lowest $\mathrm{pH}$. As the $\mathrm{pH}$ rises, concentrations of these elements decrease. The reduced nature of the groundwater is also important in allowing high Fe concentrations to occur. Within the $\mathrm{pH}$ range observed in groundwater at this site ( 5 to 7 ), Fe is highly soluble only in its reduced, ferrous $\left(\mathrm{Fe}^{2+}\right)$ form.

Plots of dissolved $\mathrm{Mg}$ and $\mathrm{Fe}$ as a function of dissolved sulfate show distinct linear trends that can be related to interaction of water and FGD by-product or water and pyrite (Figure 68). For $\mathrm{Mg}$, two distinct linear trends as a function of $\mathrm{SO}_{4}$ concentration are evident: (1) a trend defined by groundwater samples and the control area interstitial water sample group, which reflects release of $\mathrm{Mg}$ (by dissolution of $\mathrm{Mg}$-bearing carbonates or cation exchange with $\mathrm{Mg}$-rich shales) as a function of the amount of pyrite oxidation occurring in the spoil or shallow aquifer system, and (2) a more steeply sloping linear relation for interstitial water within the FGD byproduct application area, probably indicating dissolution of gypsum and soluble $\mathrm{Mg}$-bearing minerals of the FGD by-product. The higher solubility of $\mathrm{Mg}$-bearing minerals in the Mg-rich PFBC FGD by-product applied at the site leads to $\mathrm{Mg}$ :Ca mole ratios that are distinctly higher in interstitial waters collected from the application area than in groundwater and interstitial water samples collected outside of the application area. Data in Stehouwer et al (1995d) yield a $\mathrm{Mg}$ :Ca mole ratio of 5.77 for a column-leaching experiment in which a PFBC by-product was applied to minespoil at a rate of $270 \mathrm{Mg} / \mathrm{ha}$ (120 tons/acre). This ratio is similar to the mean $\mathrm{Mg}$ :Ca ratio (6.56) for interstitial water collected from inside the buffer area where the FGD by-product was applied at a rate of $280 \mathrm{Mg} / \mathrm{ha}$ ( 125 tons/acre). 

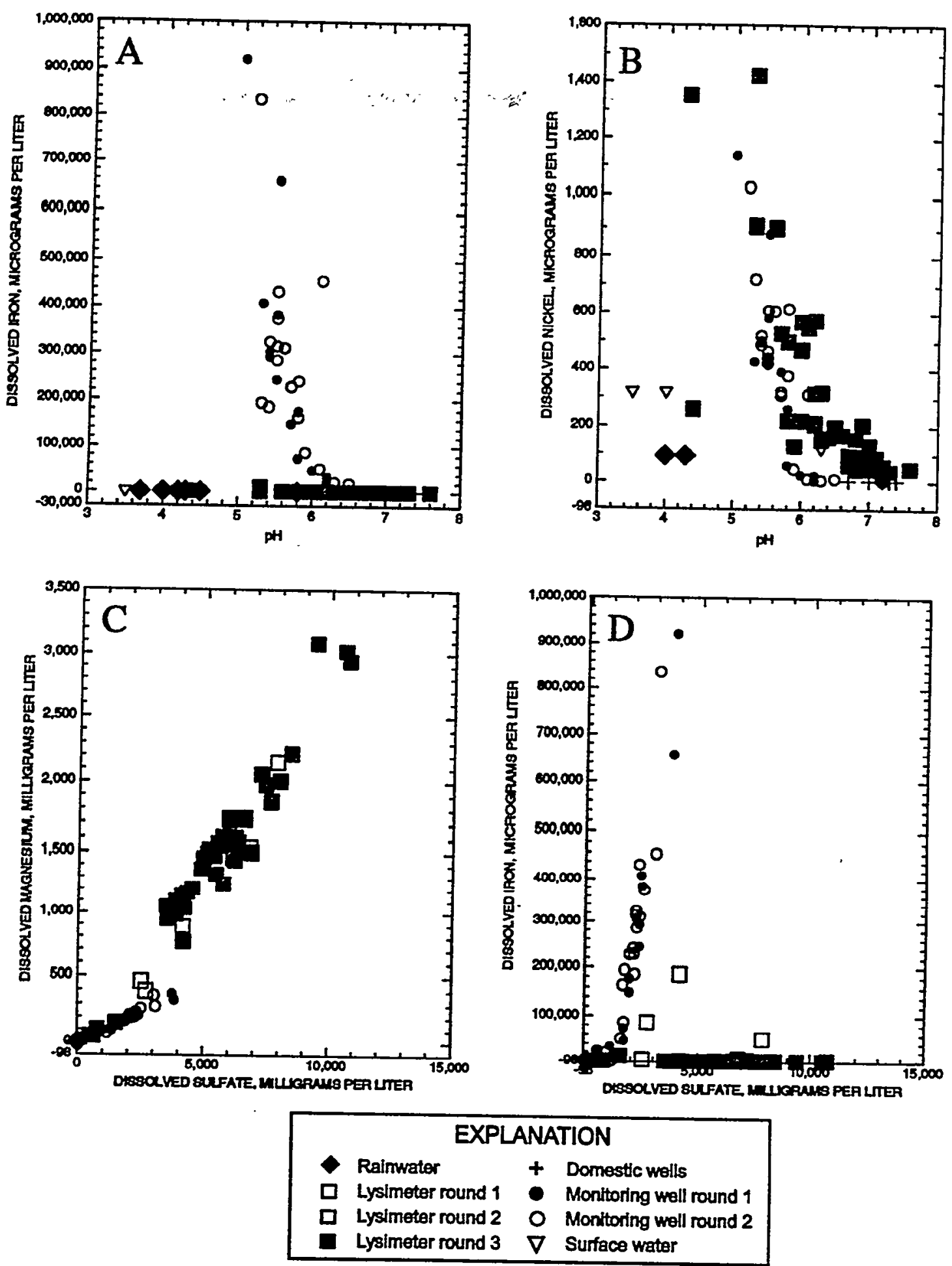

Figure 68. Plots of chemical data for all water samples: A) pH versus dissolved iron; B) pH versus dissolved nickel; $C$ ) dissolved sulfate versus dissolved magnesium; and $D$ ) dissolved sulfate versus dissolved iron. 
In the case of $\mathrm{Fe}$ (Figure 68), oxidation of pyrite results in the release of $\mathrm{Fe}$ and $\mathrm{SO}_{4}$. Hence, the concentration of these elements should increase linearly at a ratio that reflects the stoichiometry of the pyrite-oxidation reaction (release of 2 moles of $\mathrm{SO}_{4}$ and 1 mole Fe for each mole of pyrite oxidized). The $\mathrm{SO}_{4}$ : $\mathrm{Fe}$ mole ratios for groundwater beneath the Fleming site range from greater than 700 for waters with low dissolved Fe concentrations to less than 2 for high-Fe waters. Samples with dissolved Fe concentrations above a few hundred $\mathrm{mg} / \mathrm{L}$ have a much more restricted range of $\mathrm{SO}_{4}: \mathrm{Fe}$ mole ratios, typically between 3 and 5 . The value closest to the theoretical ratio was for groundwater from well $6 \mathrm{~S}\left(\mathrm{SO}_{4}: \mathrm{Fe}\right.$ mole ratio of 2.15 in round 3), which also had the highest dissolved Fe concentration $(840 \mathrm{mg} / \mathrm{L})$. The predominance of groundwater with $\mathrm{SO}_{4}: \mathrm{Fe}$ mole ratios greater than 2 indicates that $\mathrm{Fe}$ is removed from the system before it reaches anoxic parts of the aquifer. The mechanism for Feremoval is probably by oxidation of $\mathrm{Fe}^{2+}$ and subsequent precipitation as ferric hydroxide minerals in the unsaturated zone, and in oxygenated parts of the shallow aquifer. Support for this hypothesis can be seen in rock cores, where the top $6.1 \mathrm{~m}$ to $9.2 \mathrm{~m}$ ( 20 to $30 \mathrm{ft}$ ) intervals are stained brownish-orange by iron-bearing minerals. Also, in anoxic parts of the aquifer, some iron may be removed by precipitation of iron sulfide phases.

\subsection{Assessment and Analysis}

The results of our investigations indicate that the groundwater beneath the mine site and the surface water downgradient have been influenced by surface mining of coal and the formation of acid mine drainage. As of early 1996, the effects of reclamation and FGD by-product application, however, are limited to interstitial waters. The following discussion describes the specific effects of mining and reclamation and the effects of FGD by-product application on water samples obtained from the site.

Effects of mining and reclamation have been documented in many studies in Ohio (Cunningham and Jones, 1990; Razem, 1983; Hren, 1986; Nichols, 1985; Eberle and Razem, 1985; Hindall, 1984). The conclusion of all of these studies was that surface mining of coal resulted in elevated concentrations of dissolved solids, residue on evaporation, and most major elements in shallow groundwater and surface water, along with a decrease in $\mathrm{pH}$. The results of these studies also indicate that much wider ranges of concentrations are found for dissolved constituents in postmining waters. The increases are primarily due to the physical disaggregation of rock and the increase in reactive surface area subject to oxidation by downward percolating water. 
Trends in water quality after reclamation have generally been difficult to assess, primarily owing to a lack of long-term monitoring after mining and reclamation was completed. For example, a reclaimed surface mine in southeastern Ohio was monitored for only 10 months after reclamation and no statistical change in groundwater or surface water quality was found (Hindall, 1984). In another series of studies, three watersheds in eastern Ohio were monitored for a 3 year period after reclamation, yet no significant changes in the chemistry of groundwater were noted by the end of that period (Eberle and Razem, 1985). Additionally, groundwater levels did not reach a state of long-term equilibrium. Hren (1986) noted that concentrations of most constituents at the three watersheds were increasing 4 years after mining and reclamation. The US Geological Survey and other agencies reexamined two of the three sites for an additional 5 years and concluded that geochemical changes in water quality were still occurring 8 years after mining (Cunningham and Jones, 1990). These reports document that attainment of geochemical equilibrium at surface-mine sites is a slow process.

Additionally, all of these studies document that the most significant changes in groundwater quality are within shallow aquifers, presumably because of limited vertical flow through underclays.

Comparisons made between upgradient and downgradient wells at the Fleming site to establish effects of mining on water quality indicate that upgradient wells have also been affected by acid mine drainage. Therefore, water quality data from 16 wells in the Lower Kittanning Coal collected during a previous study (Razem and Sedam, 1985) are summarized and presented in Table 40. Comparison of the two data sets show that $\mathrm{pH}$ is lower in water collected during this study and that the concentrations of all other constituents are at least one order of magnitude higher than premining concentrations in the Lower Kittanning Coal. Premining groundwaters associated with Pennsylvanian coal-bearing rock in Ohio are typically the Ca- $\mathrm{Mg}-\mathrm{HCO}_{3}$ type, similar to the water quality in the domestic wells sampled during this study; but after mining, the water type changes to the $\mathrm{Ca}^{-\mathrm{SO}_{4}}$ type (Eberle and Razem, 1985).

Given the data presented herein and the above information regarding the time required for groundwater to attain chemical equilibrium, it is doubtful that effects of reclamation have been seen in groundwater at the study site 16 months after reclamation (January 1996). The particletracking model indicates that water moves through the aquifer materials fairly slowly. Thus, for a full assessment of changes in groundwater quality, the groundwater at the Fleming site would have to be monitored for an extended period of time. 
Table 40. Comparison of median values of selected constituents from premining water quality in the Lower Kittanning Coal with median values in the shallow aquifer obtained in this study.

\begin{tabular}{llccc}
\hline \hline Constituent & Units & $\begin{array}{c}\text { Values from } \\
16 \text { wells } \\
\text { (Razem and } \\
\text { Sedam, 1985) }\end{array}$ & $\begin{array}{c}\text { Values from } \\
\text { upgradient } \\
\text { shallow } \\
\text { well } \\
\text { (this study) }\end{array}$ & $\begin{array}{c}\text { Values from } \\
\text { Downgradient } \\
\text { shallow } \\
\text { wells } \\
\text { (this study) }\end{array}$ \\
\hline Specific conductance & $\mu \mathrm{S} / \mathrm{cm}$ & & & \\
ROE & $\mathrm{mg} / \mathrm{L}$ & 655 & 2,450 & 3,010 \\
pH & Standard units & 461 & 2,680 & 3,330 \\
Sulfate & $\mathrm{mg} / \mathrm{L}$ & 7.7 & 5.7 & 5.5 \\
Iron & $\mathrm{mg} / \mathrm{L}$ & 125 & 1,325 & 2,130 \\
Manganese & $\mathrm{mg} / \mathrm{L}$ & 0.070 & 172 & 305 \\
Calcium & $\mathrm{mg} / \mathrm{L}$ & 0.072 & 10.4 & 15.7 \\
Magnesium & $\mathrm{mg} / \mathrm{L}$ & 48 & 360 & 386 \\
& & 11 & 161 & 204 \\
\hline \hline
\end{tabular}

As previously discussed, the effects of FGD by-products are seen most clearly in interstitial waters. Groundwater quality at the study site has not changed significantly during the period of study. Problems in evaluating short-term effects of FGD by-product leachate on groundwater quality include the slow groundwater flow rates and the current state of hydrologic and geochemical disequilibrium at the site. Water samples from springs indicate no water quality effects of FGD by-product leachate, but only a few samples were collected.

FGD by-product is desirable for use as a spoil and soil amendment in surface mine reclamation primarily because of its neutralizing capacity. This report documents that $\mathrm{pH}$ values of interstitial waters increased with time, from a median of 6.2 at 13 months after reclamation to a median of 6.9 at 16 months after reclamation. Concerns regarding the fate and transport of 
major and trace elements derived from FGD by-product, however, require additional consideration.

The major element analysis of the FGD by-product shows that it consists of $\mathrm{Ca}, \mathrm{Al}, \mathrm{Mg}$, sulfate-S, and carbonate-C. The most notable difference in major element chemistry between interstitial waters in the control area and the FGD by-product application area is elevated $\mathrm{Mg}: \mathrm{Ca}$ mole ratios. The $\mathrm{Mg}$ :Ca mole ratios should therefore be useful for assessing the movement of FGD by-product leachate into groundwater. Although such ratios are unaffected by dilution, the ratio cannot be considered a truly conservative quantity because saturation index calculations indicate that $\mathrm{Ca}$ and $\mathrm{Mg}$ concentrations could be affected by the precipitation of secondary carbonate minerals. However, the ratio is still a useful indicator because the current difference between the Mg:Ca ratios of the two end-member waters (FGD by-product leachate and acid mine drainage-affected groundwater) is large. Furthermore, the $\mathrm{Mg}$ :Ca ratio may increase with time as the soluble MgO component of the FGD by-product continues to dissolve.

Trace elements derived from the FGD by-product that could adversely affect water quality include $\mathrm{As}, \mathrm{Hg}, \mathrm{Pb}$, and $\mathrm{Se}$. Concentrations of these elements in interstitial waters sampled during this study were well below the maximum contaminant level set by the US Environmental Protection Agency (As, $50 \mu \mathrm{g} / \mathrm{L} ; \mathrm{Hg}, 2 \mu \mathrm{g} / \mathrm{L} ; \mathrm{Pb}, 15 \mu \mathrm{g} / \mathrm{L} ;$ and Se, $50 \mu \mathrm{g} / \mathrm{L}$ ). Furthermore, concentrations of these elements in interstitial waters rarely exceeded the reporting limit. Other trace elements, such as $\mathrm{Ni}$, are likely derived from acid mine drainage generated in the mine spoil/underclay sequence and not from the FGD by-product/compost mixture. Support for this hypothesis is provided by the high Ni concentrations (230 to 910 $\mu \mathrm{g} / \mathrm{L}$ ) found in interstitial water samples from the control-area interstitial water group and in groundwater from the deep aquifer.

Concentrations of other trace elements, including $\mathrm{B}, \mathrm{Cr}, \mathrm{Co}, \mathrm{F}$. and $\mathrm{Zn}$, were elevated in interstitial waters. Boron was found in low concentrations in the control area interstitial water samples, and the median boron concentration of groundwater samples collected from onsite monitoring wells $(271 \mu \mathrm{g} / \mathrm{L})$ and offsite domestic wells $(152 \mu \mathrm{g} / \mathrm{L})$ is significantly lower than the median $B$ concentration of interstitial water samples from the FGD by-product application area $(656 \mu \mathrm{g} / \mathrm{L})$. The possibility that some $\mathrm{B}$ found in the interstitial water samples is derived from the FGD by-product/compost mixture may be a cause for concern because an important aspect of mine reclamation is reestablishment 
of vegetation and elevated B concentrations can cause phytotoxicity (Pierzynski et al., 1994). Similarly, concentrations of $\mathrm{Cr}$ were elevated in interstitial waters from the FGD by-product application area (median, $11 \mu \mathrm{g} / \mathrm{L}$ ) as compared to the control area (median, $<2 \mu \mathrm{g} / \mathrm{L}$ )

Concentrations of $\mathrm{Co}$ and $\mathrm{Zn}$ were elevated in interstitial waters in the FGD by-product application area and in the control area, an indication that these elements were derived from onsite sources during generation of acid mine drainage, not from leaching of the FGD byproduct/compost mixture. Lysimeter equipment blanks indicate that the lysimeters themselves may be a source of $\mathrm{B}, \mathrm{Co}$, and $\mathrm{Zn}$ in the interstitial water samples. Fluoride concentrations in all but one well (well 6S) and all control area interstitial waters were below the maximum contaminant level of $4 \mathrm{mg} / \mathrm{L}$. Concentrations in many interstitial water samples from the FGD by-product application area, however, exceeded this level.

One notable feature of the interstitial water samples is their high dissolved organic carbon (DOC) concentrations (median, $22 \mathrm{mg} / \mathrm{L}$ ). This compares with median DOC concentrations of $0.9 \mathrm{mg} / \mathrm{L}$ and $0.45 \mathrm{mg} / \mathrm{L}$ in the onsite monitoring and offside domestic wells, respectively. The $D O C$ is likely derived from leaching of organic acids from the compost component of the FGD by-product/compost mixture.

The range of $\delta^{34} \mathrm{~S}$ for $\mathrm{SO}_{4}$ in interstitial waters ( -13.3 to +3.0 per mil) is isotopically depleted with respect to ${ }^{34} S$ relative to the range of $\delta^{34} S$ reported for the FGD by-products $(+4.6$ to +4.8 per mil) but is within the range of $\delta^{34} \mathrm{~S}$ reported for dissolved sulfate in groundwater samples collected from onsite monitoring wells $\left(-14.1\right.$ to -5.7 per mil; median $\delta^{34} \mathrm{~S}$ of -9.5 per mil). In addition, the most depleted $\delta^{34} S$ recorded for round 2 samples, -9.8 per mil for TU154 and -13.3 per mil for TU-152, were followed by round $3 \delta^{34} S$ of -2.1 per mil and -1.6 per mil, respectively. The $\delta^{34} S$ data for these two interstitial water samples indicate the transition from an onsite acid mine drainage source of sulfate to a FGD by-product source of sulfate.

\subsection{Conclusions from Mineland Reclamation Study Using FGD}

In the first year after reclamation, good vegetative growth on minespoil amended with AFBC or PFBC and yard waste compost was achieved. Vegetative cover was nearly $100 \%$ over all areas reclaimed using FGD. The successful revegetation of the minespoil can be attributed to increased $\mathrm{pH}$ and increased concedtrations of $\mathrm{Ca}$ and $\mathrm{Mg}$ due to the FGD addition. The less vigorous initial plant growth in the FGD versus the topsoil treated areas may be attributed, in 
part, to the large soluble salt concentrations. It is expected that these concentrations will decrease over time as salts are leached from the profile surface.

Similar improvements in surface runoff water quality were observed with topsoil, FGD, or FGD+compost. All three reclamation practices increased water $\mathrm{pH}$ to neutral levels and greatly decreased soluble Al. Concentrations of trace elements of environmental concern remained at very low concentrations in waters from all three reclamation practices. In those cases where measurable concentrations were present, there were no differences among the three reclamation treatments. The salt load of waters draining from an FGD-treated minespoil will likely initially be larger than from a minespoil covered with topsoil. The duration of this increased salt load will depend upon the rate of downward salt leaching through the spoil profile and the extent of vegetative cover.

Soil restorative treatments applied to abandoned mine land improved infiltration rate and soil hydraulic conductivity. Using a rainfall simulator, runoff was found to be lowest from the topsoil treated areas and highest from the FGD only treated areas. Similarly with natural rainfall measurements, the lowest runoff occurred from the topsoil treated watershed. Soil erosion was low in all reclaimed watersheds and below the level that would cause concern, even for agricultural soils. The relative soil erosion was 100:872:479 for topsoil:AFBC+compost:AFBC treatments.

Data collected to date show no evidence that FGD by-product leachate has affected the quality of groundwater at the study site. Water quality data from interstitial waters may be used to assess the potential effects of FGD by-product leachate on groundwater quality. The chemical environments from which the two sample types are collected are vastly different. Interstitial waters are in contact with treated and untreated spoil and soil gases (such as carbon dioxide) in the unsaturated zone, whereas groundwater is mostly isolated from the atmosphere and water is in contact with aquifer materials.

To fully evaluate the effects of FGD by-product application on groundwater quality during abandoned mine reclamation would require a long-term monitoring program. The fate and transport of leachate derived from FGD by-product may be modeled with existing geochemical models, but these models require assumptions that are beyond the scope and reliability of the current data set. Additionally, predictions may not provide regulatory agencies with the same information field data would provide. 
By use of a modified version of the monitoring strategy outlined in the methods section of this report, additional useful information could be obtained. Modifications to the approach might include (1) use of lysimeters composed of inert materials to minimize chemical interference, (2) use of lysimeters that do not require vacuum extraction, (3) instrumentation of the site with soil-moisture probes to support suppositions about recharge rates, (4) installation of lysimeters to just above the saturated zone to get a more accurate assessment of waterquality during recharge events, and (5) on the basis of results of sensitivity analysis from the groundwater flow model, collect additional data regarding vertical hydraulic conductivities of aquifer materials and conductances of springs. 


\section{USE OF FGD BY-PRODUCTS FOR ROADWAY STABILIZATION}

\subsection{Introduction}

Promising beneficial uses of FGD by-products include high volume applications such as structural fills for highway embankments and ramps, backfills for retaining walls, and in subbases and base courses for roadways. In cooperation with the Ohio Department of Transportation (ODOT), two field sites were chosen to demonstrate the applicability of FGD by-products in roadway stabilization. The FGD material chosen for both demonstrations was the PFBC by-product from the American Electric Power's Tidd plant located near Brilliant, $\mathrm{OH}$. Characteristic properties of this type of material are described in Stehouwer et al. (1995a, 1998). This material was a blend of cyclone and bed ash (2:1 ratio, respectively) and was conditioned with water at the plant before its transport to the study sites. Thus the material, as delivered, would no longer be "dry". The water added water is important as the FGD byproduct has a need for water to hydrate the small amount of free lime and the significant amount of anhydrite $\left(\mathrm{CaSO}_{4}\right)$. Formation of ettringite (a swelling mineral that forms in some FGD materials) was not observed and swelling was not a problem with this particular FGD material (Stehouwer et al, 1998).

Other FGD materials being considered for road construction and repair must be carefully studied to determine their swelling potential. Obviously, a material that swells when placed into a roadbed, will not provide adequate performance. Details of studies related to the potential for swelling of various FGD by-product materials are provided in the Phase 1 and Phase 2 reports of this project (Stehouwer et al., 1995a, 1998).

Both projects involved the reconstruction of failed embankment sections of rural highways in ODOT District 5. 


\subsection{Description of Study Sites and Repair Procedures}

\subsubsection{Ohio State Route 541}

Ohio State Route 541 (SR 541) runs approximately east to west between the towns of Coshocton and Mount Vernon in east central Ohio. State Route 541 has been a major thoroughfare in this part of the state for many years. The portion of the highway chosen for repair using FGD is an embankment about 15 meters high and 1000 meters long and is located just west of Coshocton. The section that failed was a realignment of the original road built in 1920 and improved in 1966 by eliminating a series of sharp horizontal and vertical curves (ODOT Construction Plans, 1966). To minimize the vertical gradient and provide adequate roadway drainage the realignment required the construction of a large embankment involving a great deal of fill. A site map showing the location of the project is presented as Figure 69.

Ohio Department of Transportation (ODOT) records indicate there were no significant repairs made to the reconstructed section of SR 541 during the first 20 years after the embankment was completed. However, by 1985 the northern half (west bound lanes) of the road surface had visibly settled in the central portion of the embankment. The settlement became progressively worse and was accompanied by indications of a rotational slide. The north slope was reported to have been covered by numerous scarps and there were reports of soil upheaval at or near the base. In 1986, an ODOT repair crew attempted to correct the problem and prevent any further deterioration by digging a trench in the north shoulder that was approximately four meters deep for a distance of 25 meters along the length of the roadway. A row of eight meter long piles was driven into the trench and then attached to the guardrail effectively creating a 25 meter long, eight meter high retaining wall. The trench was then backfilled and the asphalt road surface repaired. Another trench was excavated on the south side of the roadway and a drain was installed to intercept surface and subsurface water coming from the adjacent hillside. This repair effectively stopped the sliding and nothing further was done to this section of highway over the following three years.

By early 1989 it became apparent that the highway was again slipping. At that time ODOT engineers, realizing that the pile-supported retaining wall had failed to prevent the road surface from settling, ordered a more comprehensive repair. An excavation of the piles revealed that although the top of the piles had remained fixed to the guardrail, the base of the pile wall had moved approximately two meters down slope for an equivalent angle of rotation of almost 20 degrees. The piles were removed and the embankment material was excavated to a depth of 13 


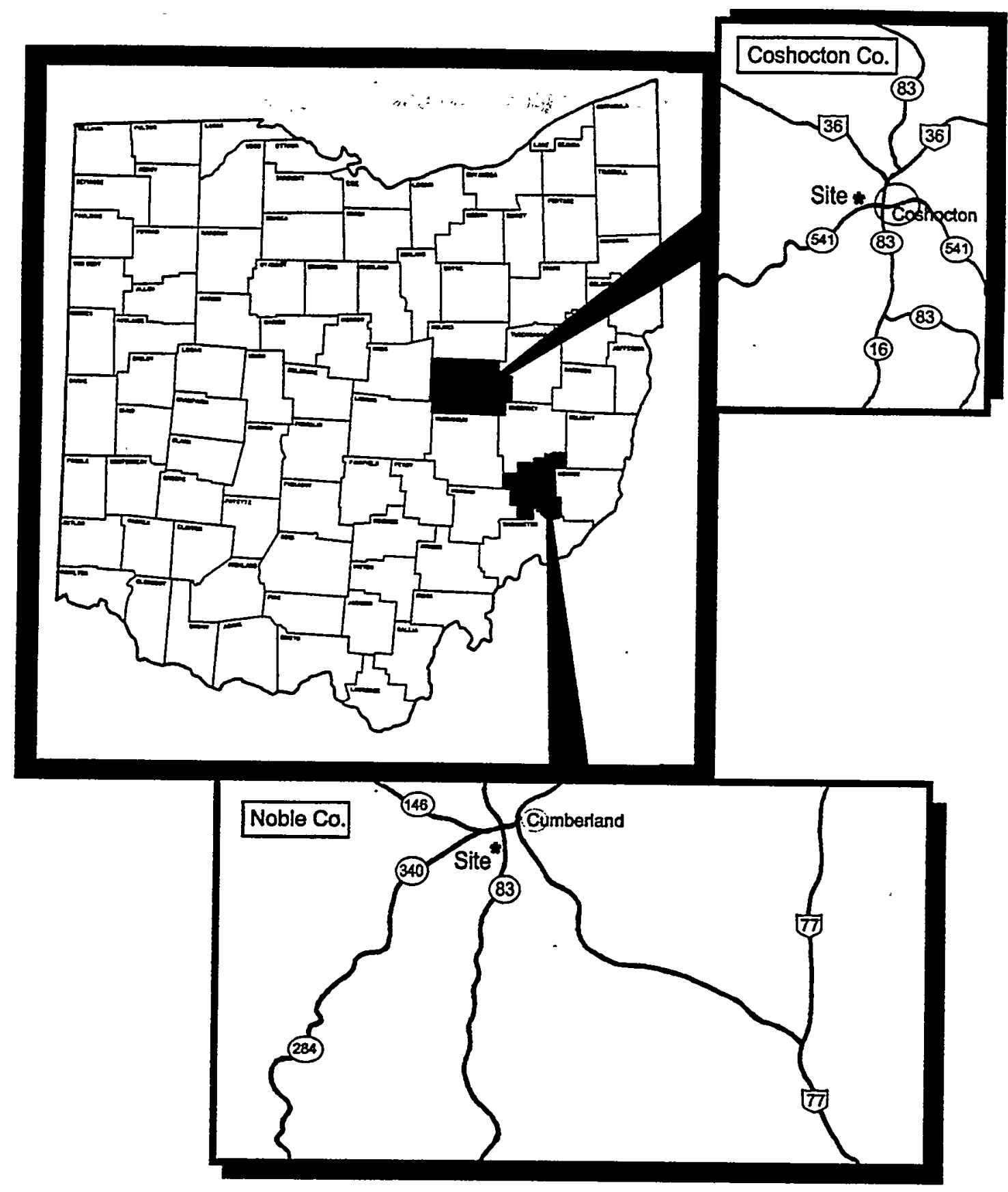

Figure 69. Location of road repair field study sites in Coshocton County (State Route 541) and Noble County (State Route 83). 
meters below the road surface and replaced with select fill. The slope was brought back to its original condition (2:1 slope). Two drains were installed at the top of the embankment to intercept a layer of water that was detected during the excavation process. These drains are still active, particularly after periods of heavy rainfall or snow melt (Neuhart, 1994).

In May 1993, ODOT maintenance crews determined that the road surface was again exhibiting signs indicative of another rotational slide. As before, there was a zone of earth flow at the base of the embankment and the slope had the rolling terrain typical of a series of rotational slides. The top of the slope was beginning to suffer significant settlement. By the end of the summer, the shoulder of the westbound lane had settled as much as one meter and the scarp appeared to be progressing toward the center of the roadway. A photograph (Figure 70) shows the top of the slide looking east along the roadway.

Repair crews from the District 5 Special Projects Branch and the Coshocton County Division began excavating the base of the embankment where a layer of moist grayish clay was exposed near the surface. After a few meters of excavation, the soil was completely saturated. The elevation of the saturated layer seemed to coincide with the elevation of the original natural ground surface beneath the embankment (approximately 11 meters below the road level at the estimated center of the slide area). The weight of the construction vehicles operating on the clay caused it to pump, temporarily halting the operation while a trench was dug to locate the source of the excess water. When the trench was approximately two meters deep, a spring was uncovered. Water rushed out of the new opening for 15 minutes and eventually settled into a steady flow that continued for three weeks at a rate of approximately 1.5 to 2.0 liters/second. (Neuhart, 1994).

Due in part to poor weather conditions at the site in the autumn of 1993, and competing schedule requirements for the ODOT work crews, the excavation of the soil above the slip plane required nearly eight weeks. During the time the excavation was ongoing, the scarp at the head of the slide progressed across the highway so that by late November, the entire roadway had slipped. The total volume of material that had to be removed was slightly in excess of $9000 \mathrm{~m}^{3}$. The bottom of the excavation was 14 to 15 meters below the original road surface. At that elevation the crews encountered a combination of exposed shale and firm blue-gray shale clay. About half this material was stockpiled on site to be used later in the reconstruction of the embankment. The balance of the soil which was predominantly a saturated clay, was transported off-site (Neuhart, 1994). 


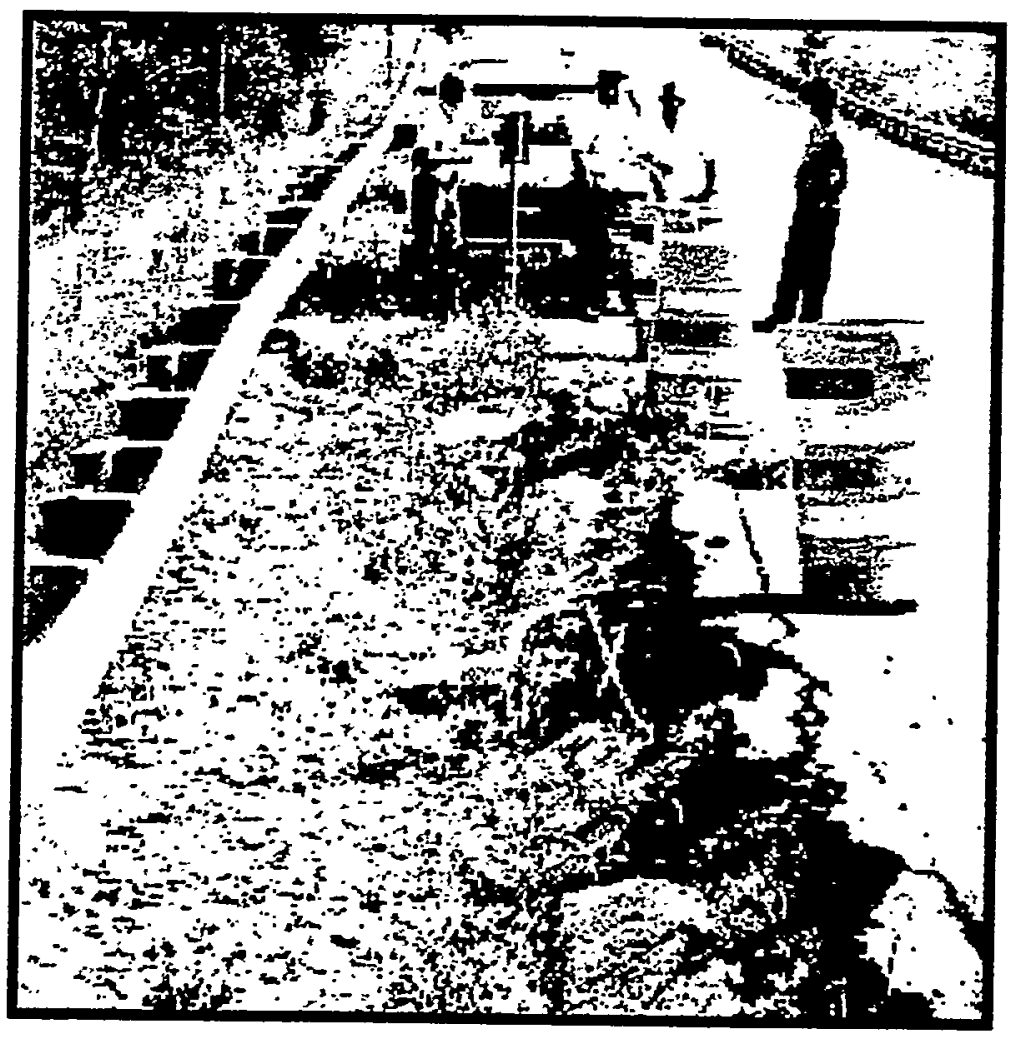

Figure 70. Landslide in the northbound shoulder of State Route 541 west of Coshocton, Ohio. Photograph taken in 1993. 
The replacement of the embankment material began in the late autumn of 1993 with the installation of a geotextile filter and a perforated PVC drainage line which were placed at the base of the hillside. The geotextile filter was located on the up-slope face of what was eventually to be a buttress made up of FGD by-product. The drain outlet was directed to empty into a stream near a culvert that runs underneath the highway. The flow, which has been relatively constant since shortly after the drain was installed, was 0.5 to 1.0 liters/second. Once the geotextile was in place, the crew began placing the dry FGD by-product which had been stockpiled at the site. Self-loading scrapers delivered the material to the excavation as bulldozers spread it evenly over an area 12 meters wide by 30 meters long (Figure 71). The first lift of approximately $60 \mathrm{~cm}$, was placed and rolled at the end of the first day. The next morning, as the 40 metric ton scrapers delivered the FGD for subsequent lifts, the operators noticed that the vehicles were not leaving tire tracks on the surface. This indicated the compacted FGD had gained significant strength in only $24 \mathrm{~h}$ or less. Construction of the FGD buttress was completed by the end of November of 1993 when approximately four to five meters of the material had been placed (Figure 72). There were no strict controls on thickness of the lifts or on the quantity of water added during compaction. It is likely that the amount of water added in the field exceeded the optimum water content as determined in the laboratory. The ODOT field personnel adjusted the size of the lifts and the amount of water added to suit the prevailing conditions. Use of FGD provides flexibility because it has a wide water content range over which it is workable and it does not require laboratory precision to yield excellent strength properties. Above the compacted FGD, the original embankment material was replaced throughout the month of December in controlled lifts that ultimately totaled almost 4 meters.

A second source of groundwater was detected during reconstruction of the embankment at an depth of six meters below the original road surface. Two additional drains were installed to intercept the water and route it away from the slope. To further strengthen the embankment another FGD layer was placed at this elevation. This second layer of FGD extended from the centerline of the road to within two meters of the leading edge of the slope. This layer of FGD measured one meter thick, ten meters wide, and twenty meters long. The top of the FGD layer is located five meters below the road surface.

To bring the embankment from this level to final grade, a grayish brown clay shale was hauled from a borrow area three kilometers west of the construction site. This material had strength properties significantly higher than the original embankment material. The base course of the repaired area was brought back to original grade in early February 1994 and the FGD by- 


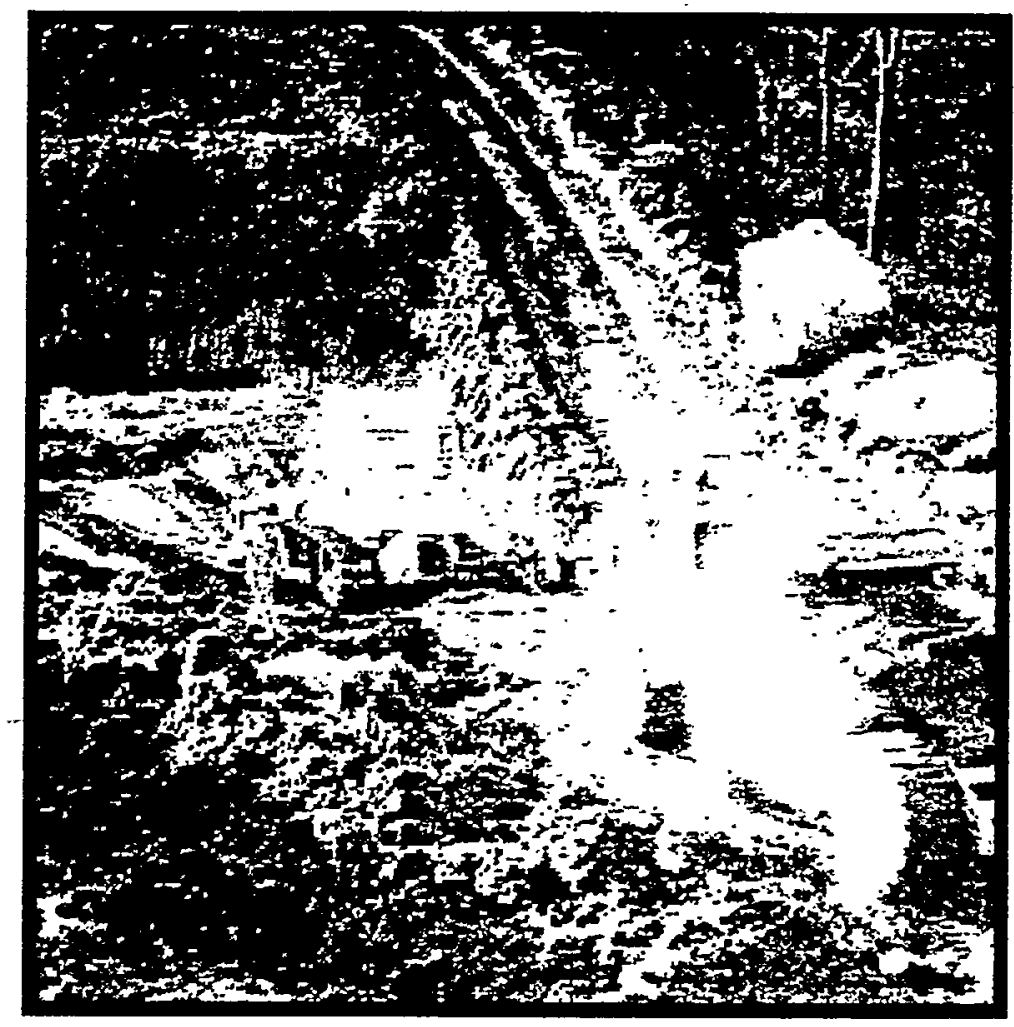

Figure 71. Delivery and placement of FGD at the base of the embankment during repair of State Route 541. 


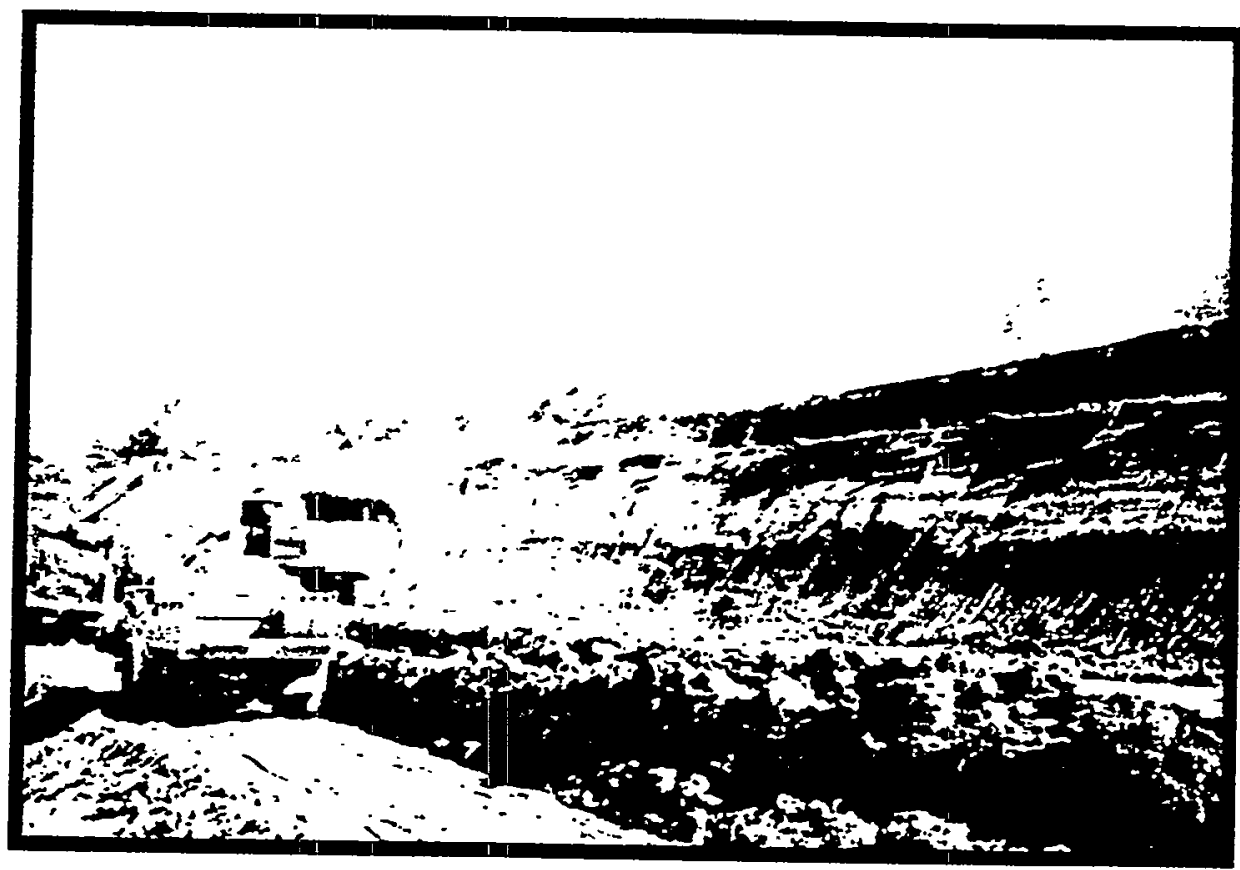

Figure 72. Construction of the FGD buttress at the base of State Route 541. 
product was mixed with aggregate to form a temporary wearing course which is shown in Figure 73. The road opened to traffic in March 1994. The final paving of SR 541 was completed early in the following summer. The road surface after paving is shown in Figure 74.

The slope was instrumented the following summer. Piezometers and inclinometers were installed in six locations on the north facing slope to measure the performance of FGD for road repair.

\subsubsection{Ohio State Route 83}

Ohio State Route 83 runs approximately north to south for nearly the entire length of the state. The section of this highway repaired to demonstrate the use of FGD is located in Noble County just south of the village of Cumberland (Figure 69). The failed portion was an embankment 15 meters high and 1000 meters long.

According to area residents this section of the roadway has caused problems for local traffic for 25 years. In the past five years, state crews have had to patch the pavement two to three times each year. In the late spring of 1993, a site inspection identified a three to five centimeter vertical off set along the centerline of the roadway (Figure 75). An investigation of the slope just beyond the right-of-way revealed the undulating terrain typical of multiple rotational landslides.

Soil borings taken by an ODOT drilling crew revealed a layer of silty clay four to six meters thick overlying clay and clay shale in the slide area. The silty clay increased in thickness across the roadway indicating a dip in the rock surface of 14 degrees away from the hillside. The slip plane was identified in the borings at the approximate location as shown in the cross-section of the hillside (Figure 76).

The repair of the failed section was completed in three stages and involved use of FGD from the American Electric Power's Tidd plant. The initial stage which was begun in late October, 1994, consisted of the excavation of the slip and roadway and the removal of the failed material. At this time approximately $11,000 \mathrm{~m}^{3}$ of embankment soil were excavated from above the slip plane. The failure plane was not intercepted during this excavation however and additional material was removed from the upslope side of the roadway to form a trench 2.5 meters wide by two meters deep. When the trench was completed, fabric drain boards similar to the ones used successfully on the SR 541 repair were installed against the natural hillside to 


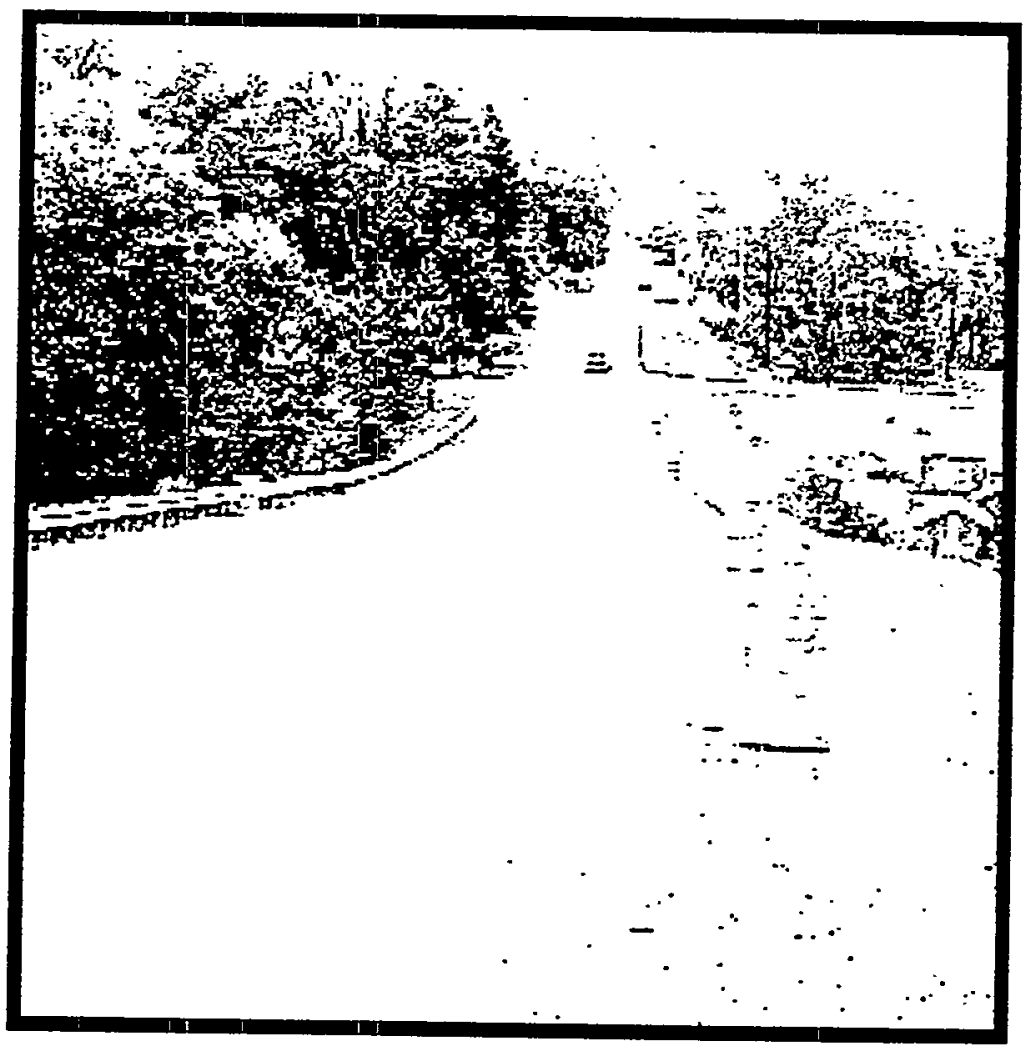

Figure 73. Temporary wearing surface on State Route 541 made from FGD. 


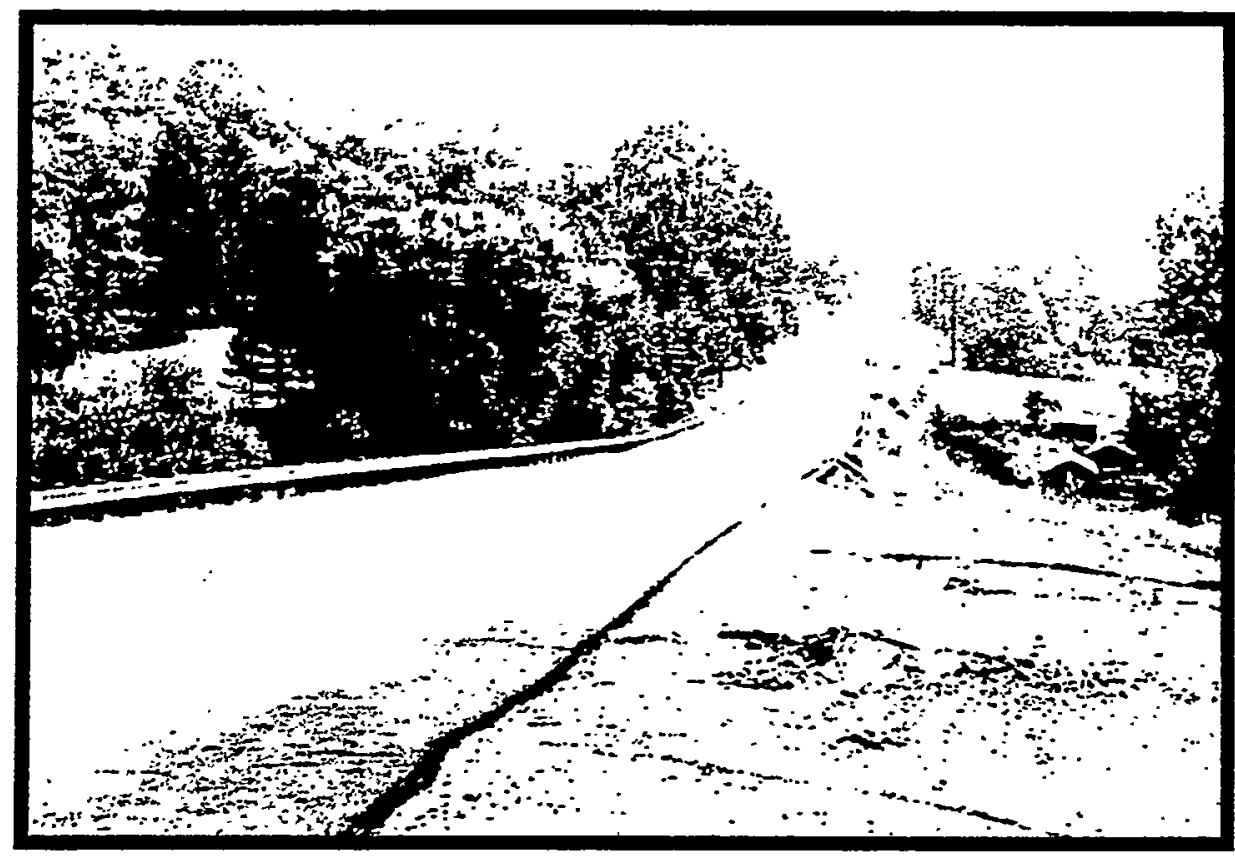

Figure 74. State Route 541 study site after repairs were completed (1994). 


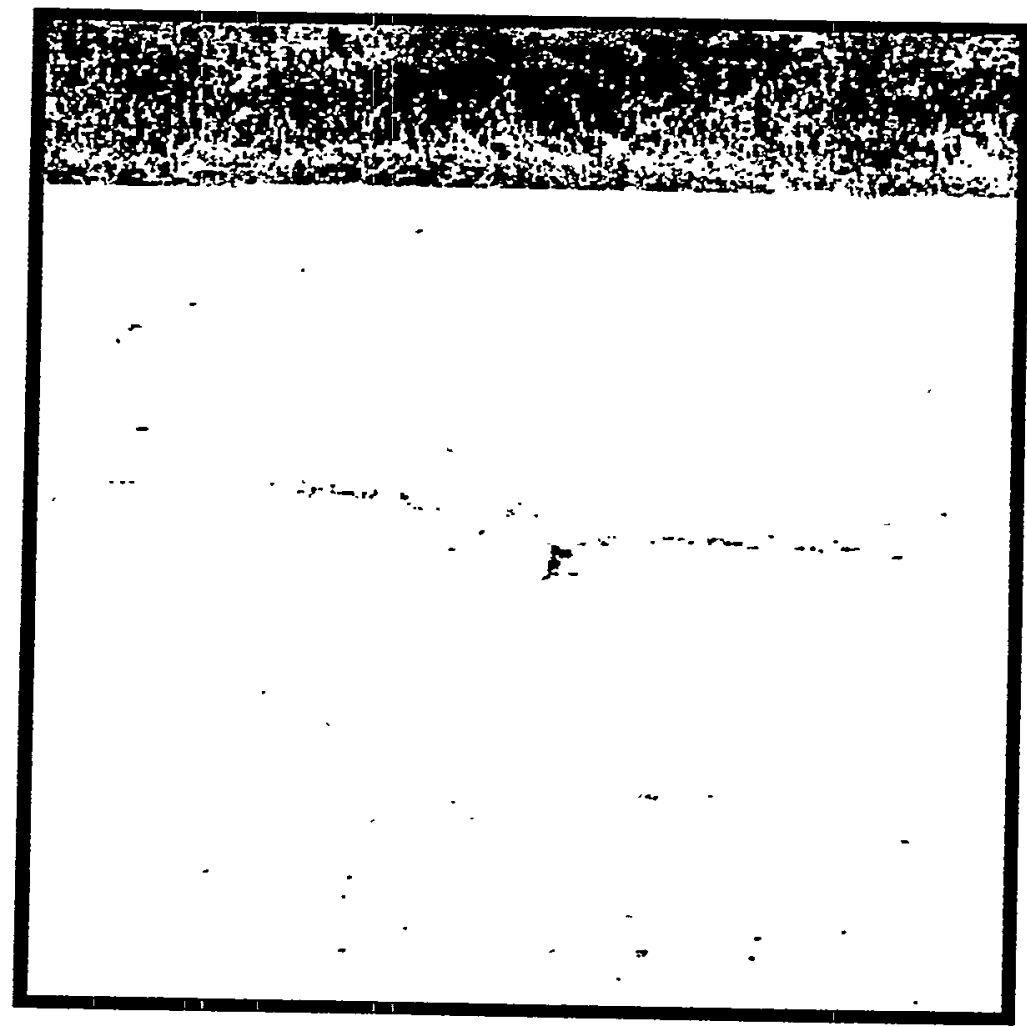

Figure 75. Vertical offset in pavement of State Route 83 (spring, 1993). 


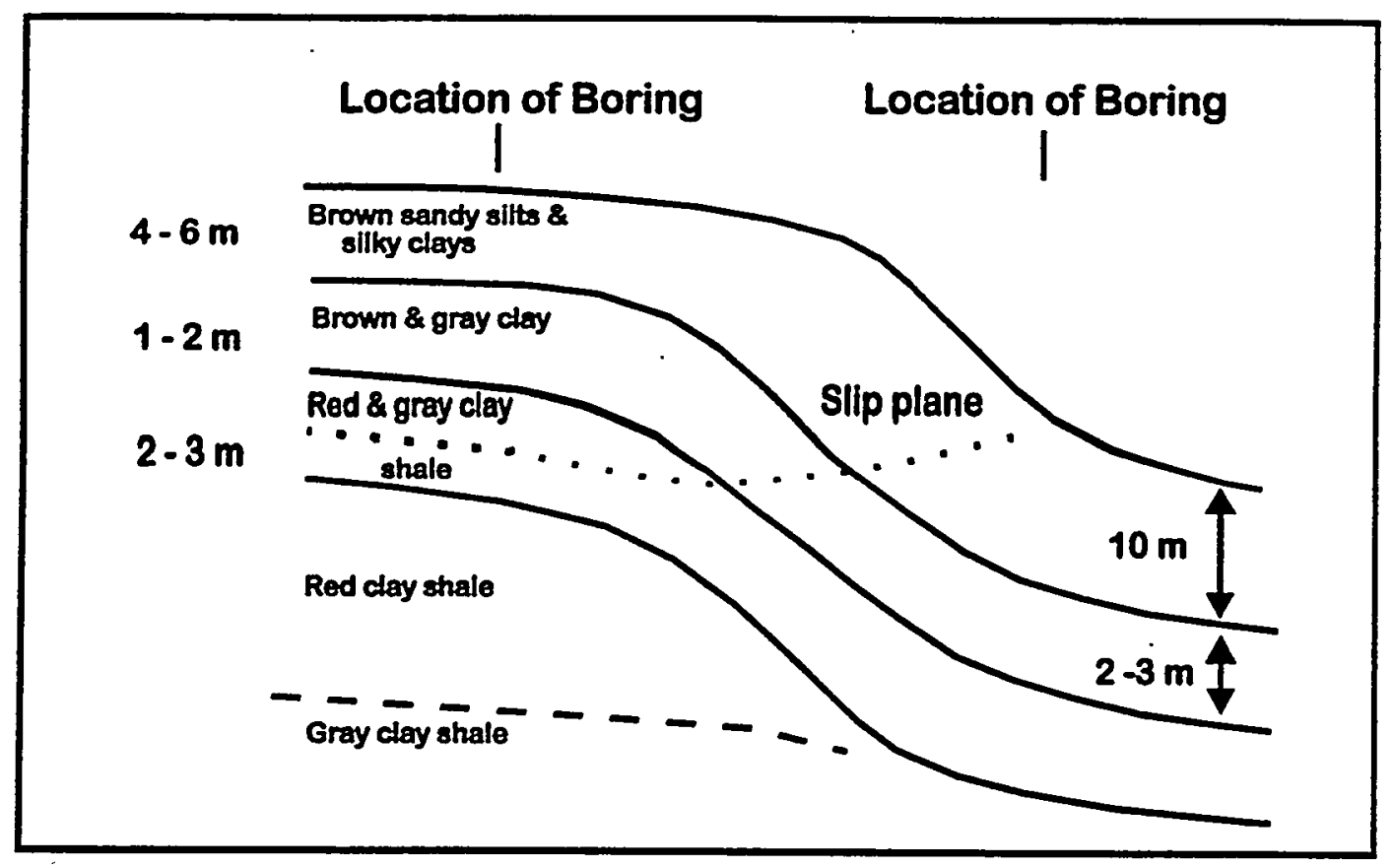

Figure 76. Subsurface profile of State Route 83 in slide area. 
intercept any subsurface water before it could reach the FGD. Drain lines were placed at the bottom of the trench to carry the intercepted water off the hillside. The trench was then backfilled with compacted FGD to form a key (Figure 77). The FGD key was constructed because a slope stability analysis indicated that such a structure would result in a repaired slope with an adequate factor of safety against sliding. The FGD in the key was placed in 30 to 45 $\mathrm{cm}$ lifts then spread using a small bulldozer and finally compacted with a single drum sheepsfoot roller.

When construction was completed and the material in the key was up to the base of the main excavation, the embankment was divided into four study zones. In two of the zones (the north and south boundaries of the project) the reconstructed embankment consisted of control sections where standard procedures for replacing and recompacting soil were followed. Between the two control sections, a third section consisting of an FGD layer similar to the one placed at SR 541 was placed. In the fourth section, the FGD was mixed with the soil that had been removed from the slide and stockpiled on site. This section was constructed to determine whether or not the FGD by-product could be used effectively as a treatment to improve the mechanical properties of in-situ soil.

The FGD section was constructed in lifts of 30 to $60 \mathrm{~cm}$ which were watered to bring the material close to optimum conditions. The same sheepsfoot roller used to densify the soil sections was used to compact the FGD and the FGD/soil mixture. The design of the FGD/soil mixture section called for the material to be placed as close to 50\% FGD and 50\% soil as field mixing conditions would allow. As was the case for the soil sections, the FGD/soil section was built up in lifts of $20 \mathrm{~cm}$ (Figure 78). The compacted water contents of the soil, FGD and FGD/soil mixture were $19 \%, 18 \%$, and $15 \%$, respectively. Typical compaction was about $95 \%$ of Standard Proctor in the four sections.

The reconstruction of the entire embankment was completed on December 14, 1994. However, before the road could be reopened to traffic, a wearing course had to be placed over the four test sections. Since the reconstruction work wasn't completed until after the last date that asphalt was available from any of the local batch plants, a temporary wearing surface had to be placed. This temporary surface was constructed by placing a layer of compacted FGD byproduct over half the site. On the other half of the roadway a macadam surface typically specified by ODOT for temporary repairs was constructed. The conventional macadam surface consisted of $50 \mathrm{~cm}$ of stone ranging in size from $0.5 \mathrm{~cm}$ to $3.5 \mathrm{~cm}$. The FGD surface consisted of $40 \mathrm{~cm}$ of compacted ash. Both sections were rolled and sealed using a rubber tired roller. 


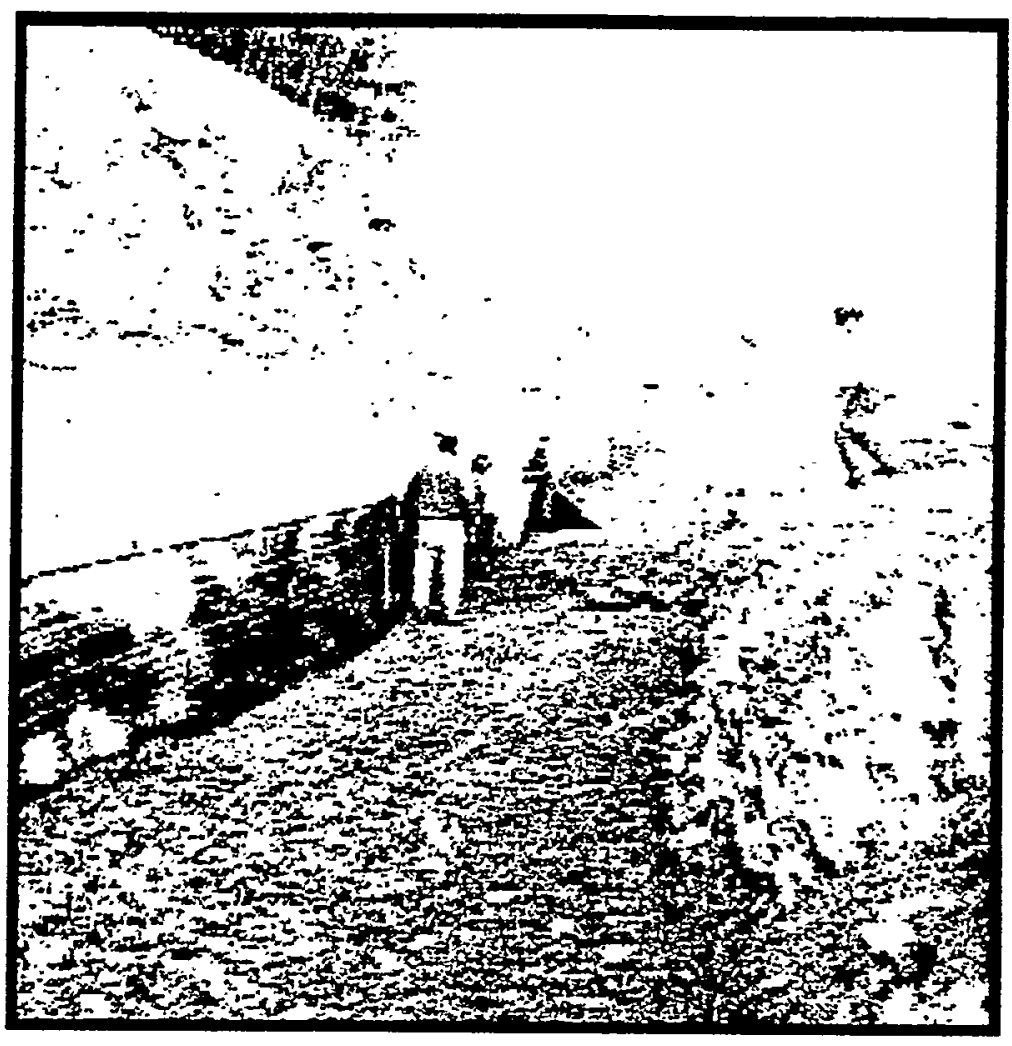

Figure 77. Construction of the FGD key on State Route 83 (1994). 


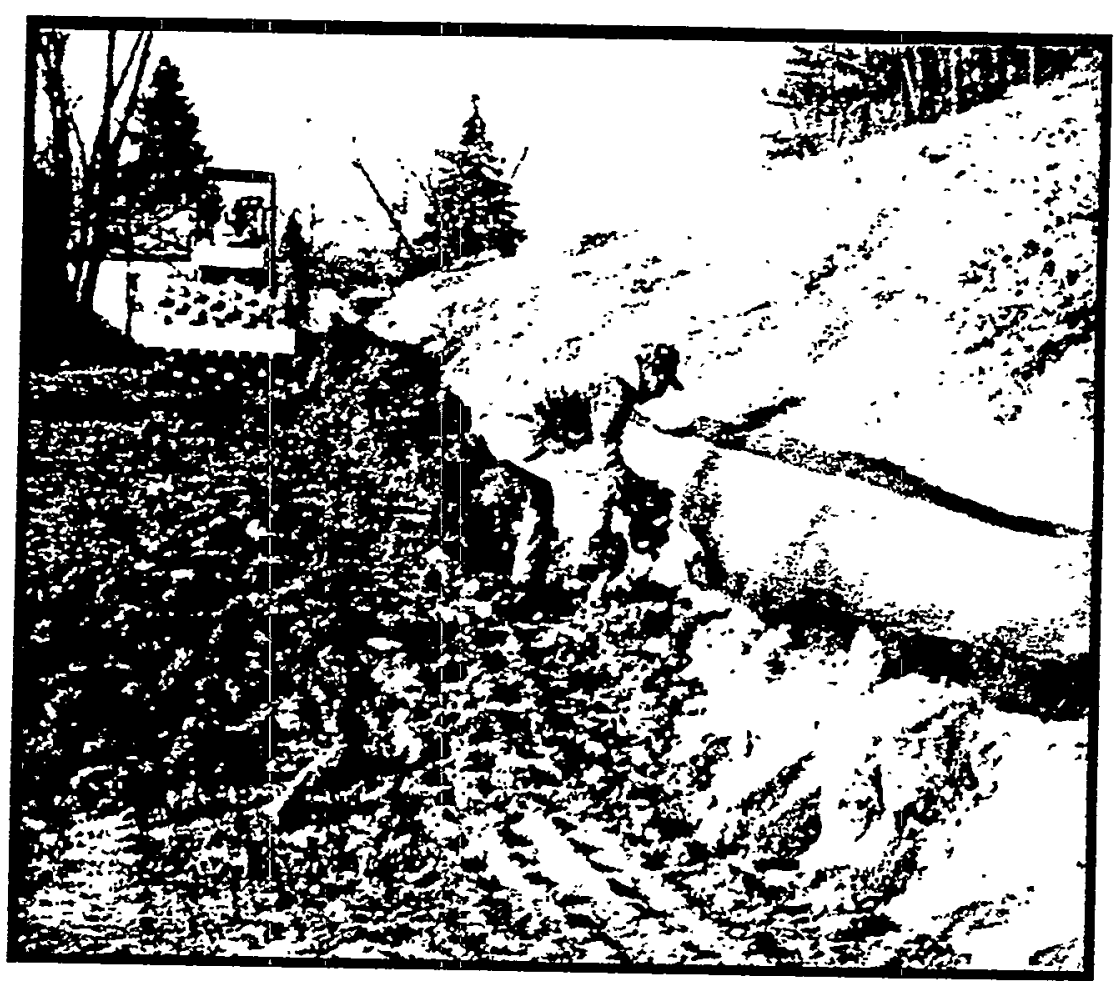

Figure 78. Construction of the FGD/soil embankment section at the State Route 83 study site. 
The completed roadway is shown in Figure 79. The road was reopened to traffic in late December, 1994. In April, 1995, ODOT installed piezometers and slope indicators in the test sections to evaluate performance of the various repair materials... . .......

\subsection{Results and Discussion}

\subsubsection{Ohio State Route 541}

Virtually no movement of the embankment has been noted after repairs were completed and the measurements were begun. Water measurements to study $\mathrm{pH}$, total dissolved solids, total alkalinity, hydroxide alkalinity, $\mathrm{SO}_{4}{ }^{2-}$ and $\mathrm{Cl}^{-}$have been made on samples at various times over the past two years. No significant differences were observed in the pre-construction and post-construction values for these quantities. Therefore, use of FGD should not be discriminated against based upon any water quality impact concerns.

Loss of soil strength attributed to the absorption of water and the development of increased porewater pressures is a common cause of slope instability. The failure of the SR 541 embankment was most likely due to an increase over time of the amount of water present in the embankment soils. Since the objective of this project was to demonstrate to the highway department and the electric producing utilities that slope stabilization is a potential beneficial use for certain types of FGD, an analysis of the stability of the slope before and after the repair was conducted. Available data on the condition of the slope prior to the slip consisted of embankment cross sections and a reasonably good estimate of water levels. Typical values for the embankment materials were taken from local records. The program PCSTABL (Lovell, 1988), commonly used by ODOT engineers, was chosen to perform stability calculations on the SR 541 embankment. Some relatively minor adjustments were made to the soil properties during the analysis to match the stability prediction with the known factor of safety of one that existed prior to repairs. The final material properties used in the analysis are presented in Table 41:

In its normal analytical mode, PCSTABL generates a series of potential failure surfaces each with an associated factor of safety once all the necessary geometric and material properties are specified. Figure 80 shows the most critical failure surface calculated for the original embankment configuration and the estimated location of the water table. This computed failure surface, with a calculated factor of safety of 0.94 is nearly identical to the one that actually occurred in the spring and summer of 1993. 


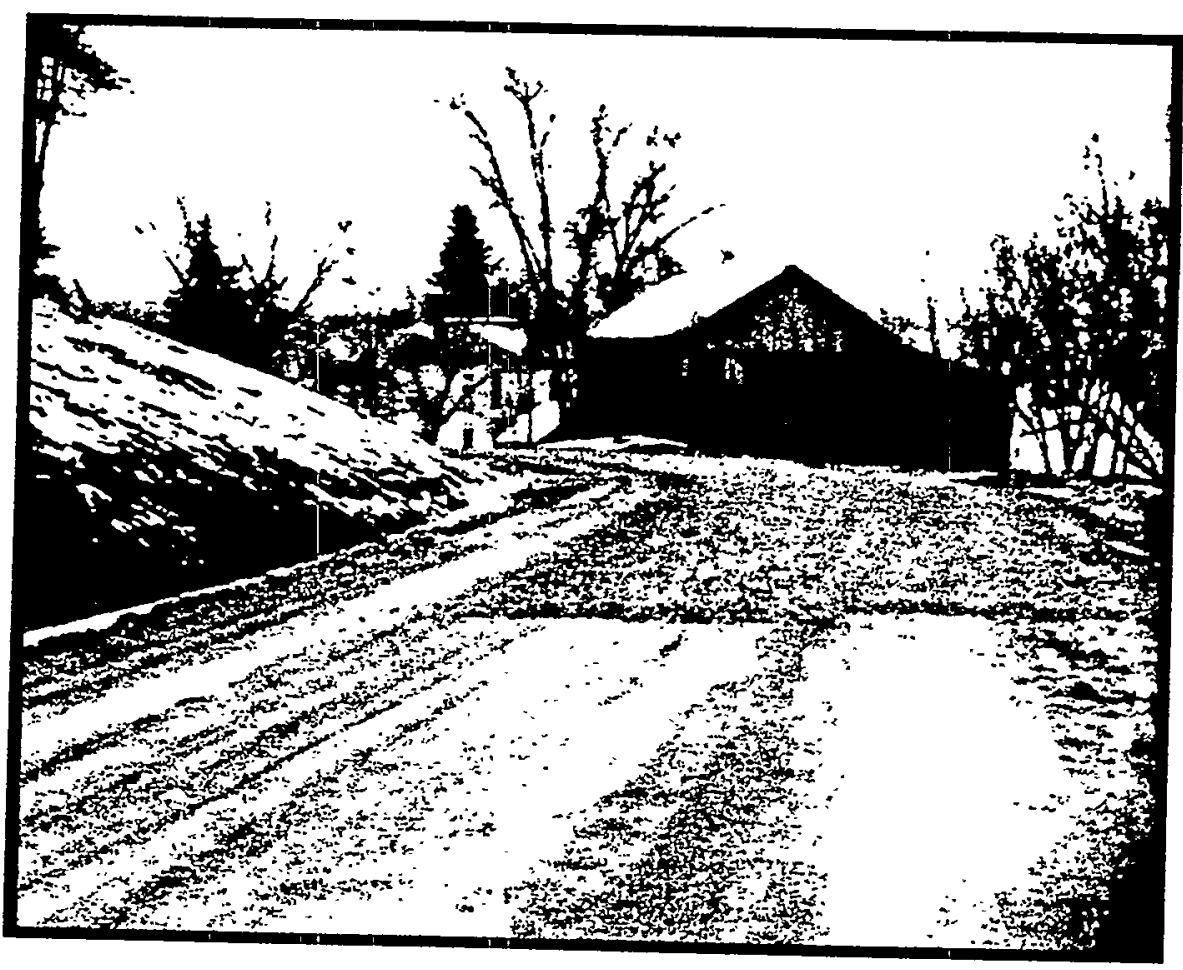

Figure 79. State Route 83 study site after completion of repairs (1994). 
Table 41. Typical soil properties used for analyses of the State Route 541 study site.

\begin{tabular}{lccc}
\hline \hline Material & $\begin{array}{c}\text { Unit weight } \\
\left(\mathrm{kN} / \mathrm{m}^{3}\right)\end{array}$ & $\begin{array}{c}\text { Cohesion } \\
(\mathrm{kPa})\end{array}$ & $\begin{array}{c}\text { Friction angle } \\
(\text { degrees })\end{array}$ \\
\hline Embankment soil & wet/sat & & \\
Borrow soil & $18.3 / 20.4$ & 38.2 & 0 \\
Recompacted fill & $18.2 / 19.8$ & 48.0 & 30 \\
\hline \hline
\end{tabular}

In a second analysis, the weak soil near the base of the slide was replaced by compacted FGD. The water table in this calculation was assumed to be unchanged until intercepted by the geotextile drain boards. To simulate a working drain, the water table was quickly lowered once it made contact with the drainage material adjacent to the FGD buttress. Water not intercepted by the filter was assumed to go around the buttress and exit at either the eastern or western edges of the slope. The program is limited to a two-dimensional analysis, so the water table was simply lowered to the bottom edge of the buttress and maintained at that elevation.

Analyses of the profile of the embankment containing the FGD by-product layers is depicted in Figures $\mathbf{8 1}$ and 82 . The critical surface no longer goes through the FGD and, as a result, is a much shallower circle with a calculated minimum factor of safety of 5.9 (Figure 81). The original failure surface shown in Figure 80 was specified for the reconstructed embankment and a new safety factor was calculated. This recalculated factor of safety was $\mathbf{5 8}$ for the repaired slope using FGD (Figure 82). Clearly, after the repairs had been completed, sliding would not initiate along the original critical surface. Rather, in the new configuration, any potential failure surfaces would be outside of the sections areas containing the FGD byproduct. 


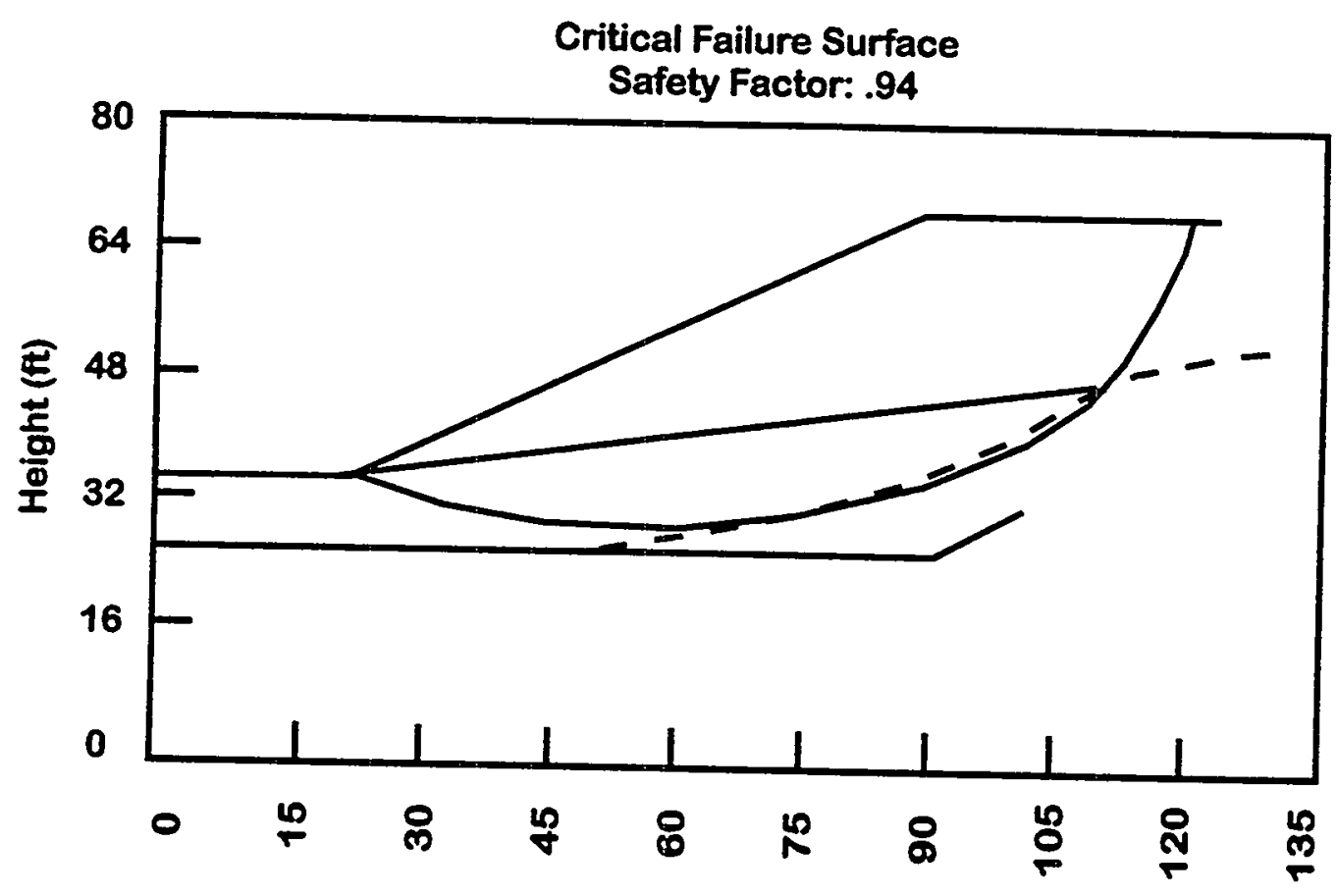

Width of Embankment (ft)

Figure 80. Critical failure surface for the original embankment at State Route 541. Dashed lines represent the estimated location of the water table. 
Possible Failure Surface

Lowest Safety Factor: $\mathbf{5 . 9}$

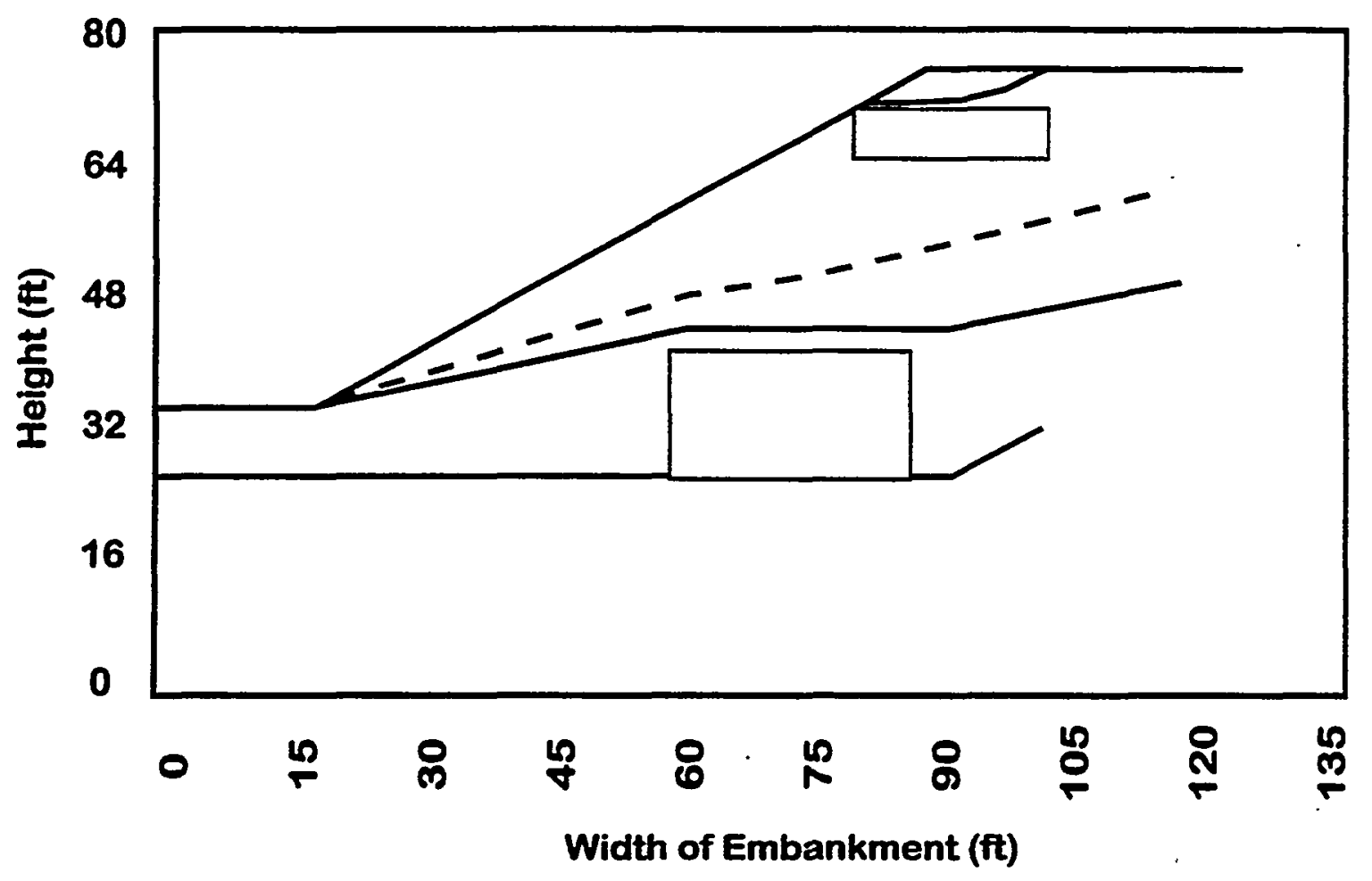

Figure 81. Potential failure surface for the repaired embankment at State Route 541. Shaded areas contain FGD. Dashed lines represent the estimated location of the water table. 


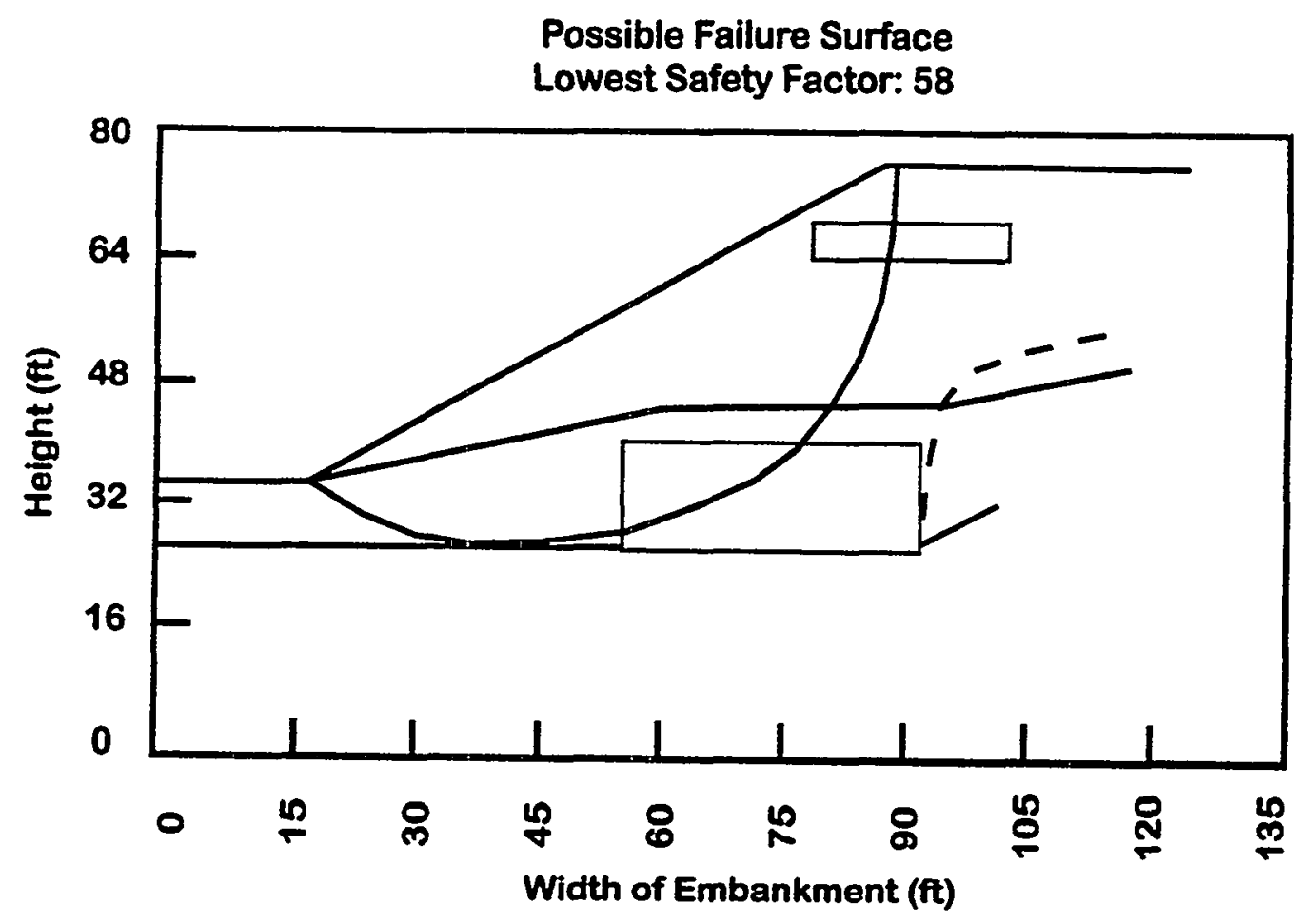

Figure 82. Analyses of factor of safety for failure surface passing through the FGD buttress. The shaded areas contain FGD. Dashed lines represent the estimated location of the water table. 


\subsubsection{Ohio State Route 83}

During the nine months following repair of State Route 83, the FGD surface supported the typical heavy coal truck traffic that occurs on that road with little difficulty. Some minor rutting was documented within only a few days of the opening of the roadway and ODOT maintenance crews applied a surface layer of stone. Over the same time period, the standard macadam surface had to be repaired four times.

A stability analysis of each of the three reconstruction configurations was performed. The locations of the structural features (e.g. material boundaries and water table), determined by the borings and verified during construction, the FGD key, and the reconstructed embankment were included in the computer models of the different study sections. The material properties used in the analyses of the stability are shown in Table 42. All three analyses showed that the presence of the FGD key caused the most critical failure surface to occur in an area away from the hillside.

In the case of the unamended compacted soil on top of the key (Figure 83), the most likely failure surface was found to be shallower than the original slide, but the factor of safety was low (1.0) and still involved a portion of the roadway. In the section where the FGD was mixed with the soil for stabilization (Figure 84), the analysis clearly indicates that a shallow slip surface has become the most likely failure mechanism. The slip surface that could affect the roadway must pass through the FGD/soil mixture, resulting in a high safety factor of 15 . In the analyses of the FGD only zone (Figure 85) the slip surface with the lowest calculated factor of safety is in a similar location as was determined for the FGD/soil mix but with an even larger factor of safety of 27.

Four months after construction had been completed, a set of six slope indicators (two in each type of repair section) was installed. These inclinometers were placed off the roadway, four on the hill side of the travel lanes and two in the downslope right-of-way. There have been some fairly large movements recorded which appear to be related to inadequate drainage. The Ohio Department of Transportation (ODOT) has begun an exploratory excavation program at the site to relieve the excess water pressures. Meanwhile, both ODOT and Ohio State University are studying the data obtained from the slope indicator tubes. The monitoring program is expected to continue for at least another two to three years. 
Table 42. Engineering properties of FGD and FGD stabilized soil used for analyses of the State Route 83 study site.

\begin{tabular}{lccccc}
\hline \hline & $\begin{array}{c}\text { Optimum } \\
\text { density } \\
\left(\mathrm{g} / \mathrm{cm}^{3}\right)\end{array}$ & $\begin{array}{c}\text { Optimum } \\
\text { water } \\
\text { content }(\%)\end{array}$ & $\begin{array}{c}\text { Unconfined } \\
\text { compressive } \\
\text { strength } \\
(\mathrm{kPa})\end{array}$ & $\begin{array}{c}\text { Permea- } \\
\text { bility } \\
(\mathrm{cm} / \mathrm{sec})\end{array}$ & $\begin{array}{c}\text { Swell } \\
(\%)\end{array}$ \\
\hline Material & 1.81 & 18 & 1518 & $4.7 \times 10^{-9}$ & 1.73 \\
FGD & 1.67 & 23 & 786 & $\mathrm{ND}^{\mathrm{b}}$ & $\mathrm{ND}$ \\
Soil/FGD mixture & 1.83 & 14 & 110 & $\mathrm{ND}$ & $\mathrm{ND}$ \\
\hline \hline
\end{tabular}

aMeasured after 28 days.

bND; not determined.

\subsection{Summary}

With the completion of these projects and several other projects (Brendel et al., 1997; Stewart et al., 1995) it has been shown that FGD by-product can be successfully incorporated into a highway construction program. The FGD, used in the projects described in this report, demonstrated high strength and ease of installation. The installation procedures followed clearly indicated no special equipment or training was necessary for its use. The performance of the FGD by-product during construction demonstrated that the level of care normally required on any construction project should be adequate when working with this material. Its excellent strength properties and workability are achieved with both the unamended FGD and FGD used in a mix to stabilize the local soil. In the repair of State Route 83, the FGD and soil were mixed on site in approximately equal proportions with the resulting strengths close to those obtained with the FGD alone. This specific FGD material appears to be well suited as a soil stabilizer and the mixes can be blended in the field and modifications simply made. 


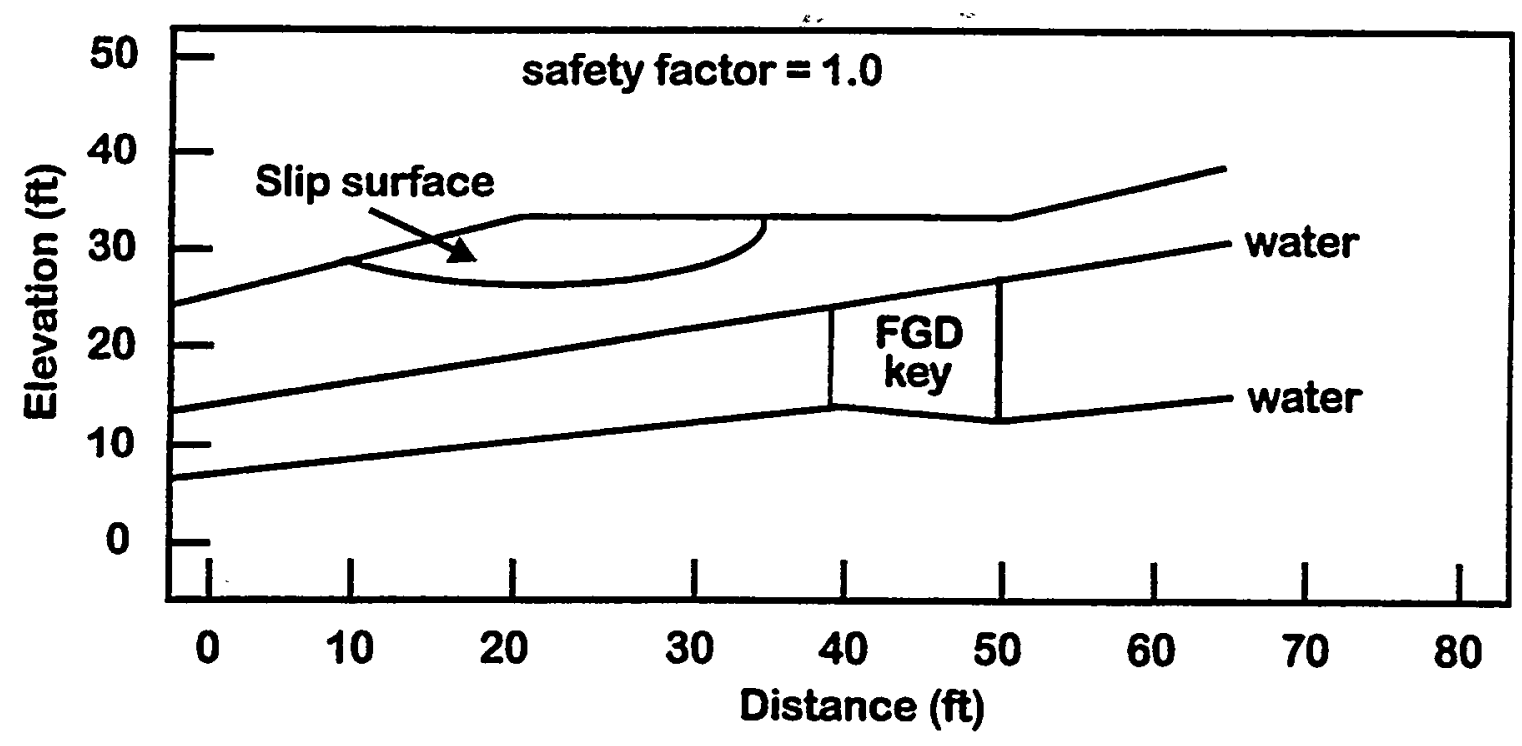

Figure 83. Analyses of a cross section through the reconstructed soil embankment showing the slip surface with the minimum factor of safety. 


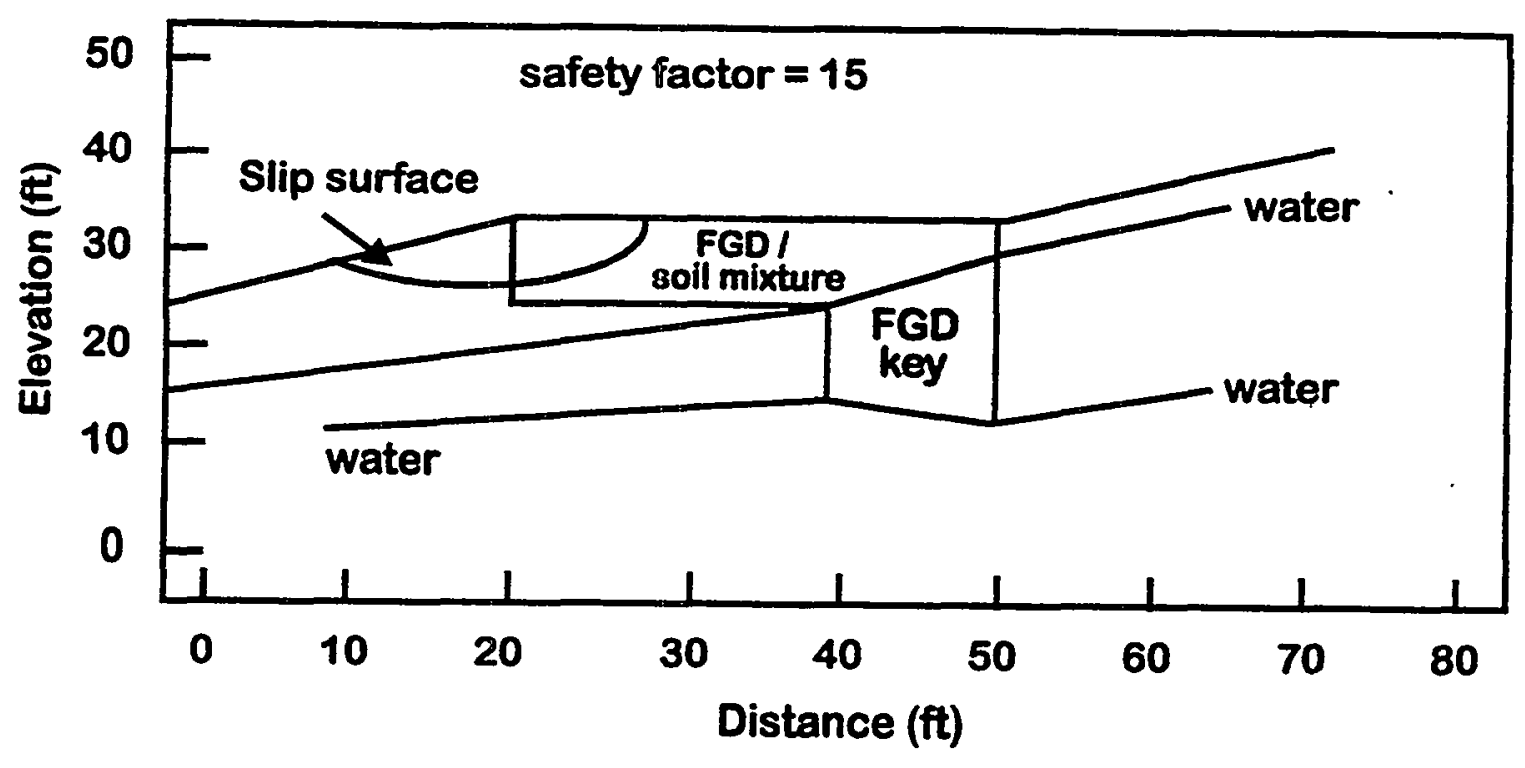

Figure 84. Analyses of a cross section through the reconstructed FGD/soil mixture embankment showing the slip surface with the minimum factor of safety. 


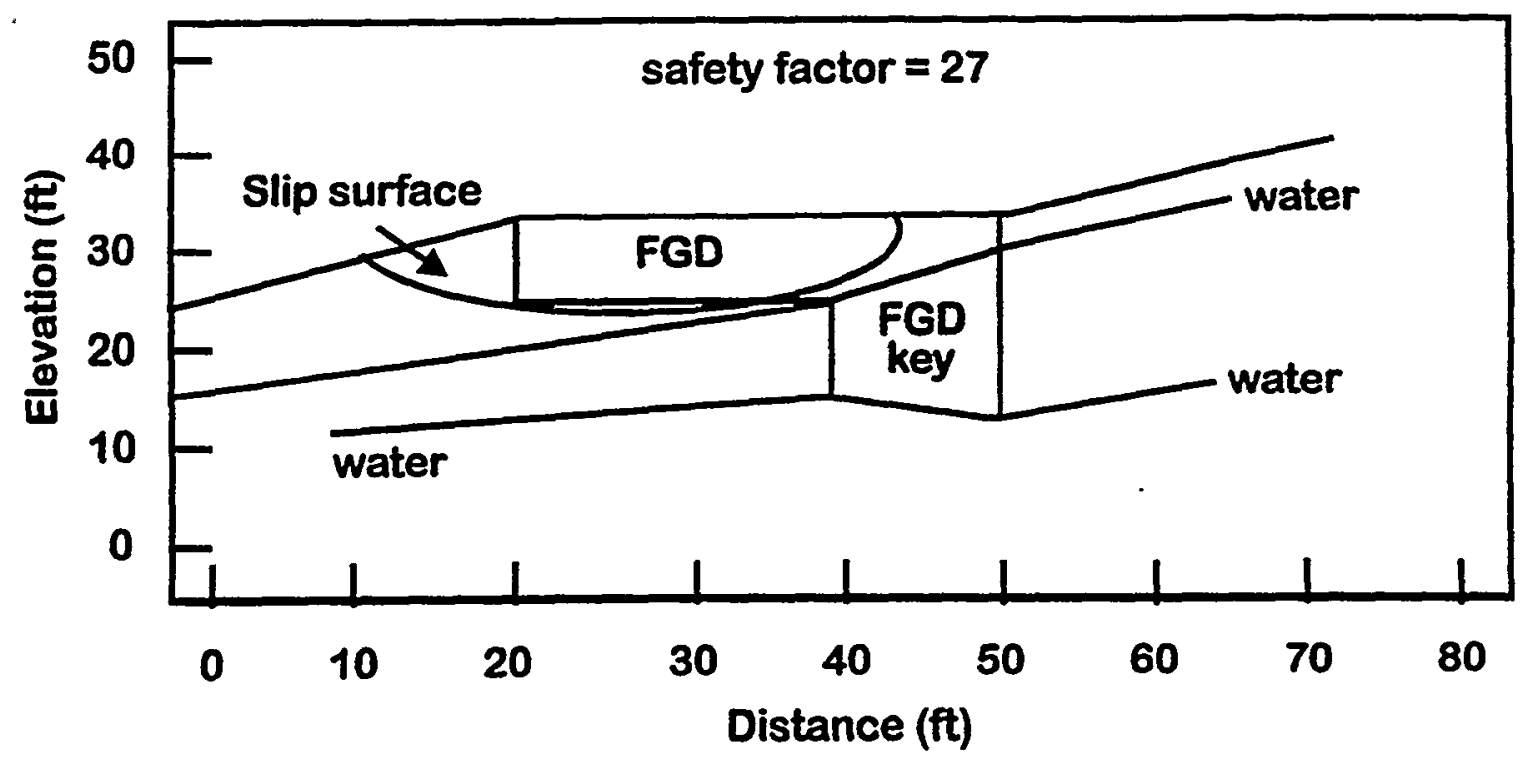

Figure 85. Analyses of a cross section through the reconstructed FGD embankment showing the slip surface with the minimum factor of safety. 


\section{5}

\section{ETTRINGITE GEOCHEMISTRY}

\subsection{Introduction}

Conditions of high $\mathrm{pH}$, large $\mathrm{Ca}$ and sulfate concentrations and adequate moisture content leads to the formation of the mineral ettringite $\left[\left(\mathrm{Ca}_{6} \mathrm{Al}_{2}\left(\mathrm{SO}_{4}\right) 3(\mathrm{OH})_{12} \cdot 26 \mathrm{H}_{2} \mathrm{O}\right)\right]$. Ettringite is highly expansive and cementitious. The formation of this mineral may be considered either positively or negatively depending on the intended end use of the FGD by-product. The cementitious reaction may be advantageous in applications where water impermeable layers or barriers are desired such as at the bottom of a fill area. A negative result of ettringite formation and expansion is when high rates of FGD by-product are applied to soil resulting in the formation of a dense, cement-like layer of ettringite that restricts root growth. Expansion can also be a problem in applications where FGD is used for road repair.

Previous studies have been conducted on a variety of dry FGD by-product materials (Stehouwer et al., 1995a; 1998). The type of process used to created the FGD greatly affects the potential of the material to form ettringite and cause swelling. Free lime in an FGD material, which also contains fly ash, is especially conducive to ettringite formation. Once ettringite is formed, its stability in the environment is of concern because in some uses, such as for road construction and repair, ettringite formation and then decomposition will result in poor performance.

Geochemical studies indicated ettringite was formed when water was allowed to react with several FGD by-products and the formation of this mineral was positively identified by $\mathrm{x}$-ray diffraction (Stehouwer et al., 1998). The chemical reactions that govern the formation and dissolution of ettringite under conditions analogous to environmental conditions have not previously been studied in detail.

The objectives of this study were to (1) estimate the standard state free energy of formation of ettringite from solubility experiments, (2) evaluate ettringite solubility at near neutral $\mathrm{pH}$, and 
(3) develop a geochemical model for the Ca-Al- $\mathrm{SO}_{4}-\mathrm{H}_{2} \mathrm{O}$ system for natural environmental conditions.

\subsection{Literature Review}

Dissolution of ettringite can occur congruently or incongruently. Congruent dissolution refers to the complete stoichiometric dissolution of a solid. Thus if one takes a mineral of composition $A_{2} B_{3}$, the ratio of $A$ to $B$ in solution will be $2: 3$. Incongruent dissolution refers to the nonstoichiometric dissolution of a soil. Thus for a solid of composition $\mathrm{A}_{2} \mathrm{~B}_{3}$, the ratio of $\mathrm{A}$ to $B$ in solution is not equal to $2: 3$. This can be due to more $A$ or $B$ being dissolved and leaving the other ion behind, or to $\mathrm{A}$ or $\mathrm{B}$ precipitating out as a secondary phase.

Congruent dissolution of ettringite under alkaline conditions can be described as:

$$
\mathrm{Ca}_{6} \mathrm{Al}_{2}\left(\mathrm{SO}_{4}\right)_{3}(\mathrm{OH})_{12} \cdot 26 \mathrm{H}_{2} \mathrm{O} \Leftrightarrow 6 \mathrm{Ca}^{2+}+2 \mathrm{Al}^{3+}+3 \mathrm{SO}_{4}^{2-}+12 \mathrm{OH}^{-}+26 \mathrm{H}_{2} \mathrm{O}
$$

This reaction can also be written using hydroxylated $\mathrm{Al}$ species (e.g. $\mathrm{Al}(\mathrm{OH})_{4}^{-}$) substituting for $\mathrm{Al}^{3+}$ in the products. Although this results in different solubility constants for ettringite dissolution, they are related to Equation 5-1 through Al-hydrolysis constants and thus there is no effect on the calculated standard state energy of formation.

According to the law of mass action the equilibrium constant for Equation 1 is given as:

$$
\mathrm{K}_{1}=\frac{\left(\mathrm{Ca}^{2+}\right)^{6}\left(\mathrm{Al}^{3+}\right)^{2}\left(\mathrm{SO}_{4}{ }^{2-}\right)^{3}\left(\mathrm{OH}^{-}\right)^{12}\left(\mathrm{H}_{2} \mathrm{O}\right)^{26}}{\left(\mathrm{Ca}_{6} \mathrm{Al}_{2}\left(\mathrm{SO}_{4}\right)_{3}(\mathrm{OH})_{12} \cdot 26 \mathrm{H}_{2} \mathrm{O}\right)}
$$

and when (ettringite) $=\left(\mathrm{H}_{2} \mathrm{O}\right)=1$, then

$$
\mathrm{K}_{1}=\mathrm{ett}^{\mathrm{K}} \mathrm{K}_{\mathrm{sp}}=\left(\mathrm{Ca}^{2+}\right)^{6}\left(\mathrm{Al}^{3+}\right)^{2}\left(\mathrm{SO}_{4}^{2-}\right)^{3}\left(\mathrm{OH}^{-}\right)^{12}
$$

where ${ }^{\text {ett. }} \mathrm{K}_{\mathbf{s p}}$ is the solubility product constant for ettringite dissolution, and the parentheses denote activities. The equilibrium constant is related to the free energy change of the reaction $\left(\Delta G^{\circ}\right)$ according to Hess's Law:

$$
\Delta G^{\circ}=-R T \ln { }^{\text {ett }} K_{s p}=\Delta G_{p}^{\circ}-\Delta G_{r}^{\circ}
$$


where $R$ is the Universal Gas Constant, $T$ is the absolute temperature and $\Delta G_{p}^{o}$ and $\Delta G^{\circ}{ }_{r}$ are the respective standard state free energies of products and reactants. In other words,

$$
-\mathrm{RT} \ln \text { ett }_{\mathrm{sp}}=\left(6 \Delta \mathrm{G}_{\mathrm{Ca}}^{\circ}+2 \Delta \mathrm{G}_{\mathrm{Al}}^{\circ}+3 \Delta \mathrm{G}_{\mathrm{SO}}^{\circ}+12 \Delta \mathrm{G}_{\mathrm{OH}}^{\circ}+26 \Delta \mathrm{G}_{\mathrm{H} 2 \mathrm{O}}^{\circ}\right)-\Delta \mathrm{G}_{\mathrm{E}}^{\circ}
$$

From Equation 5-2, the ettringite standard state free energy, $\Delta \mathrm{G}^{\circ}{ }_{\mathrm{E}}$ can be estimated using the standard state free energies of its ions and the solubility product constant $\mathrm{ett} . \mathrm{K}_{\mathrm{sp}}$. However, several conditions must be met for these equations to be valid thus permitting us to derive thermodynamic data from solubility measurements. These conditions are that ettringite is in its standard state, it dissolves congruently according to the reaction described above, and equilibrium is achieved during dissolution.

The earliest detailed ettringite solubility study was conducted by Jones (1944), who reported that ettringite (Ca sulfoaluminate) dissolves incongruently to form gypsum and Al hydroxide at low $\mathrm{pH}$, and to portlandite at high $\mathrm{pH}$. Although Jones did not estimate ettringite solubility, the aqueous ion concentrations he reported were later used to estimate a solubility product for ettringite. These data, and standard free energies for gypsum and hydrogarnet, provided estimates of ett. $\mathrm{K}_{\mathrm{sp}}$ that varied between $10^{-36}$ and $10^{-45}$ (with $\mathrm{Al}(\mathrm{OH})_{4}^{-}$in Equation 1) (Hampson and Bailey (1982). They attributed this $\mathrm{etr}_{\mathrm{sp}}$ variation to changes in ettringite crystal length and habit. More recently, Atkins et al. (1991) reported a ettK $\mathrm{K}_{\mathrm{sp}}$ value of $10^{-111.3}$ for Equation 5-1. On the basis of $\mathrm{Ca} / \mathrm{SO}_{4}$ and $\mathrm{Ca} / \mathrm{Al}$ molar ratios in ettringite and its saturated solution, these authors suggested that ettringite dissolves congruently above a pH of 10.7 . Damidot et al. (1992) also obtained similar results and showed that ett $\mathrm{K}_{\mathrm{sp}}$ is invariant with solution composition changes. The EQ3/6 computer code (Wolery and Daveler, 1992) uses another value for ett. $K_{\mathrm{sp}}$ which differs from the reported value of Atkins et al. (1991) by $3 \mathrm{log}$ units. Thus, there is great uncertainty about ettringite solubility in the literature. The discrepancy in the reported values is attributed to (1) insufficient attainment of equilibrium, (2) variations in stoichiometry of synthetic ettringite, and (3) probable carbonate contamination in the synthetic ettringites examined in previous studies.

Numerous investigators have examined the $\mathrm{Ca}-\mathrm{Al}-\mathrm{SO}_{4}-\mathrm{H}_{2} \mathrm{O}$ system at $\mathrm{pH}$ values greater than 11 (Jones, 1944; Atkins et al., 1991; Havlica and Sahu, 1992; Damidot et al., 1992; Damidot and Glasser, 1993). Little information is available, however, when the $\mathrm{pH}$ values range between 4 and 9 . Instead, past efforts to predict what would happen in this $\mathrm{pH}$ range have been 
based on data that exists at neutral pH for the much more understood systems of Ca-SO $\mathrm{S}_{4}-\mathrm{H}_{2} \mathrm{O}$ and $\mathrm{Al}-\mathrm{SO}_{4}-\mathrm{H}_{2} \mathrm{O}$.

Jones (1944) studied the stable and metastable mineral phases of the $\mathrm{Ca}-\mathrm{Al}-\mathrm{SO}_{4}-\mathrm{H}_{2} \mathrm{O}$ system and the stability of these mineral phases in the alkaline $\mathrm{pH}$ range. He concluded minerals formed in this system are solid solutions of ettringite and monosulfoaluminate $\left(\mathrm{Ca}_{4} \mathrm{Al}_{2}\left(\mathrm{SO}_{4}\right)(\mathrm{OH})_{12}{ }^{\bullet 6 \mathrm{H}_{2} \mathrm{O}}\right)$ and these coexist with portlandite $\left(\mathrm{Ca}(\mathrm{OH})_{2}\right)$, gypsum, and gibbsite (Figure 86). However, ettringite was found to be the most stable phase in highly alkaline solutions containing high sulfate concentrations (Jones, 1944; Damidot and Glasser, 1993). In addition, temperature, dissolved $\mathrm{CO}_{2}$, and $\mathrm{H}_{2} \mathrm{O}$ activities can strongly influence ettringite stability. High temperatures'stabilize monosulfoaluminate over ettringite (Damidot and Glasser, 1992) and high $\mathrm{CO}_{2}$ and low $\mathrm{H}_{2} \mathrm{O}$ activity decompose ettringite to aragonite $\left(\mathrm{CaCO}_{3}\right)$ with vaterite $\left(\mathrm{CaCO}_{3}\right)$ as an intermediate phase (Nishikawa et al., 1992).

In the $\mathrm{pH}$ range of 5 to 9 , relatively few minerals form in the $\mathrm{Ca}-\mathrm{SO}_{4}-\mathrm{H}_{2} \mathrm{O}$ system (Doner and Lynn, 1989). The known mineralogy consists of gypsum $\left(\mathrm{CaSO}_{4} \cdot 2 \mathrm{H}_{2} \mathrm{O}\right)$, bassanite $\left(\mathrm{CaSO}_{4} \cdot 0.5 \mathrm{H}_{2} \mathrm{O}\right)$, and anhydrous phases including anhydrite $\left(\mathrm{CaSO}_{4}\right)$ and its polymorphic forms $\alpha$ - and $\gamma-\mathrm{CaSO}_{4}$. Of these phases, gypsum is most commonly encountered in soils and weathered flyashes (Lu, 1981; Fowler et al., 1993).

The $\mathrm{Al}-\mathrm{SO}_{4}-\mathrm{H}_{2} \mathrm{O}$ system is more complicated and supports several $\mathrm{Al}$ hydroxide phases such as gibbsite $\left(\gamma-\mathrm{Al}(\mathrm{OH})_{3}\right)$, boehmite $(\gamma-\mathrm{AlOOH})$, and diaspore $(\alpha-\mathrm{AlOOH})$ at near neutral $\mathrm{pH}$ (Hsu, 1989; Hemmingway and Sposito, 1996). At acidic pHs (<7.0), Al-sulfate phases such as basaluminite $\left(\mathrm{Al}_{4}(\mathrm{OH})_{10}\left(\mathrm{SO}_{4}\right) \cdot 5 \mathrm{H}_{2} \mathrm{O}\right)$, aluminite $\left(\mathrm{Al}_{2}(\mathrm{OH})_{4}\left(\mathrm{SO}_{4}\right) \cdot 7 \mathrm{H}_{2} \mathrm{O}\right)$, jurbanite $\left(\mathrm{Al}(\mathrm{OH}) \mathrm{SO}_{4} \cdot 5 \mathrm{H}_{2} \mathrm{O}\right.$ ) and alunogen $\left(\mathrm{Al}_{2}\left(\mathrm{SO}_{4}\right)_{3} \cdot 17 \mathrm{H}_{2} \mathrm{O}\right)$ occur (Singh and Brydon, 1970; Adams and Rawajfih, 1977; Nordstrom, 1982; Khanna, et al., 1987; Nordstrom and Alpers, 1996). Several other $\mathrm{Al}$ sulfates containing $\mathrm{Na}$, and $\mathrm{K}$ in the crystal structures have also been reported (Nordstrom, 1982). Experimental studies on the chemistry, mineralogy and crystal structures of some Al-sulfates were conducted by Bassett and Goodwin (1949), Henry and King (1950), Johansson $(1960,1962)$ and Wang and Hsu (1994), and the available thermodynamic data on several of these phases was compiled by Nordstrom (1982) and by Hemmingway and Sposito (1996).

In spite of extensive laboratory and field studies, the chemical phases that control Al solubility in natural systems is still a subject of controversy (Nordstrom and Alpers, 1996). Several soil solutions at near neutral $\mathrm{pH}$ are commonly supersaturated with gibbsite and it has been 


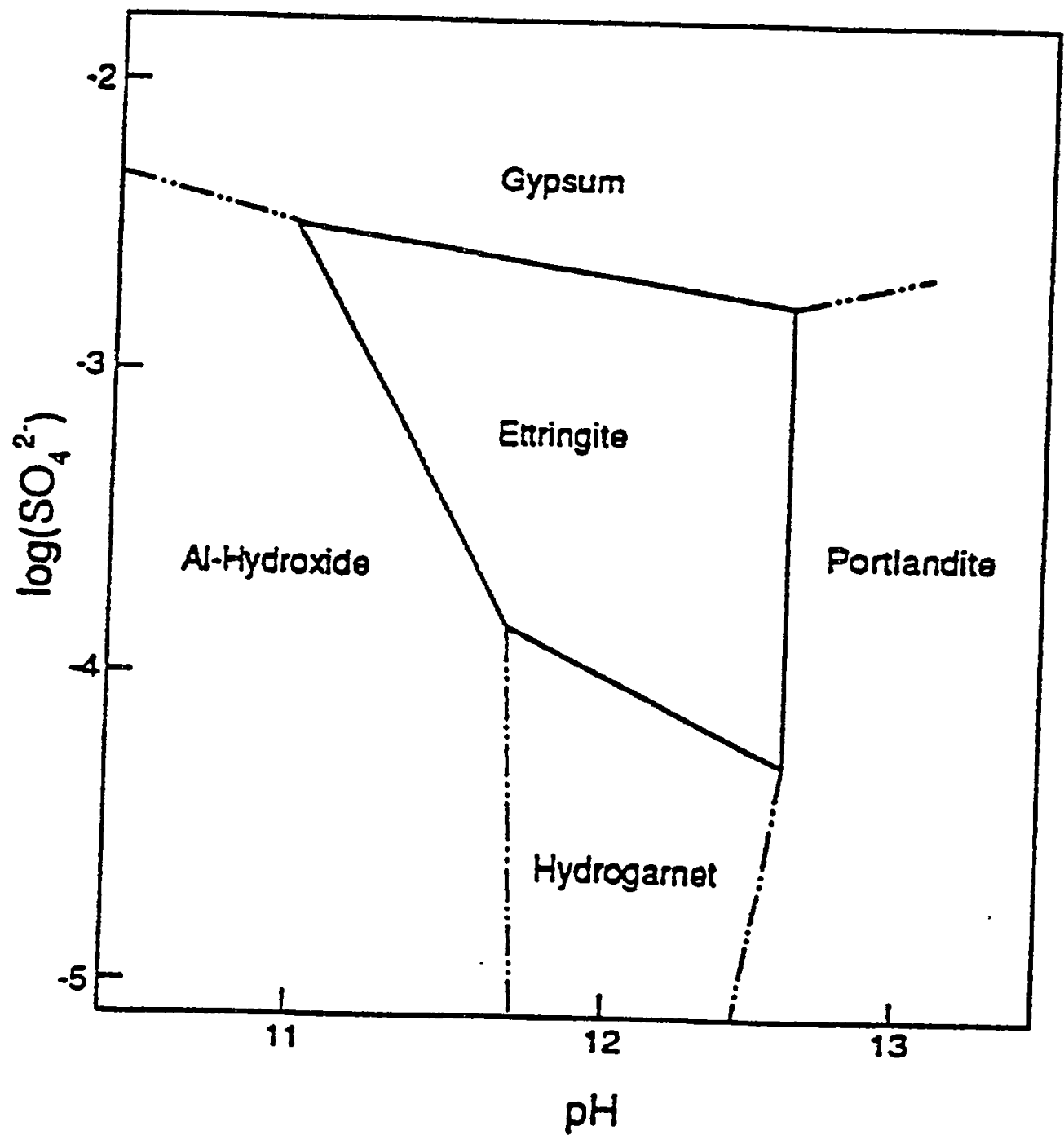

Figure 86. Ettringite stability in alkaline environments (Hampson and Bailey, 1982). 
proposed that microcrystalline and/or amorphous Al hydroxide precipitation may control Al solubility in such environments (Nordstrom and Ball, 1986; Sullivan et al., 1988; Nordstrom and Alpers, 1997). Thermodynamic speciation indicates that surface waters, groundwater $s$ and mine spoil leachates are saturated with basaluminite and jurbanite when the $\mathrm{pH}$ is approximately 5 (Theobold et al., 1963; Sjöström, 1993; Nordstrom and Ball, 1986; Sullivan et al., 1988; Eary et al., 1991; Prenzel and Schulte-Bisping, 1995). However, neither of these phases were identified in soils or weathered rock by direct physical methods (Longmire et al., 1990). Although direct precipitation of basaluminite occurred when bentonite was reacted with Al sulfate solutions (Singh and Brydon, 1970), the initial precipitates formed upon reaction of aqueous $\mathrm{Ca}(\mathrm{OH})_{2}$ and $\mathrm{Al}_{2}\left(\mathrm{SO}_{4}\right)_{3}$ were poorly crystalline basaluminite. Aging and heating were required to produce true crystalline basaluminite (Adams and Hajek, 1978). Clearly, the phases that control aqueous $\mathrm{Al}$ and $\mathrm{SO}_{4}$ activities at $\mathrm{pH}$ values of 5 and normal environmental temperatures are still unresolved.

\subsection{Materials and Methods}

\subsubsection{Solutions, Glassware, and Reagents}

Deionized water produced by a Barnstead NANOpure II system was used in all experiments. Before beginning each experiment, this water was boiled for one hour to drive off dissolved $\mathrm{CO}_{2}$ and cooled in a glove box filled with $\mathrm{N}_{2}$ gas. The dissolved $\mathrm{SO}_{4}, \mathrm{Cl}, \mathrm{Ca}$, and $\mathrm{Na}$ ion concentrations in this water were found to be below detection by inductively coupled plasma emission spectrometry and ion chromatography. Teflon ${ }^{\circledR}$ and polypropylene bottles and centrifuge tubes were used for experiments when $\mathrm{pH}$ values were greater than 8 and glassware was used when $\mathrm{pH}$ values were below 8. All labware was washed by the following protocol: 1) $24 \mathrm{~h}$ soak in $2 \%$ Micro Liquid Laboratory Cleaner (Cole-Parmer Instrument Company), 2) $24 \mathrm{~h}$ soak in $10 \% \mathrm{HCl}$, and 3 ) wash and rinse with deionized water. Reagent grade $\mathrm{CaO}$ (Aldrich), $\mathrm{Al}_{2}\left(\mathrm{SO}_{4}\right)_{3} \cdot 16 \mathrm{H}_{2} \mathrm{O}$ (Baker), sucrose (Jenneile), $\mathrm{NaOH}$ (Jenneile), and $\mathrm{HCl}$ (EM Science) were used in the ettringite synthesis and dissolution experiments. These chemicals were used as supplied. $\mathrm{X}$-ray diffraction and Fourier transform infrared spectroscopy measurements of the $\mathrm{CaO}$ indicated that it was free from $\mathrm{CaCO}_{3}$ impurities. Reference solutions (GFS Chemicals) were used to calibrate the ion chromatograph, atomic absorption spectrometer and the inductively coupled plasma emission spectrometer. 


\subsubsection{Ettringite Synthesis and Characterization}

Natural ettringite is difficult to obtain in large quantities and is usually contaminated with foreign elements such as $\mathrm{Si}, \mathrm{Fe}, \mathrm{K}, \mathrm{Na}$ and $\mathrm{CO}_{3}$. Thus, a synthesis described by Mc Murdie et al. (1986) was adopted to obtain crystalline ettringite. In this synthesis, ettringite was made by dissolving $\mathrm{Al}_{2}\left(\mathrm{SO}_{4}\right)_{3} \cdot 16 \mathrm{H}_{2} \mathrm{O}$ and $\mathrm{CaO}$ in molar proportions in $10 \%$ sucrose solution.

Nucleation was rapid and a suspension appeared immediately after mixing. This suspension was continuously stirred for $48 \mathrm{~h}$ and then the solids were separated by centrifugation. These solids were dried in a desiccator (under $\mathrm{N}_{2}$ ) after repeated washing with aqueous $\mathrm{NaOH}$ at $\mathrm{pH}$ 12.0 to remove adsorbed sucrose and any gypsum precipitated during synthesis. This synthesis was conducted at room temperature and inside a glove box filled with $\mathrm{N}_{2}$ gas. The precipitated solids were examined by X-ray diffraction, Fourier transform infrared spectroscopy, scanning electron microscopy and thermogravimetry. The chemical composition of the precipitate was examined by dissolving $0.1 \mathrm{~g}$ of oven-dried $(383 \mathrm{~K})$ material in $100 \mathrm{~mL}$ of $0.1 \mathrm{M} \mathrm{HCl}$ and analyzing for $\mathrm{Al}, \mathrm{Ca}$, and $\mathrm{SO}_{4}$. The data obtained were normalized to 6 moles of Ca per mole of ettringite. Loss of moisture (wt\%) at $383 \mathrm{~K}$ (from TG analysis) was converted to moles of $\mathrm{H}_{2} \mathrm{O}$ based on the stoichiometric composition of ettringite. The surface area of the synthetic ettringite was measured using single point $\mathrm{N}_{2}$-BET surface area measurements.

\subsubsection{Solubility Studies as Affected by $\mathbf{p H}$}

The ettringite solubility product was evaluated using ettringite synthesized as described above, and equilibrium was approached from both undersaturated and supersaturated solutions (by means of the common-ion effect). For equilibrium from undersaturation, $0.25 \mathrm{~g}$ of ettringite was reacted with $25 \mathrm{~mL}$ water in polypropylene tubes inside a glove box filled with $\mathrm{N}_{2}$ gas. Ionic strength was not maintained by use of any background electrolyte to minimize electrolyteion substitution in ettringite (Kumarathasan et al., 1991; Pöllmann et al., 1989). The headspace in tightly sealed tubes was filled with $\mathrm{N}_{2}$ gas and the tubes were agitated continuously at 298 $( \pm 1) \mathrm{K}$. After $0.02,0.08,0.17,0.25,0.5,1,4,24,120,450$ and $720 \mathrm{~h}$, three replicate tubes were removed and centrifuged for $10 \mathrm{~min}$ at $7000 \mathrm{rpm}$. The supernatant $\mathrm{pH}$ was measured and the solutions were filtered through a $0.45 \mu \mathrm{m}$ pore size Nucleopore polycarbonate membrane filter. The solids were air-dried and studied using $x$-ray diffraction and Fourier Transform Infrared to characterize the type of dissolution (congruent or incongruent). The chemical composition of the filtered solutions and solids were determined as described previously. 
The effects of the $\mathrm{pH}$ and suspension concentration on ett. $\mathrm{K}_{\mathrm{sp}}$ were evaluated as described in the above paragraph. The solution $\mathrm{pH}$ of these samples was maintained at the required values by $\mathrm{NaOH}$ or $\mathrm{HCl}$ addition. To approach equilibrium from supersaturation, ettringite saturated solutions were first prepared by equilibrating synthetic ettringite in deionized water for a week. The solutions were separated from the solid phase and spiked with $\mathrm{CaO}$ and $\mathrm{Al}_{2}\left(\mathrm{SO}_{4}\right)_{3} \cdot 16 \mathrm{H}_{2} \mathrm{O}$ solutions. Ettringite precipitation from these supersaturated solutions was induced by seeding with synthetic ettringite. The resulting solids were separated by filtration after $48 \mathrm{~h}$, and the filtered solutions and solids were analyzed.

The weathering (i.e. breakdown or solubilization) of laboratory synthesized ettringite $(0.25 \mathrm{~g})$ was studied by reacting with deionized water in polypropylene centrifuge tubes. The sample $\mathrm{pH}$ was adjusted to values ranging from 4.0 to 9.5 at $0.5 \mathrm{pH}$ unit increments by adding $1.0 \mathrm{M}$ $\mathrm{HCl}$ in a glove box filled with $\mathrm{N}_{2}$ gas. The reacted solids were continuously agitated at 298 ( \pm 1) $\mathrm{K}$. Three vials for each $\mathrm{pH}$ were collected after 10,120, and 240 days and analyzed as described previously.

$X$-ray diffraction, scanning electron microscopy and Fourier transform infrared spectroscopy were used to examine the solid phase mineralogy and composition. The $\mathrm{X}$-ray diffraction patterns were collected using $\mathrm{Cu}-\mathrm{K} \alpha$ radiation, and a Philips $\mathrm{PW}$ 1216/90 wide range goniometer fitted with a theta-compensating slit and a graphite monochromator. The instrument was calibrated using cholesterol and Si powder (NIST SRM 640b) for low and high 22 angles respectively. The samples used for the X-ray diffraction scans were finely powdered, mounted on a silicon holder, and the powder surface was smoothed with a glass slide prior to analysis. The diffraction scans ranged from 6 to $55^{\circ} 2 \theta$ with a $0.05^{\circ} 2 \theta$ step interval and a 4 seconds per step counting time. The sample d-spacings were compared with reported data from the ICDD powder files. Diffuse reflectance Fourier transform infrared spectra were collected from 4000 to $400 \mathrm{~cm}^{-1}$ with $2 \mathrm{~cm}^{-1}$ resolution on a Mattson Polaris instrument. A JEOL JSM-820 scanning electron microscope was used to study the trace mineralogy. Energy dispersive X-ray analysis of the solid phase elemental distribution was made on the same instrument and processed with sof tware supplied by Oxford Inst. (Link Analytical eXL). Single point, surface area measurements were made with a Micromeritics Flow Sorb II 2300 BET surface area analyzer, using $\mathrm{N}_{2}$ adsorption. The instrument was calibrated with specimen kaolin (standard \# 8570 , surface area $=10.3 \mathrm{~m}^{2} \mathrm{~g}^{-1}$ ) and alumina (standard \# 8571, surface area $=153 \mathrm{~m}^{2} \mathrm{~g}^{-1}$ ) supplied by National Bureau of Standards. Aqueous phase cationic concentrations were analyzed with a Perkin-Elmer 3030B atomic absorption spectrometer. A Dionex 2000i Basic Ion Chromatography Module, an AS4A $4 \mathrm{~mm}$ separator column, and an AG4A guard column 
were used to measure anion concentration. The chemical analysis obtained with the above techniques were confirmed with a Leeman PS2000 inductively coupled plasma spectrometer.

An EA 920 Orion Expandable Ion Analyzer connected to a pH electrode was used to measure solution $\mathrm{pH}$. This instrument was calibrated with $\mathrm{pH} 10.0$ and 7.0 buffers supplied (VWR Scientific). The buffer solutions were stored in an incubator at $298( \pm 1) \mathrm{K}$ and transferred to a beaker before each electrode calibration. To minimize liquid-junction potential effects, samples were first centrifuged for $15 \mathrm{~min}$ at $7000 \mathrm{rpm}$ and $\mathrm{pH}$ measurements were later made in particle free supernatants. The $\mathrm{pH}$ readings usually stabilized in 4 minutes, and the measurements were taken after that period. The sample and reference solution $\mathrm{pH}$ measurements were routinely checked for any drift in $\mathrm{pH}$.

\subsubsection{Geochemical Speciation and Modeling}

Speciation calculations were conducted for total dissolved $\mathrm{Ca}, \mathrm{Al}, \mathrm{SO}_{4}$ using the MINTEQA2 thermodynamic code (Allison et al., 1990). The Davies equation was used to calculate single ion activity coefficients. Potential mineral phase saturation indices $\left(S=\log \left[\mathrm{AP} / \mathrm{K}_{\mathrm{sp}}\right]\right.$ ) were estimated using the computed ion activities and the reported literature values of mineral solubility products. Since the experimental samples were well aerated, redox reactions were not considered in these simulations. Reaction path calculations for incongruent dissolution of ettringite were performed using EQ3/6 (Wolery and Daveler, 1992). This program considers chemical reactions to be irreversible and can be represented by a sequence of partial equilibrium states. Each equilibrium step is reversible with respect to the next, but overall the system is irreversible to the initial state (Helgeson, 1968). For each infinitesimally small step in equilibrium state, the Law of Mass Action, mass balance, charge balance and non-ideality are solved as the reaction progresses towards the final state. As the reaction proceeds from the initial stage, changes in solution composition are represented by the reaction progress variable, $\xi$, which increases as equilibrium is approached. The reaction can only proceed along the considered path if free energy change of a reaction with respect to $\xi$ is negative $(\mathrm{dG} / \mathrm{d} \xi<0)$. Since the reaction rates are not available for several reactions, the consumed reactant molar concentration was used to establish relative rates in this model. The data were simulated as a closed system such that the precipitated solid phases during the reaction remained in the system. The data were allowed to change as the reaction progressed along the reaction path. Although real geochemical systems are open to the inputs of foreign ions that are not considered in the present system, mineralogically closed models are important in providing estimates of results that may be obtained for a Ca-Al- $\mathrm{SO}_{4}-\mathrm{H}_{2} \mathrm{O}$ system. 


\subsection{Results and Discussion}

\subsubsection{Characterization of Synthetic : Ettringite :}

The synthetic ettringite was examined by $\mathrm{X}$-ray diffraction, scanning electron microscopy, Fourier transform infrared spectroscopy and thermogravimetry. The solid X-ray diffraction patterns were equivalent to the data reported in the International Center for Diffraction Data (ICDD) manual. This manual reports spectra for several different synthetic ettringite materials (card\#: 31-251, 9-414, 37-1476 and 41-1451). While the line d-spacings in these references match, their intensities are not identical. Similarly, the synthetic ettringite d-spacings also matched all previously reported data but the intensities were similar to those reported in card \# 37-1476 (McMurdie et al.,1986) (Figure 87).

The infrared spectra of the synthetic ettringite compared well with those reported by Pöllmann et al. (1989) and Kumarathasan et al. (1991). The vibrational modes of $\mathrm{SO}_{4}$ and $\mathrm{H}_{2} \mathrm{O}$ molecules in the synthetic ettringite agreed with ettringite crystal structure refinements, with the exception of the $\mathrm{SO}_{4}$ local symmetry and the measured $\mathrm{S}-\mathrm{O}$ bond lengths (Moore and Taylor, 1970; Myneni, 1995). A discussion of these is not appropriate and the interested readers may refer to Myneni (1995). Absence of $\mathrm{CO}_{3}$ vibrational frequencies around 2500 to 3000 and also at $750 \mathrm{~cm}^{-1}$ indicated that the synthetic material was initially free from calcite (White, 1974). However, upon long exposure to the atmosphere ( 60 days), a doublet appeared around $1450(1488,1430) \mathrm{cm}^{-1}$ due to $\mathrm{CO}_{2}$ adsorption. The synthetic ettringite had a surface area of $7.9 \mathrm{~m}^{2} / \mathrm{g}$ and scanning electron microscopy revealed crystals that were $2 \mu \mathrm{m}$ long and needle shaped.

The water content of the synthetic ettringite as calculated from weight loss at $383 \mathrm{~K}$, corresponded to a stoichiometry of 26 moles of $\mathrm{H}_{2} \mathrm{O}$ per formula unit. Since this number includes both the adsorbed and structural $\mathrm{H}_{2} \mathrm{O}$, the absolute quantity of structural $\mathrm{H}_{2} \mathrm{O}$ remains uncertain. Fortunately, this number does not effect the solubility product as long as $\mathrm{H}_{2} \mathrm{O}$ activity is near unity. Wet chemical analysis of synthetic ettringite (normalized to 6 moles of

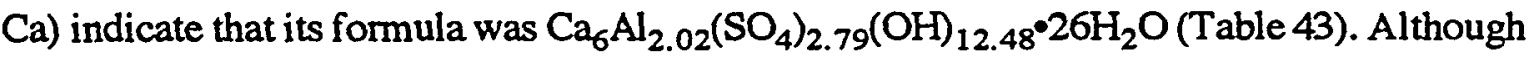
the reported stoichiometry based on the wet chemical analysis and the unit cell were similar, minor variations in $\mathrm{Al}, \mathrm{SO}_{4}$ and $\mathrm{OH}$ molar concentration exist. Similar molar proportions and non-stoichiometry have been previously reported for ettringite (Hassett et al., 1990). The solid phase composition of ettringite was found to be constant even though changes in the initial 


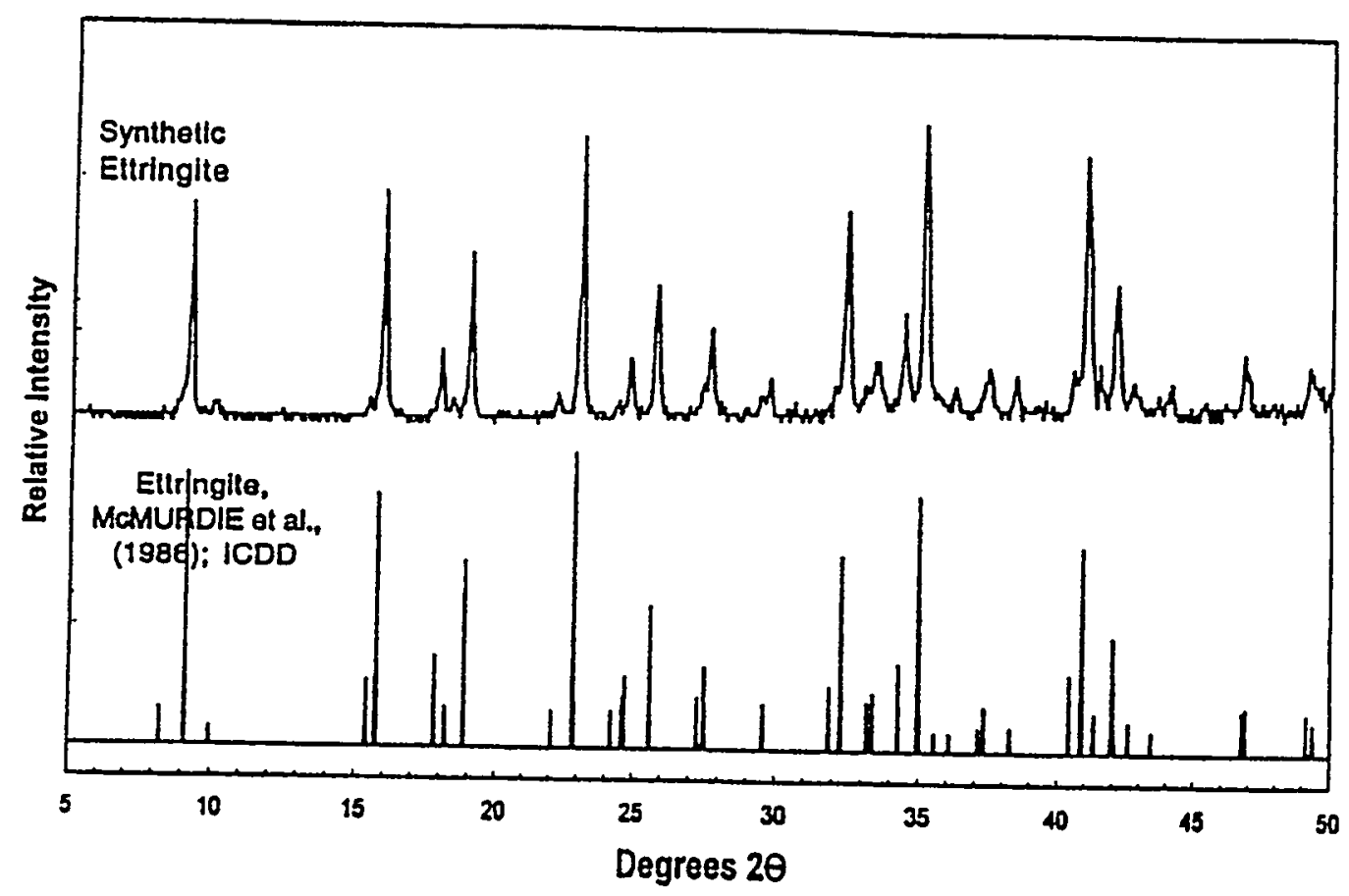

Figure 87. X-ray diffraction of synthetic ettringite. 
Table 43. Chemical analysis of synthetic ettringites.

\begin{tabular}{lcccc}
\hline Sample $^{\mathrm{a}}$ & $\mathrm{m}_{\mathrm{Ca}}$ & $\mathrm{m}_{\mathrm{Al}}$ & $\mathrm{m}_{\mathrm{SO} 4}$ & $\mathrm{~m}_{\mathrm{OH}}$ \\
\hline & $r$ & \multicolumn{4}{c}{ " moles } & - & \\
ETT1 & 6 & 2.03 & 2.76 & 12.57 \\
ETT2 & 6 & 2.02 & 2.80 & 12.46 \\
ETT3 & 6 & 2.02 & 2.79 & 12.48 \\
ETT4 & 6 & 2.03 & 2.80 & 12.49 \\
ETT5 & 6 & 2.05 & 2.73 & 12.69 \\
ETT6 & 6 & 2.02 & 2.79 & 12.48 \\
\hline
\end{tabular}

aSamples marked ETT1 and ETT2 were synthesized as reported by McMurdie et al (1986). Samples ETT3 and ETT4 and samples ETT5 and ETT6 were also synthesized in a similar way but with excess $\mathrm{CaO}$ and $\mathrm{Al}_{2}\left(\mathrm{SO}_{4}\right)_{3}$, respectively. Data is reported as number of moles of an element per one mole of ettringite and are normalized to 6 moles of $\mathrm{Ca}$.

ratios of the reactants occurred ( $\mathrm{CaO}$ and $\left.\mathrm{Al}_{2}\left(\mathrm{SO}_{4}\right)_{3}\right)$ (Table 43). However, the crystal size was longer $(6-12 \mu \mathrm{m})$ when the synthesis was conducted in absence of sucrose and at higher solution pH (Myneni, 1995).

\subsubsection{Ettringite Congruent Dissolution and Solubility Product}

Congruent dissolution of ettringite in undersaturated solutions was rapid with reaction reaching equilibrium within minutes (Tables 44-45) (Figure 88). In contrast, approach to the equilibrium from supersaturated solutions was relatively slow and took about $24 \mathrm{~h}$. However, a white ettringite precipitate appeared immediately after $\mathrm{CaO}$ and $\mathrm{Al}_{2}\left(\mathrm{SO}_{4}\right)_{3}$ solutions were mixed, and the ion activity product was close to the ett. $\mathrm{K}_{\mathrm{sp}}$ after a few minutes of mixing. Slow precipitation kinetics have been observed for several mineral systems when the ion activity product is close to the $\mathrm{K}_{\mathrm{sp}}$ (Stumm, 1993; Sposito, 1994). 
Table 44. Solubility data from three replicates used to determine the solubility product constant ( ${ }^{e t t} \cdot K_{s p}$ ) for ettringite in undersaturated and supersaturated solutions.

\begin{tabular}{|c|c|c|c|c|c|c|c|c|}
\hline \multirow{2}{*}{$\begin{array}{l}\text { Time } \\
\text { (h) }\end{array}$} & \multirow{2}{*}{$\begin{array}{c}\mathrm{pH} \\
( \pm 0.01)\end{array}$} & \multirow{2}{*}{$\begin{array}{c}\text { Ionic } \\
\text { strength } \\
\left(\mathrm{mol} / \mathrm{m}^{3}\right)\end{array}$} & \multicolumn{3}{|c|}{$\begin{array}{l}\text { Total concentrations } \\
\left(\mathrm{mol} / \mathrm{m}^{3}\right)^{\mathrm{a}}\end{array}$} & \multicolumn{3}{|c|}{$\mathrm{p}$ (ion) } \\
\hline & & & $\mathrm{Al}$ & $\mathrm{Ca}$ & $\mathrm{SO} 4$ & $\mathrm{Al}^{3+}$ & $\mathrm{Ca}^{2+}$ & $\mathrm{SO}_{4}{ }^{2-}$ \\
\hline \multicolumn{9}{|c|}{ Undersaturated solutions ${ }^{b}$} \\
\hline 0.02 & 11.0 & 6.72 & 0.78 & 2.21 & 1.26 & 24.45 & 2.86 & 3.13 \\
\hline 0.08 & 11.1 & 7.95 & 0.87 & 2.35 & 1.24 & 24.79 & 2.84 & 3.15 \\
\hline 0.17 & 11.0 & 7.35 & 0.90 & 2.12 & 1.12 & 24.38 & 2.87 & 3.18 \\
\hline 0.25 & 11.2 & 7.35 & 0.77 & 2.13 & 1.11 & 25.25 & 2.87 & 3.18 \\
\hline 0.50 & 11.2 & 8.27 & 0.77 & 2.11 & 1.08 & 25.25 & 2.88 & 3.19 \\
\hline 1.0 & 11.3 & 8.58 & 0.66 & 2.01 & 0.97 & 25.72 & 2.70 & 3.24 \\
\hline 4.0 & 11.1 & 7.48 & 0.73 & 2.05 & 1.02 & 24.87 & 2.88 & 3.22 \\
\hline 24 & 11.0 & 7.43 & 0.72 & 2.00 & 1.08 & 24.48 & 2.89 & 3.19 \\
\hline 120 & 11.0 & 8.41 & 0.75 & 2.12 & 1.05 & 24.68 & 2.71 & 3.05 \\
\hline 450 & 11.0 & 8.06 & 0.79 & 2.08 & 0.92 & 24.68 & 2.72 & 3.10 \\
\hline \multicolumn{9}{|c|}{ Supersaturated solutions ${ }^{c}$} \\
\hline 24 & 12.4 & 8.97 & 0.02 & 14.7 & 0.28 & 31.71 & 2.26 & 3.73 \\
\hline 24 & 12.2 & 9.46 & 0.11 & 13.7 & 0.23 & 30.16 & 2.24 & 4.13 \\
\hline 48 & 11.5 & 8.47 & 0.17 & 3.73 & 0.29 & 27.21 & 2.63 & 3.83 \\
\hline 48 & 11.4 & 7.98 & 0.17 & 3.03 & 0.45 & 26.72 & 2.71 & 3.61 \\
\hline
\end{tabular}

aThe ion activities were computed using MINTEQA2 computer code and reported as p(ion).

$b$ Equilibrium from undersaturated solutions was studied by adding synthetic ettringite to deionized water and collecting samples for analyses after different reaction periods. Suspension concentration was $10 \mathrm{~g} / \mathrm{L}$.

cEquilibrium from supersaturated solutions was studied by initially preparing saturated solutions by dissolving synthetic ettringite in deionized water and then allowing ettringite to precipitate from these solutions by adding excess dissolved $\mathrm{CaO}$ and $\mathrm{Al}_{2}\left(\mathrm{SO}_{4}\right)_{3}$. 
Table 45. Values of the solubility product constant (et t $\cdot K_{s p}$ or more specifically the ion activity product, IAP) for ettringite determined from the solubility data presented in Table $41^{\mathrm{a}}$.

\begin{tabular}{|c|c|c|c|c|c|}
\hline $\begin{array}{c}\text { Time } \\
\text { (h) }\end{array}$ & $\begin{array}{c}\mathrm{pH} \\
( \pm 0.01)\end{array}$ & $\begin{array}{l}\text { Ionic strength } \\
\mathrm{mol} / \mathrm{m}^{3}\end{array}$ & pIAP & $\begin{array}{l}\text { Average } \\
\text { pIAP }\end{array}$ & $\mathrm{p}(\mathrm{IAP})_{3}$ \\
\hline \multicolumn{6}{|c|}{ Undersaturated solutions } \\
\hline 0.02 & 11.0 & 6.72 & 111.4 & 111.8 & 112.9 \\
\hline 0.08 & 11.1 & 7.95 & 110.9 & 110.8 & 112.3 \\
\hline 0.17 & 11.0 & 7.35 & 111.5 & 111.6 & 113.0 \\
\hline 0.25 & 11.2 & 7.35 & 110.9 & 111.0 & 112.3 \\
\hline 0.50 & 11.2 & 8.27 & 110.9 & 111.0 & 112.3 \\
\hline 1.0 & 11.3 & 8.58 & 109.7 & 111.0 & 111.1 \\
\hline 4.0 & 11.1 & 7.48 & 111.5 & 111.4 & 112.9 \\
\hline 24 & 11.0 & 7.43 & 111.9 & 112.1 & 113.4 \\
\hline 120 & 11.0 & 8.41 & 110.8 & 111.9 & 112.3 \\
\hline 450 & 11.0 & 8.06 & 111.0 & 111.0 & 112.5 \\
\hline \multicolumn{6}{|c|}{ Supersaturated solutions } \\
\hline 24 & 12.4 & 8.97 & 107.4 & 108.0 & 108.1 \\
\hline 24 & 12.2 & 9.46 & 107.7 & 107.7 & 108.5 \\
\hline 48 & 11.5 & 8.47 & 111.5 & 112.0 & 112.6 \\
\hline 48 & 11.4 & 7.98 & 111.7 & 111.7 & 113.0 \\
\hline
\end{tabular}

aFor each reaction time, complete chemical analysis of one of three replicates was used to calculate "pIAP" according to Equation 1. These samples were analyzed in triplicate and the average $-\log$ (IAP) is give as "average pIAP". The IAP was also calculated using the measured stoichiometries according to Equation 3 and reported as P(IAP) $)_{3}$. 


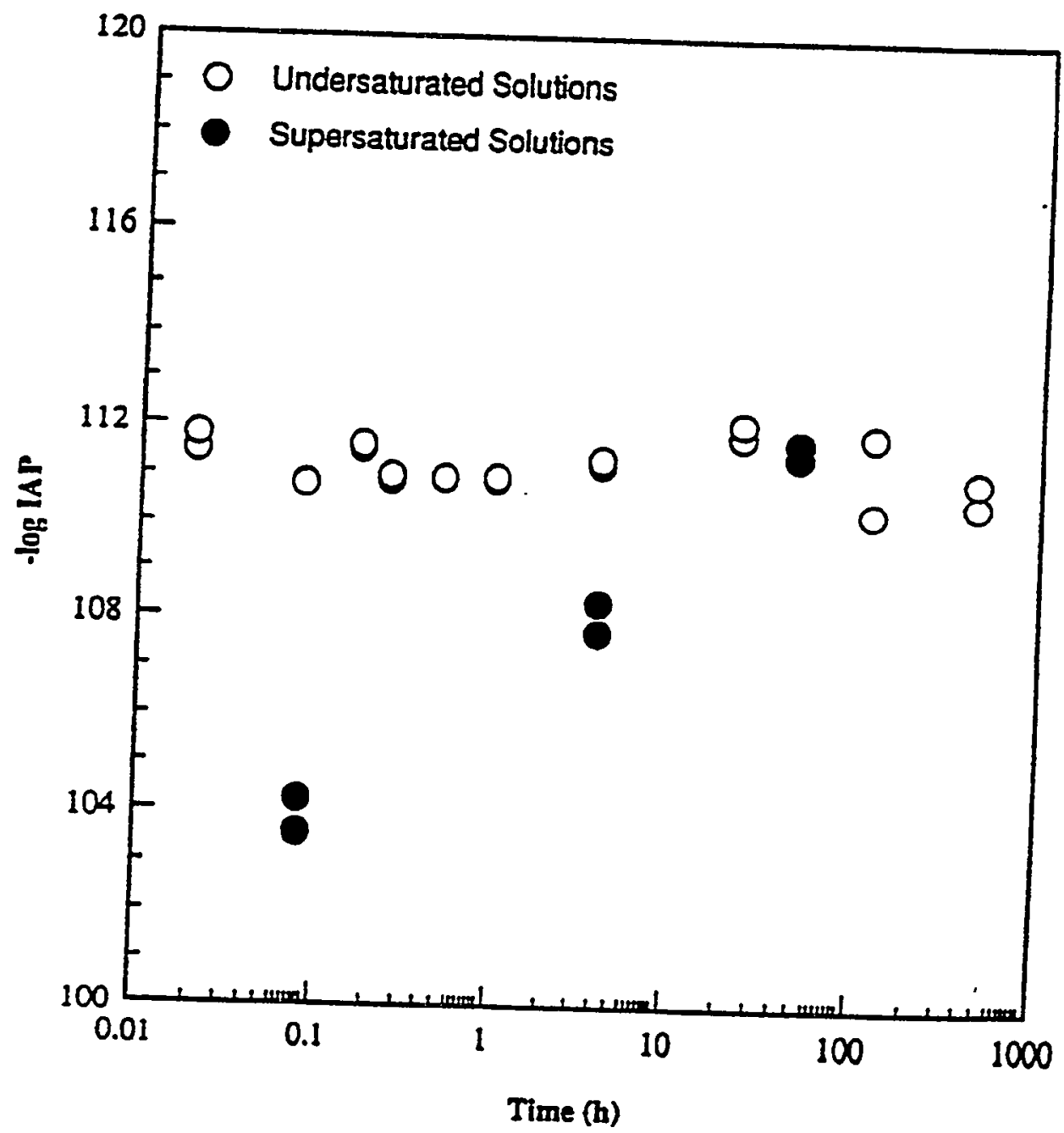

Figure 88. Ettingite solubility starting from undersaturated or supersaturated conditions. 
The $\mathrm{Ca} / \mathrm{Al}$ and $\mathrm{Ca} / \mathrm{SO}_{4}$ ratios for synthetic ettringite were 2.97 and 2.22, respectively (Tables 43 and 46). Little or no change was observed for these elemental ratios after dissolution (Table 46). In addition, similar $\mathrm{Ca} / \mathrm{Al}$ and $\mathrm{Ca} / \mathrm{SO}_{4}$ molar ratios were observed for both the solid and solution phases. These data support congruent dissolution of ettringite as proposed by Atkins etal. (1991). Further support for congruent dissolution was also provided by $\mathrm{x}$-ray diffraction and Fourier transform infrared spectroscopy analyses which showed no effect of dissolution on the spectral properties of ettringite for all samples with solution $\mathrm{pH}$ values $>10.7$. Thus, in this hyperalkaline regime, ettringite dissolution can be described by Equation 1 . At $\mathrm{pH}$ values < 10.7, incongruent ettringite dissolution produced gypsum and amorphous Al hydroxides. This will be discussed in the next section.

Modifications in crystal stoichiometry can result in different ett $\mathrm{K}_{\mathrm{sp}}$ values. The stoichiometric estimation based on the wet chemical analysis, uses normalization procedures and thus this deviates from the unit cell derived crystal formula. In the case of ettringite, the measured stoichiometry was close to the ideal stoichiometry (as described in Equation 1), but with slight deviation for $\mathrm{OH}$ and $\mathrm{SO}_{4}$ composition (Table 43). According to this measured stoichiometry, ettringite dissolution can be expressed as:

$$
\begin{aligned}
\mathrm{Ca}_{6} \mathrm{Al}_{2.02}\left(\mathrm{SO}_{4}\right)_{2.79}(\mathrm{OH})_{12.48^{\circ}} 26 \mathrm{H}_{2} \mathrm{O} \Leftrightarrow \\
6 \mathrm{Ca}^{2+}+2.02 \mathrm{Al}^{3+}+2.79 \mathrm{SO}_{4}{ }^{2-}+12.48 \mathrm{OH}^{-}+26 \mathrm{H}_{2} \mathrm{O}
\end{aligned}
$$

The solubility product constant for this reaction $\left(\mathrm{K}_{3}\right)$ is $10^{-112.9}$. Thus, ett. $\mathrm{K}_{\mathrm{sp}}$ and $\mathrm{K}_{3}$ are ettringite solubility product constants estimated from the ideal and measured stoichiometries respectively. Although, the average $K_{3}$ is about one log unit smaller than the average ett. $K_{s p}$, these two values are within the standard error of the chemical analyses.

The influence of $\mathrm{pH}$ on the solubility product constant was evaluated over the ettringite $\mathrm{pH}$ stability range (10.7 to 12.5). The solubility studies conducted at $\mathrm{pH} 10.7,11.3,12.2$, and 12.5 (at a constant suspension concentration of $4 \mathrm{~g} / \mathrm{L}$ ) produced the same ett $\mathrm{K}_{\mathrm{sp}}$ values. This indicates there is little effect of $\mathrm{pH}$, in this $\mathrm{pH}$ range, on the ${ }^{\text {ett }} \cdot \mathrm{K}_{\mathrm{sp}}$ (Table 47). However, these high $\mathrm{pH}$ samples exhibited high aqueous $\mathrm{Al}^{3+}$ activity. Similar effects were not observed for $\mathrm{Ca}^{2+}$ and $\mathrm{SO}_{4}{ }^{2-}$ activities. These observations were consistent with reports by Atkins et al. (1991) and Damidot et al. (1992).

Laboratory mineral solubility product studies frequently employ unusually low solid-tosolution ratios, which suppress secondary mineral formation. Natural systems, on the 
Table 46. Chemical analysis of synthetic ettringite sample ETT2 before and after solubility measurements. All elements of the solid are reported as the number of moles per one mole of ettringite and are normalized to six moles of Ca.

\begin{tabular}{|c|c|c|c|c|c|c|c|c|}
\hline \multirow{2}{*}{$\begin{array}{l}\text { Time } \\
\text { (h) }\end{array}$} & \multicolumn{4}{|c|}{ Solid moles of each component } & \multicolumn{2}{|c|}{ Molar ratios } & \multicolumn{2}{|c|}{$\begin{array}{l}\text { Equilibrium } \\
\text { solution } \\
\text { molar ratios }\end{array}$} \\
\hline & $\mathrm{Ca}$ & $\mathrm{Al}$ & $\mathrm{SO}_{4}$ & $\mathrm{OH}$ & $\mathrm{Ca} / \mathrm{Al}$ & $\mathrm{Ca} / \mathrm{SO}_{4}$ & $\mathrm{Ca} / \mathrm{Al}$ & $\mathrm{Ca} / \mathrm{SO}_{4}$ \\
\hline 0 & 6 & 2.02 & 2 & 1 & 2 & 2.14 & - & - \\
\hline 0.17 & 6 & 2.00 & 2 & 1 & 3 & 2.21 & 2 & 1.90 \\
\hline 4 & 6 & 2.04 & 2 & 1 & 2 & 2.25 & 2 & 2.01 \\
\hline 24 & 6 & 2.01 & 2 & 1 & 2 & 2.22 & 2 & 1.85 \\
\hline 120 & 6 & 2.01 & 2 & 1 & 2 & 2.25 & 2 & 2.02 \\
\hline 450 & 6 & 2.03 & 2 & 1 & 2 & 2.14 & 2 & 2.25 \\
\hline 720 & 6 & 2.02 & 2 & 1 & 2 & 2.22 & 2 & 2.04 \\
\hline
\end{tabular}


Table 47. Effect of $\mathrm{pH}$ and suspension concentration on ettringite solubility. The solubility product constant (et $t \cdot K_{s}$ ) was calculated on the basis of Equation 1. Ion activities are reported as $\mathbf{p}(\mathbf{i o n})$.

\begin{tabular}{|c|c|c|c|c|c|}
\hline \multirow{2}{*}{$\begin{array}{l}\text { Suspension } \\
\text { concentration } \\
(\mathrm{g} / \mathrm{L})\end{array}$} & \multicolumn{4}{|c|}{$\mathrm{p}$ (ion) } & \multirow[b]{2}{*}{$\mathrm{p}^{\mathrm{ett}} \cdot \mathrm{K}_{\mathrm{sp}}$} \\
\hline & $\mathrm{pH}$ & $\mathrm{Ca}^{2+}$ & $\mathrm{SO}_{4}^{2-}$ & $\mathrm{Al}^{3+}$ & \\
\hline & \multicolumn{5}{|c|}{ Effect of $\mathrm{pH}$} \\
\hline $\mathrm{NA}^{\mathrm{a}}$ & 10.7 & 2.62 & 2.59 & 22.50 & 109.3 \\
\hline NA & 11.3 & 2.79 & 3.12 & 26.31 & 111.1 \\
\hline $\mathrm{NA}$ & 12.2 & 3.21 & 3.32 & 29.24 & 109.8 \\
\hline \multirow[t]{2}{*}{ NA } & 12.3 & 2.31 & 4.02 & 31.81 & 110.0 \\
\hline & \multicolumn{5}{|c|}{ Effect of Suspension Concentration $b$} \\
\hline 4 & 11.4 & 2.90 & 3.14 & 25.80 & 110.1 \\
\hline 10 & 11.1 & 2.84 & 3.06 & 24.49 & 110.3 \\
\hline 12.1 & 11.0 & 2.78 & 3.00 & 25.30 & 112.4 \\
\hline 20 & 10.8 & 2.85 & 2.92 & 23.44 & 111.0 \\
\hline 30 & 10.5 & 2.66 & 2.84 & 22.14 & 110.8 \\
\hline
\end{tabular}

aNA; not applicable. Suspension concentration was maintained at $4 \mathrm{~g} / \mathrm{L}$. $\mathrm{T}=298 \mathrm{~K}$.

bEquilibrium $\mathrm{pH}$ was allowed to change. $\mathrm{T}=298 \mathrm{~K}$. 
contrary, exhibit extremely high solid-to-solution ratios. While the suspension concentration should not affect ett. $\mathrm{K}_{\mathrm{sp}}$, it may have a strong effect on its dissolution rate and thus may significantly control weathering reactions (Casey et al., 1993). Suspension concentration also modifies dissolution patterns for minerals with several chemical moieties in their unit cell (e.g. $\mathrm{SO}_{4}, \mathrm{OH}$, etc.). Different functional groups may exhibit contrasting release-rates and this facilitates secondary, metastable phase formation. To examine this behavior, ettringite dissolution experiments were conducted at suspension concentrations of $4,10,12.1,20$, and $30 \mathrm{~g}$ solid/L.

The ett $\mathrm{K}_{\mathrm{sp}}$ was invariant at all of the suspension concentrations examined and equilibrium was achieved within minutes for all cases. However, as the solid-to-solution ratio increased, $\mathrm{pH}$ dropped and the aqueous $\mathrm{Ca}, \mathrm{Al}$, and $\mathrm{SO}_{4}$ concentrations increased (Table 47). In addition, at high suspension concentration $\left(>10 \mathrm{~g} / \mathrm{L}\right.$ ), the equilibrium solution $\mathrm{Ca} / \mathrm{Al}$ and $\mathrm{Ca} / \mathrm{SO}_{4}$ molar ratios ( 2.3 and 1.7 respectively) were lower than those of the reacting synthetic ettringite ( 2.97 and 2.22 respectively). This discrepancy may be attributed to the formation of surface polymers or a secondary precipitate at high suspension concentrations (Wollast and Chou, 1992; Casey et al., 1993). Thus, these secondary phases and ettringite are at equilibrium with the solution phase at high solid concentrations. Further studies are required to examine the nature of these precipitates.

Based on the measured ett. $\mathrm{K}_{\mathrm{sp}}$ and the free energies of formation of $\mathrm{Ca}^{2+}, \mathrm{Al}^{3+}, \mathrm{SO}_{4}{ }^{2-}$, and $\mathrm{H}_{2} \mathrm{O}$, the standard state free energy of formation for ettringite was estimated as -9048.2 $\mathrm{kJ} / \mathrm{mol}$. This value is close to the value previously reported by Atkins et al. (1991).

\subsubsection{Ettringite Incongruent Dissolution}

The estimated ett. $\mathrm{K}_{\mathrm{sp}}$ indicates that ettringite undergoes incongruent dissolution to gypsum, and Al-hydroxides below a $\mathrm{pH}$ of 10.7. The nature of these reactions was examined when the $\mathrm{pH}$ was adjusted from 4 to 10 and the reactions were then allowed to proceed for up to 240 days.

The chemical compositions of the aqueous solutions that reacted with ettingite were dependent on equilibrium $\mathrm{pH}$. No effect of reaction time was evident for periods ranging from 10 to 240 days (Figure 89). This suggests that the equilibrium was achieved in less than 10 days. At pH values of 9.0 and 4.5 , the aqueous ion concentrations changed dramatically. 

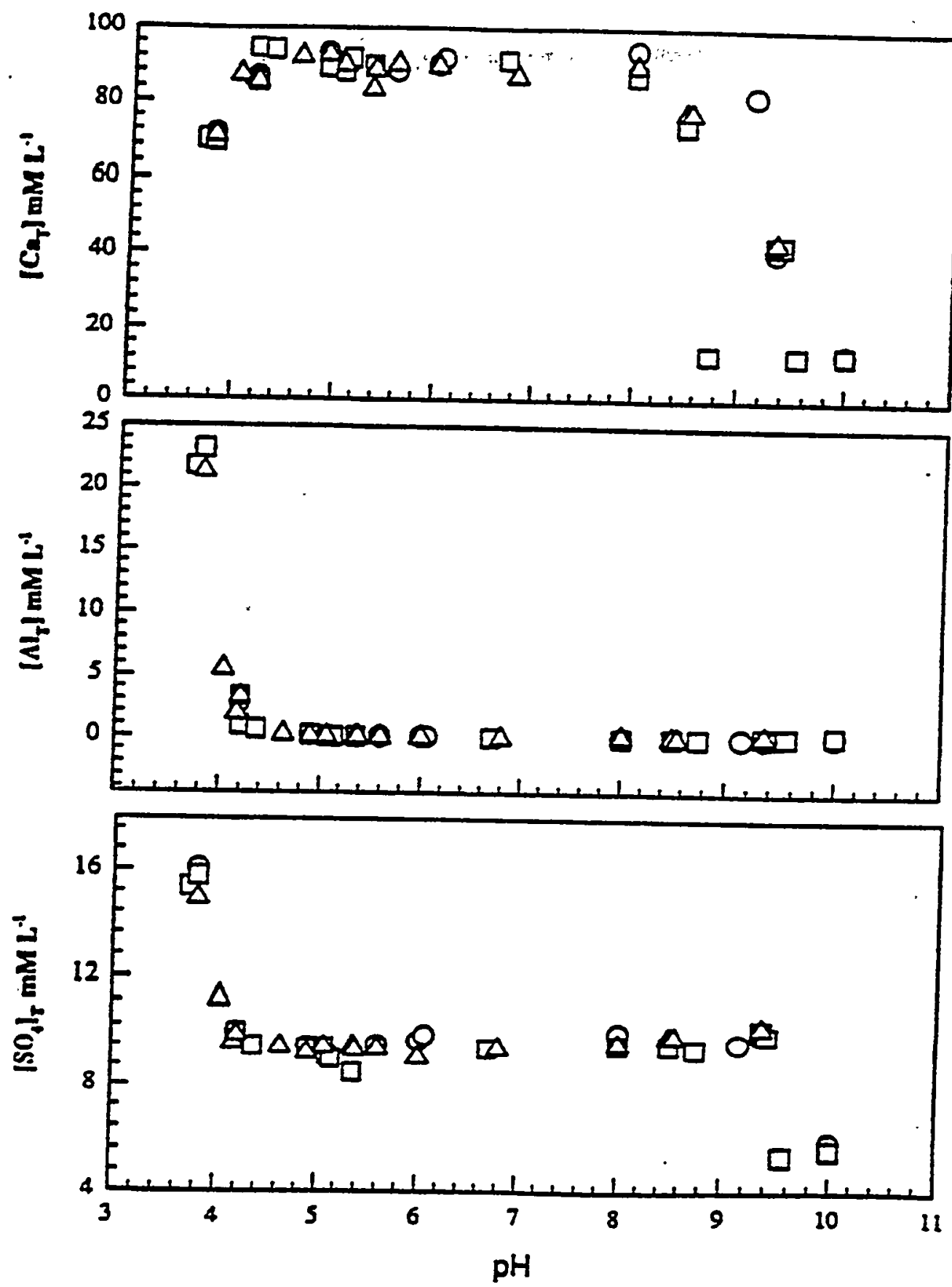

010 days $\square 120$ days $\Delta 240$ days

Figure 89. Total measured concentrations (on y axis) of $\mathrm{Ca}^{2+}, \mathrm{Al}^{3+}$ and $\mathrm{SO}_{4}{ }^{2-}$ ions for ettringite dissolution at $\mathrm{pH}<10$. 
As the $\mathrm{pH}$ was lowered from 10 , a threshold was crossed at $\mathrm{pH} \sim 9.0$. At this point dissolved $\mathrm{Ca}$ and $\mathrm{SO}_{4}$ concentration increased from $13 \mathrm{mM}$ to $90 \mathrm{mM}$ and from $5.6 \mathrm{mM}$ to $10 \mathrm{mM}$, respectively (Figure 89). Meanwhile the concentration of dissolved Al decreased from approximately $22.5 \mathrm{mM}$ to $2.5 \mathrm{mM}$. As the $\mathrm{pH}$ was lowered from the first threshold to the second threshold, the concentrations of dissolved $\mathrm{Ca}, \mathrm{Al}$ and $\mathrm{SO}_{4}$ was invariant. At $\mathrm{pH} \mathrm{9,} \mathrm{Ca}$ concentrations decreased from $90 \mathrm{mM}$ to $70 \mathrm{mM}$, whereas $\mathrm{Al}$ and $\mathrm{SO}_{4}$ concentrations increased sharply.

Prior to speciation with MINTEQA2, the program's thermodynamic data base was modified with recently reported solubility constants for various Ca-sulfate, $\mathrm{Al}$ - sulfates and oxyhydroxides (Nordstrom, 1982; Faure, 1989). With changes in $\mathrm{pH}, \mathrm{Ca}^{2+}$ and $\mathrm{SO}_{4}{ }^{2-}$ activities showed the same trend as their total concentration (Figure 90a; 90b;90c). However, the decrease in $\mathrm{Ca}^{2+}$ activity below $\mathrm{pH} 5$ is noteworthy and will be addressed below. In the experimental $\mathrm{pH}$ range, $\mathrm{Al}^{3+}$ activity exhibited several inflection points which correlate with the first, second and third Al hydrolysis constants (Figure 91) (Stumm and Morgan, 1994; Faure, 1989).

MINTEQA2 calculations of saturation indices were made after prohibiting precipitation of microcrystalline solids (gibbsite, bayerite, diaspore, boehmite). This was done due to the propensity of amorphous and microcrystalline solids to form in natural weathering environments (Lindsey, 1979; Stumm, 1993, Nordstrom and Alpers, 1996). In the case of basaluminite, solubility estimates for low or poor crystalinity are not available. Thus, the solubility product of a microcrystalline, standard state solid basaluminite was used instead.

The saturation index calculations showed that only ettringite was stable above $\mathrm{pH} 10.7$. Gypsum and amorphous Al hydroxides precipitated between 10.5 and 4.5 (Table 48). In addition, basaluminite $(\mathrm{pH}<7.5)$ and jurbanite $(\mathrm{pH}<5)$ were found to be the potential $\mathrm{Al}$ sulfate phases below neutral pH. Basaluminite was always found to be supersaturated by several orders of magnitude over the $\mathrm{pH}$ range of 4 to 8 . Indeed, saturation index values for this mineral increased from 0.25 at $\mathrm{pH} 3.8$ to a maximum of 7.0 at $\mathrm{pH} 6.0$; and then decreased to 0.3 at $\mathrm{pH}$ 7.7. This kind of supersaturation is caused either by slow precipitation kinetics or precipitation of an amorphous (i.e. noncrystalline) precursor (Sposito, 1994).

Nonequilibrium reaction path calculations were conducted to simulate acid titration of ettringite from its abient equilibrium $\mathrm{pH}$ to a value of 4.0 . The calculations indicated that ettringite dissolved incongruently to gypsum and $\mathrm{Al}$ hydroxide below $\mathrm{pH} 10.7$. Basaluminite appeared 

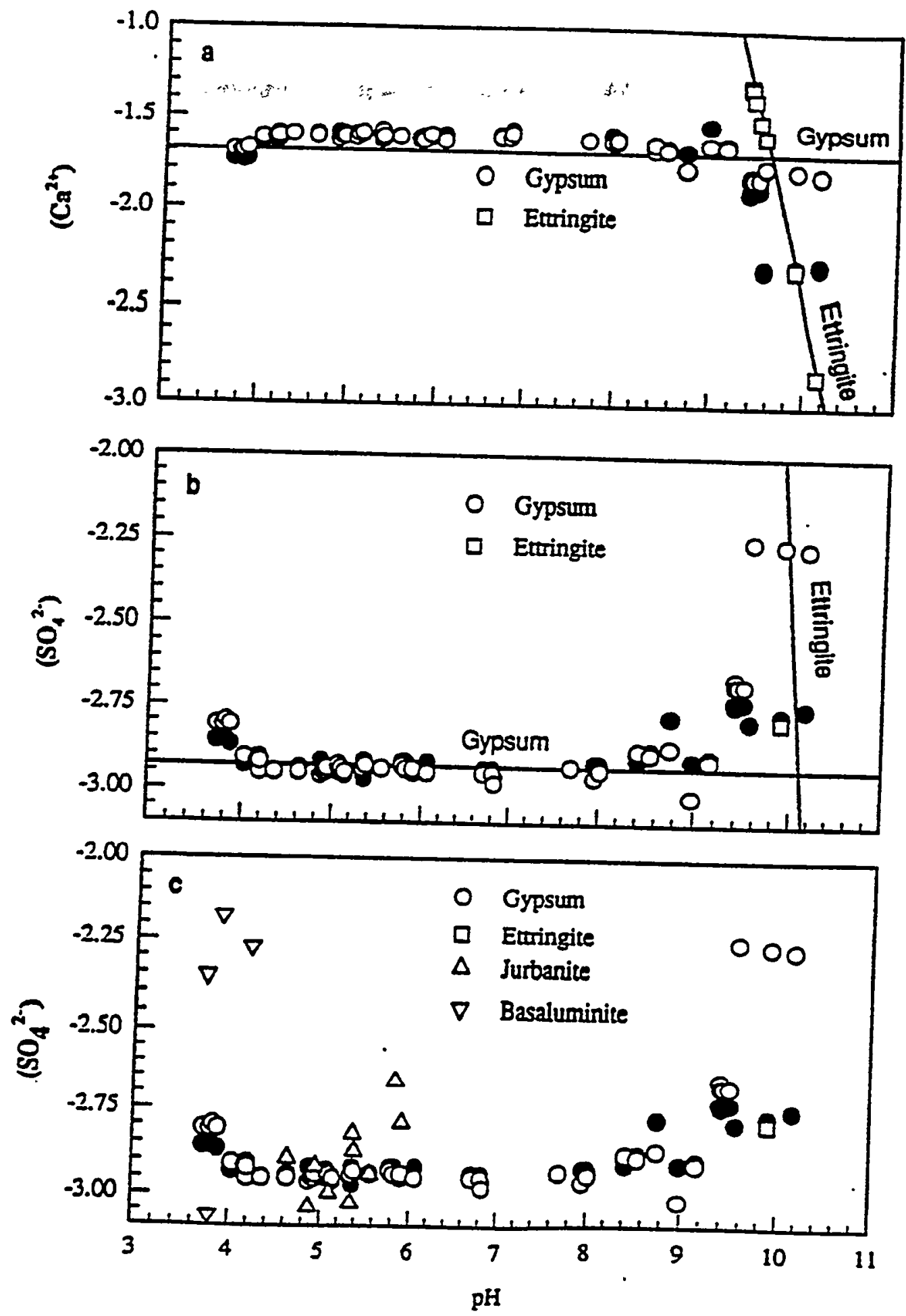

Figure 90. $\mathrm{Ca}^{2+}$ and $\mathrm{SO}_{4}{ }^{2-}$-ion activities for ettringite dissolution at $\mathrm{pH}<10$. Activities (in parentheses) are plotted in log units against $\mathrm{pH}$. Possible mineral phases are also shown (see next page for complete description). 


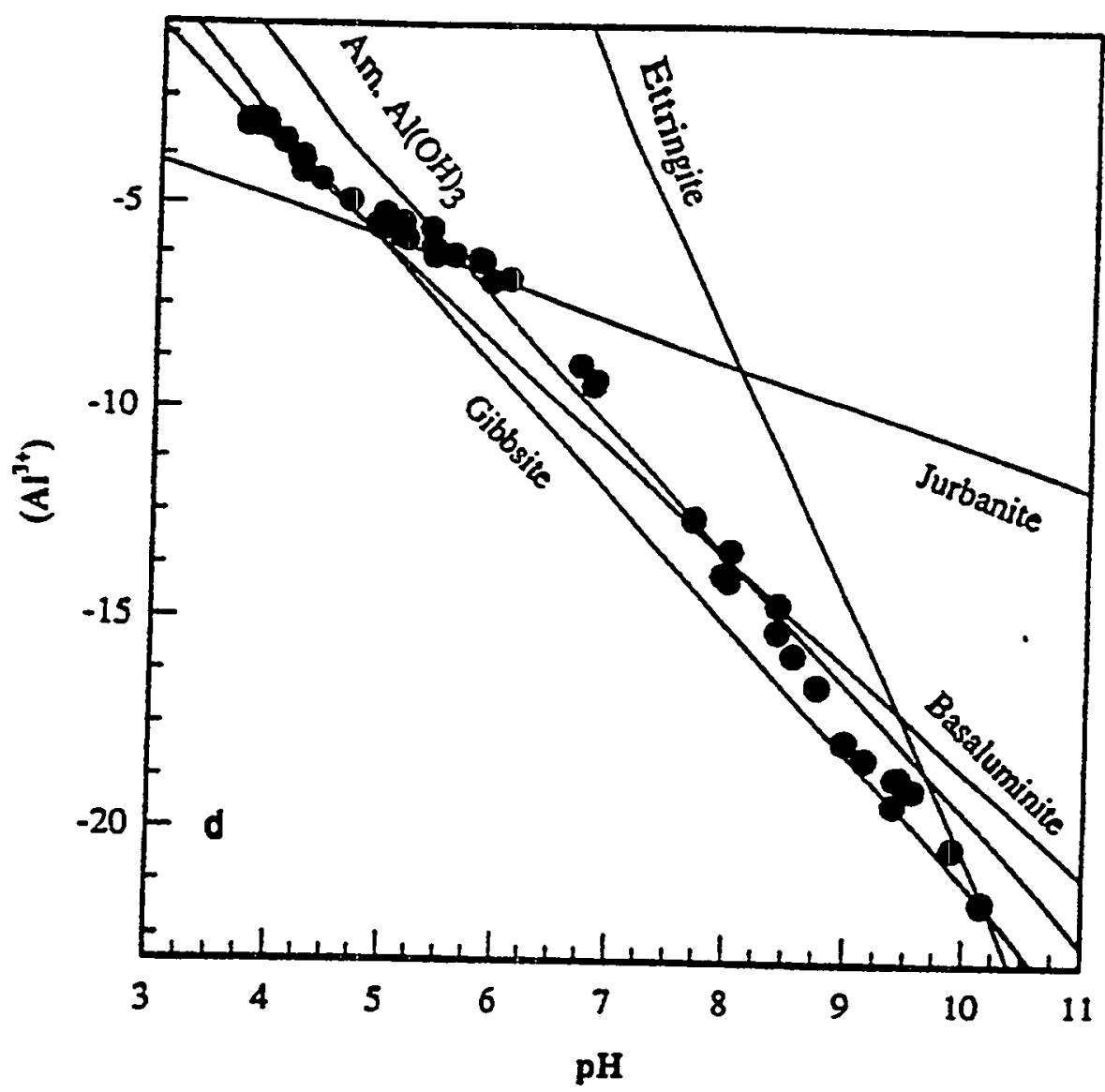

Figure 91. Al3+ ion activities for ettringite dissolution at $\mathrm{pH}<10$. Activities (in parentheses in $\log$ units) are plotted against $\mathrm{pH}$ with possible mineral phases. The solid symbols represent experimental results. Lines are drawn for different mineral phases by fixing the activities of all ions except the ion of interest. Open symbols represent the same but by considering the variability in activities of components. $\mathrm{p}\left(\mathrm{Ca}^{2+}\right)=2.5$; $\mathrm{p}\left(\mathrm{SO}_{4}{ }^{2-}\right)=3.0$; and $\mathrm{p}\left(\mathrm{Al}^{3+}\right)=21.0$ for ettringite and 6.5 for jurbanite and basaluminite. 
Table 48. Ettringite incongruent dissolution at $\mathrm{pH} \leq \mathbf{1 0 . 0}$.

\begin{tabular}{|c|c|c|c|c|c|}
\hline \multirow[b]{2}{*}{$\underset{( \pm 0.1)}{\mathrm{pH}}$} & \multirow{2}{*}{$\begin{array}{l}\text { Equilibrium } \\
\text { time (days) }\end{array}$} & \multicolumn{3}{|c|}{ Total concentrations (mM) } & \multirow[b]{2}{*}{ Identified equilibrium solidsa } \\
\hline & & $\mathrm{Ca}$ & $\mathrm{Al}$ & $\mathrm{SO}_{4}$ & \\
\hline \multirow[t]{3}{*}{3.8} & 10 & 71.28 & 23.07 & 16.03 & jurbanite $_{x}$, basaluminite ${ }_{s}$ \\
\hline & 120 & 69.58 & 23.15 & 15.78 & gypsum $_{x, 8}$ \\
\hline & 240 & 70.75 & 21.33 & 14.93 & \\
\hline \multirow[t]{3}{*}{4.2} & 10 & 86.80 & 2.63 & 10.09 & jurbanite $_{\bar{\lambda}}$ basaluminite ${ }_{3}$ \\
\hline & 120 & 85.65 & 3.22 & 10.09 & gypsum $_{x, s}$ \\
\hline & 240 & 85.45 & 3.22 & 10.00 & \\
\hline \multirow[t]{3}{*}{4.9} & 10 & 93.05 & 0.06 & 9.53 & basaluminite $_{\mathrm{s}}, \mathrm{Al}$-hydroxide $\mathrm{s}$ \\
\hline & 120 & 89.43 & 0.14 & 9.47 & gypsum $_{x, s}$ \\
\hline & 240 & 92.75 & 0.07 & 9.31 & \\
\hline \multirow[t]{2}{*}{5.6} & 10 & 88.23 & 0.03 & 9.59 & basaluminite ${ }_{s}$, Al-hydroxide $_{s}$ \\
\hline & 240 & 90.28 & 0.03 & 9.47 & gypsum $_{x, 8}$ \\
\hline \multirow[t]{2}{*}{6.0} & 10 & 90.00 & 0.03 & 9.77 & basaluminite $_{3}$, Al-hydroxide \\
\hline & 240 & 89.65 & 0.10 & 9.13 & gypsum $_{x, s}$ \\
\hline 6.8 & 240 & 93.93 & 0.02 & 9.49 & basaluminite $_{\mathrm{s}}$ Al-hydroxide ${ }_{\mathrm{s}}$ \\
\hline 7.7 & 240 & 87.30 & 0.03 & 9.47 & basaluminite $_{\mathrm{s}}$ Al-hydroxide ${ }_{\mathrm{s}}$ \\
\hline \multirow[t]{3}{*}{8.0} & 10 & 93.95 & 0.02 & 10.09 & Al-hydroxide ${ }_{s}$ gypsum $_{x, s}$ \\
\hline & 120 & 87.40 & 0.02 & 9.63 & \\
\hline & 240 & 89.83 & 0.11 & 9.66 & \\
\hline \multirow[t]{2}{*}{8.5} & 120 & 73.98 & 0.06 & 9.63 & Al-hydroxide, gypsum $_{x, s}$ \\
\hline & 240 & 77.33 & 0.06 & 9.94 & \\
\hline \multirow[t]{3}{*}{9.4} & 10 & 41.25 & 0.03 & 10.06 & Al-hydroxide ${ }_{3}$, gypsum ${ }_{x, s}$ \\
\hline & 120 & 43.05 & 0.22 & 10.31 & ettringite $\mathbf{x}_{\mathbf{x}}$ \\
\hline & 240 & 43.07 & 0.24 & 10.34 & \\
\hline \multirow[t]{2}{*}{10.0} & 10 & 13.65 & 0.22 & 5.84 & Al-hydroxide, gypsum $_{x, s}$ \\
\hline & 240 & 13.40 & 0.34 & 5.59 & ettringite $_{\mathrm{x}}$ \\
\hline
\end{tabular}

"subscript " $x$ " refers to equilibrium solid identified by $x$-ray diffraction analyses and subscript "s" refers to solid predicted based upon chemical speciation. 
as a stable phase when the $\mathrm{pH}$ reached 7.5 and persisted even at low $\mathrm{pH}$. Amorphous $\mathrm{Al}$ hydroxide disappeared at $\mathrm{pH} 4.5$ and jurbanite formed at its expense as $\mathrm{pH}$ further decreased (Figure 92). These were in agreement with the actual mineralogical and geochemical observations obtained from the laboratory weathering experiments described above. However, when the $\mathrm{pH}$ was $<5$ the predicted $\mathrm{Ca}^{2+}$ and $\mathrm{SO}_{4}{ }^{2-}$ activities were much smaller ( $1 \log$ unit) than the experimental values. Thus the stability of gypsum, jurbanite and basaluminite alone may not adequately explain this $\mathrm{Ca}^{2+}$ and $\mathrm{SO}_{4}{ }^{2-}$ ion behavior. This suggests that some other phase(s) not accounted for in the thermodynamic data base may also affect these two ion activities, or that the reaction path calculations did not fully account for kinetic constraints to the formation of reaction products.

\subsubsection{X-ray Diffraction and Microscopic Studies}

$\mathrm{X}$-ray diffraction analyses of the solids estimated from the weathering studies indicated the presence of ettringite at $\mathrm{pH}>10.7$, gypsum and ettringite between $\mathrm{pH} 9$ and 10 , and only gypsum below $\mathrm{pH} 9$ (Figure 93). No other mineral phases were evident. The presence of ettringite below $\mathrm{pH} 10.7$ is contradictory to the observations made from the solubility measurements and saturation index calculations. Although slower dissolution kinetics can cause this anomaly, this is not likely in the present system since the experimental data after 10 and 240 days gave similar results. This extended ettringite stability into the lower $\mathrm{pH}$ range may be due to its incongruent dissolution to gypsum and $\mathrm{Al}$ hydroxides. The failure of thermodynamic models to predict the presence of ettringite below $\mathrm{pH} 10.7$ is likely due to the inappropriateness of using ett. $\mathrm{K}_{\mathrm{sp}}$ determined from congruent dissolution to model incongruent processes.

Trace mineral identification was attempted with scanning electron microscopy, based on crystal morphology and energy dispersive X-ray elemental analysis. Scanning electron microscopy revealed three morphologically distinct euhedral and anhedral crystals, and poorly/micro crystalline grains. The euhedral crystals were monoclinic, and ranged in size from $<1 \mu \mathrm{m}$ to as large as $60 \mu \mathrm{m}$. These crystals were the dominant phase in all the samples equilibrated below $\mathrm{pH} 9.0$, and constituted more than $90 \%$ of the sample. The anhedral crystals were found in samples of $\mathrm{pH}<7.0$, ranging in size from 20 to $130 \mu \mathrm{m}$, and had irregular, conchoidal-type fractures. The fine-grained material was of submicron size and was found in the $\mathrm{pH}$ range 8.0 to 5.5. The abundance of this fine-grained fraction decreased dramatically below $\mathrm{pH}$ 5.0.

$\mathrm{X}$-ray elemental analysis indicated that the euhedral grains contained equimolar $\mathrm{Ca}$ and $\mathrm{S}$ suggesting that they were gypsum crystals (Figure 94). Some of these gypsum crystals also 


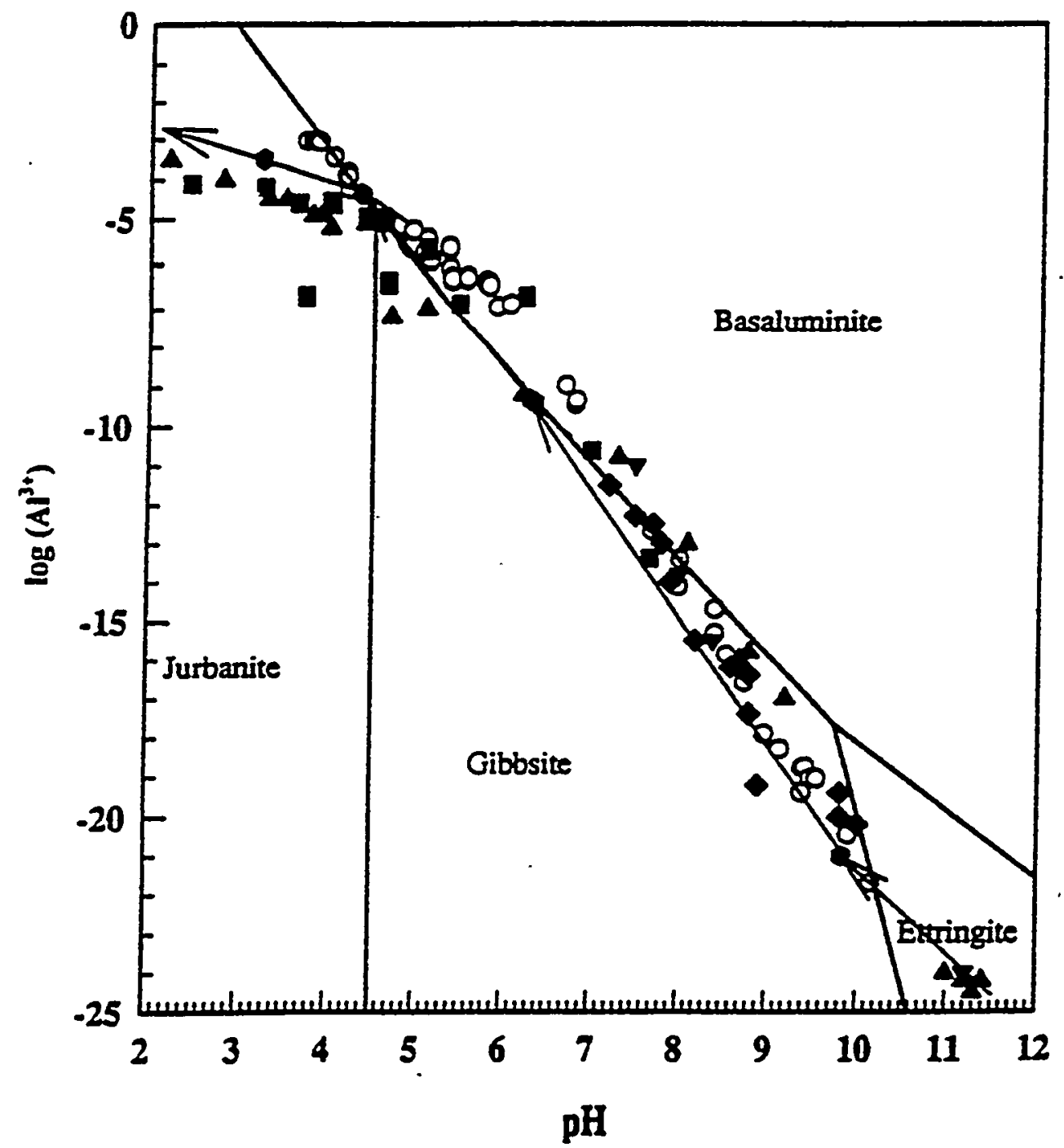

Figure 92. Mineral stability diagram for the $\mathrm{Ca}-\mathrm{Al}-\mathrm{SO}_{4}-\mathrm{H}_{2} \mathrm{O}$ system. Open circles are experimental data points and the solid line with arrow represents the reaction path predicted using $\mathrm{EQ} 3 / 6$. Estimated $\mathrm{Al}^{3+}$ activity in the flyash leach and acid mine spoils are also plotted. $\nabla$, Sullivan et al. (1988); $\square$, Fruchter et al. (1990); ४ , flyashes and $\Delta$, FGD (Mattigod et al., 1990). 


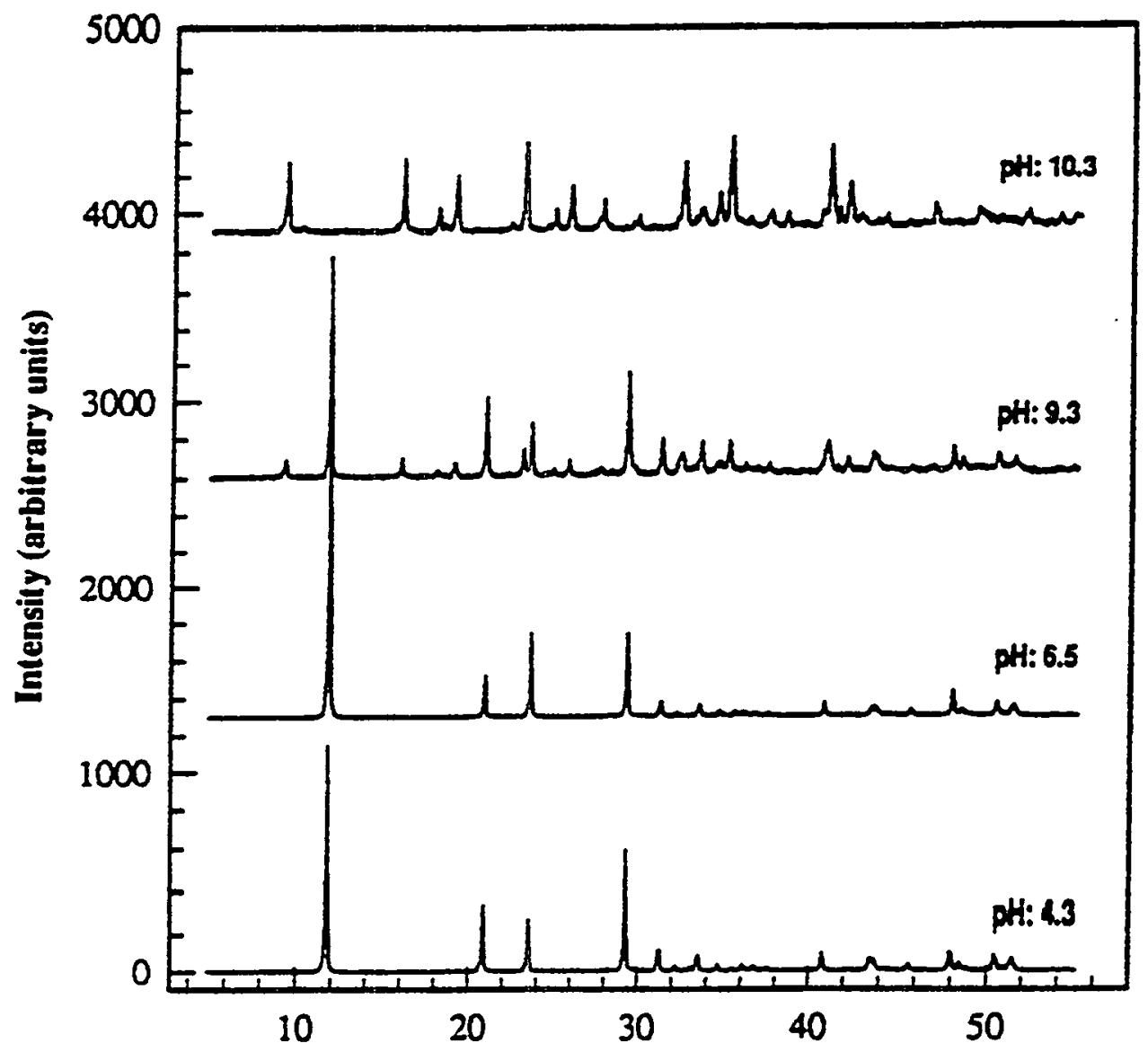

Degree $2 \theta$

Figure 93. X-ray diffraction of ettringite incongruent dissolution products. Peaks around 9.3 $2 \theta$ and $11.82 \theta$ correspond to ettringite and gypsum, respectively. 


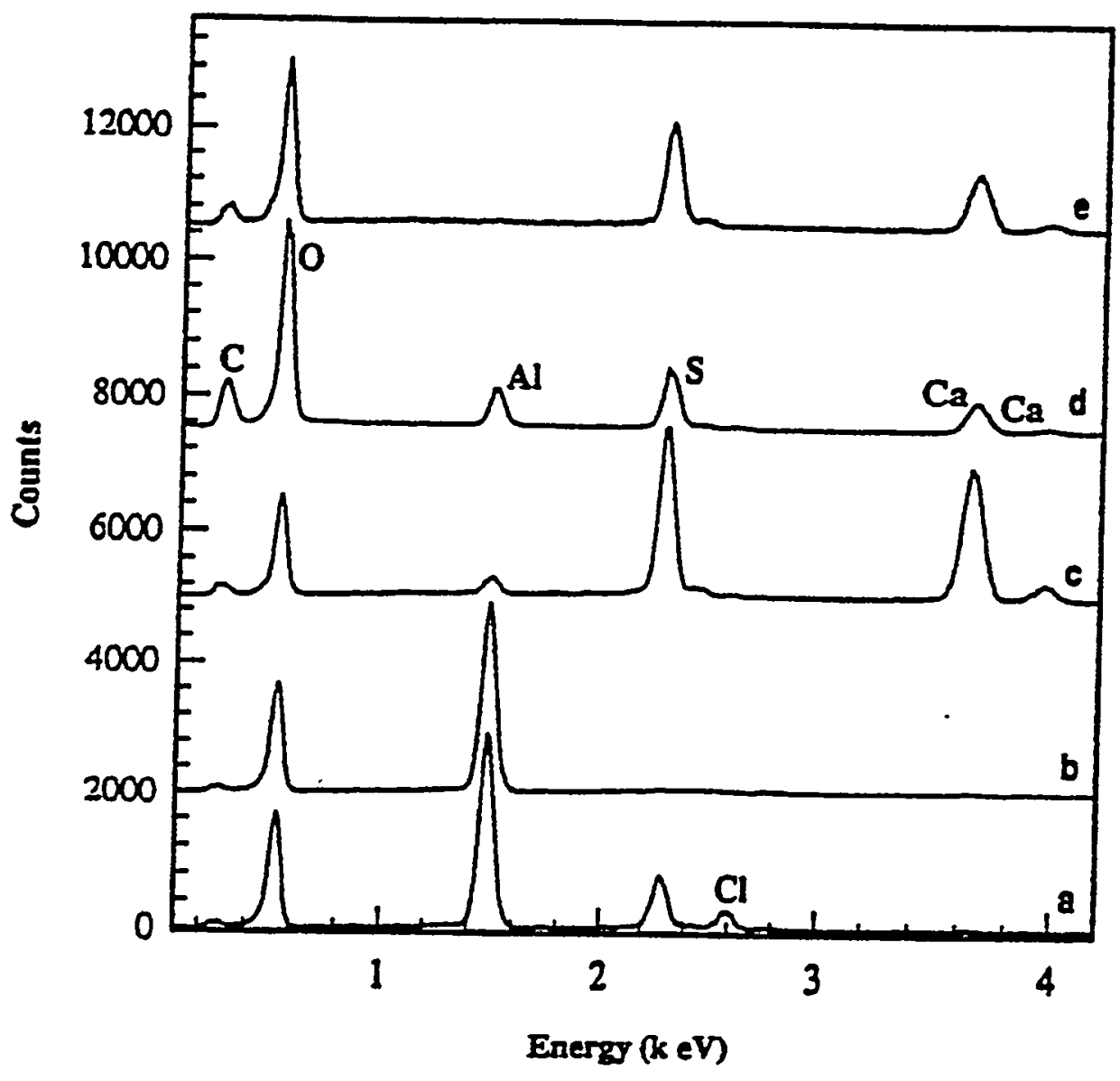

Figure 94. Energy dispersive $\mathrm{x}$-ray analysis of different mineral phases (size $<50 \mu \mathrm{m}$ ) of ettringite incongruent dissolution products ( $\mathrm{pH}$ range 4.0 to 6.0). a, Al-hydroxy suifate; b, Al-hydroxides; c \& d, Ca-Al-hydroxy-sulfates; and e, gypsum. The samples were coated with graphite prior to measurements. 
exhibited high Al contents $(0.2$ to 0.8 ( \pm 0.03 ) atomic percentage). Previous gypsum mineralogical studies have shown little variation in chemical composition, and Al substitution has not been reported before (Deer et al., 1966; Doner and Lynn, 1989). While substitution of Al into gypsum can not be ruled out, it seems likely that the measured Al fluorescence was due to adsorbed or fine nanoscale Al hydroxide coatings on gypsum. The euhedral crystals are identified as Al hydroxy sulfate phases. These grains had variable Al/S ratios (1.2 to 2.6) and contained no $\mathrm{Ca}$. No apparent correlation was observed between the $\mathrm{Al} / \mathrm{S}$ ratio and the grain size of these minerals. In comparison, aluminite and basalumanite have Al/S ratios of 2 and 4, respectively. Compositionally similar grains were also observed in prismatic form but were few in number. Morphologically similar, Al hydroxy sulfates have been previously synthesized by mixing $\mathrm{Na}_{2} \mathrm{SO}_{4}$ with $\mathrm{Al}$ hydroxide solutions (Wang and Hsu, 1994). No grains with composition similar to jurbanite were detected by $\mathrm{X}$-ray elemental analysis.

The fine grained material observed in the scanning electron micrographs showed two distinctly different compositions-one $\mathrm{Al}$ and $\mathrm{O}$ (plate-shaped grains) and the other $\mathrm{Ca}, \mathrm{Al}, \mathrm{S}$, and $\mathrm{O}$. These two phases are likely $\mathrm{Al}$ hydroxide and $\mathrm{Ca}-\mathrm{Al}$-hydroxy sulfate, respectively. However, it should be noted that $X$-ray elemental analyses can not distinguish between the adsorbed and structural atoms. Thus, it is impossible to rule out the presence of adsorbed Ca on Al hydroxy sulfate or adsorbed $\mathrm{Al}$ on gypsum. Nevertheless, the high $\mathrm{Ca}$ and $\mathrm{Al}$ atomic percentages $(0.5$ to 4.0) in these materials suggest that these ions were present in structural sites rather than as adsorbed species. To our knowledge, $\mathrm{Ca}-\mathrm{Al}-\mathrm{S}-(\mathrm{OH}, \mathrm{O})$ phases have not been reported before in low pH materials, such as acidic soils. However, specimens of a Ca-substituted alunite and minamiite $\left[\mathrm{MAl}_{3}\left(\mathrm{SO}_{4}\right)_{2}(\mathrm{OH})_{6}\right]$ where $\mathrm{M}=\mathrm{Na}, \mathrm{K}, \mathrm{Ca}$, have been identified from hydrothermally altered quartz-bearing andesites (Ossaka et al., 1982).

\subsubsection{Geochemistry of the $\mathrm{Ca}-\mathrm{Al}-\mathrm{SO}_{4}-\mathrm{H}_{2} \mathrm{O}$ System}

Several mineral phases of $\mathrm{Ca}-\mathrm{Al}-\mathrm{SO}_{4}-\mathrm{H}_{2} \mathrm{O}$ system were plotted in activity - $\mathrm{pH}$ diagrams using the available mineral thermodynamic data of the $\mathrm{Ca}-\mathrm{SO}_{4}-\mathrm{H}_{2} \mathrm{O}$ and $\mathrm{Al}-\mathrm{SO}_{4}-\mathrm{H}_{2} \mathrm{O}$ systems (Figures 90-92). The minerals considered were ettringite and gypsum in the Ca-SO $\mathrm{S}_{4}-\mathrm{H}_{2} \mathrm{O}$ system, and amorphous $\mathrm{Al}$ hydroxide, jurbanite and basaluminite in the $\mathrm{Al}-\mathrm{SO}_{4}-\mathrm{H}_{2} \mathrm{O}$ system . Although, Wang and Hsu (1994) reported several new Al hydroxy sulfates, lack of thermodynamic data prevents us from considering them here.

The incongruent dissolution of ettringite exhibited two $\mathrm{pH}$ thresholds ( $\mathrm{pH} \sim 9.0$ and 4.5) where the concentration of aqueous ions changed dramatically (Figures 90 and 91 ). At the first 
$\mathrm{pH}$ threshold ( $\mathrm{pH} \sim 9.0$ ), $\mathrm{Ca}^{2+}$ and $\mathrm{SO}_{4}{ }^{2-}$ activities were controlled by ettringite and gypsum, and $\mathrm{Al}^{3+}$ by ettringite and $\mathrm{Al}$ hydroxide (Figure $90 \mathrm{a}$ and $90 \mathrm{~b}$ ). Changes in ion activities at these $\mathrm{pH}$ values correlated with the onset of gypsum and Al-hydroxide precipitation. Precipitation of these phases begins at $\mathrm{pH} 10.7$ (i.e. where incongruent ettringite starts), but these minerals do not significantly influence solution composition above $\mathrm{pH}$ 9.5. Between the first and second $\mathrm{pH}$ thresholds (pH 9.5 and 4.5), gypsum controls $\mathrm{Ca}^{2+}$ activity and $\mathrm{Al}$ hydroxide and $\mathrm{Al}$ hydroxy sulfates control $\mathrm{Al}^{3+}$ activity (Figure 91 ). Although $\mathrm{SO}_{4}{ }^{2-}$-activity correlates to that of gypsum (solid line in Figure 90b), calculations showed that the basic Al sulfates also produce similar $\mathrm{SO}_{4}{ }^{2-}$ activities (triangles in Figure $90 \mathrm{c}$ ), especially below $\mathrm{pH}$ 7.0. In addition, scanning electron microscopy indicated the presence of different.Al hydroxy sulfate phases below this $\mathrm{pH}$. This suggests that $\mathrm{SO}_{4}{ }^{2-}$-activity is likely controlled by both gypsum and $\mathrm{Al}$ hydroxy sulfate phases below $\mathrm{pH} 7.0$ and only by gypsum in the $\mathrm{pH}$ range of 7 to 10 . Thus, the geochemistry of $\mathrm{Ca}-\mathrm{SO}_{4}-\mathrm{H}_{2} \mathrm{O}$ and $\mathrm{Al}-\mathrm{SO}_{4}-\mathrm{H}_{2} \mathrm{O}$ systems may be independent of each other in the $\mathrm{pH}$ range of 7 to 9.5. Below this $\mathrm{pH}$ regime, changes in $\mathrm{Ca}^{2+}$ activity can modify $\mathrm{SO}_{4}{ }^{2-}$ activity and thus can significantly influence $\mathrm{Al}^{3+}$ activity, or vice versa.. In this region the $\mathrm{Ca}$ $\mathrm{SO}_{4}-\mathrm{H}_{2} \mathrm{O}$ and $\mathrm{Al}-\mathrm{SO}_{4}-\mathrm{H}_{2} \mathrm{O}$ systems are no longer independent of each other.

The onset of $\mathrm{Al}$ hydroxy sulfate precipitation, at the expense of $\mathrm{Al}$ hydroxide, perturbed the $\mathrm{Ca}-\mathrm{SO}_{4}-\mathrm{H}_{2} \mathrm{O}$ system and this effect is distinct when $\mathrm{pH} \leq 5.0$. The high solubility of the basic $\mathrm{Al}$ sulfates gives rise to high $\mathrm{Al}^{3+}$ and $\mathrm{SO}_{4}{ }^{2-}$ activities which, in turn, decreases aqueous $\mathrm{Ca}^{2+}$ activity in equilibrium with gypsum and $\mathrm{Al}$ hydroxy sulfates. This may explain the experimentally observed reduction in $\mathrm{Ca}^{2+}$ activity and corresponding increase in $\mathrm{SO}_{4}{ }^{2-}$-activity below this $\mathrm{pH}$ (Figure 90a). In addition, the observed $\mathrm{Ca}^{2+}$ and $\mathrm{SO}_{4}{ }^{2-}$ activities were also in equilibrium with gypsum (circles in Figure 90). Although, the reaction path calculations predicted a decrease in $\mathrm{Ca}^{2+}$ activity at $\mathrm{pH}$ values less than 5 in the presence of gypsum, basaluminite, and jurbanite, these values are much smaller than the experimental data. Thus, the large experimental $\mathrm{Ca}$ activities may have been caused by a previously undescribed soluble $\mathrm{Ca} / \mathrm{Al}$ sulfate phase. Failure to attain equilibrium in the allotted reaction time could also explain this behavior. However, the apparent invariance in solution chemistry with time makes this condition unlikely. On the basis of these observations it is hypothesized that the observed variation in ion activities may be caused by the Ca-Al-hydroxy sulfate solid phase tentatively identified by scanning electron microscopy.

Equilibrium geochemical modeling with MINTEQA2 showed that basaluminite was supersaturated by several orders of magnitude between $\mathrm{pH} 4$ and 8 . Aluminum activity in equilibrium with basaluminite would be smaller than was observed in these weathering 
experiments. This may suggest that 1) its precipitation kinetics are very slow and/or (2) other polymorphic or amorphous forms of basaluminite, for example, those tentatively identified in the scanning electron microscopy studies, may be controlling Al ion activities.

On the basis of the observed mineralogical relations, a phase diagram was constructed for Al$\mathrm{SO}_{4}-\mathrm{H}_{2} \mathrm{O}$ system. Ettringite was also plotted in the diagram by assuming a constant $\mathrm{Ca}^{2+}$ $\left(10^{-2.5}\right)$ activity. Tie lines that separate different phases were based on the following incongruent reactions:

Ettringite $\Leftrightarrow$ gibbsite

$$
\mathrm{Ca}_{6} \mathrm{Al}_{2}\left(\mathrm{SO}_{4}\right)_{3}(\mathrm{OH})_{12} \cdot 26 \mathrm{H}_{2} \mathrm{O} \Leftrightarrow \mathrm{Al}(\mathrm{OH})_{3}+6 \mathrm{Ca}^{2+}+\mathrm{Al}^{3+}+3 \mathrm{SO}_{4}{ }^{2-}+9 \mathrm{OH}^{-}+26 \mathrm{H}_{2} \mathrm{O}
$$

Ettringite $\Leftrightarrow$ basaluminite

$$
\begin{aligned}
& \mathrm{Ca}_{6} \mathrm{Al}_{2}\left(\mathrm{SO}_{4}\right)_{3}(\mathrm{OH})_{12} \cdot 26 \mathrm{H}_{2} \mathrm{O}+ 10 \mathrm{Al}^{3+}+18 \mathrm{OH}^{-} \Leftrightarrow \\
& 3 \mathrm{Al}_{4}(\mathrm{OH})_{10} \mathrm{SO}_{4} \cdot 5 \mathrm{H}_{2} \mathrm{O}+6 \mathrm{Ca}^{2+}+11 \mathrm{H}_{2} \mathrm{O}
\end{aligned}
$$

Gibbsite $\Leftrightarrow$ basaluminite

$$
\mathrm{Al}(\mathrm{OH})_{3}+3 \mathrm{Al}^{3+}+\mathrm{SO}_{4}{ }^{2-}+5 \mathrm{H}_{2} \mathrm{O}+7 \mathrm{OH}^{-} \Leftrightarrow \mathrm{Al}_{4}(\mathrm{OH})_{10} \mathrm{SO}_{4} \cdot 5 \mathrm{H}_{2} \mathrm{O}
$$

Gibbsite $\Leftrightarrow$ jurbanite

$$
\mathrm{Al}(\mathrm{OH})_{3}+\mathrm{SO}_{4}^{2-}+5 \mathrm{H}_{2} \mathrm{O} \Leftrightarrow \mathrm{Al}(\mathrm{OH}) \mathrm{SO}_{4} \cdot 5 \mathrm{H}_{2} \mathrm{O}+2 \mathrm{OH}^{-}
$$

Basaluminite $\Leftrightarrow$ jurbanite

$$
\mathrm{Al}_{4}(\mathrm{OH})_{10} \mathrm{SO}_{4} \cdot 5 \mathrm{H}_{2} \mathrm{O} \Leftrightarrow \mathrm{Al}(\mathrm{OH}) \mathrm{SO}_{4} \cdot 5 \mathrm{H}_{2} \mathrm{O}+3 \mathrm{Al}^{3+}+9 \mathrm{OH}^{-}
$$

The set conditions, while preparing the stability diagram, were:

a) Existence of jurbanite is controversial and thus its reaction equilibria with gibbsite and basaluminite are tentative.

b) Although the basaluminite field is extended to high $\mathrm{pH}$, it may not form above $\mathrm{pH}$ 7.0. For its precipitation at these extreme high $\mathrm{pH}$ values, very high $\mathrm{Al}^{3+}$ activities are required. This is also unlikely because amorphous $\mathrm{Al}$ hydroxide rapidly precipitates in such systems. In addition small $\mathrm{Ca}^{2+}$ activity in these systems also forms several Ca-Al$\mathrm{SO}_{4}$ minerals.

c) The reactions were written to have a fraction of $\mathrm{Al}$ in both the solid and solution phases. This approach was taken, since $\mathrm{Al}$ is not completely conserved at very low $(<6.0)$ and high pH (>9.0). 
As shown in Figure 92, the reaction path calculations accurately predicted the experimentally observed $\mathrm{Ca}^{2+}, \mathrm{Al}^{3+}$, and $\mathrm{SO}_{4}{ }^{2-}$ activities above $\mathrm{pH}$ 5.0. The observed similarities between the experimental values and field results of Sullivan et al. (1988) (for acid mine drainage), Fruchter et al. (1990) (for flyash leachates) and Mattigod et al. (1990) (for flyash and FGD leachates) above $\mathrm{pH} 5$ indicate the robustness of the predicted equilibria. However, their marked disagreement at $\mathrm{pH}<5.0$ can be attributed to the formation of Ca-Al-hydroxy sulfates in the laboratory studies and the relatively $\mathrm{Ca}$ poor materials in the field sites.

With foreign ion inputs such as $\mathrm{Fe}^{3+}, \mathrm{Mg}^{2+}, \mathrm{K}^{+}, \mathrm{Si}(\mathrm{OH})_{4}{ }^{0}$, and $\mathrm{CO}_{3}{ }^{2-}$ into the Ca-Al-SO $4_{4}^{-}$ $\mathrm{H}_{2} \mathrm{O}$ system will exhibit different mineral phases. To understand these effects, equilibrium speciation modeling and reaction path calculations were conducted at different $\mathrm{pHs}$ and for a range of foreign ion concentrations. During these computations, $\mathrm{Ca}^{2+}, \mathrm{Al}^{3+}$, and $\mathrm{SO}_{4}{ }^{2-}$ activities were fixed at the values measured from the weathering experiments.

When the $\mathrm{Ca}-\mathrm{Al}-\mathrm{SO}_{4}-\mathrm{H}_{2} \mathrm{O}$ system is open to atmospheric $\mathrm{CO}_{2}$, the equilibrium reactions exhibit carbonate mineral phases such as calcite and aragonite under alkaline $\mathrm{pH}$ conditions. However, the slow precipitation kinetics of calcite delays its formation relative to ettringite and gypsum. Moreover, high $\mathrm{SO}_{4}{ }^{2-}$ activity favors the formation of gypsum over calcite (Doner and Lynn, 1989). This has also been observed from field studies of etringite-bearing, weathered, FGD materials. In these alkaline materials, calcite did not appear until 240 days of weathering (Fowler et al., 1993), whereas ettringite and gypsum precipitated within one week of their exposure to natural weathering conditions. Thus, carbonate equilibria has little influence on this system during the initial stages of weathering. However, elevations in $\mathrm{CO}_{2}$ partial pressures, due to decomposition of organic matter in subsurface soil horizons, may enhance the kinetics of calcite formation. Speciation codes indicated that the presence of $\mathrm{Mg}^{2+}$ formed dolomite $\left[\mathrm{CaMg}\left(\mathrm{CO}_{3}\right)_{2}\right]$, magnesite $\left(\mathrm{MgCO}_{3}\right)$, and huntite $\left[\mathrm{Mg}_{3} \mathrm{Ca}\left(\mathrm{CO}_{3}\right)_{4}\right]$ in addition to calcite. Although huntite formation has been observed in weathered dolomite or magnesite bearing rocks (Deer etal., 1966), its rate of formation has not been evaluated. Addition of $\mathrm{Fe}^{3+}, \mathrm{Mg}^{2+}, \mathrm{K}^{+}$, and $\mathrm{Si}(\mathrm{OH})_{4}{ }^{0}$ to the system formed $\mathrm{Fe}$ oxyhydroxides, minerals belonging to alunite-jarosite family, clays and leonhardite in addition to the other above mentioned minerals of the $\mathrm{Ca}-\mathrm{Al}-\mathrm{SO}_{4}-\mathrm{H}_{2} \mathrm{O}$ system. Of the $\mathrm{Si}$ phases, zeolites (leonhardite), and some clays such as kaolinite and halloysite may be dominant minerals in the system. However, actual experiments are necessary to support these predicted mineral equilibria. 


\subsection{Summary}

The results presented here demonstrate that ettringite dissolves congruently above $\mathrm{pH} 10.7$ with a pett. $K_{\mathrm{sp}}$ of $111.6( \pm 0,8)$ according to Equation 1 . The measured crystal stoichiometry, after normalization to six moles of $\mathrm{Ca}$, is different from that of the reported composition, but it did not affect the ett. $\mathrm{K}_{\mathrm{sp}}$ value significantly. In addition, changes in $\mathrm{pH}$ and suspension concentration had no effect on ett. $\mathrm{K}_{\mathrm{sp}}$. Ettringite can also exist at $\mathrm{pH}$ values $<10.7$ but only in association with gypsum and $\mathrm{Al}$ hydroxide. Ettringite completely dissolved at near neutral $\mathrm{pH}$ and precipitated gypsum, Al hydroxides, Al hydroxy sulfates such as basaluminite and other previously unidentified $\mathrm{Ca}$-Al-hydroxy sulfate phases. Although the geochemistry of the $\mathrm{Ca}$ $\mathrm{Al}-\mathrm{SO}_{4}-\mathrm{H}_{2} \mathrm{O}$ system is simple above $\mathrm{pH} 7.0$ and can be described as an association of the Ca$\mathrm{SO}_{4}-\mathrm{H}_{2} \mathrm{O}$ and $\mathrm{Al}-\mathrm{SO}_{4}-\mathrm{H}_{2} \mathrm{O}$ systems, it is complicated by the presence of several phases at near neutral $\mathrm{pH}$. Its simplicity above $\mathrm{pH} 7.0$ arises from the absence of $\mathrm{Al}$ hydroxy sulfate phases. EQ3/6 calculations accurately predicted the ettringite weathering sequence and relevant ion activities when the $\mathrm{pH}$ was $>5.0$. These reaction path simulations also suggested the existence of highly soluble $\mathrm{Ca}$ phases around $\mathrm{pH} 5.0$ which were confirmed by the microscopic studies. Below neutral $\mathrm{pH}, \mathrm{Ca}^{2+}$ activities can significantly influence $\mathrm{Al}^{3+}$ activity or vice versa. Further study should explore the occurrence of these phases in field weathering environments and their potential to form in the presence of other ions not considered in the present study. 


\section{6}

\section{ECONOMIC VALUATION OF RECYCLING FGD BY-PRODUCTS}

\subsection{Introduction}

The focus of the economic studies was to develop conceptual models and statistical estimation procedures related to FGD utilization. Hedonic pricing methods were used to estimate impacts of (1) FGD disposal in landfills (a disamenity or negative externality) on private property value and (2) FGD use for reclamation of surface coal mined areas (an amenity or positive externality). Also as part of Phase 3 activities, the mathematical programming model incorporating the social values from the hedonic pricing work, developed during Phase 2 of this project (Stehouwer et al., 1998) was also revised and reestimated.

Hedonic pricing is a method for determining willingness to pay for a characteristic. In the hedonic pricing model, an explicit goods market (in this case the real estate market) is analyzed in order to estimate the implicit price associated with proximity to a landfill, thus enabling estimation of willingness to pay. A number of authors such as Mendelsohn (1984), Quigley (1984), and Driscoll et al (1994) have used versions of the hedonic pricing model to measure welfare changes in implicit markets, including the market for environmental quality. In contrast to previous studies that employed the hedonic method, the current research focuses on the locational factors inherent in the real estate market by combining spatial aspects of the standard urban amenities models with the hedonic model. To fully account for locational effects, we developed a model that incorporates property taxes and commuting costs into a standard model for implicit goods.

Previously, a mathematical programming model had been developed to identify the least cost disposal methods of FGD by-product among various disposal options (Stehouwer et al., 1998). In selecting the least cost options, annualized transportation and disposal costs incurred by utilities and/or farmers were used. These costs might be labeled "private costs" since they are borne by the producer and/or user of the by-product. Conclusions from this analysis 
indicated that electric utilities have an enormous economic incentive to supply FGD by-products for land application uses. At the margin, land application represents "private" cost savings to electric utilities of about $\$ 13.6 / \mathrm{Mg}(\$ 15 / \mathrm{ton})$.

The least cost disposal analysis excluded the social amenities/disamenities associated with FGD by-product disposal, e.g. property value gain/loss from landfill activities, stripmine reclamation, and abandoned mine reclamation. This report provides a more complete analysis of costs/benefits associated with land application uses of FGD. The following sections describe the conceptual models and the implications of the results from such models for future policies related to FGD utilization.

\subsection{Nonmarket Valuation of Landfilling FGD By-Product}

When FGD byproduct is created in excess of amounts that can be recycled beneficially, the excess must be landfilled. Landfills are widely viewed as environmental disamenities and, as such, will result in decreased levels of environmental quality to nearby human populations. The fact that organized markets for environmental quality do not exist requires the application of a nonmarket valuation technique in order to measure economic impacts. In this case, an extended version of Rosen's (1974) well-known hedonic pricing model (HPM) was used.

In addition to spatial effects, the operating life expectancy and post closure impacts of a landfill may greatly affect social costs. The hypothesis that landfills impose social costs even when closed was thus tested. This was done by including both currently operating landfills and closed landfills as study sites.

Welfare impacts were measured by estimating empirical compensating variation measures associated with changes in distance to a landfill. Furthermore, social costs change with changes in population density, as pointed out by Scotchmer (1986). In addition, study areas with a variety of settlement patterns are included so that the effect of population densities on overall social welfare can be determined. The model used in this study thus explicitly accounts for changes in population patterns and densities when estimating social costs.

In order to implement the model, well-defined areas around each of four landfills in Franklin County, Ohio were chosen for the analyses. A full year of 1990 real estate transaction data from Franklin County, Ohio was collected and subsequently supplemented with 1990 census block group micro data and household level survey data. The full data set captures the marginal 
price effects of housing and environmental characteristics as well as locational effects. Finally, a two-stage econometric model was used to estimate empirical compensating variations.

\subsubsection{Theoretical Framework: The Hedonic Pricing Model}

The hedonic pricing model incorporates factors that influence location choice such as local . public goods and amenities and location relative to the workplace. The landfills studied here are in quite different geographical locations and in areas where the population demographics differ widely. The theoretical model was derived in such a way as to investigate household level welfare effects. As such, a utility maximization approach was taken from which an empirical measure of compensating variation can be derived.

Formally, the model was set up as follows. Households were assumed to first choose a location in which to purchase a home according to tastes, property characteristics, amenities and disamenities (also known as environmental goods and bads, respectively) (Diamond and Tolley, 1982) and for leisure time. The extended model assumes that each household chooses from a set of amenities and disamenities, each of which is described by a set of distance coordinates. These coordinates represent a vector of measures for distance from amenities and disamenities such as the central business district and landfills, respectively. Households then maximize utility which is a function of property characteristics, amenities, leisure time, and a composite good that represents all other expenditures. Households are constrained in their choice of amenities, housing characteristics and location by per period income, total available time per period and commute time. Income is allocated over purchase of a per period housing rent which is described by the hedonic price function, cost of commuting, property taxes, and the composite good. It must be noted that the price of housing services is assumed to be a function of property characteristics and neighborhood amenities and disamenities, and commuting cost. Furthermore, property taxes are generally levied on the basis of property characteristics, so that individuals purchasing more expensive properties in a given area will shoulder a larger share of the cost of providing local public goods. The existence of amenities and disamenities, the leisure-labor trade-off, and property characteristics are all seen to be important determinants of household location choice.

Consumers will allocate expenditures in such a way as to maximize utility which will result in a relationship that describes the marginal willingness to pay (MWTP) for an additional unit of property characteristics, leisure or amenity in terms of the composite good. These relationships form the basis for empirical MWTP curves described in the next section. The tax component 
helps to measure the MWTP for local public goods, an important determinant of location choice.

An extension of a two-stage empirical hedonic methodology first implemented by Quigley (1984) was employed. In the first stage, the hedonic pricing function and the hedonic transfer function were estimated. Then marginal implicit prices from the estimates were derived by summing the marginal implicit price of a characteristic and the marginal contribution of the characteristic to property taxes. In the second stage, a system of MWTP curves was derived from homeowners' utility functions. From the MWTP curves, parameters of the utility function were estimated and empirical measures of per household compensating variation were derived. Within this framework, a large data set was collected in order to capture the effects of housing characteristics, neighborhood characteristics, location, and environmental quality on property prices.

\subsection{Data}

The data consisted of 1990 Franklin County, OH auditor's records on single family housing and condominium transactions merged with 1990 US census STF3A block group level micro data. Condominium transactions were included under the assumption that condominiums would be owner-occupied. The sample design was chosen so that circular areas of radius 5.4 $\mathrm{km}$ (3.25 miles) around four different landfill sites were included. Within those areas, all the housing transactions that took place in 1990 were included, and the transaction prices, housing characteristics and school district were recorded, resulting in a data set with 2,913 observations. Figure 95 provides a map of Franklin County that illustrates the areas included in the study.

Except for the Alum Creek site, which is mostly urban, the landfills under investigation are located within suburban areas of Franklin County. The town of Obetz had a population of 3,167 in 1990, while Grove City's 1990 population was 19,661 and Gahanna's was 27,791. Furthermore, the demographic characteristics of these areas vary in a predictable way. Black households, for instance, range from $30.74 \%$ of the total in the Alum Creek area to only $0.24 \%$ of the Grove City area. The landfills in the Gahanna and Grove City areas are sanitary landfills, and in 1990, they had life expectancies of two and twenty years, respectively. Life expectancy estimates are difficult to make and the 20 year estimate was provided by the Ohio Environmental Protection Agency. However, the self-reported life expectancy from the landfill 


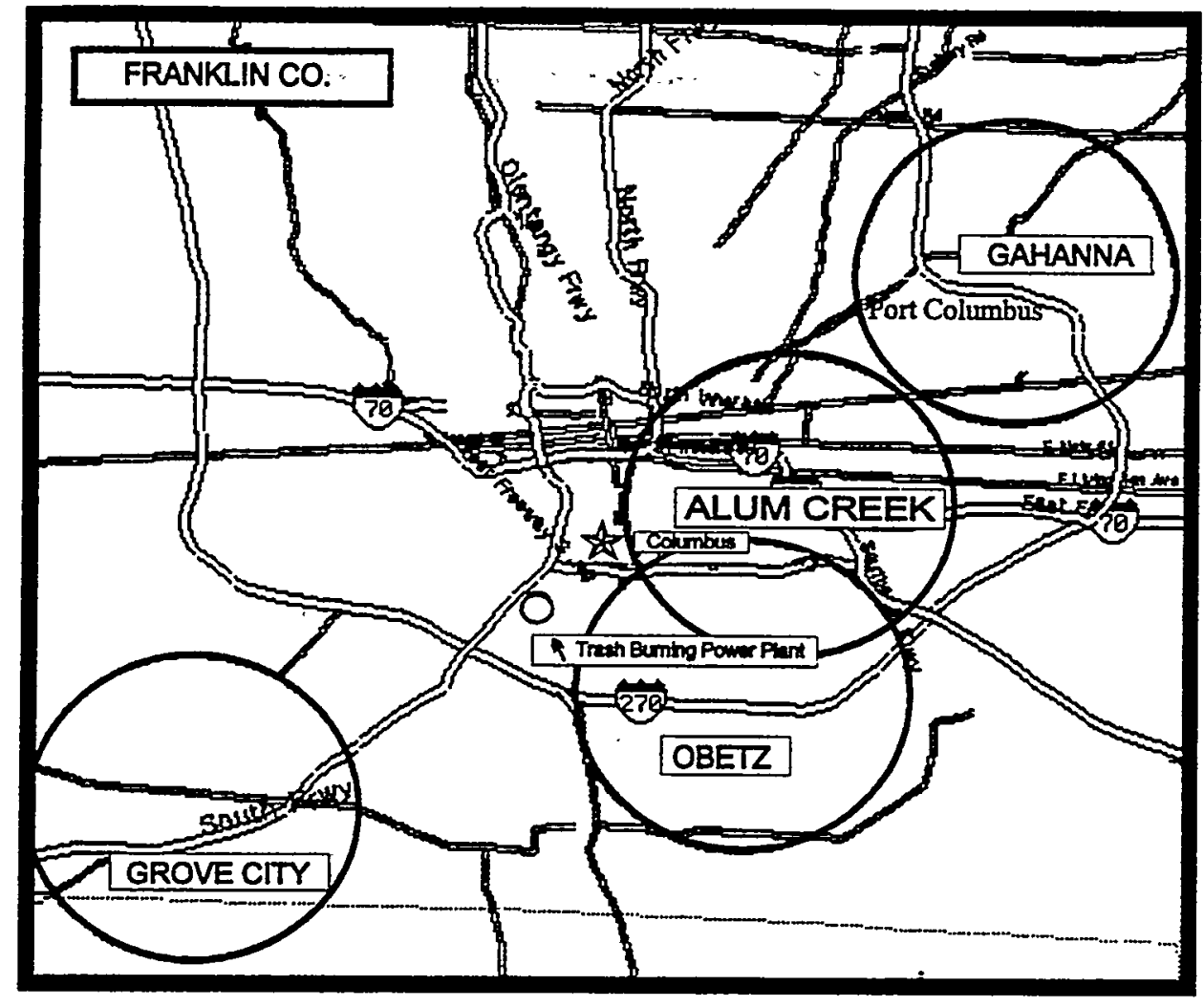

Figure 95. Map of Franklin County landfill study sites. 
operator was estimated at 6.5 years in 1990. In contrast, the landfills in Obetz and Alum Creek were demolition dumps that accepted only inorganic wastes and had been closed for six and eleven years in 1990, respectively.

Other environmental disamenities were present in the study areas chosen. First, there were different amounts of noise pollution resulting from rail and air traffic, with additional noise and air pollution from nearby freeways. The Obetz and Alum Creek sites were also downwind from a trash burning power plant that in 1994 was found to be a major source of dioxin pollution and was subsequently closed. This closure has prompted the local authorities to apply for an increase in capacity at the Grove City landfill.

The primary transaction data set were augmented by data derived from map measurements, meteorological data, census data, and responses to a direct mail survey of individuals who purchased homes in the study area (Hite, 1995). To account for environmental characteristics of the properties in each study area, distances from each property to the landfill and to the trash burning power plant were measured. Also, houses within $0.9 \mathrm{~km}(0.5$ miles $)$ of a freeway or railroad and/or within $2.5 \mathrm{~km}$ ( 1.5 miles) of the airport were assigned a dummy variable, as were properties located downwind from the landfills and trash burning plant. To account for neighborhood quality, a neighborhood safety index was constructed with data obtained from the Federal Bureau of Investigation Uniform Crime Statistics. A school competitiveness index for local high schools was constructed from proprietary data obtained from the Ohio State University Admissions Office. In addition, homes adjacent to parks and country clubs were assigned a dummy variable. Out-of-market transactions were also identified in order to help characterize the different neighborhoods in the study areas. These transactions included intrafamily transactions, bank transactions, corporate transactions, estate transactions and outlier transactions. Outlier transactions were those that appeared too low compared to other properties in a neighborhood and were discarded. Each remaining transaction was then assigned a dummy variable.

The census and direct mail survey data included variables such as average household commuting time, wages, hours worked, block group incomes, and where possible, income for individual households. Use of these data introduce some noise into the estimation procedures since they are simply proxy variables of the individual households represented by the transaction data. In total, data from 279 unique census block groups and data from responses of 504 individual households from the direct mail survey were merged with the auditor's data. 
From these data, several important variables were constructed (Hite, 1995). First, the transaction price was converted to a yearly rental equivalent and an annual property tax was estimated for each property according to a formula provided by the State of Ohio Tax equalization office. Then, block group level variables were used to estimate per household income and wage rate. Finally, proxy variables were used to estimate the composite good and the cost of commuting.

\subsection{Analysis and Results}

\subsubsection{First Stage Estimation}

In the first stage, two regressions were run. The hedonic pricing function was used to estimate the relationship between the various structural, environmental and neighborhood characteristics rental equivalents. The hedonic tax function was used to determined the relationship between property taxes and neighborhood characteristics. Housing characteristics and freeway access were segmented over the four study areas while all other neighborhood characteristics and environmental goods were pooled. The general form of the hedonic estimates for rent and taxes is:

$$
\begin{array}{ll}
\text { Equation 6-1: } & \ln (\text { Rent })=\gamma^{\prime} E+\sum D V_{i}\left(\text { Intercept }+\alpha \ln (\text { lot size })+\beta^{\prime} H+\eta^{\prime} N\right) \\
\text { Equation 6-2: } & \ln (\operatorname{Tax})=\gamma^{\prime} E+\sum D V_{i}\left(\text { Intercept }+\alpha \ln (\text { lot size })+\beta^{\prime} H+{ }^{\prime} \eta N\right)
\end{array}
$$

where $N$ represents vectors of neighborhood characteristics, environmental goods are represented as the vector $E$ and the $H$ vector represents housing characteristics. The variable $D V$ represents dummy variables used to segment the data into four different study areas. Two sets of index variables were created. One combined the effects captured by dummy variables for structural characteristics of properties in the data set. The other combined the effects of all dummy variable neighborhood characteristics. The purpose of creating the indices was to collapse dichotomous variables into two continuous variables from which marginal implicit prices could be derived and used in the second stage of the model estimation. The housing index was constructed from the dummy variables for condominium, fireplace, masonry/frame structure, finished basement and air-conditioning. The neighborhood index was constructed from the dummy variables for out of market transactions, for proximity to railroads, freeways, parks and the airport, and for properties downwind from the open landfills and the trash burning power plant. Thus five variables were used to create the house index, and 11 variables 
were used to create the neighborhood index. The indices then replaced the dummy variables in the first stage equations and were reestimated.

$$
\begin{aligned}
& \text { Equation 6-3 } \ln (\text { Rent })=\alpha_{1} \text { (Distance to Alum Creek) }+\alpha_{2} \text { (Distance to Alum Creek) }{ }^{2} \\
& +\alpha_{3} \text { (Distance to Obetz) } \quad+\alpha_{4} \text { (Distance to Obetz) }{ }^{2} \\
& +\alpha_{5} \text { (Distance to Grove City) } \quad+\alpha_{6} \text { (Distance to Grove City) }{ }^{2} \\
& +\alpha_{7} \text { (Distance to Gahanna) } \quad+\alpha_{8} \text { (Distance to Gahanna) }{ }^{2} \\
& +\alpha_{9} \text { (Distance to Trash Plant) } \quad+\alpha_{10} \text { (Distance to Trash Plant) }{ }^{2} \\
& +\alpha_{11} \text { (Distance to CBD) } \quad+\alpha_{12} \text { (Distance to CBD) }{ }^{2} \\
& +\alpha_{13} \text { (Neighborhood Safety) } \quad+\alpha_{14} \text { (School Index) } \\
& +\alpha_{15} \text { (Housing Index) } \quad+\alpha_{16} \text { (Neighborhood Index) } \\
& +\alpha_{17} \text { (Transaction Month) } \quad+\sum D v_{i} \cdot\left[\alpha_{0}+\alpha_{28} * \ln (\text { Lot Size) }]\right. \\
& +\alpha_{19} \text { (Square Footage of Structure) }+\alpha_{20} \text { (Square Footage Garage) } \\
& +\alpha_{21} \text { (Inverse Age) } \quad+\alpha_{22} \text { (Number of Stories) } \\
& +\alpha_{23} \text { (Number of Full Baths) } \quad+\alpha_{24} \text { (Number of Half Baths) } \\
& +\alpha_{25} \text { (Number of Rooms) } \quad+\alpha_{26} \text { (Number of Bedrooms) } \\
& +\varepsilon
\end{aligned}
$$

where $i=\{$ Alum Creek Area, Obetz Area, Grove City Area, Gahanna $\}$.

An equation comparable to 6-3 was also estimated to derive the property tax relationship. Derivatives of the estimated relationship of each regression were taken with respect to all of the housing, neighborhood, and environmental variables and applied to each individual household in the study. The sum of the derivatives by household for each characteristic yields estimates of the total implicit marginal price, including the contribution of property taxes, for the characteristics. Once the total implicit prices were estimated, they were merged with the primary data set for estimation of the second stage mean willingness to pay relationship.

The estimated relationships from the hedonic pricing function and the hedonic tax function have, in general, significant parameter estimates and tend to follow theoretically correct signs. For instance, the marginal implicit prices for distance to landfills, as calculated from the derivatives of the hedonic pricing function and the hedonic tax function, are increasing with distance from the landfill for three of the landfills (Alum Creek, Obetz, and Grove City) and are decreasing for the Gahanna landfill. This suggests that the implicit price for a property farther from a landfill is higher than the price closer to a landfill when all other characteristics are controlled for. 


\subsubsection{Second Stage Estimation}

The second stage of the estimation procedure links marginal implicit prices to marginal willingness to pay. The marginal willingness to pay factor is the marginal rate of substitution of a characteristic with all other goods. A set of explicitly parameterized mean willingness to pay curves were derived for environmental quality (as measured by distance from landfills) and other neighborhood and housing characteristics. Table 49 provides a set of descriptive statistics for the variables included in the second stage estimation, as well as the variables that are included in the estimate of the budget constraint and composite good. The per household level of the composite good is obtained as follows. The values of the annual rental rate, taxes for housing, and the proxy for opportunity costs of commuting and the annual average census block group commuting costs were subtracted from census block group average yearly gross income values.

The empirical mean willingness to pay curves were derived using 19 equations in the original system to be estimated, one for each of the characteristics from the first stage.

Each of the systems of equations was estimated for each of the four landfill study areas. The sets of equations included all nineteen of the variables that were estimated in the first stage regressions. The dependent variable was obtained by first taking the derivatives of the first stage equations (Equation 6-1 and Equation 6-2) with respect to each characteristic and then

summing. The estimated mean willingness to pay functions for distance to landfill showed that, in general, the coefficients of the estimated mean willingness to pay functions were significant. Although it is difficult to interpret the signs of the coefficients, the estimates of compensating variation in the next subsection clearly show that distance from the landfill is a normal good and willingness to pay for a given level of environmental quality is a decreasing function of its price.

\subsubsection{Compensating Variation Measure of Welfare Change}

Once the system of equations and empirical utility functions were derived, empirical measures of compensating variations (CV) were estimated.Compensating variation is the amount that would have to be taken away from the consumer after a price decrease in order for them to maintain their previous utility level. Compensating variations for a change in one characteristic (such as distance to a landfill), with all other characteristics held constant, can be estimated from a translog utility equation. In the analysis that follows, compensating variation is 
Table 49. Key descriptive statistics for variables included in the second stage estimates of nonmarket valuation of landfilling FGD by-product.

\begin{tabular}{|c|c|c|c|c|}
\hline Variable & $\begin{array}{c}\text { Alum Creek } \\
\mathrm{N}=1400\end{array}$ & $\begin{array}{c}\text { Obetz } \\
N=396\end{array}$ & $\begin{array}{c}\text { Gahanna } \\
N=867\end{array}$ & $\begin{array}{c}\text { Grove City } \\
N=250\end{array}$ \\
\hline \multicolumn{5}{|l|}{ Characteristics } \\
\hline Distance to nearest landfill $(\mathrm{km})^{\mathrm{a}}$ & 3.38 & 2.98 & 3.65 & 4.30 \\
\hline Distance to trash burning plant $(\mathrm{km})$ & 8.23 & 5.53 & 16.9 & 7.42 \\
\hline Distance to central shopping ( $\mathrm{km}$ ) & 8.06 & 13.1 & 19.1 & 19.5 \\
\hline Lot size $\left(m^{2}\right)^{b}$ & 680 & 1050 & 2020 & 2570 \\
\hline House size $\left(\mathrm{m}^{2}\right)$ & 132 & 109 & 148 & 133 \\
\hline Garage size $\left(\mathrm{m}^{2}\right)$ & 23.9 & 24.3 & 32.1 & 34.1 \\
\hline Number of stories & 1.59 & 1.34 & 1.55 & 1.32 \\
\hline Inverse age of structure & 0.025 & 0.048 & 0.104 & 0.091 \\
\hline Number of rooms & 5.84 & 5.54 & 6.42 & 5.94 \\
\hline Number of full baths & 1.21 & 1.12 & 1.54 & 1.40 \\
\hline Number of half baths & 0.25 & 0.27 & 0.54 & 0.36 \\
\hline Neighborhood safety & 0.01 & 0.02 & 0.02 & 0.024 \\
\hline Housing index & 10.6 & 3.84 & 8.02 & 8.50 \\
\hline School index & 34.0 & 29.1 & 67.0 & 60.2 \\
\hline Neighborhood index & 4.29 & 6.95 & 25.5 & 92.8 \\
\hline \multicolumn{5}{|l|}{ Budget Constraints } \\
\hline Yearly household income (\$) & 36,423 & 33,325 & 46,014 & 41,693 \\
\hline Yearly rent equivalent (\$) & 6,781 & 5,093 & 9,678 & 8,260 \\
\hline Yearly property tax (\$) & 747 & 496 & 865 & 646 \\
\hline Yearly commute cost (\$) & 1,407 & 1,579 & 2,288 & 2,014 \\
\hline
\end{tabular}

aTo convert $\mathrm{km}$ to miles multiply $\mathrm{km}$ by 0.621

bto convert $\mathrm{m}^{2}$ to $\mathrm{ft}^{2}$ multiply $\mathrm{m}^{2}$ by 10.76 . 
calculated for each property in the sample. Each individual household is assumed to be moved from their current location relative to the landfill, a distance of $5.23 \mathrm{~km}$ ( 3.25 miles) from the landfill as illustrated in Figure 96 . This represents an improvement in environmental quality.

With respect to the particular environmental good being investigated here, Figure 96 illustrates a per household measure of compensation variation that assumes a move from the actual household location to a distance of $5.23 \mathrm{~km}$ (3.25 miles) from the landfill. Suppose that a household in a study area is actually located at point $a$. The move from the actual household location to a location $5.23 \mathrm{~km}$ miles from the landfill (point $b$ ) results in an increase in utility from $U^{a}$ to $U^{*}$. The amount that a household should be willing to pay to move from the actual location to a location of $5.23 \mathrm{~km}$ would be indicated by a change in expenditures on goods besides housing $\left(X^{0}-X^{*}\right)$. The curved budget constraint in the figure results from the fact that implicit prices are nonlinear. It should be noted that the shift in the budget constraint from $X^{O}$ to $X^{*}$ will not necessarily be parallel. As a result, the best way to develop an average compensating variations compensation variation calculation would arguably be to first calculate the CV for each household and then average over all households, as was done in this analysis.

The compensating variations measures (Table 50) are based on the estimated marginal willingness to pay (MWTP) relationships and represent an amount that households would be willing to pay in additional taxes and rent per year to move from their present location to a location $5.23 \mathrm{~km}$ (3.25 miles) from the nearest landfill. There are three primary factors affecting these calculations: (1) the obvious effect of proximity to a landfill, (2) the landfill's life expectancy, and (3) the time since the landfill was closed. Once a landfill is closed, people may be more willing to live near a landfill leading to increased population densities and thus increases in social welfare as is evidenced from average densities in Table 50.

In comparing the estimated measures in Table 50, it is notable that compensating variations for the average household to move is positive in all cases. However, the average household willingness to pay increases with the life expectancy of the landfill in the same way that marginal implicit prices increase. The first entry in Table 50, estimated compensating variations, is calculated in two ways. First, the per household compensating variations is calculated and averaged by study area. In this case, there is no clear cut increase with the life expectancy of the landfills, with compensating variations ranging from $\$ 353.19$ per household where a landfill had been closed 11 years, up to $\$ 2,055.78$ per household, where a landfill had a 2 year life expectancy. This was thought to occur because population densities in areas with open landfills would be clustered away from the actual landfill. Thus, observing that the 


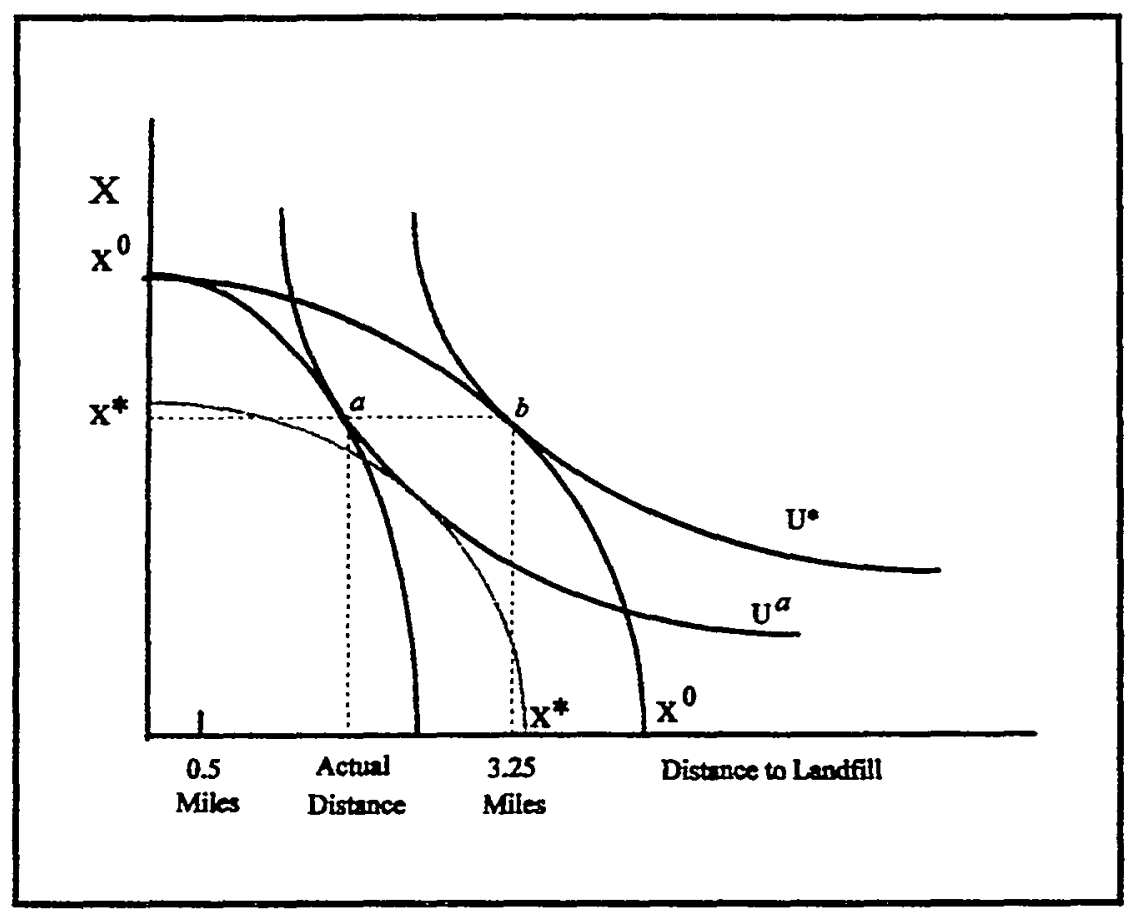

Figure 96. Compensating variation for distance from a landfill. To convert miles to kilometers, multiply by 0.621 . 
Table 50. Compensating variation (CV) measures ${ }^{a}$.

\begin{tabular}{|c|c|c|c|c|}
\hline Welfare Measure & $\begin{array}{l}\text { Alum Creek } \\
(-11 \text { years })^{b}\end{array}$ & $\begin{array}{c}\text { Obetz } \\
\text { (-6 years)b }\end{array}$ & $\begin{array}{r}\text { Gahanna } \\
\text { (2 years)b }\end{array}$ & $\begin{array}{c}\text { Grove } \\
\text { City } \\
\text { (20 years)b }\end{array}$ \\
\hline $\begin{array}{l}\text { CV estimated from mean } \\
\text { per household (actual) }\end{array}$ & $\$ 353.19$ & $\$ 1,140.07$ & $\$ 2,055.78$ & $\$ 1,362.63$ \\
\hline Distance adjustedc & $\$ 306.72$ & $\$ 797.38$ & $\$ 1,908.57$ & $\$ 2,340.62$ \\
\hline $\begin{array}{l}\text { CV estimated from integral } \\
\text { under MWTP curve from }\end{array}$ & $\$ 1,062.61$ & $\$ 2,962.96$ & $\$ 5,122.91$ & $\$ 2,249.73$ \\
\hline $\begin{array}{l}\text { miles) } \\
\text { Distance adjustedc }\end{array}$ & $\$ 974.88$ & $\$ 2,116.40$ & $\$ 5,227.46$ & $\$ 3,878.85$ \\
\hline $\begin{array}{l}\text { Integral under price gradient } \\
\text { from } 0.8 \text { to } 5.23 \mathrm{~km} \text { ( } 0.5 \text { to } \\
3.25 \text { miles) }\end{array}$ & $\$ 2,402.33$ & $\$ 3,157.78$ & $\$ 5,641.13$ & $\$ 8,432.76$ \\
\hline $\begin{array}{l}\text { Average distance moved in } \\
\mathrm{km} \text { (miles) }\end{array}$ & $1.75(1.09)$ & $2.25(1.40)$ & $1.58(0.98)$ & $0.93(0.58)$ \\
\hline $\begin{array}{l}\text { Minimum distance moved in } \\
\mathrm{km} \text { (miles) }\end{array}$ & $0.55(0.34)$ & $0.27(0.17)$ & $0.68(0.42)$ & $1.63(1.01)$ \\
\hline $\begin{array}{l}1990 \text { population } / \mathrm{km}^{2} \\
\text { (population } / \mathrm{mile}^{2} \text { ) }\end{array}$ & $2364(6,122)$ & $880(2,280)$ & $1464(3,804)$ & $963(2,494)$ \\
\hline
\end{tabular}

a Compensating variations represent an households willingness to pay additional taxes and rent per year to move from their present location to a location $5.23 \mathrm{~km}$ (3.25) miles from the nearest landfill.

bNumbers in parentheses are life expectancy of each landfill.

cPer mile moved 
average distance moved per household is quite different in the four study sites, the household compensating variations measures were standardized to a per-mile-moved compensating variations. These standardized measures take into account population patterns around landfills and are clearly monotonically increasing with landfill life expectancy, with an adjusted compensating variations of $\$ 306.72$ where a landfill was closed 11 years, up to $\$ 2,340.62$ where a landfill had a life expectancy of 20 years. With these adjustments, the compensating variations where life expectancy is 2 years drops to $\$ 1,908.57$ per household.

The results of the analysis described in this section were used to estimated the social costs of landfilling. Obviously, in an area such as Franklin County, $\mathrm{OH}$ social costs would be much higher than in a rural area where property values and population densities are lower. With these factors in mind, a model was developed that accounts for demographic differences between Franklin County and other areas in Ohio in order to estimate social impacts of landfilling FGD by-product.

\subsection{Transferring Social Benefits and Costs}

\subsubsection{Background Information}

Benefit transfer is a methodology by which social benefits based on estimates from a study site are used to establish social welfare measures at a second site known as the policy site. The methodology may also be used to transfer social costs, in which case the proper nomenclature is cost transfer. In the context of the FGD by-product project, transfers were made of both the social costs of landfilling acquired from the Franklin County landfill study, as well as the social benefits of coal mine reclamation acquired from the study of the Muskingum Watershed Conservancy District lakes. However, in this section focus was placed on the issue of cost transfer for landfills only. Applying the cost transfer terminology to the landfill analysis, the study site consists of the four landfills in Franklin County, Ohio and the policy sites refer to landfills in different areas of Ohio where landfills are currently accepting FGD by-product.

The use of benefits transfer methodologies has been limited primarily to transfers of costs and benefits that have been established through estimates from primary travel cost and contingent valuation studies (Boyle and Bergstrom, 1992). No studies on landfilling were found. Using the hedonic pricing model for cost transfer should be straightforward compared to contingent price models since actual market valuations of environmental quality provide the basis for measures of social welfare cost. 
Two methods have been developed to transfer benefits. The first model involves the actual transfer of social costs/benefits from one site to another site that appears to have quite similar characteristics. The major difficulty with this type of analyses is that it does not take into consideration underlying unobserved characteristics. Because of the shortcomings of simple transfers, it has generally been recognized that a preferable methodology would be to first estimate a demand curve at the study site and then use the coefficients of the demand curve to project costs and benefits at the policy site. However, this approach also presents problems in that it may be difficult to find common variables for the study site and the policy site with which to transfer values. In the hedonic price model, for example, there are various property characteristics that are obtained from auditor's records. The number of characteristics that are recorded can vary significantly from one county to another. It is also very time consuming and expensive to obtain household data to use in a demand equation estimated from the hedonic pricing model, which defeats the purpose of using the function-based cost transfer methodology.

\subsubsection{Cost Transfer Methodology for the Hedonic Pricing Model}

In order to perform a benefits or cost/benefits transfer study, it is necessary to identify key characteristics of the study sites and of the individuals in the market from which nonmarket demands are derived. Generalization of the model derived for the Franklin County landfill study sites should be relatively straightforward. It is probably appropriate to assume that the key externality factor experienced by households near a landfill is increased truck traffic. As a result, tons landfilled per year may be used as a proxy for the amount of truck traffic near a landfill. The second landfill characteristic of interest is life expectancy which, from the landfill study, effects the social costs of landfilling. In addition to characteristics of the landfill, itself, the demographics, population density, housing, neighborhood and environmental characteristics in the real estate markets of the study and policy sites need to be included in the analysis.

There are two possible ways to transfer the social costs of landfilling from Franklin County to policy sites across the state. The first approach involves using the hedonic price function that was previously developed to create the marginal implicit price for environmental quality as measured by distance from a landfill. In the next stage, rather than use the approach used in the Franklin County study, a demand curve is developed for environmental quality using only the block group level variables available from the census data. The coefficients from this demand curve would then be used to predict social costs at the policy sites. 
The second approach would be to first calculate total net present value of per household compensating variation and then average by census block group. The model would then be in terms of average household social cost for a sample which could then be multiplied by the number of households to get total social costs for a policy site. The total net present value for each census block group would then be merged with census STF3A block group data to create a predictive model for social cost. This model would then be used to estimate social costs in other study areas.

Of the two proposed approaches, the second has been chosen. The reason is that total welfare measures can be estimated from the most complete set of variables possible, i.e. from household level variables available from the primary and survey date set collected for 1990 housing transactions. These measures can then be associated with a wide range of socioeconomic variables that are uniform across all study areas.

The model formulated to estimate the relationship between net present value of social costs with explanatory variables at the census block group level was as follows:

Equation 6-4

$$
\begin{aligned}
& N P V_{i}=a_{0}+a_{1} \text { Neighborhood }_{i}+a_{2} \text { Environment }_{i}+a_{3} \text { House }_{i}+ \\
& a_{4} \text { Density }_{i}+a_{5} \text { Landfill Life Expectancy }_{i}+a_{6} \text { Tons Landfilled }_{i}+ \\
& a_{7} \text { Demographics }_{i}+\varepsilon_{i}
\end{aligned}
$$

In this formulation, $N P V$ (net present value) is the sum of the present values of all compensating variations per census block group as estimated in the primary study area. Neighborhood represents neighborhood variables from the census data, Environment proximity to a landfill, House represents housing characteristics available from the census data, Density represents population density from census data, Life Expectancy the life expectancy of the landfill, Tons Landfilled represents yearly tons landfilled, and Demographics represents variables from census data including race, income, and labor force characteristics. The coefficients of the predictive model are used to forecast compensating variation values for policy areas. Before implementing this model, the net present value of all welfare impacts of a landfill which includes the rate of decay associated with landfill life expectancy, as well as a rate of time preference was developed (Section 6.4).

To implement the benefits transfer predictive model, a number of steps were necessary to transform the original Franklin County welfare loss estimates from Section 6.4 into estimates 
that can be compared across the state. First, estimates are considered from the Franklin County study (hereafter called the study site) based on one year social welfare losses at landfills with various life expectancies. In order to obtain total net present values as needed to estimate Equation 6-4, a rate of decay of social costs over time was established.

The next step in implementing the benefits transfer model is to calculate social loss for the average household in each census block group in the study site. In addition, average distance of each census block group to the landfill was calculated and included in the sample to be estimated.

Third, the census block group data on social costs and distances to landfill is merged with the STF3A census microdata that includes block group averages of various housing, neighborhood and demographic characteristics. Variables such as tons landfilled per year and landfill life expectancy are also added to the data set.

Finally, the benefits transfer predictive model can be estimated using a multiple regression technique. The coefficients from this model are then used to predict the average per household social welfare cost for the policy sites which can be multiplied by the number of households at the policy site.

\subsubsection{Estimation of Total Net Present Value for Households in the Franklin County Study Site}

Preliminary analysis of landfills in Franklin County showed that welfare losses associated with landfills are a decreasing function of a landfill's life expectancy. Even after being closed, a landfill has negative effects on surrounding property values. Thus, if the total welfare loss associated with a landfill is the net present value of all losses in housing services, then it is necessary to develop a measure that discounts for time preference as well as for the rate of decay of welfare loss associated with a landfill. The Franklin County landfill study showed the relationship of compensating variation for an increase in environmental quality (Table 51).

The relationship between time and compensating variation for environmental quality from a time zero perspective is illustrated in Figure 97. That is, at the time a landfill with 20 years' life expectancy opens, the social cost of that landfill should decrease with each year of its life. By applying a simple actuarial technique, it is possible to obtain a decay rate for the life expectancy 
Table 51. Landfill life expectancy and compensating variation measures for landfills in Franklin County.

\begin{tabular}{lccc}
\hline \hline Landfill site & $\begin{array}{c}\text { Life expectancy } \\
\text { (years) }\end{array}$ & $\begin{array}{c}\text { Compensating } \\
\text { variation/month }\end{array}$ & $\begin{array}{c}\text { Compensating } \\
\text { variation/year }\end{array}$ \\
\hline Grove City & 20 & $\$ 192.05$ & $\$ 2,340.62$ \\
Gahanna & 2 & $\$ 159.05$ & $\$ 1,908.57$ \\
Obetz & -6 & $\$ 66.45$ & $\$ 797.38$ \\
Alum Creek & -11 & $\$ 25.58$ & $\$ 306.92$ \\
\hline \hline
\end{tabular}

effect of a landfill. First, assume that the relevant time horizon to measure effects is fifty years and that the discount rate is $8 \%$. From the relationships derived between time and welfare losses, a rate of decay for life expectancy can be derived. First, for the first 18 years of a landfill's life, the overall rate of decay is:

Equation 6-5

$0.815412 *(2340.62 / 1908.57)$

This rate of decay can be converted to a per year rate by solving for the geometric mean, that is

Equation 6-6

$$
\left(\beta_{1}+1\right)^{18}=1.22637
$$

where $\beta_{1}$ is the decay rate associated with the first 18 years of landfill life. Solving the equation yields a value for $\beta_{1}$ equal to 0.011401 . Following the same procedure with the three defined slopes in Figure 97, we obtain the results shown in Table 52.

By multiplying $(1+i)$ by $(1+\beta)$, where $i$ equals the rate of time preference, an appropriate total rate of discount can be developed (Table 52). 


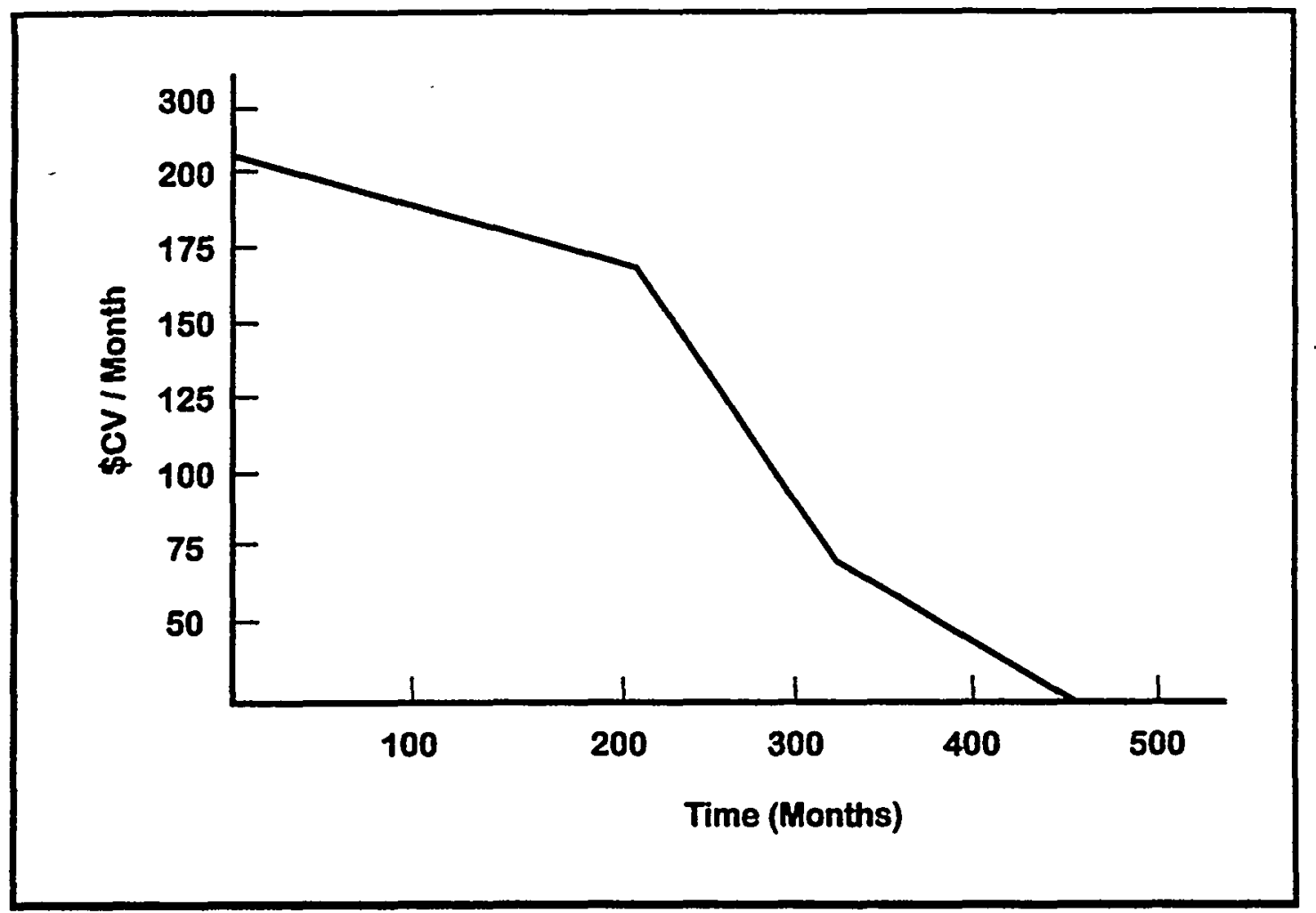

Figure 97. Idealized relationship between compensating variations and time. 
Table 52. Decay rate and total rate of discount for life of the landfill.

\begin{tabular}{lcc}
\hline \hline Time Period & $\begin{array}{c}\text { Decay rate } \\
B\end{array}$ & $\begin{array}{c}\text { Total rate of discount } \\
(1+\beta) *(1+\mathrm{i})\end{array}$ \\
\hline Years 1-18 & 0.011401 & 1.09231 \\
Years 19-26 & 0.115271 & 1.20449 \\
Years 27-50 & 0.210398 & 1.30723 \\
\hline
\end{tabular}

Table 53. Net present value factors for benefits transfer from Franklin County landfills.

\begin{tabular}{lcc}
\hline \hline Landfill site & Years & Factor \\
\hline Grove City & $0-18$ & $\left(\left(1-1.09233^{\wedge}(-18) / 0.092313=8.622216\right.\right.$ \\
& $19-26$ & $\left((1 / 1.092313)^{\wedge} 18\right)^{*}\left(1-1.204493^{\wedge}(-8)\right) / 0.204493=0.772632$ \\
& $27-50$ & $\left.(1 / 1.092313)^{\wedge}(18)^{*}(1 / 1.204493)^{\wedge} 8\right)^{*}\left(1-1.30723^{\wedge}(-23)\right) /$ \\
& $0.30723=0.149602$ \\
& Total & 9.544451 \\
Gahanna & $19-26$ & $1-1.204493^{\wedge}(-8) / 0.204493=3.768350$ \\
& $27-50$ & $\left(\left(1 / 1.204493^{\wedge}(-8)\right) /\left(1-1.30723^{\wedge}(-23)\right) / 0.30723=0.733137\right.$ \\
& Total & 4.519488 \\
Obetz & $27-50$ & $\left(1-1.30723^{\wedge}(-23)\right) / 0.30723=3.248028$ \\
& & $\left(1.30723^{\wedge}(-19)\right) / 0.30723=3.234852$ \\
\hline
\end{tabular}


These factors can then be incorporated into a formula for a varying annuity. Using this formula, an "average" household in the Grove City area was determined to have a total welfare loss due to the landfill of $\$ 22,339.93$ over a fifty year time horizon. A fifty year time horizon was used in the calculations recognizing that the rates of discount increase significantly when the landfill closes, driving present values to zero quickly. In addition, this measure recognizes that when a property is sold after a landfill is closed, the next owner will pay less for the house than would have been the case if there had been no landfill. If we divide total social costs by the estimated capacity of the landfill over its entire life, we arrive at a social cost of $\$ 6.47 / \mathrm{Mg}$ (\$7.13/ton) landfilled.

The above formula was applied appropriately to the Franklin County landfill data using a statistical program to generate per household compensating variation measures for all households in the 1990 study areas. Once the compensating variation measures were calculated, the predictive model described by Equation 6-4 can be developed and used to transfer compensating variation values to other landfill sites outside of Franklin County. Table 53 gives the solutions that correspond to the four different landfill sites in the original study and which were used to create total net present value in the final predictive model.

Table 53 also shows the factors that are applied in each of the areas surrounding the four landfills in the study site sample. The same factors were applied to each household within a given landfill area and were then used to estimate the per year compensating variations from the original model. This resulted in estimates of the net present value of the social welfare loss for the next fifty years. For example, for a household in Alum Creek with average per-year social welfare loss, the total net present value was calculated as shown below:

Equation 6-7 $\quad(3.234852)(\$ 306.92)=\$ 992.84$ over the next fifty years.

In this calculation, the 3.234853 value is the factor for Alum Creek taken from Table 53 and $\$ 306.92$ is the average per year social welfare loss obtained from the model (Table 51).

\subsubsection{Estimates from the STF3A Census Micro Data}

In this section, variables relevant to the cost transfer predictive model are presented. The variables derived from the original data set are distance to landfill and distance to central business district. These variables are created as census block group averages. For purposes of the benefit transfer analysis, the observations on all four landfills are pooled into 249 census 
block groups. The "distance to landfill" variable represents distance to the closest landfill. A number of variables that were used in the original study are not available in the STF3A census micro data and thus housing characteristics are limited to a small subset of the variables originally included in the hedonic pricing model. Additional neighborhood variables were created, such as "Percent Houses Sold - 1990" which represents the number of houses sold as measured in the original data set divided by total stock of owner occupied housing as measured by census. A simple mixed log-linear model was estimated using a simple linear regression model. The variables included in the model are those found in the set of descriptive statistics in Table 54. The predictive model is as follows:

\section{Equation 6-8}

$$
\begin{aligned}
& \log (N P V)_{i}=a_{0}+a_{1} \text { Neighborhood }_{i}+a_{2} \text { Environment }_{i}+a_{3} \text { House }_{i}+ \\
& a_{4} \text { Density }_{i}+a_{5} \text { Landfill Life Expectancy }_{i}+a_{6} \text { Tons Landfilled }_{i}+ \\
& a_{7} \text { Demographics }_{i}+\varepsilon_{i}
\end{aligned}
$$

where $N P V$ is net present value and $i=(1 . . . .249)$ represents the census block groups in the sample.

Equation 6-8 differs from Equation 6-4 in that the log of the total net present value is used as the dependent variable. The actual neighborhood, environmental and housing variables as well as their coefficients are found in Table 55.

\subsubsection{Results from Application of the Model}

After the predictive model has been estimated, policy sites comprised of landfills that are thought to represent those where FGD by-product is currently and may potentially be landfilled were located on a census map. The variables in the predictive equation were then recreated for the policy sites, which yields an average policy site household's per census block group social welfare loss. Then, for each of the census block groups in the policy site, the average per household welfare loss was multiplied by the number of owner-occupied households and summed over the entire policy site. To obtain a total policy site welfare cost of landfilling per ton of FGD, the total per year tons landfilled is summed over the future life of the landfill and divided into the sum of the total welfare loss as predicted from the benefits transfer model.

After developing this model, Census TigerLine ${ }^{T M}$ files were used to generate maps of the areas around the Zimmer, Gavin, and Conesville landfills. This was done by describing a $4.8 \mathrm{~km}$ (3 
Table 54. Descriptive statistics used to estimate cost transfer benefits from the census block group data.

\begin{tabular}{lcc}
\hline \hline Variable & $\begin{array}{c}\text { Mean } \\
\text { (census block data) }\end{array}$ & $\begin{array}{c}\text { Standard } \\
\text { deviation }\end{array}$ \\
\hline Variables from Original Data Set & & \\
Total met present value welfare loss & $\$ 3154.30$ & $\$ 5085.59$ \\
Log (total net present value welfare loss) & 7.1441303 & 0.3719694 \\
Distance to nearest landfill & 2.2634577 & 0.6257066 \\
(Distance to nearest landfill) & 5.5131770 & 0.7301807 \\
Distance to central business district & 4.5981415 & 0.4939655 \\
Landfill life expectancy & -5.4658635 & 8.5891811 \\
Million tons landfilled/yr. & 0.2820133 & 1.0459919 \\
Housing variables from STF3A & & \\
Average house value/1000 & & \\
Average number of rooms & $\$ 72.1028471$ & 50.1185743 \\
Average number of bedrooms & 5.6891892 & 1.0119358 \\
Average year built & 2.6953633 & 0.5385763 \\
Neighborhood variables from STF3A & 1943.75 & 124.570908 \\
Number of housing units & & \\
Population per square mile & & \\
Households on well water (\%) & 415.9477916 & 271.3610872 \\
Persons per household & 5830.80 & 3870.62 \\
Vacant houses (\%) & 5.3582794 & 18.0875021 \\
Single family homes (\%) & 2.5701663 & 0.4884678 \\
Renters same residence 5 years or less (\%) & 7.0471331 & 6.8476931 \\
Number of transactions / census block group & 63.6133277 & 28.6083791 \\
Housing stock sold in 1990 (\%) & 73.5925607 & 20.0792026 \\
Demographic Variables from STF3A & 12.6064257 & 14.1691153 \\
White (\%) & 4019.08 & 63372.23 \\
Black (\%) & & \\
Average age of household head & 0.7201702 & 0.3219286 \\
Average years owned home & 26.3255445 & 31.9286840 \\
Average income/1000 & 4.2951419 & 11.3728859 \\
High school education or less (\%) & 16.1364650 & 4.4155674 \\
Moved from out of city (\%) & 35.5125637 & 25.5634676 \\
\hline \hline & 77.5069138 & 19.4168941 \\
& 13.0058000 & 0.1044341 \\
\hline
\end{tabular}


Table 55. Analyses of variance for the final predictive model for benefits transfer $\left(R^{2}=0.93\right)$.

\begin{tabular}{lccccc}
\hline \hline $\begin{array}{l}\text { Source of } \\
\text { variation }\end{array}$ & $\begin{array}{c}\text { Degrees of } \\
\text { freedom }\end{array}$ & $\begin{array}{c}\text { Sum of } \\
\text { squares }\end{array}$ & Mean square & $\begin{array}{c}F \\
\text { statistic }\end{array}$ & Prob>F \\
\hline Regression & 9 & 4919.2178009 & 546.579755 & & 0.0001 \\
Error & 238 & 370.14256308 & 1.55522085 & & \\
Total & 247 & 5289.3603640 & & 351.45 &
\end{tabular}

Dependent variable log (net present value compensating variables)

\begin{tabular}{lllrrr}
\hline $\begin{array}{l}\text { Variable } \\
\text { Estimate }\end{array}$ & Parameter & $\begin{array}{c}\text { Standard } \\
\text { Error }\end{array}$ & $\begin{array}{c}\text { Type II Sum } \\
\text { of Squares }\end{array}$ & $\begin{array}{c}\mathrm{F} \\
\text { Statistic }\end{array}$ & Prob>F \\
\hline Intercept & -43.5200377 & 3.61740698 & 225.10018549 & 144.74 & 0.0001 \\
Black (\%) & -0.00555989 & 0.00104656 & 43.89304184 & 28.22 & 0.0001 \\
$\begin{array}{l}\text { Vacant (\%) } \\
\text { Private well (\%) }\end{array}$ & -0.03469864 & 0.00577915 & 56.06462950 & 36.05 & 0.0001 \\
$\begin{array}{l}\text { Average home } \\
\text { value }\end{array}$ & 0.00683073 & 0.00067233 & 160.53352299 & 103.22 & 0.0001 \\
$\begin{array}{l}\text { Average number } \\
\text { of rooms }\end{array}$ & 0.24028221 & 0.07395562 & 16.41696875 & 10.56 & 0.0013 \\
$\begin{array}{l}\text { Average number } \\
\text { of bedrooms }\end{array}$ & -0.34496713 & 0.14218902 & 9.15409425 & 5.89 & 0.0160 \\
$\begin{array}{l}\text { Average year } \\
\text { built }\end{array}$ & 0.02251928 & 0.00182123 & 37.77915999 & 152.89 & 0.0001 \\
$\begin{array}{l}\text { Life expectancy } \\
\text { of landfill }\end{array}$ & 0.08676543 & 0.00324005 & 1115.2759413 & 717.12 & 0.0001 \\
$\begin{array}{l}\text { Distance to } \\
\text { landfill }\end{array}$ & -0.12743730 & 0.04274087 & 13.82606065 & 8.89 & 0.0032 \\
\hline \hline
\end{tabular}


mile) radius around the landfill location and printing out a map with the census block groups in the study areas. From the TigerLine ${ }^{T M}$ data population counts, counts of owner-occupied housing and counts of racial groups were obtained and then converted to percentages to be used in the predictive equation. In addition to these demographic variables at census block groups level, the square $\mathrm{km}$ (square miles) that each pertinent census block groups comprises in the study area were obtained. Using geometric techniques, an estimate was made of the approximate number of households within $4.8 \mathrm{~km}$ ( 3 miles) of the landfill. To find an estimate of the average distance of households in a census block groups to the landfill, a number of averages along radii from the landfill were taken and averaged.

The following provides an example, using the Zimmer landfill for illustration, of the technique used to transfer costs for all the rural landfills. Data were estimated for the six unique census block groups near the landfill: 1) average distance of homes to the landfill, 2) number of owner occupied households, and 3) percentage black households. These estimates were then used in the cost transfer model.

Because the area near the landfill is quite rural, we were able to access the ZIP code level values for the remaining demographic variables in the cost transfer model. Variables used at the ZIP code level are 1) percentage of households on well water, 2) percentage of vacant homes, 3) average home value, 4) average number of rooms, 5) average number of bedrooms, and (6) average year built.

The final variables that were obtained for the cost transfer model were landfill life expectancy and total capacity which were obtained from the Ohio Environmental Protection Agency. By using all the available data, an estimated welfare loss of $\$ 1.29 / \mathrm{Mg}(\$ 1.42 / \mathrm{ton})$ could be attributable to landfilling of FGD by-product. This is remarkable in that the area under investigation is not densely populated. This estimate is felt to be quite robust since it takes into account the landfill life expectancy, population characteristics and density, and housing characteristics. Worksheets are attached for development of the policy site costs as Appendix E. These are the estimates incorporated in the linear optimization model in the next section (Section 6.0).

\subsection{Estimates of the Social Benefits of Strip Mine Reclamation}

\subsubsection{Background and Purpose of Study}

Surface mining of coal in the United States, particularly in the Ohio River Valley and the 
Appalachian Regions, has contributed to many environmental problems. Currently in Ohio, high sulfur coal is being mined extensively in the eastern part of the state. Combustion of this high sulfur coal for electric generation results in $\mathrm{SO}_{2}$ emissions that can lead to formation of acid rain. Scrubbers that remove the $\mathrm{SO}_{2}$ create a by-product, fluidized gas desulfurization (FGD) waste that may have potential for neutralizing acid spoils at mine sites (Stehouwer et al., 1995a, 1998). However, it may also have detrimental impacts if not handled properly.

A specific problem associated with unreclaimed surface coal mines is their impact on nearby lakes. This impact usually involves a severe discoloration of the water, due to acid mine drainage, and an unpleasant odor problem due to excess sulfur in the water.

In this study, values of cottages on two lakes (Piedmont Lake and Leesville Lake) are examined. The cottages on both lakes are used for summer vacation homes rather than permanent residences. Piedmont Lake has been impacted by abandoned surface coal mines and U.S. Geological Survey mapping in 1976 showed that one-third of this drainage basin had been mined; two-thirds of which had been reclaimed. The main impacts are concentrated at one end of the lake and these impacts were present before the construction of dams and cottages occurred. Leesville Lake has not been impacted by surface coal mining. U.S. Geological Survey mapping in 1978 showed that less than $0.5 \%$ of this drainage basin has been impacted.

The two lakes are close in geographical area and have homogeneous features. Both are used for boating, camping, and vacation home sites. Both have the same restrictions on horsepower for boating ( 10 horsepower maximum). Individuals have privately built and owned homes on lots leased from the Muskingum Water Conservancy District. They are 14 year leases with automatic renewal. Certain specifications on the homes are required under the leases. For example, guidelines regarding color, landscape, and roof style are specified in the lease. Plans must be submitted to Muskingum Water Conservancy District for any new cottages or any major renovations.

A degree of surface mining impact was present when the homes were built and purchased and so there arises a policy argument over who is the party responsible for reclamation. The parties that caused the impact, the mining companies, are frequently no longer in existence. Generally, when these companies abandon a stripmine, the company goes defunct to avoid reclamation costs or because of inability to pay. Therefore, abandoned mines are usually reclaimed with money from a mining tax, and essentially the whole industry becomes the responsible party. 
The degree of impact on Piedmont Lake has increased over time. The property owners were probably aware of some impact upon purchase. Even if they were not aware, they may have paid less because others were aware of the impact. It can be argued that they stand to gain a benefit if reclamation were done. If transactions costs are low and property rights are welldefined, it is most efficient for all parties involved to get together and solve the problem. However, with the number of property owners in this case and the nature of the responsible parties, the efficient solution is not likely to be reached.

In addition to the problem of defining a responsible party, the parties who will benefit also is not straightforward. The people who benefit (the "gainers") are not limited to property owners. Those who use the lake for recreation will gain, as well as merchants in the area who will gain from more visitors. Also, those who drive through the area will gain due to a better aesthetic view. If FGD can be used rather than landfilled, this provides an additional benefit beyond that of reclamation itself due to the avoided disposal costs of the FGD. Therefore, others that stand to gain are those who will avoid disamenities from additional landfilling.

The sum of this argument is that the solution involving the affected parties is an unlikely answer to solving the unwanted impacts of surface mining. If potential social benefits to all gainers, along with the added benefits of using FGD by-products are large enough, this may result in more reclamation using FGD being an efficient solution to impacts caused by surface coal mining.

\subsubsection{Methodology}

An early example of the use of property values to estimate willingness to pay for environmental quality improvements is the Ridker and Henning (1967) study. Their work was aimed at the measurement of the value of clean air for neighborhoods in St. Louis. They used a regression of a hedonic equation to estimate marginal implicit prices and from these prices determined willingness to pay for air quality improvements.

Freeman (1971) contends that willingness to pay can be estimated from marginal implicit prices for marginal changes, however this is inappropriate for non-marginal changes. Rosen (1974) developed a two stage procedure to estimate demand for a characteristic. Described in a general way, the first stage is the estimation of marginal implicit prices, and the second stage incorporates other variables to estimate demand. This analysis will focus on the first stage of this hedonic price analysis procedure. 
A basic concept of the hedonic method is that the value of an asset (in this case a home) is a function of the set of its characteristics. This can be expressed as:

Equation 6-9

$$
P=f(S, C, Q)
$$

where $P=$ price of value of the house, $S=$ structural characteristics, $C=$ community characteristics, and $Q=$ environmental quality characteristics. This is called the hedonic price function. Each of these variables represent the various contributors toward the value of the house. The objective of this study was to determine $Q$, the environmental quality characteristic.

The hedonic pricing function consists of property value as the dependent variable and all of the individual characteristics as independent variables. Using this function, the change in property value with a change in an environmental characteristic holding all other characteristics constant can be measured by taking the derivative with respect to the environmental quality characteristic.

When developing a hedonic model there are several things that must first be considered. One of these is the functional form that is to be used. Various forms may be tried including, linear, $\log$-linear, log-log, quadratic, etc. Anderson and Bishop (1986) state that although economic theory offers very little information dealing with choosing functional form, theory does tell us that the linear form can probably be rejected. This form assumes that the implicit price is constant regardless of the amount of the attribute. This assumption can be rejected because we know that the current level of an environmental quality attribute will influence the willingness to pay for more of the attribute. If an individual already has a great deal of an attribute, he/she is probably not willing to pay much for more, while if an individual has very little of an attribute, he/she will likely be willing to pay more for an additional unit. Therefore, it follows that the linear specification can be eliminated from the choices.

It seems most reasonable to choose the form that features the appropriate attributes of the variables such as diminishing marginal utility. In this case, the double-log form was used and it is the most logical form to use because of decreasing marginal utility of the variables.

The most appropriate way to specify property value is not always easily discerned. The most readily available data is the tax assessed value of a property which is available from any county auditors' office. This is usually measured by examining the structural characteristics of the house, as well as observing recent sales of similar, close-by houses. Both are used to predict 
what the market value of the home would be. It is commonly agreed that the use of assessed values causes a potential problem. Assessors in different counties may use different methods to value a home. Also there may be amenities or disamenities that are difficult for assessors to value, such as a particular views from a house, and may be left out.

The logical solution would be to use sale values for the dependent variable. The problem is in data availability. In a small sample, it is sometimes difficult to find a large enough sample size because each home will not sell each year. Some researchers have solved this problem by developing predictive models to estimate sale values based on assessed value, and other locational specific characteristics.

A predictive model was developed for this study. A detailed description of this model will not be presented here due to length considerations, but may be found in Friedman (1996). It was found that there was a significant difference in the regression results when assessed values were used versus when predicted sale values (based on a subset of actual values) were used for the dependent variable. It was assumed that the predicted sale values were more accurate and were used in the final model specification.

The hedonic price function for the model developed for this study can be expressed as:

Equation 6-10

$$
\begin{aligned}
\ln (\text { price }) & =a+B_{1} \ln (\text { lot })+B_{2} \ln (\text { sqft })+B_{3} \text { age }+B_{4} \text { elev }+B_{5} \text { baths } \\
+ & B_{6} \text { firepl }+B_{7} \text { base }+B_{8} \text { porch }+B_{9} \text { rooms }+B_{10} \text { \#homes } \\
& +B_{11} \text { lakev }+B_{12} \ln \text { (distlk) }+B_{13} \ln (\text { unim })+B_{14} 1 / \ln (d)+\varepsilon
\end{aligned}
$$

where,

$\ln$ (price) $=$ predicted sale value of the cottages porch $=1$ if porch, otherwise 0

$a=$ intercept term

rooms $=$ number of rooms

$\ln (l o t)=$ size of lot in square feet

$\ln ($ sqf $t)=$ square footage of the cottage

\#homes = number of homes in the.

age $=$ age of the cottage in years

development

elev $=$ elevation in feet above lake

lakev $=1$ if view is of lake, otherwise 0

baths $=$ number of bathrooms

$\ln ($ distlk) $=$ distance to the lake in feet

firepl $=1$ if fireplace, otherwise 0

$\ln ($ unim $)=$ distance to unimproved highway

$\ln (\mathrm{d})=$ distance to impacted lake area in feet

base $=1$ if basement, otherwise 0

$\varepsilon=$ stochastic disturbance term

An explanation of variables included in the model is required. The "\#homes" variable refers to the number of homes in the development. The variable named "lakev" refers to whether the 
cottage faces the lake or an inlet. An environmental quality variable is not explicitly noted and its input into the model will be clarified in the next paragraph. Due to the nature of the market for summer homes versus permanent residences, some of the community characteristics which are generally found in hedonic analyses are not relevant here. Some of these, for example crime, are assumed to be consistent between the two lakes. Demographic variables such as quality of schools, race, and education while relevant in a normal housing market, are assumed to be unimportant factors regarding decisions to buy a summer home.

Distance to the impacted part of the lake, $\ln (\mathrm{d})$, is the environmental quality variable in this model. This distance variable is used instead of paired comparisons between the impacted and unimpacted lakes. This is because the underlying hypothesis is that there is a difference in house values that is due to the impact and this is not only a difference between the two lakes but also within the impacted lake, according to the amount of distance between the cottages and the impact.

In order to account for both differences in homes between the two lakes and differences in homes within the impacted lake, a dummy variable was set up. This variable was an inverse distance variable which indicated that as the distance from the impacted part of the lake increases, its effect on property value will decrease until a value of zero is reached. This variable, $\ln (d)$, is therefore used in the equation as the environmental quality variable. The values for all of the Leesville Lake observations will be assigned a value of zero since there was no surface mining activity within its drainage area.

Data on prices and structural characteristics were collected from the county auditors offices and from the Muskingum Watershed Conservancy District offices. Data on distances was gathered from maps.

\subsubsection{Results of Applying the Social Benefits Model for Strip Mine Reclamation Using FGD}

The model was estimated using the predicted sale values as the dependent variable and the results are presented in Table 56. All of the coefficients had the expected signs except for distance to the lake. It was hypothesized that this would be negatively related to price because people generally prefer to be closer to the lake. However, it could be that closer properties have more flooding problems and/or homes further from the lake may have better views due to higher elevation. Elevation was included in the model but was not found to be significant. 
Table 56. Regression results of the hedonic pricing model applied to data from Leesville Lake and Piedmont Lake $\left(n=104 ; R^{2}=0.513\right.$; adjusted $R^{2}=0.435$; $\mathbf{F}=\mathbf{5 . 2 7}$ ).

\begin{tabular}{lccc}
\hline Variable & Coefficient & T-statistic & $\begin{array}{c}\text { Probability of } \\
\text { Committing a } \\
\text { Type I error }\end{array}$ \\
\hline Lot size & 0.0097 & 0.1312 & 0.448 \\
Square feet & 0.2199 & 4.0581 & 0.000054 \\
Elevation & -0.00035 & -0.4016 & 0.344 \\
Age & -0.00042 & -0.2483 & .402 \\
Distance to lake & 0.0497 & 1.5914 & 0.058 \\
Number of homes & 0.0021 & 0.9043 & 0.184 \\
Lake view & 0.0872 & 1.6240 & 0.054 \\
Number of rooms & 0.0541 & 3.4232 & 0.00047 \\
Number of baths & 0.0988 & 1.4777 & 0.072 \\
Fireplace & 0.0278 & 0.7087 & 0.240 \\
Basement & 0.0655 & 1.8696 & 0.032 \\
Porch & 0.0740 & 1.7550 & 0.041 \\
Distance unimproved & 0.0001 & 0.0037 & 0.499 \\
Distance to impact & -0.18297 & -1.700 & 0.046 \\
\hline \hline
\end{tabular}


These unexpected results may be due to the limitations of the data available. Distance to the lake and elevation alone, obviously, did not explain all of the differences in the quality of the lots. To provide a better estimate of property values based on elevation and distance to the lake, a more careful, individual assessment of the lots would have to be done.

The variable of greatest importance in affecting property values was the distance to the impact. As was hypothesized, the inverse distance is negatively related to price, i.e as the distance increased between the property and the impacted area, the value of the property increases.

To derive the marginal implicit price for the environmental quality variable, the first derivative of $\ln (\mathrm{P})$ was computed.

Equation 6-11

$$
\left.d \ln (P) / d \ln (d)=-a_{14}(\ln (d))^{-2}=-a_{14}(1 / \ln (d))^{2}\right)
$$

$\mathrm{dln} P / \mathrm{dln}(\mathrm{d})$ is by definition the elasticitiy. Therefore

Equation 6-12

$$
d \ln (P) / d(\ln (d)=d P / d d * d / P
$$

Rearranging allows calculation of the marginal implicit for distance to the impact.

Equation 6-13

$$
\left.d P / d d=-P / d * a_{14}(1 / \ln (d))^{2}\right)
$$

Marginal implicit prices were calculated for each observation on the impacted lake. The average marginal implicit price was 9.48 . The average distance to the impact was $7,840 \mathrm{~m}(25,800 \mathrm{ft})$. Keeping in mind that distance to the impact is measured in $300 \mathrm{~m}(1,000 \mathrm{ft})$ units, the average marginal implicit price of 9.48 can be interpreted as a $\$ 9.48$ increase in property value per year for each $300 \mathrm{~m}$ ( $1000 \mathrm{ft}$ ) increase in distance from the impact for cottages which are $7,840 \mathrm{~m}$ $(25,800 \mathrm{ft})$ away.

The marginal implicit price will be different for each observation. Each house has a different price and is a different distance from the impact. The diminishing marginal returns concept is that the incremental increases in distance from impact for homes close to the impact have a larger effect on price, than increases for homes further away. Using an average yearly house price of $\$ 3519.00$, marginal implicit prices were calculated for the average house at various distances from the impact (Table 57). 
Table 57. Marginal implicit prices as affected by distance in meters from the impacted area of the lake.

\begin{tabular}{lc}
\hline \hline Distance to impact & $\begin{array}{c}\text { Marginal } \\
\text { implicitprice }\end{array}$ \\
\hline $\begin{array}{l}5 \text { units } \\
(1,500 \mathrm{~m} ; 5,000 \mathrm{ft})\end{array}$ & $\$ 49.71$ \\
10 units & \\
$(3,000 \mathrm{~m} ; 10,000 \mathrm{ft})$ & $\$ 12.14$ \\
$\begin{array}{l}30 \text { units } \\
(9,000 \mathrm{~m} ; 30,000 \mathrm{ft})\end{array}$ & $\$ 1.86$ \\
$\begin{array}{l}50 \text { units } \\
(15,000 \mathrm{~m} ; 50,000 \mathrm{ft})\end{array}$ & $\$ 0.84$ \\
\hline \hline
\end{tabular}

These implicit prices can be interpreted as the change in property value with a one unit ( $300 \mathrm{~m}$; $1,000 \mathrm{ft}$ ) change in distance to the impact. As Table 57 illustrates, the marginal implicit price is different for cottages which are at different distances. These marginal implicit prices represent the average house in terms of value. For homes of different value the marginal implicit price will be different.

An estimate of the aggregate benefits to property owners of any future reclamation of the mines above Piedmont Lake was made. One assumption that was made is that reclamation results in complete remediation of surface coal mine impacts on the lake.

The aggregate benefits will be estimated by integrating under the hedonic price function, i.e. summing all of the individual effects. There are four housing developments that are located at different distances from the impact. The total benefit of reclamation to homeowners was estimated by summing the marginal implicit prices for each incremental increase in distance until the effect is negligible. This is done for the population of homes in each housing development. Again, the total population can be used because it is assumed that the sample is 
random. Therefore, the estimated marginal implicit prices are appropriate for all of the homes. For example, homes in development $A$ are $1,500 \mathrm{~m}(5,000 \mathrm{ft})$ from the impact. If instead a home in this development were $1,800 \mathrm{~m}(6,000 \mathrm{ft})$ from the impact, the cottage would increase in value by $\$ 50.59$. This is calculated using average annual rental equivalent for the cottages in the development. Then if the cottage were moved even further out to $2,100 \mathrm{~m}(7,000 \mathrm{ft})$, it would increase in value by $\$ 34.01$. These increments are summed for all marginal implicit prices that are greater than $\$ 1.00$. The assumption necessary here is that an observation that is far enough away from the impact that the marginal implicit price is less than $\$ 1.00$, then there is further impact from surface mining. Therefore, this is equivalent to what would be if reclamation were done.

Developments B, C, and D are 8,360 m (27,500 ft), 9,270 (30,500 ft), and 10,000 m (33,000 $\mathrm{ft}$ ) from the impact, respectively. For each of these developments, the process of summing the marginal implicit prices for increments until the effect is negligible has been done. For each development, the point at which increases in distance is negligible is between $13,400 \mathrm{~m}$ $(44,000 \mathrm{ft})$ and $14,100 \mathrm{~m}(46,500 \mathrm{ft})$.

Table 58 shows the estimation of aggregate benefits. The summation of marginal implicit prices represents the amount that the average house in the development would increase in annual rental equivalent if it were moved far enough so that the surface coal mining effect were negligible. This can also be interpreted as the amount that the average house in the development would increase in annual rental equivalent if complete reclamation were done. The product of this and the number of homes in the development is the total increase in annual rental equivalent.

The total increases in annual rental equivalent was $\$ 5,852.71$. In contrast to the annual rental equivalent values, the increase in house values due to reclamation can be determined converting the rental equivalent values to the present value house values. This was done based on the relationship between rental values and housing values given as:

Equation 6-14 housing values $=$ rental values $* 125$

Since the increase in annual rental equivalent due to reclamation was estimated to be $\$ 5852.71$, the total increase in house value is given as: 
Table 58. Estimation of Aggregate Benefits of reclamation of surface coal mines in rent equivalents determined from the hedonic pricing model.

\begin{tabular}{lccc}
\hline \hline Development & $\begin{array}{c}\text { Marginal implicit } \\
\text { price } \\
\text { (for each home) }\end{array}$ & $\begin{array}{c}\text { Number of homes in } \\
\text { development }\end{array}$ & $\begin{array}{c}\text { Total increase in } \\
\text { annual rent equivalent }\end{array}$ \\
\hline A & 263.61 & 17 & $\$ 4,481.37$ \\
B & 25.13 & 29 & $\$ 728.77$ \\
C & 23.12 & 13 & $\$ 300.56$ \\
D & 14.87 & 23 & $\$ 342.01$ \\
& & & Total $=\$ 5,852.71$ \\
\hline
\end{tabular}

In addition to this gain to property owners, local tax revenue will potentially increase due to reclamation. When property values increase by a total of $\$ 73,158.88$ and the average property tax rate is 6 percent, the increase in annual local tax revenue is calculated as follows:

Equation 6-16

$\$ 73,158.88 * 0.06=\$ 4,389.53$.

This means that with reclamation resulting in higher property values, local tax revenue will increase by an estimated $\$ 4389.53$. When the increase in local tax revenue $(\$ 4,389.53)$ is added to the total increase in house values $(\$ 73,158.88)$, the total aggregate benefit equals $\$ 77,548.41$.

Two studies were examined to determine upper and lower bounds for this study's estimates. Driscoll et al.(1994) found in a study of real estate in flood plains that a relationship of willingness to pay was only 0.873 of the value estimated from the hedonic pricing model. Hite (1995) found that a comparable measure using willingness to pay for distance from a landfill was 0.61 . It can therefore be assumed that our estimate of benefits is overstated and most likely falls within the bounds of $\$ 47,304.53$ and $\$ 67,699.76$ which is derived from multiplying $\$ 77,548.41$ by either 0.61 or 0.873 . 
According to U.S. Geological Survey mapping, one-third of the drainage basin that contains Piedmont lake has been surface mined for coal. One-third of this mined area is yet unreclaimed. The drainage basin is $47,170 \mathrm{ha}(116,480 \mathrm{acres})$ in total area. Therefore, there are 5,240 ha $(12,942$ acres $)$ of surface coal mines that still need to be reclaimed.

Initial studies estimate that approximately $450 \mathrm{Mg} / \mathrm{ha}$ ( 200 tons/acre) of FGD can be used in the reclamation of surface mines (Ohio State University, Department of Civil Engineering). This estimate maximizes FGD use rather than minimizing it, because these types of areas require much higher rates than would be recommended for agricultural soils.

Assuming $450 \mathrm{Mg} / \mathrm{ha}$ (200 tons/acre) are used to reclaim all 5,240 ha (12,942 acres), this totals $2,588,400$ tons of FGD. To estimate lakeside property value benefit per ton of FGD, the aggregate benefit estimates are divided by total tons.

$$
\begin{aligned}
& (\$ 47,304.53) / 2,588,400 \text { tons }=\$ 0.018 \\
& (\$ 67,699.76) / 2,588,400 \text { tons }=\$ 0.026
\end{aligned}
$$

Therefore, the total benefit per Mg of FGD is between $\$ 0.016$ and $\$ 0.024$ ( $\$ 0.018$ and $\$ 0.026$ per ton of FGD). It should be noted that this only includes the benefits to property owners and not other lake users or property owners near landfills who avoid property value loss due to less landfilling of FGD. In addition, it should be noted that this does not include reclamation failures that may be contributing to the problems at Piedmont lake. A substantial amount of FGD could be used to fix these past reclamations, but data for this is not available.

\subsubsection{Policy Implications and Conclusions}

The results show that the impact of the abandoned surface coal mines has a negative effect on property values for cottage owners adjacent to the lake. The value of the homes increase as they get further from the impact, holding everything else constant. In addition to this, the aggregate benefit of reclamation to property owners on the lake was estimated to be between $\$ 47,304.53$ and $\$ 67,699.76$. This can be interpreted as the total increase in property value that would occur if complete reclamation were done.

Property owners are not the only ones who would benefits from surface mine reclamation. There are also benefits to recreational users of the lake. If more stripmines were to be reclaimed 
because of the availability of FGD by-products, these benefits (attributable to reclamation with FGD) would all be realized.

The aggregate benefits are most likely less than the cost of reclamation because reclamations can cost hundreds of thousands of dollars. However, when this and the other benefits are added to the avoided costs of disposing of FGD by-products (Hite, 1995), the aggregate benefits could potentially outweigh the costs. These considerations are taken into account in the model development of the next section.

\subsection{The Linear Optimization Model}

\subsubsection{Background}

Flue gas desulfurization by-product has characteristics that make it attractive for highway construction and repair. In particular, soils in many areas of the state are susceptible to slippage, resulting in repeated highway repairs. These are not just costly in terms of construction but also because traffic through these areas can be delayed significantly and detours from interstates onto local highways results in local infrastructure damage. Because FGD by product has cement-like properties, it has been tested for use in road repairs in various parts of the state of Ohio where soils are unstable (see Chapter 4 of this report). In addition, the FGD by-product is also quite appropriate for use in repairs even where soils are stable to replace the borrow (soil) traditionally used.

Limited experience has shown that transportation of FGD by-product is similar to that of other borrow or construction materials. Only slight modification of existing equipment is necessary to transport FGD by-product obtained from a source (power plant) and apply it at a destination (road, coal mine or landfill) for highway repair and mine reclamation. Under these assumptions, FGD is expected to be back-hauled from the power plant to various locations throughout the state by trucks. Once it has reached the highway repair or mine site it is expected that conventional techniques will be used to apply the FGD in its final use.

Coal surface mine operations are required by federal statute to reclaim lands which have been mined. During the reclamation phase, lime and borrow materials are used to return the mined spoils back to a pH level conducive to plant growth, and to recontour disturbed landscapes. It has also been demonstrated at an abandoned surface mine test site (the Fleming site in northeastern Ohio - see Section 3 of this report) that FGD by-product materials can be used for 
reclamation of these sites. The estimated quantity of FGD material required to meet surface mine reclamation work was derived from data reporting tons of surface mine coal sold in each Ohio county. Using this data, the number of acres displaced by surface coal mining in a given year was estimated. Based on FGD application rates of $110 \mathrm{Mg} / \mathrm{ha}$ (250 tons/acre), an estimate of the total quantity of FGD by-product that could be used was determined.

Application of FGD to the areas of abandoned surface coal mined areas in Ohio using FGD has several potential benefits in that it can improve several problems related to coal mining. First, it can correct the acidity of the soil that deters growth of ground cover and results in serious sedimentation problems that causes flooding with ensuing property damage and disruption of traffic in eastern Ohio. Second, it can help stabilize high walls, subsidence and mine shafts left from abandoned mines that pose great risk to personal safety and property. Finally, it can prevent the problem of acid mine water run-off that causes damages to streams and lakes. By explicitly monetizing these impacts, the major benefits for use of FGD in reclamation of abandoned mines can be demonstrated.

The final end use alternative identified is landfilling. It is expected that FGD by-product will be landfilled in the event that the available quantity of the product is larger than its economical use in highway construction and/or surface coal mine reclamation. Landfills dedicated to FGD byproduct disposal are quite large and are in relatively close proximity to the power plants or sources of the FGD by products.

\subsubsection{Model Development}

An annualized least cost transportation model was analyzed under three different scenarios, all on a per annum basis. The baseline uses four source nodes (i.e. power plants) associated with the production of FGD by-product materials. These plants produce FGD by-product that is called "wet FGD". This wet FGD can be used in many of the same applications that were developed for dry FGD by-product materials (Stehouwer et al., 1995a; 1998). Flue gas desulfurization by-product use for highway construction and repair in all 88 Ohio counties, as a soil amendment in 21 Ohio counties where there is coal surface mine activity, and at four landfill sites located in proximity of the power plants constitute the demand nodes. This baseline model assumes that no social costs are associated with landfilling and no benefits are associated with mine reclamation. A second model adds the social cost of landfilling to the landfill tipping fee and the benefits of mine reclamation are subtracted from the application costs. In the third model, it was assumed that $10 \%$ of the 53,330 ha $(82,290$ acres $)$ of 
abandoned mine lands in eastern Ohio will be reclaimed each year, creating additional demand nodes. In this scenario, the social benefit were also subtracted from the application cost.

To formulate this model mathematically, the following terms are defined.

$a_{i}=$ the number of tons of FGD material available at the power plant or source $i$, $\mathrm{i}=1,2, \ldots, \mathrm{m}$;

$b_{j}=$ maximum number of tons of by product required at each destination or alternative use (e.g. for agricultural lime, mineland reclamation, or landfill), $j=1,2, \ldots n$;

$c_{i j}=$ unit transportation and application cost from each source $i$ to each destination $j$, $(i$ $=1,2, \ldots, m ; j=1,2, \ldots, n)$.

The problem then becomes determining the amount of FGD material shipped to each of these alternative end uses, given that the cost of distribution and application of the by-product is known or can be estimated. Thus, the decision variable, $\mathrm{x}_{\mathrm{ij}}$, equals the number of tons of FGD shipped from each source "i" to each destination " $j$ " annually given some cost per unit shipped.

The transportation model estimates are made as follows:

Equation 6-17

Equation 6-18

Equation 6-19

Equation 6-20
Minimize cost $=c_{i j} x_{i j}$

$x_{i j} \leq a_{i}(i=1,2, \ldots, m)$

$x_{i j}=b_{j}(j=1,2, \ldots, n)$

$x_{i j} \geq 0 \quad(i=1,2, \ldots, m ; j=1,2, \ldots, n)$.

Equation 6-17 represents the minimization of total distribution costs, assuming a linear cost structure for shipping, processing, and application of the FGD by-product material. Equation 6-18 shows that the quantity of FGD shipped from each source "i" to each alternative end use destination " $\mathrm{j}$ " must be less than or equal to the quantity of by product material available at source $a_{i}$. Equation 6-19 states that the quantity of shipped from each source " $i$ " to each destination “ $\mathrm{j}$ ", must be equal to the maximum quantity of by product demanded at that destination. Finally, Equation 6-20 indicates that the quantity of FGD shipped from each source "I" to each destination " $\mathrm{j}$ " can not be less than zero.

In all three models, estimates pertaining to the quantity of FGD by-product demanded at various demand nodes for the highway construction/repair end use alternative have been adjusted for a 10 percent rate of adoption. It is expected that the FGD by-product will not be appropriate for all highway repairs where borrow is used. Thus a conservative rate of adoption 
is assumed. However, it is important to note that the model can be rerun at various levels of adoption.

Linear distances from the power plant or source of FGD by product to the center of each county were estimated. Once these distances were determined, costs associated with moving the specified distance were estimated. It is expected that FGD by-product will be transported in much the same manner as current highway repair materials. Thus, an estimate of $\$ 0.09$ per $\mathrm{Mg}$ per mile ( $\$ 0.10$ per ton per mile) was used. In addition to moving the FGD from the source to the destination, an application expense is incurred. Again, the application of by-product is expected to be similar to that of borrow materials which has an estimated application charge of $\$ 3.18 / \mathrm{Mg}$ (\$3.50/ton). This includes equipment costs for earthmoving equipment to manipulate the by-product. Therefore, transportation costs were calculated at $\$ 0.09$ per $\mathrm{Mg}$ per mile ( $\$ 0.10$ per ton per mile), and an additional $\$ 3.18 / \mathrm{Mg}$ (\$3.50/ton)were added to each for expected application costs.

Transportation of FGD by-product to coal surface mine reclamation sites is also expected to cost $\$ 0.09$ per $\mathrm{Mg}$ per mile ( $\$ 0.10$ per ton per mile). Application of the by-product is expected to be at significantly higher levels, potentially $560 \mathrm{Mg} / \mathrm{ha}$ ( $250 \mathrm{tons} / \mathrm{acre})$, than application rates associated with agricultural use. The equipment used in applying the FGD by-product (e.g. a bulldozer or equivalent type of reclamation machinery) is assumed to be similar to that used for road repairs so that application costs would not vary significantly. Thus the estimated application cost was maintained at $\$ 3.18 \mathrm{Mg}(\$ 3.50 /$ ton $)$.

Cost estimates for landfilling were obtained from interviews with representatives of electric utilities. All landfilling activities are regulated by the Ohio Environmental Protection Agency and must follow stringent regulations. The regulation costs are borne almost entirely by the utility. Electric power plants have estimated that it would cost about $\$ 24.50 / \mathrm{kg}(\$ 27.00 / \mathrm{ton})$ of material to landfill FGD by-product and meet current guidelines.

Social cost adjustments were made for the tipping fees for each of the landfills as well as for the use of FGD by-product in mine reclamation. Based on a cost transfer estimation procedure, the additions to landfill tipping were as follows: Conesville, $\$ 0.28 / \mathrm{kg}(\$ 0.31 / \mathrm{Mg})$; Gavin, $\$ 1.15 / \mathrm{Mg}$ (\$1.27/ton); McCracken, $\$ 6.47 / \mathrm{Mg}$ (\$7.13/ton); and Zimmer, $\$ 1.28 / \mathrm{Mg}$ (\$1.42/ton). These reflect impacts on real estate values in the areas around landfills and are greatly affected by landfill size as well as population densities and property values near landfills. A social benefit for mine reclamation was derived from real estate values in eastern 
Ohio and was estimated to be approximately $\$ 0.02 / \mathrm{Mg}(\$ 0.02 /$ ton) of FGD by-product used in reclamation.

\subsubsection{Linear Optimization Model Results}

A summary of shipments by source and by disposal option is shown in Table 59. In the baseline scenario with no abandoned mines reclaimed, 16.7\% of FGD produced would be used in highway construction and repair and $46.6 \%$ would be used in mine reclamation. However, the amount of FGD produced greatly exceeds anticipated demand and $36.61 \%$ of the byproduct will be landfilled. Furthermore, the distribution of FGD end uses remains unchanged whether or not the social costs of landfills are added to the tipping fee or not.

Under Scenario 2, the assumption was made that $10 \%$ of the abandoned coal mine area in Ohio would be reclaimed per year for a 10 year period. Under this scenario, no FGD by-product would be landfilled (Table 59). This is not a realistic assumption given that the rate of reclamation of abandoned mines has greatly decreased in recent years (Deng et al. 1992). In addition, once the assumed 10 year period ends there will still be a need to landfill. The rate of active mining is in decline as well so that even assumptions based on active mine reclamation needs may be optimistic. Only if demand for eastern coal were to rise would there be increased demand for FGD by active mines, which means that more power plants would have to adopt scrubber technology and would increase FGD supply.

Shadow prices for FGD by product are calculated as the difference between landfilling (nonbinding constraint) and highway use or coal surface mine reclamation options (both binding constraints). It is expected that as the distance from the power plant increases, the cost to transport the FGD by-product also increases, resulting in lower imputed value or shadow price for binding end use options farther from the power plant. That is, the difference between landfilling and shipping FGD by-product greater distances would be smaller. Thus, counties located farther from FGD sources would have lower shadow prices or lower cost savings to the utility companies than would land application sites closer in proximity to the power plant. Figure 98 shows the shadow price associated with the distribution of FGD by-product to each Ohio county.

Another interpretation of these shadow prices is that it represents the amount the power plant would be willing to pay for the disposal of an additional ton of FGD by-product for each end use alternative. For example, Figure 98 shows Williams county in the first quartile or having a shadow price between $\$ 4.48$ to $\$ 10.30$ per $\mathrm{Mg}$ ( $\$ 4.93$ to $\$ 11.34$ per ton). The calculated 
Table 59. Summary of shipment estimates obtained from the linear optimization model (values in parentheses are percentages).

\begin{tabular}{|c|c|c|c|c|c|}
\hline \multirow[b]{2}{*}{ Identified use } & \multicolumn{4}{|c|}{ Source of FGD by-product } & \multirow[b]{2}{*}{ Total } \\
\hline & Conesville & Gavin & McCracken & Zimmer & \\
\hline & & -2 & --Tons of FG & D - - & ------.-- \\
\hline \multicolumn{6}{|c|}{ Scenario 1: No abandoned mines reclaimed (baseline scenario) } \\
\hline Total Highway & $\begin{array}{l}136,085 a \\
(20.6)\end{array}$ & $\begin{array}{l}285,015 \\
(16.5)\end{array}$ & $\begin{array}{l}15,590 \\
(100)\end{array}$ & $\begin{array}{l}223,455 \\
(14.6)\end{array}$ & $\begin{array}{l}660,187 \\
(16.8)\end{array}$ \\
\hline Total Mines & $\begin{array}{l}525,645 \\
(79.4)\end{array}$ & $\begin{array}{l}1,313,545 \\
(75.8)\end{array}$ & $\begin{array}{l}0 \\
(0)\end{array}$ & $\begin{array}{l}0 \\
(0)\end{array}$ & $\begin{array}{l}9,189 \\
(46.6)\end{array}$ \\
\hline Total Landfill & $\begin{array}{l}0 \\
(0)\end{array}$ & $\begin{array}{l}134,360 \\
(7.7)\end{array}$ & $\begin{array}{l}0 \\
(0)\end{array}$ & $\begin{array}{l}1,309,300 \\
(85.4)\end{array}$ & $\begin{array}{l}1,443,660 \\
(36.6)\end{array}$ \\
\hline Total & $\begin{array}{l}661,730 \\
(100)\end{array}$ & $\begin{array}{l}1,732,920 \\
(100)\end{array}$ & $\begin{array}{l}15,590 \\
(100)\end{array}$ & $\begin{array}{l}1,532,755 \\
(100)\end{array}$ & $\begin{array}{l}3,942,995 \\
(100)\end{array}$ \\
\hline \multicolumn{6}{|c|}{ Scenario 2: 10\% per annum abandoned mines reclaimed } \\
\hline Total Highway & $\begin{array}{l}34,748 \\
(5.3)\end{array}$ & $\begin{array}{l}108,464 \\
(6.3)\end{array}$ & $\begin{array}{l}15,590 \\
(100)\end{array}$ & $\begin{array}{l}384,601 \\
(25.1)\end{array}$ & $\begin{array}{l}543,403 \\
(13.8)\end{array}$ \\
\hline \multicolumn{6}{|l|}{ Total Mines: } \\
\hline $\begin{array}{l}\text { Ongoing } \\
\text { Abandoned }\end{array}$ & $\begin{array}{l}440,448 \\
(66.6) \\
186,534 \\
(28.2)\end{array}$ & $\begin{array}{l}516,398 \\
(29.8) \\
1,108,058 \\
(63.9)\end{array}$ & $\begin{array}{l}0 \\
(0) \\
0 \\
(0)\end{array}$ & $\begin{array}{l}620,468 \\
(40.5) \\
527,686 \\
(34.4)\end{array}$ & $\begin{array}{l}1,577,310 \\
(40.0) \\
1,822,274 \\
(46.2)\end{array}$ \\
\hline Total Landfill & $\begin{array}{l}0 \\
(0)\end{array}$ & $\begin{array}{l}0 \\
(0)\end{array}$ & $\begin{array}{l}0 \\
(0)\end{array}$ & $\begin{array}{l}0 \\
(0)\end{array}$ & $\begin{array}{l}0 \\
(0)\end{array}$ \\
\hline Total & $\begin{array}{l}661,730 \\
(100)\end{array}$ & $\begin{array}{l}1,732,920 \\
(100)\end{array}$ & $\begin{array}{l}15,590 \\
(100)\end{array}$ & $\begin{array}{l}1,532,755 \\
(100)\end{array}$ & $\begin{array}{l}3,942,995 \\
(100)\end{array}$ \\
\hline
\end{tabular}

aTo convert tons to $\mathrm{Mg}$, multiply by 0.907 . 


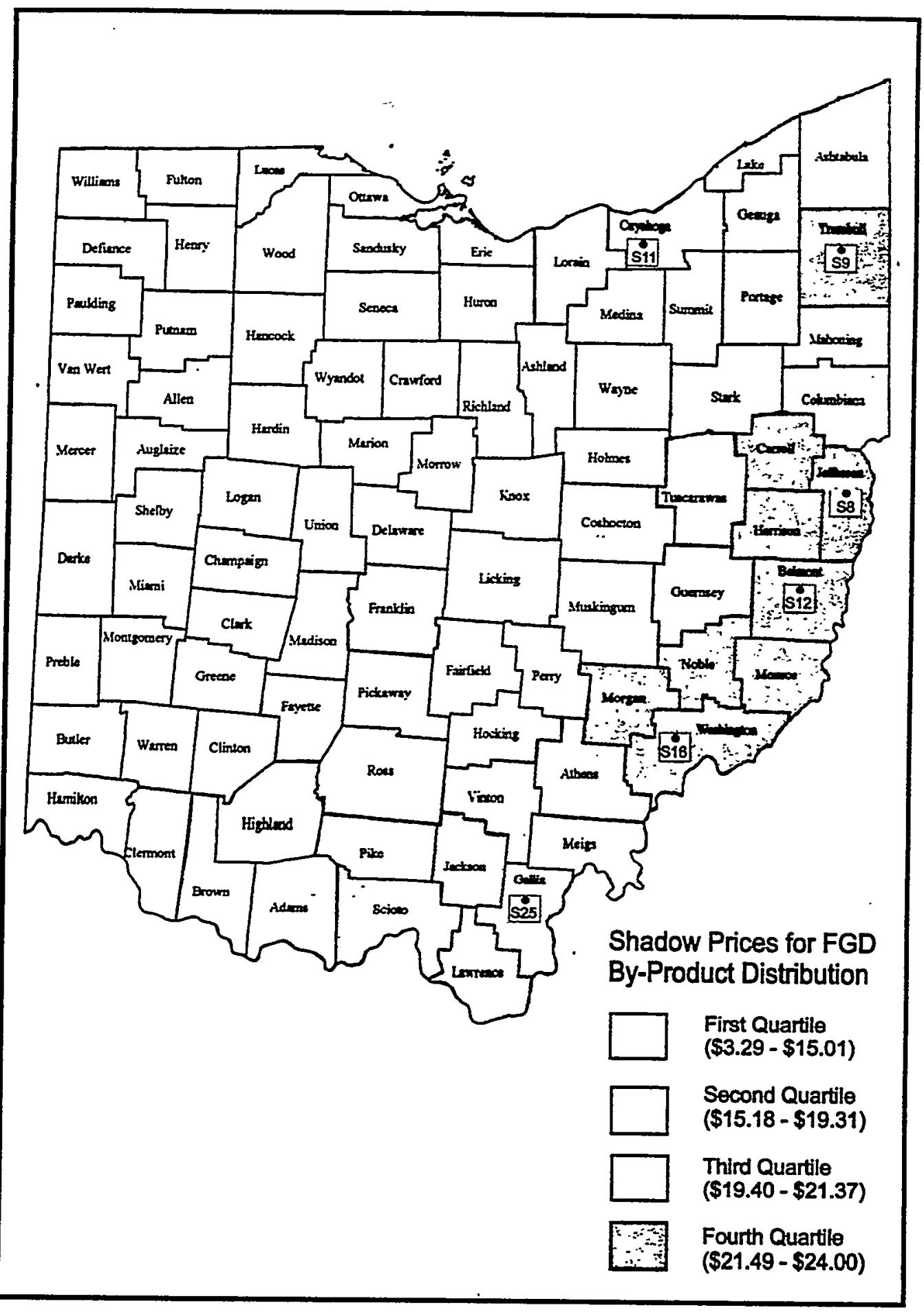

Figure 98. Marginal implicit prices associated with beneficial use of FGD by-product. 
shadow price for Williams county is $\$ 7.15 / \mathrm{Mg}$ ( $\$ 7.86 /$ ton), suggesting the power plant would be willing to pay a user in Williams County up to this amount to use an additional $\mathrm{Mg}$ (ton) of FGD by-product as opposed to landfilling it at a cost of $\$ 24.94 / \mathrm{Mg}(\$ 27.50 /$ ton).

The costs of landfilling (both the amount of the tipping fee and the social cost) are important determinants of the FGD by-products optimal use. The tipping fee used to create scenarios 1 and 2 (Table 59) was assumed to be $\$ 24.94 / \mathrm{Mg}$ ( $\$ 27.50 /$ ton) and at this tipping fee, use of the by-product for road repair and coal surface mine reclamation dominates landfilling. As much FGD by-product as possible is allocated to these construction and reclamation uses. The implication is that it costs less for FGD by-product to be transported to the farthest corners of the state to be used in road repair or mine reclamation than to be landfilled. When social costs are added to the tipping fee, the financial incentive to find an alternative to landfilling is even more pronounced. The expectation is that landfilling costs have an important impact on alternative uses. If landfilling costs were lower, more FGD by-product would be landfilled and less would be used in road repair and mine reclamation.

Using the annualized linear optimization model, sensitivity analysis is conducted to determine the effect of landfilling costs on FGD by-product uses. Figure 99 illustrates the sensitivity of FGD by-product use in the linear optimization model to landfilling costs. A reduction of landfilling costs from $\$ 24.94 / \mathrm{Mg}(\$ 27.50 /$ ton) to about $\$ 18.14 / \mathrm{Mg}(\$ 20.00 /$ ton) has relatively little impact on alternative uses. Landfilling still remains a high cost disposal option. However, as landfilling costs drop below $\$ 18.14 / \mathrm{Mg}$ (\$20.00/ton), FGD use at distant road repair or mine reclamation sites becomes less attractive than landfilling. With landfilling costs at $\$ 9.07 / \mathrm{Mg}$ (\$10/ton), much more of the material is landfilled and the amount of FGD used in road repair and reclamation is reduced by about 50 percent compared to the amount used when landfilling costs are $\$ 18.14 \mathrm{Mg}(\$ 20.00 /$ ton $)$.

Including social costs in the calculation of landfilling costs has some impact on FGD byproduct use. Adding social costs [Conesville, $\$ 0.28 / \mathrm{kg}(\$ 0.31 / \mathrm{Mg}) ;$ Gavin, $\$ 1.15 / \mathrm{Mg}$ (\$1.27/ton); McCracken, $\$ 6.47 / \mathrm{Mg}$ (\$7.13/ton); and Zimmer, $\$ 1.28 / \mathrm{Mg}$ (\$1.42/ton)] to the tipping fee results in less FGD by-product landfilled over the range of landfilling costs tested in the sensitivity analysis (Figure 99). For example, if the landfill tipping fee is $\$ 9.07 / \mathrm{Mg}$ ( $\$ 10 /$ ton), about 2.45 million $\mathrm{Mg}$ (2.7 million tons) are landfilled. However, if social costs are added to the $\$ 9.07 / \mathrm{Mg}$ ( $\$ 10 /$ ton) tipping fee, the amount of FGD by-product landfilled drops to about 2.0 million $\mathrm{Mg}$ (2.2 million tons). 

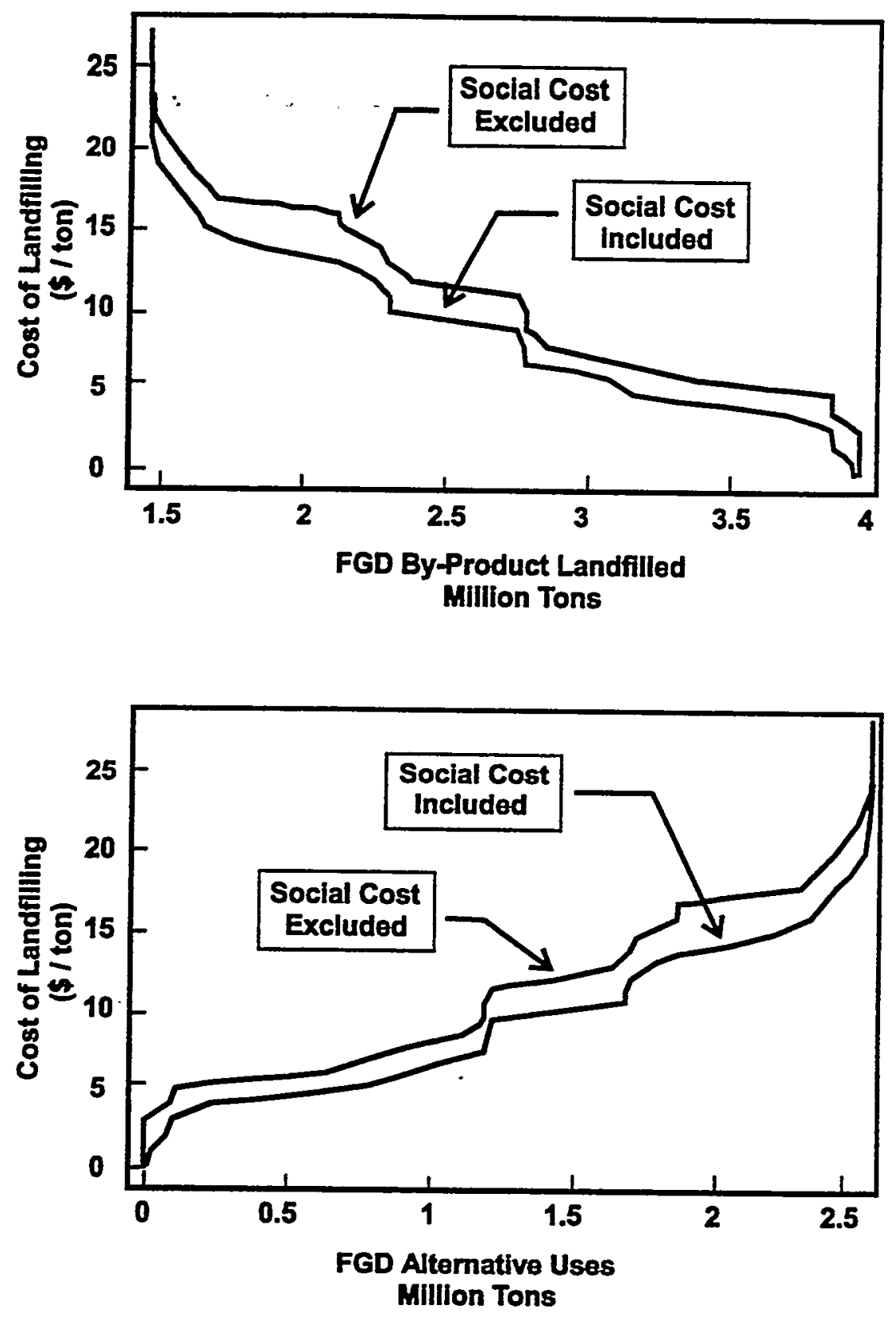

Figure 99. Effects of landfilling cost on quantities of FGD by-product landfilled and used in alternative uses (i.e. road repair and surface mine reclamation). 
This analysis indicates that at the current level of landfill tipping fees, there is a substantial financial incentive for power plants to find alternative uses for FGD by-product. Road repair and surface mine reclamation throughout the state appear to be economically viable uses. Undoubtedly, other FGD by-product markets could be developed, e.g. use as a soil amendment to neutralize acidic agricultural soils or use in the production of dry wall and other gypsum based products. When social costs of landfilling (i.e. the reduction in property values near landfills) are added to landfill tipping fees, the incentive for finding alternative uses for FGD by-product becomes even stronger.

\subsubsection{Comparisons with EPRI Disposal Economic Models}

The aforementioned economic models are used primarily by economists. It is useful to compare the results of these academic models with the methods used by the utility industry to estimate costs. The EPRI Report TR-1044731 entitled "FGD By-Product Disposal Manual, 4th Edition" (1995) contains detailed cost estimates for FGD disposal based on the industry accepted EPRI Technical Assessment Guide. The design basis for the conceptual FGD disposal system was established, in accordance with EPRI's Technical Assessment Guide, to develop levelized costs for the useful life of a plant facility. A model plant was assumed to be located in Illinois; consist of two $500 \mathrm{MW}$ boilers; burn bituminous coal (4\% S, $16 \%$ ash, and 10,100 BTU/lb HHV); be quipped with three spray tower (absorber) units including one spare; be equipped with electrostatic precipitators upstream of the $\mathrm{SO}_{2}$ absorbers; have a design life of 30 years; utilize a disposal areas located approximately $3.2 \mathrm{~km}$ ( 2 miles) from the power plant; and have an $\mathrm{SO}_{2}$ removal of $90 \%$ to be in compliance with the New Source Performance Standards.

The conceptual designs developed in the 1995 "FGD By-Product Disposal Manual" include and describe all major FGD management equipment. Thirty year levelized unit costs for the retrofit plant were estimated to be 3.270 mills $/ \mathrm{kWh}$ or $\$ 20.28 / \mathrm{Mg}$ of dry material $(\$ 22.36 / \mathrm{dry}$ ton) of FGD disposed assuming a five year tax life and a 1990 through 2020 levelization period.

Parametric cost sensitivity analyses have been conducted and results are presented to illustrate the impact of significant design parameters on FGD management costs. The following ten parameters were examined: plant size; coal S content; coal ash content; coal heating value; haul road length; transport distance; tax life; FGD system type; pretreatment options; and liner systems. Cost dependence of the parameter was determined by varying the magnitude of that parameter from its base case value. 
Results of the parametric cost sensitivity analyses in the aforementioned manual demonstrated that the parameter which had the largest impact on the amount of FGD generated, generally had the greatest impact on FGD management costs. Plant șize, coal S content, coal ash content, coal heating value, and percent $\mathrm{SO}_{2}$ removal all significantly effect on FGD quantities and, therefore, costs. Results for parameters which do not affect FGD quantities were variable. Tax life and haul road length (partially constructed within the landfill) have smaller impacts on costs than do pretreatment options, liner systems and transport distance (on public roadways).

\subsubsection{Conclusions}

Under Title IV of the 1990 Clean Air Act, electric power generating plants will be required to reduce $\mathrm{SO}_{2}$ and $\mathrm{NO}_{\mathrm{x}}$ emissions by about 40 percent no later than the year 2000 . These emission standards are most significant for power plants which burn high sulfur coal as an energy source. In order to achieve compliance with these mandates, power plants will have to encourage reduction in demand for electricity, use fuels lower in sulfur, purchase emission allowances, retrofit existing power plants with clean air technology, or some combination of the above. Currently, the only clean air technology available to existing power plants is flue gas desulfurization (FGD) technology. This technology can reduce $\mathrm{SO}_{2}$ by as much as $95 \%$. However, FGD technology creates another concern and that is what to do with the large amounts of by-product created. Based on experience at four Ohio power plants, nearly 3.45 million $\mathrm{Mg}$ ( 3.8 million tons) of FGD by-product are produced annually. The objectives of this research were to estimate a least cost disposal model for the movement of this by-product to various geographic locations throughout Ohio and for its use as a soil amendment for highway construction, coal surface mine reclamation, and landfilling. In doing so, total disposal costs and quantities were derived as well as shadow prices for each county (demand node) identified.

This analysis compares two scenarios for future FGD by-product distribution and uses. Others may be plausible and easily analyzed by this model. Under the first scenario, which is the most realistic, the annualized linear transportation model estimates that it would cost $\$ 70.1$ million to dispose of 3.45 million $\mathrm{Mg}$ (3.8 million tons) annually if the full social costs of landfilling were considered. This contrasts with the costs if no alternatives for recycling existed in which case the social cost alone is $\$ 4.7$ million per annum, and full costs of landfilling are $\$ 115.6$ million per annum $(\$ 26.88 / \mathrm{Mg}$ or $\$ 29.64 /$ ton on average including transportation to the landfill and social costs). When the social costs of landfilling are not considered, the linear model predicts least cost disposal amounts equal to $\$ 68.0$ million per annum. Thus, even in this 
scenario where significant alternative disposal means are used, the social cost from landfilling will amount to more than $\$ 2$ million per year.

Under the second and most optimistic scenario, all of the FGD by-product currently produced in Ohio would be used in alternative beneficial uses at a cost of $\$ 45.4$ million per year, which translates to $\$ 10.56 / \mathrm{Mg}$ ( $\$ 11.64 /$ ton). This alternative obviously would provide significant social benefits and save the utilities $\$ 70.2$ million in landfilling costs per year $(\$ 16.33 / \mathrm{Mg}$ or $\$ 18.00 /$ ton) even if they were to pay all transportation and application costs associated with alternative disposal options. This study demonstrates that even with relatively small social costs per $\mathrm{Mg}$ (ton) that would accrue from landfills in rural areas, aggregate costs can be significant.

The two end use alternatives currently identified for FGD by-product, in addition to landfilling, are highway construction and repair and reclamation of surface coal mines reclamation. Under the most realistic assumptions (Scenario 1) landfilling accounts for about 36 percent of the total FGD by-product produced, while highway repair and surface coal mine reclamation account for about 17 and 47 percent, respectively. Therefore, on average alternative uses of FGD byproduct represent a savings of $\$ 10.58 / \mathrm{Mg}$ ( $\$ 11.67 /$ ton) which is the difference between the cost of landfilling ( $\$ 26.88 / \mathrm{Mg}$ or $\$ 29.64 / \mathrm{ton}$ ) and the average cost associated with alternative uses $(\$ 16.30 / \mathrm{Mg}$ or $\$ 17.97 /$ ton $)$.

Highway repair use of FGD by product could occur anywhere in the state, while surface coal mine reclamation is restricted to the eastern one-third of the state. Even with all of the alternative disposal options identified, a significant portion of FGD by-product will still be landfilled. However, electric utilities have an enormous economic incentive to supply FGD byproduct to coal mine operations and the Ohio Department of Transportation. Scenario 2 illustrates it is possible to achieve even greater economic benefits of FGD alternative uses thus providing a powerful incentive to avoid landfilling altogether. 


\section{Appendix $A$ REFERENCES}

Adams, F. and B.F. Hajek. 1978. Effects of solution sulphate, hydroxide, and potassium concentrations on the crystallization of alunite, basaluminite, and gibbsite from dilute aluminum solutions. Soil Sci. 126:169-173.

Adams, F. and Z. Rawajfih. 1977. Basalunite and alunite: A possible cause of sulfate retention by acid soils. Soil Sci.Soc. Am.J. 4:686-692.

Allison, J.D., D.S. Brown, K.J. Novo-Grdac. 1990. MINTEQA2/PRODEFA2. A geochemical assessment model for environmental systems: Version 3.0 User's Manual, Environ. Res. Lab., USWPA, Athens, GA.

Anderson, G. and R. Bishop. 1986. The valuation problem. In David Bromley (ed.), pp. 89162. Natural Resource Economics, Kluwer Nijhoff Publishing, Boston, MA.

Atkins, M., D. MacPhee, A. Kindness and F.P. Glasser. 1991. Solubility properties of ternary and quaternary compounds in the $\mathrm{CaO}-\mathrm{Al}_{2} \mathrm{O}_{3}-\mathrm{SO}_{3}-\mathrm{H}_{2} \mathrm{O}$ system. Cem. Concr. Res. 21:991-998.

Ball, J.W. and D.K. Nordstrom. 1991. User's manual for WATEQ4F, with revised thermodynamic data base and test cases for calculating speciation of major, trace, and redox elements in natural waters. 189. U.S. Geological Survey Open-File Report 91-183. U.S. Geological Survey, Columbus, $\mathrm{OH}$.

Batelle, 1989. Technical support for the Ohio Clean Coal Technology Program, Volume II. Baseline knowledge concerning process modification opportunities, research needs, by-product market potential, and regulatory requirements. Final Report. Ohio Coal Development Office, Columbus, $\mathrm{OH}$. 
Bassett, H. and T.H. Goodwin. 1949. The basic aluminum sulphates. J. Chem. Soc. 71:2239-2279.

Blake, R.G. and K.H. Hartge. 1986. Bulk density. 363-375. In A.Klute (Ed.), Methods of Soil Analysis. Part I - Physical and Mineralogical Methods, 2nd Edition. American Society of Agronomy and Soil Science Society of America, Madison, WI, USA.

Bohn, H.L., B.L. McNeal and G.A. O'Connor. 1985. Soil chemistry, 2nd Ed. Wiley. New York, NY.

Boyle, K.J. and J.C. Bergstrom. 1992. Benefit transfer studies: Myths, pragmatism and idealism. Water Resources Research 28:657-663.

Brant, R.A., P.R. Dugan, C.I. Randles, K.S. Shumate and E.E. Smith. 1971. Acid mine drainage formation and abatement. The Ohio State University Research Foundation. Publ. No. 14010 FPR. U.S. Environmental Protection Agency, Washington, DC.

Brendel, G.F., N.J. Balsamo and L.H. Wei. 1997. Guidelines for the beneficial use of advanced $\mathrm{SO}_{2}$ control by-products. EPRI Report TR-108403, Electric Power Research Institute, Palo Alto, CA.

Briggs, P.H. 1990. Elemental analysis of geologic materials by inductively coupled plasma-atomic emission spectroscopy. pp. 83-91. In Arbogast, B.E., ed. Quality assurance manual for the Branch of Geochemistry. U.S. Geological Survey Open-File Report 90-668. U.S. Geological Survey, Columbus, $\mathrm{OH}$.

Carlson, C.L. and D.C. Adriano. 1993. Environmental impacts of coal combustion residues. J. Environ. Qual. 22:227-247.

Caruccio, F.T., J.C. Ferm, J. Horne, G. Geidel and B. Baganz. 1977. Paleoenvironment of coal and its relation to drainage quality. 108. U.S. EPA Report No. EPA-600/7-77-067. U.S. Environmental Protection Agency, Washington, DC.

Casey, W.H., J.F. Banfield, H.R. Westrich and L. McLaughlin..1993. What do dissolution experiments tell us about natural weathering? Chem. Geol. 105:1-15. 
Claassen, H.C. 1982. Guidelines and techniques for obtaining water samples that accurately represent the water chemistry of an aquifer. 49. U.S. Geological Survey Open-File Report 82-1024. U.S. Geological Survey, Columbus, OH.

Cooper, H.H., J.D. Bredehoeft and I.S. Papadopulos. 1967. Response of a finite-diameter well to an instantaneous charge of water. Water Resources Research 3:263-269.

Creasey, C.L. and S.J. Dreiss. 1988. Porous cup samplers-cleaning procedures and potential sample bias from trace element contamination. Soil Sci. 145:98-101.

Cunningham, W.L. and R.L. Jones. 1990. Long-term effects of surface coal mining on ground-water levels and quality in two small watersheds in eastern Ohio. 74. U.S. Geological Survey Water-Resources Investigations Report 90-4136. U.S. Geological Survey, Columbus, $\mathrm{OH}$.

Curry, K.J. 1990. Determination of total carbon in geologic materials by combustion. 114-118. In Arbogast, B.E. (ed.), Quality assurance manual for the Branch of Geochemistry. U.S. Geological Survey. U.S. Geological Survey Open-File Report 90-668.

Curry, K.J. and C.S.E. Papp. 1996. Acid-soluble sulfate, sulfide, and organic sulfur. 182-185. In Arbogast, B.E. (ed.), Analytical Methods Manual for the Mineral Resources Surveys Program. U.S. Geological Survey Open-File Report 96-525. U.S. Geological Survey, Columbus, $\mathrm{OH}$.

Damidot, D. and F.P. Glasser. 1993. Thermodynamic investigation of the $\mathrm{CaO}-\mathrm{Al}_{2} \mathrm{O}_{3}-\mathrm{CaSO}_{4}-\mathrm{H}_{2} \mathrm{O}$ at $25^{\circ} \mathrm{C}$ and the influence of $\mathrm{Na}_{2} \mathrm{O}$. Cem. Concr. Res. 23:221-238.

Damidot, D., M. Atkins, A. Kindness and F.P. Glasser. 1992. Sulphate attack on concrete: Limits of the Aft stability domain. Cem. Concr. Res. 22:229-234.

Deer, W.A., R.A. Howie and J. Zussman. 1966. An Introduction to the Rock-Forming Minerals, Longman, London. $528 \mathrm{pp}$. 
Deng, Y., N. Ennich and D. Hite. 1992. Benefit analysis of fgd by-products: A case study of muskingum watershed conservancy, ESO 2000, Department of Agricultural Economics, The Ohio State University, Columbus, $\mathrm{OH}$.

Diamond, D. B., Jr. and B. A. Smith. 1982. The economic roles of urban amenities. In D.B. Diamond and G.S. Tolley (eds.), The Economics of Urban Amenities, Academic Press, New York, NY.

Diamond, D.B. and G.S. Tolley. 1982. The Economics of Urban Amenities. Academic Press, New York, NY.

Doner, H.E. and W.C. Lynn. 1989. Carbonate, halide, sulfate and sulfide minerals. In J.B. Dixon and S.B.Weed (eds), Minerals in Soil Environments, SSSA Book Series, 1:279-324. Soil Science Society of America, Madison, WI.

Domenico, P.A. and F.W. Schwartz. 1990. Physical and Chemical Hydrogeology. John Wiley, New York, NY.

Driscoll, P. 1994. Welfare analysis when budget constraints are nonlinear. The case of flood hazard reduction. J. Environ. Econ. Management 26:181-99.

Eary, L.E., E.A. Jenne, L.W. Vail and D.C. Grivin. 1991. Recovery of the highly acidified Clearwater Lake watershed, Ontario, Canada, simulated with the ILWAS model. Appl. Geochem. 6:613-634.

Eberle, M. and A.C. Razem. 1985. Effects of surface coal mining and reclamation on ground water in small watersheds in the Allegheny Plateau, Ohio. 13. U.S. Geological Survey Water Resources Investigations Report 85-4205. U.S. Geological Survey, Columbus, $\mathrm{OH}$.

Electric Power Research Institute (EPRI). 1989. MYGRT code version 2.0: an IBM code for simulating migration of organic and inorganic chemicals in groundwater. EPRI Report EN6531, Reseach Project 2870-2, Electric Power Research Institute, Palo Alto, CA.

Faure, G. 1989. Principles and Applications of Inorganic Geochemistry. McMillan Publishing, New York, 626 pp. 
Fishman, M.J. and L.C. Friedman (eds.). 1989. Methods for the determination of inorganic substances in water and fluvial sediments. 545. U.S. Geological Survey Techniques of Water-Resources Investigations. U.S. Geological Survey, Columbus, $\mathrm{OH}$.

Fishman, M.J. (ed). 1993. Methods of analysis by the U.S. Geological Survey National Water Quality Laboratory-Determination of inorganic and organic constituents in water and fluvial sediments. 217. U.S. Geological Survey Open-File Report 93-125. U.S. Geological Survey, Columbus, $\mathrm{OH}$.

Freeman, A.M. 1971. Air pollution and property values: A methodological comment. Rev. Econ. Stat. 53:415-416

Friedman, L.J. 1996. An estimation of the benefits of stripmine reclamation to lakeside property owners. M.S. Thesis, Department of Agricultural Economics, The Ohio State University, Columbus, $\mathrm{OH}$.

Fowler, R.K., S.J. Traina, J.M. Bigham and U.I. Soto. 1993. Solution chemistry and mineralogy of clean coal technology by-products in a long term equilibration study. p. 30 , Agronomy Abstracts, American Society of Agronomy, Madison, WI.

Fruchter, J.S., D. Rai and J.M. Zachara. 1990. Identification of solubility controlling solid phases in a large fly ash field lysimeter. Environ. Sci. Tech. 24:1173-1179.

Hampson, C.J. and J.E. Bailey. 1982. On the structure of some precipitated calcium alumino-sulphate hydrates. J. Material Sci. 17:3341-3346.

Hassett, D.J., G.J. McCarthy, P. Kumarathasan and D.F.P. Hassett. 1990. Synthesis and characterization of selenate and sulfate-selenate ettringite structure phases. Material Res. Bull. 25:1347-1354.

Havlica, J. and S. Sahu. 1992. Mechanism of ettringite and monosulphate formation. Cem. Concr. Res. 22:671-677.

Helgeson, H.C. 1968. Evaluation of irreversible reactions in geochemical processes involving minerals and aqueous solutions-I. Thermodynamic relations. Geochim. Cosmochim. Acta 32:853-877. 
Helgesen, J.O., S.P. Larson and A.C Razem. 1982. Model modifications for simulation of flow through stratified rocks in eastern Ohio. 109. U.S. Geological Survey Water Resources Investigations Report 82-4019. U.S. Geological Survey, Columbus, OH.

Hem, J.D. 1989. Study and interpretation of the chemical characteristics of natural water. 263. U.S. Geological Survey Water-Supply Paper 2254. U.S. Geological Survey; Columbus, $\mathrm{OH}$.

Hemmingway, B.S. and G. Sposito. 1996. Inorganic aluminum-bearing solid phases. pp. 81-116 In Sposito, G. (ed.), The Environmental Chemistry of Aluminum. Lewis Publishers, New York, NY.

Henry, J.L. and G.B. King. 1950. Phase rule investigation of the system $\mathrm{Al}_{2} \mathrm{O}_{3}-\mathrm{SO}_{3}-\mathrm{H}_{2} \mathrm{O}$ at $60^{\circ} \mathrm{C}$, basic region. J. Amer. Chem. Soc. 72:1282-1286.

Hindall, S.M. 1984. Effects of surface coal-mine reclamation on stream quality in a small watershed near Nelsonville, southeastern Ohio. 28. U.S. Geological Survey Water Resources Investigations Report 84-4179. U.S. Geological Survey, Columbus, $\mathrm{OH}$.

Hite, D. 1995. Welfare measurements for an environmental disamentity in the residential real estate market. Ph.D. Dissertation, Department of Agricultural Economics, The Ohio State University, Columbus, $\mathrm{OH}$.

Holmes, M.A., D.C. Martens and J.N. Jones, Jr. 1979. Growth and sulfur sorption of com on soil amended with fluidized bed waste. p. 973-979. In M.K. Wali (ed.), Ecology and Coal Resource Development, Vol. 2. Pergamon Press, New York, NY.

Hren, J. 1986. Changes in ground-water quality resulting from surface coal mining of a small watershed in Jefferson County, Ohio. 38. U.S. Geological Survey Water-Resources Investigations Report 86-4108. U.S. Geological Survey, Columbus, $\mathrm{OH}$.

Hull, D.N. 1990. Generalized column of bedrock units in Ohio. 1. Ohio Geological Survey. U.S. Geological Survey, Columbus, OH. 
Janzer, V.J. 1985. The use of natural waters as U.S. Geological Survey reference samples: Special Testing Publication 867.319-333. Philadelphia, American Society for Testing and Materials, Philadelphia, PA.

Johanson, G. 1960. The crystal structures of some basic aluminum salts: Acta Chem. Scand. 14:771-773.

Johanson, G. 1962. The crystal structures of $\left\{\mathrm{Al}_{2}(\mathrm{OH})_{2}\left(\mathrm{H}_{2} \mathrm{O}\right)_{8}\right\}\left(\mathrm{SO}_{4}\right)_{2} \bullet 2 \mathrm{H}_{2} \mathrm{O}$ and $\left\{\mathrm{Al}_{2}(\mathrm{OH})_{2}\right.$ $\left(\mathrm{H}_{2} \mathrm{O}\right)_{8}\left(\mathrm{SeO}_{4}\right)_{2} \cdot 2 \mathrm{H}_{2} \mathrm{O}$. Acta Chem. Scand. 14:771-773.

Jones, F.E. 1944. The quaternary system $\mathrm{CaO}-\mathrm{Al}_{2} \mathrm{O}_{3}-\mathrm{CaSO}_{4}-\mathrm{H}_{2} \mathrm{O}$ at $25^{\circ} \mathrm{C}$ : Equilibria with crystalline $\mathrm{Al}_{2} \mathrm{O}_{3} \cdot 3 \mathrm{H}_{2} \mathrm{O}$, alumina gel, and solid solution. J. Phys. Chem. 48:311-378.

Kumarathasan P., G.J. McCarthy, D.J. Hassett and D.F.P. Hassett. 1990. Oxyanion substituted ettringites: synthesis and characterization and their potential role in immobilization of As, B, Cr, Se and V. In R.L. Day and F.P. Glasser (eds.), Fly Ash and Coal Conversion By-Products: Characterization, Utilization and Disposal VI, Mat. Res. Soc. Symp. Proc. 178, 83-103. American Coal Ash Association, Washington, DC.

Keys, W.S. and L.M. MacCary. 1971. Application of borehole geophysics to water resources investigations. 126. U.S. Geological Survey Techniques of Water Resources Investigations. U.S. Geological Survey, Columbus, $\mathrm{OH}$.

Khanna, P.K., J. Prenzel, K.J. Meiwes, B. Ulrich and E. Matzner. 1987. Dynamics of sulfate retention by acid forest soils in an acidic deposition environment. Soil Sci. Soc. Am. J. 51:446-452.

Klute, A. 1986. Water retention: Laboratory methods. 635-662. In A.Klute (Ed.), Methods of Soil Analysis. Part I - Physical and Mineralogical Methods, 2nd Edition. American Society of Agronomy and Soil Science Society of America, Madison, WI, USA.

Korcak, R.F. 1980. Fluidized bed material as a lime substitute and calcium source for apple seedlings. J. Environ. Qual. 9:147-151.

Lamborn, R.E. 1956. Geology of Tuscarawas County. 269. Ohio Geological Survey Bulletin 55. 1 plate. U.S. Geological Survey, Columbus, $\mathrm{OH}$. 
Lindberg, R.D. and Runnells, D.D. 1984. Ground water redox reactions-an analysis of equilibrium state applied to Eh measurements in geochemical modeling. Science 225: 925-927.

Lindsey, W.L. 1979. Chemical Equilibria in Soils. John Wiley, New York, NY. 449 pp.

Longmire, P., D.G.Brookins and B.M. Thomson. 1990. Hydrogeochemical interactions and evolution of acidic solutions in soil. In D.C. Melchoir and R.L. Bassett (eds.), Chemical Modeling of Aqueous Systems II, ACS Symposium Series 416:154-168. American Chemical Society, Washington, DC.

Lovell, C. W. 1988. Informational Report: User's Manual for PC STABL 5M. Purdue University, West Lafayette, IN.

Marschner, H. 1995. Mineral Nutrition of Higher Plants, Second Edition. Academic Press, New York, NY.

Marsh, B.H. and J.H. Grove. 1992. Surface and subsurface soil acidity: Soybean root response to sulfate-bearing spent lime. Soil Sci. Soc. Am. J. 56:1837-1842.

Mattigod, S.V., D. Rai, L.E. Eary and C.C. Ainsworth. 1990. Geochemical factors controlling the mobilization of inorganic constituents from fossil fuel combustion residues: I. Review of the major elements. J. Environ. Qual. 19:187-201

McDonald, M.G. and A.W. Harbaugh. 1988. A modular three-dimensional finite-difference ground-water flow model. 586. U.S. Geological Survey Techniques of Water Resources Investigations. U.S. Geological Survey, Columbus, $\mathrm{OH}$.

McGuire, P.E., B. Lowery and P.A. Helmke. 1992. Potential sampling error-trace metal adsorption on vacuum porous cup samplers: Soil Sci. Soc. Am. J. 56:74-82.

McMurdie H.F., M.C. Morris, E.H. Evans, B. Paretzkin, W. Wong and Y. Zhang. 1986. Calcium Aluminum Sulfate Hydroxide Hydrate, $\mathrm{Ca}_{6} \mathrm{Al}_{2}\left(\mathrm{SO}_{4}\right)_{3}(\mathrm{OH})_{12} \cdot 26 \mathrm{H}_{2} \mathrm{O}$. Powder Diff. 4:337. 
Mehlich, A. 1984. Mehlich III soil test extractant: A modification of Mehlich II extractant. Comm. Soil Sci. Plant Anal. 15:1409-1419.

Mendelsohn, R. 1984. Estimating the structural equations of implicit markets and household production functions. Rev. Econ. Stat. 66:673-677.

Meyer, L.D. 1994. Rainfall simulators for soil erosion research. p. 83-103. In R.Lal (ed.), Soil Erosion Research Methods, Soil and Water Conservation Society, Ankeny, IA.

Moore, A.E. and H.F.W. Taylor. 1970. Crystal structure of ettringite. Acta Cryst. B26:386.

Myneni, S.C.B. 1995. Oxyanion-mineral surface interactions in alkaline environments: $\mathrm{AsO}_{4}$ and $\mathrm{CrO}_{4}$ sorption and desorption in ettringite. Ph.D. Dissertation, The Ohio State University, Columbus, $\mathrm{OH}$.

National Atmospheric Deposition Program/National Trends Network. 1996. Precipitationweighted means: Available on the World-Wide Web at <http://nadp.nrel.colostate. edu/NADP/>, accessed March 12, 1996.

Neuhart, H. 1994. Director of Special Projects Division/District 5, ODOT. Personal Interview.

Nichols, V.E. 1985. Evaluation of the effects of coal-mine reclamation on water quality in Big Four Hollow near Lake Hope, southeastern Ohio. 215. U.S. Geological Survey Water Resources Investigations Report 85-4197. U.S. Geological Survey, Columbus, OH.

Nishikawa, T., K. Suzuki, S. Ito, K. Sato and T. Takebe. 1992. Decomposition of synthetic ettringite by carbonation. Cem. Concr. Res. 22:6-14.

Nordstrom, D.K. 1982. The effect of sulfate on aluminum concentrations in natural waters: some stability relations in the system $\mathrm{Al}_{2} \mathrm{O}_{3}-\mathrm{SO}_{3}-\mathrm{H}_{2} \mathrm{O}$ at $298 \mathrm{~K}$. Geochim. Cosmochim. Acta 46:681-692.

Nordstrom, D.K. and C.N. Alpers. 1997. Geochemistry of mine waters. In G.S.Plumlee and M.J. Logsdon (eds.), The Environmental Geochemistry of Mineral Deposits, Reviews in Economic Geology 6:102-137. 
Nordstrom, D.K. and J.W. Ball. 1986. The geochemical behavior of aluminum in acidified surface waters. Science 232: $54-56$.

Nordstrom, D.K., E.A. Jenne and J.W. Ball. 1979. Redox equilibria of iron in acid mine waters. 51-79. In Jenne, E.A., ed., Chemical Modeling in Aqueous Systems.Technical Symposium Series, No. 93, American Chemical Society, Washington, DC.

Ohio Agronomy Guide. 1990. Bulletin 472, Ohio Cooperative Extension Service, Columbus, $\mathrm{OH}$.

Ohio Department of Natural Resources. 1995. Monthly water inventory report for Ohio. 4. Division of Water, Columbus, $\mathrm{OH}$.

Ohio Department of Transportation. 1966. Project Plan Number COS-541-17.88, Columbus, $\mathrm{OH}$.

Ohio Electric Institute. 1986. Ohio electric utility rates effects of HR4567, The Acid Deposition Control Act of 1986. Prepared by Temple, Barker and Sloan, Inc., Lexington, MA for the Ohio Electric Utility Institute, Columbus, $\mathrm{OH}$.

Ossaka, J., Jun-Ichi Hirabayashi, K. Okada, R. Kobayashi and T. Hayashi. 1982. Crystal structure of minamiite, a new mineral of the alunite group. Am. Mineral. 67:114-119.

Pierzynksi, G.M., J.T. Sims and G.F. Vance. 1994. Soils and environmental quality. Lewis Publishers, Boca Raton, FL.

Pöllmann, H., H.-J. Kuzel and R. Wenda. 1989. Compounds with ettringite structure. N. Jb. Miner. Abh. 160:133-158.

Pollock, D.W. 1989. Documentation of computer programs to compute and display pathlines using results from the U.S. Geological Survey modular three-dimensional finite-difference ground-water flow model. 188. U.S. Geological Survey Open-File Report 89-381. U.S. Geological Survey, Columbus, $\mathrm{OH}$.

Preznel, J. and H. Shulte-Bisping. 1995. Some chemical parameter relations in a population of German forest soils. Geoderma 64:309-326. 
Quigley, J.M. 1984. Non-linear budget constraints and consumer demand: an application to public programs for resident housing. J. Urban Econ. 12:177-201.

Razem, A.C. 1983. Ground-water hydrology before, during, and after coal strip mining of a small watershed in Coshocton County, Ohio. 36. U.S. Geological Survey Water Resources Investigations Report 83-4155. U.S. Geological Survey, Columbus, OH.

Razem, A.C. and A.C. Sedam. 1985. Ground-water quality and geochemistry of aquifers associated with coal in the Allegheny and Monongahela Formations, southeastern Ohio. 39. U.S. Geological Survey Water-Resources Investigations Report 85-4034. U.S. Geological Survey, Columbus, $\mathrm{OH}$.

Ridker, R.G. and J.A. Henning. 1967. The determinants of residential property values with special reference to air pollution. Rev. Econ. Stat. 49:246-56.

Rosen, S. 1974. Hedonic prices and implicit markets: product differentiation in pure competition. J. Political Econ. 82:34-55.

Saad, D.A. and C.A. Cravotta. 1991. Modeling of ground-water flow along a cross section through a reclaimed surface coal mine in western Pennsylvania. 545 [Abst.] National Meeting of the ASSMR, Durango, CO. American Society of Surface Mining and Reclamation, Morgantown, WV.

Scotchmer, S. 1986. The short run and long run benefits of environmental improvement. J. Public Econ. 20:61-81.

Singh, S.S. and J.E. Brydon. 1969. Solubility of basic aluminum sulphates at equilibrium in solution and in the presence of montmorillonite. Soil Sci. 107:12-17.

Skeen, C.J. 1996. Carbon, hydrogen, and nitrogen by a CHN analyzer. 186-190. In Arbogast, B.E. (ed.), Analytical Methods Manual for the Mineral Resources Surveys Program: U.S. Geological Survey Open-File Report 96-525. U.S. Geological Survey, Columbus, $\mathrm{OH}$.

Sjöström, J. 1993. Combined studies of soil and ground water chemistry, southwest Sweden, focusing on $\mathrm{Al}$ and $\mathrm{SO}_{4}$. Appl. Geochim.( supplemental issue) 2:281-283. 
Sopper, W.E. 1992. Reclamation of mine land using municipal sewage sludge. Adv. Soil Sci. 17:351-431.

Sposito, G. 1994. Chemical Equilibria and Kinetics in Soils. Oxford University Press, New York, NY.

Stehouwer, R., W. Dick, J. Bigham, L. Forster, F. Hitzhusen, E. McCoy, S. Traina, W. Wolfe and R. Haefner. 1995a. Land application uses for dry flue gas desulfurization by-products. EPRI Report TR-105264, Electric Power Research Institute, Palo Alto, CA.

Stehouwer, R.C., P. Sutton and W.A. Dick. 1995b. Use of clean coal technology by-products as agricultural liming materials. 1-1 to 1-14. In Proceedings: 11th International Symposium on Use and Management of Coal Combustion By-Products (CCBs). Orlando, FL., January 15-19, 1995. EPRI TR-104657-V1. Electric Power Research Institute, Palo Alto, CA.

Stehouwer, R.C., P. Sutton and W.A. Dick. 1995c. Minespoil amendment with dry flue gas desulfurization by-products: plant growth. J. Environ. Qual. 24:861-869.

Stehouwer, R.C., P. Sutton, R.K. Fowler and W.A. Dick. 1995d. Minespoil amendment with dry flue gas desulfurization by-products: Element solubility and mobility. J. Environ. Qual. 24:165-174.

Stehouwer, R., W. Dick, J. Bigham, L. Forster, F. Hitzhusen, E. McCoy, S. Traina, W. Wolfe, R. Haefner and G. Rowe. 1998. Land application uses for dry FGD by-products: Phase 2, EPRI Report TR-109652, Electric Power Research Institute, Palo Alto, CA.

Stewart, M.M., M.G. Lees, D.K. Saylor, A.E.Schoedel, P.L. Steffan and M.W. Widdersheim. 1995. FGD by-product disposal manual, Fourth Edition. EPRI Report TR104731. Electric Power Research Institute, Palo Alto, Ca.

Stout, W.L., R.C. Siddle, J.L. Hern and O.L. Bennett. 1979. Effects of fluidized bed combustion waste on the $\mathrm{Ca}, \mathrm{Mg}, \mathrm{S}$, and $\mathrm{Zn}$ levels in red clover, tall fescue, oat and buckwheat. Agron. J. 71:662-665. 
Stumm, W. 1993. Chemistry of the Solid-Water Interface, Wiley-Interscience Pub., New York, NY. 428 pp.

Stumm, W. and J.J. Morgan. 1994. Aquatic Chemistry, 3rd edition. Wiley-Interscience, New York, NY.

Sullivan, P.J., J.L. Yelton and K.J. Reddy. 1988. Solubility relationships of aluminum and iron minerals associated with acid mine drainage. Environ. Geol. Water Sci. 11:283-287.

Sumner, M.E, H. Shahandeh, J. Bouton and J. Hammel. 1986. Amelioration of an acid soil profile through deep liming and surface application of gypsum. Soil Sci. Soc. Am. J. 50:1254-1258.

Telford, W.M., L.P. Geldart, R.E. Sheriff and D.A. Keys. 1974. Applied Geophysics. Cambridge University Press, London.

Terman, G.L., V.J. Kilmer, C.M. Hunt and W. Buchanan. 1978. Fluidized bed boiler waste as a source of nutrients and lime. J. Environ. Qual. 7:147-150.

Theobold, P.K. Jr., H.W. Larkin and D.B Hawkins. 1963. The precipitation of aluminum, iron, and manganese at the junction of Deer Creek with the Snake River in Summit County, CO. Geochim. Cosmochim. Acta 27:121-132.

Von Nostrand, R.G. and K.L.Cook. 1966. Interpretation of resistivity data. 310.Geological Survey Professional Paper 499. U.S. Geological Survey, Columbus, OH.

Wang, W.-Z. and P. H. Hsu. 1994. The nature of polynuclear OH-Al complexes in laboratory-hydrolyzed and commercial hydroxyaluminum solutions. Clays \& Clay Minerals 42:356-368.

Welsch, E.P. J.G. Crock and R. Sanzolone. 1990. Trace-level determination of arsenic and selenium using continuous-flow hydride generation atomic absorption spectrophotometry (HG-AAS).pp. 38-45. In Arbogast, B.E. (ed.), Quality Assurance Manual for the Branch of Geochemistry, U.S. Geological Survey Open-File Report 90-668. U.S. Geological Survey, Columbus, $\mathrm{OH}$. 
White, W.B. 1970. The Carbonate Minerals. pp. 227-284. In V.C. Farmer (ed.), The Infrared Spectra of Minerals, Wiley, New York, NY.

Wolery, T.J. and S.A. Develer. 1992. EQ6, a computer program for reaction path modeling of aqueous geochemical systems: theoretical manual, user's guide and related documentation. Version 7.0. Lawrence Livermore Laboratory, UCRL-MA-1 10662 PTN. Livermore, CA. $339 \mathrm{pp}$.

Wolfe, W. E., Wu, T. H. and Beeghly, J. H. 1992. Laboratory Determination of Engineering Properties of Dry FGD By-Products. Proceedings of the Ninth Annual International Pittsburgh Coal Conference, University of Pittsburgh, Pittsburgh, PA.

Wollast, R. and L. Chou. 1992 Surface reactions during the early stages of weathering of albite. Geochim. Cosmochim. Acta 56:3113-3122.

Wood, W.W. 1976. Guidelines for collection and field analysis of ground-water samples for selected unstable constituents. 24. U.S. Geological Survey Techniques of WaterResources Investigations. U.S. Geological Survey, Columbus, $\mathrm{OH}$.

Zohdy, A.A.R. 1973. A computer program for the automatic interpretation of Schlumberger sounding curves over horizontally stratified media. 25. National Technical Information Service, Springfield, VA, as U.S. Geological Survey Report USGS-GD-74-017, PB232. 703. U.S. Geological Survey, Columbus, $\mathrm{OH}$. 


\section{Appendix $B$ GLOSSARY}

Abandoned mined land ( $A M L$ ). An area of land that was mined for the extraction of a specific mineral resource prior to the passage of the Surface Mining Control and Reclamation Act of 1977 and not returned to an environmentally acceptable state.

Acid insoluble residue. A solid residue composed primarily of fly ash that is produced by the dissolution of dry FGD by-product with a weakly acidic buffer solution ( $\mathrm{pH}$ 5.0) prepared by mixing sodium acetate, acetic acid, and water.

Acidity. Acidity that can be neutralized by lime or other alkaline materials, but which cannot be replaced by an unbuffered salt solution.

Agricultural lime. A soil amendment containing calcium carbonate, magnesium carbonate, and other material, used to neutralize soil acidity and furnish calcium and magnesium for plant growth. Classification including calcium carbonate equivalent and limits in lime particle size is usually prescribed by law or regulation.

Alkaline amendment. Any material applied to a soil or spoil to raise the $\mathrm{pH}$.

Amenity. Any environmental good, such as a scenic view or clean water, which adds to the quality of life.

Anhydrite. The mineral name for anhydrous calcium sulfate, $\mathrm{CaSO}_{4}$.

Aquifer. An underground layer of earth or stone that stores water.

Available lime index. A method for measuring the amount of calcium oxide $(\mathrm{CaO})$ in a material (ASTM C 25). 
Baghouse. A particulate emission control device which utilizes fabric filters in the shape of elongated bags to remove particulate matter from flue gasses.

Base saturation. The extent to which the adsorption complex of a soil is saturated with alkali or alkaline earth cations expressed as a percentage of the cation exchange capacity measured at $\mathrm{pH}$ 7.0, which may include acidic cations such as $\mathrm{H}^{+}$and $\mathrm{Al}^{3+}$.

Bed (or bottom) ash. Non-combusted particulate material which accumulates on furnace beds during combustion of coal.

Beneficial reuse. Use of an industrial by-product in a manner which provides an economic and/or environmental benefit as an alternative to disposal.

Benefit-cost analysis. A procedure for evaluating decisions, or projects, in terms of their full economic consequences (i.e., social benefits and costs).

Blank (sample). A sample that is prepared and treated identically to that of an environmental sample but which does not contain any concentration of an element or elements.

Bulk density. The ratio of the dry mass of a material to its bulk volume.

Calcine. To remove all volatile components through heating. In this report the term is used to refer more specifically to the conversion of a carbonate mineral to its corresponding oxide by the removal of $\mathrm{CO}_{2}$.

Calcite. The mineral name for calcium carbonate, $\mathrm{CaCO}_{3}$.

Calcium carbonate equivalency (CCE). The quantity of acid-neutralizing substances in a material expressed relative to the acid-neutralizing capacity of $\mathrm{CaCO}_{3}$.

Cation exchange capacity (CEC). The sum of exchangeable cations that a soil, soil constituent, or other material can adsorb at a specific $\mathrm{pH}$. It is usually expressed in centimoles of charge per kilogram of exchanger $\left(\mathrm{cmol}_{\mathrm{c}} \mathrm{kg}^{-1}\right)$.

Chemical activity. The "effective" chemical concentration which can change from the absolute concentration due to variations in temperature, pressure and mixture composition. 
Chemical concentration. The total amount of a chemical element, ion or compound in a specified volume.

Coefficient of determination. The ratio of explained variation to total variation in multiple regression statistical analysis.

Cohesion. The tendency or ability of soil (or FGD) particles to stick together or remain together.

Compression index (strengths). A ratio of stress to strain used to characterize a soil subjected to one-dimensional strain.

Congruent dissolution. Refers to the complete stoichiometric dissolution of a solid such that if one takes a mineral of composition $A_{2} B_{3}$, the ratio of $A$ to $B$ in solution will be 2:3.

Detection limit. The limit of an analytical technique to detect the presence of an analyte. Specifically the concentration of an analyte which produces a signal equal to twice the standard deviation of the background signal fluctuations.

Disamenity. Any environmental intrusion, such as a landfill or air pollution which is unpleasant or even dangerous.

Dolomite. The mineral name for calcium magnesium carbonate, $\mathrm{CaMg}\left(\mathrm{CO}_{3}\right)_{2}$.

Dryprecipitation. Dust or other dry materials (in contrast to wet precipitation or rainfall) that are deposited from the air between rainfall events and contribute to the total inputs of elements to a land surface.

Dry scrubber. Any of several technologies for removing $\mathrm{SO}_{2}$ from flue gasses in which the reaction product is collected in a dry state in the particulate emission control devices (c.f. wet scrubber).

Ductinjection. A dry scrubber technology in which the sorbent is injected into the ductwork downstream from the boiler air pre-heaters in the lower flue gas temperature regions. 
Economic analysis. In contrast to financial analysis, economic analysis takes into account net economic returns to the whole society which frequently involves shadow prices to adjust for market or administered price imperfections.

\section{Elasticity (economic)}

a) price elasticity of supply (demand): the ratio of the percentage change in the quantity of a commodity supplied (demanded) per unit of time to the percentage change in the price of that commodity. If the elasticity is denoted $e$ then:

$$
\begin{array}{ll}
e>1 & \text { elastic demand/supply, } \\
\mathrm{e}<1 & \text { inelastic demand/supply, and } \\
\mathrm{e}=1 & \text { unitary elastic demand/supply. }
\end{array}
$$

b) income elasticity $\left(e_{m}\right)$ : The ratio of the percentage change in the amount of a commodity purchased per unit time to the percentage change in the buyers income. If $\mathrm{e}_{\mathrm{m}}>0$ the commodity is normal, $\mathrm{e}_{\mathrm{m}}<0$ the commodity is inferior, $e_{m}=1 \quad$ the commodity is a luxury, and $0<e_{m}<1$ the commodity is a necessity.

Electrostaticprecipitator(ESP). A particulate emission control device in which flue gasses are passed through a charged field and particulate matter is removed due to electrostatic attraction to charged plates.

Ettringite. The mineral name for hydrated calcium-aluminum hydroxysulfate, $\mathrm{Ca}_{6} \mathrm{Al}_{2}\left(\mathrm{SO}_{4}\right)_{3}(\mathrm{OH})_{12} \cdot 26 \mathrm{H}_{2} \mathrm{O}$.

Externalities. Incidental, third party or external effects from economic producers or consumption activity which is not accounted for by market prices.

Factor of safety. A value calculated using models incorporating various slope and material property values to quantify the relative stability of a embankment.

Failure surfaces. Failure planes (surfaces) generated by a computer program once all the necessary slope geometric data and material properties are specified. 
Financial analysis. Refers to net returns to private equity capital based on market or administered prices.

Flue gas desulfurization (FGD). The removal of sulfur dioxide from the combustion gasses of fossil fuel- (coal-) fired boilers.

Flue gas. Gasses resulting from the combustion of fossil fuels (coal).

Fluidized bed combustion (FBC). A coal combustion process in which a bed of mixed pulverized coal and sorbent (generally limestone) is fluidized by jets of air blowing up from the furnace floor.

Fly ash. The glassy inorganic particulate residue suspended in the flue gasses resulting from combustion of fossil fuel (coal).

Geochemicalspeciation. The equilibrium distribution of cationic, anionic, and neutral dissolved species in a solution expressed as the activity of the species.

Gypsum. The mineral name for hydrated calcium sulfate, $\mathrm{CaSO}_{4} \bullet 2 \mathrm{H}_{2} \mathrm{O}$.

Head (in a well). The top opening of a well or the top level of water in a well.

Hedonic prices. The implicit prices of attributes revealed to economic agents from the observed prices of differentiated goods and the specific amounts of characteristics associated with them.

Hedonic impacts. Impacts on the implicit prices of characteristics of differentiated goods.

Hematite. The mineral name for an iron oxide, $\mathrm{Fe}_{2} \mathrm{O}_{3}$.

Hydrated lime. Portlandite, $\mathrm{Ca}(\mathrm{OH})_{2}$, formed by the reaction of lime $(\mathrm{CaO})$ with water or steam.

Hydraulic conductivity. The rate of flow of pure water through a cross sectional area under a unit hydraulic gradient at the prevailing temperature. Synonymous with permeability coefficient, $K$. 
Hydraulic gradient. The change in water level over a given distance, be it horizontal, vertical or somewhere in between. Defined as $\Delta \mathrm{h} / \Delta \mathrm{l}$ where $\Delta \mathrm{h}$ is the change in head or water level, and $\Delta \mathrm{l}$ is the change in distance or elevation.

Hydrology. The science dealing with the distribution and movement of water.

ICP. Inductively Coupled Plasma atomic emission spectrophotometer. An instrument used to measure trace amounts (parts per million or parts per billion) of various chemical elements.

Inclinometer. An instrument capable, when placed in an embankment, of measuring movement of a soil mass.

Incongruent dissolution. Refers to the nonstoichiometric dissolution of a solid of composition $A_{2} B_{3}$ such that the ratio of $A$ to $B$ in solution is not equal to 2:3. This can be due to more $A$ or $B$ being dissolved and leaving the other ion behind, or to $A$ or $B$ precipitating out as a secondary phase.

Instrument calibration andstandardization. The optimization of an analytical instrument so as to provide specific output from analytical standards of known composition.

Interstitial water. Water that resides in soil when the soil is not in a saturated condition. This is water that resides in soil above the permanent groundwater table.

Isotope ratio. The ratio of two elemental isotopes. Usually one of the isotopes is that found in greatest abundance in the environment and the second isotope is found at a much lower concentration. The ratio of the two isotopes can be used to determine source and movement of an element in the environment. In this study, sulfur isotope ratios were used to help assess the source of sulfate in various types of water samples (e.g. surface water, groundwater, etc.).

Leachate. Water that is allowed to percolate through a soil column or soil profile.

LIMB process. Lime Injection Multistage Burners. A dry scrubber technology in which the sorbent is injected into the furnace above the combustion zone. 
Lime test index (LTI). An index value generated by reaction of a soil with an alkaline buffer and used to determine the amount of agricultural lime required to raise the $\mathrm{pH}$ of the soil to a specified level.

Lime. The mineral name for calcium oxide, $\mathrm{CaO}$.

Lime requirement. The amount of liming material required to change the soil to a specified state with respect to $\mathrm{pH}$ or soluble $\mathrm{Al}$ content.

Limestone. A rock of marine origin that is typically composed of calcite $\left(\mathrm{CaCO}_{3}\right)$.

Lithology. The scientific study of the nature and composition of stones and rocks.

Lysimeter. A device used to collect water that is in a soil. A water sample collect using a lysimeter can be used to measure both soil water volume and quality.

Magnetite. The mineral name for a magnetic iron oxide, $\mathrm{Fe}_{3} \mathrm{O}_{4}$.

Mehlich3 extractant. A solution made up of $0.2 \mathrm{M}$ acetic acid, $0.25 \mathrm{M}$ ammonium nitrate, $0.015 \mathrm{M}$ ammonium fluoride, $0.013 \mathrm{M}$ nitric acid and $0.001 \mathrm{M}$ (ethelenedinitrilo)tetracetic acid (EDTA) used to extract metals from soil.

Optimum density. The maximum density achievable with a standard compaction effort.

Optimum moisture content. The moisture content at which the optimum density is achieved.

Overburden. In surface mining practices, there is usually some quantity of rock or soil that overlies the mineral resource. This material is known as overburden and must be removed during surface mining to expose the mineral.

Oxidation-reduction potential (Eh). A measurement (expressed in $\mathrm{mV}$ ) of the tendency of a system to oxidize (accept electrons from) or reduce (donate electrons to) chemical species introduced into the system.

Particle size distribution. The fractions of the various soil separates in a soil sample, often expressed as mass percentages. 
Periclase. The mineral name for magnesium oxide, $\mathrm{MgO}$.

Permeability. A measure of the relative ease of fluid flow under unequal pressure.

Piezometer. A device for measuring the water pressure at a specific elevation in a soil mass.

Porosity. The volume of pores in a soil sample (nonsolid volume) divided by the bulk volume of the sample.

Portlandite. The mineral name for calcium hydroxide, $\mathrm{Ca}(\mathrm{OH})_{2}$.

Potential pareto improvement. An improvement in social welfare in which those who gain from the improvement could potentially compensate the perceived losses of the losers and still be no worse off.

Pressurized fluidized bed combustion (PFBC). A fluidized bed combustion technology modified such that the boiler is pressurized and the pressurized flue gas is used to turn a gas turbine for production of electricity in addition to steam generation to turn steam turbines.

Private costs/benefits (versus social costs/benefits). Costs or benefits borne by the producer and/or end user of the FGD.

Rainulator. A device used to deliver artificial rain with properties similar to that of natural rainfall.

Quality assurance $(Q A)$. Refers to a program of activities organized to insure that a laboratory produces data of adequate quality for its intended end use. To meet this data quality goal, an overall quality assurance program comprises numerous quality control activities.

Quality control $(Q C)$. Activities which address day-to-day analyses, as well as laboratory management, and are designed to insure that the data produced by a specific analytical procedure is of adequate quality for its intended end use. 
Residuals. The amount of a resource which is left over after a material has been transformed from one state to another in a economic production or consumption process, e.g., fly ash is a residual of the process of transforming coal to electric energy.

Saline soil. A nonsodic soil containing sufficient soluble salt to adversely affect the growth of most crop plants. The lower limit of saturation extract electrical conductivity of such soil solutions is conventionally set at $4000 \mu \mathrm{S} / \mathrm{cm}$. Sensitive plants may be affected at less than half this salinity value.

Saturation extract. The solution extracted from a soil at its saturation water content.

Saturation index (SI). A measurement of the degree to which a chemical system is under- or oversaturated with respect to a particular solid phase mineral. When SI is greater than 0 , the system is oversaturated and the mineral will tend to precipitate; when SI is less than 0 , the system is undersaturated and the mineral will tend to dissolve.

Social benefits (versus private benefits). Economic benefits enjoyed by all of society when FGD is appropriately used or recycled.

Social costs (versus private costs). Economic costs borne by society when FGD is inappropriately used or disposed.

Soil stabilization. The application of physical or chemical additives to a soil mass for the purpose of improving soil strength.

Specific conductance. The ability of a solution to allow the passage of an electrical current,

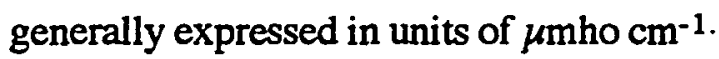

Specific surface area. The surface area per unit weight of a material, generally expressed in units of $\mathrm{m}^{2} \mathrm{~g}^{-1}$.

Spoil. Typically a mixture of overburden and uneconomic mineral deposits that are the result of mining operations. 
Spray dryer. A dry scrubber technology in which a sorbent is injected into a dry scrubber vessel located downstream from the boiler air preheater in the lower flue gas temperature region. The scrubber vessel allows for increased flue gas residence time and therefore increased time for the sorbent to react with $\mathrm{SO}_{2}$.

Stiffness (soil). The ratio of applied stress to induced strain i.e. s/e.

Stratigraphy. Assessment of the stratified geological material used to determine the historical changes in the geography of the earth.

Strength (soil). The maximum imposed stress a soil can withstand without failing.

Swell. A volume change associated with an FGD sample treated with water.

Tensiometer. A device for measuring soil water tension.

Thermal reactivity. The amount of heat generated by a material upon addition of water. Generally expressed as the increase in temperature in a specified time period from the addition of a specified amount of water to specified amount of the material.

Thermal gravimetric analysis (TGA). An analytical method for the quantification of mineral components in a sample by measuring the weight loss induced by heating over a specified temperature range.

Tipping fee. The amount charged by a facility accepting waste materials for the disposal of a given weight or volume of a specified waste.

Total neutralizing potential (TNP). The total amount of alkalinity in a material, determined by causing a complete reaction of a specified amount of the material with a specified amount of a standard acid.

Vertical Electric Soundings (VES). A series of measurements made by placing electrodes in the ground and measuring electrical resistivity that occurs between them. The resistivity is assumed to be a function of water quality and lithographic material. 
Wet scrubber. A process for removing $\mathrm{SO}_{2}$ from flue gasses in which the sorbent is injected downstream from the particulate emission control system, and the reaction product is collected in the form of a slurry consisting primarily of gypsum (c.f. dry scrubber).

Willingness to accept. This is the supply curve of an economic agent; it is the price at which the agent is willing to engage in trade with a demander of a good.

Willingness to pay (WTP). The demand curve of an economic agent. The price at which the agent is willing to purchase a good from a supplier.

$X$-ray diffraction $(X R D)$. An analytical technique for the qualitative identification of crystalline mineral components by measuring the scattering of $\mathrm{X}$-rays by the atoms of a crystal in definite directions away from the crystal (diffraction pattern). 


\section{Appendix C}

STEERING COMMITTEE

Baker, Bob

Ohio Dept. of Natural Resources

1855 Fountain Square Court

Columbus, $\mathrm{OH} 43224$

614-265-6633

Bedick, Robert C.

U.S. Department of Energy

Morgantown Energy Technology Center

P.O. Box 880

Collins Ferry Rd.

Morgantown, WV 26505

304-291-4505

Beeghly, Joel

Dravo Lime co.

Research Center

3600 Neville Rd.

Pittsburgh, PA 15225

412-777-0711

Bigham, Jerry

The Ohio State University

420A Kottman Hall

2021 Coffey Rd.

Columbus, $\mathrm{OH} 43210$

614-292-9066
Bird, Jacqueline

Ohio Coal Development Office

77 S. High Street

P.O Box 1001

Columbus, OH 43266-0101

614-466-3465

Brdicka, Ed

Ohio Env. Prot. Agency

Division of Solid Waste Management

P.O. Box 1049

1800 Water Mark Drive

Columbus, OH 43266-1049

614-644-3181

Cook, Adrian

Ohio Edison Co.

76 South Main St.

Akron, $\mathrm{OH} 44308$

216-384-4550

Dick, Warren

The Ohio State University

112 Williams Hall

OARDC/OSU

Wooster, OH 44691-4096

216-263-3877 
Forsythe, Russ

Dravo Lime Company

3600 One Oliver Plaza

Pittsburgh, PA 15222-2682

412-566-5553

Haefner, Ralph

USGS Water Resources Division

975 West Third Ave.

Columbus, $\mathrm{OH} 43212-3192$

614-469-5553 (FTS943 5553)

Harness, Jerry

U.S. Department of Energy

Morgantown Energy Technology Center

P.O. Box 880

Collins Ferry Road

Morgantown, WV 26505

304-291-4835

Hopkins, Ed

Ohio Citizens Action

17 Brickel Street

Columbus, $\mathrm{OH} 43215$

614-224-4111

Hyman, David

U:S. Bureau of Mines

Cochran Mill Road

P.O. Box 18070

Pittsburgh, PA 15236

412-892-6572
Johnson, Howard

Ohio Coal Development Office

$77 \mathrm{~S}$. High Street

P.O Box 1001

Columbus, $\mathrm{OH} 43266-0101$

614-466-3465

Keenan, Gregory

AEP Service Corporation

1 Riverside Plaza

Columbus, $\mathrm{OH} 43215$

614-223-1388

MacDonald, R. Jeffrey

ODNR Div of Reclamation AML 1855 Fountain Square Ct.

Columbus, $\mathrm{OH} 43224$

614-265-1016

Militaru, Calvin

AEP Service Corporation

1 Riverside Plaza

Columbus, $\mathrm{OH} 43215$

614-223-1384

Murarka, Ishwar P.

Electric Power Research Institute

3412 HillviewAvenue

P.O. Box 10412

Palo Alto, CA 94303

415-855-2150 
Renninger, Scott

U.S. Department of Energy

Morgantown Energy Technology Center

P.O. Box 880

Collins Ferry Road

Morgantown, WV 26505

304-285-4790

Rotering, Ernest

Ohio EPA, Div. of Solid Waste Mgmt.

P.O. Box 1049

1800 Water Mark Drive

Columbus, OH 43266-1049

614-644-3020

Seibel, Rick

Office of Surface Mining

U.S. Department of Interior

Ohio Section

2242 S. Hamilton

Columbus, $\mathrm{OH} 43232$

614-866-0578

Showman, Ray

AEP Service Corporation

1 Riverside Plaza

Columbus, $\mathrm{OH} 43215$

614-223-1000

Shupert, John

Ohio Mining \& Reclamation Association 129 N Tenth Street

Cambridge, $\mathrm{OH} 43725$

614-432-5645
Skiles, Mervin S.

USDA-Resource Conservation Service 200 N. High Street

Columbus, $\mathrm{OH} 43215$

614-469-6980

Stehouwer, Rick

Pennsylvania State University

$417 \mathrm{Ag}$ Sciences \& Industries Bldg.

University Park, PA 16802-3504

814-863-7640

Theodore, Frank W.

Consolidated Coal Co.

4000 Brownsville Road

Library, PA 15129

412-854-6663
Tostenson, Neal

Ohio Mining \& Reclamation Association

$50 \mathrm{~S}$. Young

Columbus, $\mathrm{OH} 43215$

614-228-6336 


\section{Appendix D}

\section{SUPPORTING DATA FROM THE FLEMING MINE SITE}

Table D-1. Geochemical data for aquifer materials from three core holes at the Fleming site.

Table D-2. Water quality data collected at the precipitation gage at the Dover Water Works, Dover, Ohio (February 1995 - December 1995).

Table D-3. Monitoring well water quality data in samples collected from sites surrounding the Fleming Site (June 1995 - January 1996).

Table D-4. Domestic well water quality data in samples collected from sites surrounding the Fleming Site (June 1995).

Table D-5. Interstitial water quality data in lysimeter samples collected from sites within the FGD treated areas of the Fleming Site (June 1995 - January 1996).

Table D-6. Interstitial water quality data in control area lysimeter samples and surface water quality data in samples collected from the Fleming Site (June 1995 - January 1996). 
Table D-1. Geochemical data for aquifer materials from three core holes at the Fleming site.

\begin{tabular}{|c|c|c|c|c|c|c|c|c|c|c|}
\hline \multirow{2}{*}{$\begin{array}{c}\text { Top of } \\
\text { interval } \\
\text { (feet) }\end{array}$} & \multirow{2}{*}{$\begin{array}{c}\text { Bottom of } \\
\text { interval } \\
\text { (feet) }\end{array}$} & \multirow{2}{*}{ Lithologya } & \multicolumn{8}{|c|}{ Constituent elements (weight percent) } \\
\hline & & & $\mathrm{Al}$ & $\mathrm{Ca}$ & $\mathrm{Fe}$ & $\mathbf{K}$ & $\mathrm{Mg}$ & $\mathrm{Na}$ & $\mathrm{P}$ & $\mathrm{Ti}$ \\
\hline \multicolumn{11}{|c|}{ Core Hole 1} \\
\hline 17 & 19.1 & d & 11 & 0.12 & 3.8 & 2.0 & 0.52 & 0.12 & 0.08 & 0.60 \\
\hline 19.1 & 19.3 & ss & 6.6 & 0.04 & 0.46 & 0.64 & 0.10 & 0.05 & 0.01 & 0.55 \\
\hline 19.3 & 22.3 & d & 14 & 0.17 & 1.5 & 1.9 & 0.38 & 0.14 & 0.06 & 0.70 \\
\hline 22.3 & 27.3 & d & 14 & 0.15 & 2.4 & 2.3 & 0.44 & 0.16 & 0.04 & 0.58 \\
\hline 27.3 & 30 & d & 14 & 0.24 & 2.2 & 2.6 & 0.53 & 0.17 & 0.03 & 0.61 \\
\hline 30 & 33 & sh & 12 & 0.16 & 2.1 & 2.6 & 0.49 & 0.16 & 0.03 & 0.56 \\
\hline 33 & 36 & sh & 9.7 & 0.09 & 1.2 & 2.3 & 0.39 & 0.14 & 0.02 & 0.49 \\
\hline 36 & 39.3 & sh & 8.6 & 0.17 & 2.9 & 2.1 & 0.62 & 0.12 & 0.02 & 0.42 \\
\hline 39.3 & 39.4 & sh & 9.7 & 0.36 & 5.1 & 2.4 & 0.83 & 0.14 & 0.03 & 0.48 \\
\hline 39.4 & 42.8 & sh & 7.8 & 0.08 & 1.9 & 2.1 & 0.51 & 0.12 & 0.02 & 0.47 \\
\hline 42.8 & 43.5 & ss & 5.3 & 0.05 & 1.3 & 1.3 & 0.30 & 0.08 & 0.02 & 0.36 \\
\hline 43.5 & 46.5 & sh & 7.0 & 0.08 & 2.0 & 1.7 & 0.52 & 0.11 & 0.03 & 0.39 \\
\hline 46.5 & 49.5 & sh & 7.4 & 0.09 & 2.2 & 1.9 & 0.56 & 0.11 & 0.03 & 0.43 \\
\hline 49.5 & 53 & sh & 7.1 & 0.12 & 2.5 & 1.8 & 0.54 & 0.11 & 0.03 & 0.41 \\
\hline 53 & 54.3 & ss & 5.4 & 0.09 & 2.2 & 1.3 & 0.40 & 0.08 & 0.02 & 0.31 \\
\hline 54.3 & 56.3 & sh & 8.4 & 0.09 & 2.2 & 2.0 & 0.62 & 0.13 & 0.03 & 0.45 \\
\hline 56.3 & 59.3 & ss & 5.8 & 0.09 & 2.0 & 1.4 & 0.48 & 0.09 & 0.02 & 0.31 \\
\hline 59.3 & 62.3 & ss & 5.7 & 0.07 & 1.8 & 1.4 & 0.40 & 0.08 & 0.02 & 0.34 \\
\hline 62.3 & 65.3 & ss & 3.7 & 0.06 & 1.3 & 0.75 & 0.23 & 0.05 & 0.03 & 0.29 \\
\hline 65.3 & 68.3 & ss & 2.0 & 0.04 & 0.59 & 0.35 & 0.12 & 0.03 & 0.02 & 0.20 \\
\hline 68.3 & 71.3 & ss & 1.6 & 0.02 & 0.53 & 0.24 & 0.09 & 0.02 & $0: 008$ & 0.09 \\
\hline 71.3 & 73.4 & ss & 1.4 & 0.02 & 0.48 & 0.21 & 0.07 & 0.02 & 0.007 & 0.08 \\
\hline 73.4 & 74.6 & ss & 1.2 & 0.02 & 0.41 & 0.15 & 0.0 & 0.02 & 0.01 & 0.19 \\
\hline 74.6 & 75.1 & coal & 2.3 & 0.10 & 2.2 & 0.32 & 0.10 & 0.03 & 0.008 & 0.23 \\
\hline 75.1 & 75.4 & ss & 1.8 & 0.02 & 0.75 & 0.19 & 0.06 & 0.02 & 0.007 & 0.10 \\
\hline 75.4 & 75.6 & d & 6.0 & 0.74 & 29 & 1.4 & 0.59 & 0.09 & 0.10 & 0.21 \\
\hline 75.6 & 76.8 & coal & 1.1 & 0.16 & 4.0 & 0.04 & 0.02 & 0.02 & $<0.005$ & 0.04 \\
\hline 76.8 & 80 & $\mathbf{s h}$ & 5.9 & 1.3 & 7.3 & 1.5 & 0.65 & 0.11 & 0.52 & 0.25 \\
\hline 80 & 80.6 & ss & 3.1 & 1.5 & 2.4 & 0.88 & 0.25 & 0.10 & 0.05 & 0.19 \\
\hline 80.6 & 83.6 & $\mathbf{s h}$ & 9.6 & 1.1 & 6.9 & 2.6 & 1.3 & 0.14 & 0.22 & 0.37 \\
\hline 83.6 & 86.6 & sh & 10 & 3.4 & 6.2 & 2.8 & 1.4 & 0.15 & 0.26 & 0.43 \\
\hline 86.6 & 89.6 & $\mathbf{s h}$ & 11 & 0.79 & 5.4 & 3.3 & 1.3 & 0.17 & 0.09 & 0.39 \\
\hline 89.6 & 93.4 & sh & 12 & 1.2 & 6.0 & 3.4 & 1.1 & 0.18 & 0.15 & 0.39 \\
\hline 93.4 & 97 & ls & 2.1 & 30 & 2.2 & 0.59 & 0.76 & 0.06 & 0.09 & 0.08 \\
\hline 97 & 98.7 & coal & 1.8 & 1.3 & 4.9 & 0.32 & 0.12 & 0.04 & 0.01 & 0.10 \\
\hline 98.7 & 99.5 & $\mathbf{s h}$ & 14 & 0.13 & 1.2 & 0.96 & 0.27 & 0.11 & 0.02 & 1.2 \\
\hline 99.5 & 101 & coal & 3.1 & 0.10 & 1.6 & 0.05 & 0.02 & 0.04 & $<0.005$ & 0.07 \\
\hline
\end{tabular}


Table D-1 (continued). Geochemical data for aquifer materials from three core holes at the Fleming site.

\begin{tabular}{|c|c|c|c|c|c|c|c|c|c|c|}
\hline \multirow{2}{*}{$\begin{array}{c}\text { Top of } \\
\text { interval } \\
\text { (feet) }\end{array}$} & \multirow{2}{*}{$\begin{array}{c}\text { Bottom of } \\
\text { interval } \\
\text { (feet) }\end{array}$} & \multicolumn{9}{|c|}{ Constituent elements (weight percent) } \\
\hline & & Lithologya & Al & $\mathrm{Ca}$ & $\mathrm{Fe}$ & $\mathbf{K}$ & $\mathrm{Mg}$ & $\mathrm{Na}$ & $\mathbf{P}$ & $\mathrm{Ti}$ \\
\hline \multicolumn{11}{|c|}{ Core Hole 2} \\
\hline 27 & 30 & d & 7.8 & 0.11 & 5.1 & 1.8 & 0.47 & 0.36 & 0.07 & 0.41 \\
\hline 35.5 & 39.6 & d & 9.4 & 0.1 & 2.4 & 2.2 & 0.40 & 0.13 & 0.03 & 0.52 \\
\hline 39.6 & 42.6 & ss & 4.9 & 0.04 & 1.2 & 1.1 & 0.26 & 0.07 & 0.02 & 0.27 \\
\hline 42.6 & 48.2 & ss & 2.6 & 0.04 & 0.77 & 0.53 & 0.16 & 0.04 & 0.02 & 0.19 \\
\hline 48.2 & 50.2 & ss & 2.8 & 0.04 & 0.78 & 0.58 & 0.19 & 0.04 & 0.02 & 0.18 \\
\hline 50.2 & 50.8 & d & 9.4 & 0.15 & 5.2 & 2.3 & 0.71 & 0.14 & 0.04 & 0.60 \\
\hline 50.8 & 53.8 & ss & 2.1 & 0.05 & 0.92 & 0.36 & 0.12 & 0.02 & 0.02 & 0.22 \\
\hline 53.8 & 56.8 & ss & 1.7 & 0.02 & 0.38 & 0.29 & 0.10 & 0.02 & 0.01 & 0.12 \\
\hline 56.8 & 59.5 & ss & 1.2 & 0.02 & 0.32 & 0.19 & 0.07 & 0.02 & 0.007 & 0.08 \\
\hline 59.5 & 61.6 & ss & 1.0 & 0.02 & 0.33 & 0.12 & 0.05 & 0.01 & 0.009 & 0.14 \\
\hline 61.6 & 61.9 & $\mathrm{coal} / \mathrm{sh}$ & 1.1 & 0.02 & 0.39 & 0.13 & 0.05 & 0.01 & 0.01 & 0.21 \\
\hline 61.9 & 64.9 & ss & 1.3 & 0.11 & 0.44 & 0.13 & 0.06 & 0.02 & 0.05 & 0.15 \\
\hline 64.9 & 69.5 & sh & 5.5 & 2.0 & 27 & 1.4 & 1.9 & 0.08 & 0.22 & 0.19 \\
\hline 69.5 & 70.9 & sh & 11 & 0.56 & 5.9 & 3.2 & 1.4 & 0.17 & 0.12 & 0.37 \\
\hline 70.9 & 73.6 & ls & 2.2 & 32 & 2.1 & 0.64 & 0.74 & 0.06 & 0.06 & 0.08 \\
\hline 73.6 & 75.2 & coal & 3.3 & 2.5 & 3.7 & 0.91 & 0.32 & 0.06 & 0.04 & 0.16 \\
\hline 75.2 & 77.3 & $\mathrm{cl}$ & 9.7 & 1.4 & 10 & 2.8 & 0.88 & 0.15 & 0.28 & 0.28 \\
\hline 77.3 & 78 & sh/coal & 1.2 & 0.1 & 3.6 & 0.10 & 0.03 & 0.04 & $<0.005$ & 0.06 \\
\hline 78 & 79.2 & coal & 2.6 & 0.13 & 7.7 & 0.10 & 0.03 & 0.02 & $<0.005$ & 0.08 \\
\hline
\end{tabular}

2cl, clay; ss, sandstone; sh, shale; ls, limestone; calc. sh, calcareous shale. 
Table D-1 (continued). Geochemical data for aquifer materials from three core holes at the Fleming site.

\begin{tabular}{|c|c|c|c|c|c|c|c|c|c|c|}
\hline \multirow{2}{*}{$\begin{array}{c}\text { Top of } \\
\text { interval } \\
\text { (feet) }\end{array}$} & \multirow{2}{*}{$\begin{array}{c}\text { Bottom of } \\
\text { interval } \\
\text { (feet) }\end{array}$} & \multirow{2}{*}{ Lithologya } & \multicolumn{8}{|c|}{ Constiulent elements (weight percent) } \\
\hline & & & $\mathrm{Al}$ & $\mathrm{Ca}$ & $\mathrm{Fe}$ & $\underline{\mathrm{K}}$ & $\mathrm{Mg}$ & $\mathrm{Na}$ & $\underline{P}$ & $\mathrm{Ti}$ \\
\hline \multicolumn{11}{|c|}{ Core Hole 3} \\
\hline 15 & 18.4 & d & 9.3 & 0.04 & 1.6 & 2.0 & 0.38 & 0.13 & 0.02 & 0.53 \\
\hline 18.4 & 19.8 & ss & 2.5 & 0.02 & 0.57 & 0.59 & 0.10 & 0.04 & 0.01 & 0.18 \\
\hline 19.8 & 22.8 & $\operatorname{sh}$ & 7.1 & 0.06 & 1.8 & 1.7 & 0.35 & 0.10 & 0.03 & 0.40 \\
\hline 22.8 & 25 & $\operatorname{sh}$ & 6.9 & 0.05 & 2.5 & 1.6 & 0.39 & 0.10 & 0.02 & 0.39 \\
\hline 25 & 27.9 & ss & 3.2 & 0.05 & 2.2 & 0.72 & 0.20 & 0.04 & 0.02 & 0.20 \\
\hline 27.9 & 32 & ss & 3.5 & 0.12 & 5.3 & 0.74 & 0.25 & 0.05 & 0.02 & 0.22 \\
\hline 32 & 36.5 & coal & 4.3 & 0.34 & 13 & 0.26 & 0.18 & 0.03 & 0.04 & 0.30 \\
\hline 36.5 & 38 & sh & 15 & 0.10 & 1.6 & 2.5 & 0.40 & 0.16 & 0.01 & 0.64 \\
\hline 38 & 39.5 & d & 15 & 0.11 & 1.9 & 2.7 & 0.46 & 0.17 & 0.01 & 0.66 \\
\hline 39.5 & 42.5 & $\mathrm{~d}$ & 15 & 0.10 & 2.4 & 1.7 & 0.37 & 0.16 & 0.02 & 0.83 \\
\hline 42.5 & 45.5 & $\mathrm{~d}$ & 15 & 0.12 & 1.6 & 2.1 & 0.37 & 0.16 & 0.04 & 0.68 \\
\hline 45.5 & 49.5 & $\mathbf{d}$ & 14 & 0.12 & 1.6 & 2.4 & 0.41 & 0.17 & 0.02 & 0.75 \\
\hline 49.5 & 52.5 & d & 13 & 0.11 & 1.6 & 2.4 & 0.42 & 0.17 & 0.02 & 0.53 \\
\hline 52.5 & 53 & $\mathbf{d}$ & 6.4 & 0.99 & 20 & 1.5 & 0.70 & 0.08 & 0.02 & 0.25 \\
\hline 53 & 57 & $\mathrm{sh} / \mathrm{cl}$ & 12 & 0.18 & 3.2 & 2.6 & 0.51 & 0.14 & 0.03 & 0.60 \\
\hline 57 & 59 & $\operatorname{sh}$ & 12 & 0.53 & 6.1 & 3.6 & 1.3 & 0.19 & 0.17 & 0.44 \\
\hline 59 & 61 & sh & 12 & 2.0 & 6.3 & 3.5 & 1.2 & 0.19 & 0.10 & 0.39 \\
\hline 61 & 63.5 & calc. sh & 1.2 & 32 & 3.0 & 0.32 & 0.84 & 0.04 & 0.24 & 0.04 \\
\hline 63.5 & 64.6 & sh/coal & 8.8 & 0.26 & 2.9 & 1.8 & 0.52 & 0.10 & 0.03 & 0.49 \\
\hline 64.6 & 67.6 & sh & 9.7 & 0.25 & 3.7 & 2.1 & 0.47 & 0.12 & 0.02 & 0.46 \\
\hline 67.6 & 70.2 & sh & 8.8 & 0.14 & 2.6 & 2.3 & 0.42 & 0.11 & 0.02 & 0.38 \\
\hline 70.2 & 73.2 & ss/sh & 8.9 & 0.10 & 2.7 & 2.4 & 0.60 & 0.12 & 0.02 & 0.36 \\
\hline 73.2 & 76.2 & sh & 9.9 & 0.14 & 3.3 & 2.8 & 0.85 & 0.12 & 0.04 & 0.52 \\
\hline 76.2 & 80 & sh & 9.2 & 0.27 & 5.0 & 2.5 & 0.78 & 0.12 & 0.04 & 0.39 \\
\hline 80 & 80.8 & ss & 5.9 & 0.05 & 2.0 & 1.4 & 0.32 & 0.09 & 0.01 & 0.23 \\
\hline 80.8 & 81.1 & sh & 14 & 0.16 & 2.0 & 3.5 & 0.64 & 0.19 & 0.02 & 0.48 \\
\hline 81.1 & 81.3 & $\mathrm{sh} / \mathrm{coal}$ & 12 & 0.25 & 2.6 & 1.5 & 0.40 & 0.14 & 0.25 & 0.81 \\
\hline
\end{tabular}

acl, clay; ss, sandstone; sh, shale; is, limestone; calc. sh, calcareous shale. 
Table D-1 (continued). Geochemical data for aquifer materials from three core holes at the Fleming site.

\begin{tabular}{|c|c|c|c|c|c|c|c|c|c|c|}
\hline \multirow{2}{*}{$\begin{array}{c}\text { Top of } \\
\text { interval } \\
\text { (feet) }\end{array}$} & \multirow{2}{*}{$\begin{array}{c}\text { Bottom of } \\
\text { interval } \\
\text { (feet) }\end{array}$} & \multirow{2}{*}{ Lithologya } & \multicolumn{8}{|c|}{ Constituent elements (weight percent) } \\
\hline & & & $\mathrm{Ag}$ & As & $\mathrm{Au}$ & $\mathrm{Ba}$ & $\mathrm{Be}$ & $\mathrm{Bi}$ & $\mathrm{Cd}$ & $\mathrm{Ce}$ \\
\hline \multicolumn{11}{|c|}{ Core Hole 1} \\
\hline 17 & 19.1 & d & $<2$ & 31 & $<8$ & 340 & 3 & $<10$ & $<2$ & 120 \\
\hline 19.1 & 19.3 & ss & $<2$ & 3.4 & $<8$ & 150 & 1 & $<10$ & $<2$ & 47 \\
\hline 19.3 & 22.3 & d & $<2$ & 10 & $<8$ & 730 & 3 & $<10$ & $<2$ & 210 \\
\hline 22.3 & 27.3 & d & $<2$ & 8.7 & $<8$ & 380 & 3 & $<10$ & $<2$ & 100 \\
\hline 27.3 & 30 & d & $<2$ & 1.9 & $<8$ & 470 & 3 & $<10$ & $<2$ & 94 \\
\hline 30 & 33 & sh & $<2$ & 18 & $<8$ & 520 & 3 & $<10$ & $<2$ & 110 \\
\hline 33 & 36 & sh & $<2$ & 1.1 & $<8$ & 510 & 3 & $<10$ & $<2$ & 120 \\
\hline 36 & 39.3 & sh & $<2$ & 1.4 & $<8$ & 460 & 3 & $<10$ & $<2$ & 110 \\
\hline 39.3 & 39.4 & sh & $<2$ & 1 & $<8$ & 480 & 3 & $<10$ & $<2$ & 110 \\
\hline 39.4 & 42.8 & sh & $<2$ & 1.5 & $<8$ & 440 & 2 & $<10$ & $<2$ & 95 \\
\hline 42.8 & 43.5 & ss & $<2$ & 3 & $<8$ & 290 & 1 & $<10$ & $<2$ & 56 \\
\hline 43.5 & 46.5 & sh & $<2$ & 5.6 & $<8$ & 360 & 2 & $<10$ & $<2$ & 81 \\
\hline 46.5 & 49.5 & sh & $<2$ & 4.3 & $<8$ & 390 & 2 & $<10$ & $<2$ & 84 \\
\hline 49.5 & 53 & sh & $<2$ & 3.1 & $<8$ & 380 & 2 & $<10$ & $<2$ & 84 \\
\hline 53 & 54.3 & ss & $<2$ & 4.3 & $<8$ & 280 & 2 & $<10$ & $<2$ & 58 \\
\hline 54.3 & 56.3 & sh & $<2$ & 3 & $<8$ & 400 & 3 & $<10$ & $<2$ & 100 \\
\hline 56.3 & 59.3 & ss & $<2$ & 3.4 & $<8$ & 300 & 2 & $<10$ & $<2$ & 80 \\
\hline 59.3 & 62.3 & ss & $<2$ & 2.7 & $<8$ & 300 & 2 & $<10$ & $<2$ & 73 \\
\hline 62.3 & 65.3 & ss & $<2$ & 4.1 & $<8$ & 450 & $<1$ & $<10$ & $<2$ & 68 \\
\hline 65.3 & 68.3 & ss & $<2$ & 1.9 & $<8$ & 84 & $<1$ & $<10$ & $<2$ & 56 \\
\hline 68.3 & 71.3 & ss & $<2$ & 1.1 & $<8$ & 62 & $<1$ & $<10$ & $<2$ & 19 \\
\hline 71.3 & 73.4 & ss & $<2$ & 0.8 & $<8$ & 56 & $<1$ & $<10$ & $<2$ & 22 \\
\hline 73.4 & 74.6 & ss & $<2$ & 2.1 & $<8$ & 50 & $<1$ & $<10$ & $<2$ & 86 \\
\hline 74.6 & 75.1 & coal & $<2$ & 20 & $<8$ & 250 & 9 & $<10$ & $<2$ & 28 \\
\hline 75.1 & 75.4 & ss & $<2$ & 4.5 & $<8$ & 180 & $<1$ & $<10$ & $<2$ & 23 \\
\hline 75.4 & 75.6 & d & $<2$ & 25 & $<8$ & 260 & 3 & $<10$ & $<2$ & 86 \\
\hline 75.6 & 76.8 & coal & $<2$ & 27 & $<8$ & 15 & 8 & $<10$ & $<2$ & 20 \\
\hline 76.8 & 80 & sh & $<2$ & 20 & $<8$ & 400 & 2 & $<10$ & $<2$ & 79 \\
\hline 80 & 80.6 & ss & $<2$ & 3.5 & $<8$ & 200 & 1 & $<10$ & $<2$ & 37 \\
\hline 80.6 & 83.6 & sh & $<2$ & $<0.2$ & $<8$ & 440 & 4 & $<10$ & $<2$ & 88 \\
\hline 83.6 & 86.6 & sh & $<2$ & 18 & $<8$ & 440 & 4 & $<10$ & $<2$ & 93 \\
\hline 86.6 & 89.6 & $\mathbf{s h}$ & $<2$ & 15 & $<8$ & 550 & 4 & $<10$ & $<2$ & 98 \\
\hline 89.6 & 93.4 & sh & $<2$ & 13 & $<8$ & 110 & 4 & $<10$ & $<2$ & 100 \\
\hline 93.4 & 97 & ls & $<2$ & 5.1 & $<8$ & 120 & 1 & $<10$ & $<2$ & 23 \\
\hline 97 & 98.7 & coal & $<2$ & 4.1 & $<8$ & 200 & 3 & $<10$ & $<2$ & 17 \\
\hline 98.7 & 99.5 & sh & $<2$ & 8.7 & $<8$ & 170 & 3 & $<10$ & $<2$ & 190 \\
\hline 99.5 & 101 & coal & $<2$ & 2.9 & 2.9 & 22 & 6 & $<10$ & $<2$ & $38 \AA$ \\
\hline
\end{tabular}

acl, clay; ss, sandstone; sh, shale; ls, limestone; calc. sh, calcareous shale. 
Table D-1 (continued). Geochemical data for aquifer materials from three core holes at the Fleming site.

\begin{tabular}{|c|c|c|c|c|c|c|c|c|c|c|}
\hline \multirow{2}{*}{$\begin{array}{c}\text { Top of } \\
\text { interval } \\
\text { (feet) }\end{array}$} & \multirow{2}{*}{$\begin{array}{c}\text { Bottom of } \\
\text { interval } \\
\text { (feet) }\end{array}$} & \multirow{2}{*}{ Lithologya } & \multicolumn{8}{|c|}{ Constituent elements (weight percent) } \\
\hline & & & $\mathrm{Ag}$ & As & $\mathrm{Au}$ & $\mathrm{Ba}$ & $\mathrm{Be}$ & $\mathrm{Bi}$ & $\mathrm{Cd}$ & $\mathrm{Ce}$ \\
\hline \multicolumn{11}{|c|}{ Core Hole 2} \\
\hline 27 & 30 & d & $<2$ & 27 & $<8$ & 440 & 2 & $<10$ & $<2$ & 87 \\
\hline 35.5 & 39.6 & cl & $<2$ & 4.6 & $<8$ & 490 & 2 & $<10$ & $<2$ & 120 \\
\hline 39.6 & 42.6 & ss & $<2$ & 3.2 & $<8$ & 400 & 1 & $<10$ & $<2$ & 62 \\
\hline 42.6 & 48.2 & ss & $<2$ & 2.2 & $<8$ & 250 & $<1$ & $<10$ & $<2$ & 62 \\
\hline 48.2 & 50.2 & ss & $<2$ & 1.4 & $<8$ & 150 & $<1$ & $<10$ & $<2$ & 47 \\
\hline 50.2 & 50.8 & d & $<2$ & 3.1 & $<8$ & 450 & 3 & $<10$ & $<2$ & 130 \\
\hline 50.8 & 53.8 & ss & $<2$ & 1.3 & $<8$ & 95 & $<1$ & $<10$ & $<2$ & 73 \\
\hline 53.8 & 56.8 & ss & $<2$ & 0.8 & $<8$ & 80 & $<1$ & $<10$ & $<2$ & 33 \\
\hline 56.8 & 59.5 & ss & $<2$ & 1.1 & $<8$ & 60 & $<1$ & $<10$ & $<2$ & 24 \\
\hline 59.5 & 61.6 & ss & $<2$ & 1.8 & $<8$ & 49 & $<1$ & $<10$ & $<2$ & 27 \\
\hline 61.6 & 61.9 & $\mathrm{coal} / \mathrm{sh}$ & $<2$ & 3.4 & $<8$ & 47 & $<1$ & $<10$ & $<2$ & 39 \\
\hline 61.9 & 64.9 & ss & $<2$ & 5.2 & $<8$ & 60 & $<1$ & $<10$ & $<2$ & 35 \\
\hline 64.9 & 69.5 & sh & $<2$ & 11 & $<8$ & 290 & 4 & $<10$ & $<2$ & 64 \\
\hline 69.5 & 70.9 & sh & $<2$ & 16 & $<8$ & 550 & 4 & $<10$ & $<2$ & 110 \\
\hline 70.9 & 73.6 & ls & $<2$ & 3.5 & $<8$ & 180 & $<1$ & $<10$ & $<2$ & 24 \\
\hline 73.6 & 75.2 & coal & $<2$ & 9.1 & $<8$ & 110 & 3 & $<10$ & $<2$ & 32 \\
\hline 75.2 & 77.3 & $\mathrm{cl}$ & $<2$ & 18 & $<8$ & 30 & 4 & $<10$ & $<2$ & 99 \\
\hline 77.3 & 78 & $\mathrm{sh} / \mathrm{coal}$ & $<2$ & 6.3 & $<8$ & 18 & 3 & $<10$ & $<2$ & 9 \\
\hline 78 & 79.2 & coal & $<2$ & 8.9 & $<8$ & 300 & 4 & $<10$ & $<2$ & 35 \\
\hline
\end{tabular}

acl, clay; ss, sandstone; sh, shale; ls, limestone; calc. sh, calcareous shale. 
Table D-1 (continued). Geochemical data for aquifer materials from three core holes at the Fleming site.

\begin{tabular}{|c|c|c|c|c|c|c|c|c|c|c|}
\hline \multirow{2}{*}{$\begin{array}{c}\text { Top of } \\
\text { interval } \\
\text { (feet) }\end{array}$} & \multirow{2}{*}{$\begin{array}{c}\text { Bottom of } \\
\text { interval } \\
\text { (feet) }\end{array}$} & \multirow{2}{*}{ Lithologya } & \multicolumn{8}{|c|}{ Constituent elements (weight percent) } \\
\hline & & & $\mathrm{Ag}$ & As & $\mathrm{Au}$ & $\mathrm{Ba}$ & $\mathrm{Be}$ & $\mathrm{Bi}$ & $\mathrm{Cd}$ & $\mathrm{Ce}$ \\
\hline \multicolumn{11}{|c|}{ Core Hole 3} \\
\hline 15 & 18.4 & d & $<2$ & 2.7 & $<8$ & 450 & 2 & $<10$ & $<2$ & 140 \\
\hline 18.4 & 19.8 & ss & $<2$ & 2.3 & $<8$ & 140 & $<1$ & $<10$ & $<2$ & 43 \\
\hline 19.8 & 22.8 & sh & $<2$ & 5.1 & $<8$ & 380 & 2 & $<10$ & $<2$ & 97 \\
\hline 22.8 & 25 & $\operatorname{sh}$ & $<2$ & 4 & $<8$ & 470 & 2 & $<10$ & $<2$ & 97 \\
\hline 25 & 27.9 & ss & $<2$ & 4.9 & $<8$ & 240 & $<1$ & $<10$ & $<2$ & 60 \\
\hline 27.9 & 32 & ss & $<2$ & 15 & $<8$ & 180 & $<1$ & $<10$ & $<2$ & 56 \\
\hline 32 & 36.5 & coal & $<2$ & 30 & $<8$ & 79 & 4 & $<10$ & $<2$ & 50 \\
\hline 36.5 & 38 & sh & $<2$ & 5.4 & $<8$ & 520 & 3 & $<10$ & $<2$ & 81 \\
\hline 38 & 39.5 & d & $<2$ & 8.4 & $<8$ & 500 & 3 & $<10$ & $<2$ & 90 \\
\hline 39.5 & 42.5 & d & $<2$ & 10 & $<8$ & 360 & 3 & $<10$ & $<2$ & 120 \\
\hline 42.5 & 45.5 & d & $<2$ & 7.6 & $<8$ & 440 & 3 & $<10$ & $<2$ & 140 \\
\hline 45.5 & 49.5 & d & $<2$ & 5 & $<8$ & 500 & 3 & $<10$ & $<2$ & 92 \\
\hline 49.5 & 52.5 & d & $<2$ & 5.2 & $<8$ & 490 & 3 & $<10$ & $<2$ & 120 \\
\hline 52.5 & 53 & d & $<2$ & 15 & $<8$ & 310 & 3 & $<10$ & $<2$ & 50 \\
\hline 53 & 57 & $\mathrm{sh} / \mathrm{cl}$ & $<2$ & 7.3 & $<8$ & 530 & 3 & $<10$ & $<2$ & 150 \\
\hline 57 & 59 & sh & $<2$ & 16 & $<8$ & 130 & 4 & $<10$ & $<2$ & 130 \\
\hline 59 & 61 & sh & $<2$ & 25 & $<8$ & 71 & 4 & $<10$ & $<2$ & 100 \\
\hline 61 & 63.5 & calc. sh & $<2$ & 26 & $<8$ & 90 & $<1$ & 10 & $<2$ & 47 \\
\hline 63.5 & 64.6 & $\mathrm{sh} / \mathrm{coal}$ & $<2$ & 7.2 & $<8$ & 320 & 3 & $<10$ & $<2$ & 89 \\
\hline 64.6 & 67.6 & sh & $<2$ & 5.6 & $<8$ & 420 & 3 & $<10$ & $<2$ & 100 \\
\hline 67.6 & 70.2 & sh & $<2$ & 3.6 & $<8$ & 470 & 3 & $<10$ & $<2$ & 180 \\
\hline 70.2 & 73.2 & $\mathrm{ss} / \mathrm{sh}$ & $<2$ & 1.9 & $<8$ & 490 & 2 & $<10$ & $<2$ & 110 \\
\hline 73.2 & 76.2 & sh & $<2$ & 1.5 & $<8$ & 560 & 3 & $<10$ & $<2$ & 150 \\
\hline 76.2 & 80 & sh & $<2$ & 1.8 & $<8$ & 520 & 3 & $<10$ & $<2$ & 110 \\
\hline 80 & 80.8 & ss & $<2$ & 4.1 & $<8$ & 310 & 1 & $<10$ & $<2$ & 52 \\
\hline 80.8 & 81.1 & sh & $<2$ & 4 & $<8$ & 730 & 4 & $<10$ & $<2$ & 87 \\
\hline 81.1 & 81.3 & $\mathrm{sh} / \mathrm{coal}$ & $<2$ & 91 & $<8$ & 160 & 8 & $<10$ & $<2$ & 380 \\
\hline
\end{tabular}

acl, clay; ss, sandstone; sh, shale; ls, limestone; calc. sh, calcareous shale. 
Table D-1 (continued). Geochemical data for aquifer materials from three core holes at the Fleming site.

\begin{tabular}{|c|c|c|c|c|c|c|c|c|c|c|}
\hline \multirow{2}{*}{$\begin{array}{c}\text { Top of } \\
\text { interval } \\
\text { (feet) }\end{array}$} & \multirow{2}{*}{$\begin{array}{c}\text { Bottom of } \\
\text { interval } \\
\text { (feet) }\end{array}$} & \multirow{2}{*}{ Lithologya } & \multicolumn{8}{|c|}{ Constituent elements (weight percent) } \\
\hline & & & Co & $\mathrm{Cr}$ & $\mathrm{Cu}$ & $\mathrm{Eu}$ & $\mathrm{Ga}$ & Ho & La & $\mathbf{L i}$ \\
\hline \multicolumn{11}{|c|}{ Core Hole 1} \\
\hline 17 & 19.1 & d & 20 & 120 & 38 & $<2$ & 28 & $<4$ & 62 & 130 \\
\hline 19.1 & 19.3 & ss & 8 & 66 & 23 & $<2$ & 18 & $<4$ & 29 & 56 \\
\hline 19.3 & 22.3 & d & 13 & 120 & 44 & $<2$ & 34 & $<4$ & 140 & 150 \\
\hline 22.3 & 27.3 & d & 12 & 120 & 36 & $<2$ & 36 & $<4$ & 61 & 170 \\
\hline 27.3 & 30 & d & 11 & 140 & 33 & $<2$ & 32 & $<4$ & 55 & 160 \\
\hline 30 & 33 & sh & 9 & 120 & 41 & $<2$ & 28 & $<4$ & 67 & 95 \\
\hline 33 & 36 & sh & 9 & 94 & 20 & $<2$ & 22 & $<4$ & 60 & 81 \\
\hline 36 & 39.3 & sh & 19 & 92 & 16 & $<2$ & 18 & $<4$ & 60 & 73 \\
\hline 39.3 & 39.4 & sh & 18 & 95 & 6 & $<2$ & 29 & $<4$ & 60 & 73 \\
\hline 39.4 & 42.8 & sh & 16 & 82 & 11 & $<2$ & 18 & $<4$ & 51 & 54 \\
\hline 42.8 & 43.5 & ss & 10 & 59 & 17 & $<2$ & 13 & $<4$ & 29 & 28 \\
\hline 43.5 & 46.5 & sh & 21 & 73 & 14 & $<2$ & 16 & $<4$ & 45 & 57 \\
\hline 46.5 & 49.5 & sh & 20 & 82 & 14 & $<2$ & 20 & $<4$ & 45 & 68 \\
\hline 49.5 & 53 & sh & 17 & 78 & 11 & $<2$ & 16 & $<4$ & 46 & 62 \\
\hline 53 & 54.3 & ss & 13 & 52 & 9 & $<2$ & 12 & $<4$ & 32 & 40 \\
\hline 54.3 & 56.3 & sh & 19 & 90 & 12 & $<2$ & 19 & $<4$ & 54 & 83 \\
\hline 56.3 & 59.3 & ss & 16 & 70 & 12 & $<2$ & 16 & $<4$ & 48 & 54 \\
\hline 59.3 & 62.3 & ss & 19 & 66 & 9 & $<2$ & 14 & $<4$ & 38 & 47 \\
\hline 62.3 & 65.3 & ss & 10 & 59 & 11 & $<2$ & 11 & $<4$ & 35 & 23 \\
\hline 65.3 & 68.3 & ss & 7 & 55 & 13 & $<2$ & 4 & $<4$ & 28 & 10 \\
\hline 68.3 & 71.3 & ss & 6 & 15 & 2 & $<2$ & $<4$ & $<4$ & 11 & 7 \\
\hline 71.3 & 73.4 & ss & 5 & 14 & 19 & $<2$ & $<4$ & $<4$ & 12 & 6 \\
\hline 73.4 & 74.6 & ss & 5 & 54 & 3 & $<2$ & $<4$ & $<4$ & 43 & 5 \\
\hline 74.6 & 75.1 & coal & 15 & 94 & 38 & $<2$ & 16 & $<4$ & 14 & 26 \\
\hline 75.1 & 75.4 & ss & 4 & 11 & 4 & $<2$ & $<4$ & $<4$ & 12 & 7 \\
\hline 75.4 & 75.6 & d & 22 & 44 & 10 & $<2$ & 32 & $<4$ & 45 & 61 \\
\hline 75.6 & 76.8 & coal & 14 & 25 & 13 & $<2$ & 7 & $<4$ & 9 & 25 \\
\hline 76.8 & 80 & sh & 19 & 55 & 28 & $<2$ & 14 & $<4$ & 42 & 42 \\
\hline 80 & 80.6 & ss & 10 & 31 & 9 & $<2$ & 7 & $<4$ & 21 & 19 \\
\hline 80.6 & 83.6 & sh & 20 & 100 & 28 & $<2$ & 30 & $<4$ & 49 & 80 \\
\hline 83.6 & 86.6 & sh & 21 & 99 & 31 & $<2$ & 28 & $<4$ & 51 & 86 \\
\hline 86.6 & 89.6 & sh & 23 & 100 & 30 & $<2$ & 26 & $<4$ & 51 & 87 \\
\hline 89.6 & 93.4 & sh & 22 & 100 & 36 & $<2$ & 35 & $<4$ & 50 & 61 \\
\hline 93.4 & 97 & ls & 6 & 21 & 7 & $<2$ & 4 & $<4$ & 15 & 8 \\
\hline 97 & 98.7 & coal & 5 & 28 & 12 & $<2$ & 6 & $<4$ & 8 & 9 \\
\hline 98.7 & 99.5 & sh & 29 & 210 & 140 & 3 & 45 & $<4$ & 95 & 210 \\
\hline 99.5 & 101 & coal & 18 & 67 & 20 & $<2$ & 13 & $<4$ & 17 & 60 \\
\hline
\end{tabular}


Table D-1 (continued). Geochemical data for aquifer materials from three core holes at the Fleming site.

\begin{tabular}{|c|c|c|c|c|c|c|c|c|c|c|}
\hline \multirow{2}{*}{$\begin{array}{c}\text { Top of } \\
\text { interval } \\
\text { (feet) }\end{array}$} & \multirow{2}{*}{$\begin{array}{c}\text { Bottom of } \\
\text { interval } \\
\text { (feet) }\end{array}$} & \multirow{2}{*}{ Lithologya } & \multicolumn{8}{|c|}{ Constiment elements (weight percent) } \\
\hline & & & Co & $\mathrm{Cr}$ & $\mathrm{Cu}$ & $\mathrm{Eu}$ & $\mathrm{Ga}$ & Ho & $\mathrm{La}$ & $\mathrm{Li}$ \\
\hline \multicolumn{11}{|c|}{ Core Hole 2} \\
\hline 27 & 30 & d & 17 & 78 & 22 & $<2$ & 18 & $<4$ & 45 & 68 \\
\hline 35.5 & 39.6 & d & 8 & 96 & 21 & $<2$ & 24 & $<4$ & 61 & 96 \\
\hline 39.6 & 42.6 & ss & 10 & 47 & 11 & $<2$ & 10 & $<4$ & 31 & 35 \\
\hline 42.6 & 48.2 & ss & 6 & 46 & 6 & $<2$ & 6 & $<4$ & 31 & 14 \\
\hline 48.2 & 50.2 & ss & 6 & 30 & 6 & $<2$ & 7 & $<4$ & 24 & 18 \\
\hline 50.2 & 50.8 & d & 30 & 110 & 14 & $<2$ & 23 & $<4$ & 70 & 83 \\
\hline 50.8 & 53.8 & ss & 4 & 42 & 8 & $<2$ & 4 & $<4$ & 36 & 10 \\
\hline 53.8 & 56.8 & ss & 3 & 19 & 4 & $<2$ & $<4$ & $<4$ & 17 & 7 \\
\hline 56.8 & 59.5 & ss & 2 & 14 & 19 & $<2$ & $<4$ & $<4$ & 12 & 6 \\
\hline 59.5 & 61.6 & ss & 4 & 20 & 19 & $<2$ & $<4$ & $<4$ & 13 & 4 \\
\hline 61.6 & 61.9 & $\mathrm{coal} / \mathrm{sh}$ & 6 & 37 & 25 & $<2$ & $<4$ & $<4$ & 18 & 5 \\
\hline 61.9 & 64.9 & ss & 8 & 23 & 25 & $<2$ & $<4$ & $<4$ & 17 & 5 \\
\hline 64.9 & 69.5 & sh & 19 & 64 & 8 & 2 & 19 & $<4$ & 31 & 40 \\
\hline 69.5 & 70.9 & sh & 21 & 100 & 29 & $<2$ & 30 & $<4$ & 53 & 75 \\
\hline 70.9 & 73.6 & 1s & 6 & 23 & 9 & $<2$ & 5 & $<4$ & 15 & 7 \\
\hline 73.6 & 75.2 & coal & 15 & 45 & 16 & $<2$ & 7 & $<4$ & 16 & 11 \\
\hline 75.2 & 77.3 & cl & 38 & 110 & 29 & 2 & 25 & $<4$ & 47 & 44 \\
\hline 77.3 & 78 & $\mathrm{sh} / \mathrm{coal}$ & 8 & 28 & 27 & $<2$ & 13 & $<4$ & 4 & 8 \\
\hline 78 & 79.2 & coal & 170 & 42 & 13 & $<2$ & 12 & $<4$ & 15 & 47 \\
\hline
\end{tabular}

acl, clay; ss, sandstone; sh, shale; ls, limestone; calc. sh, calcareous shale. 
Table D-1 (continued). Geochemical data for aquifer materials from three core holes at the Fleming site.

\begin{tabular}{|c|c|c|c|c|c|c|c|c|c|c|}
\hline \multirow{2}{*}{$\begin{array}{c}\text { Top of } \\
\text { interval } \\
\text { (feet) }\end{array}$} & \multirow{2}{*}{$\begin{array}{c}\text { Bottom of } \\
\text { interval } \\
\text { (feet) }\end{array}$} & \multirow{2}{*}{ Lithology } & \multicolumn{8}{|c|}{ Constituent elements (weight percent) } \\
\hline & & & Co & $\mathrm{Cr}$ & $\mathrm{Cu}$ & Eu & $\mathrm{Ga}$ & Ho & $\mathrm{La}$ & $\mathrm{Li}$ \\
\hline \multicolumn{11}{|c|}{ Core Hole 3} \\
\hline 15 & 18.4 & $\mathrm{~d}$ & 11 & 97 & 13 & $<2$ & 23 & $<4$ & 68 & 120 \\
\hline 18.4 & 19.8 & ss & 4 & 26 & 6 & $<2$ & 6 & $<4$ & 23 & 16 \\
\hline 19.8 & 22.8 & sh & 10 & 74 & 13 & $<2$ & 18 & $<4$ & 51 & 62 \\
\hline 22.8 & 25 & sh & 17 & 74 & 16 & $<2$ & 17 & $<4$ & 50 & 64 \\
\hline 25 & 27.9 & ss & 13 & 32 & 5 & $<2$ & 6 & $<4$ & 30 & 22 \\
\hline 27.9 & 32 & ss & 17 & 42 & 10 & $<2$ & 8 & $<4$ & 30 & 26 \\
\hline 32 & 36.5 & coal & 23 & 93 & 62 & $<2$ & 12 & $<4$ & 21 & 64 \\
\hline 36.5 & 38 & sh & 15 & 100 & 6 & $<2$ & 44 & $<4$ & 44 & 150 \\
\hline 38 & 39.5 & d & 18 & 110 & 5 & $<2$ & 48 & $<4$ & 48 & 180 \\
\hline 39.5 & 42.5 & d & 25 & 140 & 75 & 3 & 44 & $<4$ & 56 & 340 \\
\hline 42.5 & 45.5 & d & 18 & 130 & 44 & $<2$ & 43 & $<4$ & 80 & 230 \\
\hline 45.5 & 49.5 & $\mathrm{~d}$ & 15 & 110 & 24 & $<2$ & 43 & $<4$ & 51 & 210 \\
\hline 49.5 & 52.5 & d & 15 & 110 & 26 & $<2$ & 35 & $<4$ & 60 & 160 \\
\hline 52.5 & 53 & d & 18 & 55 & 37 & $<2$ & 13 & $<4$ & 27 & 25 \\
\hline 53 & 57 & $\mathrm{sh} / \mathrm{cl}$ & 16 & 110 & 42 & $<2$ & 37 & $<4$ & 72 & 87 \\
\hline 57 & 59 & sh & 28 & 120 & 38 & 3 & 30 & $<4$ & 60 & 100 \\
\hline 59 & 61 & sh & 23 & 130 & 22 & $<2$ & 29 & $<4$ & 55 & 71 \\
\hline 61 & 63.5 & calc. sh & 7 & 15 & 6 & $<2$ & $<4$ & $<4$ & 23 & 8 \\
\hline 63.5 & 64.6 & $\mathrm{sh} / \mathrm{coal}$ & 21 & 92 & 20 & $<2$ & 21 & $<4$ & 48 & 100 \\
\hline 64.6 & 67.6 & sh & 13 & 86 & 15 & $<2$ & 23 & $<4$ & 54 & 62 \\
\hline 67.6 & 70.2 & sh & 11 & 68 & 34 & 3 & 21 & $<4$ & 89 & 34 \\
\hline 70.2 & 73.2 & ss/sh & 19 & 71 & 26 & $<2$ & 23 & $<4$ & 56 & 38 \\
\hline 73.2 & 76.2 & $\mathbf{s h}$ & 27 & 88 & 36 & 2 & 26 & $<4$ & 76 & 49 \\
\hline 76.2 & 80 & sh & 20 & 75 & 28 & $<2$ & 26 & $<4$ & 58 & 44 \\
\hline 80 & 80.8 & ss & 7 & 35 & 8 & $<2$ & 14 & $<4$ & 28 & 18 \\
\hline 80.8 & 81.1 & $\mathbf{s h}$ & 12 & 120 & 54 & $<2$ & 43 & $<4$ & 46 & 98 \\
\hline 81.1 & 81.3 & $\mathrm{sh} /$ coal & 26 & 130 & 65 & 6 & 34 & $<4$ & 170 & 380 \\
\hline
\end{tabular}

acl, clay; ss, sandstone; sh, shale; ls, limestone; calc. sh, calcareous shale. 
Table D-1 (continued). Geochemical data for aquifer materials from three core holes at the Fleming site.

\begin{tabular}{|c|c|c|c|c|c|c|c|c|c|c|}
\hline \multirow{2}{*}{$\begin{array}{c}\text { Top of } \\
\text { interval } \\
\text { (feet) }\end{array}$} & \multirow{2}{*}{$\begin{array}{c}\text { Bottom of } \\
\text { interval } \\
\text { (feet) }\end{array}$} & \multirow{2}{*}{ Lithologya } & \multicolumn{8}{|c|}{ Constituent elements (weight percent) } \\
\hline & & & Mn & Mo & $\mathrm{Nb}$ & Nd & $\mathrm{Ni}$ & $\mathrm{Pb}$ & Sc & $\mathrm{Se}$ \\
\hline \multicolumn{11}{|c|}{ Core Hole 1} \\
\hline 17 & 19.1 & $\mathrm{~d}$ & 230 & 4 & 24 & 48 & 52 & 32 & 20 & 1.9 \\
\hline 19.1 & 19.3 & ss & 55 & 2 & 26 & 17 & 16 & $<4$ & 11 & 0.7 \\
\hline 19.3 & 22.3 & d & 94 & 6 & 26 & 79 & 45 & 36 & 23 & 22 \\
\hline 22.3 & 27.3 & d & 52 & 2 & 23 & 37 & 40 & 49 & 26 & 6.4 \\
\hline 27.3 & 30 & d & 180 & $<2$ & 24 & 37 & 40 & 14 & 24 & 3 \\
\hline 30 & 33 & sh & 190 & $<2$ & 19 & 48 & 34 & 21 & 20 & 1.8 \\
\hline 33 & 36 & sh & 75 & $<2$ & 17 & 57 & 23 & 12 & 15 & 0.2 \\
\hline 36 & 39.3 & sh & 220 & $<2$ & 11 & 51 & 38 & 17 & 16 & 0.3 \\
\hline 39.3 & 39.4 & $\operatorname{sh}$ & 400 & 4 & 13 & 50 & 36 & 33 & 18 & 0.2 \\
\hline 39.4 & 42.8 & $\mathrm{sh}$ & 120 & $<2$ & 11 & 42 & 29 & 14 & 13 & 0.4 \\
\hline 42.8 & 43.5 & ss & 81 & $<2$ & 8 & 26 & 18 & 14 & 8 & 0.4 \\
\hline 43.5 & 46.5 & sh & 140 & $<2$ & 11 & 37 & 37 & 15 & 12 & 0.5 \\
\hline 46.5 & 49.5 & sh & 170 & 2 & 12 & 38 & 37 & 19 & 12 & 0.6 \\
\hline 49.5 & 53 & sh & 290 & $<2$ & 11 & 38 & 32 & 11 & 12 & 0.5 \\
\hline 53 & 54.3 & ss & 330 & $<2$ & 8 & 26 & 25 & 10 & 9 & 0.6 \\
\hline 54.3 & 56.3 & sh & 180 & $<2$ & 15 & 43 & 37 & 16 & 14 & 0.7 \\
\hline 56.3 & 59.3 & ss & 210 & $<2$ & 7 & 36 & 30 & 16 & 11 & 0.5 \\
\hline 59.3 & 62.3 & ss & 220 & 2 & 8 & 33 & 31 & 13 & 9 & 0.4 \\
\hline 62.3 & 65.3 & ss & 160 & $<2$ & 8 & 30 & 22 & 16 & 5 & 0.3 \\
\hline 65.3 & 68.3 & ss & 94 & $<2$ & 4 & 26 & 13 & 4 & 2 & 0.2 \\
\hline 68.3 & 71.3 & ss & 120 & $<2$ & $<4$ & 8 & 10 & 4 & $<2$ & $<0.1$ \\
\hline 71.3 & 73.4 & ss & 120 & $<2$ & $<4$ & 9 & 9 & $<4$ & $<2$ & $<0.1$ \\
\hline 73.4 & 74.6 & ss & 49 & $<2$ & $<4$ & 37 & 9 & 11 & $<2$ & 0.2 \\
\hline 74.6 & 75.1 & coal & 58 & 6 & 8 & 13 & 78 & 38 & 13 & 9.0 \\
\hline 75.1 & 75.4 & ss & 25 & $<2$ & $<4$ & 9 & 9 & 7 & $<2$ & 0.5 \\
\hline 75.4 & 75.6 & $\mathbf{c l}$ & 7500 & 3 & $<4$ & 36 & 52 & 110 & 8 & 1.3 \\
\hline 75.6 & 76.8 & coal & 31 & 3 & $<4$ & 8 & 19 & 18 & 8 & 9.1 \\
\hline 76.8 & 80 & sh & 1400 & $<2$ & $<4$ & 40 & 47 & 25 & 10 & 1 \\
\hline 80 & 80.6 & ss & 970 & $<2$ & $<4$ & 16 & 23 & 12 & 4 & 0.3 \\
\hline 80.6 & 83.6 & sh & 970 & $<2$ & 13 & 34 & 48 & 36 & 17 & 1.3 \\
\hline 83.6 & 86.6 & sh & 770 & $<2$ & 11 & 46 & 55 & 29 & 17 & 1.6 \\
\hline 86.6 & 89.6 & sh & 580 & 3 & 12 & 42 & 50 & 15 & 20 & 0.8 \\
\hline 89.6 & 93.4 & sh & 390 & $<2$ & 15 & 49 & 62 & 48 & 19 & 1.9 \\
\hline 93.4 & 97 & ls & 1100 & $<2$ & $<4$ & $<4$ & 28 & 14 & 4 & 1.6 \\
\hline 97 & 98.7 & coal & 86 & 8 & $<4$ & 8 & 20 & 13 & 5 & 10.0 \\
\hline 98.7 & 99.5 & sh & 45 & 11 & 46 & 84 & 57 & 42 & 33 & 45 \\
\hline 99.5 & 101 & coal & 15 & 3 & 5 & 16 & 32 & 20 & 16 & 13.2 \\
\hline
\end{tabular}

acl, clay; ss, sandstone; sh, shale; ls, limestone; calc. sh, calcareous shale. 
Table D-1 (continued). Geochemical data for aquifer materials from three core holes at the Fleming site.

\begin{tabular}{|c|c|c|c|c|c|c|c|c|c|c|}
\hline \multirow{2}{*}{$\begin{array}{c}\text { Top of } \\
\text { interval } \\
\text { (feet) }\end{array}$} & \multirow{2}{*}{$\begin{array}{c}\text { Bottom of } \\
\text { interval } \\
\text { (feet) }\end{array}$} & \multirow{2}{*}{ Lithologya } & \multicolumn{8}{|c|}{ Constituent elements (weight percent) } \\
\hline & & & $\mathrm{Mn}$ & Mo & $\mathrm{Nb}$ & Nd & $\mathrm{Ni}$ & $\mathrm{Pb}$ & Sc & $\mathrm{Se}$ \\
\hline \multicolumn{11}{|c|}{ Core Hole 2} \\
\hline 27 & 30 & d & 880 & 2 & 14 & 35 & 30 & 30 & 13 & 1.3 \\
\hline 35.5 & 39.6 & d & 110 & $<2$ & 21 & 50 & 17 & 17 & 16 & 0.7 \\
\hline 39.6 & 42.6 & ss & 95 & $<2$ & 6 & 28 & 21 & 11 & 7 & 0.6 \\
\hline 42.6 & 48.2 & ss & 61 & $<2$ & 4 & 27 & 13 & 9 & 4 & 0.6 \\
\hline 48.2 & 50.2 & ss & 79 & $<2$ & $<4$ & 20 & 12 & 6 & 4 & 0.9 \\
\hline 50.2 & 50.8 & d & 670 & $<2$ & 18 & 55 & 57 & 7 & 17 & 0.9 \\
\hline 50.8 & 53.8 & ss & 99 & $<2$ & $<4$ & 32 & 8 & 6 & 3 & $<0.1$ \\
\hline 53.8 & 56.8 & ss & 34 & $<2$ & $<4$ & 14 & 6 & 5 & 2 & $<0.1$ \\
\hline 56.8 & 59.5 & ss & 27 & $<2$ & $<4$ & 10 & 6 & $<4$ & $<2$ & $<0.1$ \\
\hline 59.5 & 61.6 & ss & 32 & $<2$ & $<4$ & 12 & 7 & 4 & $<2$ & $<0.1$ \\
\hline 61.6 & 61.9 & $\mathrm{coal} / \mathrm{sh}$ & 41 & $<2$ & $<4$ & 16 & 11 & $<4$ & $<2$ & $<0.1$ \\
\hline 61.9 & 64.9 & ss & 34 & $<2$ & $<4$ & 16 & 16 & 8 & $<2$ & 0.6 \\
\hline 64.9 & 69.5 & sh & 4300 & $<2$ & $<4$ & 32 & 40 & 35 & 9 & 0.9 \\
\hline 69.5 & 70.9 & sh & 730 & $<2$ & 12 & 50 & 45 & 21 & 20 & 0.6 \\
\hline 70.9 & 73.6 & ls & 1200 & $<2$ & $<4$ & $<4$ & 26 & 10 & 4 & 1.5 \\
\hline 73.6 & 75.2 & coal & 1300 & 10 & 4 & 14 & 48 & 10 & 7 & 8.8 \\
\hline 75.2 & 77.3 & $\mathrm{~d}$ & 2500 & 3 & 5 & 52 & 110 & 50 & 16 & 3.5 \\
\hline 77.3 & 78 & sh/coal & 34 & 5 & 4 & 5 & 17 & 40 & 8 & 17.0 \\
\hline 78 & 79.2 & coal & 43 & 2 & 4 & 16 & 100 & 110 & 13 & 21.5 \\
\hline
\end{tabular}

acl, clay; ss, sandstone; sh, shale; ls, limestone; calc. sh, calcareous shale. 
Table D-1 (continued). Geochemical data for aquifer materials from three core holes at the Fleming site.

\begin{tabular}{|c|c|c|c|c|c|c|c|c|c|c|}
\hline \multirow{2}{*}{$\begin{array}{c}\text { Top of } \\
\text { interval } \\
\text { (feet) }\end{array}$} & \multirow{2}{*}{$\begin{array}{l}\text { Bottom of } \\
\text { interval } \\
\text { (feet) }\end{array}$} & \multirow[b]{2}{*}{ Lithologya } & \multicolumn{8}{|c|}{ Constituent elements (weight percent) } \\
\hline & & & Mn & Mo & $\mathrm{Nb}$ & $\mathrm{Nd}$ & $\mathrm{Ni}$ & $\mathrm{Pb}$ & Sc & $\mathrm{Se}$ \\
\hline \multicolumn{11}{|c|}{ Core Hole 3} \\
\hline 15 & 18.4 & d & 57 & $<2$ & 23 & 60 & 22 & 16 & 16 & $\cdot 0.6$ \\
\hline 18.4 & 19.8 & ss & 34 & $<2$ & 4 & 17 & 6 & 7 & 4 & $<0.1$ \\
\hline 19.8 & 22.8 & sh & 130 & $<2$ & 14 & 43 & 22 & 17 & 12 & 0.9 \\
\hline 22.8 & 25 & sh & 150 & $<2$ & 14 & 43 & 32 & 14 & 12 & 1.4 \\
\hline 25 & 27.9 & ss & 240 & $<2$ & 5 & 26 & 26 & 7 & 6 & 0.6 \\
\hline 27.9 & 32 & ss & 600 & $<2$ & $<4$ & 22 & 22 & 14 & 6 & 1.3 \\
\hline 32 & 36.5 & coal & 1200 & 5 & $<4$ & 28 & 31 & 32 & 16 & 23 \\
\hline 36.5 & 38 & $\mathrm{sh}$ & 79 & 4 & 28 & 32 & 32 & 16 & 20 & 2.5 \\
\hline 38 & 39.5 & d & 92 & 5 & 28 & 37 & 37 & 19 & 22 & 3.8 \\
\hline 39.5 & 42.5 & d & 73 & 6 & 34 & 66 & 66 & 82 & 30 & 13 \\
\hline 42.5 & 45.5 & d & 61 & 2 & 31 & 49 & 49 & 38 & 23 & 5.1 \\
\hline 45.5 & 49.5 & d & 60 & 5 & 33 & 36 & 36 & 34 & 24 & 4.2 \\
\hline 49.5 & 52.5 & d & 52 & $<2$ & 26 & 54 & 54 & 20 & 21 & 1.5 \\
\hline 52.5 & 53 & d & 2600 & $<2$ & $<4$ & 23 & 23 & 45 & 20 & 1.8 \\
\hline 53 & 57 & $\mathrm{sh} / \mathrm{cl}$ & 300 & 3 & 25 & 62 & 62 & 42 & 20 & 2.4 \\
\hline 57 & 59 & sh & 570 & $<2$ & 17 & 64 & 64 & 25 & 22 & $<0.1$ \\
\hline 59 & 61 & sh & 370 & 2 & 17 & 41 & 41 & 30 & 20 & 2.4 \\
\hline 61 & 63.5 & calc. sh & 1800 & $<2$ & $<4$ & 21 & 21 & 26 & 4 & 1.5 \\
\hline 63.5 & 64.6 & sh/coal & 300 & $<2$ & 16 & 36 & 40 & 11 & 14 & 1.3 \\
\hline 64.6 & 67.6 & sh & 520 & 2 & 16 & 42 & 42 & 22 & 16 & 1.2 \\
\hline 67.6 & 70.2 & $\mathbf{s h}$ & 180 & $<2$ & 15 & 86 & 86 & 20 & 15 & 1.2 \\
\hline 70.2 & 73.2 & ss/sh & 140 & $<2$ & 13 & 54 & 54 & 12 & 14 & 0.5 \\
\hline 73.2 & 76.2 & sh & 190 & $<2$ & 21 & 68 & 68 & 21 & 17 & 0.4 \\
\hline 76.2 & 80 & sh & 340 & $<2$ & 11 & 50 & 50 & 22 & 15 & 0.3 \\
\hline 80 & 80.8 & ss & 110 & $<2$ & 6 & 21 & 21 & 11 & 8 & 0.7 \\
\hline 80.8 & 81.1 & sh & 58 & $<2$ & 26 & 35 & 35 & 26 & 24 & 4.2 \\
\hline 81.1 & 81.3 & $\mathrm{sh} / \mathrm{coal}$ & 35 & 4 & 30 & 200 & 81 & 78 & 23 & 15 \\
\hline
\end{tabular}

acl, clay; ss, sandstone; sh, shale; ls, limestone; calc. sh, calcareous shale. 
Table D-1 (continued). Geochemical data for aquifer materials from three core holes at the Fleming site.

\begin{tabular}{|c|c|c|c|c|c|c|c|c|c|c|c|}
\hline \multirow{2}{*}{$\begin{array}{c}\text { Top of } \\
\text { interval } \\
\text { (feet) }\end{array}$} & \multirow{2}{*}{$\begin{array}{c}\text { Bottom of } \\
\text { interval } \\
\text { (feet) }\end{array}$} & \multirow{2}{*}{ Lithologya } & \multicolumn{9}{|c|}{ Constituent elements (weight percent) } \\
\hline & & & Sn & $\mathrm{Sr}$ & Ta & Th & $\mathrm{U}$ & $\mathrm{V}$ & $\mathrm{Y}$ & $\mathrm{Yb}$ & $\mathrm{Zn}$ \\
\hline \multicolumn{12}{|c|}{ Core Hole 1} \\
\hline 17 & 19.1 & d & $<5$ & 370 & $<40$ & 23 & $<100$ & 160 & 26 & 3 & 110 \\
\hline 19.1 & 19.3 & ss & $<5$ & 79 & $<40$ & 20 & $<100$ & 75 & 24 & 3 & 53 \\
\hline 19.3 & 22.3 & d & $<5$ & 720 & $<40$ & 29 & $<100$ & 170 & 23 & 3 & 48 \\
\hline 22.3 & 27.3 & d & $<5$ & 570 & $<40$ & 22 & $<100$ & 180 & 17 & 3 & 56 \\
\hline 27.3 & 30 & d & $<5$ & 600 & $<40$ & 24 & $<100$ & 190 & 21 & 3 & 31 \\
\hline 30 & 33 & sh & $<5$ & 310 & $<40$ & 17 & $<100$ & 140 & 23 & 3 & 27 \\
\hline 33 & 36 & sh & $<5$ & 200 & $<40$ & 14 & $<100$ & 120 & 22 & 3 & 70 \\
\hline 36 & 39.3 & $\operatorname{sh}$ & $<5$ & 120 & $<40$ & 17 & $<100$ & 110 & 25 & 3 & 140 \\
\hline 39.3 & 39.4 & sh & $<5$ & 130 & $<40$ & 15 & $<100$ & 120 & 30 & 4 & 100 \\
\hline 39.4 & 42.8 & sh & $<5$ & 110 & $<40$ & 15 & $<100$ & 93 & 20 & 3 & 91 \\
\hline 42.8 & 43.5 & ss & $<5$ & 77 & $<40$ & 12 & $<100$ & 55 & 14 & 2 & 59 \\
\hline 43.5 & 46.5 & sh & $<5$ & 95 & $<40$ & 13 & $<100$ & 82 & 18 & 2 & 83 \\
\hline 46.5 & 49.5 & sh & $<5$ & 100 & $<40$ & 11 & $<100$ & 87 & 19 & 3 & 100 \\
\hline 49.5 & 53 & $\operatorname{sh}$ & $<5$ & 99 & $<40$ & 12 & $<100$ & 81 & 19 & 2 & 77 \\
\hline 53 & 54.3 & ss & $<5$ & 75 & $<40$ & 9 & $<100$ & 60 & 15 & 2 & 61 \\
\hline 54.3 & 56.3 & sh & $<5$ & 100 & $<40$ & 16 & $<100$ & 100 & 20 & 2 & 74 \\
\hline 56.3 & 59.3 & ss & $<5$ & 73 & $<40$ & 12 & $<100$ & 79 & 19 & 2 & 77 \\
\hline 59.3 & 62.3 & ss & $<5$ & 74 & $<40$ & 10 & $<100$ & 66 & 17 & 2 & 70 \\
\hline 62.3 & 65.3 & ss & $<5$ & 49 & $<40$ & 16 & $<100$ & 41 & 16 & 2 & 83 \\
\hline 65.3 & 68.3 & ss & $<5$ & 26 & $<40$ & 11 & $<100$ & 22 & 12 & 2 & 35 \\
\hline 68.3 & 71.3 & ss & $<5$ & 19 & $<40$ & $<4$ & $<100$ & 13 & 4 & $<1$ & 36 \\
\hline 71.3 & 73.4 & ss & $<5$ & 19 & $<40$ & $<4$ & $<100$ & 12 & 4 & $<1$ & 50 \\
\hline 73.4 & 74.6 & ss & $<5$ & 18 & $<40$ & 19 & $<100$ & 12 & 19 & 2 & 45 \\
\hline 74.6 & 75.1 & coal & $<5$ & 46 & $<40$ & 8 & $<100$ & 110 & 19 & 2 & 81 \\
\hline 75.1 & 75.4 & ss & $<5$ & 25 & $<40$ & $<4$ & $<100$ & 8 & 4 & $<1$ & 23 \\
\hline 75.4 & 75.6 & d & $<5$ & 96 & $<40$ & 9 & $<100$ & 26 & 14 & 3 & 85 \\
\hline 75.6 & 76.8 & coal & $<5$ & 66 & $<40$ & $<4$ & $<100$ & 31 & 12 & 1 & 10 \\
\hline 76.8 & 80 & sh & $<5$ & 110 & $<40$ & 10 & $<100$ & 68 & 39 & 3 & 75 \\
\hline 80 & 80.6 & ss & $<5$ & 76 & $<40$ & 5 & $<100$ & 32 & 15 & 2 & 76 \\
\hline 80.6 & 83.6 & sh & $<5$ & 110 & $<40$ & 17 & $<100$ & 130 & 27 & 3 & 120 \\
\hline 83.6 & 86.6 & sh & $<5$ & 160 & $<40$ & 16 & $<100$ & 150 & 34 & 4 & 140 \\
\hline 86.6 & 89.6 & sh & $<5$ & 140 & $<40$ & 18 & $<100$ & 160 & 25 & 3 & 130 \\
\hline 89.6 & 93.4 & sh & $<5$ & 140 & $<40$ & 17 & $<100$ & 180 & 29 & 3 & 160 \\
\hline 93.4 & 97 & ls & $<5$ & 680 & $<40$ & $<4$ & $<100$ & 26 & 13 & 1 & 55 \\
\hline 97 & 98.7 & coal & $<5$ & 51 & $<40$ & $<4$ & $<100$ & 35 & 10 & 1 & 38 \\
\hline 98.7 & 99.5 & sh & $<5$ & 99 & $<40$ & 47 & $<100$ & 180 & 41 & 4 & 16 \\
\hline 99.5 & 101 & coal & $<5$ & 26 & $<40$ & 4 & $<100$ & 98 & 36 & 2 & 15 \\
\hline
\end{tabular}

acl, clay; ss, sandstone; sh, shale; ls, limestone; calc. sh, calcareous shale. 
Table D-1 (continued). Geochemical data for aquifer materials from three core holes at the Fleming site.

\begin{tabular}{|c|c|c|c|c|c|c|c|c|c|c|c|}
\hline \multirow{2}{*}{$\begin{array}{c}\text { Top of } \\
\text { interval } \\
\text { (feet) }\end{array}$} & \multirow{2}{*}{$\begin{array}{c}\text { Bottom of } \\
\text { interval } \\
\text { (feet) }\end{array}$} & \multirow{2}{*}{ Lithologya } & \multicolumn{9}{|c|}{ Constituent elements (weight percent) } \\
\hline & & & Sn & $\mathrm{Sr}$ & $\mathrm{Ta}$ & Th & $\mathrm{U}$ & V & $Y$ & $\mathrm{Yb}$ & $\mathrm{Zn}$ \\
\hline \multicolumn{12}{|c|}{ Core Hole 2} \\
\hline 27 & 30 & d & $<5$ & 130 & $<40$ & 16 & $<100$ & 120 & 21 & 3 & 91 \\
\hline 35.5 & 39.6 & $\mathrm{~d}$ & $<5$ & 120 & $<40$ & 16 & $<100$ & 120 & 22 & 3 & 40 \\
\hline 39.6 & 42.6 & ss & $<5$ & 63 & $<40$ & 9 & $<100$ & 50 & 14 & 2 & 62 \\
\hline 42.6 & 48.2 & ss & $<5$ & 34 & $<40$ & 14 & $<100$ & 30 & 16 & 2 & 50 \\
\hline 48.2 & 50.2 & ss & $<5$ & 36 & $<40$ & 8 & $<100$ & 30 & 10 & 1 & 54 \\
\hline 50.2 & 50.8 & d & $<5$ & 130 & $<40$ & 16 & $<100$ & 110 & 25 & 4 & 99 \\
\hline 50.8 & 53.8 & ss & $<5$ & 32 & $<40$ & 13 & $<100$ & 24 & 16 & 2 & 21 \\
\hline 53.8 & 56.8 & ss & $<5$ & 24 & $<40$ & 5 & $<100$ & 16 & 6 & $<1$ & 13 \\
\hline 56.8 & 59.5 & ss & $<5$ & 18 & $<40$ & $<4$ & $<100$ & 12 & 4 & $<1$ & 15 \\
\hline 59.5 & 61.6 & ss & $<5$ & 18 & $<40$ & 6 & $<100$ & 12 & 6 & $<1$ & 14 \\
\hline 61.6 & 61.9 & $\mathrm{coal} / \mathrm{sh}$ & $<5$ & 23 & $<40$ & 6 & $<100$. & 24 & 6 & $<1$ & 37 \\
\hline 61.9 & 64.9 & ss & $<5$ & 45 & $<40$ & 5 & $<100$ & 18 & 9 & 1 & 69 \\
\hline 64.9 & 69.5 & sh & $<5$ & 100 & $<40$ & 10 & $<100$ & 39 & 28 & 4 & 89 \\
\hline 69.5 & 70.9 & sh & $<5$ & 130 & $<40$ & 17 & $<100$ & 150 & 31 & 4 & 91 \\
\hline 70.9 & 73.6 & ls & $<5$ & 630 & $<40$ & $<4$ & $<100$ & 25 & 11 & 1 & 61 \\
\hline 73.6 & 75.2 & coal & $<5$ & 100 & $<40$ & 5 & $<100$ & 81 & 13 & 1 & 44 \\
\hline 75.2 & 77.3 & $\mathbf{d}$ & $<5$ & 120 & $<40$ & 17 & $<100$ & 160 & 40 & 4 & 160 \\
\hline 77.3 & 78 & $\mathrm{sh} / \mathrm{coal}$ & $<5$ & 29 & $<40$ & $<4$ & $<100$ & 24 & 14 & 1 & 20 \\
\hline 78 & 79.2 & coal & $<5$ & 110 & $<40$ & 4 & $<100$ & 62 & 20 & 2 & 19 \\
\hline
\end{tabular}

cl, clay; ss, sandstone; sh, shale; ls, limestone; calc. sh, calcareous shale. 
Table D-1 (continued). Geochemical data for aquifer materials from three core holes at the Fleming site.

\begin{tabular}{|c|c|c|c|c|c|c|c|c|c|c|c|}
\hline \multirow{2}{*}{$\begin{array}{c}\text { Top of } \\
\text { interval } \\
\text { (feet) }\end{array}$} & \multirow{2}{*}{$\begin{array}{c}\text { Bottom of } \\
\text { interval } \\
\text { (feet) }\end{array}$} & \multirow{2}{*}{ Lithologya } & \multicolumn{9}{|c|}{ Constituent elements (weight percent) } \\
\hline & & & Sn & $\mathrm{Sr}$ & $\mathrm{Ta}$ & Th & $\mathrm{U}$ & $\mathrm{V}$ & $\mathrm{Y}$ & $\mathrm{Yb}$ & $\mathrm{Zn}$ \\
\hline \multicolumn{12}{|c|}{ Core Hole 3} \\
\hline 15 & 18.4 & d & $<5$ & 92 & $<40$ & 16 & $<100$ & 120 & 32 & 3 & 53 \\
\hline 18.4 & 19.8 & ss & $<5$ & 37 & $<40$ & 5 & $<100$ & 32 & 9 & 1 & 20 \\
\hline 19.8 & 22.8 & sh & $<5$ & 87 & $<40$ & 14 & $<100$ & 90 & 22 & 3 & 77 \\
\hline 22.8 & 25 & sh & $<5$ & 90 & $<40$ & 13 & $<100$ & 88 & 24 & 3 & 110 \\
\hline 25 & 27.9 & ss & $<5$ & 53 & $<40$ & 6 & $<100$ & 39 & 16 & 2 & 59 \\
\hline 27.9 & 32 & ss & $<5$ & 61 & $<40$ & 9 & $<100$ & 33 & 14 & 2 & 69 \\
\hline 32 & 36.5 & coal & $<5$ & 55 & $<40$ & 20 & $<100$ & 86 & 20 & 3 & 24 \\
\hline 36.5 & 38 & sh & $<5$ & 76 & $<40$ & 19 & $<100$ & 160 & 20 & 3 & 60 \\
\hline 38 & 39.5 & d & $<5$ & 73 & $<40$ & 18 & $<100$ & 170 & 25 & 3 & 71 \\
\hline 39.5 & 42.5 & d & $<5$ & 110 & $<40$ & 29 & $<100$ & 180 & 36 & 4 & 86 \\
\hline 42.5 & 45.5 & d & $<5$ & 370 & $<40$ & 22 & $<100$ & 170 & 26 & 3 & 170 \\
\hline 45.5 & 49.5 & d & $<5$ & 150 & $<40$ & 23 & $<100$ & 170 & 23 & 3 & 48 \\
\hline 49.5 & 52.5 & d & $<5$ & 93 & $<40$ & 26 & $<100$ & 170 & 23 & 3 & 40 \\
\hline 52.5 & 53 & $\mathbf{d}$ & $<5$ & 59 & $<40$ & 14 & $<100$ & 64 & 29 & 5 & 130 \\
\hline 53 & 57 & $\mathrm{sh} / \mathrm{cl}$ & $<5$ & 150 & $<40$ & 21 & $<100$ & 150 & 27 & 4 & 60 \\
\hline 57 & 59 & sh & $<5$ & 140 & $<40$ & 19 & $<100$ & 190 & 43 & 4 & 110 \\
\hline 59 & 61 & sh & $<5$ & 160 & $<40$ & 24 & $<100$ & 210 & 25 & 3 & 98 \\
\hline 61 & 63.5 & calc. sh & $<5$ & 780 & $<40$ & $<4$ & $<100$ & 17 & 46 & 2 & 96 \\
\hline 63.5 & 64.6 & $\mathrm{sh} / \mathrm{coal}$ & $<5$ & 100 & $<40$ & 17 & $<100$ & 120 & 18 & 2 & 180 \\
\hline 64.6 & 67.6 & sh & $<5$ & 110 & $<40$ & 17 & $<100$ & 120 & 20 & 3 & 62 \\
\hline 67.6 & 70.2 & sh & $<5$ & 92 & $<40$ & 15 & $<100$ & 100 & 33 & 4 & 63 \\
\hline 70.2 & 73.2 & ss/sh & $<5$ & 94 & $<40$ & 15 & $<100$ & 100 & 24 & 3 & 100 \\
\hline 73.2 & 76.2 & sh & $<5$ & 100 & $<40$ & 17 & $<100$ & 120 & 39 & 4 & 150 \\
\hline 76.2 & 80 & sh & $<5$ & 160 & $<40$ & 17 & $<100$ & 99 & 27 & 4 & 98 \\
\hline 80 & 80.8 & ss & $<5$ & 100 & $<40$ & 9 & $<100$ & 61 & 14 & 2 & 37 \\
\hline 80.8 & 81.1 & sh & $<5$ & 140 & $<40$ & 22 & $<100$ & 190 & 19 & 3 & 38 \\
\hline 81.1 & 81.3 & sh/coal & $<5$ & 1900 & $<40$ & 18 & $<100$ & 180 & 34 & 4 & 48 \\
\hline
\end{tabular}

acl, clay; ss, sandstone; sh, shale; ls, limestone; calc. sh, calcareous shale. 
Table D-2. Water-quality data collected at the precipitation gage at the Dover Water Works, Dover, Ohio (February 1995 - December 1995).

\begin{tabular}{|c|c|c|c|c|c|c|c|}
\hline $\begin{array}{l}\text { End } \\
\text { date }\end{array}$ & $\begin{array}{l}\text { End } \\
\text { time }\end{array}$ & $\begin{array}{l}\text { Begin } \\
\text { date }\end{array}$ & $\begin{array}{l}\text { Begin } \\
\text { time }\end{array}$ & $\begin{array}{c}\text { Sample } \\
\text { type }\end{array}$ & $\begin{array}{c}\text { Dry } \\
\text { sample } \\
\text { wt (g) }\end{array}$ & $\begin{array}{c}\text { Sp. } \\
\text { cond. } \\
\mu \text { S/cm }\end{array}$ & $\mathrm{pH}$ \\
\hline \multirow[t]{2}{*}{ 2/3/95 } & $10: 10$ & $12 / 2 / 94$ & $10: 00$ & Wet & $--a$ & 25 & 4.5 \\
\hline & $10: 05$ & & $10: 05$ & Dry & 436.9 & 146 & 4.9 \\
\hline \multirow[t]{2}{*}{$3 / 6 / 95$} & $10: 00$ & 2/3/95 & $10: 00$ & Wet & --a & 38 & 4.2 \\
\hline & $10: 05$ & - & $10: 05$ & Dry & 501.2 & 53 & 5.9 \\
\hline \multirow[t]{2}{*}{$4 / 6 / 95$} & $8: 10$ & $3 / 6 / 95$ & $10: 00$ & Wet & $--a$ & 49 & 4.3 \\
\hline & $8: 15$ & & $10: 05$ & Dry & 370.1 & 56 & 6.4 \\
\hline \multirow[t]{2}{*}{$5 / 4 / 95$} & $11: 05$ & $4 / 6 / 95$ & $8: 15$ & Wet & $--\mathbf{a}$ & $--b$ & -- \\
\hline & $11: 00$ & & 8:10 & Dry & 481.6 & 36 & 6.4 \\
\hline \multirow[t]{2}{*}{$6 / 12 / 95$} & $16: 00$ & $5 / 4 / 95$ & $11: 05$ & Wet & $--^{a}$ & 27 & 4.3 \\
\hline & $16: 05$ & & $11: 00$ & Dry & 592.0 & 32 & 5.8 \\
\hline \multirow[t]{2}{*}{$7 / 13 / 95$} & $10: 30$ & $6 / 12 / 95$ & $16: 00$ & Wet & $--^{a}$ & 44 & 4.3 \\
\hline & $10: 35$ & & $16: 05$ & Dry & 500.8 & 20 & 6.0 \\
\hline \multirow[t]{2}{*}{$8 / 10 / 95$} & $12: 00$ & $7 / 13 / 95$ & $10: 30$ & Wet & $-a$ & 50 & 3.7 \\
\hline & $12: 05$ & & $10: 35$ & Dry & 494.1 & 32 & 5.7 \\
\hline \multirow[t]{2}{*}{ 9/8/95 } & $8: 00$ & $8 / 10 / 95$ & $12: 00$ & Wet & $--a$ & 31 & 4.2 \\
\hline & $8: 05$ & & $12: 05$ & Dry & 422.4 & 34 & 6.9 \\
\hline \multirow[t]{2}{*}{$10 / 20 / 95$} & $7: 10$ & 9/8/95 & $12: 00$ & Wet & --a & 43 & 4.2 \\
\hline & $7: 05$ & & $12: 05$ & Dry & 469.3 & 48 & 5.8 \\
\hline $12 / 14 / 95$ & $12: 00$ & $10 / 20 / 95$ & $12: 00$ & Wet & $-\mathbf{a}$ & 36 & 4.0 \\
\hline
\end{tabular}

aData heading does not apply to this case.

bSample not available for analyses. 
Table D-2 (continued). Water-quality data collected at the precipitation gage at the Dover Water Works, Dover, Ohio (February 1995 - December 1995).

\begin{tabular}{|c|c|c|c|c|c|c|c|}
\hline $\begin{array}{l}\text { End } \\
\text { date }\end{array}$ & $\begin{array}{c}\text { Sample } \\
\text { type }\end{array}$ & $\begin{array}{l}\text { Hardness } \\
\text { mg CaCO3 }\end{array}$ & $\begin{array}{c}\mathrm{Ca} \\
\mathrm{mg} / \mathrm{L}\end{array}$ & $\begin{array}{c}\mathrm{Mg} \\
\mathrm{mg} / \mathrm{L}\end{array}$ & $\begin{array}{c}\mathrm{Na} \\
\mathrm{mg} / \mathrm{L}\end{array}$ & $\begin{array}{c}\mathrm{K} \\
\mathrm{mg} / \mathrm{L}\end{array}$ & $\begin{array}{l}\mathrm{SO}_{4} \\
\mathrm{mg} / \mathrm{L}\end{array}$ \\
\hline \multirow[t]{2}{*}{$2 / 3 / 95$} & Wet & $\mathrm{ND}^{\mathrm{a}}$ & 0.14 & 0.04 & 0.12 & 0.03 & 0.8 \\
\hline & Dry & 34 & 11.0 & 1.50 & 3.10 & 0.79 & 20.0 \\
\hline \multirow[t]{2}{*}{$3 / 6 / 95$} & Wet & 1 & 0.40 & 0.05 & 0.14 & 0.02 & 1.8 \\
\hline & Dry & 11 & 3.70 & 0.41 & 3.70 & 0.10 & 8.7 \\
\hline \multirow[t]{2}{*}{$4 / 6 / 95$} & Wet & 3 & 0.85 & 0.14 & 0.19 & 0.06 & 5.0 \\
\hline & Dry & $\mathrm{ND}$ & 6.30 & 0.50 & 0.77 & 0.31 & 8.6 \\
\hline \multirow[t]{2}{*}{$5 / 4 / 95$} & Wet & 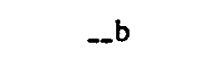 & - & -- & -- & - & - \\
\hline & Dry & $\mathrm{ND}$ & 4.40 & 0.62 & 0.23 & 0.26 & 5.1 \\
\hline \multirow[t]{2}{*}{$6 / 12 / 95$} & Wet & 1 & 0.19 & 0.03 & 0.03 & 0.04 & 2.4 \\
\hline & Dry & 10 & 2.90 & 0.55 & 0.13 & 1.70 & 5.1 \\
\hline \multirow[t]{2}{*}{$7 / 13 / 95$} & Wet & ND & 0.51 & 0.06 & 0.05 & 0.06 & 5.0 \\
\hline & Dry & ND & 2.10 & 0.31 & 0.21 & 0.39 & 3.7 \\
\hline \multirow[t]{2}{*}{$8 / 10 / 95$} & Wet & ND & 0.26 & 0.04 & 0.06 & 0.02 & 4.4 \\
\hline & Dry & ND & 3.10 & 0.38 & 0.17 & 0.48 & 5.6 \\
\hline \multirow[t]{2}{*}{ 9/8/95 } & Wet & ND & 0.76 & 0.15 & 0.06 & 0.06 & 2.2 \\
\hline & Dry & ND & 4.60 & 0.49 & 0.17 & 0.40 & 5.9 \\
\hline \multirow[t]{2}{*}{$10 / 20 / 95$} & Wet & 1 & 0.23 & 0.04 & 0.04 & 0.04 & 3.3 \\
\hline & Dry & 16 & 5.10 & 0.68 & 0.27 & 0.85 & 11.0 \\
\hline $12 / 14 / 95$ & Wet & ND & $\mathrm{ND}$ & $\mathrm{ND}$ & $\mathrm{ND}$ & $\mathrm{ND}$ & ND \\
\hline
\end{tabular}

aND, not determined.

bSample not available for analyses. 
Table D-2 (continued). Water-quality data collected at the precipitation gage at the Dover Water Works, Dover, Ohio (February 1995 - December 1995).

\begin{tabular}{lcccccccc}
\hline \hline $\begin{array}{l}\text { End } \\
\text { date }\end{array}$ & $\begin{array}{c}\text { Sample } \\
\text { type }\end{array}$ & $\begin{array}{c}\mathrm{Cl} \\
\mathrm{mg} /\end{array}$ & $\begin{array}{c}\mathrm{F} \\
\mathrm{mg} /\end{array}$ & $\begin{array}{c}\mathrm{Br} \\
\mathrm{mg} / \mathrm{L}\end{array}$ & $\begin{array}{c}\mathrm{Sum}_{\mathrm{m} / \mathrm{L}} \\
\mathrm{mg}\end{array}$ & $\begin{array}{c}\mathrm{NO}_{3}-\mathrm{N} \\
\mathrm{mg} / \mathrm{L}\end{array}$ & $\begin{array}{c}\mathrm{NH}_{3}-\mathrm{N} \\
\mathrm{mg} / \mathrm{L}\end{array}$ & $\begin{array}{c}\mathrm{PO}_{4}-\mathrm{P} \\
\mathrm{mg} / \mathrm{L}\end{array}$ \\
\hline \multirow{2}{*}{$3 / 6 / 95$} & Wet & 0.1 & 0.10 & $<0.01$ & 1 & 0.17 & $<0.01$ & $<0.01$ \\
& Dry & 11.0 & 0.40 & 0.02 & 49 & 1.40 & $<0.01$ & 0.03 \\
$4 / 6 / 95$ & Wet & 1.8 & 0.30 & 0.28 & 5 & 0.46 & 0.30 & $<0.01$ \\
& Dry & 4.6 & 0.20 & $<0.01$ & 21 & $\mathrm{ND}^{\mathrm{a}}$ & 1.50 & $<0.01$ \\
& Wet & 0.6 & 0.20 & $<0.01$ & 8 & 0.89 & 0.82 & $<0.01$ \\
$5 / 4 / 95$ & Dry & 0.9 & 0.20 & $<0.01$ & 20 & 0.69 & 2.00 & $<0.01$ \\
& Wet &.$- \mathrm{b}$ & -- & -- & - & -- & - & - \\
$6 / 12 / 95$ & Dry & 0.5 & 0.20 & $<0.01$ & 12 & 0.12 & 0.87 & $<0.01$ \\
& Wet & 0.1 & $<0.01$ & $<0.01$ & 3 & $\mathrm{ND}$ & 0.44 & $<0.01$ \\
$7 / 13 / 95$ & Dry & 1.1 & 0.10 & $<0.01$ & 12 & $\mathrm{ND}$ & 0.90 & 0.13 \\
& Wet & 0.2 & 0.10 & $<0.01$ & 6 & $\mathrm{ND}$ & 0.49 & $<0.01$ \\
$8 / 10 / 95$ & Dry & 0.4 & 0.10 & $<0.01$ & 7 & $\mathrm{ND}$ & 0.49 & 0.04 \\
& Wet & 0.2 & 0.00 & $<0.01$ & 5 & $\mathrm{ND}$ & 0.51 & $<0.01$ \\
$9 / 8 / 95$ & Dry & 0.4 & 0.10 & $<0.01$ & 10 & $\mathrm{ND}$ & 0.61 & 0.04 \\
& Wet & 0.9 & $<0.01$ & $<0.01$ & 4 & $\mathrm{ND}$ & 0.67 & $<0.01$ \\
$10 / 20 / 95$ & Dry & 0.5 & 0.10 & $<0.01$ & 13 & $\mathrm{ND}$ & 0.98 & 0.03 \\
& Wet & 1.0 & 0.00 & $<0.01$ & 5 & $\mathrm{ND}$ & 0.36 & $<0.01$ \\
$12 / 14 / 95$ & Dry & 1.0 & 0.20 & $<0.01$ & 20 & $\mathrm{ND}$ & 0.88 & 0.24 \\
& Wet & $\mathrm{ND}$ & $\mathrm{ND}$ & $\mathrm{ND}$ & $\mathrm{ND}$ & $\mathrm{ND}$ & 0.60 & $<0.001$ \\
\hline \hline & & & & & & & & \\
\hline
\end{tabular}

aND. Not determined.

bSample not available for analyses. 
Table D-2 (continued). Water-quality data collected at the precipitation gage at the Dover Water Works, Dover, Ohio (February 1995 - December 1995).

\begin{tabular}{|c|c|c|c|c|c|c|c|c|}
\hline $\begin{array}{l}\text { End } \\
\text { date }\end{array}$ & $\begin{array}{c}\text { Sample } \\
\text { type }\end{array}$ & $\begin{array}{c}\mathrm{Al} \\
\mathrm{mg} / \mathrm{L}\end{array}$ & $\begin{array}{c}\mathrm{Ar} \\
\mathrm{mg} / \mathrm{L}\end{array}$ & $\begin{array}{c}\mathrm{Be} \\
\mathrm{mg} / \mathrm{L}\end{array}$ & $\begin{array}{c}\mathrm{B} \\
\mathrm{mg} / \mathrm{L}\end{array}$ & $\begin{array}{c}\mathrm{Cd} \\
\mathrm{mg} / \mathrm{L}\end{array}$ & $\begin{array}{c}\mathrm{Cr} \\
\mathrm{mg} / \mathrm{L}\end{array}$ & $\begin{array}{c}\mathrm{Co} \\
\mathrm{mg} / \mathrm{L}\end{array}$ \\
\hline \multirow[t]{2}{*}{$6 / 12 / 95$} & Wet & $<0.03$ & $<0.04$ & $<0.001$ & $<6$ & $<1$ & $<2$ & $<6$ \\
\hline & Dry & $<0.03$ & $<0.04$ & $<0.001$ & $<6$ & $<1$ & $<2$ & $<6$ \\
\hline \multirow[t]{2}{*}{$12 / 14 / 95$} & Wet & $<0.03$ & $<0.04$ & $<0.001$ & $<6$ & 1 & $<2$ & $<6$ \\
\hline & & $\begin{array}{c}\mathrm{Cu} \\
\mathrm{mg} / \mathrm{L}\end{array}$ & $\begin{array}{c}\mathrm{Fe} \\
\mathrm{mg} / \mathrm{L}\end{array}$ & $\begin{array}{c}\mathrm{Pb} \\
\mathrm{mg} / \mathrm{L}\end{array}$ & $\begin{array}{c}\mathrm{L} \\
\mathrm{mg} / \mathrm{L}\end{array}$ & $\begin{array}{c}\mathrm{Mn} \\
\mathrm{mg} / \mathrm{L}\end{array}$ & $\begin{array}{c}\mathrm{Mo} \\
\mathrm{mg} / \mathrm{L}\end{array}$ & $\begin{array}{c}\mathrm{Ni} \\
\mathrm{mg} / \mathrm{L}\end{array}$ \\
\hline \multirow[t]{2}{*}{$6 / 12 / 95$} & Wet & $<2$ & $<11$ & $<20$ & $<4$ & 1 & $<11$ & $<4$ \\
\hline & Dry & $<2$ & $<11$ & $<20$ & $<4$ & 34 & $<11$ & $<4$ \\
\hline \multirow[t]{2}{*}{$12 / 14 / 95$} & Wet & $<2$ & 10 & $<20$ & 6 & 3 & 29 & $<4$ \\
\hline & & $\begin{array}{c}\mathrm{Se} \\
\mathrm{mg} / \mathrm{L}\end{array}$ & $\underset{\mathrm{mg} / \mathrm{Ag}}{\mathrm{Ag}}$ & $\begin{array}{c}\mathrm{Sr} \\
\mathrm{mg} / \mathrm{L}\end{array}$ & $\begin{array}{c}\mathrm{V} \\
\mathrm{mg} / \mathrm{L}\end{array}$ & $\begin{array}{c}\mathrm{Zn} \\
\mathrm{mg} / \mathrm{L}\end{array}$ & & \\
\hline \multirow[t]{2}{*}{$6 / 12 / 95$} & Wet & $<93$ & 10 & $<1$ & $<5$ & 15 & & \\
\hline & Dry & $<93$ & $<10$ & 1 & $<5$ & 11 & & \\
\hline $12 / 14 / 95$ & Wet & $<93$ & $<10$ & 5 & $<5$ & 14 & & \\
\hline
\end{tabular}

aInformation not determined.

bSample not available for analyses. 
Table D-3. Monitoring well water quality data in samples collected from sites surrounding the Fleming Site (June 1995 - January 1996).

\begin{tabular}{|c|c|c|c|c|c|c|c|c|}
\hline \multirow{2}{*}{$\begin{array}{l}\text { Local } \\
\text { number }\end{array}$} & \multirow[b]{2}{*}{ Date } & \multirow[b]{2}{*}{ Time } & \multirow{2}{*}{$\begin{array}{l}\text { Depth to } \\
\text { water } \\
\text { table (ft)a }\end{array}$} & \multirow{2}{*}{$\begin{array}{l}\text { Sp. Cond. } \\
(\mu \mathrm{S} / \mathrm{cm})^{\mathrm{b}}\end{array}$} & \multirow{2}{*}{$\begin{array}{l}\mathrm{pH} \text { of } \\
\text { water in } \\
\text { the field }\end{array}$} & \multirow{2}{*}{$\begin{array}{l}\text { Redox } \\
\text { potential } \\
(\mathbf{m v})^{b}\end{array}$} & \multicolumn{2}{|c|}{ Temperature $\left({ }^{\circ} \mathrm{C}\right)$} \\
\hline & & & & & & & Air & Water \\
\hline \multirow[t]{2}{*}{ Tu-100-W1S } & $6 / 21 / 95$ & $9: 20$ & 44.69 & 3130 & 5.5 & 392 & 33 & 14.0 \\
\hline & $1 / 17 / 96$ & $14: 30$ & 45.36 & 3190 & 5.5 & 336 & 10 & 12.9 \\
\hline \multirow[t]{2}{*}{ TU-101-W1D } & 6/28/95 & $10: 40$ & 44.91 & 2410 & 7.2 & 222 & 26 & 15.5 \\
\hline & $1 / 18 / 96$ & $8: 30$ & 45.20 & 2560 & 7.2 & 163 & 13 & 14.5 \\
\hline \multirow[t]{2}{*}{ TU-102-W2 } & $6 / 27 / 95$ & $19: 30$ & 46.23 & 2960 & 5.3 & 402 & 29 & 13.0 \\
\hline & $1 / 19 / 96$ & $13: 50$ & 46.80 & 3090 & 5.5 & 362 & -8 & 11.3 \\
\hline \multirow[t]{2}{*}{ TU-103-W3S } & $7 / 6 / 95$ & $14: 10$ & 42.20 & 2250 & 5.8 & 360 & 29 & 13.5 \\
\hline & $1 / 19 / 96$ & $12: 10$ & 42.57 & 2460 & 5.9 & 320 & -7 & 12.0 \\
\hline \multirow[t]{2}{*}{ TU-104W3D } & $6 / 28 / 95$ & $16: 00$ & 42.02 & 2350 & 6.0 & 313 & 27 & 13.0 \\
\hline & $1 / 19 / 96$ & $11: 05$ & 42.36 & 2370 & 6.1 & 301 & -5 & 12.5 \\
\hline \multirow[t]{2}{*}{ TU-105-W4S } & 6/29/95 & $13: 00$ & 17.57 & 2910 & 5.4 & 389 & 29 & 13.0 \\
\hline & $1 / 18 / 98$ & $15: 20$ & 18.04 & 3120 & 5.4 & 334 & 16 & 12.5 \\
\hline \multirow[t]{2}{*}{ TU-106-W4D } & $6 / 29 / 95$ & $11: 30$ & 41.53 & 2960 & 5.5 & 359 & 28 & 13.0 \\
\hline & $1 / 18 / 96$ & $14: 05$ & 40.83 & 3060 & 5.5 & 321 & 18 & 13.5 \\
\hline \multirow[t]{2}{*}{ TU-107-W4P } & $7 / 6 / 95$ & $16: 00$ & 66.84 & 1780 & 6.2 & 298 & 28 & 13.5 \\
\hline & $1 / 19 / 96$ & $9: 45$ & 65.98 & 1880 & 6.5 & 263 & -7 & 12.5 \\
\hline \multirow[t]{2}{*}{ TU-109-W5S } & $6 / 27 / 95$ & $15: 26$ & 16.18 & 2930 & 5.4 & 389 & 33 & 13.0 \\
\hline & $1 / 18 / 96$ & $12: 00$ & 16.78 & 3060 & 5.4 & 312 & 15 & 13.5 \\
\hline \multirow[t]{2}{*}{ TU-110-W6S } & $6 / 22 / 95$ & $13: 00$ & 18.12 & 4440 & 5.0 & 457 & 30 & 13.5 \\
\hline & $1 / 20 / 96$ & $11: 00$ & 18.83 & 3830 & 5.2 & 619 & -2 & 12.9 \\
\hline \multirow[t]{2}{*}{ TU-111-W6D } & $6 / 28 / 95$ & $11: 30$ & 18.62 & 4280 & 5.5 & 374 & 27 & 12.5 \\
\hline & $1 / 20 / 96$ & 9:00 & 19.36 & 3900 & 6.1 & 92 & -11 & 10.0 \\
\hline \multirow[t]{2}{*}{ TU-112-W7 } & $6 / 21 / 95$ & $16: 30$ & 25.44 & 2470 & 5.7 & 408 & 33 & 13.5 \\
\hline & $1 / 19 / 96$ & $16: 00$ & 26.88 & 2150 & 5.8 & 356 & -8 & 12.7 \\
\hline \multirow[t]{2}{*}{ TU-113-W8S } & $6 / 27 / 95$ & $13: 00$ & 42.24 & 1114 & 6.2 & 275 & 29 & 13.0 \\
\hline & $1 / 20 / 96$ & $15: 40$ & 43.02 & 1160 & 6.3 & 298 & -3 & 12.7 \\
\hline \multirow[t]{2}{*}{ TU-114-W8D } & $6 / 21 / 95$ & $13: 45$ & 40.96 & 2640 & 5.8 & 357 & 33 & 14.0 \\
\hline & $1 / 20 / 96$ & $14: 20$ & 41.98 & 2880 & 5.7 & 341 & -4 & 12.5 \\
\hline TU-115-W9 & 1/17/95 & $8: 45$ & 17.99 & 2420 & 5.3 & 350 & 8 & 13.0 \\
\hline TU-116-W10 & $1 / 16 / 96$ & $11: 30$ & 23.14 & 3230 & 5.6 & 355 & 3 & 12.8 \\
\hline TU-117-W11 & $1 / 16 / 96$ & $14: 45$ & 22.99 & 2760 & 5.8 & 378 & 6 & 14.2 \\
\hline TU-118-W12 & $1 / 17 / 96$ & $10: 30$ & 24.38 & 3120 & 5.4 & 354 & 9 & 13.0 \\
\hline TU-119-W13 & $1 / 17 / 96$ & $12: 40$ & 37.67 & 3150 & 5.7 & 305 & 9 & 13.5 \\
\hline
\end{tabular}

Given in feet below land surface.

$\mathrm{b} \mu \mathrm{S} / \mathrm{cm}$, microsiemens per centimeter and $\mathrm{mv}$, millivolts. 
Table D-3 (continued). Monitoring well water quality data in samples collected from sites surrounding the Fleming Site (June 1995 - January 1996).

\begin{tabular}{|c|c|c|c|c|c|c|c|}
\hline \multirow{2}{*}{$\begin{array}{l}\text { Local } \\
\text { number }\end{array}$} & \multirow{2}{*}{$\begin{array}{c}\text { Turbidity } \\
(\text { NTU) }\end{array}$} & \multirow{2}{*}{$\begin{array}{l}\text { Diss. } \\
\text { oxygen }\end{array}$} & Hardness & Acidity & Alkalinity & Bicarb. & \multirow{2}{*}{$\begin{array}{c}\mathrm{ROE} \\
(\mathrm{mg} / \mathrm{L})^{\mathrm{a}}\end{array}$} \\
\hline & & & \multicolumn{4}{|c|}{$\left(\mathrm{mg} / \mathrm{Las} \mathrm{CaCO}_{3}\right)$} & \\
\hline \multirow[t]{2}{*}{ TU-100-W1S } & 5 & $<0.100$ & 1871 & 12.6 & 119 & 145 & 3930 \\
\hline & 3 & $<0.100$ & 8705 & 11.5 & 68 & 84 & 3609 \\
\hline \multirow[t]{2}{*}{ TU-101-W1D } & 41 & $<0.100$ & 953 & 0.5 & 172 & 211 & 2190 \\
\hline & 64 & $<0.100$ & 4092 & 0.1 & 190 & 237 & 1864 \\
\hline \multirow[t]{2}{*}{ TU-102-W2 } & 9 & 0.130 & 1721 & 14.1 & 97 & 121 & 3572 \\
\hline & 1 & $<0.100$ & 5261 & 14.4 & 56 & 78 & 3731 \\
\hline \multirow[t]{2}{*}{ TU-103-W3S } & 44 & 0.220 & 1024 & 2.4 & 131 & 159 & 2410 \\
\hline & 6 & $<0.100$ & 3767 & 0.6 & 105 & 131 & 2285 \\
\hline \multirow[t]{2}{*}{ TU-104W3D } & 3 & 0.230 & 1747 & 2.2 & 169 & 211 & 2510 \\
\hline & $<1$ & $<0.100$ & 4024 & 0.5 & 122 & 149 & 2407 \\
\hline \multirow[t]{2}{*}{ TU-105-W4S } & 2 & 0.274 & 1844 & 11.4 & 54 & 68 & 3460 \\
\hline & $<1$ & $<0.100$ & 5688 & 10.5 & 54 & 73 & 3413 \\
\hline \multirow[t]{2}{*}{ TU-106-W4D } & 2 & 0.285 & 1978 & 10.4 & 75 & 92 & 3530 \\
\hline & 16 & $<0.100$ & 5615 & 8.1 & 73 & 92 & 3408 \\
\hline \multirow[t]{2}{*}{ TU-107-W4P } & 18 & $<0.100$ & 780 & 0.6 & 199 & 244 & 1740 \\
\hline & 35 & 0.870 & 3601 & 0.4 & 194 & 238 & 1457 \\
\hline \multirow[t]{2}{*}{ TU-109-W5S } & 15 & 0.532 & 1710 & 11.4 & 53 & 66 & 3220 \\
\hline & 50 & 0.600 & 5069 & 9.7 & 57 & 73 & 3228 \\
\hline \multirow[t]{2}{*}{ TU-110-WGS } & 22 & $<0.100$ & 1354 & 29.8 & 87 & 122 & 5860 \\
\hline & 44 & 0.190 & 3477 & 29.5 & 52 & 68 & 5591 \\
\hline \multirow[t]{2}{*}{ TU-111-Wळ } & 16 & $<0.100$ & 2716 & 21.1 & 132 & 171 & 5940 \\
\hline & 5 & 1.500 & 5594 & 10.3 & 236 & 288 & 4947 \\
\hline \multirow[t]{2}{*}{ TU-112-W7 } & 14 & $<0.100$ & 1490 & 5.9 & 136 & 168 & 2830 \\
\hline & $<1$ & 1.500 & 4614 & 4.6 & 88 & 106 & 2503 \\
\hline \multirow[t]{2}{*}{ TU-113-W8S } & 18 & 0.400 & 239 & 1.1 & 125 & 155 & 848 \\
\hline & 13 & 0.190 & 1577 & 0.0 & 115 & 139 & 918 \\
\hline \multirow[t]{2}{*}{ TU-114-W8D } & 1 & $<0.100$ & 687 & 4.2 & 160 & 203 & 3140 \\
\hline & $<1$ & $<0.100$ & 3727 & 5.8 & 111 & 140 & 3104 \\
\hline TU-115-W9 & 1 & 0.140 & 4310 & 6.5 & 44 & 63 & 2528 \\
\hline TU-116-W10 & $<1$ & $<0.100$ & 5479 & 10.7 & 45 & 55 & 3480 \\
\hline TU-117-W11 & 4 & 3.400 & 4994 & 8.8 & 59 & 76 & 3092 \\
\hline TU-118-W12 & 1 & $<0.100$ & 6414 & 6.1 & 52 & 66 & 3103 \\
\hline TU-119-W13 & 1 & $<0.100$ & 5796 & 6.9 & 75 & 92 & 3199 \\
\hline
\end{tabular}

aNTU, nepholometric turbidity umits; ROE, residue on evaporation. 
Table D-3 (continued). Monitoring well water quality data in samples collected from sites surrounding the Fleming Site (June 1995 - January 1996).

\begin{tabular}{|c|c|c|c|c|c|c|c|c|c|}
\hline \multirow{2}{*}{$\begin{array}{l}\text { Local } \\
\text { number }\end{array}$} & \multicolumn{2}{|c|}{$\mathrm{Al}(\mu \mathrm{g} / \mathrm{L})$} & \multirow{2}{*}{$\begin{array}{c}\mathrm{Ar} \\
\mu \mathrm{g} / \mathrm{L}\end{array}$} & \multirow{2}{*}{$\begin{array}{c}\mathrm{Ba} \\
\mu \mathrm{g} / \mathrm{L}\end{array}$} & \multirow{2}{*}{$\begin{array}{c}\mathrm{Be} \\
\mu \mathrm{g} / \mathrm{L}\end{array}$} & \multirow{2}{*}{$\begin{array}{c}\text { B } \\
\mu \mathrm{g} / \mathrm{L} .\end{array}$} & \multirow{2}{*}{$\begin{array}{c}\mathrm{Cd} \\
\mu \mathrm{g} / \mathrm{L}\end{array}$} & \multirow{2}{*}{$\begin{array}{c}\mathrm{Cr} \\
\mu \mathrm{g} / \mathrm{L}\end{array}$} & \multirow{2}{*}{$\begin{array}{c}\text { Co } \\
\mu \mathrm{g} / \mathrm{L}\end{array}$} \\
\hline & Total & Diss." & & & & & & & \\
\hline \multirow[t]{2}{*}{ TU-100-W1S } & 83 & 117 & $<1$ & 16 & 3.0 & 403 & $<1$ & 7 & 239 \\
\hline & 30 & 127 & $<1$ & 25 & 4.0 & 468 & $<1$ & 18 & $248^{\circ}$ \\
\hline \multirow[t]{2}{*}{ TU-101-W1D } & 722 & 79 & $<1$ & 17 & $<1$ & 300 & 3 & 8 & $<6$ \\
\hline & 540 & 57 & $<1$ & 16 & $<1$ & 301 & $<1$ & 4 & 11 \\
\hline \multirow[t]{2}{*}{ TU-102-W2 } & 517 & 629 & $<1$ & 17 & 7.0 & 232 & $<1$ & 4 & 230 \\
\hline & 640 & 727 & $<1$ & 16 & 9.0 & 231. & 2 & 6 & 218 \\
\hline \multirow[t]{2}{*}{ TU-103-W3S } & 657 & 42 & 1 & 15 & $<1$ & 142 & $<1$ & 8 & 50 \\
\hline & 360 & 186 & $<1$ & 15 & $<1$ & 125 & $<1$ & 6 & 49 \\
\hline \multirow[t]{2}{*}{ TU-104-W3D } & 76 & 88 & $<1$ & 22 & 7.0 & 202 & 11 & 15 & 17 \\
\hline & 70 & 124 & $<1$ & 15 & $<1$ & 181 & $<1$ & 6 & 7 \\
\hline \multirow[t]{2}{*}{ TU-105-W4S } & 54 & 128 & 2 & 16 & 5.0 & 301 & 5 & 12 & 240 \\
\hline & 50 & 69 & $<1$ & 16 & 3.0 & 296 & $<1$ & 6 & 222 \\
\hline \multirow[t]{2}{*}{ TU-106-W4D } & 150 & 105 & $<1$ & 14 & 5.0 & 291 & 6 & 12 & 200 \\
\hline & 250 & 55 & 1 & 12 & 3.0 & 311 & 1 & 8 & 200 \\
\hline \multirow[t]{2}{*}{ TU-107-W4P } & 272 & $<30$ & $<1$ & 14 & $<1$ & 322 & 2 & 10 & 8 \\
\hline & 330 & 61 & 1 & 20 & $<1$ & 329 & 1 & 5 & 9 \\
\hline \multirow[t]{2}{*}{ TU-109-W5S } & 177 & 196 & $<1$ & 14 & 4.0 & 235 & $<1$ & 7 & 269 \\
\hline & 460 & 178 & $<1$ & 17 & 5.0 & 257 & 2 & 6 & 234 \\
\hline \multirow[t]{2}{*}{ TU-110-W6S } & 622 & 6620 & $<1$ & 9 & 37.0 & 12 & $<1$ & 7 & 775 \\
\hline & 560 & 5101 & $<1$ & 9 & 36.0 & 10 & $<1$ & 6 & 673 \\
\hline \multirow[t]{2}{*}{ TU-111-W6D } & 1601 & 1010 & $<1$ & 14 & 11.0 & 89 & $<1$ & 9 & 557 \\
\hline & 150 & 250 & $<1$ & 15 & 4.0 & 209 & $<1$ & 4 & 263 \\
\hline \multirow[t]{2}{*}{ TU-112-W7 } & 389 & 59 & $<1$ & 15 & $<1$ & 303 & $<1$ & $<2$ & 167 \\
\hline & 60 & 171 & $<1$ & 20 & 2.0 & 271 & $<1$ & 2 & 162 \\
\hline \multirow[t]{2}{*}{ TU-113-W8S } & $<30$ & 58 & $<1$ & 28 & $<1$ & 159 & $<1$ & 4 & $<6$ \\
\hline & 100 & 65 & $<1$ & 28 & $<1$ & 159 & $<1$ & 4 & 7 \\
\hline \multirow[t]{2}{*}{ TU-114-W8D } & 51 & 67 & $<1$ & 13 & $<1$ & 200 & $<1$ & $<2$ & 106 \\
\hline & 30 & 111 & $<1$ & 18 & 2.0 & 150 & $<1$ & 6 & 112 \\
\hline TU-115-W9 & 290 & 367 & $<1$ & 16 & 13.0 & 349 & $<1$ & 4 & 313 \\
\hline TU-116-W10 & 160 & 289 & $<1$ & 17 & 4.0 & 317 & $<1$ & 3 & 299 \\
\hline TU-117-W11 & 160 & 366 & $<1$ & 13 & 6.0 & 384 & $<1$ & 11 & 259 \\
\hline TU-118-W12 & 290 & 366 & $<1$ & 18 & 9.0 & 332 & $<1$ & 6 & 211 \\
\hline TU-119-W13 & 30 & 71 & $<1$ & 21 & 3.0 & 276 & 3 & 2 & 123 \\
\hline
\end{tabular}

aDiss., dissolved. 
Table D-3 (continued). Monitoring well water quality data in samples collected from sites surrounding the Fleming Site (June 1995 - January 1996).

\begin{tabular}{|c|c|c|c|c|c|c|c|c|c|}
\hline \multirow{2}{*}{$\begin{array}{l}\text { Local } \\
\text { number }\end{array}$} & \multirow{2}{*}{$\begin{array}{c}\mathrm{Ca} \\
\mu \mathrm{g} / \mathrm{L}\end{array}$} & \multirow{2}{*}{$\begin{array}{c}\mathrm{Cl} \\
\mu \mathrm{g} / \mathrm{L}\end{array}$} & \multirow{2}{*}{$\begin{array}{c}\mathrm{Cu} \\
\mu \mathrm{g} / \mathrm{L}\end{array}$} & \multirow{2}{*}{$\begin{array}{c}F \\
\mu \mathrm{g} / \mathrm{L}\end{array}$} & \multicolumn{2}{|c|}{$\mathrm{Fe}(\mathrm{mg} / \mathrm{L})$} & \multirow[b]{2}{*}{$\begin{array}{c}\mathrm{Li} \\
\mu \mathrm{g} / \mathrm{L}\end{array}$} & \multicolumn{2}{|c|}{$M(m g / L)$} \\
\hline & & & & & Total & Diss. ${ }^{a}$ & & Total & Diss. \\
\hline \multirow[t]{2}{*}{ TU-100-W 1S } & 404.7 & 3 & $<2$ & 2 & 409 & 383 & 158 & 17.9 & 17.9 \\
\hline & 481.0 & $<0.1$ & $<2$ & $<0.1$ & 374 & 375 & 171 & 16.8 & 18.9 \\
\hline \multirow[t]{2}{*}{ TU-101 } & 231.2 & $<1$ & $<2$ & $<1$ & 7 & 6 & 32 & 0.7 & 0.7 \\
\hline & 230.0 & 5 & 2 & $<0.1$ & 3 & 0.9 & 26 & 0.3 & 0.3 \\
\hline \multirow[t]{2}{*}{ TU-102-W2 } & 339.8 & $<1$ & $<2$ & $<1$ & 400 & 408 & 230 & 18.1 & 19.0 \\
\hline & 386.0 & 3 & $<2$ & $<0.1$ & 455 & 433 & 232 & 20.2 & 19.3 \\
\hline \multirow[t]{2}{*}{ TU-103-W3S } & 409.9 & 3 & $<2$ & $<1$ & 75 & 73 & 98 & 9.6 & 8.7 \\
\hline & 450.0 & $<0.1$ & $<2$ & $<0.1$ & 92 & 86 & 122 & 8.9 & 8.5 \\
\hline \multirow[t]{2}{*}{ TU-104 } & 459.0 & $<1$ & 5 & $<1$ & 47 & 47 & 89 & 3.1 & 3.4 \\
\hline & 454.0 & $<0.1$ & $<2$ & $<0.1$ & 56 & 51 & 88 & 3.5 & 3.3 \\
\hline \multirow[t]{2}{*}{ TU-105-W4S } & 403.9 & $<1$ & $<2$ & $<1$ & 299 & 292 & 188 & 14.1 & 14.8 \\
\hline & 404.0 & $<0.1$ & $<2$ & $<0.1$ & 346 & 325 & 206 & 15.5 & 15.2 \\
\hline \multirow[t]{2}{*}{ TU-106 } & 449.1 & $<1$ & $<2$ & $<1$ & 245 & 243 & 190 & 11.7 & 12.5 \\
\hline & 441.0 & 4 & $<2$ & $<0.1$ & 309 & 285 & 211 & 14.2 & 13.7 \\
\hline \multirow[t]{2}{*}{ TU-107-W4P } & 312.2 & $<1$ & $<2$ & $<1$ & 34 & 34 & 35 & 2.3 & 2.5 \\
\hline & 280.0 & 3 & $<2$ & $<0.1$ & 31 & 20 & 68 & 2.2 & 2.0 \\
\hline \multirow[t]{2}{*}{ TU-109-W5S } & 340.2 & 3 & $<2$ & $<1$ & 316 & 304 & 223 & 15.6 & 15.8 \\
\hline & 395.0 & 3 & $<2$ & $<0.1$ & 342 & 316 & 227 & 16.6 & 16.2 \\
\hline \multirow[t]{2}{*}{ TU-110-W6S } & 336.2 & 5 & $<2$ & 7 & 957 & 921 & 256 & 66.2 & 67.2 \\
\hline & 358.0 & 3 & $<2$ & 4 & 031 & 836 & 249 & 66.1 & 61.5 \\
\hline \multirow[t]{2}{*}{ TU-111 } & 472.6 & $<1$ & $<2$ & $<1$ & 639 & 657 & 402 & 45.0 & 47.2 \\
\hline & 531.0 & $<0.1$ & $<2$ & 2 & 508 & 457 & 429 & 33.1 & 30.5 \\
\hline \multirow[t]{2}{*}{ TU-112-W7 } & 369.2 & 3 & $<2$ & 1 & 164 & 149 & 218 & 10.4 & 10.5 \\
\hline & 351.0 & 6 & $<2$ & $<0.1$ & 176 & 164 & 285 & 10.8 & 10.3 \\
\hline \multirow[t]{2}{*}{ TU-113-W8S } & 133.9 & $<1$ & $<2$ & $<1$ & 22 & 24 & 64 & 1.1 & 1.2 \\
\hline & 154.0 & $<0.1$ & $<2$ & $<0.1$ & 29 & 22 & 65 & 0.9 & 0.9 \\
\hline \multirow[t]{2}{*}{ TU-114 } & 434.1 & 3 & $<2$ & 2 & 196 & 176 & 147 & 10.4 & 10.0 \\
\hline & 441.0 & 3 & $<2$ & $<0.1$ & 247 & 227 & 170 & 13.1 & 12.3 \\
\hline TU-115-W9 & 313.0 & 4 & $<2$ & $<0.1$ & 216 & 194 & 292 & 20.4 & 20.4 \\
\hline TU-116-W10 & 412.0 & 3 & $<2$ & $<0.1$ & 344 & 311 & 228 & 20.2 & 20.5 \\
\hline TU-117-W11 & 395.0 & 3 & $<2$ & $<0.1$ & 195 & 240 & 237 & 12.5 & 15.8 \\
\hline TU-118-W12 & 441.0 & 5 & $<2$ & $<0.1$ & 207 & 185 & 181 & 18.1 & 18.2 \\
\hline TU-119-W13 & 444.0 & $<0.1$ & $<2$ & $<0.1$ & 260 & 228 & 130 & 0.9 & 0.9 \\
\hline
\end{tabular}

aDiss., dissolved. 
Table D-3 (continued). Monitoring well water quality data in samples collected from sites surrounding the Fleming Site (June 1995 - January 1996).

\begin{tabular}{|c|c|c|c|c|c|c|c|c|}
\hline $\begin{array}{l}\text { Local } \\
\text { number }\end{array}$ & $\begin{array}{c}\mathrm{Hg} \\
\mu \mathrm{g} / \mathrm{L}\end{array}$ & $\begin{array}{c}\mathrm{K} \\
\mu \mathrm{g} / \mathrm{L}\end{array}$ & $\begin{array}{l}\mathrm{Mg} \\
\mu \mathrm{g} / \mathrm{L}\end{array}$ & $\begin{array}{l}\text { Mo } \\
\mu g / L\end{array}$ & $\begin{array}{l}\mathrm{Na} \\
\mu \mathrm{g} / \mathrm{L}\end{array}$ & $\begin{array}{c}\mathrm{Ni} \\
\mu \mathrm{g} / \mathrm{L}\end{array}$ & $\begin{array}{c}\mathrm{P} \\
\mu \mathrm{g} / \mathrm{L} \\
\end{array}$ & $\begin{array}{c}\mathrm{Pb} \\
\mu \mathrm{g} / \mathrm{L}\end{array}$ \\
\hline \multirow[t]{2}{*}{ TU-100-W1S } & $<0.1$ & 16.2 & 209 & $<11$ & 13.5 & 583 & 0.05 & $<1$ \\
\hline & $<0.1$ & 19.1 & 264 & 22 & 16.2 & 610 & 0.05 & $<5$ \\
\hline \multirow[t]{2}{*}{ TU-101-W1D } & $<0.1$ & 10.7 & 91 & $<11$ & 273 & $<4$ & $<0.01$ & $<1$ \\
\hline & $<0.1$ & 9.6 & 75 & 14 & 245 & $<4$ & $<0.01$ & $<5$ \\
\hline \multirow[t]{2}{*}{ TU-102-W2 } & $<0.1$ & 13.0 & 212 & $<11$ & 11.3 & 428 & 0.03 & $<1$ \\
\hline & $<0.1$ & 13.2 & 205 & $<10$ & 10.8 & 441 & 0.03 & $<1$ \\
\hline \multirow[t]{2}{*}{ TU-103-W3S } & $<0.1$ & 7.1 & 155 & $<11$ & 9.2 & 59 & $<0.01$ & $<1$ \\
\hline & $<0.1$ & 7.7 & 163 & $<10$ & 9.4 & 47 & $<0.01$ & $<2$ \\
\hline \multirow[t]{2}{*}{ TU-104-W3D } & $<0.1$ & 7.6 & 146 & $<11$ & 10.2 & 25 & $<0.01$ & $<1$ \\
\hline & $<0.1$ & 7.6 & 138 & $<10$ & 10.3 & 11 & 0.01 & $<1$ \\
\hline \multirow[t]{2}{*}{ TU-105-W4S } & $<0.1$ & 11.6 & 203 & $<11$ & 9.6 & 503 & 0.03 & $<1$ \\
\hline & $<0.1$ & 13.0 & 197 & $<10$ & 10.0 & 488 & 0.02 & $<5$ \\
\hline \multirow[t]{2}{*}{ TU-106-W4D } & $<0.1$ & 10.8 & 208 & $<11$ & 9.7 & 417 & 0.04 & $<1$ \\
\hline & $<0.1$ & 12.2 & 202 & 17 & 10.2 & 423 & 0.02 & $<5$ \\
\hline \multirow[t]{2}{*}{ TU-107-W4P } & $<0.1$ & 17.8 & 98 & $<11$ & 14.5 & 23 & $<0.01$ & $<1$ \\
\hline & $<0.1$ & 29.7 & 86 & 18 & 18.6 & 11 & $<0.01$ & $<1$ \\
\hline \multirow[t]{2}{*}{ TU-109-W5S } & $<0.1$ & 10.8 & 209 & $<11$ & 10.0 & 496 & 0.03 & $<1$ \\
\hline & $<0.1$ & 12.7 & 203 & $<10$ & 9.9 & 465 & 0.02 & $<5$ \\
\hline \multirow[t]{2}{*}{ TU-110-W6S } & $-^{a}$ & 13.5 & 329 & $<11$ & 10.7 & 1140 & $<0.01$ & $<1$ \\
\hline & $<0.1$ & 13.1 & 281 & 14 & 9.4 & 1027 & 0.01 & $<2$ \\
\hline \multirow[t]{2}{*}{ TU-111-W6D } & $<0.1$ & 15.9 & 373 & $<11$ & $\cdot 15.0$ & 883 & 0.07 & $<1$ \\
\hline & $<0.1$ & 24.5 & 361 & $<10$ & 24.5 & 312 & 0.01 & $<2$ \\
\hline \multirow[t]{2}{*}{ TU-112-W7 } & $<0.1$ & 14.2 & 158 & $<11$ & 14.2 & 391 & 0.02 & $<1$ \\
\hline & $<0.1$ & 13.9 & 156 & $<10$ & 13.9 & 378 & 0.02 & $<2$ \\
\hline \multirow[t]{2}{*}{ TU-113-W8S } & $<0.1$ & 5.9 & 58 & $<11$ & 5.9 & $<4$ & 0.01 & $<1$ \\
\hline & - & 5.3 & 57 & $<10$ & 5.3 & 6 & 0.02 & $<1$ \\
\hline \multirow[t]{2}{*}{ TU-114-W8D } & $<0.1$ & 9.3 & 167 & $<11$ & 9.3 & 261 & 0.06 & $<1$ \\
\hline & $<0.1$ & 7.8 & 177 & $<10$ & 7.8 & 309 & $<0.01$ & $<2$ \\
\hline TU-115-W9 & $<0.1$ & 12.4 & 165 & $<10$ & 12.4 & 721 & 0.01 & $<5$ \\
\hline TU-116-W10 & $<0.1$ & 12.5 & 234 & $<10$ & 12.5 & 608 & 0.02 & 6 \\
\hline TU-117-W11 & $<0.1$ & 13.7 & 201 & 12 & 13.7 & 616 & 0.01 & $<5$ \\
\hline TU-118-W12 & $<0.1$ & 12.7 & 213 & 16 & 12.7 & 519 & 0.02 & $<5$ \\
\hline TU-119-W13 & $<0.1$ & 10.3 & 213 & $<10$ & 10.3 & 320 & 0.02 & $<5$ \\
\hline
\end{tabular}

Data not available. 
Table D-3 (continued). Monitoring well water quality data in samples collected from sites surrounding the Fleming Site (June 1995 - January 1996).

\begin{tabular}{|c|c|c|c|c|c|c|c|}
\hline $\begin{array}{l}\text { Local } \\
\text { number }\end{array}$ & $\begin{array}{l}\mathrm{NH}_{3} \\
\mu \mathrm{g} / \mathrm{L}\end{array}$ & $\begin{array}{l}\mathrm{NO}_{2} \\
\mu \mathrm{g} / \mathrm{L}\end{array}$ & $\begin{array}{c}\text { Total } N^{a} \\
\mu g / L\end{array}$ & $\begin{array}{c}\mathrm{Sb} \\
\mu \mathrm{g} / \mathrm{L}\end{array}$ & $\begin{array}{c}\mathrm{Se} \\
\mu \mathrm{g} / \mathrm{L}\end{array}$ & $\begin{array}{c}\mathrm{Si} \\
\mu \mathrm{g} / \mathrm{L}\end{array}$ & $\begin{array}{c}\mathrm{Sr} \\
\mu \mathrm{g} / \mathrm{L}\end{array}$ \\
\hline \multirow[t]{2}{*}{ TU-100-W1S } & 2.10 & 0.01 & $<0.05$ & $<106$ & $<5$ & 13.9 & 5240 \\
\hline & 1.40 & $<0.01$ & $<0.05$ & $<100$ & $<1$ & 13.9 & 5620 \\
\hline \multirow[t]{2}{*}{ TU-101-W1D } & 1.80 & $<0.01$ & $<0.05$ & $<106$ & $<1$ & 10.5 & 2890 \\
\hline & 1.90 & $<0.01$ & $<0.05$ & $<100$ & $<1$ & 9.2 & 2807 \\
\hline \multirow[t]{2}{*}{ TU-102-W2 } & 1.40 & 0.01 & 0.06 & $<106$ & $<5$ & 12.0 & 2970 \\
\hline & 1.20 & $<0.01$ & $<0.05$ & $<100$ & $<5$ & 11.6 & 3022 \\
\hline \multirow[t]{2}{*}{ TU-103-W3S } & 0.48 & $<0.01$ & $<0.05$ & $<106$ & $<1$ & 10.5 & 1530 \\
\hline & 0.44 & $<0.01$ & $<0.05$ & $<100$ & $<1$ & 10.8 & 1729 \\
\hline \multirow[t]{2}{*}{ TU-104W3D } & 0.64 & $<0.01$ & 0.06 & $<106$ & $<2$ & 10.9 & 1940 \\
\hline & 0.58 & $<0.01$ & $<0.05$ & $<100$ & $<1$ & 10.7 & 2034 \\
\hline \multirow[t]{2}{*}{ TU-105-W4S } & 1.40 & $<0.01$ & $<0.05$ & $<106$ & $<5$ & 11.6 & 3210 \\
\hline & 0.95 & $<0.01$ & $<0.05$ & $<100$ & $<1$ & 11.5 & 3388 \\
\hline \multirow[t]{2}{*}{ TU-106-W4D } & 1.10 & 0.01 & $<0.05$ & $<106$ & $<5$ & 12.0 & 2880 \\
\hline & 0.83 & $<0.01$ & $<0.05$ & $<100$ & 1 & 12.1 & 3225 \\
\hline \multirow[t]{2}{*}{ TU-107-W4P } & 1.40 & $<0.01$ & $<0.05$ & $<106$ & $--^{a}$ & 11.3 & 2120 \\
\hline & 1.40 & $<0.01$ & 0.14 & $<100$ & 1 & 10.5 & 2233 \\
\hline \multirow[t]{2}{*}{ TU-109-W5S } & 1.00 & 0.01 & 0.06 & $<106$ & $<5$ & 11.3 & 2590 \\
\hline & 0.75 & $<0.01$ & $<0.05$ & $<100$ & $<1$ & 10.8 & 2845 \\
\hline \multirow[t]{2}{*}{ TU-110-W6S } & 1.20 & $<0.01$ & $<0.05$ & $<106$ & $<5$ & 9.0 & 1310 \\
\hline & 1.10 & 0.02 & $<0.05$ & $<100$ & $<5$ & 8.2 & 1249 \\
\hline \multirow[t]{2}{*}{ TU-111-Wద } & 1.40 & $<0.01$ & 0.09 & $<106$ & $<5$ & 15.6 & 1990 \\
\hline & 0.90 & $<0.01$ & $<0.05$ & $<100$ & $<5$ & 20.6 & 2437 \\
\hline \multirow[t]{2}{*}{ TU-112-W7 } & 1.10 & $<0.01$ & $<0.05$ & $<106$ & $<5$ & 12.8 & 3060 \\
\hline & 0.78 & $<0.01$ & $<0.05$ & $<100$ & $<1$ & 11.6 & 2709 \\
\hline \multirow[t]{2}{*}{ TU-113-W8S } & 0.32 & $<0.01$ & 0.06 & $<106$ & $<5$ & 10.5 & 744 \\
\hline & 0.32 & $<0.01$ & $<0.05$ & $<100$ & - & 10.1 & 840 \\
\hline \multirow[t]{2}{*}{ TU-114-W8D } & 0.91 & 0.02 & $<0.05$ & $<106$ & - & 12.2 & 2030 \\
\hline & 0.63 & $<0.01$ & $<0.05$ & $<100$ & $<2$ & 12.2 & 1663 \\
\hline TU-115-W9 & 1.00 & $<0.01$ & $<0.05$ & $<100$ & $<1$ & 13.8 & 2496 \\
\hline TU-116-W10 & 0.78 & $<0.01$ & $<0.05$ & $<100$ & $<1$ & 10.6 & 3055 \\
\hline TU-117-W11 & 1.00 & $<0.01$ & $<0.05$ & $<100$ & $<1$ & 14.9 & 2784 \\
\hline TU-118-W12 & 1.10 & $<0.01$ & $<0.05$ & $<100$ & $<1$ & 12.5 & 3885 \\
\hline TU-119-W13 & 0.87 & $<0.01$ & $<0.05$ & $<100$ & $<1$ & 10.9 & 3337 \\
\hline
\end{tabular}

a Data not available. 
Table D-3 (continued). Monitoring well water quality data in samples collected from sites surrounding the Fleming Site (June 1995 - January 1996).

\begin{tabular}{|c|c|c|c|c|c|c|c|}
\hline $\begin{array}{l}\text { Local } \\
\text { number }\end{array}$ & $\begin{array}{l}\mathrm{Ag} \\
\mu \mathrm{g} / \mathrm{L}\end{array}$ & $\begin{array}{c}D O C^{a} \\
\mu g / L\end{array}$ & $\begin{array}{r}\text { Tritium } \\
\text { pCi/L }\end{array}$ & $\begin{array}{l}\mathrm{SO}_{4} \\
\mu \mathrm{g} / \mathrm{L}\end{array}$ & $\begin{array}{l}\delta^{34}-S \\
\text { per mil }\end{array}$ & $\begin{array}{c}\mathrm{V} \\
\mu \mathrm{g} / \mathrm{L}\end{array}$ & $\begin{array}{c}\mathrm{Zn} \\
\mu \mathrm{g} / \mathrm{L}\end{array}$ \\
\hline \multirow[t]{2}{*}{ TU-100-W1S } & $<10$ & 0.6 & 66.2 & 1583 & -10.0 & $<5$ & 373 \\
\hline & $<10$ & 0.7 & $-\mathbf{b}$ & 2071 & -10.2 & $<5$ & 370 \\
\hline \multirow[t]{2}{*}{ TU-101-W1D } & $<10$ & 1.2 & 4.8 & 1337 & -6.0 & $<5$ & 4 \\
\hline & 14 & 0.4 & - & 1106 & -6.1 & $<5$ & $<1$ \\
\hline \multirow[t]{2}{*}{ TU-102-W2 } & $<10$ & 0.8 & 64.6 & 2336 & -9.4 & $<5$ & 402 \\
\hline & $<10$ & 0.9 & - & 2203 & -9.4 & 6 & 355 \\
\hline \multirow[t]{2}{*}{ TU-103-W3S } & $<10$ & 0.8 & 45.8 & 1418 & -13.2 & 13 & 26 \\
\hline & 18 & 1.2 & - & 1450 & -13.7 & $<5$ & 14 \\
\hline \multirow[t]{2}{*}{ TU-104-W3D } & $<10$ & 0.8 & 71.0 & 1531 & -13.5 & 25 & 9 \\
\hline & 14 & 1.0 & - & 1463 & -14.1 & 6 & $<1$ \\
\hline \multirow[t]{2}{*}{ TU-105-W4S } & $<10$ & 0.9 & 63.0 & 223 & -9.5 & 18 & 471 \\
\hline & $<10$ & 1.0 & - & 2040 & -9.3 & $<5$ & 465 \\
\hline \multirow[t]{2}{*}{ TU-106-W4D } & $<10$ & 0.7 & 60.8 & 2014 & -9.6 & 19 & 301 \\
\hline & $<10$ & 0.8 & - & 2070 & -9.4 & $<5$ & 326 \\
\hline \multirow[t]{2}{*}{ TU-107-W4P } & $<10$ & 1.6 & 18.0 & 951 & -9.2 & 16 & 5 \\
\hline & 15 & 2.4 & - & 755 & -8.5 & $<5$ & 6 \\
\hline \multirow[t]{2}{*}{ TU-109-W5S } & $<10$ & 1.2 & 46.1 & 2256 & -9.7 & $<5$ & 545 \\
\hline & $<10$ & 1.7 & - & 2130 & -9.6 & $<5$ & 483 \\
\hline \multirow[t]{2}{*}{ TU-110-W6S } & $<10$ & 1.6 & 68.5 & 2089 & -8.2 & $<5$ & 1860 \\
\hline & $<10$ & 1.6 & - & 3430 & -8.7 & 9 & 1618 \\
\hline \multirow[t]{2}{*}{ TU-111-W6D } & $<10$ & 1.4 & 35.5 & 3706 & -8.0 & $<5$ & 674 \\
\hline & $<10$ & 2.0 & - & 3108 & -8.2 & 12 & 5 \\
\hline \multirow[t]{2}{*}{ TU-112-W7 } & $<10$ & 0.8 & 67.8 & 1051 & -10.4 & 15 & 228 \\
\hline & 10 & 1.2 & - & 1503 & -11.0 & $<5$ & 211 \\
\hline \multirow[t]{2}{*}{ TU-113-W8S } & $<10$ & 0.8 & 5.8 & 516 & -5.9 & $<5$ & 6 \\
\hline & 23 & 0.8 & - & 438 & -6.4 & $<5$ & 2 \\
\hline \multirow[t]{2}{*}{ TU-114W8D } & $<10$ & 1.0 & 58.0 & 1113 & -12.0 & $<5$ & 87 \\
\hline & $<10$ & 1.0 & - & 1880 & -12.2 & 9 & 98 \\
\hline TU-115-W9 & $<10$ & 0.5 & - & 1604 & -11.4 & $<5$ & 933 \\
\hline TU-116-W10 & $<10$ & 1.0 & - & 2241 & -10.1 & 7 & 799 \\
\hline TU-117-W11 & $<10$ & 0.8 & - & 1974 & -9.9 & $<5$ & 574 \\
\hline TU-118-W12 & $<10$ & 0.6 & - & 2005 & -11.8 & 6 & 584 \\
\hline TU-119-W13 & 11 & 0.6 & - & 2033 & -5.7 & $<5$ & 70 \\
\hline
\end{tabular}

aDOC, dissolved organic carbon.

bData not available. 
Table D-4. Domestic well water quality data in samples collected from sites surrounding the Fleming Site (June 1995).

\begin{tabular}{|c|c|c|c|c|c|c|c|c|}
\hline \multirow{2}{*}{$\begin{array}{l}\text { Local } \\
\text { number }\end{array}$} & \multirow[b]{2}{*}{ Date } & \multirow[b]{2}{*}{ Time } & \multirow{2}{*}{$\begin{array}{l}\text { Depth to } \\
\text { water } \\
\text { table (ft)a }\end{array}$} & \multirow{2}{*}{$\begin{array}{c}\text { Sp. } \\
\text { Cond. } \\
(\mu \mathrm{S} / \mathrm{cm})^{b}\end{array}$} & \multirow{2}{*}{$\begin{array}{l}\mathrm{pH} \text { of } \\
\text { water in } \\
\text { the field }\end{array}$} & \multirow{2}{*}{$\begin{array}{l}\text { Redox } \\
\text { potential } \\
(\mathrm{mv})^{\mathbf{b}}\end{array}$} & \multicolumn{2}{|c|}{ Temperature $\left({ }^{\circ} \mathrm{C}\right)$} \\
\hline & & & & & & & Air & Water \\
\hline TU-170 & $6 / 12 / 95$ & $14: 45$ & $--^{c}$ & 581 & 7.4 & 216 & 22 & 12.0 \\
\hline TU-171 & $6 / 13 / 95$ & $16: 45$ & - & 468 & 7.0 & 318 & 23 & 12.0 \\
\hline TU-172 & $6 / 12 / 95$ & 10:15 & - & 966 & 6.7 & 230 & 20 & 13.0 \\
\hline TU-173 & $6 / 14 / 95$ & $10: 45$ & 83.53 & 462 & 7.3 & 268 & 18 & 12.5 \\
\hline TU-174 & $6 / 13 / 95$ & $10: 15$ & 35.70 & 631 & 7.0 & 301 & 18 & 12.5 \\
\hline TU-175 & 6/20/95 & $13: 45$ & 94.67 & 757 & 7.2 & 448 & 28 & 13.0 \\
\hline TU-176 & 6/20/95 & $9: 45$ & 60.00 & 523 & 6.7 & 319 & 26 & 12.0 \\
\hline TU-177 & 6/13/95 & $13: 40$ & -- & 843 & 6.7 & 312 & 20 & 12.5 \\
\hline TU-178 & $6 / 14 / 95$ & $14: 15$ & 78.00 & 524 & 7.2 & 366 & 23 & 12.5 \\
\hline
\end{tabular}

a Given in feet below land surface.

$\mathrm{b} \mu \mathrm{S} / \mathrm{cm}$, microsiemens per centimeter and $\mathrm{mv}$, millivolts.

cData not available.

Table D.4 (continued).

\begin{tabular}{|c|c|c|c|c|c|c|c|}
\hline \multirow{2}{*}{$\begin{array}{l}\text { Local } \\
\text { number }\end{array}$} & \multirow{2}{*}{$\begin{array}{c}\text { Turbidity } \\
\text { (NTU) }^{\mathbf{a}}\end{array}$} & \multirow{2}{*}{$\begin{array}{l}\text { Diss. } \\
\text { oxygen }\end{array}$} & Hardness & Acidity & Alkalinity & Bicarb. & \multirow[b]{2}{*}{$\underset{(\mathrm{mg} / \mathrm{L})^{\mathrm{a}}}{\mathrm{ROE}}$} \\
\hline & & & \multicolumn{4}{|c|}{$\left(\mathrm{mg} / \mathrm{L}\right.$ as $\left.\mathrm{CaCO}_{3}\right)$} & \\
\hline TU-170 & 2 & $<0.100$ & 123 & $<0.1$ & 312 & 382 & 266 \\
\hline TU-171 & $<1$ & $<0.100$ & 242 & 0.2 & 247 & 303 & 231 \\
\hline TU-172 & 1 & $<0.100$ & 570 & 0.4 & 204 & 250 & 721 \\
\hline TU-173 & $<1$ & $<0.100$ & 143 & 0.1 & 232 & 284 & 195 \\
\hline TU-174 & $<1$ & $<0.100$ & 282 & 0.2 & 228 & 282 & 367 \\
\hline TU-175 & 2 & 4.95 & 87 & 0.3 & 350 & 428 & 473 \\
\hline TU-176 & 1 & $<0.100$ & 257 & 0.3 & 173 & 210 & 319 \\
\hline TU-177 & 1 & $<0.100$ & 416 & 0.2 & 207 & 256 & 538 \\
\hline TU-178 & 1 & $<0.100$ & -.b & 0.1 & 264 & 322 & 256 \\
\hline
\end{tabular}

aNTU, nepholometric turbidity units; ROE, residue on evaporation bData not determined or not available 
Table D-4 (continued). Domestic well water quality data in samples collected from sites surrounding the Fleming Site (June 1995).

\begin{tabular}{|c|c|c|c|c|c|c|c|c|c|}
\hline \multirow{2}{*}{$\begin{array}{l}\text { Local } \\
\text { number }\end{array}$} & \multicolumn{2}{|c|}{$\mathrm{Al}(\mu \mathrm{g} / \mathrm{L})$} & \multirow{2}{*}{$\begin{array}{c}\mathrm{Ar} \\
\mu \mathrm{g} / \mathrm{L}\end{array}$} & \multirow{2}{*}{$\begin{array}{c}\mathrm{Ba} \\
\mu \mathrm{g} / \mathrm{L}\end{array}$} & \multirow{2}{*}{$\begin{array}{c}\mathrm{Be} \\
\mu \mathrm{g} / \mathrm{L}\end{array}$} & \multirow{2}{*}{$\underset{\mu \mathrm{g} / \mathrm{L}}{\mathrm{B}}$} & \multirow{2}{*}{$\begin{array}{c}\mathrm{Cd} \\
\mu \mathrm{g} / \mathrm{L}\end{array}$} & \multirow{2}{*}{$\begin{array}{c}\mathrm{Cr} \\
\mu \mathrm{g} / \mathrm{L}\end{array}$} & \multirow{2}{*}{$\begin{array}{r}\text { Co } \\
\mu g / L\end{array}$} \\
\hline & Total & Diss. $^{a}$ & & & & & & & \\
\hline TU-170 & $<30$ & $<30$ & $<1$ & 99 & $<1$ & 359 & $<1$ & $<2$ & $<6$ \\
\hline TU-171 & $<30$ & $<30$ & $<1$ & 243 & $<1$ & 364 & $<1$ & $<2$ & $<6$ \\
\hline TU-172 & $<30$ & 66 & $<1$ & 62 & $<1$ & 84 & $<1$ & 6 & $<6$ \\
\hline TU-173 & $<30$ & 34 & $<1$ & 178 & $<1$ & 125 & $<1$ & $<2$ & $<6$ \\
\hline TU-174 & $<30$ & 38 & $<1$ & 64 & $<1$ & 152 & $<1$ & $<2$ & $<6$ \\
\hline TU-175 & $<30$ & $<30$ & $<1$ & 38 & $<1$ & 643 & $<1$ & $<2$ & $<6$ \\
\hline TU-176 & $<30$ & $<30$ & $<1$ & 60 & 2.0 & 86 & $<1$ & $<2$ & $<6$ \\
\hline TU-177 & $<30$ & $<30$ & 2 & 61 & $<1$ & 173 & $<1$ & $<2$ & $<6$ \\
\hline TU-178 & $<30$ & $<30$ & $<1$ & $<1$ & $<1$ & 65 & $<1$ & $<2$ & $<6$ \\
\hline
\end{tabular}

aDiss., dissolved.

Table D-4 (continued).

\begin{tabular}{|c|c|c|c|c|c|c|c|c|c|}
\hline \multirow{2}{*}{$\begin{array}{l}\text { Local } \\
\text { number }\end{array}$} & \multirow{2}{*}{$\begin{array}{c}\mathrm{Ca} \\
\mu \mathrm{g} / \mathrm{L}\end{array}$} & \multirow{2}{*}{$\begin{array}{c}\mathrm{Cl} \\
\mu \mathrm{g} / \mathrm{L}\end{array}$} & \multirow{2}{*}{$\begin{array}{c}\mathrm{Cu} \\
\mu \mathrm{g} / \mathrm{L}\end{array}$} & \multirow{2}{*}{$\underset{\mu \mathrm{g} / \mathrm{L}}{\mathrm{F}}$} & \multicolumn{2}{|c|}{$\mathrm{Fe}(\mu \mathrm{g} / \mathrm{L})$} & \multirow{2}{*}{$\underset{\mu \mathrm{L} / \mathrm{L}}{\mathrm{i}}$} & \multicolumn{2}{|c|}{$\operatorname{Mn}(\mu g / L)$} \\
\hline & & & & & Total & Diss. $^{a}$ & & Total & Diss. \\
\hline Тu-170 & 33.1 & 12 & $<2$ & 2 & 452 & 436 & 13 & 74 & 75 \\
\hline TU-171 & 68.4 & 3 & $<2$ & 1 & 322 & 295 & 17 & 145 & 137 \\
\hline TU-172 & 186.6 & 25 & $<2$ & $<1$ & 1400 & 1430 & 28 & 688 & 692 \\
\hline TU-173 & 40.6 & 12 & 12 & 1 & 177 & 164 & $<4$ & 51 & 47 \\
\hline TU-174 & 84.5 & 9 & $<2$ & 1 & 1058 & 603 & 11 & 441 & 440 \\
\hline TU-175 & 24.3 & 7 & 24 & 2 & 140 & 24 & 8 & 84 & 82 \\
\hline TU-176 & 87.8 & 4 & 3 & 1 & 983 & 969 & 15 & 279 & 276 \\
\hline TU-177 & 133.7 & 29 & 3 & 1 & 1637 & 1460 & 21 & 754 & 743 \\
\hline TU-178 & 3.0 & 6 & $<2$ & 1 & 11 & 11 & $<4$ & $<1$ & $<1$ \\
\hline
\end{tabular}

aNTU, nepholometric turbidity units; ROE, residue on evaporation bData not determined or not available 
Table D-4 (continued). Domestic well water quality data in samples collected from sites surrounding the Fleming Site (June 1995).

\begin{tabular}{|c|c|c|c|c|c|c|c|c|}
\hline $\begin{array}{l}\text { Local } \\
\text { number }\end{array}$ & $\begin{array}{c}\mathrm{Hg} \\
\mu \mathrm{g} / \mathrm{L}\end{array}$ & $\underset{\mu \mathrm{g} / \mathrm{L}}{\mathrm{K}}$ & $\begin{array}{c}\mathrm{Mg} \\
\mu \mathrm{g} / \mathrm{L}\end{array}$ & $\begin{array}{r}\text { Mo } \\
\mu \mathrm{g} / \mathrm{L}\end{array}$ & $\begin{array}{c}\mathrm{Na} \\
\mu \mathrm{g} / \mathrm{L}\end{array}$ & $\begin{array}{c}\mathrm{Ni} \\
\mu \mathrm{g} / \mathrm{L}\end{array}$ & $\begin{array}{c}\mathrm{P} \\
\mu \mathrm{g} / \mathrm{L}\end{array}$ & $\begin{array}{c}\mathrm{Pb} \\
\mu \mathrm{g} / \mathrm{L}\end{array}$ \\
\hline TU-170 & $<0.1$ & 3.2 & 9.9 & $<11$ & 115 & $<4$ & 0.03 & $<1$ \\
\hline TU-171 & $<0.1$ & 5.4 & 17.9 & $<11$ & 11.0 & $<4$ & $<0.01$ & $<1$ \\
\hline TU-172 & $<0.1$ & 3.8 & 25.3 & $<11$ & 8.5 & $<4$ & $<0.01$ & $<1$ \\
\hline TU-173 & $<0.1$ & 2.3 & 10.1 & $<11$ & 47.7 & $<4$ & 0.01 & $<1$ \\
\hline TU-174 & $<0.1$ & 2.9 & 17.3 & $<11$ & 21.8 & $<4$ & $<0.01$ & $<1$ \\
\hline TU-175 & $<0.1$ & 3.9 & 6.4 & $<11$ & 144 & 10 & $<0.01$ & $<1$ \\
\hline TU-176 & $<0.1$ & 1.8 & 9.2 & $<11$ & 6.8 & $<4$ & $<0.01$ & $<1$ \\
\hline TU-177 & -- & 3.7 & 19.9 & $<11$ & 20.1 & $<4$ & $<0.01$ & $<1$ \\
\hline TU-178 & - & 0.2 & 0.5 & $<11$ & 55.1 & $<4$ & 0.03 & 1 \\
\hline
\end{tabular}

aDiss., dissolved.

Table D-4 (continued).

\begin{tabular}{|c|c|c|c|c|c|c|c|}
\hline $\begin{array}{l}\text { Local } \\
\text { number }\end{array}$ & $\begin{array}{l}\mathrm{NH}_{3} \\
\mu \mathrm{g} / \mathrm{L}\end{array}$ & $\begin{array}{l}\mathrm{NO}_{2} \\
\mu \mathrm{g} / \mathrm{L}\end{array}$ & $\begin{array}{c}\text { Total Na } \\
\mu \mathrm{g} / \mathrm{L}\end{array}$ & $\begin{array}{c}\mathrm{Sb} \\
\mu \mathrm{g} / \mathrm{L}\end{array}$ & $\begin{array}{c}\mathrm{Se} \\
\mu \mathrm{g} / \mathrm{L}\end{array}$ & $\begin{array}{c}\mathrm{Si} \\
\mu \mathrm{g} / \mathrm{L}\end{array}$ & $\begin{array}{c}\mathrm{Sr} \\
\mu \mathrm{g} / \mathrm{L}\end{array}$ \\
\hline TU-170 & 0.72 & $<0.01$ & 0.05 & $<106$ & $<1$ & 10.8 & $<5$ \\
\hline TU-171 & 0.97 & $<0.01$ & $<0.05$ & $<106$ & $<1$ & 10.1 & $<5$ \\
\hline TU-172 & 0.14 & $<0.01$ & 0.06 & $<106$ & $<1$ & 8.1 & $<5$ \\
\hline TU-173 & 1.00 & $<0.01$ & $<0.05$ & $<106$ & $<1$ & 8.8 & $<5$ \\
\hline TU-174 & 0.65 & $<0.01$ & $<0.05$ & $<106$ & $<1$ & 12.9 & $<5$ \\
\hline TU-175 & 0.47 & $<0.01$ & 0.07 & $<106$ & $<1$ & 7.3 & $<5$ \\
\hline TU-176 & 0.12 & $<0.01$ & $<0.05$ & $<106$ & $<1$ & 8.8 & $<5$ \\
\hline TU-177 & 0.31 & $<0.01$ & $<0.05$ & $<106$ & $<1$ & 8.8 & $<5$ \\
\hline TU-178 & 0.06 & $<0.01$ & 0.07 & $<106$ & $<1$ & 3.4 & $<5$ \\
\hline
\end{tabular}

aDiss., dissolved. 
Table D-4 (continued). Domestic well water quality data in samples collected from sites surrounding the Fleming Site (June 1995).

\begin{tabular}{lccccccc}
\hline \hline $\begin{array}{l}\text { Local } \\
\text { number }\end{array}$ & $\begin{array}{c}\mathrm{Ag} \\
\mu \mathrm{g} / \mathrm{L}\end{array}$ & $\begin{array}{c}\mathrm{DOC}^{\mathrm{a}} \\
\mu \mathrm{g} / \mathrm{L}\end{array}$ & $\begin{array}{c}\mathrm{Tritium} \\
\mathrm{pCi} / \mathrm{L}\end{array}$ & $\begin{array}{c}\mathrm{SO}_{4} \\
\mu \mathrm{g} / \mathrm{L}\end{array}$ & $\begin{array}{c}\delta^{34}-\mathrm{S} \\
\text { permil }\end{array}$ & $\begin{array}{c}\mathrm{V} \\
\mu \mathrm{g} / \mathrm{L}\end{array}$ & $\begin{array}{r}\mathrm{Zn} \\
\mu \mathrm{g} / \mathrm{L}\end{array}$ \\
\hline TU-170 & $<10$ & 0.4 & $<1.0$ & 17 & 12.3 & $<5$ & 2 \\
TU-171 & $<10$ & 0.7 & 2.0 & 22 & 0.7 & $<5$ & $<1$ \\
TU-172 & $<10$ & 1.0 & 50.0 & 346 & -7.3 & $<5$ & 10 \\
TU-173 & $<10$ & 0.8 & $<1.0$ & 9 & - & $<5$ & 15 \\
TU-174 & $<10$ & 0.4 & 45.0 & 95 & -7.5 & $<5$ & $<1$ \\
TU-175 & $<10$ & 0.4 & 25.3 & 125 & -11.2 & $<5$ & 8 \\
TU-176 & $<10$ & 0.5 & 48.0 & 100 & -6.7 & $<5$ & 2 \\
TU-177 & $<10$ & - & 58.0 & 226 & -6.6 & $<5$ & $<1$ \\
TU-178 & $<10$ & - & $<1.0$ & 10 & - & $<5$ & $<1$ \\
& & & & & & & $<$ \\
\hline \hline
\end{tabular}


Table D-5. Interstitial water quality data in lysimeter samples collected from sites within the FGD treated areas of the Fleming Site (June 1995 - January 1996).

\begin{tabular}{|c|c|c|c|c|c|c|c|c|}
\hline \multirow{2}{*}{$\begin{array}{l}\text { Local } \\
\text { number }\end{array}$} & \multirow[b]{2}{*}{ Date } & \multirow[b]{2}{*}{ Time } & \multirow{2}{*}{$\begin{array}{l}\text { Depth to } \\
\text { water } \\
\text { table (ft)a }\end{array}$} & \multirow{2}{*}{$\begin{array}{l}\text { Sp. } \\
\text { Cond. } \\
(\mu \mathrm{S} / \mathrm{cm})\end{array}$} & \multirow{2}{*}{$\begin{array}{l}\mathrm{pH} \text { of } \\
\text { water in } \\
\text { the field }\end{array}$} & \multirow{2}{*}{$\begin{array}{l}\text { Redox } \\
\text { potential } \\
(\mathrm{mv})\end{array}$} & \multicolumn{2}{|c|}{ Temperature $\left({ }^{\circ} \mathrm{C}\right)$} \\
\hline & & & & & & & Air & Water \\
\hline TU-130-L1A-1.5 & $1 / 18 / 96$ & $9: 50$ & 1.5 & 7990 & 7.1 & $--b$ & -- & -- \\
\hline \multirow[t]{3}{*}{ TU-131-L1A-2.5 } & $7 / 7195$ & $10: 05$ & 2.5 & - & - & -- & -- & -- \\
\hline & $10 / 20 / 95$ & $9: 00$ & 2.5 & 7660 & 4.3 & -- & - & -- \\
\hline & $1 / 18 / 96$ & $9: 45$ & 2.5 & 8050 & 5.6 & -- & -- & -- \\
\hline TU-132-L1A-3.5 & $1 / 18 / 96$ & 9.40 & 3.5 & 9540 & -- & -- & - & - \\
\hline \multirow[t]{3}{*}{ TU-133-L1B-1.5 } & $7 / 7 / 95$ & $10: 15$ & 1.5 & -- & -- & -- & - & -- \\
\hline & $10 / 20 / 95$ & 9.05 & 1.5 & 10610 & 6.3 & -- & - & - \\
\hline & $1 / 18 / 96$ & $9: 35$ & 1.5 & 13100 & 7.0 & - & -- & -- \\
\hline TU-134-L1B-2.5 & 7/7/95 & $10: 20$ & 2.5 & -- & - & -- & -- & -- \\
\hline \multirow{2}{*}{ TU-136-L2A-1.5 } & $10 / 20 / 95$ & $9: 10$ & 1.5 & 11070 & 6.2 & -- & -- & -- \\
\hline & $1 / 18 / 96$ & $9: 30$ & 1.5 & 7240 & 7.2 & -- & -- & - \\
\hline \multirow[t]{3}{*}{ TU-137-L-2A-2.5 } & $7 / 7 / 95$ & $10: 35$ & 2.5 & -- & -- & -- & -. & -- \\
\hline & $10 / 20 / 95$ & $9: 20$ & 2.5 & 14620 & 6.2 & - & -- & -- \\
\hline & $1 / 18 / 96$ & $9: 25$ & 2.5 & 7810 & 6.8 & - & -- & -- \\
\hline \multirow[t]{2}{*}{ TU-138-L2A-3.5 } & $10 / 20 / 95$ & $9: 30$ & 3.5 & 11970 & 6.2 & -- & - & - \\
\hline & $1 / 18 / 96$ & $9: 20$ & 3.5 & 7440 & 6.7 & -- & - & - \\
\hline \multirow[t]{3}{*}{ TU-139-L2B-1.5 } & $7 / 7 / 95$ & $10: 45$ & 1.5 & -- & -- & -- & - & -- \\
\hline & $10 / 20 / 95$ & $9: 40$ & 1.5 & 14660 & 6.7 & -- & -- & -- \\
\hline & $1 / 18 / 96$ & $9: 15$ & 1.5 & 7600 & 7.3 & -- & - & - \\
\hline \multirow[t]{3}{*}{ TU-140-L2B-2.5 } & $7 / 7 / 95$ & $10: 50$ & 2.5 & - & - & - & -- & -- \\
\hline & $10 / 20 / 95$ & $9: 50$ & 2.5 & 10410 & 6.1 & - & -- & - \\
\hline & $1 / 18 / 96$ & $9: 10$ & 2.5 & 9760 & 6.0 & - & -- & -- \\
\hline \multirow[t]{3}{*}{ TU-141-L2B-3.5 } & $7 / 7 / 95$ & $10: 55$ & 3.5 & -- & -- & -- & -- & -- \\
\hline & $10 / 20 / 95$ & $10: 00$ & 3.5 & 9410 & 6.4 & -- & -- & -- \\
\hline & $1 / 18 / 96$ & 9.05 & 3.5 & 6560 & 7.2 & -- & -- & -- \\
\hline TU-142-L3A-4.5A & $1 / 18 / 96$ & $10: 25$ & 4.5 & 5920 & 6.5 & -- & - & - \\
\hline \multirow[t]{2}{*}{ TU-144-L3B-1.5 } & $10 / 20 / 95$ & $10: 10$ & 1.5 & 8790 & 6.0 & - & - & - \\
\hline & $1 / 18 / 96$ & $9: 00$ & 1.5 & 5890 & 7.0 & -- & -- & -- \\
\hline \multirow[t]{2}{*}{ TU-145-L3B-2.5 } & $7 / 7 / 95$ & 11:05 & 2.5 & -- & -- & -- & - & -- \\
\hline & $1 / 18 / 96$ & $8: 55$ & 2.5 & 6600 & 6.9 & -- & -- & -- \\
\hline TU-147-L3C-1.5 & $1 / 18 / 96$ & $8: 50$ & 1.5 & 6460 & - & -. & -. & -- \\
\hline TU-148-L3C-2.5 & $10 / 20 / 95$ & $10: 15$ & 2.5 & 9020 & 5.8 & -- & -- & -- \\
\hline & $1 / 18 / 96$ & $8: 30$ & 2.5 & 6050 & 6.8 & - & - & $\cdot-$ \\
\hline TU-149-L3C-3.5 & $1 / 18 / 96$ & $8: 45$ & 3.5 & 6380 & 6.6 & - & - & $-\cdot$ \\
\hline TU-150-LAA-1.5 & $1 / 18 / 96$ & $7: 00$ & 1.5 & 9330 & 7.6 & -. & - & -- \\
\hline TU-151-L4A-2.5 & $7 / 7 / 95$ & $11: 55$ & 2.5 & - & - & - & - & -- \\
\hline & $10 / 20 / 95$ & $10: 20$ & 2.5 & 0260 & 5.9 & -- & - & - \\
\hline & $1 / 18 / 96$ & 7:05 & 2.5 & 7650 & 6.7 & -- & $-\cdot$ & -- \\
\hline TU-152-LAA-3.5 & $10 / 20 / 95$ & $10: 30$ & 3.5 & 5810 & 5.3 & - & $\cdots$ & -- \\
\hline & $1 / 18 / 96$ & $7: 10$ & 3.5 & 7480 & 6.3 & - & $\cdots$ & -- \\
\hline TU-153-LAB-1.5 & $10 / 20 / 95$ & $10: 40$ & 1.5 & 8830 & 5.8 & -- & - & -- \\
\hline TU-154-LAB-2.5 & $10 / 20 / 95$ & $10: 50$ & 2.5 & 8360 & 6.3 & -- & - & - \\
\hline & $1 / 18 / 96$ & $7: 15$ & 2.5 & 7340 & 6.9 & 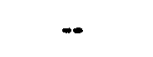 & .. & $\cdots$ \\
\hline TU-155-LAB-3.5 & $10 / 20 / 95$ & 11:00 & 3.5 & 9190 & 6.2 & -- & - & -- \\
\hline & $1 / 18 / 96$ & $7: 20$ & 3.5 & 6200 & 7.0 & -- & -- & -- \\
\hline TU-156-LAC-1.5UP & $7 / 7 / 95$ & $12: 20$ & 1.5 & -- & - & - & -- & -- \\
\hline & $1 / 18 / 96$ & $7: 25$ & 1.5 & 8400 & 6.9 & -- & - & - \\
\hline TU-157-LAC-2.5UP & $7 / 7 / 95$ & $12: 25$ & 2.5 & - & -- & - & - & -- \\
\hline & $1 / 18 / 96$ & $11: 20$ & 2.5 & 9610 & 6.0 & -- & -- & -- \\
\hline TU-158-LAC-3.5UP & $7 / 7 / 95$ & $12: 30$ & 3.5 & - & - & - & -- & $\cdots$ \\
\hline & $1 / 18 / 96$ & $10: 20$ & 3.5 & 7150 & 6.8 & - & - & -- \\
\hline
\end{tabular}

aln feet below land surface. bData not available. 
Table D-5 (continued). Interstitial water quality data in lysimeter samples collected from sites within the FGD treated areas of the Fleming Site (June 1995 - January 1996).

\begin{tabular}{|c|c|c|c|c|c|c|c|}
\hline \multirow{2}{*}{$\begin{array}{l}\text { Local } \\
\text { number }\end{array}$} & \multirow{2}{*}{$\begin{array}{l}\text { Turbidity } \\
\text { (NTU) }\end{array}$} & \multirow{2}{*}{$\begin{array}{l}\text { Diss. } \\
\text { oxygen }\end{array}$} & Hardness & Acidity & Alkalinity & Bicarb. & \multirow{2}{*}{$\begin{array}{c}\mathrm{ROE} \\
(\mathrm{mg} / \mathrm{L})^{\mathrm{a}}\end{array}$} \\
\hline & & & \multicolumn{4}{|c|}{$\left(\mathrm{mg} / \mathrm{Las} \mathrm{CaCO}{ }_{3}\right)$} & \\
\hline & & $\therefore$ & $b^{4}+t^{2}$ & $z^{2}$ & $x^{2}=$ & & \\
\hline TU-130-L1A-1.5 &.$-\mathrm{b}$ & -. & 8686 & 0.3 & - & -- & -- \\
\hline \multirow[t]{3}{*}{ TU-131-L1A-2.5 } & -- & -- & -- & -- & - & - & -- \\
\hline & $\cdots$ & - & 7187 & 4.7 & -- & -- & 9415 \\
\hline & -- & - & 8199 & 0.2 & -- & -- & - \\
\hline TU-132-L1A-3.5 & -- & -- & 8840 & -- & - & -- & -- \\
\hline \multirow[t]{3}{*}{ TU-133-L1B-1.5 } & -- & -- & -- & -- & - & - & -- \\
\hline & - & -- & 10996 & 0.7 & - & -- & 13850 \\
\hline & -- & - & 14985 & 0.5 & - & - & 18040 \\
\hline TU-134-L1B-2.5 &.- & - & 130 & 0.9 & -- & -- & -- \\
\hline \multirow[t]{2}{*}{ TU-136-L2A-1.5 } & $-\cdot$ & - & 11415 & 0.3 & -- & - & 14860 \\
\hline & -- & - & 7926 & -. & -- & - & -- \\
\hline \multirow[t]{3}{*}{ TU-137-L2A-2.5 } & - & $\cdots$ & - & -- & - & - & -- \\
\hline & -- & - & 15355 & 1.1 & -- & -- & 20850 \\
\hline & -- & - & 8208 & -- & - & - & 9604 \\
\hline \multirow[t]{2}{*}{ TU-138-L2A-3.5 } & -. & - & 11891 & 1.1 & - & -- & 16110 \\
\hline & - & - & 7858 & 0.1 & - & -- & 8832 \\
\hline \multirow[t]{3}{*}{ TU-139-L2B-1.5 } & -- & -- & - & -- & -- & - & -- \\
\hline & -- & -- & 15243 & 0.5 & - & $\cdots$ & 20490 \\
\hline & -- & $-\cdot$ & 8136 & -. & $\cdots$ & -- & 8956 \\
\hline \multirow[t]{3}{*}{ TU-140-L2B-2.5 } & -- & -- & 342 & 0.7 & - & -- & -- \\
\hline & -- & -- & 10308 & 0.3 & - & - & 13535 \\
\hline & -- & - & 10779 & 0.0 & - & -- & 11832 \\
\hline \multirow[t]{3}{*}{ TU-141-L2B-3.5 } & -- & -- & 1344 & 1.8 & - & -- & - \\
\hline & -- & -- & 9107 & 0.6 & - & - & 11905 \\
\hline & -- & -. & 6386 & -- & - & -- & 7434 \\
\hline TU-142-L3A-4.5A & - & -- & 5807 & 0.0 & -- & -- & 6756 \\
\hline \multirow[t]{2}{*}{ TU-144-L3B-1.5 } & -- & - & 7919 & 0.2 & - & - & 11195 \\
\hline & - & -- & 5478 & - & - & - & 6492 \\
\hline \multirow[t]{2}{*}{ TU-145-L3B-2.5 } & -- & -- & 605 & 1.3 & -- & -- & - \\
\hline & - & -- & 6322 & - & -- & -- & 5654 \\
\hline TU-147-L3C-1.5 & -- & -- & 5229 & - & - & - & - \\
\hline \multirow[t]{2}{*}{ TU-148-L3C-2.5 } & -- & - & 8330 & 0.8 & - & - & 11080 \\
\hline & $\cdots$ & - & 5726 & - & -- & -- & 6686 \\
\hline TU-149-L3C-3.5 & -. & - & 6348 & - & - & - & -- \\
\hline TU-150-LAA-1.5 & -- & - & 5167 & -- & -. & - & - \\
\hline \multirow[t]{3}{*}{ TU-151-LAA-2.5 } & -- & -- & - & - & -- & - & - \\
\hline & -- & - & 8547 & 0.6 & - & -- & 11415 \\
\hline & -- & - & 7887 & 0.0 & - & - & 8706 \\
\hline \multirow[t]{2}{*}{ TU-152-LAA-3.5 } & $\cdots$ & -- & 5081 & 0.3 & - & -- & 6560 \\
\hline & - & -- & 7489 & 0.0 & - & - & 8452 \\
\hline TU-153-LAB-1.5 & - & - & 7891 & 0.4 & - & - & 10590 \\
\hline TU-154-LAB-2.5 & - & -. & 7510 & 0.7 & -- & - & 10065 \\
\hline & - & -. & 7815 & - & -. & -- & 8916 \\
\hline TU-155-LAB-3.5 & - & - & 8647 & 0.5 & - & - & 11530 \\
\hline & -- & - & 6114 & -- & - & -. & 6880 \\
\hline TU-156-LAC-1.5UP & - & -- & 654 & 0.7 & -. & - & - \\
\hline & - & -- & 9089 & - & -- & - & 10430 \\
\hline TU-157-LAC-2.5UP & $\cdots$ & - & 169 & 0.9 & - & - & - \\
\hline & -- & - & 8829 & 0.2 & -- & - & 12475 \\
\hline TU-158-LAC-3.5UP & - & - & - & - & - & - & -- \\
\hline & - & - & 7428 & -- & - & - & - \\
\hline
\end{tabular}

aNTU, nepholometric turbidity units; ROE, residue on evaporation. bData not determined or not available. 
Table D-5 (continued). Interstitial water quality data in lysimeter samples collected from sites within the FGD treated areas of the Fleming Site (June 1995 - January 1996).

\begin{tabular}{|c|c|c|c|c|c|c|c|c|c|}
\hline \multirow{2}{*}{$\begin{array}{l}\text { Local } \\
\text { number }\end{array}$} & \multicolumn{2}{|c|}{$\mathrm{Al}(\mu \mathrm{g} / \mathrm{L})$} & \multirow{2}{*}{$\begin{array}{c}\mathrm{Ar} \\
\mu \mathrm{g} / \mathrm{L}\end{array}$} & \multirow{2}{*}{$\begin{array}{c}\mathrm{Ba} \\
\mu \mathrm{g} / \mathrm{L}\end{array}$} & \multirow{2}{*}{$\begin{array}{c}\mathrm{Be} \\
\mu \mathrm{g} / \mathrm{L}\end{array}$} & \multirow{2}{*}{$\begin{array}{c}\text { B } \\
\mu \mathrm{g} / \mathrm{L}\end{array}$} & \multirow{2}{*}{$\begin{array}{l}\mathrm{Cd} \\
\mu \mathrm{g} / \mathrm{L}\end{array}$} & \multirow{2}{*}{$\begin{array}{l}\mathrm{Cr} \\
\mu \mathrm{g} / \mathrm{L}\end{array}$} & \multirow{2}{*}{$\begin{array}{l}\text { Co } \\
\mu \mathrm{g} / \mathrm{L}\end{array}$} \\
\hline & Total & Diss. $^{a}$ & & & & & & & \\
\hline TU-130-L1A-1.5 & $--b$ & 245 & -- & 12 & $<1.0$ & 492 & 2 & 4 & 9 \\
\hline \multirow[t]{3}{*}{ TU-131-L1A-2.5 } & - & 2368 & -- & 22 & 3.0 & 700 & 5 & 10 & 720 \\
\hline & -- & 3558 & -. & 14 & 14.0 & 529 & 6 & 17 & 586 \\
\hline & -- & 1290 & -- & 8 & 1.0 & 290 & 1 & 6 & 423 \\
\hline TU-132-L1A-3.5 & -- & 308 & -- & 14 & $<1.0$ & 348 & $<1$ & 13 & 557 \\
\hline \multirow[t]{3}{*}{ TU-133-L1B-1.5 } & -- & 303 & 2 & 38 & $<1.0$ & 900 & 2 & 10 & 80 \\
\hline & -- & 404 & -- & 26 & $<1.0$ & 731 & $<1$ & 13 & 43 \\
\hline & - & 325 & 2 & 15 & $<1.0$ & 396 & $<1$ & 11 & 8 \\
\hline TU-134-L1B-2.5 & 844 & 809 & 2 & 23 & 1.0 & 500 & 3 & 10 & 1000 \\
\hline \multirow[t]{2}{*}{ TU-136-L2A-1.5 } & - & 424 & - & 21 & $<1.0$ & 823 & 2 & 21 & 460 \\
\hline & -- & 233 & -. & 11 & $<1.0$ & 416 & $<1$ & 6 & 16 \\
\hline \multirow[t]{3}{*}{ TU-137-L.2A-2.5 } & -- & 343 & - & 33 & $<1.0$ & 1000 & 2 & 20 & 230 \\
\hline & -- & 552 & -- & 27 & $<1.0$ & 1018 & 1 & 24 & 266 \\
\hline & -- & 293 & -- & 14 & $<1.0$ & 469 & $<1$ & 6 & 123 \\
\hline \multirow{2}{*}{ TU-138-L2A-3.5 } & -- & 360 & -- & 25 & $<1.0$ & 794 & 2 & 16 & 245 \\
\hline & -- & 241 & -- & 11 & $<1.0$ & 389 & $<1$ & 5 & 94 \\
\hline \multirow[t]{3}{*}{ TU-139-L2B-1.5 } & -- & 282 & -- & 33 & $<1.0$ & 800 & $<1$ & 20 & 60 \\
\hline & -- & 448 & - & 29 & $<1.0$ & 891 & 1 & 15 & 51 \\
\hline & -- & 201 & -- & 12 & $<1.0$ & 429 & $<1$ & 3 & 10 \\
\hline \multirow[t]{3}{*}{ TU-140-L-2B-2.5 } & 201 & 298 & 1 & 22 & $<1.0$ & 800 & 1 & 20 & 290 \\
\hline & - & 551 & -- & 20 & $<1.0$ & 692 & 1 & 24 & 435 \\
\hline & - & 417 & $<1$ & 11 & $<1.0$ & 437 & $<1$ & 11 & 398 \\
\hline \multirow[t]{3}{*}{ TU-141-L2B-3.5 } & 149 & 312 & 10 & 41 & $<1.0$ & 1100 & $<1$ & 20 & 440 \\
\hline & -- & 258 & -- & 24 & $<1.0$ & 989 & $<1$ & 8 & 132 \\
\hline & -- & 102 & $<1$ & 15 & $<1.0$ & 431 & $<1$ & 7 & 11 \\
\hline TU-142-L3A-4.5A & -- & 126 & -- & 6 & $<1.0$ & 473 & $<1$ & 3 & 118 \\
\hline \multirow[t]{2}{*}{ TU-144-L3B-1.5 } & -- & 362 & - & 13 & $<1.0$ & 774 & 2 & 11 & 106 \\
\hline & -- & 195 & -- & 7 & $<1.0$ & 495 & $<1$ & 3 & 24 \\
\hline TU-145-L3B-2.5 & 224 & 381 & $<1$ & 12 & $<1.0$ & 1200 & $<1$ & 20 & 90 \\
\hline & .. & 229 & -- & 9 & $<1.0$ & 645 & $<1$ & 3 & 86 \\
\hline TU-147-L3C-1.5 & -- & 92 & -- & 7 & $<1.0$ & 411 & $<1$ & $<2$ & $<600$ \\
\hline TU-148-L3C-2.5 & -- & 411 & - & 11 & $<1.0$ & 1063 & 3 & 9 & 95 \\
\hline & -. & 191 & -- & 5 & $<1.0$ & 479 & $<1$ & 5 & $<600$ \\
\hline TU-149-L3C-3.5 & -- & 201 & $<1$ & 6 & $<1.0$ & 399 & $<1$ & 9 & 68 \\
\hline TU-150-LAA-1.5 & -- & 176 & -- & 5 & $<1.0$ & 306 & $<1$ & $<2$ & $<600$ \\
\hline TU-151-L4A-2.5 & -- & 232 & - & 19 & $<1.0$ & 800 & $<1$ & 10 & 70 \\
\hline & .. & 305 & -- & 15 & $<1.0$ & 833 & $<1$ & 13 & 49 \\
\hline & -- & 256 & 1 & 9 & $<1.0$ & 448 & $<1$ & $<2$ & 9 \\
\hline TU-152-LAA-3.5 & -- & 4126 & -- & 27 & $<1.0$ & 656 & 8 & 26 & 654 \\
\hline & - & 290 & -- & 7 & $<1.0$ & 519 & 1 & 8 & 23 \\
\hline TU-153-L4B-1.5 & - & 557 & -- & 21 & $<1.0$ & 784 & 5 & 13 & 200 \\
\hline TU-154-LAB-2.5 & -- & 282 & -- & 20 & $<1.0$ & 1100 & $<1$ & 15 & 146 \\
\hline & -- & 236 & -- & 10 & $<1.0$ & 520 & $<1$ & 4 & 17 \\
\hline TU-155-LAB-3.5 & -- & 310 & -- & 17 & $<1.0$ & 896 & $<1$ & 11 & 79 \\
\hline & -- & 182 & 1 & 7 & $<1.0$ & 542 & $<1$ & 7 & 10 \\
\hline TU-156-LAC-1.5UP & -- & 296 & 2 & 71 & $<1.0$ & 1200 & $<1$ & 10 & 130 \\
\hline & -- & 293 & $<1$ & 25 & $<1.0$ & 495 & $<1$ & 4 & 33 \\
\hline TU-157-LAC-2.5UP & -- & 361 & 2 & 75 & $<1.0$ & 1000 & $<1$ & 20 & 1000 \\
\hline & -- & 425 & -- & 44 & $<1.0$ & 939 & 3 & 21 & 374 \\
\hline TU-158-LAC-3.5UP & -- & 185 & 6 & 54 & 1.0 & 800 & 22 & 10 & 110 \\
\hline & -- & 220 & - & 16 & $<1.0$ & 546 & $<1$ & 9 & 50 \\
\hline
\end{tabular}

aDiss., dissolved. bData not determined or not available. 
Table D-5 (continued). Interstitial water quality data in lysimeter samples collected from sites within the FGD treated areas of the Fleming Site (June 1995 - January 1996).

\begin{tabular}{|c|c|c|c|c|c|c|c|c|c|}
\hline \multirow{2}{*}{$\begin{array}{l}\text { Local } \\
\text { number }\end{array}$} & \multirow{2}{*}{$\begin{array}{c}\mathrm{Ca} \\
\mu \mathrm{g} / \mathrm{L}\end{array}$} & \multirow{2}{*}{$\begin{array}{c}\mathrm{Cl} \\
\mu \mathrm{g} / \mathrm{L}\end{array}$} & \multirow{2}{*}{$\begin{array}{c}\mathrm{Cu} \\
\mu \mathrm{g} / \mathrm{L}\end{array}$} & \multirow{2}{*}{$\begin{array}{c}F \\
\mu \mathrm{g} / \mathrm{L}\end{array}$} & \multicolumn{2}{|c|}{$\mathrm{Fe}(\mu \mathrm{g} / \mathrm{L})$} & \multirow{2}{*}{$\underset{\mu \mathrm{L} / \mathrm{L}}{\mathrm{L}}$} & \multicolumn{2}{|c|}{$\mathrm{Mn}(\mu \mathrm{g} / \mathrm{L})$} \\
\hline & & & & & Total & Diss. $^{\mathrm{a}}$ & & Total & Diss. \\
\hline TU-130-L1A-1.5 & 406 & $81^{6 H_{1}}$ & 45 & 9 & .-b & 30 & 41 & -- & 2673 \\
\hline \multirow[t]{3}{*}{ TU-131-L1A-2.5 } & 495 & -- & 40 & - & - & 34757 & 318 & -- & 38769 \\
\hline & 411 & 36 & 308 & 10 & - & 564 & 354 & -- & 27850 \\
\hline & 361 & 101 & 67 & 9 & - & 30 & 181 & -- & 23716 \\
\hline TU-132-L1A-3.5 & 340 & - & 19 & -- & -- & 170 & 143 & - & 70010 \\
\hline \multirow[t]{3}{*}{ TU-133-L1B-1.5 } & 507 & -- & 53 & -. & - & 70 & 232 & -. & 16943 \\
\hline & 434 & 112 & 81 & 8 & - & 53 & 121 & -- & 7340 \\
\hline & 364 & 260 & 110 & 15 & - & 60 & 56 & -- & 2341 \\
\hline TU-134-L1B-2.5 & 531 & $<1$ & $<2$ & 28 & 188501 & 186224 & 347 & 56392 & 59400 \\
\hline \multirow[t]{2}{*}{ TU-136-L2A-1.5 } & 417 & 54 & 254 & 9 & -- & 143 & 156 & - & 73020 \\
\hline & 389 & 44 & 87 & 9 & -- & 30 & 64 & -- & 16928 \\
\hline \multirow[t]{3}{*}{ TU-137-L2A-2.5 } & 534 & -- & 12 & -- & -- & 16922 & 76 & -- & 64327 \\
\hline & 427 & 72 & 46 & 14 & -- & 1405 & 105 & -- & 72630 \\
\hline & 368 & 38 & 30 & 9 & -- & 40 & 65 & -- & 27330 \\
\hline \multirow[t]{2}{*}{ TU-138-L2A-3.5 } & 446 & 58 & 20 & 8 & -- & 252 & 172 & - & 52790 \\
\hline & 377 & 34 & 5 & 9 & -. & 30 & 62 & -- & 17477 \\
\hline \multirow[t]{3}{*}{ TU-139-L2B-1.5 } & 499 & -. & 44 & -. & -. & 125 & 88 & 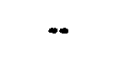 & 52262 \\
\hline & 433 & 90 & 78 & 14 & - & 123 & 109 & - & 23950 \\
\hline & 350 & 50 & 18 & $<0.1$ & -- & 50 & 53 & -- & 14115 \\
\hline \multirow[t]{3}{*}{ TU-140-L2B-2.5 } & 504 & 74 & 8 & $<1$ & 7830 & 6535 & 63 & 75683 & 76025 \\
\hline & 438 & 54 & 40 & 6 & -- & 70 & 86 & - & 85310 \\
\hline & 376 & 78 & 33 & $<0.1$ & - & 160 & 51 & -- & 62499 \\
\hline \multirow[t]{3}{*}{ TU-141-L.2B-3.5 } & 533 & 80 & $<2$ & 6 & 51308 & 50455 & 166 & 53415 & 51355 \\
\hline & 394 & 32 & 23 & 5 & -- & 743 & 152 & -- & 18830 \\
\hline & 355 & 26 & 12 & $<0.1$ & - & 30 & 50 & -- & 1882 \\
\hline TU-142-L3A-4.5A & 386 & 40 & 8 & 6 & -- & 40 & 69 & -- & 21116 \\
\hline \multirow[t]{2}{*}{ TU-144-L3B-1.5 } & 403 & 76 & 33 & 5 & -- & 38 & 203 & -- & 31620 \\
\hline & 348 & 63 & 10 & 5 & - & 10 & 49 & -- & 7561 \\
\hline \multirow[t]{2}{*}{ TU-145-L3B-2.5 } & 489 & 85 & 21 & 6 & 1733 & 2812 & 123 & 16335 & 18444 \\
\hline & 385 & 55 & 30 & $<0.1$ & - & 30 & 74 & -- & 13478 \\
\hline TU-147-L3C-1.5 & 314 & - & 22 & - & -- & 10 & 35 & - & 593 \\
\hline TU-148-L3C-2.5 & 390 & 51 & 36 & 9 & - & 46 & 146 & -. & 15570 \\
\hline & 373 & 39 & 9 & 6 & - & 20 & 26 & -- & 2037 \\
\hline TU-149-L3C-3.5 & 370 & -- & 7 & - & - & 20 & 63 & -. & 14688 \\
\hline TU-150-LAA-1.5 & 222 & -- & 15 & -- & - & 11 & 48 & - & 2231 \\
\hline TU-151-L4A-2.5 & 469 & - & 17 & - & - & 31 & 237 & - & 18367 \\
\hline & 453 & 223 & 28 & 9 & -- & 24 & 180 & -- & 8330 \\
\hline & 403 & 231 & 9 & 9 & -- & 10 & 53 & -- & 5311 \\
\hline TU-152-L4A-3.5 & 482 & 56 & 73 & 6 & -- & 396 & 416 & - & 86740 \\
\hline & 365 & 166 & 14 & 8 & -- & 30 & 46 & -- & 4216 \\
\hline TU-153-LAB-1.5 & 478 & 83 & 90 & 11 & -. & 60 & 217 & -- & 18950 \\
\hline TU-154-LAB-2.5 & 461 & 63 & 35 & 9 & -. & 28 & 141 & - & 15730 \\
\hline & 411 & 74 & 18 & $<0.1$ & -- & 10 & 34 & - & 6729 \\
\hline TU-155-LAB-3.5 & 450 & 145 & 48 & 11 & -- & 37 & 106 & -. & 11680 \\
\hline & 374 & 53 & 22 & 7 & -- & 20 & 22 & -- & 936 \\
\hline TU-156-LAC-1.5UP & 629 & 20 & 10 & $<1$ & -- & 3403 & 296 & -- & 27721 \\
\hline & 430 & 102 & 25 & 10 & .. & 20 & 58 & -- & 6152 \\
\hline TU-157-LAC-2.5UP & 607 & 28 & $<$ & $<1$ & -- & 86911 & 381 & -- & 113630 \\
\hline & 572 & 68 & 23 & 9 & -- & 58 & 211 & - & 73660 \\
\hline TU-158-LAC-3.5UP & 481 & -- & $<$ & -- & -- & 128691 & 133 & - & 73021 \\
\hline & 395 & -- & 9 & -- & -- & 40 & 34 & - & 20679 \\
\hline
\end{tabular}

aDiss., dissolved. bData not determined or not available. 
Table D-5 (continued). Interstitial water quality data in lysimeter samples collected from sites within the FGD treated areas of the Fleming Site (June 1995 - January 1996).

\begin{tabular}{|c|c|c|c|c|c|c|c|c|}
\hline $\begin{array}{l}\text { Local } \\
\text { number }\end{array}$ & $\underset{\mu \mathrm{g} / \mathrm{L}}{\mathrm{Hg}}$ & $\underset{\mu \mathrm{g} / \mathrm{L}}{\mathrm{K}}$ & $\begin{array}{l}\mathrm{Mg} \\
\mu \mathrm{g} / \mathrm{L}\end{array}$ & $\begin{array}{l}\text { Mo } \\
\mu \mathrm{g} / \mathrm{L}\end{array}$ & $\begin{array}{c}\mathrm{Na} \\
\mu \mathrm{g} / \mathrm{L}\end{array}$ & $\begin{array}{c}\mathrm{Ni} \\
\mu \mathrm{g} / \mathrm{L}\end{array}$ & $\begin{array}{c}P \\
\mu \mathrm{g} / \mathrm{L}\end{array}$ & $\begin{array}{c}\mathrm{Pb} \\
\mu \mathrm{g} / \mathrm{L}\end{array}$ \\
\hline TU-130-LIA-1.5 & $--^{2}$ & 93.9 & 1513 & $<10$ & 0.04 & 89 & 47.7 & -- \\
\hline \multirow[t]{3}{*}{ TU-131-L1A-2.5 } & $<0.1$ & 17.9 & 1102 & $<11$ & $<0.01$ & 1607 & 183.0 & -- \\
\hline & - & 30.6 & 1244 & $<11$ & -- & 1355 & 90.7 & -- \\
\hline & -- & 23.1 & 1566 & 26 & $<0.01$ & 902 & 81.9 & $<10$ \\
\hline TU-132-L1A-3.5 & -- & 29.1 & 1723 & 23 & -- & 1008 & 65.0 & -- \\
\hline \multirow[t]{3}{*}{ TU-133-L1B-1.5 } & $<0.1$ & 96.0 & 1667 & $<11$ & 0.04 & 175 & 207.0 & $<4$ \\
\hline & - & 99.9 & 1979 & $<11$ & -- & 151 & 116.1 & -- \\
\hline & $<0.1$ & 106.7 & 3082 & $<10$ & 0.02 & 134 & 71.5 & $<10$ \\
\hline TU-134L1B-2.5 & $<0.1$ & 33.5 & 886 & $<11$ & $<0.01$ & 2049 & 249.0 & $<1$ \\
\hline \multirow[t]{2}{*}{ TU-136-L2A-1.5 } & - & 52.4 & 2009 & 12 & - & 574 & 224.8 & -- \\
\hline & $<0.1$ & 66.2 & 1475 & 21 & $<0.01$ & 59 & 28.7 & $<10$ \\
\hline \multirow[t]{3}{*}{ TU-137-L2A-2.5 } & $<0.1$ & 66.5 & 2299 & $<11$ & $<0.01$ & 172 & 459.0 & -- \\
\hline & -- & 96.6 & 2939 & 18 & -- & 316 & 237.2 & -. \\
\hline & $<0.1$ & 65.6 & 1595 & 32 & 0.01 & 156 & 28.8 & $<10$ \\
\hline \multirow[t]{2}{*}{ TU-138-L2A-3.5 } & -- & 41.1 & 2217 & $<11$ & -- & 208 & 274.9 & -. \\
\hline & $<0.1$ & 63.6 & 1488 & 19 & $<0.01$ & 98 & 19.8 & $<10$ \\
\hline \multirow[t]{3}{*}{ TU-139-L2B-1.5 } & $<0.1$ & 81.5 & 2098 & $<11$ & -- & 81 & 405.0 & -- \\
\hline & -- & 115.8 & 3023 & 32 & -- & 96 & 191.2 & -. \\
\hline & $<0.1$ & 79.7 & 1554 & 53 & 0.04 & 38 & 37.4 & $<10$ \\
\hline \multirow[t]{3}{*}{ TU-140-L2B-2.5 } & $<0.1$ & 42.5 & 1533 & $<11$ & $<0.01$ & 321 & 355.0 & $<4$ \\
\hline & -- & 53.5 & 1855 & 18 & -- & 549 & 199.5 & -. \\
\hline & $<0.1$ & 48.0 & 2061 & 14 & 0.02 & 470 & 99.7 & $<10$ \\
\hline \multirow{3}{*}{ TU-141-L2B-3.5 } & $<0.1$ & 43.6 & 2150 & $<11$ & $<0.01$ & 367 & 403.0 & $<4$ \\
\hline & - & 111.4 & 1730 & 24 & -- & 161 & 54.9 & -- \\
\hline & $<0.1$ & 68.3 & 1207 & 47 & 0.01 & 24 & 13.5 & $<10$ \\
\hline TU-142-L3A-4.5A & $<0.1$ & 72.4 & 1038 & 35 & $<0.01$ & 201 & 21.0 & $<10$ \\
\hline \multirow[t]{2}{*}{ TU-144-L3B-1.5 } & -- & 114.4 & 1458 & $<11$ & - & 222 & 155.5 & -- \\
\hline & $<0.1$ & 77.4 & 980 & 34 & 0.05 & 56 & 47.3 & $<10$ \\
\hline \multirow{2}{*}{ TU-145-L3B-2.5 } & $<0.1$ & 161.4 & 2058 & $<11$ & 0.03 & 200 & 41.0 & $<4$ \\
\hline & -- & 61.6 & 1107 & 20 & - & 207 & 27.2 & -. \\
\hline TU-147-L3C-1.5 & -- & 62.4 & 944 & $<10$ & - & 20 & 15.6 & -- \\
\hline \multirow[t]{2}{*}{ TU-148-L3C-2.5 } & - & 126.1 & 1589 & $<11$ & - & 222 & 31.8 & -- \\
\hline & $<0.1$ & 65.1 & 1057 & $<10$ & 0.02 & 45 & 13.1 & $<10$ \\
\hline TU-149-L3C-3.5 & $<0.1$ & 59.2 & 1171 & $<10$ & 0.01 & 170 & 17.7 & $<10$ \\
\hline TU-150-LAA-1.5 & -- & 25.7 & 1055 & 20 & -- & 49 & 91.7 & -- \\
\hline \multirow[t]{3}{*}{ TU-151-L4A-2.5 } & -- & 18.9 & 832 & $<11$ & - & 178 & 118.0 & -. \\
\hline & -- & 73.3 & 1565 & $<11$ & - & 130 & 168.4 & -- \\
\hline & $<0.1$ & 77.5 & 1488 & $<10$ & 0.05 & 60 & 82.1 & $<10$ \\
\hline \multirow[t]{2}{*}{ TU-152-L4A-3.5 } & -- & 25.5 & 762 & 23 & -- & 1424 & 74.8 & -. \\
\hline & $<0.1$ & 96.7 & 1451 & 15 & $<0.01$ & 156 & 38.0 & $<10$ \\
\hline TU-153-L4B-1.5 & -- & 62.3 & 1441 & 19 & - & 500 & 117.6 & -. \\
\hline \multirow[t]{2}{*}{ TU-154-LAB-2.5 } & - & $46.1^{\circ}$ & 1326 & 18 & - & 319 & 159.8 & -- \\
\hline & $<0.1$ & 87.9 & 1437 & 21 & 0.05 & 60 & 48.9 & - \\
\hline \multirow[t]{2}{*}{ TU-155-L4B-3.5 } & - & 118.7 & 1596 & 11 & - & 213 & 69.3 & -- \\
\hline & $<0.1$ & 91.4 & 1150 & 11 & 0.04 & 47 & 15.7 & $<10$ \\
\hline \multirow{2}{*}{ TU-156-LAC-1.5UP } & - & 17.0 & 462 & $<11$ & - & 218 & 17.0 & $<1$ \\
\hline & - & 106.4 & 1728 & $<10$ & 0.03 & 96 & 106.4 & -- \\
\hline \multirow[t]{2}{*}{ TU-157-LAC-2.5UP } & - & 14.0 & 391 & $<11$ & - & 1137 & 14.0 & $<1$ \\
\hline & - & 305.3 & 1498 & $<11$ & - & 570 & 305.3 & -- \\
\hline \multirow[t]{2}{*}{ TU-158-LAC-3.5UP } & $<0.1$ & 13.0 & 271 & $<11$ & $<0.01$ & 78 & 13.0 & $<1$ \\
\hline & - & 68.6 & 1367 & $<10$ & $<0.01$ & 93 & 68.6 & -- \\
\hline
\end{tabular}

Data not determined or not available. 
Table D-5 (continued). Interstitial water quality data in lysimeter samples collected from sites within the FGD treated areas of the Fleming Site (June 1995 - January 1996).

\begin{tabular}{|c|c|c|c|c|c|c|c|}
\hline $\begin{array}{l}\text { Local } \\
\text { number }\end{array}$ & $\begin{array}{l}\mathrm{NH}_{3} \\
\mu \mathrm{g} / \mathrm{L}\end{array}$ & $\begin{array}{l}\mathrm{NO}_{2} \\
\mu \mathrm{g} / \mathrm{L}\end{array}$ & $\begin{array}{c}\text { Total Na } \\
\mu \mathrm{g} / \mathrm{L}\end{array}$ & $\begin{array}{l}\mathrm{Sb} \\
\mu \mathrm{g} / \mathrm{L}\end{array}$ & $\begin{array}{c}\mathrm{Se} \\
\mu \mathrm{g} / \mathrm{L}\end{array}$ & $\begin{array}{c}\mathrm{Si} \\
\mu \mathrm{g} / \mathrm{L}\end{array}$ & $\begin{array}{c}\mathrm{Sr} \\
\mu \mathrm{g} / \mathrm{L}\end{array}$ \\
\hline TU-130-L1A-1.5 & 0.31 & $<0.01$ & 0.42 & $<100$ & $\ldots$ & 27.0 & 1271 \\
\hline \multirow[t]{3}{*}{ TU-131-L1A-2.5 } & 4.80 & $<0.01$ & $<0.05$ & $<106$ & -- & - & 771 \\
\hline & -- & -- & - & $<106$ & -- & 48.3 & 916 \\
\hline & 1.60 & $<0.01$ & 0.11 & $<100$ & -- & 21.6 & 753 \\
\hline TU-132-L1A-3.5 & -- & -- & -- & $<100$ & .. & 17.1 & 796 \\
\hline \multirow[t]{3}{*}{ TU-133-L1B-1.5 } & 1.50 & 1.00 & 6.0 & $<106$ & $<5$ & -. & 1808 \\
\hline & -- & - & -- & $<106$ & -. & 51.7 & 1556 \\
\hline & 0.13 & $<0.01$ & 1.1 & $<100$ & 2 & 26.8 & 1230 \\
\hline TU-134L1B-2.5 & 4.20 & $<0.01$ & $<0.05$ & $<106$ & $<5$ & $\ldots$ & 1051 \\
\hline \multirow{2}{*}{ TU-136-L-2A-1.5 } & -- & - & -- & $<106$ & -- & 47.0 & 1851 \\
\hline & 0.13 & $<0.01$ & 0.06 & $<100$ & - & 15.9 & 779 \\
\hline \multirow[t]{3}{*}{ TU-137-L2A-2.5 } & 1.70 & $<0.01$ & $<0.05$ & $<106$ & -- & - & 2053 \\
\hline & - & -. & -- & $<106$ & .. & 39.0 & 1932 \\
\hline & 0.09 & $<0.01$ & $<0.05$ & $<100$ & -- & 16.3 & 642 \\
\hline \multirow[t]{2}{*}{ TU-138-L2A-3.5 } & $-\cdot$ & -- & -- & $<106$ & -- & 26.9 & 1455 \\
\hline & 0.12 & $<0.01$ & $<0.05$ & $<100$ & -- & 9.5 & 700 \\
\hline \multirow[t]{3}{*}{ TU-139-L2B-1.5 } & -- & -- & -- & $<106$ & -- & -- & 1556 \\
\hline & - & -- & -- & 155 & -- & 34.5 & 1519 \\
\hline & 0.08 & $<0.01$ & $<0.05$ & $<100$ & -- & 12.5 & 764 \\
\hline \multirow[t]{3}{*}{ TU-140-L2B-2.5 } & 1.30 & $<0.01$ & $<0.05$ & $<106$ & $<5$ & - & 1392 \\
\hline & - & -- & -- & $<106$ & -- & 35.2 & 1391 \\
\hline & 0.13 & $<0.01$ & 0.05 & $<100$ & $<1$ & 19.1 & 1197 \\
\hline \multirow[t]{3}{*}{ TU-141-L2B-3.5 } & 1.20 & $<0.01$ & $<0.05$ & $<106$ & $<5$ & -. & 1184 \\
\hline & -- & - & -- & $<106$ & - & 29.3 & 886 \\
\hline & 0.08 & $<0.01$ & $<0.05$ & $<100$ & $<1$ & 19.5 & 470 \\
\hline TU-142-L3A-4.5A & 0.19 & $<0.01$ & $<0.05$ & $<100$ & - & 9.1 & 505 \\
\hline \multirow[t]{2}{*}{ TU-144-LBB-1.5 } & -- & - & -- & $<106$ & -- & 23.2 & 805 \\
\hline & 0.09 & $<0.01$ & 0.06 & $<100$ & - & 9.0 & 508 \\
\hline \multirow[t]{2}{*}{ TU-145-L3B-2.5 } & 0.52 & $<0.01$ & $<0.05$ & $<106$ & $<5$ & -- & 762 \\
\hline & -- & -- & - & $<100$ & - & 14.6 & 709 \\
\hline TU-147-L3C-1.5 & -- & -- & -- & $<100$ & -- & 11.0 & 494 \\
\hline \multirow[t]{2}{*}{ TU-148-L3C-2.5 } & -. & - & -. & $<106$ & - & 20.3 & 721 \\
\hline & 0.12 & $<0.01$ & 0.07 & $<100$ & -- & 7.5 & 394 \\
\hline TU-149-L3C-3.5 & 0.12 & $<0.01$ & $<0.05$ & $<100$ & $<1$ & 8.9 & 535 \\
\hline TU.150-LAA-1:5 & -- & - & - & $<100$ & - & 8.6 & 242 \\
\hline \multirow[t]{3}{*}{ TU-151-LAA-2.5 } & - & -- & -- & $<106$ & - & - & 412 \\
\hline & $\cdots$ & -- & -- & $<106$ & - & 25.8 & 860 \\
\hline & 0.10 & $<0.01$ & $<0.05$ & $<100$ & 1 & 13.2 & 668 \\
\hline \multirow[t]{2}{*}{ TU-152-LAA-3.5 } & -- & - & -- & $<106$ & - & 50.1 & 651 \\
\hline & 0.12 & $<0.01$ & 0.16 & $<100$ & -- & 17.1 & 536 \\
\hline TU-153-LAB-1.5 & - & - & -- & $<106$ & -- & 38.9 & 678 \\
\hline \multirow[t]{2}{*}{ TU-154-LAB-2.5 } & -- & -- & -- & 144 & -- & 44.5 & 794 \\
\hline & 0.23 & $<0.01$ & $<0.05$ & $<100$ & - & 18.7 & 772 \\
\hline \multirow[t]{2}{*}{ TU-155-LAB-3.5 } & -- & - & - & $<106$ & - & 50.1 & 842 \\
\hline & 1.10 & $<0.01$ & $<0.01$ & $<100$ & 1 & 18.1 & 396 \\
\hline \multirow[t]{2}{*}{ TU-156-LAC-1.5UP } & -- & -- & -- & $<106$ & $<5$ & - & 602 \\
\hline & 0.10 & $<0.01$ & $<0.01$ & $<100$ & $<1$ & 17.5 & 798 \\
\hline \multirow[t]{2}{*}{ TU-157-LAC-2.5UP } & - & - & -- & $<106$ & $<5$ & - & 671 \\
\hline & -- & -- & - & $<106$ & -- & 37.9 & 1087 \\
\hline \multirow[t]{2}{*}{ TU-158-LAC-3.5UP } & 0.94 & $<0.01$ & $<0.01$ & $<106$ & $<5$ & - & 677 \\
\hline & 0.50 & $<0.01$ & $<0.01$ & $<100$ & - & 18.3 & 719 \\
\hline
\end{tabular}

aNitrite-N plus nitrate-N. b Data not determined or not available. 
Table D-5 (continued). Interstitial water quality data in Iysimeter samples collected from sites within the FGD treated areas of the Fleming Site (June 1995 - January 1996).

\begin{tabular}{|c|c|c|c|c|c|c|c|}
\hline $\begin{array}{l}\text { Local } \\
\text { number }\end{array}$ & $\begin{array}{c}\mathrm{Ag} \\
\mu \mathrm{g} / \mathrm{L}\end{array}$ & $\begin{array}{c}D O C^{a} \\
\mu g / L\end{array}$ & $\begin{array}{c}\text { Tritium } \\
\mathrm{pCi} / \mathrm{L}\end{array}$ & $\begin{array}{l}\mathrm{SO}_{4} \\
\mu \mathrm{g} / \mathrm{L}\end{array}$ & $\begin{array}{l}\delta^{34}-S \\
\text { per mil }\end{array}$ & $\begin{array}{c}V \\
\mu g / L\end{array}$ & $\underset{\mu \mathrm{g} / \mathrm{L}}{\mathrm{Zn}}$ \\
\hline TU-130-L1A-1.5 & $<10$ & $--^{b}$ & $\cdots$ & 5253 & 3.0 & 14 & 59 \\
\hline \multirow[t]{3}{*}{ TU-131-L1A-2.5 } & $<10$ & - & - & -- & -- & 13 & 2566 \\
\hline & $<10$ & - & -- & 6501 & -1.3 & 8 & 2640 \\
\hline & $<10$ & - & -- & 6075 & -1.2 & 13 & 1433 \\
\hline TU-132-L1A-3.5 & $<10$ & -- & -- & - & -- & 11 & 341 \\
\hline \multirow[t]{3}{*}{ TU-133-L1B-1.5 } & $<10$ & - & - & -- & -- & 43 & 106 \\
\hline & $<10$ & -- & -- & 8057 & -0.2 & 29 & 173 \\
\hline & $<10$ & -- & -- & 11320 & 0.0 & 7 & 156 \\
\hline TU-134-L1B-2.5 & $<10$ & 22.0 & -- & 4150 & -- & 19 & 1468 \\
\hline \multirow{2}{*}{ TU-136-L2A-1.5 } & $<10$ & -- & - & 8327 & -2.8 & 22 & 663 \\
\hline & $<10$ & 22.0 & -- & 5267 & 1.7 & 19 & 74 \\
\hline \multirow{3}{*}{ TU-137-L-2A-2.5 } & $<10$ & -. & -- & -. & - & 21 & 74 \\
\hline & $<10$ & .. & -- & 11936 & -0.9 & 17 & 217 \\
\hline & $<10$ & 26.0 & $\cdots$ & 5785 & 1.0 & $<5$ & 81 \\
\hline \multirow[t]{2}{*}{ TU-138-L2A-3.5 } & $<10$ & -- & -- & 10123 & -3.3 & 18 & 104 \\
\hline & $<10$ & 19.0 & -- & 5705 & 1.8 & 10 & 28 \\
\hline \multirow[t]{3}{*}{ TU-139-L2B-1.5 } & $<10$ & -- & - & -- & - & 43 & 68 \\
\hline & $<10$ & - & -- & 13475 & 0.7 & 34 & 54 \\
\hline & $<10$ & 30.0 & -- & 5811 & 1.8 & 13 & 35 \\
\hline \multirow[t]{3}{*}{ TU-140-L2B-2.5 } & $<10$ & 36.0 & -- & 6804 & -- & 18 & 15 \\
\hline & $<10$ & - & -- & 8250 & -3.0 & 22 & 423 \\
\hline & $<10$ & 28.0 & -. & 7910 & 0.2 & 16 & 376 \\
\hline \multirow[t]{3}{*}{ TU-141-L2B-3.5 } & $<10$ & 64.0 & -- & 7865 & - & 26 & 31 \\
\hline & $<10$ & -- & $\cdots$ & 7311 & 0.4 & 11 & 54 \\
\hline & $<10$ & 20.0 & .. & 4588 & 1.9 & 15 & 6 \\
\hline TU-142-L3A-4.5A & $<10$ & 14.0 & -- & 4020 & -2.1 & 14 & 73 \\
\hline \multirow[t]{2}{*}{ TU-144-L3B-1.5 } & $<10$ & - & -- & 6279 & -4.6 & 19 & 169 \\
\hline & $<10$ & -- & -- & 3774 & -1.9 & 15 & 27 \\
\hline \multirow[t]{2}{*}{ TU-145-L3B-2.5 } & $<10$ & 64.0 & - & 7202 & - & 22 & 71 \\
\hline & $<10$ & -- & -- & 3982 & -2.3 & 27 & 107 \\
\hline TU-147-L3C-1.5 & $<10$ & -- & - & - & -- & 17 & 27 \\
\hline \multirow[t]{2}{*}{ TU-148-L3C-2.5 } & $<10$ & - & - & 7424 & -4.1 & 12 & 132 \\
\hline & $<10$ & 20.0 & -- & 4097 & -2.2 & 7 & 14 \\
\hline TU-149-L3C-3.5 & $<10$ & 17.0 & -- & - & -3.2 & 13 & 50 \\
\hline TU-150-LAA-1.5 & $<10$ & - & -- & -- & -4.5 & 7 & 39 \\
\hline \multirow[t]{3}{*}{ TU-151-L4A-2.5 } & $<10$ & - & -- & -- & - & 21 & 22 \\
\hline & $<10$ & -- & -- & 7349 & -2.7 & 18 & 117 \\
\hline & $<10$ & 24.0 & -- & 5284 & -4.1 & 5 & 25 \\
\hline \multirow[t]{2}{*}{ TU-152-L4A-3.5 } & 15 & - & -- & 4511 & -13.3 & 19 & 1400 \\
\hline & $<10$ & 24.0 & -- & 5020 & -2.1 & $<5$ & 74 \\
\hline TU-153-LAB-1.5 & $<10$ & - & - & 8267 & -4.2 & 16 & 737 \\
\hline \multirow[t]{2}{*}{ TU-154LAB-2.5 } & $<10$ & -- & -- & 6025 & -9.8 & 42 & .274 \\
\hline & $<10$ & 2.0 & -- & 5013 & -1.6 & 8 & 42 \\
\hline \multirow[t]{2}{*}{ TU-155-LAB-3.5 } & $<10$ & -- & -- & 7024 & -4.2 & 25 & 180 \\
\hline & $<10$ & 28.0 & -- & 4078 & -4.5 & $<5$ & 25 \\
\hline \multirow[t]{2}{*}{ TU-156-LAC-1.5UP } & $<10$ & - & -- & 2518 & - & 33 & 122 \\
\hline & $<10$ & -- & -- & 5583 & -0.9 & 7 & 116 \\
\hline \multirow[t]{2}{*}{ TU-157-LAC-2.5UP } & $<10$ & -- & -- & 2704 & - & 19 & 786 \\
\hline & $<10$ & -- & - & 7944 & -4.1 & 13 & 402 \\
\hline \multirow[t]{2}{*}{ TU-158-LAC-3.5UP } & $<10$ & - & -- & -- & -- & 16 & 14 \\
\hline & $<10$ & 0.6 & -- & -- & -2.0 & 8 & 31 \\
\hline
\end{tabular}

aDOC, dissolved organic carbon. ${ }^{\mathrm{b}} \mathrm{Data}$ not determined or not available. 
Table D-6. Interstitial water quality data in control area lysimeter samples and surface water quality data in samples collected from the Fleming Site (June 1995 - January 1996).

\begin{tabular}{|c|c|c|c|c|c|c|c|c|}
\hline \multirow{2}{*}{ Local number } & \multirow{2}{*}{ Date } & \multirow{2}{*}{ Time } & \multirow{2}{*}{$\begin{array}{l}\text { Depth to } \\
\text { water } \\
\text { table (ft)a }\end{array}$} & \multirow{2}{*}{$\begin{array}{l}\text { Sp. } \\
\text { Cond. } \\
\mu \mathrm{S} / \mathrm{cm}\end{array}$} & \multirow{2}{*}{$\begin{array}{l}\mathrm{pH} \text { of } \\
\text { water in } \\
\text { the field }\end{array}$} & \multirow{2}{*}{$\begin{array}{l}\text { Redox } \\
\text { potential } \\
\text { (mv)b }\end{array}$} & \multicolumn{2}{|c|}{$\begin{array}{l}\text { Temperature } \\
\left({ }^{\circ} \mathrm{C}\right)\end{array}$} \\
\hline & & & & & & & Air & Water \\
\hline \multicolumn{9}{|c|}{ Interstital water from control area } \\
\hline TU-159-L5A-1.5 & $1 / 18 / 96$ & $10: 00$ & 1.5 & 1210 & 4.4 &.$--b$ & -- & -- \\
\hline TU-160-L5A-2.5 & $1 / 18 / 96$ & 10:05 & 2.5 & 1360 & -- & - & -- & -- \\
\hline TU-161-L5A-3.5 & $1 / 18 / 96$ & 10:10 & 3.5 & 1530 & 5.7 & -- & -- & -- \\
\hline TU-162-L5B-1.5 & $1 / 18 / 96$ & $10: 15$ & 1.5 & 2580 & 5.3 & -- & -- & -- \\
\hline TU-163-L5B-2.5 & $7 / 7 / 95$ & $12: 55$ & & -- & -- & -- & -- & -- \\
\hline \multicolumn{9}{|c|}{ Surface Water } \\
\hline TU-120 & $6 / 26 / 95$ & 14:00 & -- & 1680 & 4.0 & 746 & 30 & 25.5 \\
\hline TU-124 & 9/8/95 & $11: 00$ & -- & 2380 & 3.5 & 789 & 25 & 20.0 \\
\hline TU-125 & $6 / 26 / 95$ & 17:00 & -- & 609 & 6.3 & 469 & 30 & 24.0 \\
\hline
\end{tabular}

a Given in feet below land surface.

cData not available.

Table D-6 (continued).

\begin{tabular}{|c|c|c|c|c|c|c|c|}
\hline \multirow{2}{*}{ Local number } & \multirow{2}{*}{$\begin{array}{l}\text { Turbidity } \\
(\mathrm{NTU})^{\mathrm{a}}\end{array}$} & \multirow{2}{*}{$\begin{array}{c}\text { Diss. } \\
\text { oxygen }\end{array}$} & Hardness & Acidity & Alkalinity & Bicarb. & \multirow{2}{*}{$\begin{array}{c}\mathrm{ROE} \\
(\mathrm{mg} / \mathrm{L})^{\mathrm{a}}\end{array}$} \\
\hline & & & \multicolumn{4}{|c|}{$\left(\mathrm{mg} / \mathrm{L}\right.$ as $\left.\mathrm{CaCO}_{3}\right)$} & \\
\hline \multicolumn{8}{|c|}{ Interstital water from control area } \\
\hline TU-159-L5A-1.5 & $--\mathrm{b}$ & -- & 807 & -- & -- & -- & -- \\
\hline TU-160-L5A-2.5 & $\cdots$ & -- & 661 & 0.0 & -- & -- & -- \\
\hline TU-161-L5A-3.5 & -- & -- & 1236 & 0.0 & -- & -- & -- \\
\hline TU-162-LSB-1.5 & -- & -- & 2002 & 0.0 & -- & - & -- \\
\hline TUं-163-L5B-2.5 & -- & -- & -- & -- & -- & -- & -- \\
\hline \multicolumn{8}{|c|}{ Surface Water } \\
\hline TU-120 & 1 & -- & $-\cdot$ & 0.9 & -- & -- & 1221 \\
\hline TU-124 & 14 & 7.00 & -- & 1.0 & -- & -- & 2945 \\
\hline TU-125 & 10 & 9.28 & -- & 0.1 & 17 & 22 & 402 \\
\hline
\end{tabular}

aNTU, nepholometric turbidity units; ROE, residue on evaporation

bData not determined or not available 
Table D-6 (continued). Interstitial water quality data in control area lysimeter samples and surface water quality data in samples collected from the Fleming Site (June 1995 - January 1996).

\begin{tabular}{|c|c|c|c|c|c|c|c|c|c|}
\hline \multirow{2}{*}{$\begin{array}{l}\text { Local } \\
\text { number }\end{array}$} & \multicolumn{2}{|c|}{$\mathrm{Al}(\mu \mathrm{g} / \mathrm{L})$} & \multirow{2}{*}{$\begin{array}{c}\mathrm{Ar} \\
\mu \mathrm{g} / \mathrm{L}\end{array}$} & \multirow{2}{*}{$\begin{array}{c}\mathrm{Ba} \\
\mu \mathrm{g} / \mathrm{L}\end{array}$} & \multirow{2}{*}{$\begin{array}{c}\mathrm{Be} \\
\mu \mathrm{g} / \mathrm{L}\end{array}$} & \multirow{2}{*}{$\begin{array}{c}\text { B } \\
\mu \mathrm{g} / \mathrm{L}\end{array}$} & \multirow{2}{*}{$\begin{array}{c}\mathrm{Cd} \\
\mu \mathrm{g} / \mathrm{L}\end{array}$} & \multirow{2}{*}{$\begin{array}{c}\mathrm{Cr} \\
\mu \mathrm{g} / \mathrm{L}\end{array}$} & \multirow{2}{*}{$\begin{array}{l}\text { Co } \\
\mu \mathrm{g} / \mathrm{L}\end{array}$} \\
\hline & Total & Diss. $^{a}$ & & & & & & & \\
\hline \multicolumn{10}{|c|}{ Interstital water from control area } \\
\hline TU-159-L5A-1.5 & $--b$ & 3764 & -- & 9 & 2.0 & 41 & 3 & $<2$ & 124 \\
\hline TU-160-L5A-2.5 & - & 117 & -- & 10 & $<1.0$ & 45 & 1 & $<2$ & 116 \\
\hline TU-161-L5A-3.5 & -- & 303 & -- & 16 & 2.0 & -- & $<1$ & $<2$ & 47 \\
\hline TU-162-L5B-1.5 & - & 1279 & $<1$ & 20 & 3.0 & 56 & $<1$ & 5 & 466 \\
\hline TU-163-L5B-2.5 & - & 123 & - & 61 & $<1.0$ & 200 & 2 & 10 & 150 \\
\hline \multicolumn{10}{|c|}{ Surface Water } \\
\hline TU-120 & 5459 & 5852 & $<1$ & 19 & 2.0 & 177 & $<1$ & 6 & 163 \\
\hline TU-124 & - & 2182 & $<1$ & 28 & 2.0 & 300 & 3 & 16 & 193 \\
\hline TU-125 & 213 & 178 & $<1$ & 35 & $<1.0$ & 61 & 1 & 5 & $<6$ \\
\hline
\end{tabular}

aDiss., dissolved. bData not determined or not available.

Table D-6 (continued).

\begin{tabular}{|c|c|c|c|c|c|c|c|c|c|}
\hline \multirow{2}{*}{ Local number } & \multirow{2}{*}{$\begin{array}{c}\mathrm{Ca} \\
\mu \mathrm{g} / \mathrm{L}\end{array}$} & \multirow{2}{*}{$\begin{array}{c}\mathrm{Cl} \\
\mu \mathrm{g} / \mathrm{L}\end{array}$} & \multirow{2}{*}{$\begin{array}{c}\mathrm{Cu} \\
\mu \mathrm{g} / \mathrm{L}\end{array}$} & \multirow{2}{*}{$\begin{array}{c}F \\
\mu \mathrm{g} / \mathrm{L}\end{array}$} & \multicolumn{2}{|c|}{$\mathrm{Fe}(\mu \mathrm{g} / \mathrm{L})$} & \multirow{2}{*}{$\begin{array}{c}\mathrm{Li} \\
\mu \mathrm{g} / \mathrm{L}\end{array}$} & \multicolumn{2}{|c|}{$\mathrm{Mn}(\mu \mathrm{g} / \mathrm{L})$} \\
\hline & & & & & Total & 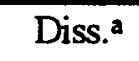 & & Total & Diss. \\
\hline \multicolumn{10}{|c|}{ Interstital water from control area } \\
\hline TU-159-L5A-1.5 & 109 & 17 & 75 & $<0.1$ &.$--\mathrm{b}$ & 40 & 48 & -- & 16100 \\
\hline TU-160-L5A-2.5 & 88 & 16 & 8 & $<0.1$ & -- & 180 & 45 & -- & 14900 \\
\hline TU-161-L5A-3.5 & 158 & 18 & 32 & $<0.1$ & -- & 230 & 195 & -- & 5400 \\
\hline TU-162-LSB-1.5 & 300 & 28 & 11 & 1.0 & -- & 11300 & 122 & -- & 36100 \\
\hline TU-163-L5B-2.5 & 195 & -- & $<2$ & -- & -- & 11569 & 304 & -- & 14600 \\
\hline \multicolumn{10}{|c|}{ Surface Water } \\
\hline TU-120 & 184 & 9 & 14 & $<1.0$ & 400 & 557 & 167 & 22450 & 23000 \\
\hline TU-124 & 318 & 2 & 5 & 2.0 & -- & 978 & 228 & -- & 15500 \\
\hline TU-125 & 48 & 17 & $<2$ & $<1.0$ & 409 & 697 & 51 & 5481 & 5701 \\
\hline
\end{tabular}

aDiss., dissolved.

bData not determined or not available. 
Table D.6 (continued). Interstitial water quality data in control area lysimeter samples and surface water quality data in samples collected from the Fleming Site (June 1995 - January 1996).

\begin{tabular}{lcrrrrrrc}
\hline \hline $\begin{array}{l}\text { Local } \\
\text { number }\end{array}$ & $\begin{array}{c}\mathrm{Hg} \\
\mu \mathrm{g} / \mathrm{L}\end{array}$ & $\begin{array}{c}\mathrm{K} \\
\mu \mathrm{g} / \mathrm{L}\end{array}$ & $\begin{array}{c}\mathrm{Mg} \\
\mu \mathrm{g} / \mathrm{L}\end{array}$ & $\begin{array}{c}\mathrm{Mo} \\
\mu \mathrm{g} / \mathrm{L}\end{array}$ & $\begin{array}{c}\mathrm{Na} \\
\mu \mathrm{g} / \mathrm{L}\end{array}$ & $\begin{array}{c}\mathrm{Ni} \\
\mu \mathrm{g} / \mathrm{L}\end{array}$ & $\begin{array}{c}\mathrm{P} \\
\mu \mathrm{g} / \mathrm{L}\end{array}$ & $\begin{array}{c}\mathrm{Pb} \\
\mu \mathrm{g} / \mathrm{L}\end{array}$ \\
\hline \multicolumn{7}{c}{ Interstital } \\
water from control area & & \\
TU-159-L5A-1.5 & $<0.1$ & 10.1 & 48 & $<10$ & 52.5 & 260 & $<0.01$ & 3 \\
TU-160-L5A-2.5 &.-- & 9.9 & 51 & $<10$ & 41.3 & 232 & -- & - \\
TU-161-L5A-3.5 & $<0.1$ & 15.1 & 104 & 24 & 34.9 & 528 & $<0.01$ & $<10$ \\
TU-162-L5B-1.5 & $<0.1$ & 16.6 & 154 & $<10$ & 102.9 & 909 & $<0.01$ & -- \\
TU-163-L5B-2.5 & -- & 28.4 & 114 & $<11$ & 21.0 & 754 & -- & - \\
& & & Surface & Water & & & & \\
TU-120 & $<0.1$ & 6.1 & 114 & $<11$ & 11.0 & 319 & -- & $<1$ \\
TU-124 & $<0.1$ & 15.2 & 189 & $<11$. & 8.1 & 319 & 735 & $<1$ \\
TU-125 & $<0.1$ & 3.5 & 31 & $<11$ & 15.3 & 123 & -- & $<1$ \\
\hline \hline
\end{tabular}

bData not determined or not available.

Table D-6 (continued).

\begin{tabular}{|c|c|c|c|c|c|c|c|}
\hline $\begin{array}{l}\text { Local } \\
\text { number }\end{array}$ & $\begin{array}{l}\mathrm{NH}_{3} \\
\mu \mathrm{g} / \mathrm{L}\end{array}$ & $\begin{array}{l}\mathrm{NO}_{2} \\
\mu \mathrm{g} / \mathrm{L}\end{array}$ & $\begin{array}{c}\text { Total Na } \\
\mu \mathrm{g} / \mathrm{L}\end{array}$ & $\begin{array}{c}\mathrm{Sb} \\
\mu \mathrm{g} / \mathrm{L}\end{array}$ & $\begin{array}{c}\mathrm{Se} \\
\mu \mathrm{g} / \mathrm{L}\end{array}$ & $\begin{array}{c}\mathrm{Si} \\
\mu \mathrm{g} / \mathrm{L}\end{array}$ & $\begin{array}{r}\mathrm{Sr} \\
\mu \mathrm{g} / \mathrm{L}\end{array}$ \\
\hline \multicolumn{8}{|c|}{ Interstital water from control area } \\
\hline $\begin{array}{l}\text { TU-159-L5A- } \\
1.5\end{array}$ & 0.93 & $<0.01$ & 0.07 & $<100$ &.$- \mathrm{b}$ & 22.4 & 297 \\
\hline $\begin{array}{l}\text { TU-160-L5A- } \\
2.5\end{array}$ & -- & -- & -- & $<100$ & -- & 23.3 & 203 \\
\hline $\begin{array}{l}\text { TU-161-L5A- } \\
3.5\end{array}$ & 0.32 & $<0.01$ & 0.06 & $<100$ & -- & 23.1 & 360 \\
\hline TU-162-L5B-1.5 & 0.92 & $<0.01$ & $<0.05$ & $<100$ & $<1$ & 24.5 & 542 \\
\hline TU-163-L5B-2.5 & -- & -- & -- & $<106$ & -- & -- & 458 \\
\hline \multicolumn{8}{|c|}{ Surface Water } \\
\hline TU-120 & 0.44 & $<0.01$ & 0.14 & $<106$ & $<1$ & -- & 493 \\
\hline TU-124 & 0.26 & $<0.01$ & $<0.05$ & $<106$ & $<1$ & -- & 1425 \\
\hline TU-125 & 0.21 & 0.01 & 0.45 & $<106$ & $<1$ & -- & 159 \\
\hline
\end{tabular}

aNitrite-N plus nitrate-N. bData not determined or not available. 
Table D-6 (continued). Interstitial water quality data in control area lysimeter samples and surface water quality data in samples collected from the Fleming Site (June 1995 - January 1996).

\begin{tabular}{lccccccc}
\hline \hline $\begin{array}{l}\text { Local } \\
\text { number }\end{array}$ & $\begin{array}{c}\mathrm{Ag} \\
\mu \mathrm{g} / \mathrm{L}\end{array}$ & $\begin{array}{c}\mathrm{DOCa} \\
\mu \mathrm{g} / \mathrm{L}\end{array}$ & $\begin{array}{c}\mathrm{Tritium} \\
\mathrm{pCi} / \mathrm{L}\end{array}$ & $\begin{array}{c}\mathrm{SO}_{4} \\
\mu \mathrm{g} / \mathrm{L}\end{array}$ & $\begin{array}{l}\delta^{34}-\mathrm{S} \\
\mathrm{per} \text { mil }\end{array}$ & $\begin{array}{c}\mathrm{V} \\
\mu \mathrm{g} / \mathrm{L}\end{array}$ & $\begin{array}{c}\mathrm{Zn} \\
\mu \mathrm{g} / \mathrm{L}\end{array}$ \\
\hline \multicolumn{7}{c}{ Interstital } \\
TU-159-L5A-1.5 & $<10$ &.$--\mathrm{b}$ & -- & 554 & -12.1 & 15 & 422 \\
TU-160-L5A-2.5 & $<10$ & -- & -- & 458 & -- & 9 & 1717 \\
TU-161-L5A-3.5 & $<10$ & 2.8 & -- & 741 & -12.2 & 19 & 312 \\
TU-162-L5B-1.5 & $<10$ & 8.6 & -- & 1395 & -15.5 & 8 & 814 \\
TU-163-L5B-2.5 & $<10$ & -- & -- & 294 & -- & 13 & 180 \\
& & & Surface Water & & & \\
TU-120 & $<10$ & 1.9 & -- & 1178 & -14.0 & $<5$ & 338 \\
TU-124 & $<10$ & 1.0 & -- & 1663 & -9.4 & 6 & 259 \\
TU-125 & $<10$ & 3.1 & -- & 515 & -13.0 & $<5$ & 110 \\
\hline \hline
\end{tabular}

aDOC, dissolved organic carbon. bData not determined or not available. 


\section{Appendix E}

\section{SUPPORTING DATA FOR ECONOMICS MODEL}

Table E-1. Estimated hedonic price function ${ }^{\mathrm{a}}$.

Table E-2. Estimated hedonic tax functiona.

Table E-3. Mean willingness to pay curves (MWTP) for the translog utility specification.

Table E-4. Social cost transfer estimate worksheets for Conesville, Gavin and Zimmer landfills.

Table E-5. Cost transfer model worksheets for Conesville, Gavin and Zimmer landfills. 
Table E-1. Estimated hedonic price functiona.

\begin{tabular}{|c|c|c|c|c|c|c|c|}
\hline \multicolumn{4}{|c|}{$\begin{array}{l}\text { Dependent Variable Log(Rent) } \\
\text { Adj. } R 2=.9970, F(57,2856)=16,990.9\end{array}$} & $\begin{array}{l}\text { Intercept Gahanna } \\
\text { Distance Gahanna }\end{array}$ & $\begin{array}{l}-0.02926 \\
0.18621\end{array}$ & $\begin{array}{l}0.08403 \\
0.02494\end{array}$ & $\begin{array}{l}-0.34816 \\
7.46548\end{array}$ \\
\hline ' & & Std. & & (Distance Gahanna)2 & 0.00187 & 0.00231 & 0.81080 \\
\hline$\frac{\text { Variable }}{\text { Intercept Alum Creek }}$ & $\frac{\text { Estimate }}{-0.06574}$ & $\frac{\text { Error }}{0.05024}$ & $\frac{\text { Statistic }}{-1.30845}$ & Distance Power Plant & -0.10557 & 0.04134 & $-2.55621^{\circ}$ \\
\hline Distance Alum Creek & 0.19083 & 0.02812 & $7.30730 \cdots$ & $\begin{array}{l}\text { (Dlstance Power Plant) } \\
2\end{array}$ & 0.01124 & 0.00345 & 3.257 \\
\hline (Dist. Alum Creek)2 & -0.02364 & 0.00346 & $-6.80792-$ & Distance to CBD & 0.13017 & 0.05049 & $2.57826^{\circ}$ \\
\hline Intercept Obetz & 0.75836 & 0.00583 & 1.51422 & (Distance to CBD)2 & -0.00655 & 0.00358 & $-1.83050^{\circ}$ \\
\hline Distance Obetz & 0.22470 & 0.04214 & 5.33150 & Neighborhood Safety & 0.02420 & 0.00941 & $2.57099^{\circ}$ \\
\hline (Distance Obetz)2 & -0.00903 & 0.00239 & $3.77464^{\infty 000}$ & School Index & 0.00586 & 0.00055 & $10.70250^{\circ}$ \\
\hline Intercept Grove City & -0.02926 & 0.53147 & 0.35932 & Housing Index & 0.01923 & 0.00152 & 12.67989 \\
\hline Distance Grove Ctty & 0.52282 & 0.05346 & $9.77964^{-}$ & ood Index & 0.00117 & 0.00035 & $3.36307^{m}$ \\
\hline (Dist. Grove City)2 & -0.01998 & 0.00310 & $-6.45059 \infty$ & Transaction Month & 0.00687 & 0.00265 & $2.59775^{\circ}$ \\
\hline ook Araa & & & & Obetz Area & & & \\
\hline $\log ($ & 0.18508 & 0.02830 & $6.54033^{-m}$ & Log(Lot Size) & 0.07394 & 0.04283 & $1.72623^{\circ}$ \\
\hline $\begin{array}{l}\text { Square Footage } \\
\text { House/100 }\end{array}$ & 0.01957 & 0.00958 & $2.04407^{\circ}$ & $\begin{array}{l}\text { Square Footage } \\
\text { Housed100 }\end{array}$ & -0.00970 & 0.02328 & -0.41656 \\
\hline $\begin{array}{l}\text { Square Footage } \\
\text { Garage/100 }\end{array}$ & 0.04494 & 0.00793 & $5.66658-$ & $\begin{array}{l}\text { Square Footage } \\
\text { Garage/100 }\end{array}$ & 0.03483 & 0.01214 & $2.86777^{m}$ \\
\hline Inverse Age & 0.00798 & 0.00339 & $2.35435^{\circ}$ & Inverse Age & 0.01058 & 0.00391 & $2.70457^{\infty}$ \\
\hline Number of Stories & -0.10781 & 0.04626 & $-233040^{-}$ & Number of Stories & $-0.01164^{\circ}$ & 0.11032 & 0.10550 \\
\hline Number of Full Baths & 0.17425 & 0.05185 & 3.36054 & Number of Full Baths & 0.12158 & 0.10162 & 1.19410 \\
\hline Number of Half Baths & 0.21248 & 0.03348 & $6.34659^{-m}$ & Number of Half Baths & -0.00532 & 0.02931 & -0.18147 \\
\hline Number of Rooms & 0.03083 & 0.02948 & 1.04594 & Number of Rooms & 0.03610 & 0.05948 & 0.60682 \\
\hline Vumber of Bedrooms & -0.03698 & 0.03395 & -1.08945 & Number of Bedrooms & 0.11711 & 0.06641 & $1.76329^{\circ}$ \\
\hline
\end{tabular}

\section{Grove Chy Aroa}

Log(Lot Size)

Square Footage

House/100

Square Footage

Garage/100

Inverse Age

Number of Stories

Number of Full Baths

Number of Half Baths

Number of Rooms

Number of Bedrooms

\begin{tabular}{|c|c|c|c|}
\hline 0.08611 & 0.04084 & $219857^{\circ}$ & Gahanna Area \\
\hline 0.03217 & 0.01217 & $2.64355^{-}$ & Square Footage \\
\hline 0.04765 & 0.01573 & 3.02993 - & \\
\hline 0.00493 & 0.00117 & $4.23097^{\circ 00}$ & Garage/100 \\
\hline-0.10397 & 0.08041 & -1.29302 & Nhmbar of Storie \\
\hline 0.00305 & 0.08451 & 0.20584 & 年 \\
\hline 0.01740 & 0.08038 & 0.58308 & 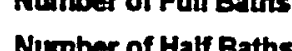 \\
\hline 0.08427 & 0.03786 & $222569^{\circ}$ & Number of Roo \\
\hline 0.11000 & 0.07402 & $1.48598^{\circ}$ & Number of Bedrooms \\
\hline
\end{tabular}

$\begin{array}{ccc}0.16434 & 0.02227 & 7.37987 \\ 0.04103 & 0.00809 & 5.06919 \\ & & \\ & & \\ 0.03550 & 0.00657 & 5.32392^{\infty} \\ 0.00126 & 0.00059 & 2.13486^{-} \\ -0.17432 & 0.04337 & -4.01919^{\infty} \\ 0.03858 & 0.03401 & 1.13415 \\ 0.17409 & 0.04001 & 4.22230^{\cdots} \\ 0.07200 & 0.03266 & 2.20485 \cdots \\ -0.06898 & 0.03764 & -1.23248\end{array}$

\section{Test of Market Segmentation, $\mathrm{H}_{0}$ : No Segmentation Exists} $F_{(27,2856)}=2.9247^{* * *}$, Chi-square $27=804.02^{* * *}$

- Denotes significance at $10 \%\left({ }^{\circ}\right), 5 \%\left({ }^{\circ}\right)$, and $1 \%\left({ }^{\circ+0}\right)$ levels 
Table E-2. Estimated hedonic tax functiona.

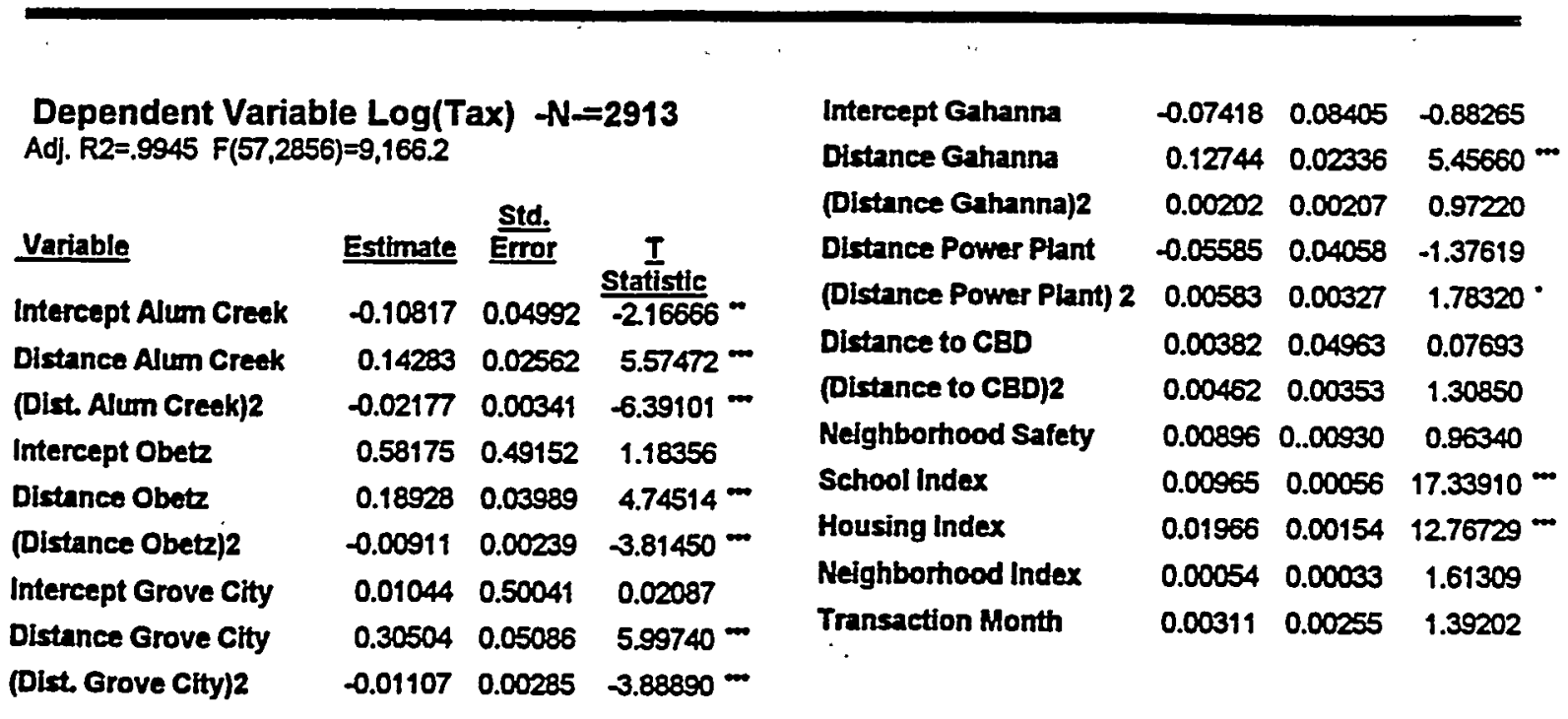

Alum Cregk Area
Log(Lot Size)
Square Footage
House/100
Square Footage
Garage/100
Inverse Ags
Number of Stories
Number of Full Baths
Number of Half Baths
Number of Rooms
Number of Bedrooms

\begin{tabular}{|c|c|c|c|}
\hline 0.15552 & 0.02644 & 5.881390 & $\frac{\text { Obetz Area }}{\text { Log(Lot Size) }}$ \\
\hline 0.02198 & 0.01051 & $2.09210^{-\infty}$ & $\begin{array}{l}\text { Square Footage } \\
\text { House/100 }\end{array}$ \\
\hline 0.04807 & 0.00794 & $6.05600^{-}$ & $\begin{array}{l}\text { Square Footage } \\
\text { Garage } 1400\end{array}$ \\
\hline 0.00735 & 0.00300 & $2.45139^{\circ}$ & Inverse Age \\
\hline-0.10954 & 0.04649 & $-2.35624^{\circ}$ & Number of Stories \\
\hline 0.16571 & 0.05413 & $3.06129^{-00}$ & Number of Full Baths \\
\hline 0.222998 & 0.03382 & 6.79935 & Number of Haif Baths \\
\hline 0.03780 & 0.03046 & 1.24098 & Number of Rooms \\
\hline-0.04510 & 0.03361 & -1.34164 & Number of Bedrooms \\
\hline
\end{tabular}

$\begin{array}{ccc}0.06711 & 0.04233 & 1.58543 \\ -0.01163 & 0.02335 & -0.49795 \\ 0.03429 & 0.01211 & 2.83159 \\ 0.01349 & 0.00374 & 3.60616^{\cdots} \\ -0.00096 & 0.10984 & -0.00875 \\ 0.14453 & 0.09911 & 1.45826 \\ -0.00162 & 0.02683 & -0.06031 \\ 0.04473 & 0.05929 & 0.75446 \\ 0.11492 & 0.06556 & 1.75293\end{array}$

Grove Chy Area Log(Lot Size)

Square Footage House/100 Square Footage Garage/100 Inverse Age Number of Stories Number of Full Baths Number of Half Baths Number of Rooms Number of Bedrooms

\begin{tabular}{|c|c|c|c|}
\hline 0.05983 & 0.03668 & 1.63126 & Gabanna Aras \\
\hline 0.03169 & 0.01092 & $2.90257^{\infty 00}$ & Square Footage \\
\hline 0.04670 & 0.01462 & $3.19499-$ & $\begin{array}{l}\text { House/100 } \\
\text { Square Footage }\end{array}$ \\
\hline 0.00395 & 0.00105 & 3.76999 & Garage/100 \\
\hline-0.09332 & 0.07358 & -1.26834 & Number of Stories \\
\hline 0.00104 & 0.07974 & 0.01302 & Number of Full Baths \\
\hline 0.03557 & 0.07204 & 0.49374 & Number of Half Baths \\
\hline 0.06096 & 0.03384 & $1.80132^{\circ}$ & Number of Rooms \\
\hline 0.11676 & 0.07401 & 1.5777 & \\
\hline
\end{tabular}

$\begin{array}{ccc}0.13551 & 0.02159 & 6.27729^{\circ} \\ 0.04388 & 0.00819 & 5.35668^{\circ} \\ 0.03501 & 0.00575 & 5.19038 \\ 0.001002 & 0.00058 & -1.71842^{\circ} \\ -0.18827 & 0.04372 & 4.30210^{\circ} \\ 0.02839 & 0.03447 & 0.82357 \\ 0.17619 & 0.04219 & 4.17617^{\circ} \\ 0.06481 & 0.03330 & 1.94609^{\circ} \\ -0.06035 & 0.03827 & -1.57671\end{array}$

Test of Market Segmentation, $\mathrm{H}_{0}$ : No Segmentation Exists $F_{(27,2856)}=2.8206^{* * *}$, Chi-square $27=753.01^{* * *}$

- Denotes significance at $10 \%\left({ }^{\circ}, 5 \%\left({ }^{\circ}\right)\right.$, and $1 \%\left({ }^{\circ}\right)$ levets 
Table E-3. Mean willingness to pay curves (MWTP) for the translog utility specification.

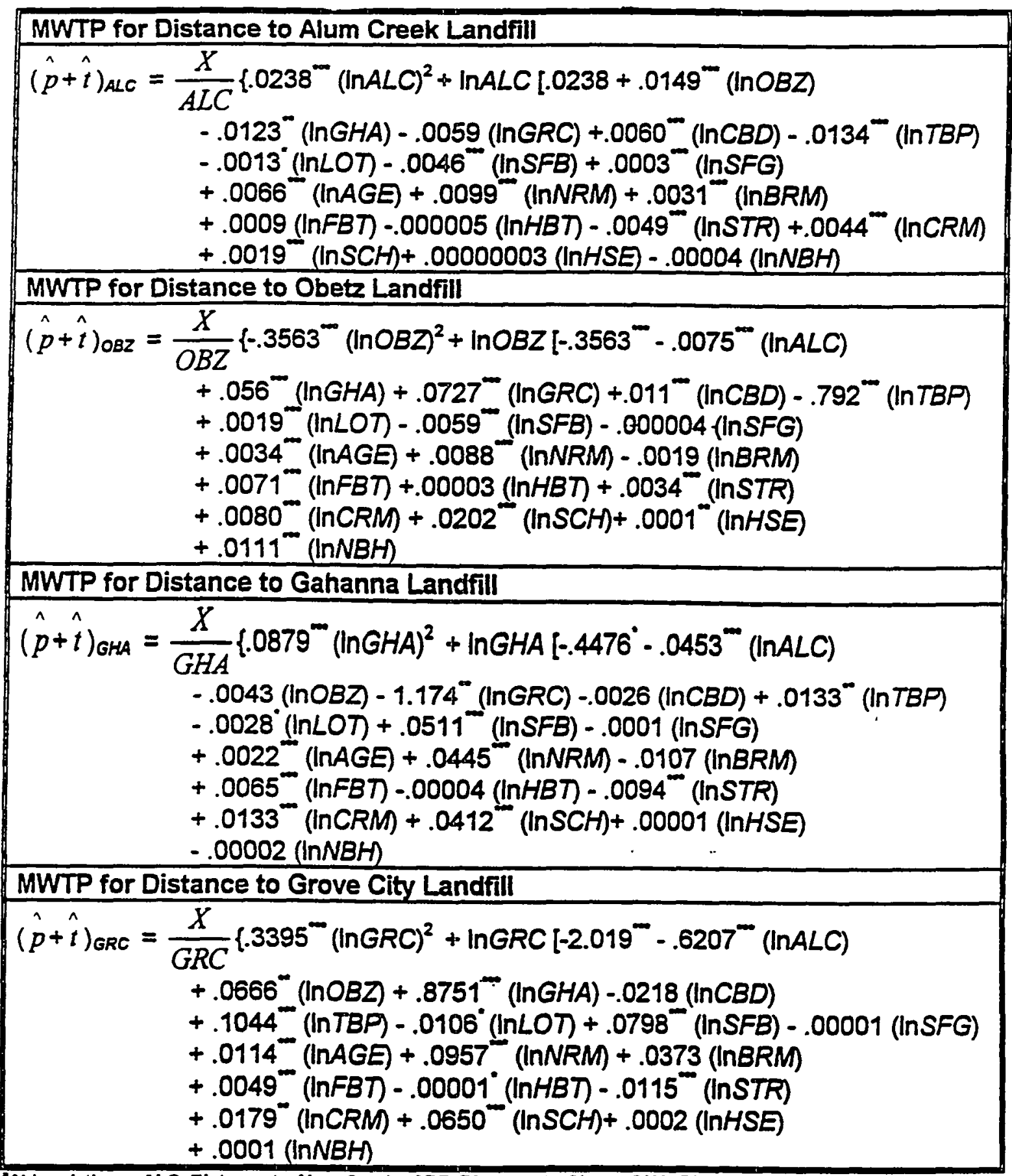

Abbreviations: ALC: Distance to Alum Creek; OBZ: Distance to Obetz; GHA: Distance to Gahanna; GRC: Distance to Grove City; CBD: Distance to CBD; TBP= Distance to Trush Plant; LOT= Sq. Ft Lotstze; SFBA(Sq. Ft. Structure)/100; SFG: (Sq. FL Garage)/100 ; AGE:: Inverse Age; NRM: \# Rooms; BRM:\# Bedrooms; FBT: \# Fullbaths; HBT.\# of Half Baths; STR: \# Stories; CRM:Safety Index ;SCH: School Index; HSEHousing Index; NBH: Neighborhood Index. 
Table E-4. Social cost transfer estimate worksheets for Conesville, Gavin and Zimmer landfills.

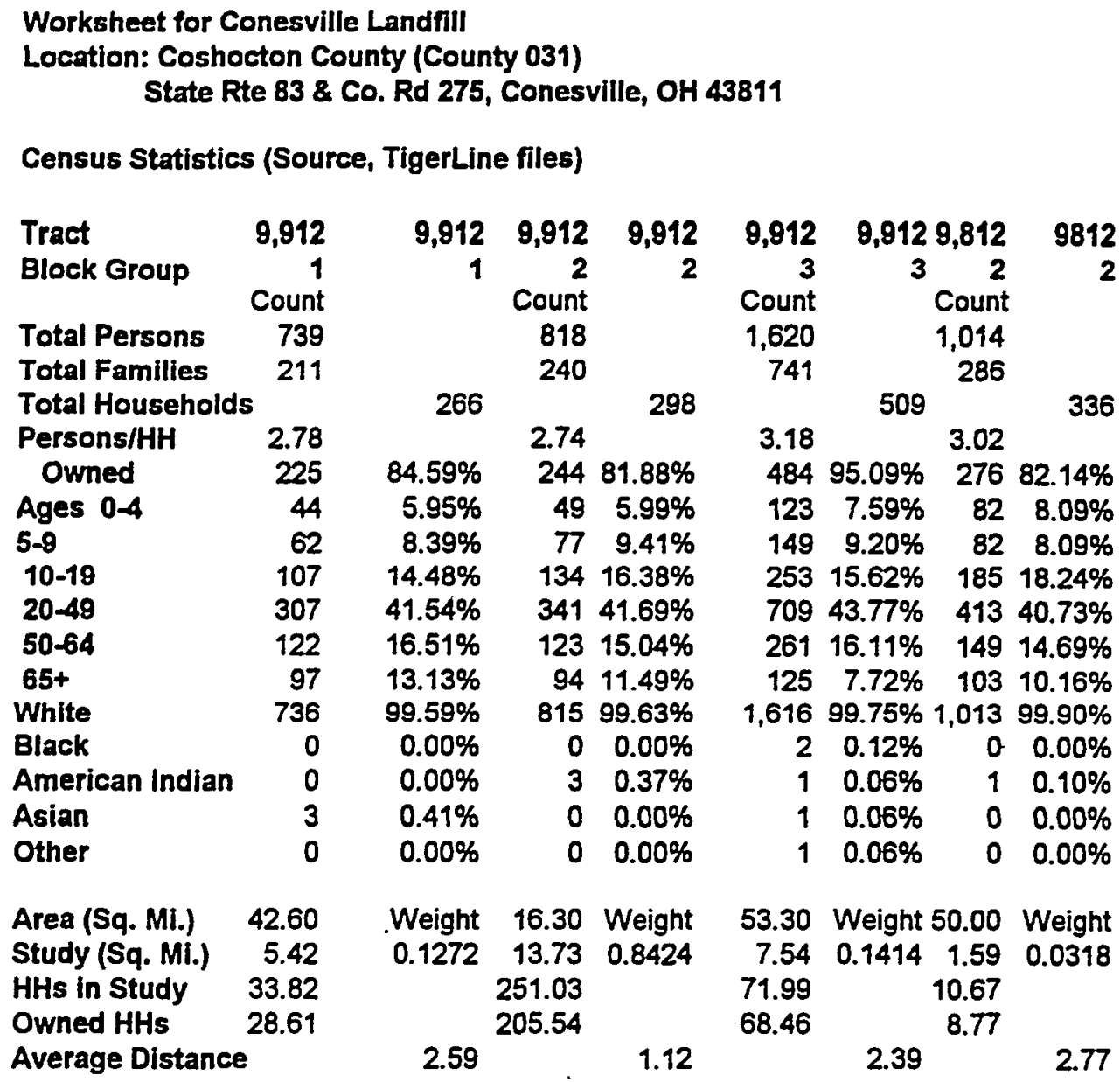

SUMMARYTotal Households in Study Area

Total Owned Households in Study Area
Weghted Average Distance 1.5542

1.5828

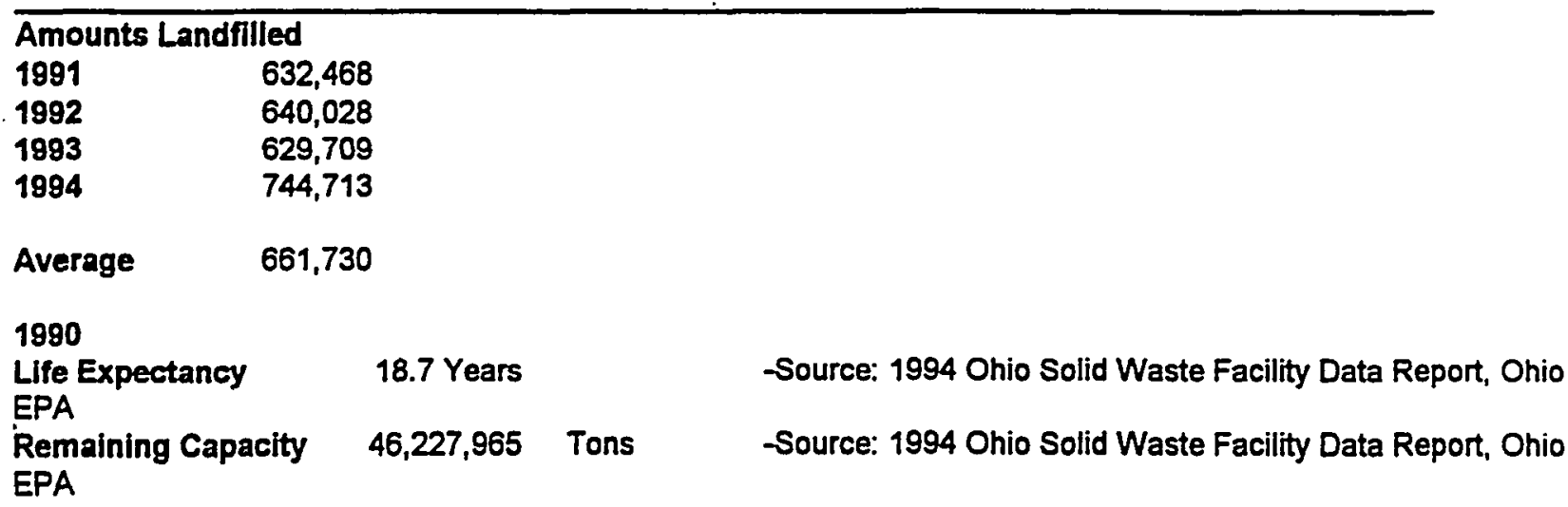


Table E-4 (continued). Social cost transfer estimate worksheets for Conesville, Gavin and Zimmer landfills.

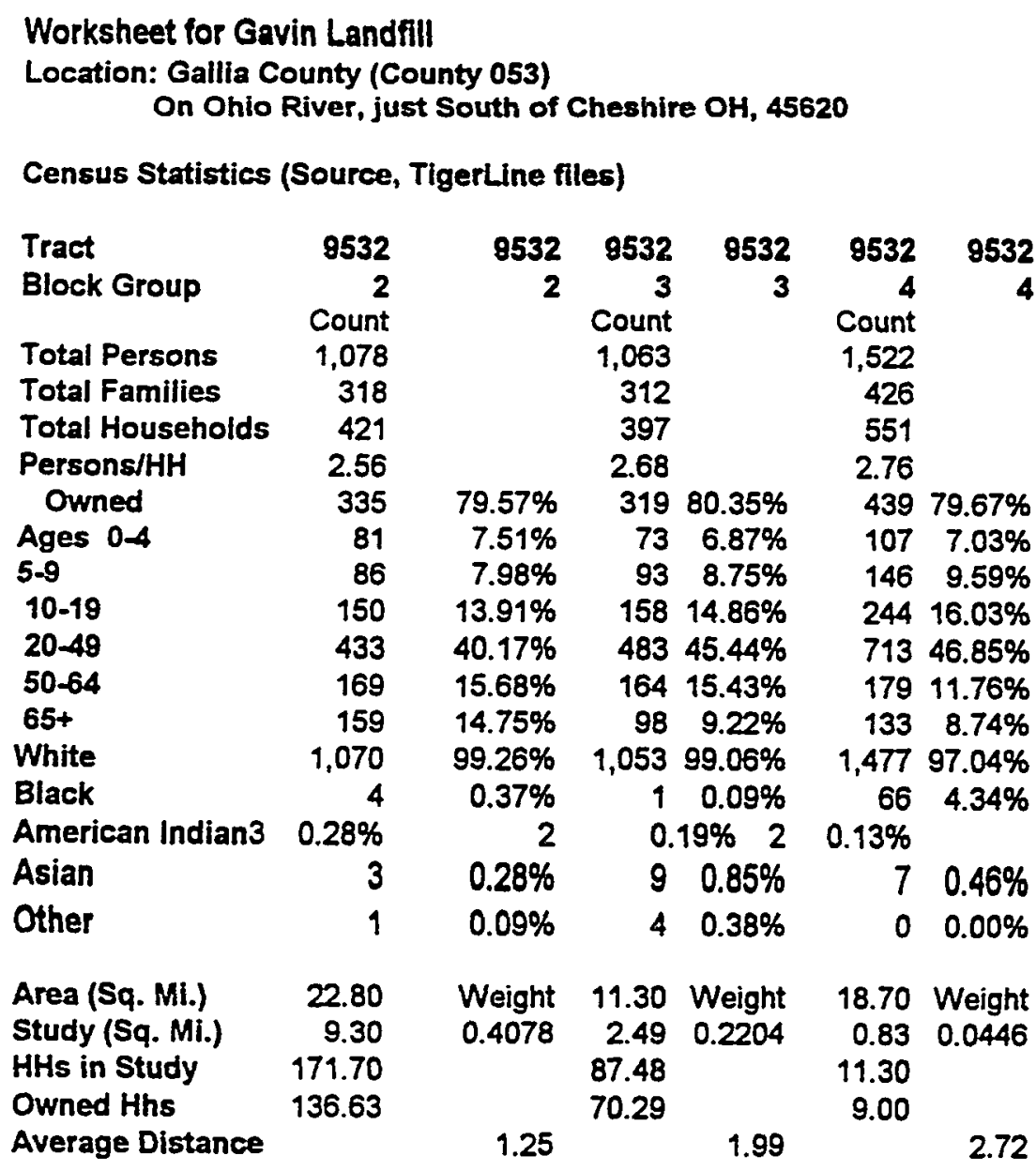

SUMMARY

Total Households in Study Area 270

Total Owned Households in Study Area 216
Weighted Average Distance 1.553

Amts. Landfilled

1991

1992

1993

1994

Average

0

1990

Life Expectancy

Remaining Capacity
35 Source: 1994 Ohio Solid Waste Facility Data Report, Ohio EPA Tons -Source: 1994 Ohio Solid Waste Facility Data Report, Ohio EPA 
Table E-4 (continued). Social cost transfer estimate worksheets for Conesville, Gavin and Zimmer landfills.

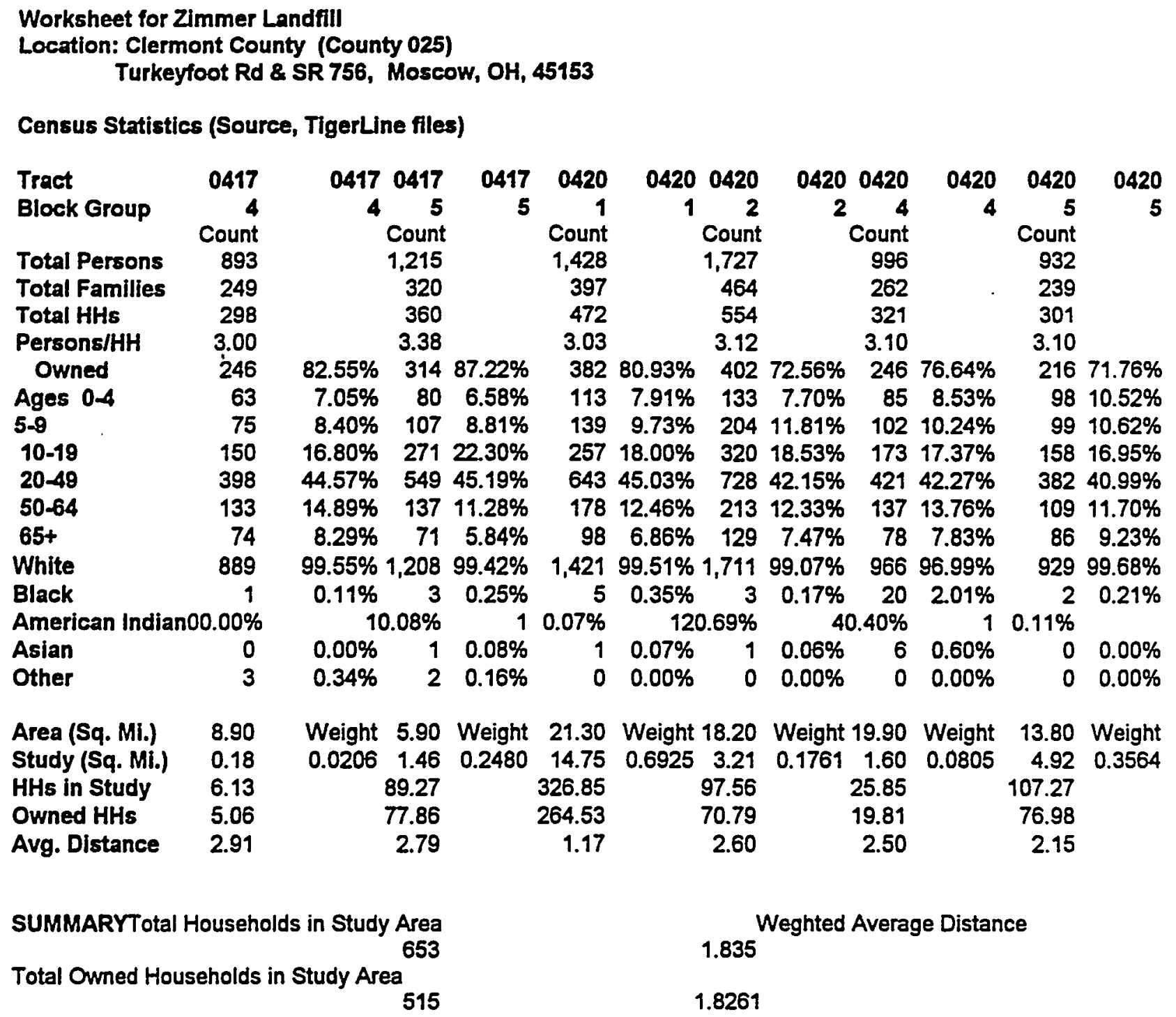


Table E-5. Cost transfer model worksheets for Conesville, Gavin and Zimmer landfills.

Benefits Transfer Model for Conesville Landfill in Coshocton County, $\mathrm{OH}$

Model was developed by stepwise regression of $\log$ of Franklin County compensating variation estimates a battery of characteristics drawn from Census STF3A data at the census block group level. Franklin County is the Study Site of the benefits transfer model, and the Conesville landfill is the Policy Site.

The application to the Conesville site in Coshocton County, $\mathrm{OH}$ was made using census block group data where available and ZIP level data whenever CBG data was not available.

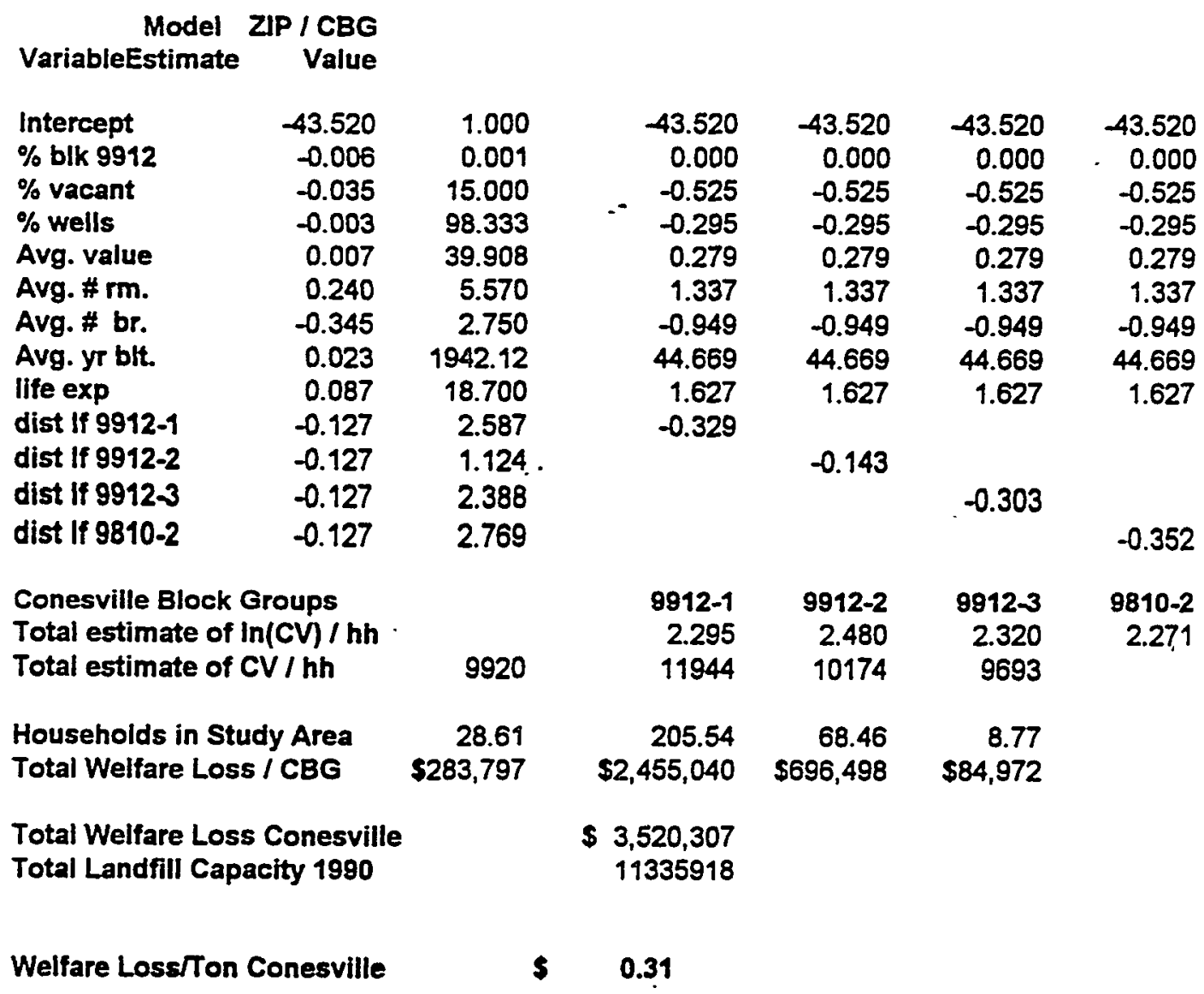


Table E-5 (continued). Cost transfer model worksheets for Conesville, Gavin and Zimmer landfills.

Cost Transfer Model for Gavin Landfill in Gallia County

Model was developed by stepwise regression of $\log$ of Franklin County compensating variation estimates on a battery of characteristics drawn from Census STF3A data at the census block group level. Franklin County is the Study Site of the cost transfer model, and the Conesville landfill is the Policy Site.

The application to the Gavin site in Gallia County, OH was made using census block group data where available and ZIP level data whenever CBG data was not available.

\begin{tabular}{|c|c|c|c|c|c|}
\hline \multirow{2}{*}{ VariableEstimate } & & ZJP / CBG & \multirow[b]{2}{*}{$9912-1$} & \multirow[b]{2}{*}{ 8912-2 } & \multirow[b]{2}{*}{9912} \\
\hline & Value & & & & \\
\hline Intercept & -43.520 & 1.000 & -43.520 & -43.520 & -43.52 \\
\hline$\%$ blk & -0.006 & 1.938 & -0.012 & -0.012 & -0.012 \\
\hline$\%$ vacant & -0.035 & 11.640 & -0.407 & -0.407 & -0.40 \\
\hline$\%$ wells & -0.003 & 15.873 & -0.048 & -0.048 & -0.04 \\
\hline Avg. value & 0.007 & 43.480 & 0.304 & 0.304 & 0.30 \\
\hline Avg. \# rm. & 0.240 & 5.661 & 1.359 & 1.359 & 1.35 \\
\hline Avg. \# br. & -0.345 & 2.820 & -0.973 & -0.973 & -0.97 \\
\hline Avg. yr blt. & 0.023 & 1953.200 & 44.924 & 44.924 & 44.92 \\
\hline life exp & 0.087 & 35.000 & 3.045 & 3.045 & 3.045 \\
\hline dist If $9535-2$ & -0.127 & 1.252 & -0.159 & & \\
\hline dist If 9535-3 & -0.127 & 1.994 & & -0.253 & \\
\hline dist If 95354 & -0.127 & 2.715 & & & -0.34 \\
\hline \multirow{3}{*}{\multicolumn{2}{|c|}{$\begin{array}{l}\text { Gavin Block Groups } \\
\text { Total estimate of } \ln (\mathrm{CV}) / \mathrm{hh} \\
\text { Total estimate of } \mathrm{CV} / \mathrm{hh}\end{array}$}} & & $9912-1$ & $9912-2$ & 9912 \\
\hline & & & 4.513 & 4.419 & 4.3 \\
\hline & & $\$ 91,201$ & $\$ 82,997$ & $\$ 75,739$ & \\
\hline \multirow{2}{*}{\multicolumn{2}{|c|}{$\begin{array}{l}\text { Households in Study Area } \\
\text { Total Welfare Loss / CBG }\end{array}$}} & 136.63 & 70.29 & 9.00 & \\
\hline & & $\$ 12,460,765$ & $5,834,129$ & 681,888 & \\
\hline \multicolumn{3}{|c|}{$\begin{array}{l}\text { Total Weifare Loss Conesville } \\
\text { Tons Total Landfill Capacity } 1990\end{array}$} & $\begin{array}{r}\$ 18,976,782 \\
15,000,000\end{array}$ & & \\
\hline
\end{tabular}

Welfare Loss/Ton Gavin $\$ 1.27$ / ton 
Table E-5 (continued). Cost transfer model worksheets for Conesville, Gavin and Zimmer landfills.

Cost Transfer Model for Zimmer Landfill in Clermont County, OH

Model was developed by stepwise regression of log of Franklin County compensating variation estimates a battery of characteristics drawn from Census STF3A data at the census block group level. Franklin County is the Study Site of the cost transfer model, and the Zimmer landfill is the Policy Site.

The application to the Zimmer site in Clermont County, $\mathrm{OH}$ was made using census block group data where available and ZIP level data whenever CBG data was not available.

\begin{tabular}{|c|c|c|c|c|c|c|c|c|}
\hline Variable & $\begin{array}{l}\text { Model } \\
\text { Estimate }\end{array}$ & $\begin{array}{r}\text { ZIP / CBG } \\
\text { Value }\end{array}$ & $0417-4$ & $0417-5$ & $0420-1$ & $0420-2$ & $0420-4$ & $0420-5$ \\
\hline Intercept & -43.520 & 1.000 & -43.520 & -43.520 & -43.520 & -43.520 & -43.520 & -43.520 \\
\hline$\%$ blk 4174 & $\begin{array}{l}-0.006 \\
-0.006\end{array}$ & $\begin{array}{l}0.110 \\
0.250\end{array}$ & $\begin{array}{l}-0.001 \\
-0.002\end{array}$ & -0.001 & -0.001 & -0.001 & -0.001 & -0.001 \\
\hline $\begin{array}{l}\% \text { blk } 4175 \\
\% \text { blk } 4201\end{array}$ & -0.006 & 0.350 & & -0.002 & & & & \\
\hline$\%$ blk 4202 & -0.006 & 0.170 & & & -0.001 & & & \\
\hline$\%$ blk 4204 & -0.006 & 2.010 & & & & -0.012 & & \\
\hline$\%$ blk 4205 & -0.006 & 0.210 & & & & & -0.001 & \\
\hline$\%$ vacant & -0.035 & 10.680 & & & & & & -0.374 \\
\hline \% wells & -0.003 & 19.480 & -0.058 & -0.058 & -0.058 & -0.058 & -0.058 & -0.058 \\
\hline Avg. value & 0.007 & 61.211 & 0.428 & 0.428 & 0.428 & 0.428 & 0.428 & 0.428 \\
\hline Avg. \# rm. & 0.240 & 5.417 & 1.300 & 1.300 & 1.300 & 1.300 & 1.300 & 1.300 \\
\hline Avg. \# br. & -0.345 & 2.613 & -0.902 & -0.902 & -0.902 & -0.902 & -0.902 & -0.902 \\
\hline Avg. yr blt. & 0.023 & 1956.81 & 45.007 & 45.007 & 45.007 & 45.007 & 45.007 & 45.007 \\
\hline life exp & 0.087 & 33.000 & 2.871 & 2.871 & 2.871 & 2.871 & 2.871 & 2.871 \\
\hline dist If $\mathbf{4 1 7 4}$ & -0.127 & 2.910 & -0.370 & & & & & \\
\hline dist If $\mathbf{4 1 7 5}$ & -0.127 & 2.790 & & -0.354 & & & & \\
\hline dist If $\mathbf{4 2 0 1}$ & -0.127 & 1.170 & & & -0.149 & & & \\
\hline dist If $\mathbf{4 2 0 2}$ & -0.127 & 2.600 & & & & -0.330 & & \\
\hline dist If $\mathbf{4 2 0 4}$ & -0.127 & 2.500 & & & & & -0.318 & \\
\hline dist If 4205 & -0.127 & 2.150 & & & & & & -0.273 \\
\hline \multirow{3}{*}{\multicolumn{3}{|c|}{$\begin{array}{l}\text { Zimmer site Block Groups } \\
\text { Total estimate of } \ln (\mathrm{CV}) / \mathrm{hh} \\
\text { Total estimate of } \mathrm{CV} / \mathrm{hh}\end{array}$}} & $0417-4$ & $0417-5$ & $0420-1$ & $0420-2$ & $0420-4$ & $0420-5$ \\
\hline & & & 4.754 & 4.769 & 4.976 & 4.783 & 4.807 & 4.479 \\
\hline & & & 116097 & 117809 & 144877 & 119491 & 122332 & 88116 \\
\hline \multirow{2}{*}{\multicolumn{3}{|c|}{$\begin{array}{l}\text { Households in Study Area } \\
\text { Total Welfare Loss / CBG }\end{array}$}} & 5.06 & 77.86 & 264.53 & 70.79 & 19.81 & 76.98 \\
\hline & & & $\$ 587,452$ & $\$ 9,172,644 \$ 3$ & $8,324,4435$ & $58,458,746 \$ 2$ & $2,423,397 \mathrm{SE}$ & $56,783,132$ \\
\hline \multicolumn{3}{|c|}{$\begin{array}{l}\text { Total Welfare Loss Zimmer } \\
\text { Total Landfill Capacity } 1990\end{array}$} & \multicolumn{6}{|c|}{$\begin{array}{l}\$ 65,749,813 \\
\$ 46,229,765\end{array}$} \\
\hline
\end{tabular}

Welfare Loss/Ton Zimmer \$ 1.42 


\section{Appendix $F$ QUALITY CONTROL}

An extensive quality assurance/quality control program was conducted by the US Geological Survey. The Ohio State University's Agricultural Research and Development Center (OARDC) participated in this program by contributing samples, running duplicate samples in cooperation with the Geological Survey, and by hosting an inspection by quality control experts from the National Water Quality Laboratory (NWQL), located in Arvada, CO.

One-quarter (37) of the 148 samples collected and analyzed during rounds 1, 2, and 3 were external or internal quality control (QC) samples. The three types of $Q C$ samples used to evaluate the water-quality of data collected for this study were blanks (18 total), reference samples ( 8 total), and splits and replicates (11 total). After receipt of data from either NWQL or the OARDC laboratory, analytical results for each QC sample were reviewed to determine if acceptance criteria pertaining to the various $\mathrm{QC}$ sample types were met. Other QC checks included comparisons of field and laboratory values for $\mathrm{pH}$, specific conductance, and alkalinity and calculation of the charge balance for each sample. Quality control analytical data and results of various QC checks and comparisons are summarized in Appendix Tables F-1 through F-12.

Several types of blanks were collected and analyzed to assess bias caused by contamination from equipment, field methods, containers, and preservatives. An initial set of blanks was collected to evaluate contamination of interstitial water samples by the lysimeters used to collect the samples. These included laboratory experiments in which lysimeters were placed in contact with ultrapure distilled water (Inorganic Blank Water, IBW, provided by the US Geological Survey's Quality of Water Services Unit in Ocala, Florida) and were sampled daily over 4 days. To assess contamination associated with the silica flour that was used to pack the porous sample cups in the soil, lysimeters were placed in a solution of IBW and silica flour. To test sorption and leaching potential, a trace metal reference water of known composition was put in contact with the lysimeters and sampled over a 4-day period. The trace metal reference water was acidified to a pH less than 2 . For all three tests, regular and "ultrapure" lysimeters were 
both used ("ultrapure" lysimeters are composed entirely of ceramic material, whereas "regular" lysimeters are composed of a PVC casing with small ceramic cup at the end). Individual samples from each lysimeter collected over the 4-day period were composited for analysis.

Results of the lysimeter equipment blanks, silica flour, and sorption/leaching tests indicate that the lysimeters and the silica flour pack may be a source of $\mathrm{Al}, \mathrm{B}, \mathrm{Co}, \mathrm{Pb}, \mathrm{Li}, \mathrm{Sr}, \mathrm{V}$, and $\mathrm{Zn}$, especially under acidic conditions (Appensix Table F-1). The data also indicate that traceelement contamination is more significant in the "ultrapure" lysimeters than in the "regular" lysimeters. This probably reflects the fact that the "ultrapure" lysimeters have a much greater volume of ceramic material available for leaching than the regular lysimeters do, even though the ceramic used for the "ultrapure" lysimeter is made of high purity materials. A positive finding is that concentrations of trace elements believed to be derived from the ceramic and (or) silica flour in the control and application area lysimeters were consistently less than those found in the blanks. Although silica concentrations were not measured in blanks, the silica flour is probably responsible for the high dissolved silica concentrations in the interstitial-water samples.

Results for equipment/field blanks collected during rounds 1,2, and 3 were generally satisfactory (Appendix Tables F-2 and F-3). Some blanks contained trace amounts of $\mathrm{Ca}, \mathrm{Mg}$, $\mathrm{Al}, \mathrm{Fe}, \mathrm{Mn}$, and $\mathrm{SO}_{4}$. However the low level contamination observed for these constituents was deemed unimportant given the fact that these constituents are found at very high concentrations in both interstitial water and groundwater samples. Each lysimeter and groundwater sampling pump had dedicated sampling tubes; therefore, this contamination may reflect incomplete flushing of the inductively coupled plasma emission spectrometry (ICP) lines between regular samples and the blanks. In two of three round 1 field blanks, $\mathrm{Cd}$ was detected at concentrations above the reporting limit ( $1 \mu \mathrm{g} / \mathrm{L}$; Appendix Table F-2). Because these detections were near the maximum contaminant level (MCL) for $\mathrm{Cd}(5 \mu \mathrm{g} / \mathrm{L})$, round 1 detections for this element in regular samples at or slightly above the reporting limit may also represent contamination. The field blank for round 2 (sample 103-A; Appendix Table F-3) yielded detections for various major and minor elements. A preservative blank consisting of IBW and nitric acid was used to assess affects of preservatives in filtered, acidified (FA) and raw, acidified (RA) samples. Analysis of this blank indicated no contamination.

Reference samples were submitted as blind samples to NWQL and OARDC to assess analytical bias and intralaboratory bias. Reference standards were provided by the USGS Standard 
Table F-1. Results of equipment blanks for quality control sample analyses for lysimetersa.

\begin{tabular}{lcccccccc}
\hline $\begin{array}{l}\text { Test number and } \\
\text { descriptionb }\end{array}$ & $\begin{array}{c}\mathrm{Ca} \\
\mathrm{mg} / \mathrm{L}\end{array}$ & $\begin{array}{c}\mathrm{Mg} \\
\mathrm{mg} / \mathrm{L}\end{array}$ & $\begin{array}{c}\mathrm{Na} \\
\mathrm{mg} / \mathrm{L}\end{array}$ & $\begin{array}{c}\mathrm{K} \\
\mathrm{mg} / \mathrm{L}\end{array}$ & $\begin{array}{c}\mathrm{SO}_{4} \\
\mathrm{mg} / \mathrm{L}\end{array}$ & $\begin{array}{c}\mathrm{NO}_{3}-\mathrm{N} \\
\mathrm{mg} / \mathrm{L}\end{array}$ & $\begin{array}{c}\mathrm{NO}_{2}-\mathrm{N} \text { Total-Nc } \\
\mathrm{mg} / \mathrm{L}\end{array}$ \\
$\mathrm{mg} / \mathrm{L}$
\end{tabular}

aUnless otherwise noted, all analyses were completed by Ohio State University. bIBW, inorganic blank water; UP, ultrapure lysimeter; REG, regular lysimeter; MPV, most probable value. IBW lot\# 94272-17 and 940929 and $\mathrm{HNO}_{3}$ lot\# Na-3253-1GS. cSum of $\mathrm{NO}_{3}-\mathrm{N}$ and $\mathrm{NO}_{2}-\mathrm{N}$. 
Table F-1 (continued). Results of equipment blanks for quality control sample analyses for lysimetersa.

Test number and description ${ }^{b}$ $\begin{array}{ccccccc}\frac{\mathrm{PO}_{4}-\mathrm{P}}{\mathrm{mg} / \mathrm{L}} & \mathrm{mg} / \mathrm{Lc} & \mathrm{Al} & \frac{\mathrm{Ar}}{\mathrm{g} / \mathrm{L}} & \mathrm{Be} & \mathrm{B} & \mathrm{Cd} \\ / \mathrm{L} & \mu \mathrm{g} / \mathrm{L}^{c} & \mu \mathrm{g} / \mathrm{L} & \mu \mathrm{g} / \mathrm{L} & \mu \mathrm{g} / \mathrm{L}\end{array}$

1. IBW in lysimeter UP -1

2. IBW in lysimeter UP - 2

3. IBW in lysimeter UP -3

4. IBW in lysimeter REG 6

5. IBW in lysimeter REG 12

6. IBW and $\mathrm{SiO}_{2}$ flour in lysimeter REG-12

$\begin{array}{llllllll}0.07 & 0.02 & 70 & 37 & <1 & <1 & 89 & <1\end{array}$

$\begin{array}{llllllll}0.07 & 0.02 & 80 & <5 & <1 & <1 & 76 & <1\end{array}$

$\begin{array}{llllllll}0.05 & 0.03 & 88 & <5 & <1 & <1 & 90 & <1\end{array}$

$\begin{array}{llllllll}0.06 & 0.02 & 50 & <5 & 1 & <1 & 7 & <1\end{array}$

$\begin{array}{llllllll}0.08 & 0.09<30<35<1 & <1\end{array}$

7. IBW and $\mathrm{SiO}_{2}$ flour in lysimeter REG 6

8. SWRS T 127 in lysimeter REG 6

9. SWRS T 127 in lysimeter UP 3

10. MPV T 127

$\begin{array}{llllllll}0.11 & -- & 44 & 44 & 1 & <1 & 9 & <1\end{array}$

$\begin{array}{llllllll}0.04 & - & 83 & <5 & <1 & <1 & 157\end{array}$

$\begin{array}{llllllll}0.08 & -- & 5110 & 46 & <1 & 16 & 47 & 8\end{array}$

11. IBW and preservative $\quad<0.02 \quad-\quad<\begin{array}{lllllll}30 & < & <5 & - & <1 & 35 & <1\end{array}$ blankb

aUnless otherwise noted, all analyses were completed by Ohio State University.

bIBW, inorganic blank water; UP, uitrapure lysimeter; REG, regular lysimeter; MPV, most probable value. IBW lot\# 94272-17 and 940929 and $\mathrm{HNO}_{3}$ lot\# Na-3253-1GS.

cAnalyzed by the NWQL laboratory. 
Table F-1 (continued). Results of equipment blanks for quality control sample analyses for lysimetersa.

Test number and descriptionb

$$
\begin{array}{ccccccc}
\mathrm{Cr} & \mathrm{Co} & \mathrm{Cu} & \mathrm{Fe} & \frac{\mathrm{Pb}}{\mathrm{L}} & \mathrm{Mn} \\
\mu \mathrm{g} / \mathrm{L} & \mu \mathrm{g} / \mathrm{L} & \mu \mathrm{g} / \mathrm{L} & \mu \mathrm{g} / \mathrm{L} & \frac{\mu \mathrm{g} / \mathrm{L}}{\mu \mathrm{g} / \mathrm{Lc}} & \mu \mathrm{g} / \mathrm{L} & \mu \mathrm{g} / \mathrm{L}
\end{array}
$$

1. IBW in lysimeter

$\begin{array}{llllllll}3<6 & <2 & <10 & <20 & <1 & 227\end{array}$

UP - 1

2. IBW in lysimeter UP - 2

3. IBW in lysimeter UP -3

4. IBW in lysimeter REG 6

5. IBW in lysimeter REG 12 lysimeter REG-12

7. IBW and $\mathrm{SiO}_{2}$ flour in lysimeter REG 6

8. SWRS T 127 in lysimeter REG 6

9. SWRS T 127 in lysimeter UP 3

10. MPV T 127

$<2<6 \quad<2<10<20 \quad<1 \quad 155<1$

$4<6<2<10<20<1 \quad 310<1$

$3<6<2<10<20 \quad 2 \quad 12<1$

$<2<6 \quad<2 \quad<10<20 \quad<1 \quad 12<1$

$\begin{array}{llllllll}4<6 & <2 & <10 & <20 & <1 & 13 & 1\end{array}$

$\begin{array}{lllllll}4 & <2 & <10 & 35 & <1 & 115\end{array}$

$\begin{array}{llllllll}16 & 18 & 63 & 334 & <20 & 3 & 28 & 9\end{array}$

$\begin{array}{llllllll}18 & 108 & 33 & 93 & <20 & 27 & 536 & 41\end{array}$

$\begin{array}{llllllll}11.5 & 11.6 & 42.0 & 135 & 3.25 & 3.25 & 24.0 & 5.43\end{array}$

11. IBW and preservative $\quad \begin{array}{llllllll}2 & <6 & <2 & <10 & <20 & -- & <4 & <1\end{array}$ blank

aUnless otherwise noted, all analyses were completed by Ohio State University.

bIBW, inorganic blank water; UP, ultrapure lysimeter; REG, regular lysimeter; MPV, most probable value. IBW lot\# $94272-17$ and 940929 and $\mathrm{HNO}_{3}$ lot\# Na-3253-1GS.

cAnalyzed by the NWQL laboratory. 
Table F-1 (continued). Results of equipment blanks for quality control sample analyses for lysimetersa.

\begin{tabular}{|c|c|c|c|c|c|c|c|c|c|}
\hline \multirow{2}{*}{$\begin{array}{l}\text { Test number and } \\
\text { descriptionb }\end{array}$} & \multirow{2}{*}{$\underset{\mu \mathrm{g} / \mathrm{L}}{\mathrm{Hg}}$} & \multirow{2}{*}{$\begin{array}{r}\mathrm{Mo} \\
\mu \mathrm{g} / \mathrm{L}\end{array}$} & \multirow{2}{*}{$\begin{array}{c}\mathrm{Ni} \\
\mu \mathrm{g} / \mathrm{L}\end{array}$} & \multicolumn{2}{|c|}{$\mathrm{Se}$} & \multirow{2}{*}{$\begin{array}{c}\mathrm{Si} \\
\mu \mathrm{g} / \mathrm{L}\end{array}$} & \multirow{2}{*}{$\begin{array}{c}\mathrm{Sr} \\
\mu \mathrm{g} / \mathrm{L}\end{array}$} & \multirow{2}{*}{$\begin{array}{c}V \\
\mu g / L\end{array}$} & \multirow{2}{*}{$\begin{array}{l}\mathrm{Zn} \\
\mu \mathrm{g} / \mathrm{L}\end{array}$} \\
\hline & & & & $\overline{\mu g / L}$ & $\mu \mathrm{g} / \mathrm{L}^{\mathrm{c}}$ & & & & \\
\hline $\begin{array}{l}\text { 1. IBW in lysimeter } \\
\text { UP - } 1\end{array}$ & $<0.1$ & $<15$ & 5 & 147 & $<1$ & $<10$ & 10 & 196 & $<1$ \\
\hline $\begin{array}{l}\text { 2. IBW in lysimeter } \\
\text { UP - } 2 \text {. }\end{array}$ & $<0.1$ & $<15$ & $<4$ & $<100$ & $<1$ & $<10$ & 9 & 174 & $<1$ \\
\hline $\begin{array}{l}\text { 3. IBW in lysimeter } \\
\text { UP -3 }\end{array}$ & $<0.1$ & $<15$ & 9 & $<100$ & $<1$ & $<10$ & 10 & 279 & $<1$ \\
\hline $\begin{array}{l}\text { 4. IBW in lysimeter } \\
\text { REG } 6\end{array}$ & $<0.1$ & $<15$ & 8 & 155 & $<1$ & $<10$ & 8 & 259 & 24 \\
\hline $\begin{array}{l}\text { 5. IBW in lysimeter } \\
\text { REG } 12\end{array}$ & $<0.1$ & 18 & $<4$ & $<100$ & $<1$ & $<10$ & 3 & 226 & $<1$ \\
\hline $\begin{array}{l}\text { 6. } \mathrm{IBW} \text { and } \mathrm{SiO}_{2} \text { flour in } \\
\text { lysimeter } \mathrm{REG}-12\end{array}$ & - & $<15$ & $<4$ & $<100$ & $<1$ & $<10$ & 48 & 121 & $<1$ \\
\hline $\begin{array}{l}\text { 7. IBW and } \mathrm{SiO}_{2} \text { flour in } \\
\text { lysimeter } \mathrm{REG} 6\end{array}$ & - & $<15$ & $<4$ & $<100$ & $<1$ & $<10$ & 34 & 48 & $<1$ \\
\hline $\begin{array}{l}\text { 8. SWRS T } 127 \text { in } \\
\text { lysimeter REG } 6\end{array}$ & -- & $<15$ & 18 & 108 & 8 & $<10$ & 83 & 124 & 123 \\
\hline $\begin{array}{l}\text { 9. SWRS T } 127 \text { in } \\
\text { lysimeter UP } 3\end{array}$ & - & $<15$ & 19 & $<100$ & 4 & $<10$ & 2440 & 15 & 136 \\
\hline 10. MPV T 127 & -- & 1.25 & 9.00 & 7.38 & 7.38 & 2.71 & 51.1 & 10.2 & 32.9 \\
\hline $\begin{array}{l}\text { 11. IBW and preservative } \\
\text { blankb }\end{array}$ & -- & $<15$ & $<4$ & $<100$ & - & $<10$ & $<1$ & $<5$ & $<1$ \\
\hline
\end{tabular}

aUnless otherwise noted, all analyses were completed by Ohio State University. bIBW, inorganic blank water; UP, ultrapure lysimeter; REG, regular lysimeter; MPV, most probable value. IBW lot\# 94272-17 and 940929 and $\mathrm{HNO}_{3}$ lot\# Na-3253-1GS.

cAnalyzed by the NWQL laboratory. 
Table F-2. Quality control analyses of field blanks and trip blanks, sampling round 1 .

\begin{tabular}{|c|c|c|c|}
\hline Constituent $^{\mathrm{a}}$ & Blank 103-A & Blank 103-B & Blank 103-C \\
\hline$\overline{\text { Sample date \& time }}$ & $950627-1545$ & $950706-0630$ & $950707-1500$ \\
\hline Blank type & Field blank & Trip blank & Field blank \\
\hline OARDC lab numbers & 1069 & 1093 & 1128 \\
\hline Acidity as $\mathrm{H}^{+}$(meq/L) & 0.1 & 0.2 & $<0.1$ \\
\hline Calcium (mg/L) & 0.1 & 2.1 & 0.1 \\
\hline Magnesium (mg/L) & $<0.02$ & 0.9 & 0.02 \\
\hline Sodium (mg/L) & $<0.05$ & $<0.05$ & $<0.05$ \\
\hline Potassium & $<0.18$ & 0.3 & 0.2 \\
\hline Alkalinity (mg/L as $\mathrm{CaCO}_{3}$ ) & 2 & $68^{b}$ & 8 \\
\hline Sulfate-IC $\left(\mathrm{mg} / \mathrm{L}\right.$ as $\left.\mathrm{SO}_{4}\right)$ & 342 & 329 & 369 \\
\hline Sulfate-ICP $\left(\mathrm{mg} / \mathrm{L}\right.$ as $\left.\mathrm{SO}_{4}\right)$ & $<0.5$ & 10 & $<0.5$ \\
\hline Chloride $(\mathrm{mg} / \mathrm{L})$ & $<1.0$ & $<1.0$ & $<1.0$ \\
\hline Fluoride (mg/L) & 42 & 30 & 46 \\
\hline Silicon (mg/L) & $<0.014$ & $<0.014$ & $<0.014$ \\
\hline ROE (mg/L) & $<1$ & 40 & 34 \\
\hline Ammonia-NWQL (mg/L) & No data & 0.02 & Nodata \\
\hline Nitrite-NWQL (mg/L) & Nodata & $<0.01$ & Nodata \\
\hline Nitrate-NWQL (mg/L) & No data & $<0.05$ & Nodata \\
\hline Orthophosphate (mg/L) & No data & $<0.01$ & Nodata \\
\hline Aluminum-total $(\mu g / L)$ & $<30$ & $<30$ & $<30$ \\
\hline Aluminum-diss $(\mu \mathrm{g} / \mathrm{L})$ & 63 & 42 & $<30$ \\
\hline Antimony $(\mu \mathrm{g} / \mathrm{L})$ & $<106$ & $<106$ & $<106$ \\
\hline Arsenic-NWQL $(\mu \mathrm{g} / \mathrm{L})$ & $<1$ & $<1$ & $<1$ \\
\hline Arsenic-OARDC $(\mu \mathrm{g} / \mathrm{L})$ & $<40$ & $<40$ & $<40$ \\
\hline Barium $(\mu \mathrm{g} / \mathrm{L})$ & $<1$ & $<1$ & $<1$ \\
\hline Beryllium $(\mu \mathrm{g} / \mathrm{L})$ & $<1$ & $<1$ & $<1$ \\
\hline Boron $(\mu \mathrm{g} / \mathrm{L})$ & $<6$ & $<6$ & 7 \\
\hline Cadmium $(\mu \mathrm{g} / \mathrm{L})$ & $<1$ & 5 & 4 \\
\hline Chromium $(\mu g / L)$ & $<2$ & 6 & 3 \\
\hline Cobalt $(\mu \mathrm{g} / \mathrm{L})$ & $<6$ & $<6$ & $<6$ \\
\hline Copper $(\mu g / L)$ & $<2$ & 3 & 4 \\
\hline Iron-Total $(\mu \mathrm{g} / \mathrm{L})$ & 13 & 65 & $<11$ \\
\hline Iron-Diss $(\mu \mathrm{g} / \mathrm{L})$ & 14 & 876 & $<11$ \\
\hline Lead-NWQL $(\mu \mathrm{g} / \mathrm{L})$ & $<1$ & $<1$ & $<1$ \\
\hline Lead-OARDC $(\mu \mathrm{g} / \mathrm{L})$ & 37 & $<0$ & $<0$ \\
\hline Lithium $(\mu \mathrm{g} / \mathrm{L})$ & $<4$ & $<4$ & $<4$ \\
\hline Manganese-total $(\mu \mathrm{g} / \mathrm{L})$ & $<1$ & 2 & $<1$ \\
\hline Manganese-diss $(\mu \mathrm{g} / \mathrm{L})$ & 2 & 54 & $<1$ \\
\hline Mercury-NWQL $(\mu \mathrm{g} / \mathrm{L})$ & $<0.1$ & $<0.1$ & $<0.1$ \\
\hline
\end{tabular}


Table F-2 (continued). Quality control analyses of field blanks and trip blanks, sampling round 1 .

$\begin{array}{lccc}\text { Molybdenum }(\mu \mathrm{g} / \mathrm{L}) & <11 & <11 & <11 \\ \text { Nickel }(\mu \mathrm{g} / \mathrm{L}) & <4 & <4 & <4 \\ \text { Selenium-NWQL }(\mu \mathrm{g} / \mathrm{L}) & <5 & <1 & <1 \\ \text { Selenium-OARDC }(\mu \mathrm{g} / \mathrm{L}) & <93 & <93 & <93 \\ \text { Silver }(\mu \mathrm{g} / \mathrm{L}) & <10 & <10 & <10 \\ \text { Strontium }(\mu \mathrm{g} / \mathrm{L}) & <1 & 14 & <1 \\ \text { Vanadium }(\mu \mathrm{g} / \mathrm{L}) & <5 & 10 & 21 \\ \text { Zinc }(\mu \mathrm{g} / \mathrm{L}) & 4 & 9 & 2 \\ \text { Dissolved Org. C-NWQL }(\mathrm{mg} / \mathrm{L}) & \text { Nodata } & <0.1 & \text { Nodata }\end{array}$

aROE, residue on evaporation at $180^{\circ}$ Celsius.

bBold values represent constituents present at concentrations above detection level. Laboratory duplicate data for selected constituents are given where provided. 
Table F-3. Quality control analyses of equipment blanks and field blanks, sampling rounds 2 and 3.

\begin{tabular}{|c|c|c|c|c|c|}
\hline Constituent $^{\mathbf{a}}$ & Blank 103-A & Blank 103-B & Blank 103-C & Blank 103-D & Blank-103-E \\
\hline $\begin{array}{l}\text { Sample date \& time } \\
\text { Blank type }\end{array}$ & $\begin{array}{c}951020 \\
\text { Equipment }\end{array}$ & $\begin{array}{l}96011 \\
\text { Field }\end{array}$ & $\begin{array}{c}960118 \\
\text { Field }\end{array}$ & $\begin{array}{c}960119 \\
\text { Field }\end{array}$ & $\begin{array}{c}960120 \\
\text { Field }\end{array}$ \\
\hline OARDC lab numbers & 1181,1182 & 1191 & 1239 & 1205 & 1208 \\
\hline Acidity as $\mathrm{H}^{+}(\mathrm{meq} / \mathrm{L})$ & 0.09 & 0.03 & 0.04 & 0.03 & 0.01 \\
\hline Calcium (mg/L) & $0.70, \quad 0.63^{b}$ & $<0.01$ & 0.12 & $<0.01$ & $<0.01$ \\
\hline Magnesium (mg/L) & $0.73,1.05$ & 1.1 & 0.10 & 1.0 & 0.9 \\
\hline Sodium (mg/L) & $0.1,<0.05$ & $<0.05$ & 0.19 & $<0.05$ & $<0.05$ \\
\hline Potassium & $<0.18,<0.18$ & $<0.18$ & $<0.18$ & $<0.18$ & $<0.18$ \\
\hline Alkalinity $\left(\mathrm{mg} / \mathrm{L}\right.$ as $\mathrm{CaCO}_{3}$ ) & 6.0 & 1.0 & ND & 1.0 & 1.0 \\
\hline Sulfate-IC (mg/L as $\left.\mathrm{SO}_{4}\right)$ & 4.0 & $<1.0$ & ND & $<1.0$ & $<1.0$ \\
\hline Sulfate-ICP $\left(\mathrm{mg} / \mathrm{L}\right.$ as $\left.\mathrm{SO}_{4}\right)$ & $7.3,6.7$ & $<0.16$ & 2.4 & $<0.16$ & $<0.16$ \\
\hline Chloride (mg/L) & $<0.5$ & $<0.1$ & ND & $<0.1$ & $<0.1$ \\
\hline Fluoride (mg/L) & 0.2 & $<0.1$ & ND & $<0.1$ & $<0.1$ \\
\hline Silicon (mg/L) & $0.08, \quad 0.15$ & $<0.01$ & $<0.14$ & $<0.01$ & $<0.01$ \\
\hline $\operatorname{ROE}(\mathbf{m g} / \mathrm{L})$ & 45 & 27 & ND & 23 & 41 \\
\hline Ammonia-NWQL (mg/L) & ND & $<0.015$ & ND & $<0.015$ & $<0.015$ \\
\hline Nitrite-NWQL (mg/L) & ND & $<0.01$ & ND & $<0.01$ & $<0.01$ \\
\hline Nitrate-NWQL (mg/L) & ND & $<0.05$ & ND & $<0.05$ & $<0.05$ \\
\hline Orthophosphate (mg/L) & ND & $<0.01$ & ND & $<0.01$ & $<0.01$ \\
\hline Aluminum-total $(\mu \mathrm{g} / \mathrm{L})$ & ND & ND & ND & $<0.03$ & $<0.03$ \\
\hline Aluminum-diss $(\mu \mathrm{g} / \mathrm{L})$ & 64,55 & $<30$ & 65 & 63 & 76 \\
\hline Antimony $(\mu \mathrm{g} / \mathrm{L})$ & $<106 ;<106$ & $<100,<93$ & $<100$ & $<100,<93$ & $<100,170$ \\
\hline Arsenic-NWQL $(\mu \mathrm{g} / \mathrm{L})$ & ND & $<1.0$ & $\mathrm{ND}$ & $<1.0$ & $<1.0$ \\
\hline Arsenic-OARDC $(\mu \mathrm{g} / \mathrm{L})$ & $<40,<40$ & $<40,42$ & $<40$ & $51,<40$ & $<40,<40$ \\
\hline Barium $(\mu g / L)$ & $<1,1$ & $1,<1$ & $<1$ & $1,<1$ & $1,<1$ \\
\hline Beryllium ( $\mu$ g/L) & $<1,<1$ & $<1,<1$ & $<1$ & $<1,<1$ & $<1,<1$ \\
\hline Boron $(\mu \mathrm{g} / \mathrm{L})$ & 10,8 & $<6$ & 13 & $<6$ & $<6$ \\
\hline Cadmium $(\mu g / L)$ & $<1,2$ & $<1,<1$ & $<1$ & $<1,<1$ & $<1,<1$ \\
\hline Chromium $(\mu \mathrm{g} / \mathrm{L})$ & 2,4 & 3,3 & $<2$ & 3,5 & $3,<2$ \\
\hline Cobalt $(\mu \mathrm{g} / \mathrm{L})$ & $<6,11$ & $<6$ & $<6$ & $<6$ & $<6$ \\
\hline Copper $(\mu g / L)$ & 3,7 & $<2,<2$ & $<2$ & $<,<2$ & $<2,<2$ \\
\hline Iron-total $(\mu \mathrm{g} / \mathrm{L})$ & ND & ND & ND & 26 & 11 \\
\hline Iron-diss $(\mu \mathrm{g} / \mathrm{L})$ & 135,78 & 100 & $<11$ & 180 & 50 \\
\hline Lead-NWQL $(\mu \mathrm{g} / \mathrm{L})$ & ND & $<1.0$ & $\mathrm{ND}$ & $<1.0$ & $<1.0$ \\
\hline Lead-OARDC $(\mu \mathrm{g} / \mathrm{L})$ & $<20,<20$ & $<20,<20$ & $<20$ & $<20,<20$ & $<20,<20$ \\
\hline Lithium $(\mu \mathrm{g} / \mathrm{L})$ & 11,7 & $<4$ & 6 & 8 & 6 \\
\hline Manganese-total $(\mu \mathrm{g} / \mathrm{L})$ & ND & ND & ND & 10 & 10 \\
\hline Manganese-diss $(\mu \mathrm{g} / \mathrm{L})$ & 13,10 & 5 & 16 & 10 & 5 \\
\hline Mercury-NWQL $(\mu \mathrm{g} / \mathrm{L})$ & ND & $<0.1$ & ND & $<0.1$ & $<0.1$ \\
\hline Molybdenum $(\mu \mathrm{g} / \mathrm{L})$ & 21,14 & 27 & $<10$ & $<10$ & $<10$ \\
\hline $\operatorname{Nickel}(\mu \mathrm{g} / \mathrm{L})$ & $<4,<4$ & $<4,<4$ & $<4$ & $<4,<4$ & $<4,<4$ \\
\hline Selenium-NWQL ( $\mu g / L)$ & ND & $<1.0$ & ND & $<1.0$ & $<1.0$ \\
\hline Selenium-OARDC $(\mu \mathrm{g} / \mathrm{L})$ & $224,<93$ & $<93$ & $<93$ & $<93$ & 179 \\
\hline Silver $(\mu \mathrm{g} / \mathrm{L})$ & $<10,<10$ & $20,<10$ & $<10$ & $21,<10$ & $21,<10$ \\
\hline Strontium $(\mu \mathrm{g} / \mathrm{L})$ & 3,4 & 5 & $<1$ & 5 & 3 \\
\hline Vanadium $(\mu \mathrm{g} / \mathrm{L})$ & $<5$ & $<5$ & $<5$ & $<5$ & $<5$ \\
\hline Zinc $(\mu g / L)$ & 66,45 & $<1$ & $<1$ & $<1$ & 5 \\
\hline Dissolved Org. C-NWQL (mg/L) & ND & ND & ND & ND & 0.5 \\
\hline
\end{tabular}

adiss, dissolved; ROE, residue on evaporation at 1800 Celsius.

bBold values represent constituents present at concentrations above detection level. Laboratory duplicate data for selected constituents are given where provided. 
Reference Water Samples (SRWS) produced by the USGS Branch of Technical Development and Quality Systems (BTDQS) and included samples designed to assess major and trace element results in a dilute streamwater matrix and an acid mine drainage matrix. The acceptance criteria was that the reported value must fall within 2 pseudo-sigma (2f, nonparametric equivalent of $2 \sigma$ ) of the most probable value (MPV) reported by the BTDQS. Tabulated summaries of the blind-sample results are given in Appendix Tables F-4 and F-5.

Results for $\mathrm{V}, \mathrm{Cl}, \mathrm{SO}_{4}$, and residue on evaporation (ROE) did not meet acceptance criteria for round 1 blind SRWSs analyzed by OARDC (Appendix Table $\mathrm{F}-4$ ). The data for $\mathrm{Cl}$, and $\mathrm{SO}_{4}$ were produced by an ion chromatograph that used an old column; these data are considered unreliable. Sulfate data produced by inductively coupled plasma emission spectrometry were acceptable.The NWQL results for $\mathrm{As}, \mathrm{Pb}, \mathrm{Hg}$, and Se were within acceptance criteria for all round 1 samples. Round 2 and 3 blind SRWSs did not satisfy acceptance criteria for $\mathrm{pH}$, specific conductance, $\mathrm{Al}, \mathrm{B}, \mathrm{Be}, \mathrm{Cd}, \mathrm{Cl}, \mathrm{Cr}, \mathrm{F}, \mathrm{Fe}, \mathrm{Mn}, \mathrm{Mo}$, and $\mathrm{Zn}$ (Tables F-5 and F-6). Failure to meet the acceptance criteria for $\mathrm{pH}$ and specific conductance may be related to changes in the chemistry of the acid-mine-drainage SRWS due to oxidation of ferrous iron. In addition, many of the trace elements that failed to meet the acceptance criteria were for the dilute river water SRWS and had trace-element concentrations near or slightly above inductively coupled plasma emission reporting limits. Trace element results were generally much better for the more concentrated acid-mine-drainage SRWS. It should be noted that none of the currently available SRWS closely match the concentrated $\mathrm{Ca}-\mathrm{Mg}-\mathrm{Fe}-\mathrm{SO}_{4}$ composition of interstitial water and groundwater samples collected at the study site.

Replicate samples were used to monitor NWQL and OARDC laboratory precision, whereas splits were sent to both laboratories to provide a means of assessing intralaboratory precision and bias. The acceptance criterion was that the relative percent deviation (RPD) between the sample and replicate data should be less than 20 percent. Replicate samples were done only for round 1 and 3 interstitial water samples because the small volumes available for the round 2 samples precluded submission of split or replicate samples. Data for round 1 and 3 split and replicate samples are summarized in Appendix Tables F-7 and F-8.

Acceptance criteria for split and replicate results for major ions and field measurements were generally met, but a few problems were noted. For example, relative percent deviations for $\mathrm{pH}$ and alkalinity in several round 1 and round 3 split and replicate sets were unacceptable. Analyses of splits and replicates indicate a bias toward low concentrations (negative bias) in the OARDC results for samples with residue on evaporation concentrations less than $500 \mathrm{mg} / \mathrm{L}$. 
Table F-4. Quality control analyses of blind samples, sampling round 1.

\begin{tabular}{|c|c|c|c|}
\hline Constituenta & $\begin{array}{c}\text { Sample } \\
\text { A } \\
\text { data } \\
\end{array}$ & $\begin{array}{c}\text { Most probable } \\
\text { value } \\
( \pm 2 \mathrm{f}) \\
\end{array}$ & $\begin{array}{c}\text { Meets } \\
\text { QCcriteria } \\
\end{array}$ \\
\hline $\begin{array}{l}\text { Sample date } \\
\text { Sample time }\end{array}$ & $\begin{array}{c}950707 \\
1159\end{array}$ & $\begin{array}{l}-b \\
-\end{array}$ & - \\
\hline OARDC lab numbers & 1131 & & \\
\hline pH (standard units) & 6.2 & $6.9 \pm 0.6$ & yes \\
\hline Specific cond. $(\mu \mathrm{S} / \mathrm{cm})$ & 130 & $134 \pm 10$ & yes \\
\hline Acidity (meq/L) & 0.1 & - & - \\
\hline Calcium (mg/L) & 10.0 & $9.1 \pm 0.8$ & yes \\
\hline Magnesium (mg/L) & 3.9 & $3.5 \pm 0.4$ & yes \\
\hline Sodium (mg/L) & 9.0 & $9.1 \pm 0.8$ & yes ${ }^{\circ}$ \\
\hline Potassium (mg/L) & 0.6 & $0.7 \pm 0.2$ & yes \\
\hline Alkalinity (mg/L as $\mathrm{CaCO}_{3}$ ) & 9.0 & $7.8 \pm 2.2$ & yes \\
\hline Sulfate-IC (mg/L) & $329 c$ & $27.8 \pm 3.4$ & no \\
\hline Sulfate-ICP (mg/L) & 26.0 & $27.8 \pm 3.4$ & yes \\
\hline Chloride (mg/L) & 26.0 & $13.0 \pm 2.4$ & no \\
\hline Fluoride (mg/L) & $<1.0$ & $0.3 \pm 0.06$ & yes \\
\hline Silicon (mg/L) & 1.4 & $1.6 \pm 0.2$ & yes \\
\hline Residue on evaporation (mg/L) & 16 & $78 \pm 16$ & no \\
\hline Aluminum-total $(\mathrm{mg} / \mathrm{L})$ & $<30$ & - & - \\
\hline Aluminum-diss (mg/L) & $<30$ & - & - \\
\hline Antimony $(\mu \mathrm{g} / \mathrm{L})$ & $<106$ & - & - \\
\hline Arsenic-NWQL $(\mu \mathrm{g} / \mathrm{L})$ & $<1.0$ & $0.6 \pm 2.3$ & - \\
\hline Arsenic-OARDC $(\mu \mathrm{g} / \mathrm{L})$ & $<40$ & - & - \\
\hline Barium $(\mu \mathrm{g} / \mathrm{L})$ & 6 & - & - \\
\hline Beryllium $(\mu \mathrm{g} / \mathrm{L})$ & 3 & - & - \\
\hline Boron $(\mu \mathrm{g} / \mathrm{L})$ & 31 & $44 \pm 78$ & yes \\
\hline Cadmium $(\mu \mathrm{g} / \mathrm{L})$ & 4 & - & - \\
\hline Chromium $(\mu \mathrm{g} / \mathrm{L})$ & 9 & - & - \\
\hline Cobalt $(\mu \mathrm{g} / \mathrm{L})$ & $<6$ & - & - \\
\hline Copper $(\mu \mathrm{g} / \mathrm{L})$ & 6 & - & - \\
\hline Iron-total $(\mu g / \mathrm{L})$ & $<11$ & - & - \\
\hline Iron-diss $(\mu \mathrm{g} / \mathrm{L})$ & 25 & - & - \\
\hline Lead-NWQL $(\mu \mathrm{g} / \mathrm{L})$ & $<1$ & $1 \pm 2.7$ & yes \\
\hline Lead-OARDC $(\mu \mathrm{g} / \mathrm{L})$ & $<20$ & - & - \\
\hline Lithium $(\mu g / L)$ & $<4$ & - & - \\
\hline Manganese-total $(\mu \mathrm{g} / \mathrm{L})$ & $<1$ & - & - \\
\hline Manganese-diss $(\mu \mathrm{g} / \mathrm{L})$ & 24 & - & - \\
\hline Mercury-NWQL $(\mu \mathrm{g} / \mathrm{L})$ & 1.3 & $1.3 \pm 0.4$ & yes \\
\hline Molybdenum $(\mu \mathrm{g} / \mathrm{L})$ & $<11$ & - & - \\
\hline Nickel $(\mu \mathrm{g} / \mathrm{L})$ & 13 & - & - \\
\hline Selenium-NWQL $(\mu \mathrm{g} / \mathrm{L})$ & $<1$ & $1.6 \pm 3.2$ & yes \\
\hline Selenium-OARDC $(\mu \mathrm{g} / \mathrm{L})$ & $<93$ & - & - \\
\hline Silver $(\mu \mathrm{g} / \mathrm{L})$ & $<10$ & - & - \\
\hline Strontium $(\mu \mathrm{g} / \mathrm{L})$ & 174 & $177 \pm 18$ & yes \\
\hline Vanadium $(\mu \mathrm{g} / \mathrm{L})$ & 31 & 4.4 & no \\
\hline $\operatorname{Zinc}(\mu \mathrm{g} / \mathrm{L})$ & 7 & - & - \\
\hline
\end{tabular}

adiss, dissolved.

b.-, no data or not evaluated

cBold values indicate analyses that do not meet acceptance criteria. 
Table F-4 (continued). Quality control analyses of blind samples, sampling round 1.

\begin{tabular}{|c|c|c|c|}
\hline Constituenta & $\begin{array}{c}\text { Sample } \\
\text { B } \\
\text { data }\end{array}$ & $\begin{array}{c}\text { Most probable } \\
\text { value } \\
( \pm 2 \mathrm{f})\end{array}$ & $\begin{array}{c}\text { Meets } \\
\text { QC criteria }\end{array}$ \\
\hline $\begin{array}{l}\text { Sample date } \\
\text { Sample time }\end{array}$ & $\begin{array}{l}950707 \\
1201\end{array}$ & $-b$ & - \\
\hline $\begin{array}{l}\text { OARDC lab numbers } \\
\text { pH (standard units) }\end{array}$ & $\begin{array}{c}1134 \\
8.3\end{array}$ & $8.3 \pm 0.2$ & yes \\
\hline Specific cond $(\mu \mathrm{S} / \mathrm{cm})$ & $960 c$ & 1076 & no \\
\hline Acidity (meq/L) & $<0.1$ & - & - \\
\hline Calcium (mg/L) & 85.7 & $78.9+7.9$ & yes \\
\hline Magnesium (mg/L) & 17.1 & $17.4+1.5$ & yes \\
\hline Sodium (mg/L) & 125 & $126 \pm 10$ & yes \\
\hline Potassium (mg/L) & 8.4 & $9.4 \pm 1.3$ & yes \\
\hline Alkalinity (mg/L as $\mathrm{CaCO}_{3}$ ) & 170 & $168 \pm 6.8$ & yes \\
\hline Sulfate-IC (mg/L) & 462 & $206 \pm 16$ & no \\
\hline Sulfate-ICP (mg/L) & 220 & $206 \pm 16$ & yes \\
\hline Chloride (mg/L) & 67.0 & $98.2 \pm 5.1$ & no \\
\hline Fluoride (mg/L) & $<1.0$ & $1.2 \pm 0.2$ & yes \\
\hline Silicon $(\mathrm{mg} / \mathrm{L})$ & 4.3 & $5.0 \pm 0.8$ & yes \\
\hline Residue on evaporation (mg/L) & 593 & $689 \pm 39$ & no \\
\hline Aluminum-total $(\mathrm{mg} / \mathrm{L})$ & $<30$ & - & - \\
\hline Aluminum-diss (mg/L) & $<30$ & _ & - \\
\hline Antimony $(\mu \mathrm{g} / \mathrm{L})$ & $<106$ & - & - \\
\hline Arsenic-NWQL $(\mu \mathrm{g} / \mathrm{L})$ & 3 & $4.3 \pm 1.5$ & yes \\
\hline Arsemic-OARDC $(\mu \mathrm{g} / \mathrm{L})$ & 43 & - & - \\
\hline Barium $(\mu g / L)$ & 31 & - & - \\
\hline Beryllium $(\mu \mathrm{g} / \mathrm{L})$ & $<1$ & - & - \\
\hline Boron $(\mu \mathrm{g} / \mathrm{L})$ & 276 & $285 \pm 43$ & yes \\
\hline Cadmium $(\mu \mathrm{g} / \mathrm{L})$ & 2 & - & - \\
\hline Chromium $(\mu \mathrm{g} / \mathrm{L})$ & 3 & - & - \\
\hline Cobalt $(\mu \mathrm{g} / \mathrm{L})$ & $<6$ & - & - \\
\hline Copper $(\mu \mathrm{g} / \mathrm{L})$ & 5 & - & - \\
\hline Iron-total $(\mu \mathrm{g} / \mathrm{L})$ & $<11$ & - & - \\
\hline Iron-diss $(\mu \mathrm{g} / \mathrm{L})$ & 13 & - & - \\
\hline Lead-NWQL $(\mu \mathrm{g} / \mathrm{L})$ & 3 & $3.3 \pm 1.8$ & yes \\
\hline Lead-OARDC $(\mu \mathrm{g} / \mathrm{L})$ & $<20$ & - & - \\
\hline Lithium $(\mu \mathrm{g} / \mathrm{L})$ & 13 & - & - \\
\hline Manganese-total $(\mu \mathrm{g} / \mathrm{L})$ & $<1$ & _ & - \\
\hline Manganese-diss $(\mu \mathrm{g} / \mathrm{L})$ & 3 & _ & - \\
\hline Mercury-NWQL $(\mu \mathrm{g} / \mathrm{L})$ & - & - & - \\
\hline Molybdenum $(\mu \mathrm{g} / \mathrm{L})$ & 21 & - & - \\
\hline Nickel $(\mu \mathrm{g} / \mathrm{L})$ & 10 & - & - \\
\hline Selenium-NWQL $(\mu \mathrm{g} / \mathrm{L})$ & 8 & $7.4 \pm 2.8$ & yes \\
\hline Selenium-OARDC $(\mu \mathrm{g} / \mathrm{L})$ & $<93$ & - & - \\
\hline Silver $(\mu \mathrm{g} / \mathrm{L})$ & $<10$ & - & - \\
\hline Strontium $(\mu \mathrm{g} / \mathrm{L})$ & 671 & $705 \pm 85$ & yes \\
\hline Vanadium $(\mu \mathrm{g} / \mathrm{L})$ & 24 & 2.6 & no \\
\hline $\operatorname{Zinc}(\mu \mathrm{g} / \mathrm{L})$ & 23 & - & - \\
\hline
\end{tabular}

adiss, dissolved.

b..., no data or not evaluated

cBold values indicate analyses that do not meet acceptance criteria. 
Table F-4 (continued). Quality control analyses of blind samples, sampling round 1.

\begin{tabular}{|c|c|c|c|}
\hline Constituenta & $\begin{array}{c}\text { Sample } \\
\text { C } \\
\text { data }\end{array}$ & $\begin{array}{c}\text { Most probable } \\
\text { value } \\
( \pm 2 \mathrm{f})\end{array}$ & $\begin{array}{c}\text { Meets } \\
\text { QC criteria }\end{array}$ \\
\hline $\begin{array}{l}\text { Sample date } \\
\text { Sample time }\end{array}$ & $\begin{array}{c}950707 \\
1800\end{array}$ & $\begin{array}{l}-b \\
-\end{array}$ & - \\
\hline $\begin{array}{l}\text { OARDC lab numbers } \\
\text { pH (standard units) }\end{array}$ & $\begin{array}{l}1137 \\
7.9 c\end{array}$ & $6.9 \pm 0.6$ & no \\
\hline Specific cond $(\mu \mathrm{S} / \mathrm{cm})$ & 130 & $134 \pm 10$ & yes \\
\hline Acidity (meq/L) & $<0.1$ & - & - \\
\hline Calcium $(\mathrm{mg} / \mathrm{L})$ & 10.0 & $9.1+0.8$ & yes \\
\hline Magnesium (mg/L) & 3.4 & $3.5+0.4$ & yes \\
\hline Sodium (mg/L) & 9.1 & $9.1 \pm 0.8$ & yes \\
\hline Potassium (mg/L) & 0.4 & 0.7 & no \\
\hline Alkalinity (mg/L as $\left.\mathrm{CaCO}_{3}\right)$ & 11 & 7.8 & no \\
\hline Sulfate-IC (mg/L) & 329 & 27.8 & no \\
\hline Sulfate-ICP (mg/L) & 26.0 & $27.8 \pm 3.4$ & yes \\
\hline Chloride (mg/L) & 28.0 & $13.0 \pm 2.4$ & no \\
\hline Fluoride (mg/L) & $<1.0$ & $0.3 \pm 0.06$ & yes \\
\hline Silicon $(\mathbf{m g} / \mathrm{L})$ & 1.4 & $1.6 \pm 0.2$ & yes \\
\hline Residue on evaporation (mg/L) & 6 & $78 \pm 16$ & no \\
\hline Aluminum-total (mg/L) & $<30$ & - & - \\
\hline Aluminum-diss (mg/L) & $<30$ & - & - \\
\hline Antimony $(\mu g / L)$ & $<106$ & - & - \\
\hline Arsenic-NWQL $(\mu \mathrm{g} / \mathrm{L})$ & 9 & $0.6 \pm 2.3$ & - \\
\hline Arsenic-OARDC $(\mu \mathrm{g} / \mathrm{L})$ & $<40$ & - & - \\
\hline $\operatorname{Barium}(\mu \mathrm{g} / \mathrm{L})$ & 3 & - & _ \\
\hline Beryllium $(\mu \mathrm{g} / \mathrm{L})$ & $<1$ & - & - \\
\hline Boron $(\mu \mathrm{g} / \mathrm{L})$ & 31 & $44 \pm 78$ & yes \\
\hline Cadmium $(\mu \mathrm{g} / \mathrm{L})$ & 2 & - & - \\
\hline Chromium $(\mu \mathrm{g} / \mathrm{L})$ & 7 & - & - \\
\hline Cobalt $(\mu \mathrm{g} / \mathrm{L})$ & $<6$ & - & - \\
\hline Copper $(\mu \mathrm{g} / \mathrm{L})$ & 8 & - & - \\
\hline Iron-total $(\mu \mathrm{g} / \mathrm{L})$ & 20 & - & - \\
\hline Iron-diss $(\mu \mathrm{g} / \mathrm{L})$ & $<11$ & - & - \\
\hline Lead-NWQL $(\mu \mathrm{g} / \mathrm{L})$ & 9 & $1 \pm 2.7$ & yes \\
\hline Lead-OARDC $(\mu \mathrm{g} / \mathrm{L})$ & $<20$ & - & - \\
\hline Lithium $(\mu \mathrm{g} / \mathrm{L})$ & $<4$ & - & - \\
\hline Manganese-total $(\mu \mathrm{g} / \mathrm{L})$ & $<1$ & - & - \\
\hline Manganese-diss $(\mu \mathrm{g} / \mathrm{L})$ & $<1$ & - & - \\
\hline Mercury-NWQL $(\mu \mathrm{g} / \mathrm{L})$ & 1.4 & $1.3 \pm 0.4$ & yes \\
\hline Molybdenum $(\mu \mathrm{g} / \mathrm{L})$ & $<11$ & - & - \\
\hline Nickel $(\mu g / L)$ & 4 & - & - \\
\hline Selenium-NWQL $(\mu \mathrm{g} / \mathrm{L})$ & 10 & $9.8 \pm 3.2$ & yes \\
\hline Selenium-OARDC $(\mu \mathrm{g} / \mathrm{L})$ & $<93$ & - & - \\
\hline Silver $(\mu \mathrm{g} / \mathrm{L})$ & $<10$ & - & - \\
\hline Strontium $(\mu \mathrm{g} / \mathrm{L})$ & 175 & $177 \pm 18$ & yes \\
\hline Vanadium $(\mu \mathrm{g} / \mathrm{L})$ & 25 & 4.4 & no \\
\hline $\operatorname{Zinc}(\mu \mathrm{g} / \mathrm{L})$ & 4 & - & - \\
\hline
\end{tabular}

adiss, dissolved.

b.-. no data or not evaluated

cBold values indicate analyses that do not meet acceptance criteria. 
Table F-5. Quality control analyses of blind samples, sampling round 2.

\begin{tabular}{|c|c|c|c|c|}
\hline Constituent $\mathbf{a}^{\mathbf{a}}$ & $\begin{array}{c}\text { Sample } \\
\text { A2 }\end{array}$ & $\begin{array}{c}\text { Most probable } \\
\text { value }( \pm 2 f)\end{array}$ & $\begin{array}{c}\text { Meets } \\
\text { 2f Criteria }\end{array}$ & $\begin{array}{l}\text { Relative percent } \\
\text { deviation }\end{array}$ \\
\hline Sample date & 951020 & $-b$ & - & - \\
\hline Sample time & 1205 & - & - & - \\
\hline OARDC lab numbers & 1177,1178 & & & \\
\hline pH (standard units) & $4.4 c$ & $2.5 \pm 0.22$ & No & 55.1 \\
\hline Specific Cond $(\mu \mathrm{S} / \mathrm{cm})$ & 22 & $4,000 \pm 460$ & No & .197 .8 \\
\hline Acidity $(\mathrm{meq} / \mathrm{L})$ & 0.44 & - & - & - \\
\hline Calcium (mg/L) & 295 & $330 \mathrm{~d}$ & Yes & -11.2 \\
\hline Magnesium (mg/L) & 123 & 112 & Yes & 9.4 \\
\hline Sodium (mg/L) & 25.4 & $26^{d}$ & Yes & 2.3 \\
\hline Potassium $(\mathrm{mg} / \mathrm{L})$ & 3.5 & - & - & - \\
\hline Alkalinity (mg/L CaCO$)_{3}$ ) & 0 & 0 & Yes & - \\
\hline Sulfate-IC (mg/L) & 125 & $27.6 \pm 3.4$ & No & 127.7 \\
\hline Sulfate-ICP $(\mathrm{mg} / \mathrm{L})$ & 2000 & $1,980 \pm 490$ & Yes & 1 \\
\hline Chloride (mg/L) & 20.2 & $13 \pm 2.4$ & No & 43.4 \\
\hline Fluoride (mg/L) & $<0.1$ & $0.25 \pm 0.06$ & No & - \\
\hline Silicon $(\mathrm{mg} / \mathrm{L})$ & 39.2 & $46 \pm 6.6$ & No & -16 \\
\hline Residue on evaporation (mg/L) & 555 & - & - & - \\
\hline Aluminum-diss (mg/L) & 20.3 & $20.6 \pm 3.6$ & Yes & -1.5 \\
\hline Antimony $(\mu \mathrm{g} / \mathrm{L})$ & $<106$ & - & - & - \\
\hline Arsenic-OARDC $(\mu \mathrm{g} / \mathrm{L})$ & $<40$ & $56 \pm 28.1$ & - & - \\
\hline Barium $(\mu \mathrm{g} / \mathrm{L})$ & 5 & $1^{d}$ & - & 133.3 \\
\hline Beryllium $(\mu \mathrm{g} / \mathrm{L})$ & 12 & $14 \pm 5.4$ & Yes & -15.4 \\
\hline Boron $(\mu \mathrm{g} / \mathrm{L})$ & 55 & $15 \mathrm{~d}$ & No & 114.3 \\
\hline Cadmium $(\mu \mathrm{g} / \mathrm{L})$ & 125 & $130 \pm 28$ & Yes & -3.9 \\
\hline Chromium $(\mu \mathrm{g} / \mathrm{L})$ & 24 & $34^{d}$ & No & -34.5 \\
\hline Cobalt $(\mu \mathrm{g} / \mathrm{L})$ & 148 & $170 \mathrm{~d}$ & - & -13.8 \\
\hline Copper $(\mu \mathrm{g} / \mathrm{L})$ & 4620 & $5,100 \pm 410$ & No & -9.9 \\
\hline Iron-Total $(\mu \mathrm{g} / \mathrm{L})$ & ND & - & - & - \\
\hline Iron-Diss $(\mu \mathrm{g} / \mathrm{L})$ & 99700 & $100-145,000$ & Yes & - \\
\hline Lead-OARDC $(\mu \mathrm{g} / \mathrm{L})$ & 46 & $43 \pm 53$ & Yes & 6.7 \\
\hline Lithium $(\mu \mathrm{g} / \mathrm{L})$ & 51 & $47 \pm 31$ & Yes & 8.2 \\
\hline Manganese-total $(\mu \mathrm{g} / \mathrm{L})$ & ND & - & - & - \\
\hline Manganese-diss $(\mu \mathrm{g} / \mathrm{L})$ & 83600 & $87,300 \pm 6400$ & Yes & -4.3 \\
\hline Mercury-NWQL $(\mu \mathrm{g} / \mathrm{L})$ & ND & - & - & - \\
\hline Molybdenum $(\mu \mathrm{g} / \mathrm{L})$ & 22 & - & - & - \\
\hline Nickel $(\mu \mathrm{g} / \mathrm{L})$ & 220 & 190 & - & 14.6 \\
\hline Selenium-OARDC $(\mu \mathrm{g} / \mathrm{L})$ & 160 & - & - & - \\
\hline Silver $(\mu \mathrm{g} / \mathrm{L})$ & $<10$ & - & - & - \\
\hline Strontium $(\mu \mathrm{g} / \mathrm{L})$ & 398 & $1,570 \pm 156$ & No & -119.1 \\
\hline Vanadium $(\mu \mathrm{g} / \mathrm{L})$ & $<5$ & - & - & - \\
\hline $\operatorname{Zinc}(\mu \mathrm{g} / \mathrm{L})$ & 43890 & $44,000 \pm 7400$ & - & -0.25 \\
\hline
\end{tabular}

adiss, dissolved.

b--, no data or not evaluated.

cBold values indicate analyses that do not meet acceptance criteria.

dData generated by NWQL (personal communication, Keith Long, U.S. Geological Survey, 1996) 
Table F-5 (continued). Quality control analyses of blind samples, sampling round 2.

\begin{tabular}{|c|c|c|c|c|}
\hline Constituent $^{\mathbf{a}}$ & $\begin{array}{c}\text { Sample } \\
\text { B2 }\end{array}$ & $\begin{array}{c}\text { Most probable } \\
\text { value }( \pm 2 f)\end{array}$ & $\begin{array}{c}\text { Meets } \\
\text { 2f criteria }\end{array}$ & $\begin{array}{c}\text { Relative } \\
\text { deviation (\%) }\end{array}$ \\
\hline$\overline{\text { Sample date }}$ & 951020 & $:-\mathbf{b}$ & - & - \\
\hline Sample time & 1210 & - & - & - \\
\hline OARDC lab numbers & 1179,1180 & & & \\
\hline pH (standard units) & 4.2 & - & - & - \\
\hline Specific Cond $(\mu \mathrm{S} / \mathrm{cm})$ & 18 & - & - & - \\
\hline Acidity (meq/L) & 0.39 & - & - & - \\
\hline Calcium (mg/L) & 21 & $20.9 \pm 2.4$ & Yes & 0.5 \\
\hline Magnesium (mg/L) & $11.9 c$ & $10.1 \pm 0.4$ & No & 16.9 \\
\hline Sodium (mg/L) & 19.6 & $20 \pm 2.5$ & Yes & -2.0 \\
\hline Potassium (mg/L) & 1.7 & $2.1 \pm 0.4$ & Yes & -21.5 \\
\hline Alkalinity $(\mathrm{mg} / \mathrm{L} \mathrm{CaCO})$ & 0 & 0 & Yes & - \\
\hline Sulfate-IC (mg/L) & 32 & $27.8 \pm 3.4$ & No & 14.1 \\
\hline Sulfate-ICP (mg/L) & 69 & $27.8 \pm 3.4$ & No & 85.1 \\
\hline Chloride (mg/L) & 18.4 & $13 \pm 2.4$ & No & 34.4 \\
\hline Fluoride (mg/L) & $<0.1$ & $0.25 \pm 0.06$ & No & -. \\
\hline Silicon (mg/L) & 10.4 & $11.9 \pm 1.3$ & No & -13.0 \\
\hline $\mathrm{ROE}(\mathrm{mg} / \mathrm{L})$ & 490 & - & - & - \\
\hline Aluminum-diss (mg/L) & 0.26 & $0.08 \vee 0.04$ & No & $\cdots$ \\
\hline Antimony $(\mu \mathrm{g} / \mathrm{L})$ & $<106$ & $5.5 \pm 1.9$ & - & - \\
\hline Arsenic-OARDC $(\mu \mathrm{g} / \mathrm{L})$ & $<40,87$ & $6.9 \pm 2.8$ & - & - \\
\hline Barium $(\mu \mathrm{g} / \mathrm{L})$ & 92 & $98.5 \pm 6.3$ & Yes & -6.8 \\
\hline Beryllium $(\mu g / L)$ & $\mathbf{3}$ & $4.8 \pm 0.8$ & No & -46.2 \\
\hline Boron $(\mu \mathrm{g} / \mathrm{L})$ & 145 & $151 \pm 42$ & Yes & -4.1 \\
\hline Cadmium $(\mu \mathrm{g} / \mathrm{L})$ & 1.5 & $2.2 \pm 0.4$ & No & -37.8 \\
\hline Chromium $(\mu \mathrm{g} / \mathrm{L})$ & 10.5 & $10.4 \pm 3.2$ & Yes & 1.4 \\
\hline Cobalt $(\mu \mathrm{g} / \mathrm{L})$ & $<6$ & $4.4 \pm 1.5$ & - & - \\
\hline Copper $(\mu g / L)$ & 21.5 & $6.0 \pm 3.5$ & No & 112.7 \\
\hline Iron-Total $(\mu \mathrm{g} / \mathrm{L})$ & $\mathrm{ND}$ & - & - & - \\
\hline Iron-Diss $(\mu \mathrm{g} / \mathrm{L})$ & 900 & $474 \pm 36$ & No & 62.0 \\
\hline Lead-OARDC $(\mu \mathrm{g} / \mathrm{L})$ & $<2$ & $5 \pm 2.7$ & - & - \\
\hline Lithium $(\mu \mathrm{g} / \mathrm{L})$ & 30 & $20 \pm 2.5$ & No & 40.0 \\
\hline Manganese-total $(\mu \mathrm{g} / \mathrm{L})$ & ND & $220 \pm 30$ & - & - \\
\hline Manganese-diss $(\mu \mathrm{g} / \mathrm{L})$ & 630 & $220 \pm 30$ & No & 96.5 \\
\hline Mercury-NWQL $(\mu \mathrm{g} / \mathrm{L})$ & ND & - & - & - \\
\hline Molybdenum $(\mu \mathrm{g} / \mathrm{L})$ & 23.5 & $11.8 \pm 4.0$ & No & 66.3 \\
\hline Nickel $(\mu \mathrm{g} / \mathrm{L})$ & $<4,6$ & $10 \pm 4.9$ & - & - \\
\hline Selenium-OARDC $(\mu \mathrm{g} / \mathrm{L})$ & $<93$ & $6 \pm 2.9$ & - & - \\
\hline Silver $(\mu \mathrm{g} / \mathrm{L})$ & $<10$ & $1.4 \pm 1.3$ & - & - \\
\hline Strontium $(\mu \mathrm{g} / \mathrm{L})$ & 260 & $265 \pm 22$ & Yes & -1.9 \\
\hline Vanadium $(\mu \mathrm{g} / \mathrm{L})$ & $<5$ & $4.7 \pm 3.6$ & - & - \\
\hline $\operatorname{Zinc}(\mu \mathrm{g} / \mathrm{L})$ & 356 & $176 \pm 19$ & No & 67.7 \\
\hline
\end{tabular}

adiss, dissolved.

b.-, no data or not evaluated.

cBold values indicate analyses that do not meet acceptance criteria. 
Table F-6. Quality control analyses of blind sample A3 (sampling round 3).

\begin{tabular}{|c|c|c|c|c|}
\hline Constituent $^{\mathbf{a}}$ & $\begin{array}{c}\text { Sample } \\
\text { A3 }\end{array}$ & $\begin{array}{l}\text { Most probable } \\
\text { value }( \pm 2 f)\end{array}$ & $\begin{array}{l}\text { Meets 2f } \\
\text { criteria }\end{array}$ & $\begin{array}{c}\text { Relative } \\
\text { deviation (\%) }\end{array}$ \\
\hline Sample date \& time & 960118@1030 & & & \\
\hline Sample round & 3 & & & \\
\hline OARDC lab numbers & 1197 & & & \\
\hline $\mathrm{pH}$ (standard units) & 6.3 & $6.9 \pm 0.6$ & Yes & -9.1 \\
\hline Specific cond $(\mu S / \mathrm{cm})$ & $149 c$ & $134 \pm 10$ & No & 10.6 \\
\hline Acidity (meq/L) & 0.02 & $-\mathrm{b}$ & - & - \\
\hline Calcium (mg/L) & 279 & 330 & - & -16.8 \\
\hline Magnesium (mg/L) & 116 & 112 & yes & 3.5 \\
\hline Sodium (mg/L) & 26.5 & 26 & yes & 1.9 \\
\hline Potassium (mg/L) & 3.8 & - & - & - \\
\hline Alkalinity (mg/L as $\mathrm{CaCO}_{3}$ ) & 8 & $8.0 \pm 2.2$ & Yes & 0 \\
\hline Sulfate-IC (mg/L) & 28 & $27.6 \pm 3.4$ & Yes & 1.4 \\
\hline Sulfate-ICP (mg/L) & 884 & $1980 \pm 490$ & Yes & -5 \\
\hline Chloride (mg/L) & 25.9 & - & - & - \\
\hline Fluoride (mg/L) & $<0.1$ & - & - & - \\
\hline Silicon $(m g / L)$ & 39.9 & $46 \pm 6.6$ & Yes & -14.2 \\
\hline Residue on evaporation (mg/L) & 108 & $78 \pm 16$ & No & - \\
\hline Aluminum-total (mg/L) & 21.9 & $20.6 \pm 3.6$ & Yes & 6.1 \\
\hline Aluminum-diss (mg/L) & 22.5 & $20.6 \pm 3.6$ & Yes & 8.8 \\
\hline Antimony $(\mu \mathrm{g} / \mathrm{L})$ & $<100$ & - & - & - \\
\hline Arsenic-OARDC $(\mu \mathrm{g} / \mathrm{L})$ & $<40$ & $56 \pm 28$ & - & - \\
\hline Barium $(\mu \mathrm{g} / \mathrm{L})$ & 5.5 & 1 & - & 138.5 \\
\hline Beryllium $(\mu \mathrm{g} / \mathrm{L})$ & 14.5 & $14 \pm 5.4$ & Yes & 3.5 \\
\hline Boron $(\mu \mathrm{g} / \mathrm{L})$ & 35 & 15 & - & 80 \\
\hline Cadmium $(\mu \mathrm{g} / \mathrm{L})$ & 131 & $130 \pm 28$ & Yes & 0. \\
\hline Chromium $(\mu \mathrm{g} / \mathrm{L})$ & 21 & 34 & No & -47.3 \\
\hline Cobalt $(\mu \mathrm{g} / \mathrm{L})$ & 159 & 170 & Yes & -6.7 \\
\hline Copper $(\mu g / L)$ & 4934 & $5100 \pm 410$ & Yes & -3.3 \\
\hline Iron-total $(\mu \mathrm{g} / \mathrm{L})$ & 132900 & $100-145000$ & Yes & - \\
\hline Iron-diss $(\mu \mathrm{g} / \mathrm{L})$ & 121300 & $100-145000$ & Yes & - \\
\hline Lead-OARDC $(\mu \mathrm{g} / \mathrm{L})$ & 98 & $43 \pm 53$ & Yes & 78 \\
\hline Lithium $(\mu \mathrm{g} / \mathrm{L})$ & 44 & $47 \pm 31$ & Yes & -6.6 \\
\hline Manganese-total $(\mu \mathrm{g} / \mathrm{L})$ & 91100 & - & - & - \\
\hline Manganese-diss $(\mu \mathrm{g} / \mathrm{L})$ & 86400 & $87300 \pm 6400$ & Yes & -1 \\
\hline Mercury-NWQL $(\mu \mathrm{g} / \mathrm{L})$ & ND & - & - & - \\
\hline Molybdenum $(\mu \mathrm{g} / \mathrm{L})$ & 26 & - & - & - \\
\hline $\operatorname{Nickel}(\mu \mathrm{g} / \mathrm{L})$ & 236 & 190 & - & 21.6 \\
\hline Selenium-OARDC $(\mu \mathrm{g} / \mathrm{L})$ & $<93$ & - & - & - \\
\hline Silver $(\mu \mathrm{g} / \mathrm{L})$ & $<10,15$ & - & - & - \\
\hline Strontium $(\mu g / L)$ & 1240 & $1,570 \pm 160$ & No & -23.5 \\
\hline Vanadium $(\mu \mathrm{g} / \mathrm{L})$ & $<5$ & - & - & - \\
\hline $\operatorname{Zinc}(\mu \mathrm{g} / \mathrm{L})$ & 43,400 & $44,000 \pm 7400$ & Yes & -1.4 \\
\hline
\end{tabular}

adiss, dissolved.

b--, no data or not evaluated.

cBold numbers indicate analyses that do not meet acceptance criteria. 
Table F-6 (continued). Quality control analyses of blind sample B3 (sampling round 3).

\begin{tabular}{|c|c|c|c|c|}
\hline Constituenta & $\begin{array}{c}\text { Sample } \\
\text { B3 } \\
\end{array}$ & $\begin{array}{c}\text { Most probable } \\
\text { number }( \pm 2 f)\end{array}$ & $\begin{array}{c}\text { Meets 2f } \\
\text { criteria }\end{array}$ & $\begin{array}{c}\text { Relative } \\
\text { deviation }(\%)\end{array}$ \\
\hline Sample date \& time & $960118 @ 1035$ & $\therefore$ & & \\
\hline Sample round & 3 & & & \\
\hline OARDC lab numbers & 1198 & & & \\
\hline pH (standard units) & 2.3 & $2.5 \pm 0.2$ & Yes & -8.3 \\
\hline Specific cond $(\mu \mathrm{S} / \mathrm{cm})$ & $4500 c$ & $4,000 \pm 460$ & No & 11.8 \\
\hline Acidity (meq/L) & 20 & $18 \pm 1.8$ & No & 10.5 \\
\hline Calcium (mg/L) & 361 & 330 & - & 9 \\
\hline Magnesium (mg/L) & 117 & 112 & Yes & 4.4 \\
\hline Sodium (mg/L) & 26.6 & 26 & Yes & 2.3 \\
\hline Potassium (mg/L) & 3.7 & $-b$ & - & - \\
\hline Alkalinity $\left(\mathrm{mg} / \mathrm{L}\right.$ as $\mathrm{CaCO}_{3}$ ) & 0 & - & - & - \\
\hline Sulfate-IC $(\mathbf{m g} / \mathrm{L})$ & 1933 & $1,980 \pm 490$ & Yes & -2.4 \\
\hline Sulfate-ICP (mg/L) & 2070 & $1,980 \pm 490$ & Yes & 4.4 \\
\hline Chloride (mg/L) & 15.1 & $7 \pm 6$ & No & 73.3 \\
\hline Fuoride (mg/L) & 3.7 & - & - & - \\
\hline Silicon $(\mathrm{mg} / \mathrm{L})$ & 39.9 & $46 \pm 6.6$ & Yes & -14.2 \\
\hline $\operatorname{ROE}(\mathbf{m g} / \mathrm{L})$ & 2924 & - & - & - \\
\hline Aluminum-total (mg/L) & 22.2 & $20.6 \pm 3.6$ & Yes & 7.5 \\
\hline Aluminum-diss (mg/L) & 22.4 & $20.6 \pm 3.6$ & Yes & 8.4 \\
\hline Antimony $(\mu \mathrm{g} / \mathrm{L})$ & $<100$ & - & - & - \\
\hline Arsenic-OARDC $(\mu \mathrm{g} / \mathrm{L})$ & $100,<40$ & $56 \pm 28$ & No & - \\
\hline Barium $(\mu \mathrm{g} / \mathrm{L})$ & 5.5 & 1 & - & 138.5 \\
\hline Beryllium $(\mu \mathrm{g} / \mathrm{L})$ & 14.5 & $14 \pm 5.4$ & Yes & 3.5 \\
\hline Boron $(\mu \mathrm{g} / \mathrm{L})$ & 36 & 15 & - & 82.4 \\
\hline Cadmium $(\mu \mathrm{g} / \mathrm{L})$ & 130 & $130 \pm 28$ & Yes & 0 \\
\hline Chromium $(\mu \mathrm{g} / \mathrm{L})$ & 21 & 34 & No & -47.3 \\
\hline Cobalt $(\mu \mathrm{g} / \mathrm{L})$ & 153 & 170 & - & -10.5 \\
\hline Copper $(\mu g / L)$ & 4930 & $5,100 \pm 410$ & Yes & -3.4 \\
\hline Iron-total $(\mu \mathrm{g} / \mathrm{L})$ & 134800 & $100-145,000$ & Yes & - \\
\hline Iron-diss $(\mu \mathrm{g} / \mathrm{L})$ & 122800 & $100-145,000$ & Yes & - \\
\hline Lead-OARDC $(\mu \mathrm{g} / \mathrm{L})$ & 74 & $43 \pm 53$ & Yes & 53 \\
\hline Lithium $(\mu \mathrm{g} / \mathrm{L})$ & 50 & $47 \pm 31$ & Yes & 6.2 \\
\hline Manganese-total $(\mu \mathrm{g} / \mathrm{L})$ & 92400 & $87,300 \pm 6,400$ & Yes & 5.7 \\
\hline Manganese-diss $(\mu \mathrm{g} / \mathrm{L})$ & 86800 & $87,300 \pm 6,400$ & Yes & -0.6 \\
\hline Mercury-NWQL $(\mu \mathrm{g} / \mathrm{L})$ & $\mathrm{ND}$ & - & - & - \\
\hline Molybdenum $(\mu \mathrm{g} / \mathrm{L})$ & $<10$ & - & - & - \\
\hline $\operatorname{Nickel}(\mu \mathrm{g} / \mathrm{L})$ & 232 & 190 & - & 19.9 \\
\hline Selenium-OARDC $(\mu \mathrm{g} / \mathrm{L})$ & 114 & - & - & - \\
\hline Silver $(\mu g / L)$ & $19,<10$ & - & - & - \\
\hline Strontium $(\mu \mathrm{g} / \mathrm{L})$ & 1,525 & $1,570 \pm 160$ & Yes & -2.9 \\
\hline Vanadium $(\mu \mathrm{g} / \mathrm{L})$ & $<5$ & - & - & - \\
\hline $\operatorname{Zinc}(\mu g / L)$ & 44,200 & $44,000 \pm 7400$ & Yes & 0.5 \\
\hline
\end{tabular}

adiss, dissolved.

b-., no data or not evaluated.

cBold numbers indicate analyses that do not meet acceptance criteria. 
Table F-6 (continued). Quality control analyses of blind sample C3 (sampling round 3).

\begin{tabular}{|c|c|c|c|c|}
\hline Constituent $^{2}$ & $\begin{array}{c}\text { Sample } \\
\text { C3 }\end{array}$ & $\begin{array}{l}\text { Most probable } \\
\text { number }( \pm 2 f)\end{array}$ & $\begin{array}{l}\text { Meets 2f } \\
\text { criteria }\end{array}$ & $\begin{array}{c}\text { Relative } \\
\text { deviation (\%) }\end{array}$ \\
\hline Sample date \& time & 960118@1130 & & & \\
\hline $\begin{array}{l}\text { Sample round } \\
\text { OARDC lab numbers }\end{array}$ & $\begin{array}{c}3 \\
1109\end{array}$ & b & & 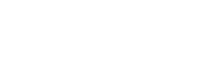 \\
\hline $\begin{array}{l}\text { pH (standard units) } \\
\text { pH lab numbers }\end{array}$ & $\begin{array}{c}1199 \\
6.4\end{array}$ & $6.9 \pm 0.6$ & $\overline{\text { Yes }}$ & $\overline{-7.5}$ \\
\hline Specific cond $(\mu S / \mathrm{cm})$ & $149 c$ & $134 \pm 10$ & No & 10.6 \\
\hline Acidity (meq/L) & 0.02 & - & - & - \\
\hline Calcium (mg/L) & 22.2 & $21.1 \pm 2.0$ & Yes & 5.1 \\
\hline Magnesium (mg/L) & 6.3 & $5.8 \pm 0.5$ & Yes & 7.8 \\
\hline Sodium (mg/L) & 37.5 & $35.5 \pm 3.0$ & Yes & 5.5 \\
\hline Potassium (mg/L) & 3.04 & $3.0 \pm 0.4$ & Yes & 1.3 \\
\hline Alkalinity (mg/L as $\mathrm{CaCO} 3$ ) & 8 & $8.0 \pm 2.2$ & Yes & 2.5 \\
\hline Sulfate-IC (mg/L) & 27 & $27.6 \pm 3.4$ & Yes & -2.2 \\
\hline Sulfate-ICP (mg/L) & 56.7 & - & - & - \\
\hline Chloride (mg/L) & 24.4 & $13 \pm 2.4$ & No & 61 \\
\hline Fluoride (mg/L) & $<0.1$ & $0.25 \pm 0.06$ & No & -- \\
\hline Silicon $(\mathrm{mg} / \mathrm{L})$ & 8 & $9.2 \pm 1.7$ & Yes & -13.4 \\
\hline $\operatorname{ROE}(\mathrm{mg} / \mathrm{L})$ & 3433 & - & - & - \\
\hline Aluminum-total (mg/L) & $<30$ & $50 \pm 24$ & Yes & - \\
\hline Aluminum-diss (mg/L) & 50 & $50 \pm 24$ & Yes & 0 \\
\hline Antimony $(\mu \mathrm{g} / \mathrm{L})$ & $<100$ & $0.55 \pm 1.9$ & Yes & - \\
\hline Arsemic-OARDC $(\mu \mathrm{g} / \mathrm{L})$ & $<40$ & $0.55 \pm 2.28$ & Yes & - \\
\hline Barium $(\mu \mathrm{g} / \mathrm{L})$ & 32.5 & $34 \pm 3.8$ & Yes & -4.5 \\
\hline Beryllium $(\mu \mathrm{g} / \mathrm{L})$ & $<1$ & $0.12 \pm 0.26$ & Yes & - \\
\hline Boron $(\mu \mathrm{g} / \mathrm{L})$ & $<6$ & $11.6 \pm 5.6$ & Yes & - \\
\hline Cadmium $(\mu g / L)$ & $<1$ & $0.34 \pm 0.30$ & Yes & - \\
\hline Chromium $(\mu \mathrm{g} / \mathrm{L})$ & $<2,5$ & $0.68 \pm 2.8$ & - & - \\
\hline Cobalt $(\mu \mathrm{g} / \mathrm{L})$ & $<6$ & $0.74 \pm 2.4$ & - & - \\
\hline Copper $(\mu \mathrm{g} / \mathrm{L})$ & $8,<2$ & $2.7 \pm 2.8$ & No & -- \\
\hline Iron-total $(\mu \mathrm{g} / \mathrm{L})$ & 80 & $10.4 \pm 16.4$ & No & 154 \\
\hline Iron-diss $(\mu \mathrm{g} / \mathrm{L})$ & 60 & $10.4 \pm 16.4$ & No & 140.9 \\
\hline Lead-OARDC $(\mu \mathrm{g} / \mathrm{L})$ & $<20$ & $1.0 \pm 2.8$ & - & - \\
\hline Lithium $(\mu \mathrm{g} / \mathrm{L})$ & 20 & $18 \pm 5.2$ & Yes & 10.5 \\
\hline Manganese-total $(\mu \mathrm{g} / \mathrm{L})$ & 90 & $25.2+4.4$ & No & 112.5 \\
\hline Manganese-diss $(\mu \mathrm{g} / \mathrm{L})$ & 60 & $25.2 \pm 4.4$ & No & 81.7 \\
\hline Mercury-NWQL $(\mu \mathrm{g} / \mathrm{L})$ & 1.2 & $1.3 \pm 0.4$ & Yes & -8 \\
\hline Molybdenum $(\mu \mathrm{g} / \mathrm{L})$ & 51 & $20.3 \pm 2.1$ & No & 86.1 \\
\hline Nickel $(\mu \mathrm{g} / \mathrm{L})$ & $<4$ & $1.7 \pm 3.4$ & - & - \\
\hline Selenium-OARDC $(\mu \mathrm{g} / \mathrm{L})$ & $<93$ & $1.6 \pm 4.0$ & - & - \\
\hline Silver $(\mu \mathrm{g} / \mathrm{L})$ & $22,<10$ & $0.37 \pm 2.8$ & No & $\cdots$ \\
\hline Strontium $(\mu \mathrm{g} / \mathrm{L})$ & 187 & $181 \pm 22$ & Yes & 3.3 \\
\hline Vanadium $(\mu \mathrm{g} / \mathrm{L})$ & $<5$ & $1.0 \pm 4.8$ & Yes & - \\
\hline $\operatorname{Zinc}(\mu \mathrm{g} / \mathrm{L})$ & 85 & $72 \pm 9.6$ & No & 16.6 \\
\hline
\end{tabular}

adiss, dissolved.

b--, no data or not evaluated.

cBold numbers indicate analyses that do not meet acceptance criteria. 
Table F-7. Quality control analyses of split and replicate samples, sampling round 1. Results are given in relative percent deviation between OARDC and NWQL split samples OARDC split samples.

\begin{tabular}{|c|c|c|c|c|c|c|c|}
\hline \multirow[b]{2}{*}{ Constituenta $^{\mathbf{a}}$} & \multicolumn{2}{|c|}{ TU-170 } & \multicolumn{2}{|c|}{ TU-107 } & \multicolumn{2}{|c|}{ TU-108 } & \multirow{2}{*}{$\begin{array}{c}\text { M-106 } \\
\text { (ref split) } \\
\text { OARDC }\end{array}$} \\
\hline & OARDC & $\begin{array}{l}\text { OARDC- } \\
\text { NWQL }\end{array}$ & OARDC & $\begin{array}{l}\text { OARDC- } \\
\text { NWQL }\end{array}$ & OARDC & $\begin{array}{l}\text { OARDC- } \\
\text { NWQL }\end{array}$ & \\
\hline $\begin{array}{l}\text { Sample date } \\
\text { Sample time }\end{array}$ & $\begin{array}{c}950612 \\
1440,1445\end{array}$ & $\begin{array}{c}950612 \\
1440,1445\end{array}$ & $\begin{array}{c}950706 \\
1600,1605\end{array}$ & $\begin{array}{c}950706 \\
1600,1605\end{array}$ & $\begin{array}{c}950621 \\
1345,1350\end{array}$ & $\begin{array}{c}950621 \\
1345,1350\end{array}$ & $\begin{array}{c}950707 \\
1159,1800\end{array}$ \\
\hline OARDC lab numbers & 1016,1019 & 1016,1019 & 1096,1099 & 1096,1099 & 1048,1051 & 1048,1051 & 1131,1137 \\
\hline pH (standard units) & -1.3 & -4.6 & 3.0 & 6.2 & 0.0 & -5.3 & $.24 .1 \mathrm{c}$ \\
\hline Specific cond $(\mu \mathrm{S} / \mathrm{cm})$ & 2.8 & 2.6 & -0.6 & -12.2 & 4.0 & -5.4 & 0.0 \\
\hline Acidity (meq/L) & $A^{3}$ & $-\mathrm{b}$ & 18.2 & - & -19.4 & - & $\mathrm{NA}$ \\
\hline Calcium (mg/L) & 9.2 & 5.4 & 1.1 & - & 0.9 & - & 0.0 \\
\hline Magnesium (mg/L) & 8.4 & 6.5 & 0.5 & - & 1.2 & - & 13.7 \\
\hline Sodium (mg/L) & 9.1 & 9.5 & 2.8 & -11.2 & 0.9 & - & -1.1 \\
\hline Potassium (mg/L) & 28.6 & - & 2.8 & - & 1.1 & - & 40.0 \\
\hline Alkalinity $\left(\mathrm{mg} / \mathrm{L} \mathrm{CaCO}_{3}\right)$ & -1.6 & 2.1 & 0.0 & -35.5 & -15.4 & -169 & -20.0 \\
\hline Sulfate-IC (mg/L) & 0.0 & - & 5.0 & - & -0.7 & - & 0.0 \\
\hline Sulfate-ICP (mg/L) & -13.3 & - & 1.9 & _- & 0.8 & - & 20.7 \\
\hline Chloride (mg/L) & 5.9 & - & 0.0 & - & - & - & -7.4 \\
\hline Fluoride (mg/L) & 66.7 & - & $A^{c}$ & - & - & - & A \\
\hline Silicon (mg/L) & 10.3 & - & 1.9 & - & 0.0 & - & 0.0 \\
\hline $\mathrm{ROE}(\mathrm{mg} / \mathrm{L})$ & 18.0 & -43.6 & 2.4 & 1.1 & -4.0 & 4.3 & 90.9 \\
\hline Aluminum-total (mg/L) & $A^{d}$ & A & -0.4 & 16.9 & -40.6 & 72.3 & A \\
\hline Aluminum-diss (mg/L) & A & A & NA & - & -16.4 & 114 & A \\
\hline Antimony $(\mu \mathrm{g} / \mathrm{L})$ & A & - & A & - & A & - & A \\
\hline Arsenic-OARDC $(\mu \mathrm{g} / \mathrm{L})$ & $\mathrm{A}$ & - & $\mathbf{N} \mathbf{A}$ & - & A & - & 66.7 \\
\hline Barium $(\mu \mathrm{g} / \mathrm{L})$ & 9.5 & -1.6 & 0.0 & 7.4 & 8.0 & - & A \\
\hline Beryllium $(\mu \mathrm{g} / \mathrm{L})$ & A & A & A & A & A & - & $\mathbf{N A}$ \\
\hline Boron $(\mu \mathrm{g} / \mathrm{L})$ & 8.7 & -7.3 & 2.8 & -9.7 & 4.1 . & -41.9 & 0.0 \\
\hline Cadmium $(\mu \mathrm{g} / \mathrm{L})$ & A & A & $\mathbf{N A}$ & - & A & - & 66.7 \\
\hline Chromium $(\mu \mathrm{g} / \mathrm{L})$ & A & A & 22.2 & - & NA & - & 25.0 \\
\hline Cobalt $(\mu \mathrm{g} / \mathrm{L})$ & A & A & -11.8 & - & 6.8 & - & A \\
\hline Copper $(\mu \mathrm{g} / \mathrm{L})$ & A & A & 22.2 & - & $\mathbf{N A}$ & - & -28.6 \\
\hline Inon-Total $(\mu \mathrm{g} / \mathrm{L})$ & 5.9 & -2.5 & 0.9 & 5.6 & 1.0 & 13.7 & A \\
\hline Iron-Diss $(\mu \mathrm{g} / \mathrm{L})$ & 8.6 & -0.5 & 2.7 & 17.4 & 1.1 & - & NA \\
\hline Lead-OARDC $(\mu \mathrm{g} / \mathrm{L})$ & $\mathrm{A}$ & A & $\mathrm{A}$ & - & A & - & A \\
\hline Lithium $(\mu \mathrm{g} / \mathrm{L})$ & 0.0 & .63 .2 & 18.8 & 19.7 & 2.1 & - $\cdot$ & A \\
\hline Manganese-total $(\mu \mathrm{g} / \mathrm{L})$ & 2.7 & -20.9 & 0.0 & - & 0.0 & -14.3 & $\mathrm{~A}$ \\
\hline Manganese-diss $(\mu \mathrm{g} / \mathrm{L})$ & 8.3 & 0.0 & 4.1 & 5.9 & 0.9 & - & $\mathbf{N A}$ \\
\hline Molybdenum $(\mu g / \mathrm{L})$ & A & A & $\mathrm{A}$ & $\mathrm{A}$ & $\mathrm{A}$ & - & A \\
\hline Nickel $(\mu \mathrm{g} / \mathrm{L})$ & A & A & 19.0 & $\mathbf{N A}$ & 1.2 & - & 106 \\
\hline Selenium-OARDC $(\mu \mathrm{g} / \mathrm{L})$ & A & $\mathbf{A}$ & A & A & A & - & A \\
\hline Silver $(\mu \mathrm{g} / \mathrm{L})$ & $\mathbf{A}$ & A & A & A & A & - & A \\
\hline Strontium $(\mu \mathrm{g} / \mathrm{L})$ & 8.7 & 3.1 & 2.9 & -0.5 & 1.0 & _ & -0.6 \\
\hline Vanadium $(\mu g / \mathrm{L})$ & A & A & 6.5 & NA & A & - & 21.4 \\
\hline $\operatorname{Zinc}(\mu \mathrm{g} / \mathrm{L})$ & .66 .7 & .80 & 0.0 & $\mathbf{N A}$ & -5.6 & _ & 54.5 \\
\hline
\end{tabular}

adiss, dissolved.

b.-., no data or not evaluated.

cBold numbers indicate analyses that do not meet acceptance criteria.

dA indicates both replicates had concentrations below the detection limit and NA indicates one split had a concentration that was below the detection limit and one split had a concentration above the detection limit precluding calculation of the relative percent deviation. 
Table F-8. Quality control analyses of split and replicate samples (sampling round 3)a.

\begin{tabular}{|c|c|c|c|c|c|}
\hline Constituent & $\begin{array}{c}\text { OARDC } \\
\text { regular }\end{array}$ & $\begin{array}{l}\text { OARDC } \\
\text { laboratory } \\
\text { duplicate }\end{array}$ & $\begin{array}{l}\text { NWQL } \\
\text { split }\end{array}$ & $\begin{array}{c}\text { OARDCl } \\
\text { OARDC } \\
\text { RPD } \\
\text { (percent) }\end{array}$ & $\begin{array}{c}\text { Average } \\
\text { OARDCl } \\
\text { NWQL RPD } \\
\text { (percent) }\end{array}$ \\
\hline Sample Date & 960117 & 960117 & 960117 & $-b$ & - \\
\hline Sample time & 1035 & 1035 & 1035 & - & - \\
\hline Sample round & 3 & 3 & 3 & - & - \\
\hline Sample submitted as & TU-118 & TU-118 & TU-118 & _ & _ \\
\hline OARDC lab numbers & 1187 & 1188 & - & - & $\bar{z}$ \\
\hline pH (standard units) & $4.4 \mathrm{c}$ & 4.4 & 5.7 & $\mathbf{0}$ & -25.7 \\
\hline Specific cond $(\mu \mathrm{S} / \mathrm{cm})$ & 2596 & 2777 & 2960 & -6.7 & -9.7 \\
\hline Acidity (meq/L) & 6.1 & 5.8 & 5.7 & 5 & 4.3 \\
\hline Calcium (mg/L) & 441 & 447 & 420 & -1.4 & 5.6 \\
\hline Magnesium (mg/L) & 213 & 218 & 190 & -2.3 & 12.6 \\
\hline Sodium (mg/L) & 13.1 & 13 & 12 & 0.8 & 8.4 \\
\hline Potassium (mg/L) & 12.7 & 12.6 & 12 & 0.8 & 5.3 \\
\hline Alkalinity $\left(\mathrm{mg} / \mathrm{L}\right.$ as $\mathrm{CaCO}_{3}$ ) & 0 & 0 & 52 & - & - \\
\hline Sulfate-IC $(\mathrm{mg} / \mathrm{L})$ & 2005 & 2029 & 2100 & -1.2 & 4 \\
\hline $\begin{array}{l}\text { Sulfate-ICP }(\mathrm{mg} / \mathrm{L}) \\
\text { Chloride (m } / \mathrm{L})\end{array}$ & $\begin{array}{l}2123 \\
5.5\end{array}$ & $\begin{array}{l}2070 \\
5.6\end{array}$ & $\begin{array}{l}2100 \\
1.8\end{array}$ & $\begin{array}{l}2.5 \\
-1.8\end{array}$ & $\begin{array}{r}-0.2 \\
102\end{array}$ \\
\hline Fuoride (mg/L) & $<0.1$ & $<0.1$ & 0.5 & Accept & Unaccept \\
\hline Bromide (mg/L) & $<0.1$ & $<0.1$ & 0.27 & Accept & Unaccept \\
\hline Silicon (mg/L) & 12.5 & 12.4 & 15 & 0.8 & -18.6 \\
\hline Residue on evap. (mg/L) & 3103 & 3123 & 3180 & -0.6 & -2.1 \\
\hline Aluminum-Total (mg/L) & 0.29 & - & 0.33 & - & -12.9 \\
\hline Aluminum-Diss (mg/L) & 0.37 & 0.41 & 0.33 & -10.3 & 16.7 \\
\hline Arsenic-OARDC ( $\mu \mathrm{g} / \mathrm{L})$ & $<40,120$ & $<40,<40$ & $<1$ & - & - \\
\hline Barium $(\mu g / L)$ & 17 & 17.5 & 19 & -2.9 & -9.7 \\
\hline $\begin{array}{l}\text { Beryllium }(\mu \mathrm{g} / \mathrm{L} \\
\text { Boron }(\mu \mathrm{g} / \mathrm{L})\end{array}$ & $\begin{array}{r}8.5 \\
\mathbf{3 3 2}\end{array}$ & $\begin{array}{c}8 \\
335\end{array}$ & $\begin{array}{c}7 \\
450\end{array}$ & $\begin{array}{c}6.1 \\
-0.9\end{array}$ & $\begin{array}{c}16.4 \\
-29.7\end{array}$ \\
\hline Cadmium $(\mu \mathrm{g} / \mathrm{L})$ & $<1,<1$ & $<1, \quad 1.0$ & 30 & Accept & Unaccept \\
\hline $\begin{array}{l}\text { Chromium }(\mu g / L) \\
\text { Cobalt }(\mu g / L)\end{array}$ & $\begin{array}{c}8 \\
211\end{array}$ & $\begin{array}{l}5.5 \\
227\end{array}$ & $\begin{array}{l}20 \\
90\end{array}$ & $\begin{array}{l}37 \\
-7.3\end{array}$ & $\begin{array}{l}-99.1 \\
83.5\end{array}$ \\
\hline Copper $(\mu \mathrm{g} / \mathrm{L})$ & $<2$ & $<2$ & 30 & Accept & Unaccept \\
\hline Iron-total $(\mu \mathrm{g} / \mathrm{L})$ & 206 & - & 170 & - & 19.2 \\
\hline Iron-diss $(\mu \mathrm{g} / \mathrm{L})$ & 185.4 & 184.6 & 170 & 0.4 & 8.5 \\
\hline Lead-OARDC $(\mu \mathrm{g} / \mathrm{L})$ & 30,67 & $<20,28$ & $<1$ & - & - \\
\hline Lithium $(\mu \mathrm{g} / \mathrm{L})$ & 181 & 183 & 180 & -1.1 & 1.1 \\
\hline Manganese-total $(\mu \mathrm{g} / \mathrm{L})$ & 18.11 & - & 20 & - & -9.9 \\
\hline Manganese-diss $(\mu \mathrm{g} / \mathrm{L})$ & 18.2 & 18.28 & 20 & -0.4 & -9.2 \\
\hline Mercury-NWQL $(\mu g / L)$ & - & - & - & - & - \\
\hline Molybdenum $(\mu \mathrm{g} / \mathrm{L})$ & 16 & $<10$ & $<30$ & Accept & Accept \\
\hline Nickel $(\mu \mathrm{g} / \mathrm{L})$ & 509 & 499 & 550 & 2 & -8.7 \\
\hline Selenium-OÁRDC $(\mu \mathrm{g} / \mathrm{L})$ & 154 & $<93$ & $<1$ & - & - \\
\hline Silver $(\mu \mathrm{g} / \mathrm{L})$ & $<10$ & $<10$ & $<30$ & Accept & Accept \\
\hline Strontium $(\mu \mathrm{g} / \mathrm{L})$ & 3,890 & 3,880 & 3,900 & 0.3 & -0.4 \\
\hline Vanadium $(\mu \mathrm{g} / \mathrm{L})$ & 6 & $<5$ & $<18$ & Accept & Accept \\
\hline $\operatorname{Zinc}(\mu \mathrm{g} / \mathrm{L})$ & 584 & 582 & 690 & $0.3^{2}$ & -16.8 \\
\hline
\end{tabular}

aRelative percent deviation (RPD) for OARDC replicate samples and for OARDC and NWQL split samples. OARDC value used in calculation is average of the two OARDC split samples.

b .., no data or not evaluated;

cBold numbers indicate analyses that do not meet acceptance criteria. 
Table F-8 (continued). Quality control analyses of split and replicate samples (sampling round $3)^{\mathbf{a}}$.

\begin{tabular}{|c|c|c|c|c|c|}
\hline Constituent & $\begin{array}{l}\text { OARDC } \\
\text { regular }\end{array}$ & $\begin{array}{c}\text { OARDC } \\
\text { laboratory } \\
\text { duplicate }\end{array}$ & $\begin{array}{c}\text { NWQL } \\
\text { split }\end{array}$ & $\begin{array}{c}\text { OARDCl } \\
\text { OARDC } \\
\text { RPD } \\
\text { (percent) }\end{array}$ & $\begin{array}{c}\text { Average } \\
\text { OARDCl } \\
\text { NWQL RPD } \\
\text { (percent) }\end{array}$ \\
\hline Sample Date & 960117 & 960117 & 960117 & $-b$ & - \\
\hline Sample time & 1035 & 1035 & 1035 & - & - \\
\hline Sample round & 3 & 3 & 3 & - & - \\
\hline Sample submitted as & TU-105 & TU-105 & TU-105 & - & - \\
\hline OARDC lab numbers & 1195 & 1196 & - & - & - \\
\hline pH (standard units) & $4.2 \mathrm{c}$ & 4.2 & 5.4 & $\mathbf{0}$ & .25 \\
\hline Specific cond $(\mu S / \mathrm{cm})$ & 2990 & 2905 & 3120 & 2.9 & -5.7 \\
\hline Acidity (meq/L) & 10.5 & 10.3 & 9.5 & 1.9 & 9.1 \\
\hline Calcium (mg/L) & 404 & 395 & 410 & 2.3 & -2.6 \\
\hline Magnesium (mg/L) & 197 & 192 & 200 & 2.6 & -2.8 \\
\hline Sodium (mg/L) & 10 & 9.7 & 9.7 & 3.1 & 1.5 \\
\hline Potassium (mg/L) & 13 & 12.5 & 13 & 3.9 & -1.9 \\
\hline Alkalinity (mg/L as $\mathrm{CaCO}_{3}$ ) & 0 & 0 & 54 & - & - \\
\hline Sulfate-IC (mg/L) & 2,040 & 2,050 & 2,200 & -0.5 & -7.3 \\
\hline Sulfate-ICP (mg/L) & 2,160 & 2,110 & 2,200 & 2.3 & -3 \\
\hline Chloride (mg/L) & $<0.1$ & $<0.1$ & 1.1 & Accept & Acoept \\
\hline Fluoride (mg/L) & $<0.1$ & $<0.1$ & 0.4 & Accept & Unaccept \\
\hline Bromide (mg/L) & $<0.1$ & $<0.1$ & $<0.01$ & Accept & Accept \\
\hline Silicon (mg/L) & 11.5 & 11.2 & 14 & 2.6 & -20.9 \\
\hline $\mathrm{ROE}(\mathrm{mg} / \mathrm{L})$ & 3,410 & 3430 & 3,400 & -0.6 & 0.6 \\
\hline Aluminum-Total (mg/L) & $\mathbf{5 0}$ & 50 & 40 & 0 & 22.2 \\
\hline Aluminum-Diss (mg/L) & 70 & 40 & 40 & 54.5 & 31.6 \\
\hline Arsenic-OARDC $(\mu \mathrm{g} / \mathrm{L})$ & $56,<40$ & $41,<40$ & $<1,1$ & - & - \\
\hline Barium $(\mu g / L)$ & 15 & 14.5 & 17 & 3.4 & -14.2 \\
\hline $\begin{array}{l}\text { Beryllium }(\mu \mathrm{g} / \mathrm{L}) \\
\text { Boron }(\mu \mathrm{g} / \mathrm{L})\end{array}$ & $\begin{array}{l}2.5 \\
296\end{array}$ & $\begin{array}{l}2.5 \\
290\end{array}$ & $\begin{array}{l}<2 \\
470\end{array}$ & $\begin{array}{c}\text { Accept } \\
2.1\end{array}$ & $\begin{array}{l}\text { Accept } \\
-46.4\end{array}$ \\
\hline Cadmium $(\mu g / L)$ & $<1$ & $<1$ & 51 & Accept & Unaccept \\
\hline Chromium $(\mu \mathrm{g} / \mathrm{L})$ & 7 & 7.5 & 20 & -6.9 & -93.6 \\
\hline Cobalt $(\mu \mathrm{g} / \mathrm{L})$ & 222 & 230 & $<9$ & -3.5 & Unaccept \\
\hline Copper $(\mu g / L)$ & $\begin{array}{l}<2 \\
3456\end{array}$ & $\begin{array}{l}<2 \\
3486\end{array}$ & $<30$ & Accept & Accept \\
\hline $\begin{array}{l}\text { Iron-total }(\mu \mathrm{g} / \mathrm{L}) \\
\text { Iron-diss }(\mu \mathrm{g} / \mathrm{L})\end{array}$ & $\begin{array}{l}345.6 \\
324.6\end{array}$ & $\begin{array}{l}348.6 \\
317.4\end{array}$ & $\begin{array}{l}280 \\
270\end{array}$ & $\begin{array}{l}-0.9 \\
2.2\end{array}$ & $\begin{array}{l}21.4 \\
17.3\end{array}$ \\
\hline Lead-OARDC $(\mu \mathrm{g} / \mathrm{L})$ & $<20,34$ & $<20,37$ & $<5,<1$ & - & - \\
\hline Lithium $(\mu \mathrm{g} / \mathrm{L})$ & 206 & 199 & 190 & 3.5 & 6.4 \\
\hline $\begin{array}{l}\text { Manganese-total }(\mu \mathrm{g} / \mathrm{L}) \\
\text { Manganese-diss }(\mu \mathrm{g} / \mathrm{L})\end{array}$ & $\begin{array}{l}15.5 \\
15.2\end{array}$ & $\begin{array}{l}15.6 \\
14.9\end{array}$ & $\begin{array}{l}19 \\
17\end{array}$ & $\begin{array}{l}-0.6 \\
2\end{array}$ & $\begin{array}{l}-20 \\
-12.2\end{array}$ \\
\hline Mercury-NWQL $(\mu \mathrm{g} / \mathrm{L})$ & - & - & - & - & - \\
\hline Molybdenum $(\mu \mathrm{g} / \mathrm{L})$ & $<10$ & 12 & 30 & - & - \\
\hline Nickel $(\mu \mathrm{g} / \mathrm{L})$ & 497 & 494 & 620 & 0.6 & -22.3 \\
\hline Selenium-OARDC $(\mu \mathrm{g} / \mathrm{L})$ & $<93$ & $<93$ & $<1$ & - & - \\
\hline Silver $(\mu \mathrm{g} / \mathrm{L})$ & $<10$ & $<10$ & 4 & Accept & Accept \\
\hline Strontium $(\mu g / L)$ & 3,340 & 3,320 & 3,400 & 0.6 & -2.1 \\
\hline Vanadium $(\mu g / L)$ & $<5$ & $<5$ & $<18$ & Accept & Accept \\
\hline $\operatorname{Zinc}(\mu \mathrm{g} / \mathrm{L})$ & 465 & 456 & 640 & 2 & -32.6 \\
\hline
\end{tabular}

aRelative percent deviation (RPD) for OARDC replicate samples and for OARDC and NWQL split samples. OARDC value used in calculation is average of the two OARDC split samples.

b --, no data or not evaluated

cBold numbers indicate analyses that do not meet acceptance criteria. 
Table F-8 (continued). Quality control analyses of split and replicate samples (sampling round $3)^{2}$.

\begin{tabular}{|c|c|c|c|}
\hline Constituent & OARDC regular & $\begin{array}{c}\text { NWQL } \\
\text { split }\end{array}$ & $\begin{array}{l}\text { Average OARDC } \\
\text { NWQL RPD } \\
\text { (percent) }\end{array}$ \\
\hline $\begin{array}{l}\text { Sample Date } \\
\text { Sample time }\end{array}$ & $\begin{array}{l}960117 \\
1035\end{array}$ & $\begin{array}{l}960117 \\
1035\end{array}$ & $-b$ \\
\hline Sample round & 3 & 3 & $\begin{array}{l}- \\
-\end{array}$ \\
\hline Sample submitted as & TU-113 & TU-113 & _ \\
\hline OARDC lab numbers & 1211 & - & _- \\
\hline pH (standard units) & 6.3 & 6.3 & 0 \\
\hline Specific cond $(\mu \mathrm{S} / \mathrm{cm})$ & 1043 & 1160 & -10.6 \\
\hline Acidity (meq/L) & 0 & 0.1 & Accept \\
\hline Calcium (mg/L) & 154 & 130 & 16.9 \\
\hline Magnesium (mg/L) & 57 & 54 & 5.4 \\
\hline Sodium (mg/L) & 6.5 & 6.9 & -6 \\
\hline Potassium (mg/L) & 5.3 & 5.6 & -5.5 \\
\hline Alkalinity $\left(\mathrm{mg} / \mathrm{L}\right.$ as $\left.\mathrm{CaCO}_{3}\right)$ & $91 \mathrm{c}$ & 115 & -23.3 \\
\hline Sulfate-IC (mg/L) & 438 & 510 & -15.2 \\
\hline Sulfate-ICP (mg/L) & 492 & 510 & -3.6 \\
\hline Chloride (mg/L) & $<0.1$ & 0.7 & Accept \\
\hline Fuoride (mg/L) & $<0.1$ & 0.1 & Accept \\
\hline Bromide (mg/L) & $<0.1$ & 0.27 & Unaccept \\
\hline Silicon $(\mathrm{mg} / \mathrm{L})$ & 10.1 & 11 & -8.5 \\
\hline $\operatorname{ROE}(\mathbf{m g} / \mathrm{L})$ & 918 & 828 & 10.3 \\
\hline Aluminum-Total (mg/L) & 100 & 130 & -26.1 \\
\hline Aluminum-Diss (mg/L) & 70 & $<10$ & Unaccept \\
\hline Arsenic-OARDC $(\mu \mathrm{g} / \mathrm{L})$ & $<40,101$ & $<1$ & - \\
\hline Barium $(\mu \mathrm{g} / \mathrm{L})$ & 27.5 & 26 & 5.6 \\
\hline Beryllium $(\mu g / L)$ & $<1$ & $<0.5$ & Accept \\
\hline Boron $(\mu \mathrm{g} / \mathrm{L})$ & 159 & 190 & -17.8 \\
\hline Cadmium $(\mu \mathrm{g} / \mathrm{L})$ & $<1$ & 3 & Accept \\
\hline Chromium $(\mu \mathrm{g} / \mathrm{L})$ & 5 & $<5$ & Accept \\
\hline Cobalt $(\mu \mathrm{g} / \mathrm{L})$ & 7 & ND & - \\
\hline $\begin{array}{l}\text { Copper }(\mu \mathrm{g} / \mathrm{L}) \\
\text { Iron-total }(\mu \mathrm{g} / \mathrm{L})\end{array}$ & 282 & $\begin{array}{l}<10 \\
20\end{array}$ & Accept \\
\hline Iron-diss $(\mu \mathrm{g} / \mathrm{L})$ & 22.3 & 19 & 16 \\
\hline Lead-OARDC $(\mu \mathrm{g} / \mathrm{L})$ & 30,37 & $<10$ & - \\
\hline Lithium $(\mu \mathrm{g} / \mathrm{L})$ & 65 & 62 & 4.7 \\
\hline Manganese-total $(\mu \mathrm{g} / \mathrm{L})$ & 910 & 840 & 8 \\
\hline Manganese-diss $(\mu \mathrm{g} / \mathrm{L})$ & 880 & 760 & 14.6 \\
\hline Mercury-NWQL $(\mu \mathrm{g} / \mathrm{L})$ & - & - & - \\
\hline Molybdenum $(\mu \mathrm{g} / \mathrm{L})$ & $<10$ & $<10$ & Accept \\
\hline Nickel $(\mu \mathrm{g} / \mathrm{L})$ & $<4,6$ & 20 & Unaccept \\
\hline Selenium-OÁRDC $(\mu \mathrm{g} / \mathrm{L})$ & $<93$ & $<1$ & - \\
\hline Silver $(\mu g / L)$ & $<10, \quad 23$ & $<1$ & Unaccept \\
\hline Strontium $(\mu \mathrm{g} / \mathrm{L})$ & 840 & 840 & 0 \\
\hline Vanadium $(\mu g / L)$ & $<5$ & $<6$ & Accept \\
\hline $\operatorname{Zinc}(\mu g / L)$ & 2 & $<3$ & Accept \\
\hline
\end{tabular}

aRelative percent deviation (RPD) for OARDC replicate samples and for OARDC and NWQL split samples. OARDC value used in calculation is average of the two OARDC split samples. b -, no data or not evaluated.

cBold numbers indicate analyses that do not meet acceptance criteria. 
For trace element determinations at concentrations near the method reporting limit, relative percent deviations (RPDs) commonly exceeded $20 \%$ for many elements. This is the case for $\mathrm{Al}, \mathrm{Cr}, \mathrm{Cu}, \mathrm{Ni}, \mathrm{V}$, and $\mathrm{Zn}$ in splits and replicates collected during round 1. Results marked NA in Tables F-7 indicates samples where concentrations of an element were detected in one split and not in the other. Where the detectable concentration was near the method reporting limit, this result likely represents variability introduced by the analytical method. However, for a few constituents such as $\mathrm{Ni}$ and $\mathrm{V}$, detectable concentrations were found in both OARDC splits whereas no detections were found in the NWQL split. This finding indicates that inductively coupled plasma emission spectrometry data for these elements is positively biased.

For round 3, the RPDs for the OARDC replicate sets are almost all within acceptance criteria, with RPDs generally less than 5 or 10 percent. One exception is $\mathrm{Cr}$ in the samples collected at well TU-118, for which the RPD is 37 percent. Comparison of the OARDC/NWQL splits reveals discrepancies in the following elements: $\mathrm{B}, \mathrm{Cd}, \mathrm{Co}, \mathrm{Al}, \mathrm{Fe}, \mathrm{Ni}$, and $\mathrm{Zn}$. Of greatest concern are the $\mathrm{Cd}$ results for TU-118 and TU-105 where the NWQL reported concentrations of 30 and $51 \mu \mathrm{g} / \mathrm{L}$, whereas OARDC reported less than $1 \mu \mathrm{g} / \mathrm{L}$. These samples were reanalyzed by NWQL and the values were identical (within analytical error). Hence, OARDC $\mathrm{Cd}$ data for round 3 may be negatively biased. Bias in Co data is toward high concentrations (positive bias) relative to the NWQL data, whereas bias in $\mathrm{B}, \mathrm{Cr}, \mathrm{Ni}$, and $\mathrm{Zn}$ data is toward low concentrations relative to the NWQL data. Results for other constituents were within acceptance criteria.

An additional quality control check was done for all samples where field and laboratory measurements of $\mathrm{pH}$, specific conductance, and alkalinity were made. NWQL criteria for these measurements were that laboratory and field values for $\mathrm{pH}$ should agree within $1 \mathrm{pH}$ unit, whereas specific conductance and alkalinity should agree within 10 percent (relative percent deviation $<10$ percent). Appendix Tables F-9 and F-10 summarize results of comparisons of field and laboratory measurements of $\mathrm{pH}$, specific conductance, and alkalinity for samples from all three rounds.

For round 1, comparison of the OARDC pH data indicates that all analyses are within $1.0 \mathrm{pH}$ units of the field-measured values. Specific conductance differences were greater than 10 percent for 8 samples, and alkalinity differences exceeded 10 percent for 16 samples (Appendix Table F-9). pH data for samples that failed to meet the acceptance criteria may be explained by (1) degassing of $\mathrm{CO}_{2}$ before laboratory analysis, which would shift sample $\mathrm{pH}$ to higher 
Table F-9. Summary of round 1 samples that did not meet acceptance criteria for field/laboratory comparison of $\mathrm{pH}$, specific conductance, and alkalinity data.

\begin{tabular}{|c|c|c|c|c|}
\hline Sample name & $\begin{array}{l}\text { Sample } \\
\text { date }\end{array}$ & $\begin{array}{l}\text { USGS } \\
\text { value }\end{array}$ & $\begin{array}{c}\text { OARDC } \\
\text { value }\end{array}$ & $\begin{array}{c}\text { Relative } \\
\text { deviation (\%) }\end{array}$ \\
\hline \multicolumn{5}{|c|}{ pH(no samples failed acceptance criteria } \\
\hline \multicolumn{5}{|c|}{ Specific conductance (microsiemens per centimeter) } \\
\hline TU-113-W8S & 950627 & 1110 & 975 & 13.3 \\
\hline TU-107-W4P & 950627 & 1780 & 1580 & 12.5 \\
\hline TU-107-W4P (split) & 950627 & 1780 & 1570 & 11.9 \\
\hline TU-174 & 950613 & 631 & 538 & 15.9 \\
\hline TU-177 & 950613 & 843 & 735 & 13.7 \\
\hline TU-178 & 950614 & 524 & 473 & 10.2 \\
\hline TU-176 & 950620 & 523 & 452 & 14.6 \\
\hline TU-175 & 950620 & 757 & 666 & 12.8 \\
\hline \multicolumn{5}{|c|}{ Alkalinity (mg/L as $\left.\mathrm{CaCO}_{3}\right)$} \\
\hline TU-100-W1S & 950621 & 119 & 10 & 169.0 \\
\hline TU-114-W8D & 950621 & 160 & 12 & 172.1 \\
\hline TU-114-W8D (split) & 950621 & 160 & 14 & 167.8 \\
\hline TU-112-W7 & 950621 & 136 & 49 & 94.1 \\
\hline TU-110-W6S & 950621 & 87 & 16 & 137.9 \\
\hline TU-113-W8S & 950627 & 125 & 89 & 33.6 \\
\hline TU-109-W5D & 950627 & 53 & 23 & 78.9 \\
\hline TU-102-W2 & 950627 & 97 & 55 & 55.3 \\
\hline TU-111-W6D & 950628 & 132 & 13 & 164.0 \\
\hline TU-104-W3D & 950628 & 169 & 114 & 38.9 \\
\hline TU-106-W4D & 950629 & 75 & 65 & 14.3 \\
\hline TU-105-W4S & 950629 & 54 & 47 & 13.9 \\
\hline TU-107-W4P & 950706 & 199 & 139 & 35.5 \\
\hline TU-10B-W3S & 950706 & 131 & 63 & 70.1 \\
\hline TU-175 & 950620 & 350 & 281 & 21.9 \\
\hline TU-125 & 950626 & 17 & 15 & 12.5 \\
\hline
\end{tabular}


Table F-10. Field /aboratory comparisons of $\mathrm{pH}$, specific conductance, and alkalinity for round 2 and 3 samples.

\begin{tabular}{|c|c|c|c|c|c|}
\hline Site name & Date & Sample round & $\begin{array}{c}\text { USGS field } \\
\text { pH } \\
\text { (standard } \\
\text { units) }\end{array}$ & $\begin{array}{l}\text { OARDC lab } \\
\text { pH(standard } \\
\text { units) }\end{array}$ & $\begin{array}{c}\text { Absolute } \\
\text { difference } \\
\text { between } \\
\text { field/lab pH }\end{array}$ \\
\hline TU-116-W10 & 960116 & 3 & $5.6^{2}$ & 4.1 & 1.5 \\
\hline TU-117-W11 & 960116 & 3 & 5.8 & 4.3 & 1.5 \\
\hline TU-115-W9 & 960117 & 3 & 5.3 & 4.6 & 0.7 \\
\hline TU-119-W13 & 960117 & 3 & 5.7 & 3.9 & 1.8 \\
\hline TU-100-W1S & 960117 & 3 & 5.5 & 4.1 & 1.4 \\
\hline TU-101-W1D & 960118 & 3 & 7.2 & 7.2 & 0.0 \\
\hline TU-109-W5S & 960118 & 3 & 5.5 & $\mathbf{3 . 3}$ & 2.2 \\
\hline TU-106-W4D & 960118 & 3 & 5.5 & 3.2 & 2.3 \\
\hline TU-107-W4P & 960119 & 3 & 6.5 & 6.5 & 0.0 \\
\hline TU-104-W3D & 960119 & 3 & 6.1 & 5.8 & 0.3 \\
\hline TU-105-W4S & 960118 & 3 & 5.4 & 4.2 & 1.2 \\
\hline TU-103-W3S & 960119 & 3 & 5.9 & 5.2 & 0.7 \\
\hline TU-102-W2 & 960119 & 3 & 5.5 & 4.3 & 1.2 \\
\hline TU-112-W7 & 960119 & 3 & 5.8 & 4.6 & 1.2 \\
\hline TU-111-W6D & 960120 & 3 & 6.1 & 4.5 & 1.6 \\
\hline TU-110-W6S & 960120 & 3 & 5.2 & 4.1 & 1.1 \\
\hline TU-113-W8S & 960120 & 3 & 6.3 & 6.3 & 0.0 \\
\hline TU-114-W8D & 960120 & 3 & 5.7 & 4.7 & 1.0 \\
\hline TU-118-W12 & 960117 & 3 & 5.4 & 4.4 & 1.0 \\
\hline TU-118-W12 & 960117 & 3 & 5.4 & 4.4 & 1.0 \\
\hline TU-131-L1A-2.5 & 951020 & 2 & 4.3 & 4.5 & 0.2 \\
\hline TU-133-L1B-1.5 & 951020 & 2 & 6.3 & 7.4 & 1.1 \\
\hline TU-136-L2A-1.5 & 951020 & 2 & 6.2 & 7.5 & 1.3 \\
\hline TU-137-L2A-2.5 & 951020 & 2 & 6.2 & 7.2 & 1.0 \\
\hline TU-138-L2A-3.5 & 951020 & 2 & 6.2 & 7.2 & 1.0 \\
\hline TU-139-L.2B-1.5 & 951020 & 2 & 6.7 & 7.7 & 1.0 \\
\hline TU-140-L2B-2.5 & 951020 & 2 & 6.1 & 7.0 & 0.9 \\
\hline TU-141-L2B-3.5 & 951020 & 2 & 6.4 & 7.5 & 1.1 \\
\hline TU-144-L3B-1.5 & 951020 & 2 & 6.0 & 7.1 & 1.1 \\
\hline TU-148-L3C-2.5 & 951020 & 2 & 5.8 & 7.2 & 1.4 \\
\hline TU-151-L4A-2.5 & 951020 & 2 & 5.9 & 7.3 & 1.4 \\
\hline TU-152-LAA-3.5 & 951020 & 2 & 5.3 & 6.1 & 0.8 \\
\hline TU-153-LAB-1.5 & 951020 & 2 & 5.8 & 7.3 & 1.5 \\
\hline TU-154-LAB-2.5 & 951020 & 2 & 6.3 & 7.4 & 1.1 \\
\hline TU-155-LAB-3.5 & 951020 & 2 & 6.2 & 7.2 & 1.0 \\
\hline TU-157-LAC-2.5UP & 951020 & 2 & 6.0 & 7.4 & 1.4 \\
\hline TU-150-LAA-1.5 & 960118 & 3 & 7.6 & - & - \\
\hline TU-151-LAA-2.5 & 960118 & 3 & 6.7 & 8.1 & 1.4 \\
\hline TU-152-LAA-3.5 & 960118 & 3 & 6.3 & 7.6 & 1.3 \\
\hline TU-154-LAB-2.5 & 960118 & 3 & 6.9 & 7.4 & 0.5 \\
\hline TU-155-LAB-3.5 & 960118 & 3 & 7.0 & 7.8 & 0.8 \\
\hline TU-156-LAC-1.5UP & 960118 & 3 & 6.9 & - & - \\
\hline
\end{tabular}

cBold numbers indicate analyses that do not meet acceptance criteria. 
Table F-10 (continued). Field /laboratory comparisons of $\mathrm{pH}$, specific conductance, and alkalinity for round 2 and 3 samples.

\begin{tabular}{|c|c|c|c|c|c|}
\hline Site name & Date & Sample round & $\begin{array}{l}\text { USGS field pH } \\
\text { (standand } \\
\text { units) }\end{array}$ & $\begin{array}{c}\text { OARDC lab } \\
\text { pH } \\
\text { (standard units) }\end{array}$ & $\begin{array}{c}\text { Absolute } \\
\text { difference } \\
\text { between } \\
\text { field/lab pH }\end{array}$ \\
\hline TU-148-L3C-2.5 & 960118 & 3 & $6.8 \mathrm{a}$ & 8.2 & 1.4 \\
\hline TU-149-L3C-3.5 & 960118 & 3 & 6.6 & - & - \\
\hline TU-147-L3C-1.5 & 960118 & 3 & 5.0 & - & - \\
\hline TU-145-L3B-2.5 & 960118 & 3 & 6.9 & - & - \\
\hline TU-144-L3B-1.5 & 960118 & 3 & 7.0 & 8.2 & 1.2 \\
\hline TU-141-L2B-3.5 & 960118 & 3 & 7.2 & 8.1 & 0.9 \\
\hline TU-140-L2B-2.5 & 960118 & 3 & 6.0 & 7.5 & 1.5 \\
\hline TU-139-L2B-1.5 & 960118 & 3 & 7.3 & 7.8 & 0.5 \\
\hline TU-138-L2A-3.5 & 960118 & 3 & 6.7 & 7.5 & 0.8 \\
\hline TU-137-L2A-2.5 & 960118 & 3 & 6.8 & 7.5 & 0.7 \\
\hline TU-136-L2A-1.5 & 960118 & 3 & 7.2 & 7.8 & 0.6 \\
\hline TU-133-L1B-1.5 & 960118 & 3 & 7.0 & 7.7 & 0.7 \\
\hline TU-131-L1A-2.5 & 960118 & 3 & 5.6 & 6.9 & 1.3 \\
\hline TU-130-L1A-1.5 & 960118 & 3 & 7.1 & 7.9 & 0.8 \\
\hline TU-159-L5A-1.5 & 960118 & 3 & 4.4 & 4.8 & 0.4 \\
\hline TU-161-L5A-3.5 & 960118 & 3 & 5.7 & - & - \\
\hline TU-162-L5B-1.5 & 960118 & 3 & 5.3 & - & - \\
\hline TU-158-LAC-3.5UP & 960118 & 3 & 6.8 & - & - \\
\hline TU-142-L3A-4.5A & 960118 & 3 & 6.5 & 8.0 & 1.6 \\
\hline
\end{tabular}

aBold numbers indicate analyses that do not meet acceptance criteria. 
Table F-10 (continued). Field /aboratory comparisons of $\mathrm{pH}$, specific conductance, and alkalinity for round 2 and 3 samples.

\begin{tabular}{|c|c|c|c|c|c|}
\hline Site name & Date & Sample round & $\begin{array}{l}\text { USGS field } \\
\text { Spec. Cond. } \\
(\mu S / \mathrm{cm})\end{array}$ & $\begin{array}{c}\text { OARDC lab } \\
\text { Spec. Cond. } \\
(\mu \mathrm{S} / \mathrm{cm})\end{array}$ & $\begin{array}{c}\text { Absolute } \\
\text { difference } \\
\text { between } \\
\text { field/lab pH }\end{array}$ \\
\hline TU-116-W10 & 960116 & 3 & 3,230 & 2,936 & 9.5 \\
\hline TU-117-W11 & 960116 & 3 & 2,760 & 2,670 & 3.3 \\
\hline TU-115-W9 & 960117 & 3 & 2,420 & 2,308 & 4.7 \\
\hline TU-119-W13 & 960117 & 3 & 3,150 & 2,713 & 14.9 \\
\hline TU-100-W1S & 960117 & 3 & 3,190 & 3,223 & 1.1 \\
\hline TU-101-W1D & 960118 & 3 & 2,560 & 2,138 & 17.9 \\
\hline TU-109-W5S & 960118 & 3 & 3,060 & 3,106 & 1.5 \\
\hline TU-106-W4D & 960118 & 3 & 3,060 & 3,043 & 0.6 \\
\hline TU-107-W4P & 960119 & 3 & 1,880 & 1,564 & 18.3 \\
\hline TU-104-W3D & 960119 & 3 & 2,370 & 2,255 & 4.9 . \\
\hline TU-105-W4S & 960118 & 3 & 3,120 & 2,989 & 4.3 \\
\hline TU-103-W3S & 960119 & 3 & 2,460 & 2,255 & 8.7 \\
\hline TU-102-W2 & 960119 & 3 & 3,090 & 2,787 & 10.3 \\
\hline TU-112-W7 & 960119 & 3 & 2,150 & 2,138 & 0.5 \\
\hline TU-111-W6D & 960120 & 3 & 3,900 & 3,745 & 4.0 \\
\hline TU-110-W6S & 960120 & 3 & 3,830 & 4,053 & 5.7 \\
\hline TU-113-W8S & 960120 & 3 & 1,160 & 1,042 & 10.6 \\
\hline TU-114-W8D & 960120 & 3 & 2,880 & 2,660 & 7.9 \\
\hline TU-118-W12 & 960117 & 3 & 3,120 & 2,777 & 11.6 \\
\hline TU-118-W12 & 960117 & 3 & 3,120 & 2,596 & 18.3 \\
\hline TU-131-L1A-2.5 & 951020 & 2 & 7,760 & 6,080 & 24.3 \\
\hline TU-133-L1B-1.5 & 951020 & 2 & 10,610 & 9,370 & 12.4 \\
\hline TU-136-L2A-1.5 & 951020 & 2 & 11,070 & 9,500 & 15.3 \\
\hline TU-137-L2A-2.5 & 951020 & 2 & 14,620 & 12,580 & 15.0 \\
\hline TU-138-L2A-3.5 & 951020 & 2 & 11,970 & 10,300 & 15.0 \\
\hline TU-139-L2B-1.5 & 951020 & 2 & 14,660 & 12,700 & 14.3 \\
\hline TU-140-L2B-2.5 & 951020 & 2 & 10,410 & 9,300 & 11.3 \\
\hline TU-141-L2B-3.5 & 951020 & 2 & 9,410 & 8,070 & 15.3 \\
\hline TU-144-L3B-1.5 & 951020 & 2 & 8,790 & 7,750 & 12.6 \\
\hline TU-148-L3C-2.5 & 951020 & 2 & 9,020 & 7,960 & 12.5 \\
\hline TU-151-L4A-2.5 & 951020 & 2 & 9,260 & 7,310 & 23.5 \\
\hline TU-152-L4A-3.5 & 951020 & 2 & 5,810 & 5,080 & 13.4 \\
\hline TU-153-L4B-1.5 & 951020 & 2 & 8,830 & 7,720 & 13.4 \\
\hline TU-154-LAB-2.5 & 951020 & 2 & 8,360 & 7,190 & 15.0 \\
\hline TU-155-LAB-3.5 & 951020 & 2 & 9,190 & 7,950 & 14.5 \\
\hline TU:157-LAC-2.5UP & 951020 & 2 & 9,610 & 8,540 & 11.8 \\
\hline TU-150-LAA-1.5 & 960118 & 3 & 9,330 & - & - \\
\hline TU-151-LAA-2.5 & 960118 & 3 & 7,650 & 6,767 & 12.2 \\
\hline TU-152-LAA-3.5 & 960118 & 3 & 7,480 & 6,852 & 8.8 \\
\hline TU-154-L4B-2.5 & 960118 & 3 & 7,340 & - & - \\
\hline TU-155-LAB-3.5 & 960118 & 3 & 6,200 & 5405 & 13.7 \\
\hline TU-156-LAC-1.5UP & 960118 & 3 & 8,400 & - & - \\
\hline
\end{tabular}

cBold numbers indicate analyses that do not meet acceptance criteria. 
Table F-10 (continued). Field /laboratory comparisons of pH, specific conductance, and alkalinity for round 2 and 3 samples.

\begin{tabular}{|c|c|c|c|c|c|}
\hline Site name & Date & Sample round & $\begin{array}{l}\text { USGS field } \\
\text { Spec. Cond. } \\
(\mu \text { S/cm) }\end{array}$ & $\begin{array}{l}\text { OARDC lab } \\
\text { Spec. Cond. } \\
(\mu \mathrm{S} / \mathrm{cm})\end{array}$ & $\begin{array}{c}\text { Absolute } \\
\text { difference } \\
\text { between } \\
\text { field/lab pH }\end{array}$ \\
\hline TU-148-L3C-2.5 & 960118 & 3 & 6,050 & 5,064 & 17.7 \\
\hline TU-149-L3C-3.5 & 960118 & 3 & 6,380 & 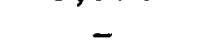 & - \\
\hline TU-147-L3C-1.5 & 960118 & 3 & - & - & - \\
\hline TU-145-L3B-2.5 & 960118 & 3 & 6,600 & - & - \\
\hline TU-144-L3B-1.5 & 960118 & 3 & 5,890 & 4,947 & 17.4 \\
\hline TU-141-L2B-3.5 & 960118 & 3 & 6,560 & 5,551 & 17.4 \\
\hline TU-140-L2B-2.5 & 960118 & 3 & 9,760 & 8,341 & 15.7 \\
\hline TU-139-L2B-1.5 & 960118 & 3 & 7,600 & 6,277 & 19.1 \\
\hline TU-138-L2A-3.5 & 960118 & 3 & 7,440 & 6,288 & 16.8 \\
\hline TU-137-L2A-2.5 & 960118 & 3 & 7,810 & 6,628 & 16.4 \\
\hline TU-136-L2A-1.5 & 960118 & 3 & 7,240 & 6,213 & 15.3 \\
\hline TU-133-L1B-1.5 & 960118 & 3 & 13,100 & 10,863 & 18.7 \\
\hline TU-131-L1A-2.5 & 960118 & 3 & 8,050 & 6,926 & 15.0 \\
\hline TU-130-L1A-1.5 & 960118 & 3 & 7,990 & 6,820 & 15.8 \\
\hline TU-159-L5A-1.5 & 960118 & 3 & 1,210 & 1,021 & 16.9 \\
\hline TU-161-L5A-3.5 & 960118 & 3 & 1,530 & - & - \\
\hline TU-162-L5B-1.5 & 960118 & 3 & 2,580 & - & - \\
\hline TU-158-LAC-3.5UP & 960118 & 3 & 7,150 & - & - \\
\hline TU-142-L3A-4.5A & 960118 & 3 & 5,920 & 5,149 & 13.9 \\
\hline
\end{tabular}

aBold numbers indicate analyses that do not meet acceptance criteria. 
Table F-10 (continued). Field /aboratory comparisons of $\mathrm{pH}$, specific conductance, and alkalinity for round 2 and 3 samples.

\begin{tabular}{|c|c|c|c|c|c|}
\hline Site name & Date & Sample round & $\begin{array}{l}\text { USGS field } \\
\text { alkalinity } \\
(\mathrm{mg} / \mathrm{L} \text { as } \\
\left.\mathrm{CaCO}_{3}\right)\end{array}$ & $\begin{array}{l}\text { OARDC lab } \\
\text { alkalinity } \\
\text { (mg/L as } \\
\left.\mathrm{CaCO}_{3}\right)\end{array}$ & $\begin{array}{c}\text { Absolute } \\
\text { difference } \\
\text { between } \\
\text { field/lab pH }\end{array}$ \\
\hline TU-116-W10 & 960116 & 3 & $45^{2}$ & O & $200.0^{b}$ \\
\hline TU-117-W11 & 960116 & 3 & 59 & $\mathbf{0}$ & 200.0 \\
\hline TU-115-W9 & 960117 & 3 & 44 & 0 & 200.0 \\
\hline TU-119-W13 & 960117 & 3 & 75 & $\mathbf{0}$ & 200.0 \\
\hline TU-100-W1S & 960117 & 3 & 68 & 0 & 200.0 \\
\hline TU-101-W1D & 960118 & 3 & 190 & $\mathbf{0}$ & 200.0 \\
\hline TU-109-W5S & 960118 & 3 & 57 & 0 & 200.0 \\
\hline TU-106-W4D & 960118 & 3 & 73 & 0 & 200.0 \\
\hline TU-107-W4P & 960119 & 3 & 194 & 187 & 3.7 \\
\hline TU-104-W3D & 960119 & 3 & 122 & 76 & 46.5 \\
\hline TU-105-W4S & 960118 & 3 & 54 & 0 & 200.0 \\
\hline TU-103-W3S & 960119 & 3 & 105 & 1 & 196.2 \\
\hline TU-102-W2 & 960119 & 3 & 56 & $\mathbf{0}$ & 200.0 \\
\hline TU-112-W7 & 960119 & 3 & 88 & $\mathbf{0}$ & 200.0 \\
\hline TU-111-W6 & 960120 & 3 & - & - & - \\
\hline TU-110-W6S & 960120 & 3 & 52 & - & - \\
\hline TU-113-W8S & 960120 & 3 & - & 91 & - \\
\hline TU-114W8D & 960120 & 3 & 111 & - & - \\
\hline TU-118-W12 & 960117 & 3 & 52 & $\mathbf{0}$ & 200.0 \\
\hline TU-118-W12 & 960117 & 3 & 52 & $\mathbf{0}$ & 200.0 \\
\hline TU-131-L1A-2.5 & 951020 & 2 & - & 0 & - \\
\hline TU-133-L1B-1.5 & 951020 & 2 & - & 707 & - \\
\hline TU-136-L2A-1.5 & 951020 & 2 & - & 529 & - \\
\hline TU-137-L2A-2.5 & 951020 & 2 & - & 557 & -- \\
\hline TU-138-L2A-3.5 & 951020 & 2 & - & 661 & - \\
\hline TU-139-L2B-1.5 & 951020 & 2 & - & 575 & - \\
\hline TU-140-L2B-2.5 & 951020 & 2 & - & 116 & - \\
\hline TU-141-L2B-3.5 & 951020 & 2 & - & 537 & - \\
\hline TU-144-L3B-1.5 & 951020 & 2 & - & 247 & - \\
\hline TU-148-L3C-2.5 & 951020 & 2 & - & 428 & - \\
\hline TU-151-L4A-2.5 & 951020 & 2 & - & 371 & - \\
\hline TU-152-L4A-3.5 & 951020 & 2 & - & 30 & - \\
\hline TU-153-L4B-1.5 & 951020 & 2 & - & 189 & - \\
\hline TU-154-L4B-2.5 & 951020 & 2 & - & 681 & - \\
\hline TU-155-L4B-3.5 & 951020 & 2 & - & 557 & - \\
\hline TU-157-LAC-2.5UP & 951020 & 2 & - & 230 & - \\
\hline TU-150-L4A-1.5 & 960118 & 3 & - & - & - \\
\hline TU-151-L4A-2.5 & 960118 & 3 & - & 153 & - \\
\hline TU-152-L4A-3.5 & 960118 & 3 & - & 124 & - \\
\hline TU-154-L4B-2.5 & 960118 & 3 & - & 0 & - \\
\hline TU-155-LAB-3.5 & 960118 & 3 & - & - & - \\
\hline TU-156-LAC-1.5UP & 960118 & 3 & - & 0 & - \\
\hline
\end{tabular}

aBold numbers indicate analyses that do not meet acceptance criteria.

bThis is a default value. 
Table F-10 (continued). Field /aboratory comparisons of $\mathrm{pH}$, specific conductance, and
alkalinity for round 2 and 3 samples.

\begin{tabular}{|c|c|c|c|c|c|}
\hline Site name & Date & Sample round & $\begin{array}{l}\text { USGS field } \\
\text { alkalinity } \\
(\mathrm{mg} / \mathrm{L} \text { as } \\
\left.\mathrm{CaCO}_{3}\right) \\
\end{array}$ & $\begin{array}{l}\text { OARDC lab } \\
\text { alkalinity } \\
\text { (mg/L as } \\
\mathrm{CaCO}_{3} \text { ) }\end{array}$ & $\begin{array}{c}\text { Absolute } \\
\text { difference } \\
\text { between } \\
\text { field/lab pH } \\
\end{array}$ \\
\hline TU-148-L3C-2.5 & 960118 & 3 & - & 118 & - \\
\hline TU-149-L3C-3.5 & 960118 & 3 & - & - & - \\
\hline TU-147-L3C-1.5 & 960118 & 3 & - & - & - \\
\hline TU-145-L3B-2.5 & 960118 & 3 & - & 0 & - \\
\hline TU-144-L3B-1.5 & 960118 & 3 & - & 107 & - \\
\hline TU-141-L2B-3.5 & 960118 & 3 & - & 102 & - \\
\hline TU-140-L2B-2.5 & 960118 & 3 & - & 52 & - \\
\hline TU-139-L2B-1.5 & 960118 & 3 & - & 111 & $\cdot$ \\
\hline TU-138-12A-3.5 & 960118 & 3 & - & 112 & - \\
\hline TU-137-L2A-2.5 & 960118 & 3 & - & 244 & - \\
\hline TU-136-L2A-1.5 & 960118 & 3 & - & 346 & - \\
\hline TU-133-L1B-1.5 & 960118 & 3 & - & 806 & - \\
\hline TU-131-L1A-2.5 & 960118 & 3 & - & 80 & - \\
\hline TU-130-L1A-1.5 & 960118 & 3 & - & 793 & - \\
\hline TU-159-L5A-1.5 & 960118 & 3 & - & 1 & - \\
\hline TU-161-LSA-3.5 & 960118 & 3 & - & - & - \\
\hline TU-162-L5B-1.5 & 960118 & 3 & - & - & - \\
\hline TU-158-LAC-3.5UP & 960118 & 3 & - & - & - \\
\hline TU-142-L3A-4.5A & 960118 & 3 & - & 78 & - \\
\hline
\end{tabular}

aBold numbers indicate analyses that do not meet acceptance criteria. 
values, and (2) oxidation of ferrous iron, which would shift $\mathrm{pH}$ to lower values during precipitation of ferric-iron minerals through reactions such as

$$
\mathrm{Fe}^{2+}+2.5 \mathrm{H}_{2} \mathrm{O}+0.25 \mathrm{O}_{2} \Rightarrow \underset{\mathrm{it}}{\mathrm{Fe}}(\mathrm{OH})_{3}+2 \mathrm{H}^{+} \text {. }
$$

Precipitates, which may have consisted of amorphous iron hydroxides or jarosite, were observed in many of the unacidified and acidified samples. Hence, $\mathrm{pH}$ measured in the laboratory may be accurate and may not necessarily reflect analytical error. Discrepancies between field and laboratory specific conductances are most pronounced in the round 2 and 3 interstitial water samples: OARDC specific conductances were consistently low relative to the USGS field measurements. A decrease in specific conductance would be consistent with formation of ferrihydrite or jarosite precipitates; however, degassing of $\mathrm{CO}_{2}$ (as indicated by the increase in $\mathrm{pH}$ for these samples) should not lead to a notable decrease in specific conductance unless it was coincident with precipitation of a secondary phase.

Alkalinity comparisons are restricted to the groundwater samples because insufficient sample volumes prohibited USGS field determinations of alkalinity on the round 2 interstitial-water samples. Decreases in alkalinity between field and laboratory measurements for ground-water samples are consistent with the oxidation of $\mathrm{Fe}^{2+}$ and resultant decrease in $\mathrm{pH}$.

The final QC check was evaluation of the charge balance error (CBE) for all samples where sufficient major-ion data were reported by the OARDC laboratory. Charge balance error is calculated by use of the formula:

$$
\mathrm{CBE}(\text { percent })=\frac{\left(\sum \text { cations }-\sum \text { anions }\right) \times 100}{\left(\sum \text { cations }+\sum \text { anions }\right) / 2},
$$

where the sums of cation and anion species are given in milliequivalents. The maximum charge balance error possible by this calculation is \pm 200 percent, whereas the acceptance criterion is \pm 10 percent. Charge balance errors calculated for round 1 , and for rounds 2 and 3 are reported in Appendix Tables F-11 and F-12, respectively. The charge balance error was evaluated twice, first with $\mathrm{SO}_{4}$ data obtained by ion chromatography and then with $\mathrm{SO}_{4}$ data obtained by inductively coupled plasma emission spectrometry and only when alkalinity data were available. (Alkalinity typically constituted only a small percentage ( $<10$ percent) of the anion sum for interstitia water and on-site groundwater samples.) The charge balance error indicated that the inductively coupled plasma emission spectrometry was providing the more accurate $\mathrm{SO}_{4}$ data for the round 1 samples. All dissolved $\mathrm{Fe}$ was assumed to exist as ferrous $\left(\mathrm{Fe}^{2+}\right)$ iron 
Table F-11. Charge balance errors for round 1 samples evaluated with sulfate data generated by ion chromatography (IC) and inductively-coupled plasma
(ICP) methods.

\begin{tabular}{|c|c|c|}
\hline Sample name & $\begin{array}{l}\text { Charge balance } \\
\mathrm{IC}^{-} \mathrm{SO}_{4} \text { data }\end{array}$ & $\begin{array}{l}\text { Charge balance } \\
\mathrm{ICP}_{-} \mathrm{SO}_{4} \text { data }\end{array}$ \\
\hline $\begin{array}{l}\text { TU-100-W1S } \\
\text { TU-114-W8D } \\
\text { TU-114-W8D } \\
\text { TU-112-W7 } \\
\text { TU-110-W6S } \\
\text { TU-113-W8S } \\
\text { TU-109-W5S } \\
\text { TU-102-W2 } \\
\text { TU-101-W1D } \\
\text { TU-111-W6D } \\
\text { TU-104-W3D } \\
\text { TU-106-W4D } \\
\text { TU-105-W4S } \\
\text { TU-107-W4P } \\
\text { TU-107-W4P } \\
\text { TU-103-W3S } \\
\text { TU-172 } \\
\text { TU-170 } \\
\text { TU-170 } \\
\text { TU-174 } \\
\text { TU-177 } \\
\text { TU-171 } \\
\text { TU-173 } \\
\text { TU-178 } \\
\text { TU-176 } \\
\text { TU-175 } \\
\text { TU-131-L1A-2.5 } \\
\text { TU-133-L1B-1.5 } \\
\text { TU-134-L1B-2.5 } \\
\text { TU-137-L2A-2.5 } \\
\text { TU-139-L2A-1.5 } \\
\text { TU-140-L2A-2.5 } \\
\text { TU-141-L2A-3.5 } \\
\text { U-145-L3B-2.5 } \\
\text { U-151-LAA-2.5 } \\
\text { U-156LAC-1.5UP } \\
\text { U-157-LAC-2.5UP } \\
\text { U-158-LAC-3.5UP } \\
\text { TU-LB-2.5 }\end{array}$ & $\begin{array}{c}39.3 \mathrm{a} \\
\mathbf{3 6 . 6} \\
\mathbf{3 4 . 7} \\
\mathbf{3 7 . 8} \\
\mathbf{5 5 . 2} \\
-\mathbf{3 2 . 0} \\
-1.8 \\
3.3 \\
-3.5 \\
8.3 \\
3.5 \\
14.6 \\
5.5 \\
-4.3 \\
15.0 \\
-6.6 \\
3.1 \\
-12.0 \\
-\mathbf{2 0 . 4} \\
-17.5 \\
-5.8 \\
-\mathbf{2 6 . 1} \\
-\mathbf{3 0 . 1} \\
-\mathbf{1 0 0 . 0} \\
-\mathbf{1 9 . 6} \\
-\mathbf{2 7 . 8} \\
--b \\
-- \\
-- \\
-- \\
-- \\
-- \\
- \\
-- \\
-- \\
-- \\
-- \\
-- \\
-- \\
-27.2 \\
-71.2 \\
-1\end{array}$ & $\begin{array}{c}-2.2 \\
1.2 \\
0.7 \\
-9.6 \\
-5.1 \\
1.6 \\
-3.0 \\
-2.3 \\
1.8 \\
-1.8 \\
-0.7 \\
-0.8 \\
-2.1 \\
0.3 \\
0.4 \\
-15.7 \\
-2.2 \\
15.7 \\
7.1 \\
1.9 \\
5.2 \\
3.7 \\
1.3 \\
-76.7 \\
-0.2 \\
-9.7 \\
\mathbf{- 9 1 . 2} \\
-110.0 \\
\mathbf{4 4 . 8} \\
-\mathbf{6 2 . 0} \\
\mathbf{1 1 . 3} \\
\mathbf{1 9 . 0} \\
-\mathbf{2 1 . 0} \\
3.9 \\
\mathbf{7 7 . 8} \\
\mathbf{5 6 . 8} \\
8.6 \\
\mathbf{4 0 . 2} \\
\mathbf{5 8 . 7} \\
-\mathbf{1 2 . 0} \\
-\mathbf{8 . 5}\end{array}$ \\
\hline
\end{tabular}


Table F-12. Charge balance errors for round 2 and 3 samples evaluated with sulfate data generated by ion chromatography (IC) and inductively-coupled plasma (ICP) methods.

\begin{tabular}{|c|c|c|c|}
\hline Sample name & Sample date & $\begin{array}{c}\text { Charge balance } \\
\mathrm{IC}^{-S} \mathrm{O}_{4}\end{array}$ & $\begin{array}{c}\text { Charge balance } \\
\mathrm{ICP}_{-} \mathrm{SO}_{4}\end{array}$ \\
\hline $\begin{array}{l}\text { TU-116-W10 } \\
\text { TU-117-W11 }\end{array}$ & $\begin{array}{l}960116 \\
960116\end{array}$ & $\begin{array}{l}9.90 \\
9.18\end{array}$ & $\begin{array}{l}5.87 \\
5.24\end{array}$ \\
\hline TU-115-W9 & 960117 & 8.83 & 4.72 \\
\hline TU-119-W13 & 960117 & 11.542 & 9.34 \\
\hline TU-100-W1S & 960117 & 31.66 & 12.99 \\
\hline TU-101-W1D & 960118 & 6.32 & 2.93 \\
\hline TU-109-W5S & 960118 & 7.37 & 6.19 \\
\hline TU-106-W4D & 960118 & 11.61 & 5.70 \\
\hline TU-107-W4P & 960119 & 17.37 & 5.80 \\
\hline TU-104W3D & 960119 & 10.81 & 5.63 \\
\hline TU-103-W3S & 960119 & 20.98 & 8.30 \\
\hline TU-102-W2 & 960119 & 12.25 & 9.05 \\
\hline TU-112-W7 & 960119 & 12.37 & 6.76 \\
\hline TU-111-W6D & 960120 & 8.06 & 10.44 \\
\hline TU-110-W6S & 960120 & 2.73 & 12.71 \\
\hline TU-114-W8D & 960120 & 9.91 & 8.73 \\
\hline TU-131-L1A-2.5 & 951020 & -2.65 & 9.57 \\
\hline TU-133-L1B-1.5 & 951020 & 3.90 & 11.38 \\
\hline TU-136-L2A-1.5 & 951020 & 7.53 & 11.61 \\
\hline TU-137-L2A-2.5 & 951020 & 6.29 & 16.22 \\
\hline TU-138-L2A-3.5 & 951020 & -2.67 & 14.28 \\
\hline TU-139-L_2B-1.5 & 951020 & -4.17 & 18.75 \\
\hline TU-140-L2B-2.5 & 951020 & 6.65 & 14.25 \\
\hline TU-141-L2B-3.5 & 951020 & 2.48 & 12.17 \\
\hline TU-144-L3B-1.5 & 951020 & 9.10 & 11.46 \\
\hline TU-148-L3C-2.5 & 951020 & -5.70 & 11.66 \\
\hline TU-151-LAA-2.5 & 951020 & -3.54 & 10.05 \\
\hline TU-152-LAA-3.5 & 951020 & -1.84 & 5.67 \\
\hline TU-153-LAB-1.5 & 951020 & -17.29 & 10.44 \\
\hline TU-154LAB-2.5 & 951020 & 0.01 & 8.98 \\
\hline TU-155-LAB-3.5 & 951020 & -0.74 & 10.32 \\
\hline TU-157-LAC-2.5UP & 951020 & -1.83 & 12.38 \\
\hline TU-150-LAA-1.5 & 960118 & $-b$ & 33.65 \\
\hline TU-151-LAA-2.5 & 960118 & 21.44 & 24.66 \\
\hline TU-152-LAA-3.5 & 960118 & 23.84 & 24.92 \\
\hline TU-154LAB-2.5 & 960118 & 29.54 & 31.17 \\
\hline TU-155-LAB-3.5 & 960118 & 26.32 & 25.23 \\
\hline TU-156-LAC-1.5UP & 960118 & 35.02 & 28.95 \\
\hline TU-148-L3C-2.5 & 960118 & 19.39 & 22.59 \\
\hline TU-149-L3C-3.5 & 960118 & - & 27.09 \\
\hline TU-147-L3C-1.5 & 960118 & - & 25.78 \\
\hline TU-145-L3B-2.5 & 960118 & 29.38 & 31.57 \\
\hline TU-144-L3B-1.5 & 960118 & 21.46 & 18.92 \\
\hline TU-141-L2B-3.5 & 960118 & 19.44 & 21.23 \\
\hline TU-140-L2B-2.5 & 960118 & 16.17 & 24.66 \\
\hline TU-139-L2B-1.5 & 960118 & 18.17 & 23.01 \\
\hline TU-138-L2A-3.5 & 960118 & 16.81 & 22.76 \\
\hline TU-137-L2A-2.5 & 960118 & 19.38 & 20.64 \\
\hline TU-136-L2A-1.5 & 960118 & 20.28 & 18.45 \\
\hline TU-133-L1B-1.5 & 960118 & 6.92 & 23.44 \\
\hline TU-132-L1A-3.5 & 960118 & -- & 27.71 \\
\hline TU-131-L1A-2.5 & 960118 & 17.97 & 17.97 \\
\hline TU-130-L1A-1.5 & 960118 & 17.23 & 17.23 \\
\hline
\end{tabular}


Table F-12 (continued). Charge balance errors for round 2 and 3 samples evaluated with sulfate data generated by ion chromatography (IC) and inductively-coupled plasma (ICP) methods.

\begin{tabular}{lccc}
\hline Sample name & Sample date & $\begin{array}{c}\text { Charge balance } \\
\mathrm{IC}^{-S_{4}}\end{array}$ & $\begin{array}{c}\text { Charge balance } \\
\mathrm{ICP}_{4} \mathrm{SO}_{4}\end{array}$ \\
\hline TU-159-LSA-1.5 & 960118 & -2.34 & -2.34 \\
TU-160-L5A-2.5 & 960118 & 6.07 & 6.07 \\
TU-161-LSA-3.5 & 960118 & $\mathbf{1 2 . 5 2}$ & $\mathbf{1 2 . 5 2}$ \\
TU-162-L5B-1.5 & 960118 & $\mathbf{7 . 0 5}$ & $\mathbf{7 . 0 5}$ \\
TU-158-L4C-3.5UP & 960118 & $\mathbf{3 0 . 1 3}$ & $\mathbf{3 0 . 1 3}$ \\
TU-142-L3A-4.5A & 960118 & $\mathbf{1 8 . 3 6}$ & $\mathbf{1 8 . 3 6}$ \\
TU-124 & 950908 & -4.59 & -4.59 \\
TU-118-W12 & 960117 & 5.29 & 5.29 \\
TU-118-W12 & 960117 & -3.02 & -3.02 \\
TU-105-W4S & 960118 & 6.70 & 6.70 \\
TU-105-W4S & 960118 & 2.27 & 2.27 \\
\hline
\end{tabular}

aBold values indicate analyses that do not meet acceptance criteria.

b--, no sulfate data. 
because the low solubility of ferric hydroxide at the near-neutral $\mathrm{pH}$ of most water samples would preclude significant concentrations of ferric iron in solution (Hem, 1989).

Round 1 samples for which large CBE's were found included the groundwater sample from TU-178 (an offsite domestic well) and many of the interstitial water samples. The laboratory report for the TU-178 sample lacked $\mathrm{Ca}, \mathrm{Mg}$, and $\mathrm{K}$ data; this reflects a reporting error in the OARDC data set. No trend is evident in the round 1 CBEs for interstitial water samples because large positive and negative errors were both observed. Most of the round 3 groundwater analyses met the \pm 10 percent criteria. Round 2 and 3 interstitial water samples were characterized by CBEs of 30 percent. Positive errors may be related to changes in sample alkalinity that occurred between sample collection and analysis, or they may simply reflect analytical error. Most CBEs for round 3 groundwater samples were within acceptance criteria. 